ivia

Instituto Valenciano

de Investigaciones Agrarias

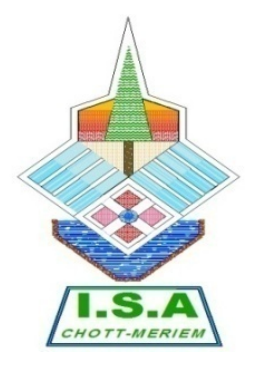

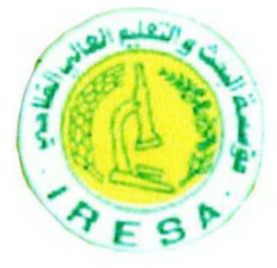
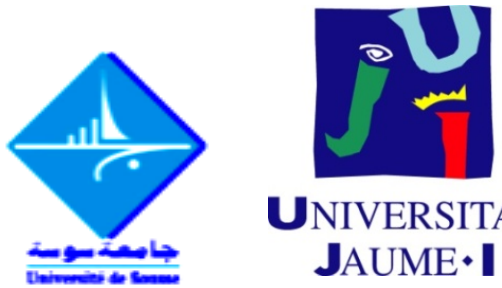

UNIVERSITAT JAUME•I

\title{
Diachasmimorpha longicaudata as Biological Control agent of the Mediterranean fruit fly, Ceratitis capitata: biotic and abiotic factors affecting its implementation in citrus crops of the Mediterranean basin
}

\section{Ahlem HARBI}

Thesis submitted to the

High Agronomic Institute of Chott-Mariem (Sousse, Tunisia) and to the University Jaume I (Castellon, Spain) for the degree of

\section{$\frac{\text { DOCTOR OF PHILOSOPHY }}{\text { in }}$}

Plant Protection and Environment: High Agronomic Institute of Chott-Mariem (Sousse, Tunisia) Agricultural Engineering: University Jaume I (Castellon, Spain)

On 24 February 2017

Kaouthar Lebdi-Grissa

Tatiana Pina

Mohieddine Ksantini

Brahim Chermiti

Francisco J. Beitia

Beatriz Sabater-Muñoz

Monica A. Hurtado Ruiz
INAT

UJI

IO-Sfax

ISA-CM

UJI-IVIA

UJI-IVIA

UJI
President/Examiner

Referee

Referee

Supervisor

Supervisor

Supervisor

Tutor 


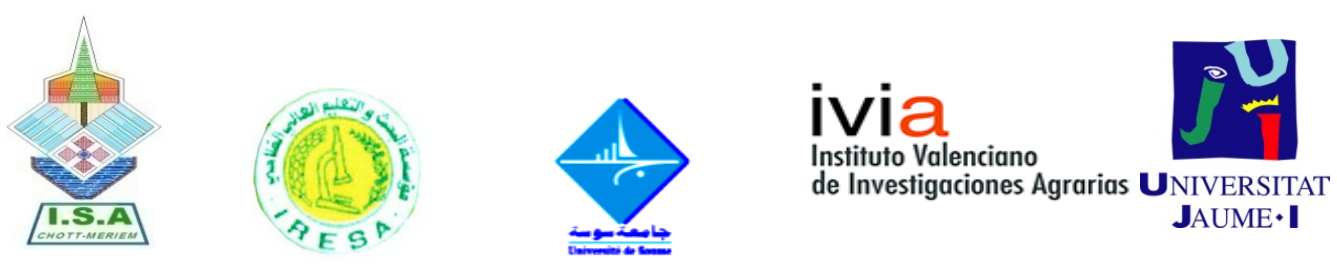

\section{Legal Statements}

Dr. Brahim Chermiti, Doctor of Philosophy in Agricultural Engineering, and Full Professor at the High Agronomic Institute of Chott-Mariem (ISA-CM, Sousse, Tunisia);

Dr. Francisco J. Beitia, Doctor of Philosophy in Biological Sciences, and Research Full Professor at the Valencia Institute of Agricultural Research (IVIA, Moncada (Valencia), Spain), at the Entomology joint unit IVIA-UJI;

and Dr. Beatriz Sabater Muñoz, Doctor of Philosophy in Biological Sciences, speciality of Molecular Biology and Evolution, and Research Associate professor at the Valencian Institute of Agricultural Research (IVIA, Moncada (Valencia), Spain) at the Entomology joint unit IVIA-UJI, and actually at the Smurfit Insitute of Genetics (University of Dublin, Trinity College, Dublin, Ireland).

\section{CERTIFY:}

That Mrs. Ahlem HARBI, Agricultural engineer (speciality Horticulture) with Master in Plant and Environment Protection by the High Agronomic Institute of Chott-Mariem, registered at the Plant Protection Doctoral school of ISA-CM and at the Sciences doctoral school of the University Jaume I (UJI), had realized under their supervision the doctoral thesis titled "Diachasmimorpha longicaudata as Biological Control agent of the Mediterranean fruit fly, Ceratitis capitata: biotic and abiotic factors affecting its implementation in citrus crops of the Mediterranean basin"

Signed by the supervisors as legal statement in compliance with current legislation covered by the international joint tutelage ISA-CM and UJI.

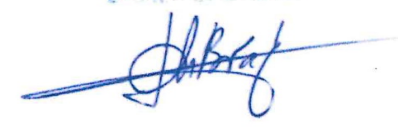

Dr. B. Chermiti

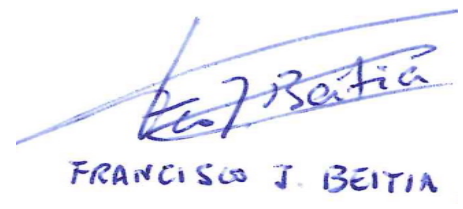

Dr. F.J. Beitia

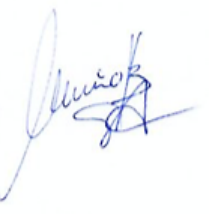

Dr. B. Sabater-Muñoz 


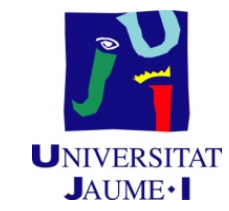

Dr. Monica A. Hurtado Ruiz, Doctor of Philosophy in Agricultural Engineering, and Associated Professor at the University Jaume I (UJI, Castellon, Spain), as Tutor of Mrs. Ahlem HARBI at the Sciences doctoral school, speciality Plant production, of the University Jaume I

\section{CERTIFY:}

That Mrs. Ahlem HARBI, Agricultural engineer (speciality Horticulture) with Master in Plant and Environment Protection by the High Agronomic Institute of Chott-Mariem, is registered at at Sciences doctoral school of the University Jaume I (UJI), and has accomplished all the courses, experimental work, public presentation of results (at International and National scientific meetings, along publication of the results in scientific journals) and has wrote the presented dissertation titled "Diachasmimorpha longicaudata as Biological Control agent of the Mediterranean fruit fly, Ceratitis capitata: biotic and abiotic factors affecting its implementation in citrus crops of the Mediterranean basin", fulfilling the University Jaume I Doctoral school requirements to allow her the deposit of the present dissertation as first step to achieve the degree of Doctor of Philosophy.

Signed in compliance with current University Jaume I and Spanish Ministry of Higher education legislation covered by the international joint tutelage UJI-ISA CM.

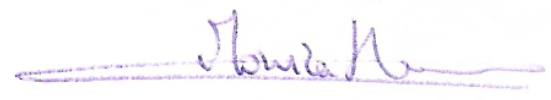

Dr. M. A. Hurtado Ruiz 


\section{Declaration}

This thesis dissertation is submitted by the undersigned, after endorsement by the supervisors and Doctoral school tutor, for the degree of Doctor of Philosophy at the University Jaume I of Castellon (Spain) and at the High Agronomic Institute of Chott-Mariem (ISA-CM) (Tunisia). This work has not previously been submitted as an exercise for a degree at these two, or at any other University. Except where otherwise stated, the work described herein has been carried out by the author alone. The experimental work had been conducted at the IVIA research station and/or at the ISA-CM research station as indicated in the International Joint Tutelage contract. To fulfil with this contract, the present thesis dissertation has been fully written in English, with an extended abstract in the official languages of the University Jaume I and from the High Agronomic Institute of Chott-Mariem.

According to Spanish legislation, this thesis has been deposited at the TESEO (Spanish Ministry of Education Thesis database) and may be borrwoed or copied upon request with the permission of the Librarian, University Jaume I.

According with Tunisian legislation, by agreement with decree number 1823 of date $6^{\text {th }}$ September 1993 (article no. 17) and with decree 47 of date $4^{\text {th }}$ January 2013 (article no. 14), this thesis subject, approved by the Doctoral Commission, is recorded at the site of the national Ministry of Higher Education and Scientific Research "theses-tn.net", becoming available for researchers and professors.

\section{Ahlem Harbi}

High Agronomic Institute of Chott-Mariem

Entomology joint unit Valencian Institute of Agricultural Research - University Jaume I

2017 


\section{Table of Contents}

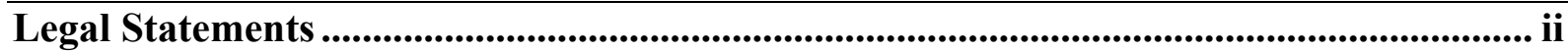

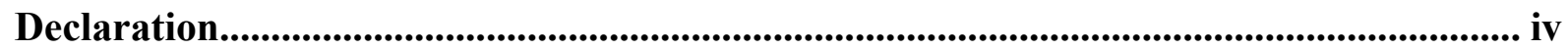

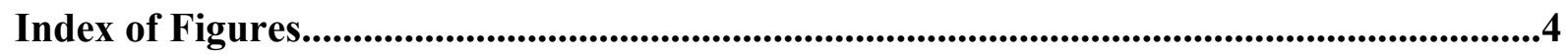

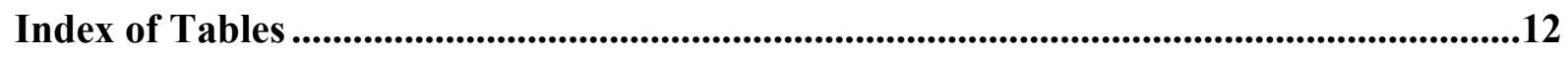

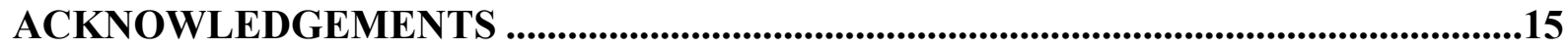

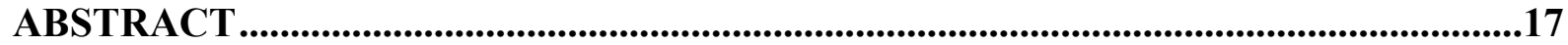

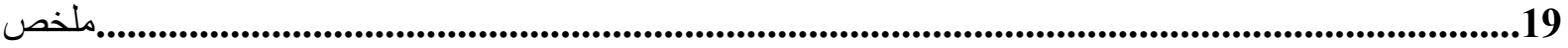

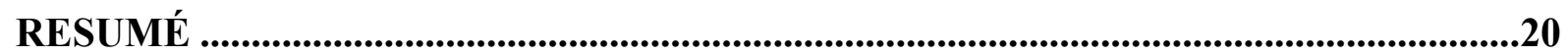

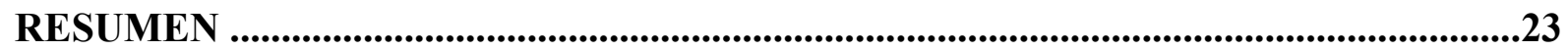

CHAPTER 1. Citrus crops, their pests and control methods in the Mediterranean basin:

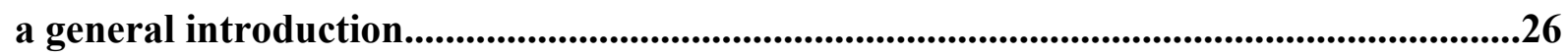

1.1. Current situation of citrus pests in the Mediterranean region ...................................27

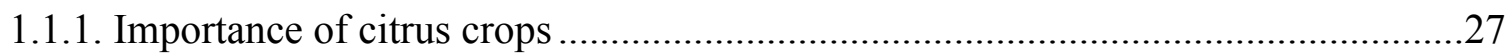

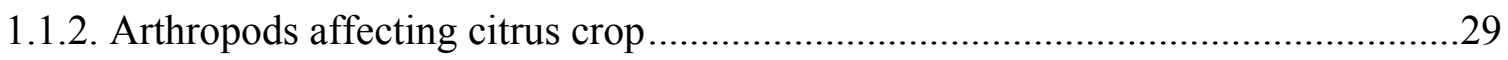

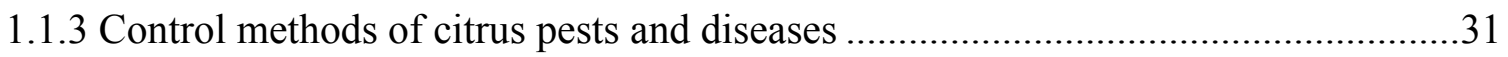

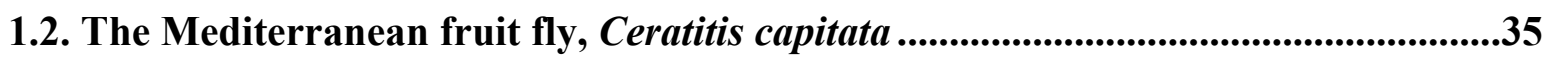

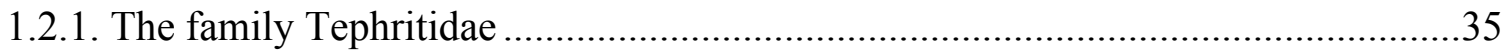

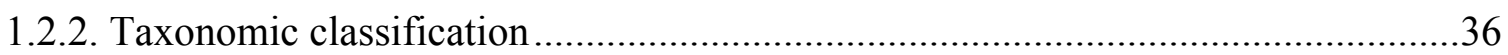

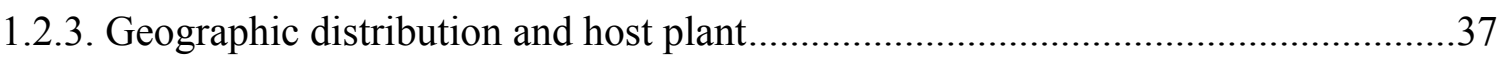

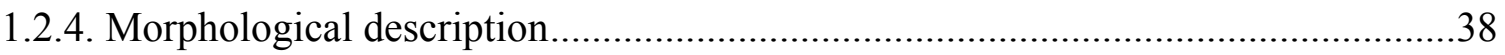

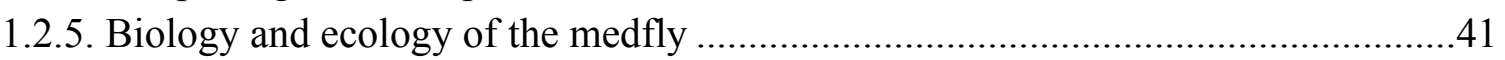

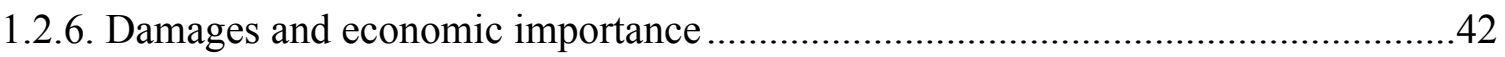

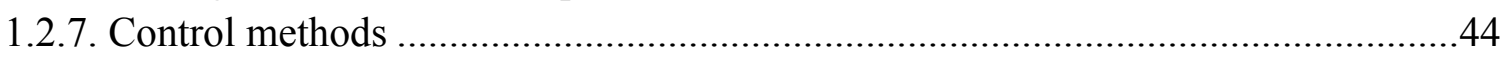

1.3. Objectives and rationale ..................................................................................54

CHAPTER 2. Biotic and abiotic factors affecting parasitic activity of Diachasmimorpha

longicaudata over the Mediterranean fruit fly, Ceratitis capitata .....................................55

2.1. Diachasmimorpha longicaudata ......................................................................56

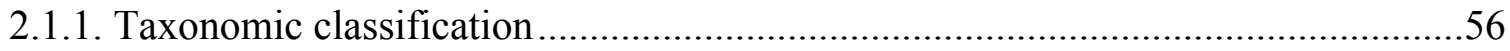

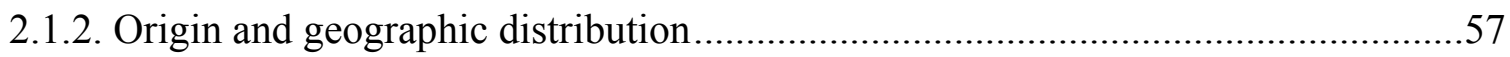

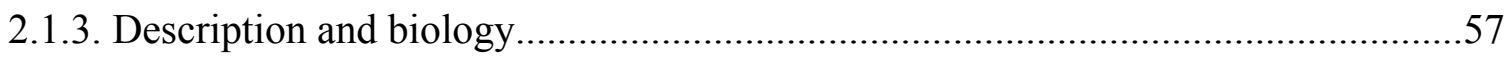

2.1.4. Importance of biological parameters of D. longicaudata for Biological Control ...61

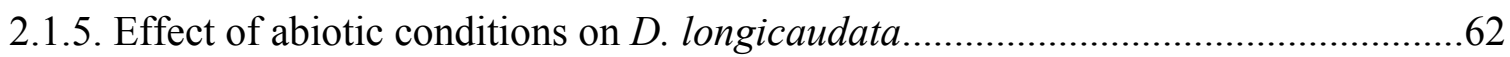

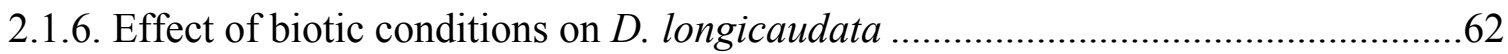

2.2. Material and Methods.....................................................................................63

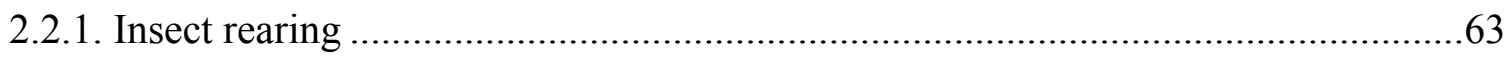

2.2.2. Life history parameters of $D$. longicaudata IVIA laboratory strain.......................67

2.2.3. Effect of the temperature on the longevity of $D$. longicaudata adults ....................69 


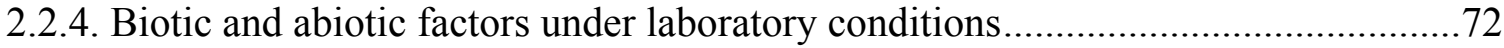

2.3. Results and Discussion ..........................................................................................78

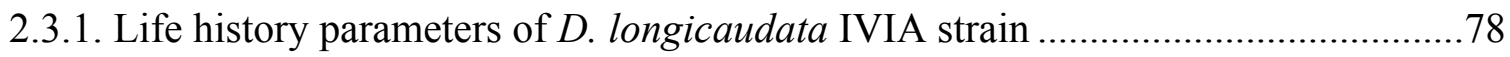

2.3.2. Abiotic factors affecting $D$. longicaudata adult longevity: temperature ..................83

2.3.3. Abiotic and biotic factors: effect of the temperature and host larvae density on the offspring production of $D$. longicaudata reared on Ceratitis capitata larvae under

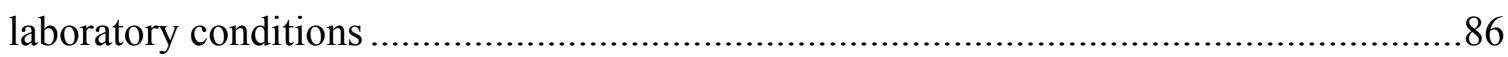

2.3.4. Influence of fruit location and host density in semi-field conditions on $D$.

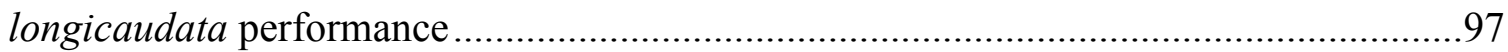

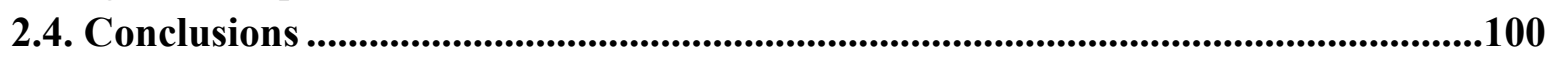

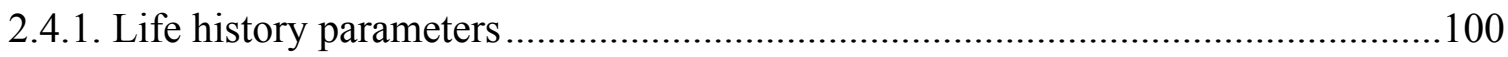

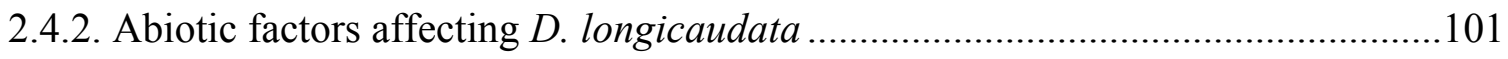

2.4.3. Biotic factors affecting D. longicaudata parasitism ........................................... 101

CHAPTER 3. Biotic and abiotic factors affecting parasitic activity of Diachasmimorpha

longicaudata over the Mediterranean fruit fly, Ceratitis capitata, under Mediterranean

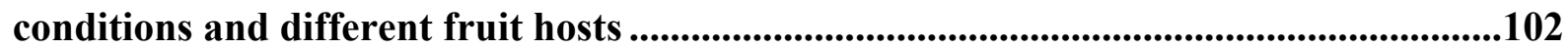

3.1. Abiotic and biotic factors affecting parasitoids performance..................................103

3.1.1. Abiotic factors affecting parasitoid foraging abilities .........................................103

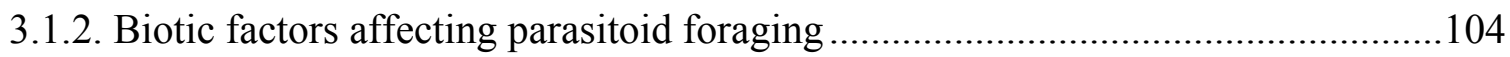

3.2. Material and Methods......................................................................................105

3.2.1. Determination of abiotic factors influencing $D$. longicaudata parasitism activity

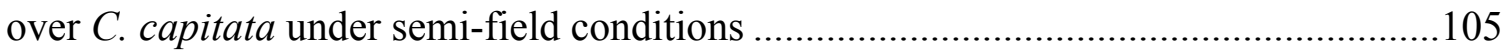

3.2.2. Determination of $D$. longicaudata ability to control medfly focal points ..............108

3.2.3. Effect of $C$. capitata host fruit on the behavior of D. longicaudata: from chemical

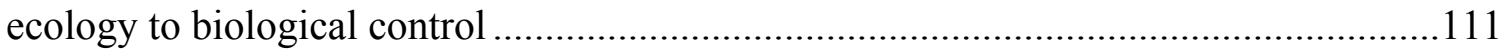

3.3. Results and Discussion ...................................................................................117

3.3.1. Determination of abiotic factors influencing $D$. longicaudata parasitism activity

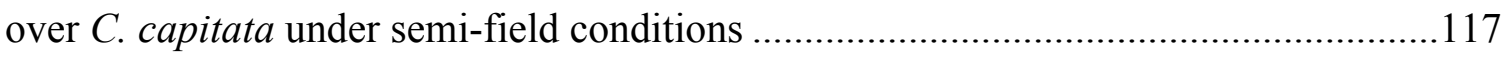

3.3.2. Determination of $D$. longicaudata ability to control medfly focal points ..............130

3.3.3. Effect of $C$. capitata host fruit on the behavior of D. longicaudata: from chemical

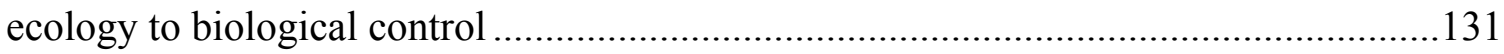

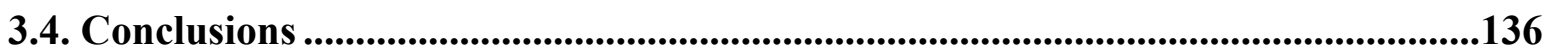

3.4.1. Determination of abiotic factors influencing $D$. longicaudata parasitism activity

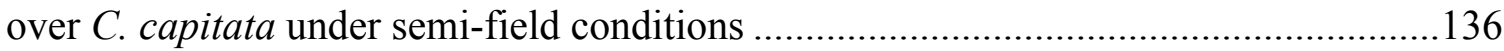
3.4.2. Determination of $D$. longicaudata ability to control medfly focal points ..............136 3.4.3. Effect of $C$. capitata host' fruit on the behavior of $D$. longicaudata: from chemical

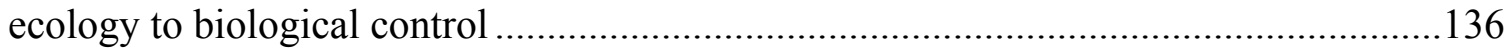

CHAPTER 4. Integration of Biological control within the IPM program against Ceratitis capitata in Spain. ..............................................................................................................................137

4.1. Introduction: the IPM program against $C$. capitata in Spain ................................138

4.1.1. Natural enemy release methods within Biological control programs....................139

4.1.2. Integration of Biological Control and the Sterile Insect technique .......................140 


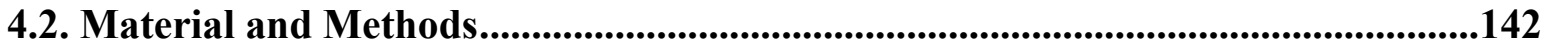

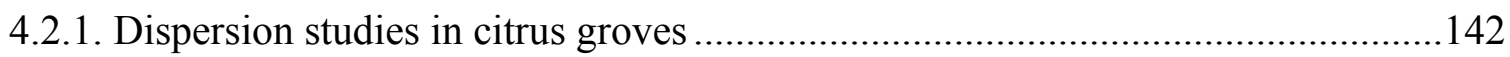

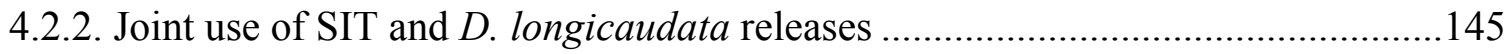

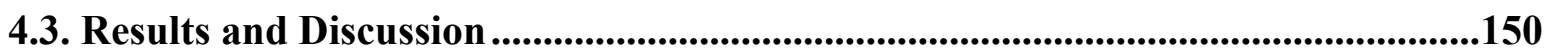

4.3.1. Dispersion pattern under natural conditions in citrus groves ............................... 150

4.3.2. Integration of $D$. longicaudata within the SIT program to control C. capitata ....157

4.4. Conclusions and Perspectives.....................................................................................161

4.4.1. Dispersal mode of $D$. longicaudata under Mediterranean conditions....................161

4.4.2. Integration of D. longicaudata releases within SIT program ............................... 161

CHAPTER 5. How to integrate Diachasmimorpha longicaudata in the Ceratitis capitata

control program in Tunisia? ....................................................................................................162

5.1. The Ceratitis capitata control program in Tunisia ........................................................163

5.1.1. Native versus imported exotic parasitoids........................................................... 164

5.1.2. Integrated pest management: the use of insecticides and their impact on $D$.

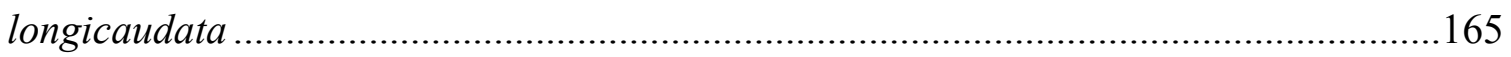

5.2. Material and Methods....................................................................................166

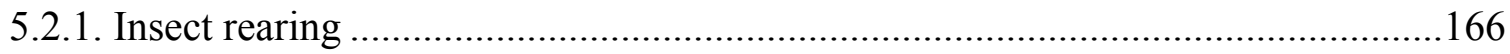

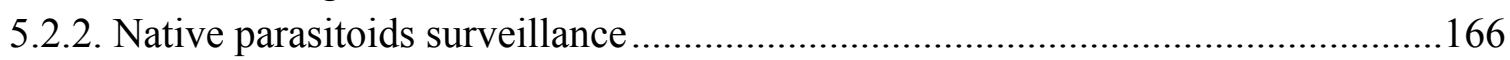

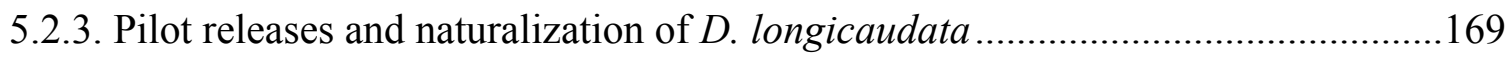

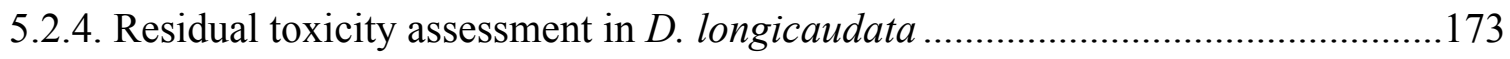

5.3. Results and Discussion ..........................................................................................176

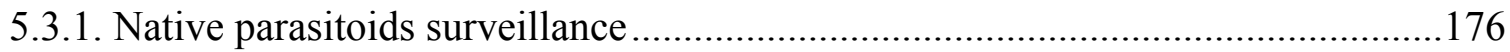

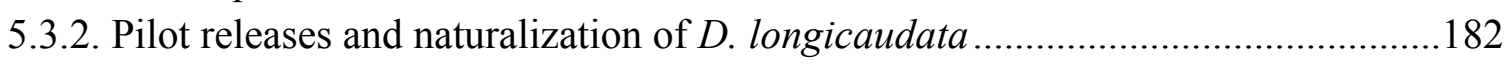

5.3.3. Residual toxicity of some insecticides on D. longicaudata ....................................189

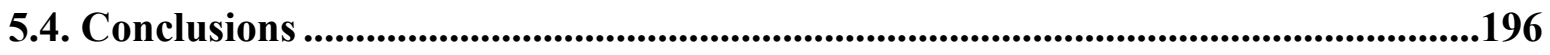

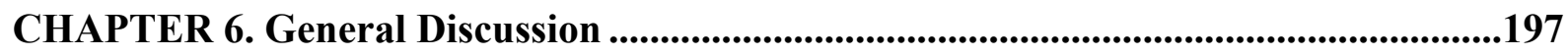

6.1. Determination of $\boldsymbol{D}$. longicaudata parasitic potential (and its affecting factors) against $C$. capitata ...............................................................................................198

6.2. Biotic and abiotic factors affecting parasitic activity of $D$. longicaudata against $C$.

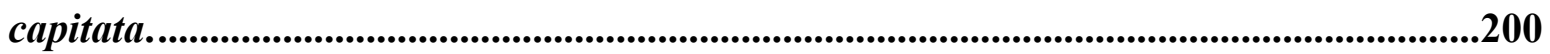

6.3. Integration of $D$. longicaudata within the IPM program in Spain .......................201

6.4 Key points for the establishment of a Biological Control program, based on $D$.

longicaudata, against $C$. capitata in Tunisia ...........................................................203

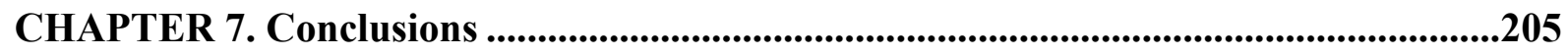

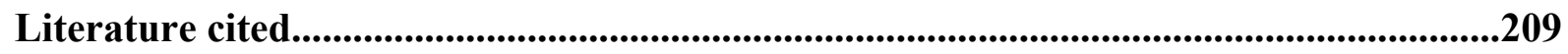




\section{Index of Figures}

CHAPTER 1. Citrus crops, their pests and control methods in the Mediterranean basin: a general introduction

Figure 1.1. Population and distribution of agriculture land in the Mediterranean basin. A) World map with indication of cropland fraction. B) A Mediterranean basin zoom with indication of agricultural land and human population. As can be seen, olive growing (green), viticulture (cayenne color) and irrigated areas (teal) form a patchy landscape in almost all the countries, specially in Spain, Greece, Italy and Tunisia (taken from Beilstein and Bournay 2011)

Figure 1.2. Distribution of citrus production in the Mediterranean basin, Spain as a first country and Tunisia as object of this thesis had been highlighted in the graph (data obtained from FAO 2016).

Figure 1.3. Some Ceratitis species with indication of species specific taxonomic characters. A) forewing of C. capitata; B) General habitus of C. quinaria (Bezzi) (five spotted fruit fly); C) General habitus of C. silvestrii Bezzi (Ekesi and Billah 2007).

Figure 1.4. Geographical distribution of the Medfly in the world (FAO/IAEA, 2013).

Figure 1.5. Morfology of developmental stages of Ceratitis capitata. A and B: Medfly eggs; C: Lateral view of a mature larva (from Thomas et al. 2014); D: L3 larva; E: several pupae ordered by age, from recent to nearly ready to emerge; F: adult male; G: adult female; the bar $=1 \mathrm{~mm}$........

Figure 1.6. Life cycle of the Mediteranean fruit fly

Figure 1.7. Damages on fruits caused by C. capitata. A, B and C:on peach fruits; D and E: on oranges; F and G: on apples; H and I: massive dropped damaged fruits.

CHAPTER 2. Biotic and abiotic factors affecting parasitic activity of Diachasmimorpha longicaudata over the Mediterranean fruit fly, Ceratitis capitata

Figure 2.1. Mandibles of the larvae of D. longicaudata, Ashmead; A-D, first through fourth instars (Ibrahim et al. 1994).

Figure 2.2. Immature stage of development of $D$. longicaudata. a: Egg. Bar: $500 \mu \mathrm{m}$; b: First instar larva; c: Late First instar larva; d: Second instar larva, arrowhead points to the mouth; e: Third instar larva; f: Mandibles of third instar larva. Bar: $500 \mu \mathrm{m}$; g: Prepupa, arrowhead pointed to the pigmented eyes; h: Male pupa, arrowhead points to the end of the antennae; i: Female pupa, 
arrowhead points to the end of the antennae, arrow shows the ovipositor; $\mathrm{j}$ : Male pharate adult; $\mathrm{k}$ : Female pharate adult. Bar: $1 \mathrm{~mm}$ (modified from Carbajal-Paladino, 2010)

Figure 2.3. Diachasmimorpha longicaudata adult lateral view. A: Female; B: Male.

Figure 2.4. Climatic chamber (walking in; built-in-house) of the IVIA research station on which several insect species are reared and where some of the tests took place.

Figure 2.5. Medfly rearing cage with collecting-eggs recipients and a detail (right) of the oviposition mesh frame that attracts almost all medfly females.

Figure 2.6. Development of medfly immature instars (from eggs to pupae) in different plastic cages.

Figure 2.7. Diachasmimorpha longicaudata rearing cage (left) with a detail (right) of females upside-down, some of them locating medfly larva for egg oviposition.

Figure 2.8. Developmental units where $D$. longicaudata parasitized medfly pupa were allowed to develop till emergency of male parasitoids (10-25 days).

Figure 2.9. Flow diagram of $C$. capitata and $D$. longicaudata rearing established at ISA-CM (Tunisia) and IVIA (Spain).

Figure 2.10. Experimental dispositive for the life table study of $D$. longicaudata.

Figure 2.11. SANYO climatic chamber with temperature, humidity and photoperiod control used to determine effect of temperature on adult longevity.

Figure 2.12. Experimental units used to determine adult longevity at each temperature, showing water container and ventilation frames.

Figure 2.13. Field cage used to determine D. longicaudata longevity. Wood-framed cage was protected under the shadow of a lemon tree, plus covered with a plastic roof to protect experimental units from rain.

Figure 2.14. Experimental set up used to study the effect of host density on parasitism rate.

Figure 2.15. Apple artificial infestation system. At the left, medfly L2-L3 larva were selected by washing artificial rearing diet with a sugar saturated water solution, and distributing three larvae per hole, holes were closed with apple plugs reducing larva exposure (right).

Figure 2.16. a) Experimental greenhouse, b) cages installed inside the greenhouse.

Figure 2.17. Experimental design. A) Prepared sentinel fruits, B) Disposition of sentinel apples in citrus young tree and in tray in each cage, C) control apples in individual cylinders, D) released parasitoid in the cage, E) $D$. longicaudata parasitizing host located at the tree canopy, F) $D$. longicaudata parasitizing larvae in ground-located fruits.

Figure 2.18. Daily fertility (mean) of $D$. longicaudata females reared on medfly.

Figure 2.19. Survivorship ( $l x)$ curves of D. longicaudata males and females reared on Ceratitis capitata third instar larva. 
Figure 2.20. Dichasmimorpha longicaudata IVIA strain progeny daily sex ratio $\left(\mathrm{n}_{\mathrm{F}} / \mathrm{n}_{\mathrm{F}}+\mathrm{n}_{\mathrm{M}}\right)$, reared on C. capitata third instar larvae.

Figure 2.21. Average longevity ( $\pm \mathrm{SE}$ ) (in days) of $D$. longicaudata adults at constant temperatures $\left(\mathrm{C}^{\circ}\right)$, separated by sex

Figure 2.22. Longevity (mean $\pm \mathrm{SE}$ ) (days) of $D$. longicaudata adults at field conditions during the different seasons tested. Climatic data for these seasons are listed in Table 2.4.

Figure 2.23. Longevity (mean $\pm \mathrm{SE}$ ) (days) of $D$. longicaudata adults (females in blue, males in red) batches at laboratory conditions $\left(25 \pm 2{ }^{\circ} \mathrm{C}, 50-70 \% \mathrm{RH}, 16: 8 \mathrm{~h} \mathrm{~L}: \mathrm{D}\right)$ used as controls for longevity at field conditions

Figure 2.24. Parasitism percentage (\%) recorded for each third instart medfly larvae density (45, 180 and 360) at a different range of temperatures $\left({ }^{\circ} \mathrm{C}\right)$......

Figure 2.25. Relationship between the parasitism percentage of $D$. longicaudata and $C$. capitata third instart medfly larvae density (log density) at a different range of temperatures $\left({ }^{\circ} \mathrm{C}\right)$.

Figure 2.26. Fertility (as number of offspring $\pm \mathrm{SE}$ ) of $D$. longicaudata at different third instart medfly larvae densities $(45,180$ and 360$)$ and different range of temperatures $\left({ }^{\circ} \mathrm{C}\right)$. The trendline for the high temperatures range (logaritmic scale) is also shown with its $\mathrm{R}^{2}$ coefficient value.

Figure 2.27. Relationship between the fertility (as number of offspring produced) of $D$. longicaudata and the supplied third instart medfly larvae densities (log density) at a different range of temperatures $\left({ }^{\circ} \mathrm{C}\right)$

Figure 2.28. Variation of the parasitism percentage (\%) and the fertility (number of offspring produced) of $D$. longicaudata at three third instar medfly larvae density $(45,180$ or 360$) \ldots \ldots$.

Figure 2.29. Sex ratio (expressed as female percentage produced; mean $\pm \mathrm{SE}$ ) of $D$. longicaudata offspring at a different range of temperatures $\left({ }^{\circ} \mathrm{C}\right)$ obtained at three supplied medfly host densities $(45,180$ or 360$)$.

Figure 2.30. Corrected mortality percentage (mean \pm SE) per medfly host density (45, 180 or 360 ) obtained by D. longicaudata at a different range of temperatures $\left({ }^{\circ} \mathrm{C}\right) \ldots$

Figure 2.31. Functional response of $D$. longicaudata parasitizing C. capitata larvae at three different prey densities. Number of parasitized preys was the averaged medfly larvae number (emerged parasitoids plus uneclosed pupa due to parasitoid activity). Data fitted to logarithmic equation at both temperature ranges.

Figure 2.32. Diachasmimorpha longicaudata parasitism percentage (\%) (mean $\pm \mathrm{SE})$ per medfly host density, when the host is provided within fruit, resembling natural conditions. 
Figure 2.33. Diachasmimorpha longicaudata fertility (as number of offspring produced $\pm \mathrm{SE}$ ) per medfly host density, when the host is provided within fruit, resembling natural conditions

Figure 2.34. Diachasmimorpha longicaudata sex-ratio (\%) (as female percentage produced, mean $\pm \mathrm{SE}$ ) per medfly host density, when the host is provided within fruit, resembling natural conditions.

Figure 2.35. Parasitism percentage (mean $\% \pm \mathrm{SE}$ ) per host density and fruit locations (in blue fruits located at canopy, in red those located at ground level).

Figure 2.36. Fertility (mean \pm SE) per host density 1.2:1, 6:1 or 12:1 (L2-L3 medfly larvae : $D$. longicaudata female) and fruit location (canopy or ground-level)

Figure 2.37. Sex-ratio (mean $n \pm S E$ ) of offspring per host density (1.2, 6 or 12 L2-L3 medfly larvae per D. longicaudata female) and fruit location (canopy or ground level).

Figure 2.38. The induced mortality (\%) (mean \pm SE) per host density (1.2, 6 or 12 L2-L3 medfly larvae per D. longicaudata female)

CHAPTER 3. Biotic and abiotic factors affecting parasitic activity of Diachasmimorpha longicaudata over the Mediterranean fruit fly, Ceratitis capitata, under Mediterranean conditions and different fruit hosts.

Figure 3.1. a) Experimental unit, b) experimental unit and parasitized pupae in the frame cage in the field..

Figure 3.2. The climatic station at the IVIA research fields, and data logger used to record temperature and relative humidity inside the wood framed mesh cages used for the trials.

Figure 3.3. Experimental design for the medfly focal point control assays. a) One of the caged clementine (var. Clemenules) tree used; b) C. capitata artificially infested apples; c) experimental installation and d) released $D$. longicaudata on the caged tree.

Figure 3.4. Olfactometer device set up at the IVIA research station. a) Dark room and illumination over the olfactometer; b) and c) compressed air pump and manometer; d) and e) detail of Y-shaped tube.

Figure 3.5. Setup for fruit host cues as biotic factor affecting D. longicaudata parasitism. a) and b) no-choice experimental units containing Royal gala apples or clementines; c) dual-choice experimental unit with Royal gala apples and clementines; d) isolated 6 to 8-d-old D. longicaudata couples ready for release; e) view of climatic chamber with one assay; f) recovered pupae isolated in $150 \mathrm{ml}$ ventilated vials for adult emergence..

Figure 3.6. Setup for fruit host cues as biotic factor affecting $D$. longicaudata parasitism under semi-field trials. a) and b) top view of inside of experimental units containing medfly infested 
Royal gala apples or nectarines; c) lateral view of the cabinet; d) isolated 6 to 8-d-old $D$. longicaudata couples ready for release; e) view of closed experimental unit with one assay.

Figure 3.7. Parasitism percentage $\%$ (mean $\pm \mathrm{SE}$ ) induced by D. longicaudata on C. capitata infested fruits subjected to field climatic conditions along a year round assay. Different letters above the bars indicate statistical differences among means.

Figure 3.8. Parasitism percentage \% (mean $\pm \mathrm{SE}$ ) induced by D. longicaudata on C. capitata infested fruits subjected to field climatic conditions along a year round assay and transferred to laboratory to avoid parasitoid immature death (field-lab series). Different letters above the bars indicate statistical differences among means.

Figure 3.9. Comparision of parasitism percentage $\%$ (mean $\pm \mathrm{SE}$ ) induced by D. longicaudata on C. capitata infested fruits subjected to field climatic conditions along a year round assay or transferred to laboratory to avoid parasitoid immature death. Different letters indicate above the bars indicate statistical differences $(\mathrm{P}<0.05)$ among each pair of values on the same month.

Figure 3.10. Identification of specimens from dissected uneclosed medfly pupae subjected to parasitism by $D$. longicaudata. a) visualization of non emerged $D$. longicaudata pharate adults; and b) some $D$. longicaudata late third instar larva or early pupa observed in dissected uneclosed pupae

Figure 3.11. Induced mortality $\%$ (mean $\pm \mathrm{SE}$ ) by $D$. longicaudata on $C$. capitata infested fruits subjected to field climatic conditions along a year round assay. Different letters above the bars indicate statistical differences $(\mathrm{P}<0.05)$ among means of each trial.

Figure 3.12. Variation of parasitism activity $\%$ (mean $\pm \mathrm{SE}$ ) and mean induced mortality $\%$ (mean $\pm \mathrm{SE}$ ) of D. longicaudata on $C$. capitata infested fruits subjected to field climatic conditions along a year round assay

Figure 3.13. Medfly population reduction $\%($ mean $\pm \mathrm{SE})$ by the activity of $D$. longicaudata along a year round assay under Mediterranean natural conditions. ...

Figure 3.14. PCA ordination graph of the correlation among the D. longicaudata parasitism percentage and environmental variables. a) F1 and F2; b) F1 and F3. Principal component 1 (F1) explained $56.4 \%$ of the variability of the data; principal component 2 (F2) explained $24.5 \%$ of the variability and the principal component 3 (F3) explained $10.6 \%$ of the

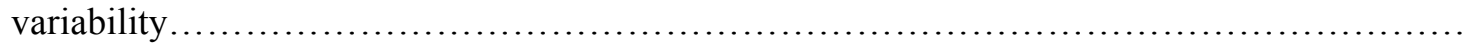

Figure 3.15. Pattern of D. longicaudata parasitism percentage depending on temperature and relative humidity obtained from the proposed ML regression model.

Figure 3.16. PCA ordination graph of the correlation among the induced mortality percentage and environmental factors measured in 12 different trials 
Figure 3.17. Relationship between the induced mortality and the relative humidity parameters (at the left, F2: Min RH + Mean RH; at the right, F3: Max RH + CV RH).

Figure 3.18. Diachasmimorpha longicaudata female odour response to different odour sources in percentage of responding females. Data were obtained with a Y-tube olfactometer, with different fruit host combinations, including medfly infested and uninfested fruits, as indicated in the graph. The number of individuals recorded (n) for each odor pair is shown between brackets. Asterisk represents significant $(P<0.05)$ differences in the distribution of side arm choices.

CHAPTER 4. Integration of Biological control within the IPM program against Ceratitis capitata in Spain.

Figure 4.1. Aerial pictures of the two 1-ha citrus plots used for this study with indication of the releasing point, sampling points and numbers, and location of Meteorological station (MS) in site for first year (A) and second year (B). Both plots are within the IVIA Research station and separated less than $1 \mathrm{~km}$. The blanks within the pictures do not mean absence of trees, these aerial pictures were done in some cases 5 years before this experiment.

Figure 4.2. Releasing cages of $D$. longicaudata used in the experiment.

Figure 4.3. Experimental dispositive to assess the dispersion and the parasitism of released $D$. longicaudata, containing infested sentinel apples within a semiprotective environment, and location of a sticky-yellow plate

Figure 4.4. Experimental citrus clementina field with a row of single-isolated trees with antithrips screened cages for field trials purpose, with a detail of the zippered door in one of the sides.

Figure 4.5. Jars used to maintain adult flies from emergence to introduction into field cages....

Figure 4.6. Experimental set up inside the field cages trees

Figure 4.7. Controlling the presence of $C$. capitata L2-L3 instar larvae inside the sentinel apple

Figure 4.8. Set up with collected females in the release pots (left picture) and a detailed released

D. longicaudata female (right picture) within the cage.

Figure 4.9. Parasitoids number recorded in the yellow sticky traps in the different trials. The star on the graphs mean the center of the orchard which is the release point. Each color represents a tree row with a trap, numbers indicate the tree number within each row.

Figure 4.10. Parasitism percentage generated by the released D. longicaudata in the different trials. The star on the graphs mean the center of the orchard which is the release point... Each color represents a tree row with a trap, numbers indicate the tree number within each row. 
Figure 4.11. Pattern of monitored climatic conditions during trial in field cages.

Figure 4.12. Parasitism percentage $(\%$, average \pm SE) obtained at each successful trial. Statistical differences were found between $D$. longicaudata release ratios (1:1, 3:1 and 5:1) and among trials ( $t$-paired)

Figure 4.13. Induced mortality $(\% \pm \mathrm{SE}$; corrected by natural mortality in control plots) exerted by D. longicaudata at different release ratios (1:1,3:1 and 5:1).

Figure 4.14. Box plot of Induced mortality (corrected by natural mortality in control plots) exerted by $D$. longicaudata at different release ratios $(1: 1,3: 1$ and $5: 1)$, where it can be observed the presence of outliers in all the release ratios with statistical differences $(F=4.5173 ; d f=2,8$; $P=0.01845$ ). As demonstrated in previous studies, seasonality is affecting parasitoid performance.

Figure 4.15. Corrected average $C$. capitata population reduction (\%) by the joint use of v8 sterile males and D. longicaudata at different release ratios $(1: 1,3: 1$ and 5:1).

CHAPTER 5. How to integrate Diachasmimorpha longicaudata in the Ceratitis capitata control program of Tunisia.

Figure 5.1. Map of Tunisia and location of three experimental sites (stars) where the screening of native Medfly parasitoids was carried out.

Figure 5.2. Medfly infested fruits recovered and retrieved to the laboratory for parasitoid screening (left), and containers used to allow development of recovered medfly pupae (right)..

Figure 5.3. Aereal view of the Technical Center of Organic Agriculture (CTAB) experimental site aerial view. As can be seen, the 1-hectare orchard is evenly planted with citrus, and surrounded by cypress in the entire perimeter.

Figure 5.4. Diachasmimorpha longicaudata release in the CTAB experimental site. As can be seen, one 'bug dorm' cage was placed in the center of the citrus plot, allowing leave of parasitoids by opening one window. Some parasitoids landed in the citrus leaves.

Figure 5.5. Diachasmimorpha longicaudata releases monitorization system. The left picture shows a sentinel fruit within a pupa containment system. The center picture shows one of the sentinel fruit situated within the release site. The right picture shows some ripe citrus fruits, naturally infested, collected for parasitism determination.

Figure 5.6. Diachasmimorpha longicaudata adult longevity determination system. The woodframed cage was protected with a rigid plastic cover as shelter for rain. A data logger was placed inside to determine the climatic parameters of each season.

Figure 5.7. Experimental dispositive to assess Diachasmimorpha longicaudata immature development under Tunisian natural climatic conditions. Left picture shows the boxes used to 
contain the parasitized medfly pupae. Right picture shows the disposition of boxes within woodframed cage under citrus shadow at the ISA-CM experimental site.

Figure 5.8. Isolator. Experimental dispositive to conserve turgid the pesticide treated leaves...

Figure 5.9. Experimental dispositive (unit) to assess $D$. longicaudata adult susceptibility to selected pesticides.

Figure 5.10. a) $P$. vindemmiae female parasitizing a pupa of $C$. capitata; b) the emergence hole of $P$. vindemmiae in the puparium of $C$. capitata; c) $P$. vindemmiae pupa over $C$. capitata pupa......

Figure 5.11. Some morphologic characters of $P$. vindemmiae. a) the wing, b) the male antennae, c) $P$. vindemmiae female in dorsal view, d) the leg

Figure 5.12. Some Psyttalia concolor (Szépligeti, 1910) female individuals found in ChottMeriem region. Notice the short ovipositor compared with the abdomen length.

Figure 5.13. Individual identified as Eulophidae, Tetraschinae, emerged from C.capitata pupa infesting citrus orchards in Tunisia.

Figure 5.14. Individuals identified as Diapriidae emerged from C. capitata pupae collected from citrus orchards in Tunisia..

Figure 5.15. Parasitism percentage (\%) induced by released D. longicaudata. Parasitism was recorded in sentinel fruits distributed in 20 points ( 5 columns and 4 rows of citrus trees). Each graph corresponds to the parasitism percentage obtained in each release (from Sept. 2013 to Dec. 2013).

Figure 5.16. Longevity (mean days $\pm \mathrm{SE}$ ) of $D$. longicaudata adults during the different seasons in Tunisia. 


\section{Index of Tables}

CHAPTER 1. Citrus crops, their pests and control methods in the Mediterranean basin: a general introduction.

Table 1.1. Some of the most common pests and diseases of citrus. Phytophagous pest arthropods are classified accordling its status in the Mediterranean region (reviewed from GIP citricos; www.gipcitricos.ivia.es and OILB).

Table 1.2. Natural enemies introduced in Spain for Classical Biological Control programs against citrus pests (modified from Jacas and Urbaneja 2010).

Table 1.3. Introduced natural enemies in Tunisia against citrus pests (B. Chermiti, personal communication)

Table 1.4. Classification and commercially available products of attract and kill.....

CHAPTER 2. Biotic and abiotic factors affecting parasitic activity of Diachasmimorpha longicaudata over the Mediterranean fruit fly, Ceratitis capitata.

Table 2.1. Ingredients of $C$. capitata artificial diet

Table 2.2. Biological parameters of $D$. longicaudata on different fruit fly host species.

Table 2.3 Demographic population parameters of $D$. longicaudata reported in the literature on different fruit fly species

Table 2.4. Recorded climatic conditions (mean, maxima and minima temperature and relative humidity, and rainfall) for the field assay for D. longicaudata adult longevity.

Table 2.5. Maximum likelihood estimation parameters from the generalised linear model of the proportion of parasitised hosts as a function of initial host densities by fertilized D.longicaudata females under laboratory and greenhouse conditions.

Table 2.6. Attack rate (a) $\left(\right.$ days $\left.^{-1}\right)$ and estimated prey-handling time (Th) (days) obtained from non-linear regression of the number of hosts by fertilized $D$. longicaudata females under laboratory and greenhouse conditions.

CHAPTER 3. Biotic and abiotic factors affecting parasitic activity of Diachasmimorpha longicaudata over the Mediterranean fruit fly, Ceratitis capitata, under Mediterranean conditions and different fruit hosts.

Table 3.1. Climatic conditions recorded during the parasitoid exposition period. 
Table 3.2. Climatic conditions during the parasitism and the immature development periods..

Table 3.3. Principal components extracted and quantitative characters.

Table 3.4. Results of Type III Sum of Squares analysis on the factors affecting the induced mortality

Table 3.5. Results of the analysis of the different principal component affecting the induced mortality

Table 3.6. Parasitism percentage, mortality percentage and population reduction induced by $D$. longicaudata activity on medfly larvae during the different medfly focal points control trials.

Table 3.7. Climatic conditions recorded during the different medfly focal points control trials

Table 3.8. Mean parasitism percentage (mean \pm S.E.), fertility (mean \pm S.E.) and sex ratio (mean \pm S.E.) of $D$. longicaudata comparing different fruit species in a non-choice and a dual choice test.

Table 3.9. Mean parasitism percentage (mean \pm S.E.), fertility (mean \pm S.E.) and sex ratio (mean \pm S.E.) of D. longicaudata produced on C. capitata larvae comparing different fruit species in a non choice test and a dual choice test in a laboratory conditions

CHAPTER 4. Integration of Biological control within the IPM program against Ceratitis capitata in Spain.

Table 4.1. Number of released $D$. longicaudata during the different trials

Table 4.2. Climatic data for each trial, with indication of mean values for the week on which was conducted each one

Table 4.3. Number and sex of recovered parasitoids in each trap and trial. The release point trap $154-$ is trap no. 13 .

CHAPTER 5. How to integrate Diachasmimorpha longicaudata in the Ceratitis capitata control program in Tunisia?

Table 5.1. Number of released D. longicaudata individuals at each trial.

Table 5.2. Insecticides evaluated for their acute toxicity to $D$. longicaudata adults

Table 5.3. Number of fruits, recovered pupae, emerged medfly and parasitoids identified, per screening region. 
Table 5.4. Climatic conditions registered in the release site of Technical center of organic agriculture (CTAB) in Chott-Meriem region

Table 5.5. Number and identity of recovered specimens from naturally infested fruits from the Pilot release citrus plot one week after each release.

Table 5.6. Number and identity of recovered specimens from naturally infested fruits from the Pilot release citrus plot one month after the last release.

Table 5.7. Temperature conditions, developmental time (in days) and emerged number of individuals during the trials for immature development under Tunisian winter climatic conditions.

Table 5.8. Percent mortality (mean \pm SE) of $D$. longicaudata adults after 3 days of exposure to selected residues and water-treated control

Table 5.9. Classification of selected pesticides at different residue age on D. longicaudata 6-8 days-old adults, according to IOBC classification 


\section{ACKNOWLEDGEMENTS}

This PhD project has been finanacially supported by the projects AGL2010-21349-C02-02 from the Spanish Ministry of Research, Development and Innovation (MICINN, actually known as MINECO), projects A/024220/09 and A/018277/08 from the Spanish Agency for International Development and Cooperation (AECID), and from projects from the Tuninisian Ministry of Agriculture, Hydraulic resources and Fisheries.

Additionally, I was the recipient of a grant from the Ministry of Higher Education of Tunisia, and I also obtained from the French government a travel grant for performing some of the stays in Spain not covered by AECID. I gratefully acknowledge the support and generosity of these institutions without which the present study could not have been completed.

This dissertation would not have been possible without the professional support of my profesors Prof. Brahim Chermiti, Dr. Fransisco J. Beitia and Dr. Beatriz Sabater-Muñoz. I would like to express my sincere gratitude and deep appreciation to them for their kind guidance, valuable time, encouragement and understanding for everything that happened during my study. I thank them for their patience and support during the long and arduous process of completing my research and writing the results.

I thank Dr. Monica A. Hurtado Ruiz, my academic tutor, for her administrative link with the UJI, it has been fundamental.

My gratitude to the TRAGSA biofactory for providing me the Ceratitis capitata sterile male to perform my trials. To Pepe Tormos, Maria Jesus Verdu, Alberto Urbaneja, Alejandro Tena, Josep Jacas, Meritxell Perez and César Monzó for their hospitality.

Many thanks to my colleagues and friends; Luisin, Azucena and Omarin for their help, unconditional support and love, they were my family in Spain. Amparo, Fernando and Maria José for helping me in laboratory, field and insectary work.

Thanks to all the team work of the entomological department in the IVIA: Juan Pedro, Francesc, Miguel, José, Tati, Ruth, Marian, Pablo Bru, Pili, Laura, Consuelo, Sara and Molli for their sympathy in my everyday work.

In Tunisia, I would like to thank Prof. Najet Raouani for her encouragement and kindness.

I'm so gratefull to all my friend in ISA-CM: Hania, Ilhem, Hajer, lobna, Abir, Soukaina, Mohamed, Hatem, Khaled, Ridha, Essia, Eya, Asma. Thank you for the happy moment and all the laughs we have had together. Thanks to Sawssen, Amel, Imen, Sana and Aymen. 
$\mathcal{A}$ mes chers parents $\mathcal{H}$ abib et $\mathcal{N}$ ejia.

Vous représentez pour moi le symbole de la bonté par excellence, la source de tendresse et lexemple du dévouement quí n'a pas cessé de m'encourager et de prier pour moí. Vos prières et bénédictions m'ont été dun grand secours pour mener à bien mes études. Aucune dédicace ne saurait être assez éloquente pour exprimer ce que vous méritez pour tous les sacrifices que vous n'avez cessé de me donner depuis ma naissance, durant mon enfance et jusqu'à maintement.

A mon Frère Helmi et ma sour Ikram, $\mathcal{A}$ la mémoire de mon grand père $\mathcal{C} \mathcal{A} I d$, $\mathcal{A}$ mes tantes et mes ancles,

$\mathcal{A}$ ma belle mère Rekaya, et mes belles sours $\mathcal{N a j w a , ~ H a j e r , ~ F e i z a ~ e t ~}$ Refka,

$\mathcal{A}$ mon cher mari Khaled, Ton encouragement et ton soutien étaient la bouffée doxygène qui me ressourçait dans les moments pénibles. Mercí dêtre toujours à mes côtés.

$\mathcal{A}$ mon petit bout de chou Mahdi que Dieu te préserve et te bénie. Que ce travail soit témoígnage de ma reconnaissance et de mon amour 


\section{ABSTRACT}

Ceratitis capitata Wiedemann (Diptera: Tephritidae) is a cosmopolitan pest, originary from West-Africa, that has invaded almost all the temperate and tropical countries by the unwanted aid of the men. During its adaptation to these new environments, $C$. capitata has widened its host plant portfolio, being nowadays a key pest for more than 400 plant species of economic importance. Due to this importance, many importing countries had established quarantine measures and borders against fruit world-wide trade, which had directly impacted on the plant protection policies of producer countries.

Spain and Tunisia are located in the Mediterranean basin; the first known world-wide dispersal point of $C$. capitata. In these two countries, $C$. capitata is considered a key pest mainly for citrus species and other soft-fruits. From a historical point of view, Plant Protection policies in Spain were switched from a nearly ecological management (with great losses) to mainly chemical-based treatments with the spread of organosphosphate compounds early on $\mathrm{XX}$ century. With the development of European Union, national Plant Protection plans were modified, introducing the Integrated Pest Management programs (IPM), on which environment and human-friendly methods should be selected instead of the most damaging chemical treatments. Following these steps, Tunisia is integrating the use of biorrational methods while keeping the use of chemicals as low as possible.

To this end, in the present thesis dissertation, I would focus on the use of natural enemies as the best and sustainable control method, coming back to the Biological Control programs that were successful in the past against other pests in both countries. More precisely, this dissertation is presenting the results on the implementation of Classical Biological Control against $C$. capitata in citrus, by the importation, evaluation and release of the parasitoid species Diachasmimorpha longicaudata (Ashmead) (Hymenoptera: Braconidae) in both countries. This parasitoid species, native from East Asia, is currently used against other tephritid pest species, key species for other countries and commodities.

In the First Chapter I will present a literature review on the Plant protection policies against this key pest, and what is know about the performance and success of this parasitoid species.

At the Second Chaper, I will present the results of the implementation of laboratory rearings of both insects to achieve all the remaining objectives, along with the determination of life parameters of the specie that will determine its success as natural enemy. In this second chapter I will also present the determination of biotic (host densities and availability) and abiotic 
(temperature, RH, rainfall) factors affecting the performance of D. longicaudata over $C$. capitata.

During the Third Chapter, I will demonstrate that D. longicaudata is able to exhert control of C. capitata under natural Mediterranean climatic conditions when either challenging the parasitoid with hosts directly from the laboratory rearing or in a more natural condition, within the fruits, a forestep required to determine its inclusion in the national Plant Protection Policies. Results show that $D$. longicaudata exhert up to $30 \%$ of medfly population reduction by means of induced mortality along the provisioning of new parasitoid offspring that would propagate and establish in the country. Along these results, I showed that D. longicaudata was able to control medfly infestation foci at a rate that depend on climatic conditions and on the number of released females.

At the Fourth Chapter, I will reveal the results of $D$. longicaudata dispersion abilities along its capability to exhert control of $C$. capitata populations while applied joinly with SIT, by means of open-field test trials, with a new developed sentinel fruits methodology. In this chapter, I consider also the abiotic factors that could determine its naturalization in other Mediterranean countries with similar climatic conditions. The results of this chapter highlight the need of such dispersal studies at the corresponding local climatic conditions to establish the release procedures.

At the Fifth Chapter, I will expose the results of importation and naturalization of $D$. longicaudata in Tunisia, with the required studies on the presence of native enemies and the identification of a new parasitoid Pachycrepoideus vindemmiae Rondani (Hymenoptera: Pteromalidae), the establishment of laboratory rearings for the release trials, and the side-effects of the available control measures that will face D. longicaudata in Tunisian citrus orchards which will determine the procedure in tempo and mode for the releases.

At the end of this dissertation, I will present the main conclusions achieved that can be summarized in: (i) D. longicaudata is a viable natural enemy that can be successfully released in Mediterranean countries against C. capitata; (ii) Its biotic potential under the mild climatic conditions identified will help in the naturalization of this species, and in the establishment of release protocols, but also, (iii) its climatic requirements highlight the need of switching from Classical Biological Control to Inoculative Biological control, that means that both countries require mass-rearing facilities to provide these insects, along the involvement of growers in the application of IPM measures including the augmentoriums to facilitate the naturalization of the introduced species along the preservation of the native ones. 
Ceratitis capitata (Diptera: Tephritidae)

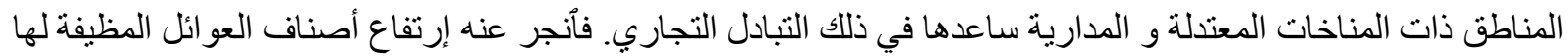

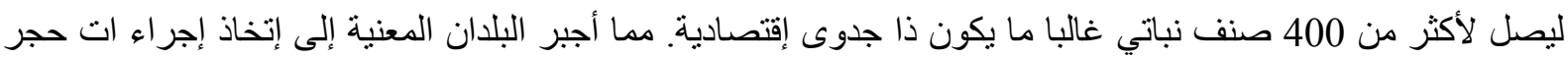

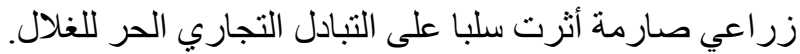

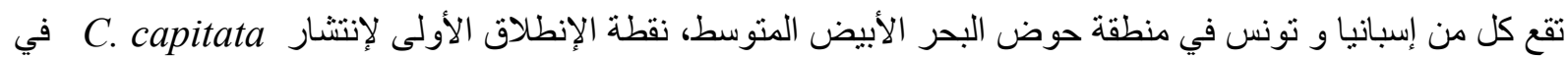

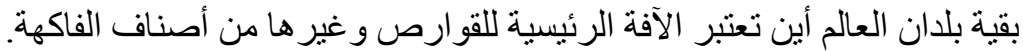

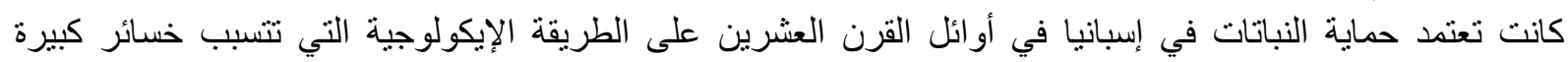

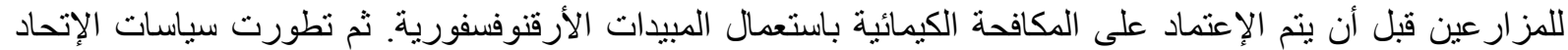

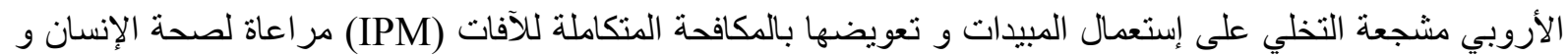

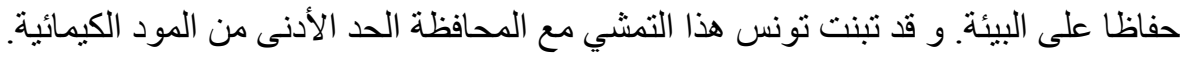

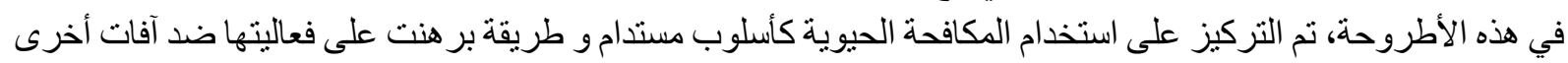

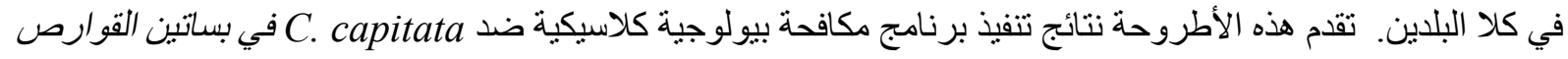

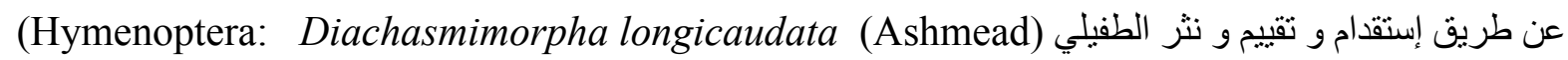
Braconidae) في الفصل الأول من هذه الأطروحة تم إستعر اض سياسات حماية النبات المعتمدة ضد هذه الآند الفيا في في العالم مع تقييم النجاحات التي نم تحقيقها في هذا الميدان.

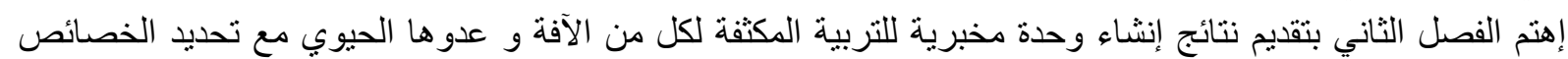

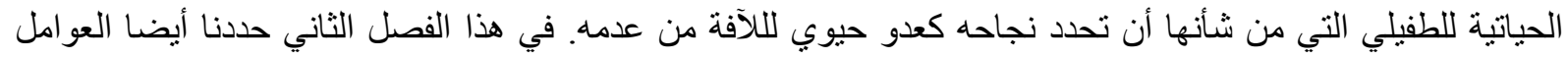

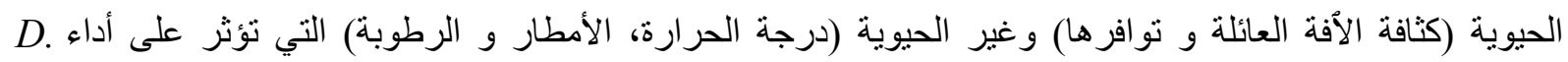
. longicaudata

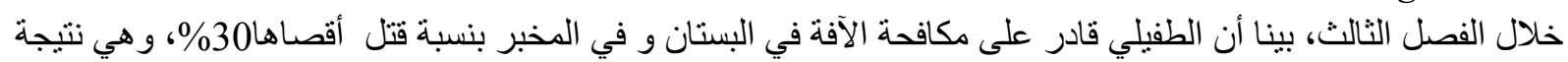

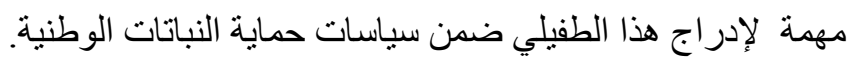

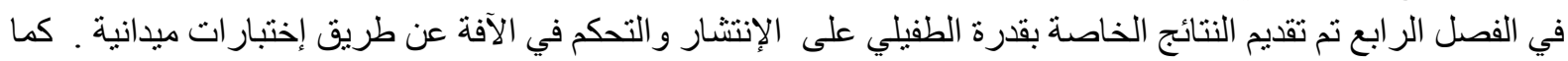

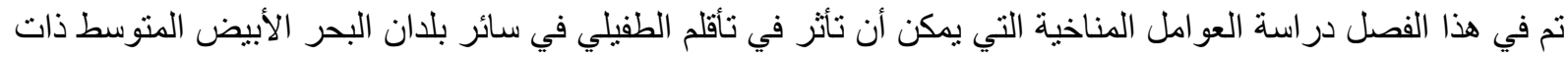

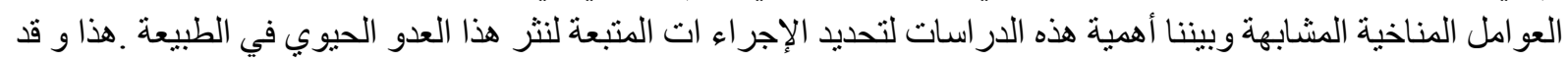

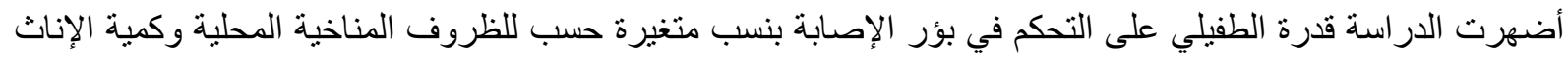

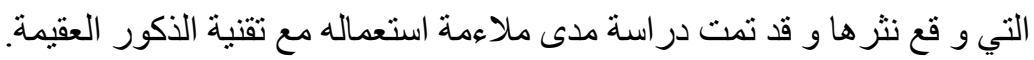

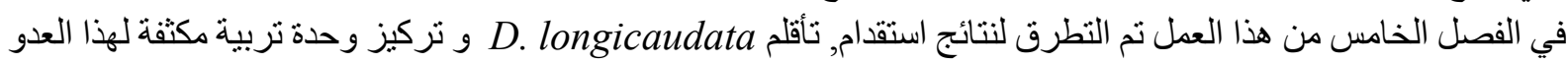
الحيوي في تونس. كما إهتم أيضا بدراسة الأعداء الحيوية المحلية منها Pachycrepoideus vindemmiae Rondani

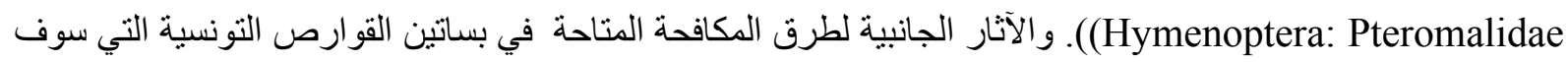
تحدد طريقة و توقيت إطلاق الطفيلي المستورد.

في نهاية هذه الأطروحة، قدمنا الاستتناجات الرئيسية التي يمكن تلخيصها في:D. longicaudata (i) هو عدو حيوي للذبابة

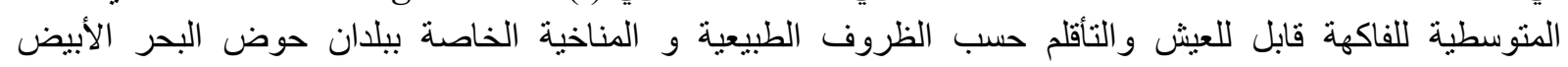

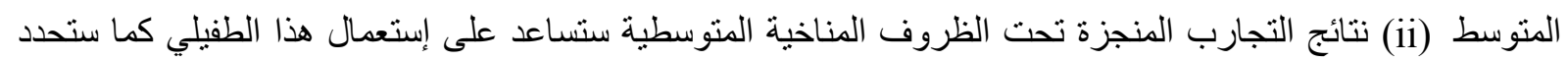
بروتوكول نثره في البساتين (iii) عدم قدرة هذا الطفيلي على قضاء فصل الثتاء في البساتين يحتم إنشاء مر افق تربية مكثفة

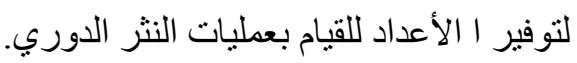




\section{RESUMÉ}

Ceratitis capitata Wiedemann (Diptera: Tephritidae) est un ravageur cosmopolite, originaire de l'Afrique occidentale. Il a envahi presque tous les pays tempérés et tropicaux suite à sa dissémination accidentelle facilitée par les activités humaines. Au cours de son adaptation à ces nouveaux environnements, $C$. capitata a élargi son éventail de la plantes hôtes pour devenir un ravageur clé pour plus de 400 espèces de plantes d'importance économique. De ce fait, de nombreux pays importateurs ont établi des mesures de quarantaine contre le commerce mondial des fruits, ce qui avait un impact direct sur les politiques de protection des végétaux des pays producteurs.

L'Espagne et la Tunisie sont situées dans le bassin méditerranéen, le premier point de dispersion connu de C. capitata vers le monde entier. Dans ces deux pays, C. capitata est considéré comme un ravageur clé principalement pour les espèces d'agrumes et d'autres fruits-doux. D'un point de vue historique, les politiques de protection des végétaux en Espagne, sont passés d'une gestion presque écologique (avec de grandes pertes) à des traitements à base de produits chimiques notamment des composés organosphosphorés dès le début du XXe siècle. Cependant, avec le développement de l'Union européenne, les plans de protection des végétaux nationaux ont été modifiés pour promouvoir les programmes de lutte intégrée (IPM), favorisant les méthodes de lutte respectueuses de l'environnement et de l'homme. Suite à ces mesures, la Tunisie, un pays exportateur de fruits vers l'Europe a adopté plusieurs méthodes alternatives de lutte contre ce ravageur tout en limitant l'utilisation des produits chimiques au minimum nécessaire.

Dans ce contexte, cette thèse de doctorat s'est intéressée à la lutte biologique contre la cératite comme la méthode la plus durable. Cette durabilité est attestée par la réussite des programmes de lutte biologique contre d'autres ravageurs dans les deux pays. En particulier, cette thèse présente les résultats relatifs à la mise en œuvre d'un programme de lutte biologique classique contre $C$. capitata en verger d'agrumes par l'importation, l'évaluation et le lâcher du parasitoïde Diachasmimorpha longicaudata (Ashmead) (Hymenoptera: Braconidae) en Espagne et en Tunisie. Ce parasitoïde est originaire d'Asie de l'Est et il est actuellement employé contre d'autres espèces de mouches tephritidae, ravageurs clés des fruits à travers le monde. 
Le premier chapitre de la thèse a été consacré à une revue bibliographique avec un focus sur les politiques de protection des plantes contre $C$. capitata ainsi que la performance et de la réussite de $D$. longicaudata dans autres pays.

Dans le deuxième chapitre, les résultats relatifs de la mise en œuvre des élevages de laboratoire des deux insectes pour atteindre tous les autres objectifs fixés pour ce travail de recherche ont été présentés. De même, les paramètres de la vie de l'espèce qui détermineront son succès comme ennemi naturel ont été évalués. En outre, les facteurs biotiques (densités de l'hôte et sa disponibilité) et abiotiques (température, humidité, précipitations) affectant la performance de D. longicaudata sur C. capitata ont été déterminés.

Au cours du troisième chapitre, on a démontré que $D$. longicaudata est capable de contrôler $C$. capitata sous les conditions climatiques méditerranéennes naturelles avec des larves nues issues de l'élevage du laboratoire ou dans les fruits. Cette étape est nécessaire pour son inclusion dans les programmes de lutte intégrée. Les résultats ont montré que le taux de réduction de la population de la mouche par D. longicaudata peut atteindre les $30 \%$ par le biais de la mortalité induite.

Au niveau du quatrième chapitre, la capacité de dispersion de $D$. longicaudata a été évaluée moyennant des d'essais de plein champ, tout en faisant recours aux fruits sentinels, une nouvelle approche récemment développée. La possibilité de son intégration avec la technique du mâle stérile a été évalué. Cette partie de la thèse s'est intéressé aussi aux facteurs abiotiques qui pourraient conditionner l'acclimatation de ce hymenoptère dans les autres pays méditerranéens ayant des conditions climatiques similaires. Les résultats présentés dans ce chapitre mettent en évidence la nécessité de telles études de dispersion sous conditions climatiques locales correspondantes afin d'établir les procédures de lâcher. Globalement, D. longicaudata était en mesure de contrôler les foyers l'infestation de la mouche méditerranéenne avec un taux de réduction qui dépend des conditions climatiques et du nombre de femelles lâchée.

Dans le dernier chapitre, les résultats des études de pré-introduction du parasitoïde $D$. longicaudata et la présence de parasitoides autochtone en Tunisie, avec l'identification d'un nouveau parasitoide Pachycrepoideus vindemmiae Rondani (Hymenoptera: Pteromalidae). En plus de présenter les résultats relatifs à l'importation et l'acclimatation de D. longicaudata en Tunisie ainsi que l'étude des ennemis endémique, l'établissement d'élevages de laboratoire pour effectuer des lâchers et des tests portant sur les effets secondaires des pesticides qui peuvent limiter les pouvoir d'établissement de D. longicaudata en vergers d'agrumes. 
Les principales conclusions de ce travail sont: (i) D. longicaudata est un ennemi naturel viable qui peut être libéré avec succès dans les pays méditerranéens contre C. capitata; (ii) Son potentiel biotique dans les conditions climatiques optimales déjà identifiées dans ce travail aidera à l'acclimatation de cette espèce et la mise en place des procédures de lâchers (iii) Les exigences climatiques de ce parasitoïde a mis en évidence la nécessité de passer de la lutte biologique classique à la lutte inoculative (ou périodique), ceci implique que les deux pays ont besoin d'élevages de masse avec l'implication des producteurs par la mise en œuvres des augmentoriums favorisant à la fois l'acclimatation du parasitoïde exotique et les auxiliaires locaux. 


\section{RESUMEN}

Ceratitis capitata Wiedemann (Diptera: Tephritidae), originaria de África Occidental, ha invadido casi todos los países templados y tropicales durante el ultimo siglo, invasión mediada inadvertidamente por el hombre. Hoy en día es una plaga clave para más de 400 especies de plantas de importancia económica. Muchos países han establecido medidas de cuarentena y de control de fronteras frente a fruta proveniente de países productores con esta plaga, lo que ha tenido un impacto directo sobre las políticas de protección fitosanitaria en los países productores.

En España y Túnez, situados en la cuenca mediterránea, $C$. capitata se considera una plaga clave, principalmente para cítricos y otros frutos de hueso y pepita. Desde un punto de vista histórico, las políticas de protección vegetal en España, han ido cambiando desde una gestión casi ecológica (llamada así por la falta de insecticidas efectivos, y por falta de programas a gran escala, que resultaban en grandes pérdidas de producción) a tratamientos basados en productos químicos, principalmente con compuestos organofosforados a principios del siglo XX, pasando por intervalos de adopción del control biológico. Desde la integración en la Unión Europea, con la política agraria común, se ha redirigido al manejo integrado de plagas (MIP), en el cual se favorecen métodos ecológicamente respetuosos con el medio ambiente y la salud humana, en detrimento de los tratamientos químicos, como son la monitorización, métodos culturales, trampeo masivo, sistemas quimioesterilizantes, implementación de la Técnica del Insecto Estéril (TIE), e importación de parasitoides exóticos. Siguiendo estos pasos, Túnez está integrando el uso de métodos biorracionales mientras se mantiene el uso de productos químicos tan bajo como sea posible.

Con este fin, la presente tesis se centra en la utilización de enemigos naturales como el mejor método de control, además de sostenible, retomando los programas de control biológico que tuvieron éxito en el pasado contra otras plagas en ambos países. Más concretamente, esta tesis presenta los resultados de la aplicación de control biológico clásico contra $C$. capitata en cítricos, con la importación, la evaluación y la liberación del parasitoide Diachasmimorpha longicaudata (Ashmead) (Hymenoptera: Braconidae) en ambos países. Esta especie parasitoide, nativa de Asia oriental, se utiliza actualmente contra otras especies de tefrítidos plaga de interés económico en zonas tropicales, similares a su zona de origen, por lo que para su implementación era necesario determinar ciertos parámetros que avalen su uso en un programa de Control biologico clásico en condiciones climáticas Mediterráneas. 
En el primer capítulo presento una revisión de la literatura sobre las políticas de Protección vegetal contra esta plaga clave, y lo que se sabe sobre el rendimiento y el éxito de esta especie parasitoide en otros países.

En el segundo capítulo describo los resultados del establecimiento de crias de laboratorio de ambos insectos para lograr todos los objetivos restantes, incluyendo la determinación de sus parámetros vitales que van a determinar su éxito como enemigo natural. Además, presento los factores bióticos (densidades de hospedador y disponibilidad) y abióticos (temperatura, humedad relativa, precipitaciones) que afectan el rendimiento de D. longicaudata sobre $C$. capitata.

Durante el tercer capítulo demuestro que $D$. longicaudata es capaz de ejercer el control de $C$. capitata en condiciones climáticas naturales del Mediterráneo, tanto al ofrecer las larvas directamente de la cría o en un estado más natural, como es la fruta infestada. Los resultados muestran que $D$. longicaudata es capaz de reducir hasta un 30\% de reducción de la población mosca ya sea en forma de perpetuación de la especie, como en la mortalidad inducida.

En el capítulo cuarto presento los ensayos en campo abierto, con una nueva metodología desarrollada como son los frutos centinela para determinar la dispersión del parasitoide. En este mismo capitulo también testo la capacidad de control de focos mediante ensayos en semicampo, y con alguna liberación puntual. Y se evalua su integración con la liberación de machos estériles o TIE, puesto que es la actual base del MIP en la Comunidad Valenciana. Además, se consideran qué factores abióticos podrían determinar su naturalización en otros países mediterráneos con condiciones climáticas similares. Los resultados presentados en este capítulo ponen de relieve la necesidad de tales estudios para establecer los procedimientos de liberación, tanto en la forma como en el número necesario de hembras.

En el capítulo quinto y último, presento los resultados de los estudios de pre-importación del parasitoide D. longicaudata en Túnez y de cómo integrarlo con los actuales planes de protección. En un primer punto se ha investigado la presencia de parasitoides nativos en Túnez, obteniendo la identificación de un nuevo parasitoide Pachycrepoideus vindemmiae Rondani (Hymenoptera: Pteromalidae) atacando C. capitata en cítricos. Además de presentar los resultados sobre la importación y la naturalización de $D$. longicaudata en condiciones de laboratorio y en los primeros ensayos de liberación. Además, se ha realizado un estudio sobre los efectos secundarios de los principales compuestos químicos utilizados en protección de cítricos en Túnez que determinará el procedimiento y forma de las liberaciones de $D$. longicaudata en condiciones naturales. 
Al final de esta tesis doctoral, se presentan las principales conclusiones, que se pueden resumir en: (i) D. longicaudata es un enemigo natural viable que se puede liberar con éxito en los países del Mediterráneo contra C. capitata; (ii) su potencial biótico en las condiciones climáticas Mediterráneas identificadas ayudará a su naturalización, y al establecimiento de protocolos de liberación, (iii) la determinación de estos requerimientos climáticos pone de manifiesto la necesidad de pasar de control biológico clásico a inoculativo o inondativo, lo que significa que ambos países requieren de la instalación de biofábricas de producción masiva o insectarios, además de la participación de los productores en la aplicación de las medidas de manejo integrado de plagas, incluyendo los augmentoriums para facilitar la naturalización de las especies introducidas así como preservar las especies de parasitoides nativos. 


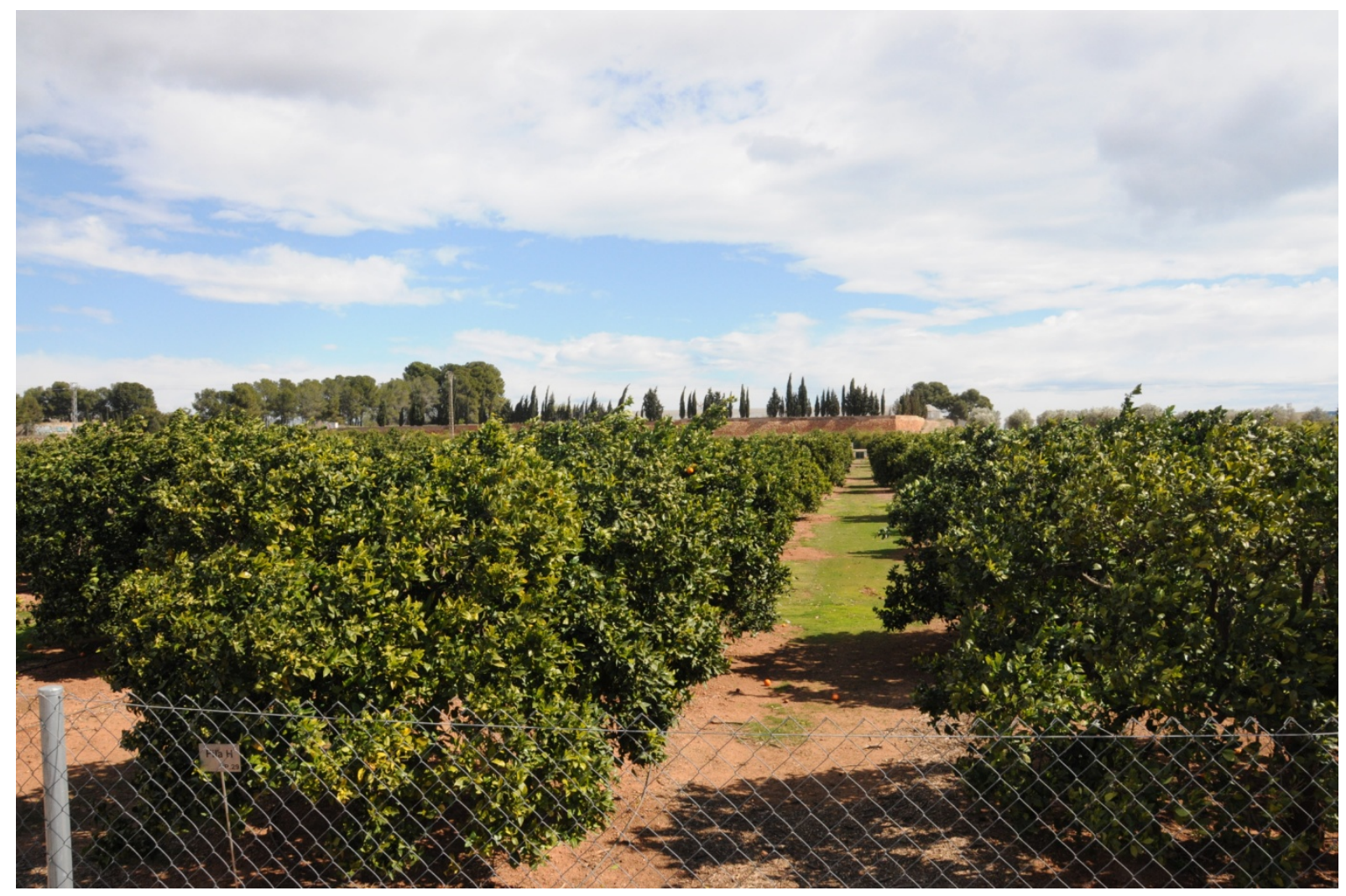

CHAPTER 1. Citrus crops, their pests and control methods in the Mediterranean basin: a general introduction 


\subsection{Current situation of citrus pests in the Mediterranean region}

\subsubsection{Importance of citrus crops}

The Mediterranean basin is one of the ecoregions of the world that concentrates one of the biggests cropland areas (Figure 1.1.A) in a delicate equilibrium with human populations (Figure 1.1.B).

A)
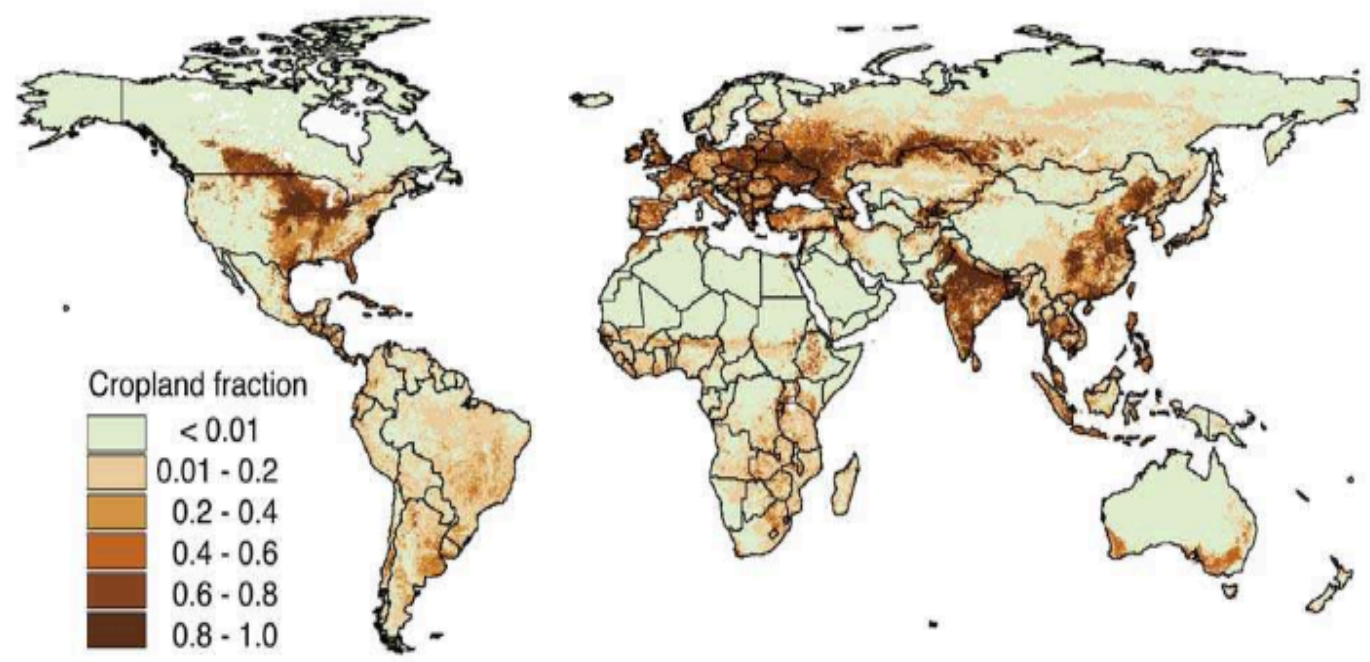

B)
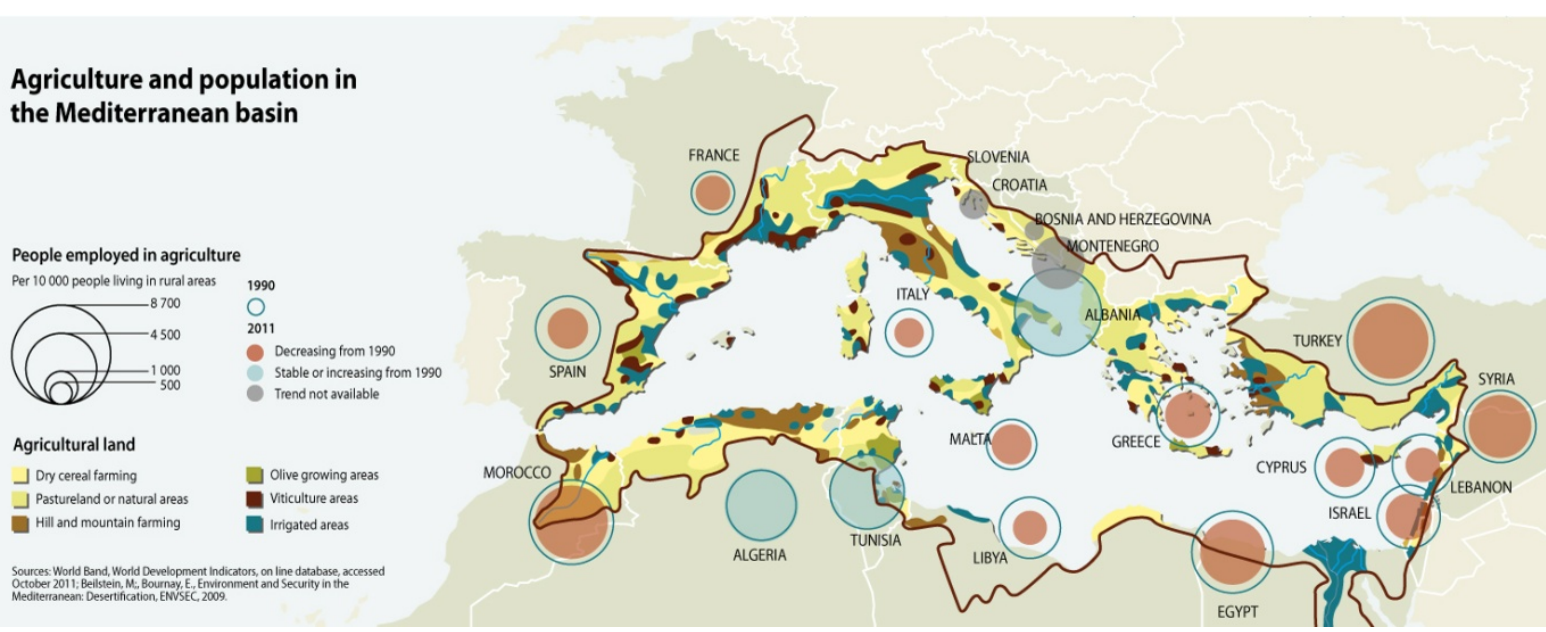

Figure 1.1. Population and distribution of agriculture land in the Mediterranean basin. A) World map with indication of cropland fraction. B) A Mediterranean basin zoom with indication of agricultural land and human population. As can be seen, olive growing (green), viticulture (cayenne color) and irrigated areas (teal) form a patchy landscape in almost all the countries, specially in Spain, Greece, Italy and Tunisia (taken from Beilstein and Bournay 2011).

Citrus is one of the most important fruit crop in the Mediterranean basin which contributes over $20 \%$ of the overall citrus production in the world and about $60 \%$ of fresh citrus world trade 
(CLAM 2007). Indeed, developing countries account for almost $40 \%$ of the citrus production, representing the major source of income to a significant number of farmers in these countries. This geographic area, the Mediterranean basin, is the homeland of 'easy peelers' varieties, primarily Clementines and mandarins, accounting for $75 \%$ of the worldwide citrus exportation trade. This percentage is being increased over the last two decades at the expense of fresh oranges, due to the evolution of consumer preferences (CLAM 2007). Despite this fact, a number of citrus processing industries have developed in some Mediterranean countries, mainly for refreshing juice, jams, candies, flavors and other by-products destined to pharmaceutical and cosmetic industries (Lacirignola and D'Onghia 2009).

Citriculture is therefore of strategic importance for the Mediterranean region for its socioeconomic role as a source of income, of employment opportunities at various levels of the chain (production, processing trade and farming consumable suppliers) and for its contribution to the well being of people and the political stability of the countries (Lacirignola and D'Onghia 2009). Spain is the largest producer country of the Mediterranean basin (27\%) (Figure 1.2), and also is the leading exporter of fresh citrus fruits to the world, comprising of oranges, mandarins and lemons (FAO 2016). It produces around 7.04 M tonnes of citrus fruit annually and has a cultivated area of around 301,124 hectares (MAGRAMA 2015, FAO 2016). Around 60\% of the volume is produced in Valencia, in east Spain. Oranges are the most common citrus planted in Spain (49\%) followed by mandarins (38\%) (Lacirignola and D'Onghia 2009; Gonzales 2013; MAGRAMA 2015).

In Tunisia, citrus cultivation is an important agricultural sector that covers about 21,000 hectares with 6.4 million trees which represent $0.3 \%$ of the total useful agricultural area and $3.4 \%$ of total fruit crop area. Annual production is estimated to approximately 393,000 tons, $9.45 \%$ of fruit production value (FAO 2016). The main varieties actually cultivated in Tunisia are Maltese, Navels, Lemon and Clementine (Laajimi and Ben Mimoun 2007; Lebdi-Grissa 2010; Benmahmoud et al. 2015). Despite the fact that Tunisia contributes with only $1.6 \%$ to the Mediterranean citrus production, it stills a relevant crop at local scale from and economic and social perspectives. In fact, it is a labor consuming sector producing an important exportation commodity which generates significant income for the country (Lacirignola and D'Onghia 2009; FAO 2016). 


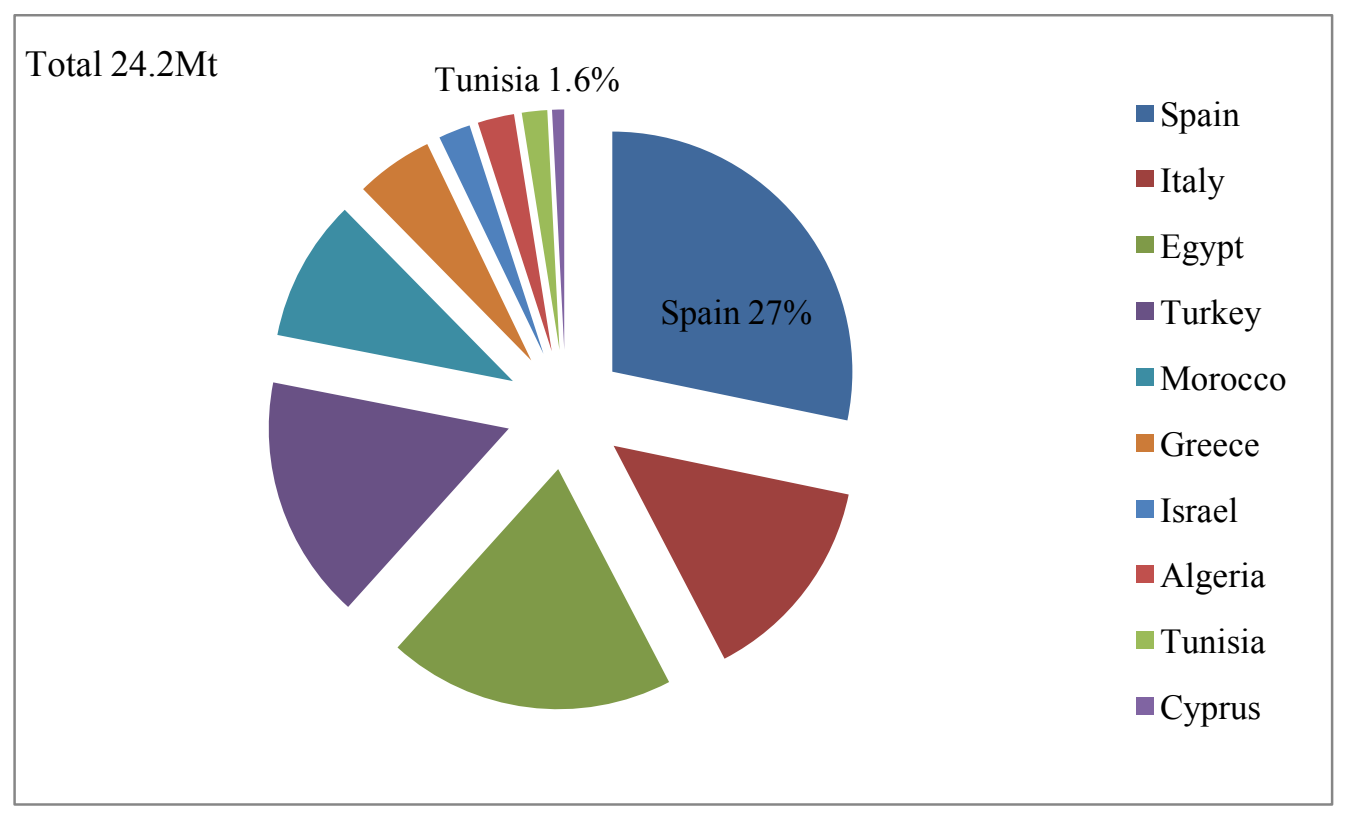

Figure 1.2. Distribution of citrus production in the Mediterranean basin, Spain as a first country and Tunisia as object of this thesis had been highlighted in the graph (data obtained from FAO 2016).

\subsubsection{Arthropods affecting citrus crop}

Citrus pests and diseases are common in the different citrus producing countries. However, their relative importance varies among countries and changes throughout the years.

Citrus ecosystems usually are formed as single-crop farming, but usually they form a highly diverse variety and cultivated species patchy landscape. As example, in the Valencia region, many citrus groves are of small size, usually of $\sim 2-5$ ha; owners have only one citrus variety (usually different from his neighbor) but also, they have between 1 to 5 trees of other fruits species (mainly loquats, plum trees, fig tree, prickly-pear cactus, among others). On such patchy landscape arthropods, phytophagous and entomophagous, are some time at equilibrium, whereas some other not. In this last case, when phytophagous species do not have an effective entomophagous species that control it, a pest status is achieved. But phytophagous species are not only harming the citrus trees by feeding on them, usually they are vectors of different disease organisms (virus, phytoplasms, bacteria), or they induce cosmetic damage to the fruit that renders it unvaluable, or induces a premature ripening of fruits with the consecuent economic losses, or even not feeding on citrus, like the ants, they allow the development of other arthropods that are really damaging them.

Precisely, these losses shape the requirements of pest control and establishment of pest status for each arthropod species. Pest arthropods are classified according to their status, under no 
intervention, as: (i) well controlled species, (ii) badly-controlled species, and (iii) key species; or as belonging to EPPO lists (Table 1.1) (Franco et al. 2006, Tena and Garcia-Mari 2011). However, this classification can vary from country to country depending on the established control methods.

Table 1.1. Some of the most common pests and diseases of citrus. Phytophagous pest arthropods are classified accordling its status in the Mediterranean region (reviewed from GIP citricos; www.gipcitricos.ivia.es and OILB).

\begin{tabular}{lll} 
& Species name & Status $^{*}$ \\
\hline Diseases & Alternaria alternata, Phytophthora spp. & Fungal diseases \\
& $\begin{array}{l}\text { Citrus tristeza virus (CTV) } \\
\text { Citrus canker (Xanthomonas axonopodis, X. citri), Greening (HLB; } ; \\
\text { Candidatus Liberibacter } \text { spp.) }\end{array}$ & Bacterial diseases \\
\end{tabular}

\section{Pests}

Scales (Parlatoria ziziphi, Chrysomphalus dictyospermi), coccids Well controlled (Saissetia oleae, Ceroplastes sinensis), whitefly (Aleurothrixus species floccosus), citrus leafminer (Phyllocnistis citrella) Mealybugs (Planococcus citri), Cottony cushion scale (Icerya Badly-controlled purchasi), Kelly's citrus thrips (Pezothrips kellyanus) species

Mediterranean fruit fly (medfly; Ceratitis capitata), California red Key species scale (CRS; Aonidiella aurantii), aphids (Aphis spiraecola and Aphis gossypii), two-spotted red mite (Tetranychus urticae), citrus red mite (Panonychus citri),

\begin{tabular}{l}
\hline $\begin{array}{l}\text { African psila (Trioza erytreae), oriental red mite (Eutetranychus } \\
\text { orientalis) }\end{array}$ \\
\hline $\begin{array}{l}\text { Natal fruit fly (Ceratitis rosa), Oriental fruit fly (Bactrocera List A1 } \\
\text { dorsalis complex including } \quad \text { B. invadens), Peach fruit fly } \\
\text { (Bactrocera zonata) }\end{array}$
\end{tabular}

*Indicate pest status under no-intervention when pest is present at survey area, or as belonging to EPPO classification list (A1 pest are absent from whole EPPO region; A2: pests are locally present in the EPPO region).

Of this list, one of the key insect pest affecting citrus that arose in the Mediterranean basin is the Mediterranean fruit fly, also known as medfly, Ceratitis capitata (Wiedemann) (Diptera: Tephritidae), as I will explain later in this chapter.

However, I should also highlight some of the species listed, also belonging to the Tephritidae family, that are menacing the borders of Europe and Tunisia. These invasive species (Ceratitis rosa Karsch (Diptera: Tephritidae), Bactrocera dorsalis Hendel (Diptera: Tephritidae), Bactrocera invadens Drew, Tsuruta \& White (Diptera: Tephritidae), Bactrocera zonata (Saunders) (Diptera: Tephritidae)) have been recently the focus of one study, on which an overall invasion threat of 0.7691 with a potential invasion cost of $\$ 949.2$ (millions US\$) for 
Tunisia and of 0.3459 (overall invasion threat) with an invasion cost of \$5,576 (millions US\$) for Spain (Paini et al. 2016). These data indicate that new tephritids will displace the actual one in citrus, being necessary to develop a protection plan that covers also these new species.

\subsubsection{Control methods of citrus pests and diseases}

Nowadays there are different methods to control citrus pests and diseases that differ between countries. But due to actual legal frames, mainly imposed by the European Union, along with national directives, the citrus protection plan is performed under the umbrella of Integrated Pest Management (IPM). The control methods can be divided into Indirect (where no direct action is performed) or Direct (where an action tooks place after detection of the pest or disease). The basis of this IPM and Integrated Production has the aim of reducing the pest/disease population level below an economic threshold by applying rationally all available control methods, include three steps (Vacante and Bonsignore 2012):

1. Application of Indirect methods: by means of legal exclusion barriers, quarantines, by the use of resistant and clean varieties (in citrus mainly those resistant to Citrus Tristeza Virus, CTV, and other diseases), by applying cultural methods (removal of infested fruits, arable measures, tree pruning, ...), and by the enhancement of Conservative Biological Control (CBC).

2. Monitorization and Sampling methods: to determine the economic and treatment thresholds to develop intervention models based on pest population level.

3. Application of Direct methods: by means of application of non-persistent or semipersistent methods like Augmentative Biological Control (ABC), technical control (different trapping systems, Sterile insect technique, protective nets, ...), and chemical control (mainly with botanicals' and Bacillus thuringiensis' based products); by enhancement of persistent methods like Classical Biological Control (CBC, also named importation as natural enemies are usually imported from exotic countries).

As can be seen, synthetic chemicals had been limited in the IPM, per definition, and per legal directives like European normatives 2009/128/CE, CE 1107/2009 and Spanish Royal order $1311 / 2012$ for the sustainable use of phytosanitary products by reducing the development of resistance and damage to the environment and human health. All these normatives and directives are of legal application in all the EU countries since $1^{\text {st }}$ January 2014. 
This fact retrieves the FAO definition of Integrated Pest Management for its implementation under the horizon 2025, to assure the access to food to the growing human populations (food security). This definition includes all available pest control techniques that discourage the development of pest populations keeping pesticides and other interventions to economically justified levels minimizing risk to human health and to the environment. In other words, IPM emphasizes the healthy crop growth with the low disruption of agro-ecosystem encouraging natural pest control mechanisms.

Is this last point, the encouragement of natural pest control mechanisms, and more precisely the use of Biological control, the final objective of this thesis work, as I will depict in the next pages.

Biological control refers to the use of natural enemies, mainly entomophagous arthropods, against a pest population to reduce the pest's density and damage to a level lower than would occur in their absence. The use of biological control to manage pests is divided into three types: classical biological control, augmentation, and conservation (van Driesche and Bellows 1996).

- Classical biological control: also, called importation and inoculation of natural enemies. It involves the importation, screening and release of natural enemies to their permanently establish in new areas. It is primarily used against exotic pests that have inadvertently been introduced from elsewhere.

- Augmentation: is a method of increasing the population of a natural enemy that attacks pests. This can be done by mass producing a natural enemy in a laboratory and releasing it into the field at the proper time or breeding a better natural enemy that can attack its prey more effectively. Mass rearings can be released at special times when the pest is most susceptible and natural enemies are not yet present, or they can be released in such large numbers that few pests go untouched by their enemies.

- Conservation: this approach is an important part of any biological control effort. It involves identifying any factors that limit the effectiveness of a particular natural enemy and changing them to help the beneficial species. Conservation of natural enemies involves either reducing factors that interfere with the natural enemies or providing needed resources to increase their number.

Biological control is not a new technique; it was applied in ancestral times (in 1000 B.C. in China citrus growers noticed that the presence of red ants in their fields reduced the levels of scale pests) and thanks to the implementation of IPM is nowadays recovering its importance, lost after the enhanced development of synthetic organic pesticides during the Second World war (reviewed in van Driesche et al. 2007). 
In the Mediterranean basin, at least 26 natural enemies were introduced during the past century (Jacas et al. 2006; EPPO 2009; Vacante 2012). Some of them are still present in the region, and have become naturalized, being 'key' species for pest management of several citrus pests, becoming a compelling reason to protect them (Jacas et al. 2006). More precisely, at least 36 exotic biological control agents were imported during the last century into Spain following classical (= inoculative) BC programs, some of them are now naturalized (Table 1.2., next page). Whereas in Tunisia, less than ten have been introduced so far (Table 1.3.) (Chermiti, personal communication), but with almost half successful introductions.

These successes had become the basis of the actual focus of IPM, on which all these naturalized natural enemies are taken into account for the selection of the less harmful active material to be used when the only control method that can be applied is the chemical control. This also retrieves the FAO's proposal for enhancement of Biological control as the best control method, which constitute the cornerstone of this thesis work.

Table 1.3. Introduced natural enemies in Tunisia against citrus pests (B. Chermiti, personal communication).

\begin{tabular}{|c|c|c|c|}
\hline Target pest & Natural enemy & Year & Results \\
\hline Iceria purchasi & Rodolia cardinalis & 1910 & Total control of the cottony cushion scale \\
\hline $\begin{array}{l}\text { Aleurothrixus } \\
\text { floccosus }\end{array}$ & Cales noaki & 1991 & Total control of the woolly whitefly \\
\hline Parabemisia myricae & Eretmocerus debachi & 1993 & Total control of the japanese bayberry whitefly \\
\hline Phyllocnistis citrella & $\begin{array}{l}\text { Ageniaspis citricola } \\
\text { Semielacher petiolatus } \\
\text { Citrostrichus } \\
\text { phyllocnistoides }\end{array}$ & $\begin{array}{l}1996 \\
1997 \\
2010\end{array}$ & $\begin{array}{l}\text { Failure of acclimatation } \\
\text { Partial control of the citrus leafminer } \\
\text { In rearing }\end{array}$ \\
\hline Planococcus citri & $\begin{array}{l}\text { Cryptolaemus montrouziei } \\
\text { Leptomastix dactylopii }\end{array}$ & $\begin{array}{l}2005 \\
2006\end{array}$ & $\begin{array}{l}\text { Rearing and periodical releases of } 500,000 \\
\text { ladybirds every year } \\
\text { Rearing and periodical releases of } 250,000 \\
\text { Hymenoptera every year }\end{array}$ \\
\hline
\end{tabular}


Table 1.2. Natural enemies introduced in Spain for Classical Biological Control programs against citrus pests (modified from Jacas and Urbaneja 2010).

\begin{tabular}{|c|c|c|c|c|}
\hline Target pest & Natural enemy & Year & Establishment & Success $^{\mathrm{a}}$ \\
\hline Diaspididae & Rhyzobius lophanthae & 1908 & Yes & $\mathrm{P}$ \\
\hline Cornuaspis beckii & Aphytis lepidosaphes & 1970 & Yes & $\mathrm{P}$ \\
\hline Aphis gossypii & Lysiphlebus testaceipes & 1976 & Yes & $\mathrm{P}$ \\
\hline Insulaspis gloverii & Encarsia herndoni & 1979 & Yes & $\mathrm{C}$ \\
\hline Aleyrodidae & Encarsia strenua & $<2001$ & Yes & $\mathrm{P}$ \\
\hline Parabemisia myricae & Eretmocerus debachi & 1982 & Yes & $\mathrm{S}$ \\
\hline Dialeurodes citri & Encarsia lahorensis & 1992 & No & - \\
\hline \multirow[t]{2}{*}{ Aleurothrixus floccosus } & Cales noacki & 1970 & Yes & $\mathrm{S}$ \\
\hline & Amitus spiniferus & 1971 & Yes & $\mathrm{P}$ \\
\hline $\begin{array}{l}\text { Chrysomphalus } \\
\text { dictyospermi }\end{array}$ & Comperiella bifasciata & 1936 & No & - \\
\hline \multirow[t]{2}{*}{ Icerya purchasi } & Rodolia cardinalis & 1922 & Yes & $\mathrm{C}$ \\
\hline & Cryptochaetum iceryae & 1997 & No & - \\
\hline \multirow[t]{3}{*}{ Saissetia oleae } & Microterys nietneri & $<1921$ & No & - \\
\hline & Metaphycus helvolus & $<1971$ & Yes & $P$ \\
\hline & Metaphycus lounsburyi & $<1978$ & Yes & $\mathrm{P}$ \\
\hline \multirow[t]{2}{*}{ Planococcus citri } & Cryptolaemus montrouzieri & 1927 & Yes & $\mathrm{P}$ \\
\hline & Leptomastix dactylopii & 1977 & Yes & $P$ \\
\hline \multirow[t]{6}{*}{ Phyllocnistis citrella } & Ageniaspis citricola, & 1995 & Yes $^{b}$ & $\mathrm{C}$ \\
\hline & Cirrospilus ingenuus & 1995 & No & - \\
\hline & Semialacher petiolatus & 1995 & Yes & $P$ \\
\hline & Quadrastichus citrella & 1996 & No & - \\
\hline & Galeopsomyia fausta & 1997 & No & - \\
\hline & Citrostichus phyllocnistoides & 1999 & Yes & S \\
\hline \multirow{4}{*}{ Aonidiella aurantii } & Encarsia perniciosi & 1971 & Yes & $\mathrm{P}$ \\
\hline & Aphytis lingnanensis, & 1976 & Yes & $P$ \\
\hline & A. melinus & 1976 & Yes & $\mathrm{P}$ \\
\hline & Comperiella bifasciata & 2000 & No & - \\
\hline Tetranychus urticae & Galendromus occidentalis & 1985 & No & - \\
\hline \multirow[t]{7}{*}{ Ceratitis capitata } & Diachasma fullawayi & 1931 & No & - \\
\hline & Diachasmimorpha tryoni & 1931 & No & - \\
\hline & Psyttalia incisi & 1931 & No & - \\
\hline & Tetrastichus giffardianus & 1960 & $\mathrm{Yes}^{\mathrm{b}}$ & $\overline{\mathrm{P}}$ \\
\hline & Diachasmimorpha & 1979 & $\mathrm{No}^{\mathrm{c}}$ & _- \\
\hline & longicaudata & & & - \\
\hline & Fopius arisanus & 2002 & $\mathrm{No}^{\mathrm{c}}$ & \\
\hline
\end{tabular}




\subsection{The Mediterranean fruit fly, Ceratitis capitata}

As presented in the first part of this general introduction, the Mediterranean fruit fly Ceratitis capitata (Wiedemann) (Diptera: Tephritidae) constitutes one of the key pests of citrus, being the target of many IPM programs around the Mediterranean sea, and the focus of this thesis, as I will present in this part.

\subsubsection{The family Tephritidae}

The Tephritidae family comprises roughly 4,000 species and of these, about 1,400 species are known to develop in ripening fruits, including many commercial ones. Around 250 species are known to attack fruits, either grown commercially or harvested from the wild, which are classified of economic importance. Although they are commonly known as "fruit flies", larval development can occur in other parts of the host plants, such as flowers and stems. The wings of these flies are covered with colour patterns of variable size (taxonomical character) (White and Elson- Harris 1992).

Tephritidae are characterized by a sub - costal vein Sc that bends at a $90^{\circ}$ angle towards costal on $3^{\text {rd }}$ break (sub-costal break). Dorsal side of radial vein $\mathrm{R}_{1}$ with setulae. Wing cell with acute extension (know as cup extension). Wings are usually patterned with coloured bands (Figure $1.3)$

According to White and Elson-Harris (1992), there are about 70 species of fruit flies that are considered important agricultural pests, being Bactrocera, Anastrepha, Ceratitis, Rhagoletis, and Dacus the most important genera.

The genus Ceratitis is endemic to tropical Africa (also known as the Afro-tropical Region, in the Southern Sahara) and contains about 65 species, the majority of which are highly polyphagous (White and Elson-Harris 1992). One species of this genus is C. capitata, also known as "The Mediterranean fruit fly" or "medfly". It is the most widespread member of the Tephritidae family (White and Elson Harris 1992), with a worldwide distribution being recorded in 132 countries and groups of islands in Africa, Asia, Central America-Caribbean, Europe, North America, Oceania and South America (Commonwealth-Institute-of-Entomology 1984; CAB-International 1999). 


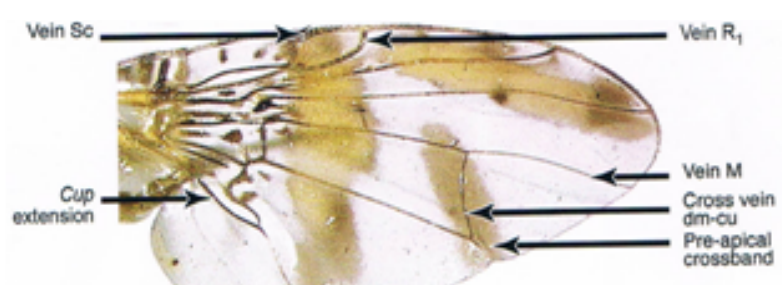

A

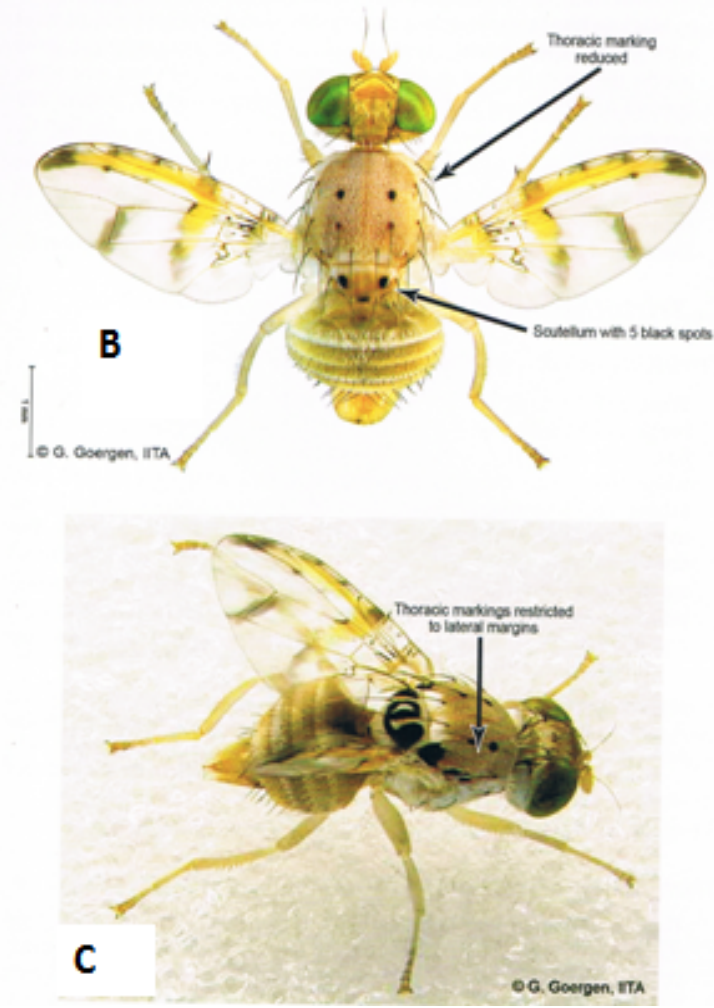

Figure 1.3. Some Ceratitis species with indication of species specific taxonomic characters. A) Forewing of C. capitata; B) General aspect of C. quinaria (Bezzi) (five spotted fruit fly); C) General aspect of C. silvestrii Bezzi (Ekesi and Billah 2007).

\subsubsection{Taxonomic classification}

Over time, medfly has had several different synonyms: Tephritis capitata Wiedemann (1824), Trypeta capitata Wiedemann (1824), Ceratitis citriperda MacLeay (1829), Ceratitis hispanica De Brême (1842) and Pardalaspis asparagi Bezi (1924). Being its actual name Ceratitis capitata Wiedemann 1824, the most widespread and renowned (White and Elson-Harris 1992). Its common name varied even within countries: Mediterranean fruit fly, medfly (English), Mouche méditerranéenne des fruits, mouche de l'oranger, mouche des fruits (French), Mittelmeerfruchtfliege (German), Mosca mediterránea, moscamed (Spanish).

Along this thesis the name C. capitata, medfly or Mediterranean fruit fly will be used to refer to this species. 
According to this, the taxonomy of this species is:

Order: Diptera

Suborder: Brachycera

Family: Tephritidae

Subfamily: Dacinae

Genus: Ceratitis

Subgenus: Ceratitis

Species: Ceratitis capitata (Wiedemann), 1824

\subsubsection{Geographic distribution and host plant}

The Mediterranean fruit fly (Medfly) is a fast colonizing species which in the last 100 years has spread from its supposed origin in tropical Africa to a number of countries including the Mediterranean basin, part of South and Central America, and Australia (Fletcher 1989; Liquido et al. 1991). The zones most affected by the medfly are in tropical and subtropical latitudes, where daily temperatures in winter rarely go below $5^{\circ} \mathrm{C}$ (Navarro-Llopis 2004). The actual distribution in the world is presented in the figure 1.4. The history of infestation and geographical spread of this species are well documented. The oldest derived populations are found in the Mediterranean area, from which in different colonization and dispersal events, the actual geographical distribution is shaped (Malacrida et al. 1998; Wharton et al. 2000; Malacrida et al. 2007; Argov and Gazit 2008). In the Mediterranean countries, it was first recorded from Spain in 1842, from Algeria in 1859, from southern Italy in 1870, from Sicily in 1882, from Tunisia in 1885, from Malta in 1893, from Egypt in 1904, and from France in 1900 (Quayle 1914).

This species has a great ability to disperse, to use alternative hosts and presents a great developmental plasticity which allow its survival during most of the year, and which has allowed its fast dispersal along the globe. 


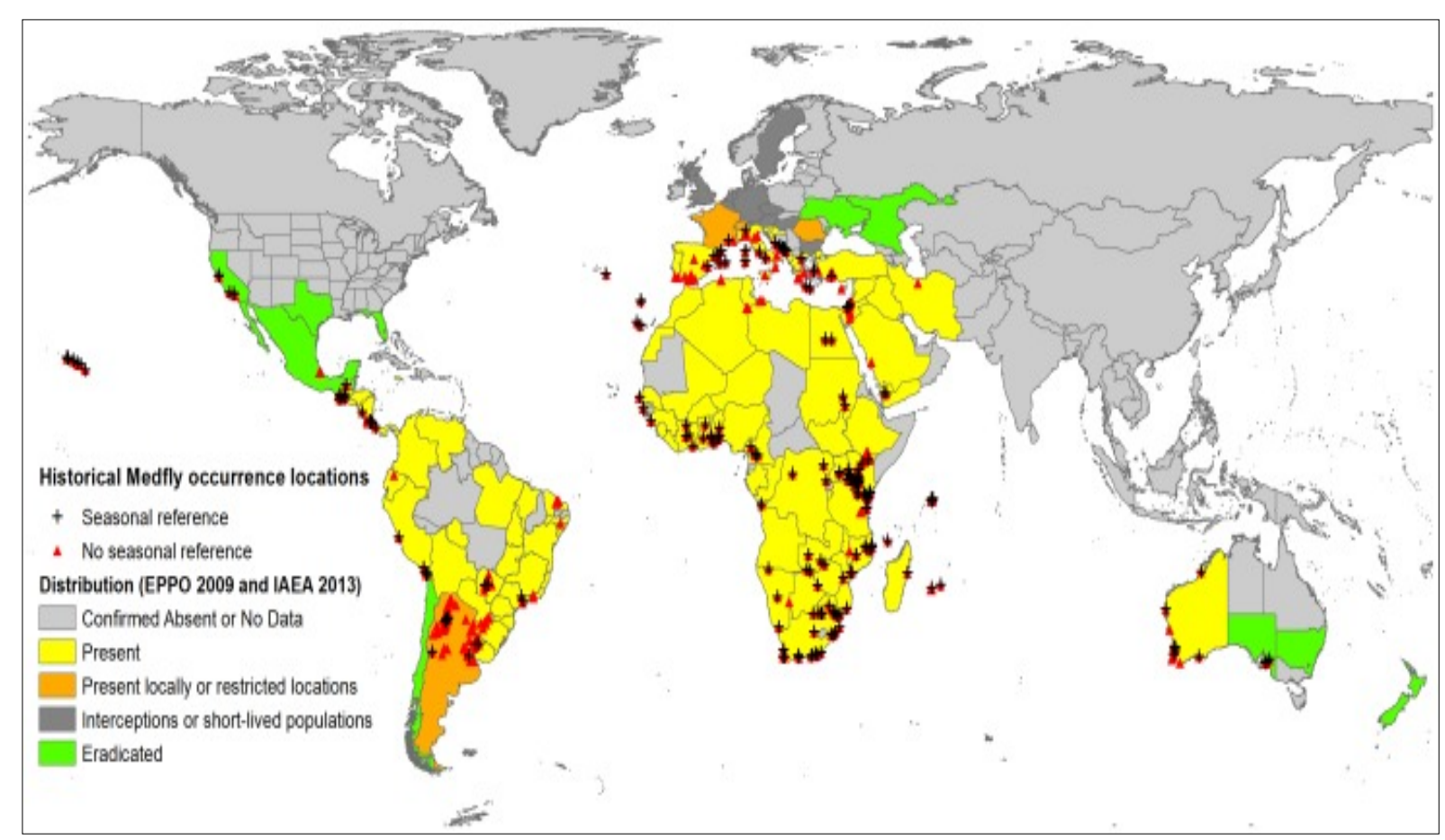

Figure 1.4. Geographical distribution of the medfly in the world (FAO/IAEA, 2013).

This species can develop on more than 300 plant species around the world, belonging to 67 different families (Liquido et al. 1991; Enkerlin and Mumford 1997). Although several species of cucurbits have been recorded as hosts of the medfly, they are considered to be very poor hosts. Some hosts have been recorded as medfly hosts only under laboratory conditions and may not be attacked in the field. Knowledge of the hosts in one country often aids in correctly predicting those which are most likely to be infested in a newly infested country, but what may be a preferred host in one part of the world may be a poor host in another (Thomas et al. 2014). Apples (Malus pumila), avocados (Persea americana), citrus, figs (Ficus carica), kiwi fruits (Actinidia deliciosa), mangoes (Mangifera indica), medlars (Mespilus germanica), pears (Pyrus communis), Prunus spp. (especially peaches, P. persica), in fact practically all the tree fruit crops are considered host plants, and thus, they are in risk in all the areas (EPPO 2012).

\subsubsection{Morphological description}

The medfly is a holometabolous insect, with a complete metamorphosis, consisting of four stages: egg, larvae, pupa and adult (Figure 1.5). 
Egg: The egg is very slender, curved, $1 \mathrm{~mm}$ long, smooth, shiny white when recently oviposited and later on yellowish. The micropylar region is distinctly tubercular (Ros 1988; Filippi 2003; Thomas et al. 2014).

Larva: Larva are white with a typical fruit fly larval shape, i.e. cylindrical maggot-shape, elongate, anterior end narrowed and somewhat recurved ventrally, with anterior mouth hooks, and flattened caudal end (Thomas et al. 2014). The first larva instar is $2 \mathrm{~mm}$ and the third has an average length of $6.5-9 \mathrm{~mm}$ and width $1.2-1.5 \mathrm{~mm}$ with eight ventral fusiform areas (White and Elson-Harris 1992). The anterior buccal carinae are usually nine to 10 in number. The anterior spiracles are usually nearly straight on dorsal edge of tubule row. There are usually 9 to 10 tubules, although there may be 7 to 11 (Thomas et al. 2014).

Pupa: The pupa is cylindrical, 4 to $4.3 \mathrm{~mm}$ long, dark reddish brown, and resembles a swollen grain of wheat (Thomas et al. 2014). This developmental stage takes part in the soil, being susceptible to death by abiotic (temperature and humidity (raining or flowding)) and biotic factors (predators and parasitoids).

Adult: The adult fly is 3.5 to $5 \mathrm{~mm}$ in length showing sexual dimorphism. The color is yellowish with brown tinge, especially on abdomen, legs, and some markings on wings. The lower corners of the face have white setae. Eyes are reddish purple (fluorescent green, turning blackish within 24 hours after death) (White and Elson-Harris 1992). Ocellar bristles are present. The male has a pair of bristles with enlarged spatulate tips next to the inner margins of the eyes while the female does not have them. The thorax is creamy white to yellow with a characteristic pattern of black blotches. Light areas have very fine white bristles. Humeral bristles are present. Dorso-central bristles are anterior of the halfway point between supraalar and acrostichal bristles. The scutellum is inflated and shiny black. The abdomen is oval with fine black bristles scattered on dorsal surface and two narrow transverse light bands on basal half (Thomas et al. 2014). The males are easily separated from all other members of this family by the black pointed expansion at the apex of the anterior pair of orbital setae. The females can be separated from most other species by the characteristic yellow wing pattern and the apical half of the scutellum being entirely black (White and Elson-Harris 1992). The female's extended oviscaptor is $1.2 \mathrm{~mm}$ long. 


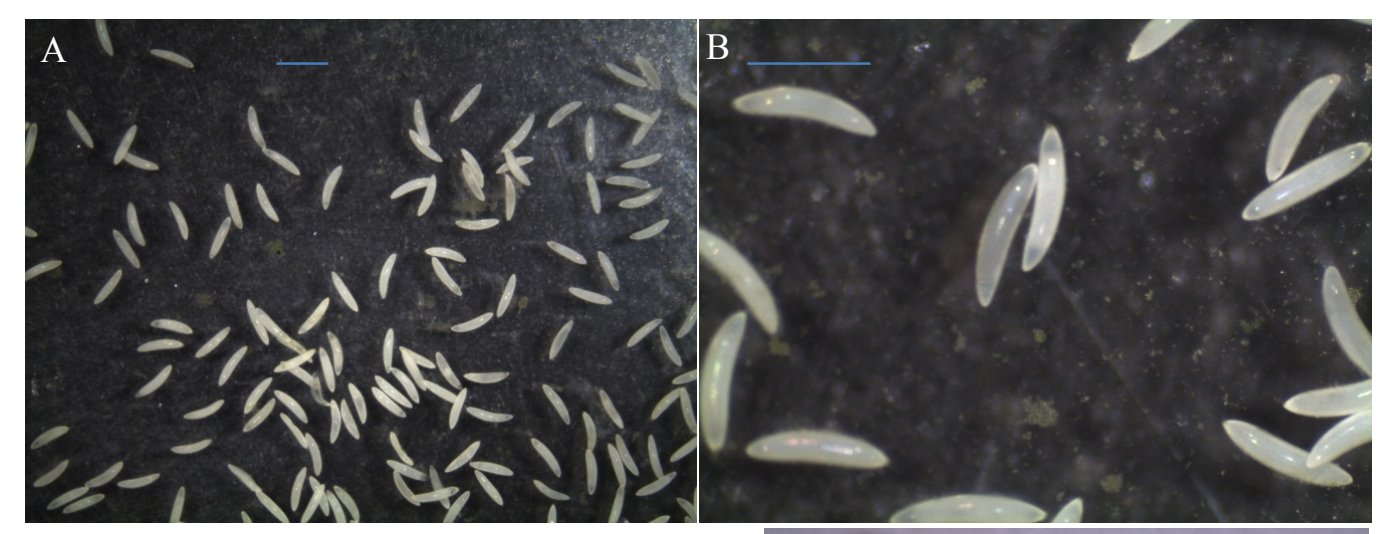

$\mathrm{C}$
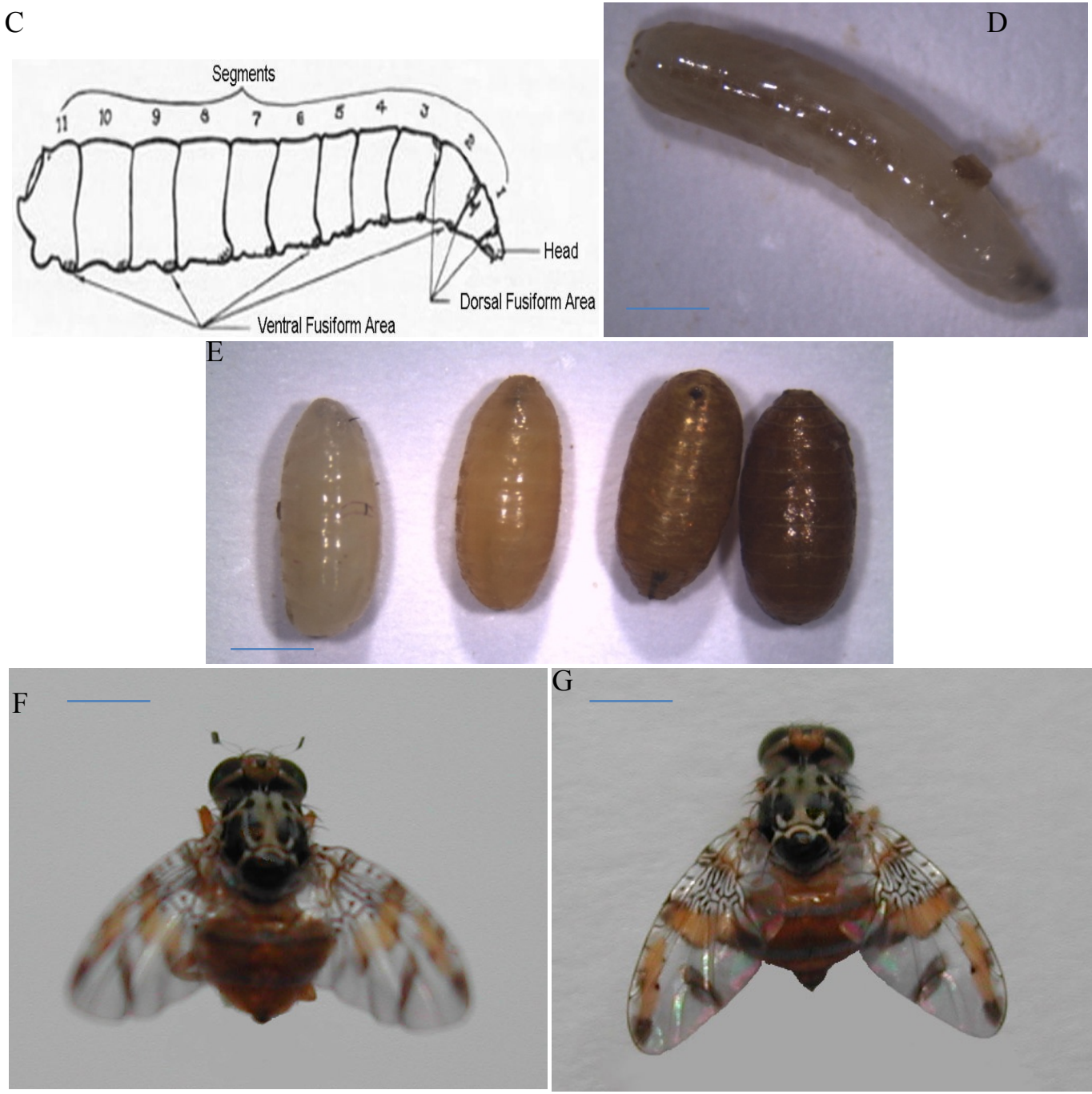

Figure 1.5. Morfology of developmental stages of C. capitata. A and B: Medfly eggs; C: lateral view of a mature larva (from Thomas et al. 2014); D: L3 larva; E: several pupae ordered by age, from left to right, recent to nearly ready to emerge; F: adult male; G: adult female; The bar $=1 \mathrm{~mm}$. 


\subsubsection{Biology and ecology of the medfly}

A female medfly may lay as many as 800 eggs during her lifetime. The average daily oviposition rate is 11 eggs (Aluja 1993; Papadopoulos et al. 2002; Thomas et al. 2014). Eggs are deposited under the skin of fruit which is just beginning to ripen, often in an area where some break in the skin has already occurred (Filippi 2003). Several females may use the same deposition hole with 75 or more eggs clustered in one spot. When the eggs hatch, the larvae promptly begin eating, and at first tunnels are formed, but may keep close together in feeding until nearly full grown. Fruit in a hard or semi ripe condition is better for oviposition than fully ripened fruit. Ripe fruit is likely to be juicier, and such fruits are often associated with a high mortality of eggs and young larvae due to suffocation by fruit juice (Thomas et al. 2014). After larva complete its last stage, the larva punctures the fruit, goes out and starts jumping until it reaches a soil area suitable for pupation, usually in the ground (Figure 1.6).

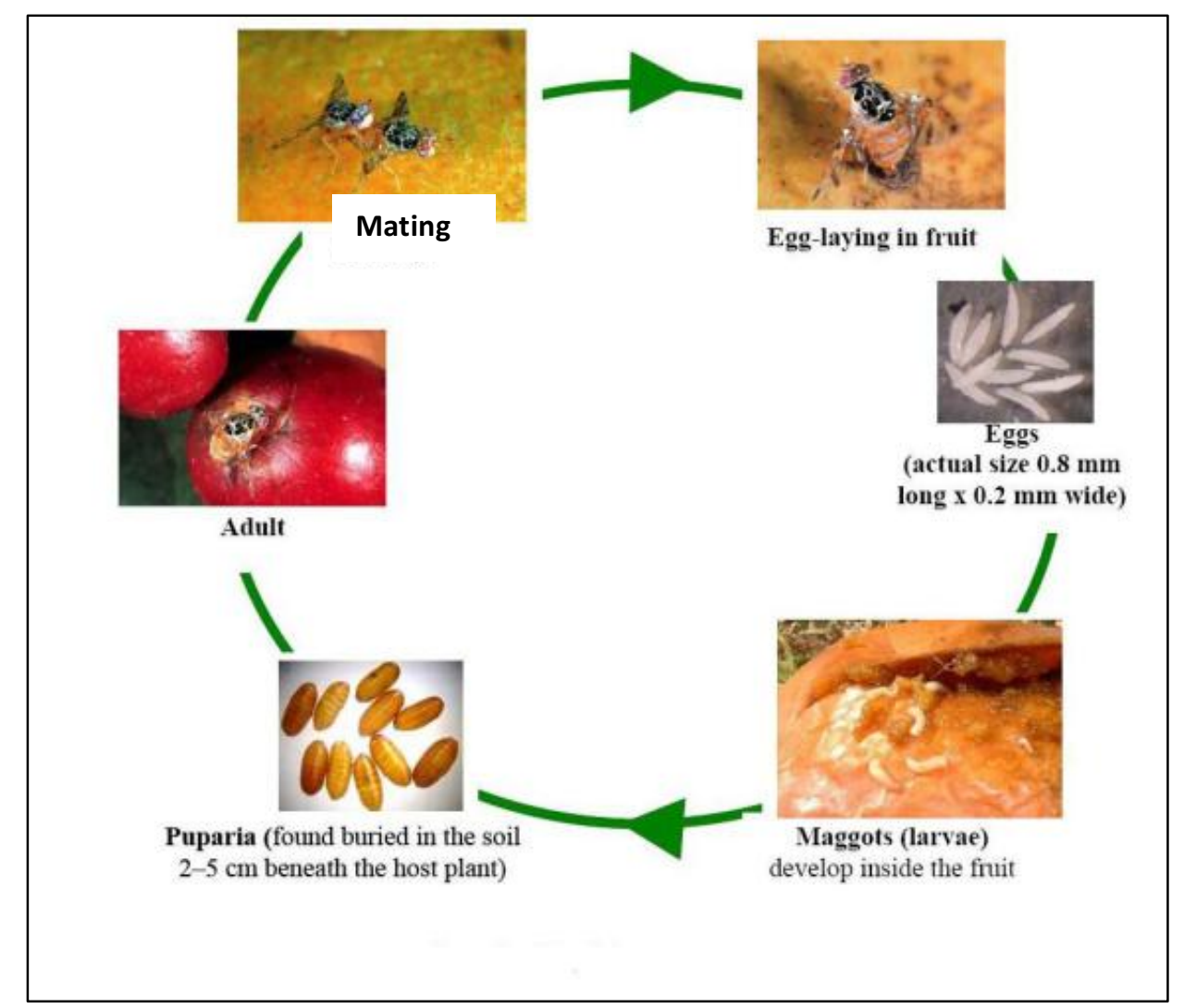

Figure 1.6. Life cycle of the Mediterranean fruit fly. Eggs hatch below fruit skin, and larva develop inside. After third stage, larva jumps and become buried in the soil. Imagos emerge from pupae, and when ready to fly, they flight back to the host trees where males establish mating arena and achieve mating with females. 
Citrus are cultivated all along the Mediterranean coast, where climate is characterized by seasonal changes in average temperature and rainfall. Its growing season expands from spring to fall and the harvesting season from early autumn to early summer (due to the expansion of very early and very late citrus varieties). It is during spring to autumn seasons, in which medflies proliferate, whereas medfly populations decrease during the cool season (winter), surviving mainly as larvae in many mild zones (Papadopoulos et al. 2001, Israely et al. 2004). However, winter survival of medfly is greater in coastal areas, where citrus groves are mainly located (Mavrikakis et al. 2000). Medfly populations usually increase during citrus blossom season, from May to July, and then fluctuate until the end of autumn, when decreasing temperatures reduce the population of flying adults (Bodenheimer 1951; Fimiani 1989; Del Pino 2000). Thus, in temperate zones with cold winters and without the presence of alternative fruits from autumn to spring, C. capitata has only 3-4 generations per year. This generation number can be increased to 7 - 8 when the minimum winter temperatures do not fall below $0{ }^{\circ} \mathrm{C}$ (below zero temperatures kills eggs, pupa and adults, whereas larva inside the fruits are protected against freeze). However, this species is capable to perform more than 12 generations at optimal environmental conditions (Aluja 1993).

The fluctuations of C. capitata populations, in Mediterranean citrus groves, differ from year to year in the same area, and also between different areas in the same year. In some areas, the adult population peaks at the end of spring or at the beginning of summer, as observed in Crete (Michelakis 1992), whereas in other areas populations grow throughout the summer and reach maximum levels in fall, as in Sardinia and Sicily (Italy) (Del Río 1986; Benfatto et al. 1987; Ortu et al. 2005). Several factors are considered directly or indirectly responsible for these variations in C. capitata populations: climate (temperature and rainfall mainly), abundance and temporal sequence of suitable host fruits throughout the year, and crop sanitation practices (Aluja 1993; Harris et al. 1993; Katsoyannos et al. 1998; Pierre 2007; Martínez-Ferrer et al. 2010; Thomas et al. 2014).

\subsubsection{Damages and economic importance}

Medfly is one of the most destructive agricultural pests in the world (Papadopoulos et al. 2001, 2002). Medfly reduces the yield of fruit and vegetable crops and also affects their quality. Ripened fruits infested by medfly are discarded for trade (Figure 1.7). The tunnels produced by larval feeding allow the entry of secondary pathogens, which destroy the fruit, such as fungi and bacteria (Cayol et al. 1994) and produce the ripening and early drop-out of the fruit. 
Moreover, recently it has been demonstrated its potential as vector of plant pathogens, like the bacteria Erwinia amylovora which causes fire blight in apples and pear trees (among other Rosaceae) (Ordax et al. 2015), increasing the damage and economic losses to growers (Kasai 1951).

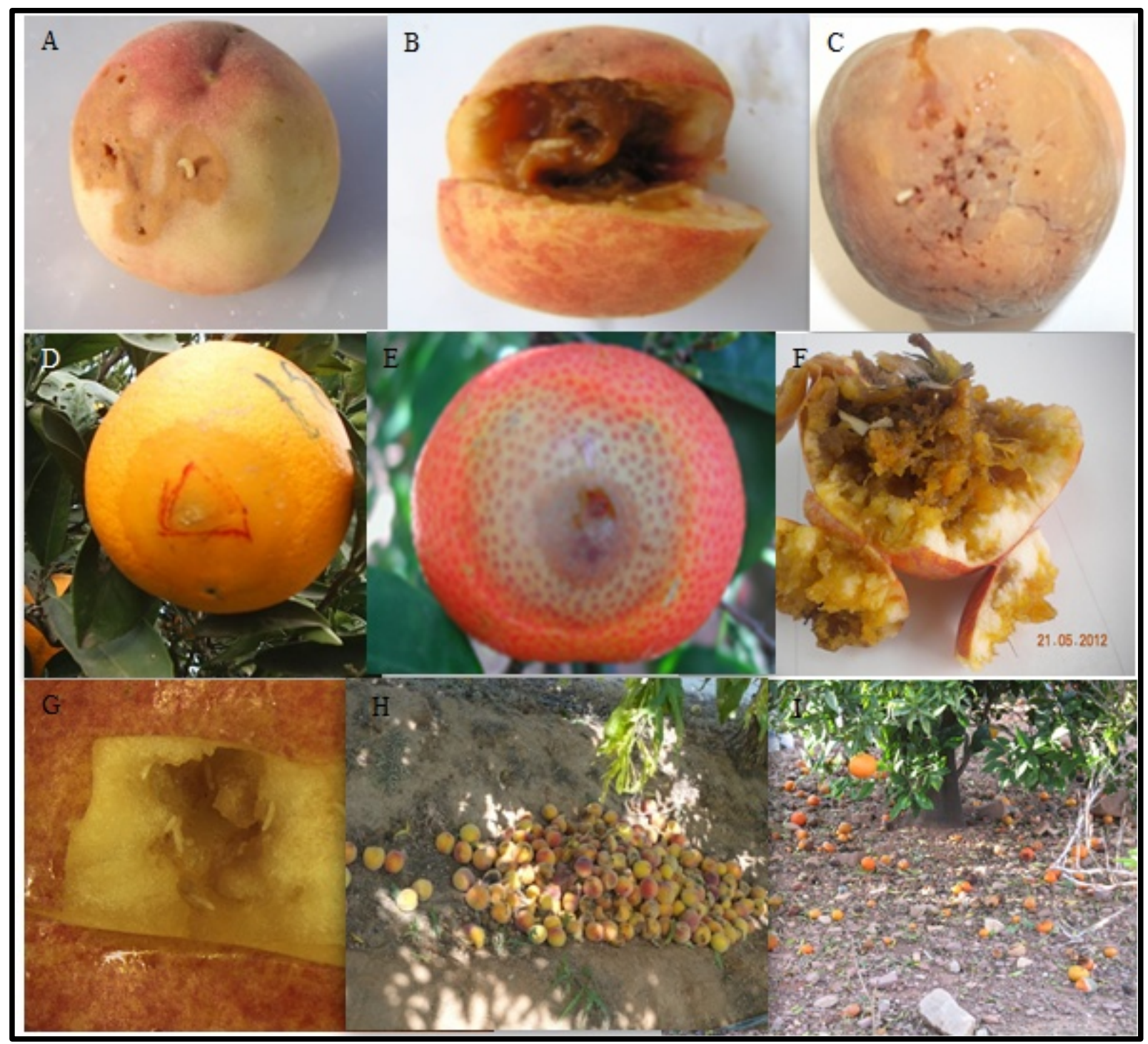

Figure 1.7. Damages on fruits caused by C. capitata. A, B and C: on peach fruits; D and E: on oranges; F and G: on apples; $\mathrm{H}$ and I: massive dropped damaged fruits.

As a flying insect, it can fly as long as $20 \mathrm{~km}$ or even more, which greatly complicates the efforts to control this insect (Israely and Calun 2005; Meats and Smallridge 2007). On the other hand, the medfly can be spread via man-driven trade of fruits either at local or inter-country level. Even being spread throughout more than 70 countries, it is considered a quarantine pest 
species in many of them (EPPO 1981). Countries where it is established are forced to follow strict protocols imposed by importing countries in order to avoid its invasion and establishment. Such protocols incur costs related to surveillance and monitoring of plots, area-wide and local chemical treatments, post-harvesting treatments and quarantine systems (Chueca 2007). Indeed, this was one of the reasons for the establishment of new control measures in Spain in early 2000's (Castañera et al. 2003).

\subsubsection{Control methods}

Till early 2010's, the most common medfly control technique was the application of chemical treatments with synthetic insecticides against adults (Chueca 2007), but with the current normative (EU-91/414) and with the Horizon 2020, medfly control methods must be economically viable, respectful with the environment and human health. This has been stated as Integrate Pest Management system (IPM) (as part of Horizon 2014 program), which consists in combining different methodologies to control almost all pest species and reducing to the maximum the number of chemical applications (as indicated in 1.1.3).

\subsubsection{Legal control}

Legal control is defined by the measures to protect the crops against any pest. On $1^{\text {st }}$ January 2014, the EU directives 91/414/EEC, EC 1107/2009 and 2000/29/EC entry into force for all the states. These directives provide the basis for sustainable agricultural, horticultural and forestry production through plant health protection. Mainly by regulating the introduction of plants and plant products into and within the EU, by placing obligations on countries outside the EU which want to export plants or plants product to the EU, and finally by imposing eradication and containment measures in cases of outbreaks.

\subsubsection{Cultural control}

Cultural control is defined as the practice of modifying the growing environment including crop sanitation, to reduce the prevalence of pests. It is considered a preventive practice. Even being the more logical and traditionally applied, it became neglected after the Second World War by the rise of synthetic pesticides and by the cost of its application as is a labor consuming measure. Nowadays, it has been reintegrated as essential part of an IPM program. Concerning control of medfly, crop sanitation plays an important role in the reduction of the pest population level at ground level. As gathering, removal and destroyment of all ripe fallen fruits diminish the 
available host for medfly immature stages development and by hence reduce pest population. The increased development of machines that fit the different groves sizes that facilitates the destruction of all fallen fruits without any damage to tree, had improve the application of cultural practices in citrus management (Chueca 2007).

\subsubsection{Chemical control}

Traditionally, the chemical control of C. capitata in Tunisia and Spain is based on aerial and terrestrial applications. The target stage is the adult, because eggs, larvae and pupae are protected inside fruits and in the ground, respectively, a chemical shelter acting site (Chueca 2007).

Chemical treatments were based on regular applications of organophosphate and pyrethroids insecticides, particularly Malathion ${ }^{\circledR}$ baited with a food attractant (hydrolyzed proteins) in the Valencia region from late 90's to late 2000's (Primo-Millo et al. 2003). The high frequency of treatments induced the appearance of resistant populations in the Valencia coast (Ortego et al. 2005; Magaña et al. 2007; Couso-Ferrer et al. 2011). In addition, this practice has not proved able to keep the pest below the economic threshold of damage and has shown itself to have harmful effects on human health, on the environment and negative impacts on beneficial insects (Flessel et al. 1993; Mañosa et al. 2001; Urbaneja et al. 2009). For these reasons, the European directive $91 / 414$ prohibited the use of Malathion ${ }^{\circledR}$ and other organophosphorated pesticides since 2009 (Monzó 2010).

However, growers are proned to use chemicals by their feeling of control measures as they saw pest insect death directly. In their help, pesticide firms are developing alternatives based on natural substances with pesticide function. Spinosad ${ }^{\circledR}$, a natural insecticide produced by two different strains of the actinobacteria Saccharopolyspora spinosa, seems to be the best substitute being successfully applied to control different species of Tephritidae in different parts of the world (Stark et al. 2004; Wang et al. 2005; Chueca et al. 2007; Urbaneja et al. 2009; Monzó 2010). However, some recent works have demonstrated the cross-resistance to Spinosad $^{\circledR}$ in the Malathion ${ }^{\circledR}$ resistant populations (Ortego et al. 2012).

\subsubsection{Post-harvest control}

Exporting citrus from production areas where the medfly is present into pest-free regions requires effective quarantine measures, which should combine complete insect kill, minimal damage to plant tissues and a reasonable treatment cost. 
The use of methyl bromide for phytosanitary purposes has become problematic (CE 2037/2000, see also Montreal Protocol) and its use as a quarantine treatment may soon be prohibited (the Montreal Protocol established a critical use in several crops, which allows a low application in several commodities when the import country do not have to apply this normative). The postharvest phytosanitary control methods include: cold treatment; heat treatments, such as immersion in hot water, vapor heat, heating with radio frequency or with microwaves; treatments involving ionizing radiation and chemical fumigation (Del Rio and Cocco 2012).

Currently, mostly high- or low-temperature treatments are used for quarantine fruit fly disinfestations of different commodities. The heat treatments in general consist of using an immersion in hot water by a system of batches or an uninterrupted bath. These treatments are then followed or not by a fruit fast cooling which can be carried out by ventilation (cold air) or hydrocooling (water). Heat can also be obtained by use of forced hot air or hot vapor, because a higher temperature than $45{ }^{\circ} \mathrm{C}$ kills fly eggs and larvae (Ducamp Collin et al. 2007). For example, ripe Valencia oranges can be disinfested by exposure to forced air so that the interior of the fruit reaches $47^{\circ} \mathrm{C}$ for about 0.5 hours. However, the primary obstacle to the widespread use of heat treatments is the sensitivity of many citrus fruits to the high temperatures required for disinfestations (Del Rio and Cocco 2012). In the case of the mango fruit, disinfestation treatments are only done by heat, because of the strong sensitivity of this fruit to cold temperatures. Thus, for most citrus fruits, the best post-harvest treatment consists in cold treatments during transport. Temperature and time at temperature that allows for a lethal dose of $99.9 \%$ for the pre-imaginal stages varied among countries and even among citrus varieties (Del Rio and Cocco 2012).

\subsubsection{Trapping systems}

Trapping has been also a traditional control method, which targets flying adults. There are a lot of traps and different attractants on the market; their selection can have a high impact on the effectiveness of the technique (Navarro-Llopis et al. 2008; Escudero et al. 2009). Traps designs, including different colors and shapes, are essential to obtain a high efficacy in fruit fly capture (Navarro-Llopis et al. 2008). In addition, factors such as the type of crop, the climatic conditions, and pest population level in this field influence the role of trapping within the control of the pest (Peñarrubia-Maria 2010). Depending on the number of traps, attractants and killing factors, trapping can be classified into monitoring traps, mass-trapping, male-anhilation traps, wet or dry traps. 
At the beginning, traps were used with liquid attractants, which are labile, cumbersome, and difficult to service. These difficulties motivated the development of synthetic food-based attractants and the use of dry traps, which are easier to use, and with reduced costs (NavarroLlopis and Vacas 2014). Several trap models have been designed and tested, each with its own efficacy level, depending on factors such as the crop, the climatic conditions and the study area, the density, traps, attractants, ... (Peñarrubia-María 2010; Navarro-Llopis and Vacas 2014).

In the last decade, the development of new powerful attractants has increased the possibility of using mass trapping as a more economical Mediterranean fruit fly control method (MartínezFerrer et al. 2010). Recent studies demonstrate that the International Pheromone McPhail Trap baited with Biolure ${ }^{\circledR}$ (three-component food-type attractant: trimethylamine with ammonium acetate and putrescine) is highly efficacious in capturing adult medfly (both males and females) with respect to other traps and attractants (Gazit et al. 1998; Katsoyannos and Papadopoulos 2004). Letting the use of traps baited with male lures (trimedlure) limited to survey purposes but not for conventional mass trapping. Another used trap is the Tephri ${ }^{\circledR}$-trap combined with the Tri-pack ${ }^{\circledR}$ (Kenogard SA, Barcelona, Spain) (a food-based attractant formed by a mixture of the three components (trimethylamine with ammonium acetate and putrescine) and the Ceratrap $^{\circledR}$ (BIOIBERICA) which is baited with a solution containing 95\% of hydrolysed proteins and $5 \%$ of additives.

In any case, these dry traps also require in addition to the attractant an insecticide to kill the captured flies, being the dichlorvos the most used, which constitute a problem into IPM. An updating of the European Council directive 91/414 EEC relative to the pesticide marketing and use, signified the withdrawal of the active ingredient dichlorvos or 2.2-dichlorovinyl dimethyl phosphate (DDVP), letting this kind of control in half way. Despite this legal limitation, dichlorvos is still authorized but only into medfly traps for citrus and only from July to October, or from October to March, depending on the region, till the development of other sustainable insecticides (Peñarrubia-María 2010; MAGRAMA 2012a).

The efficacy of the Male Annihilation Technique drops severely when the proportion of responding (and subsequently killed) males is not sufficiently high, and trapping a large number of males is not a reliable indicator of fruit damage reduction. In contrast, a trapping strategy focused on females is always more efficient as female population reduction can be directly related with fruit damage reduction. For this reason, research on synthetic female attractants and the development of traps or attract and kill devices focused on females were the key points in the development of mass trapping systems. 
Although mass trapping reduced $C$. capitata adult numbers and fruit damage in Tunisian and Spanish orchards (Boulahia Kheder et al. 2012; Navarro Llopis et al. 2013; Hafsi et al. 2015), the high costs of traps and attractants are considered a limiting factor for its complete implementation (Navarro Llopis et al. 2013; Navarro-Llopis and Vacas 2014). Another factor that can affect the use of mass trapping is the potential side effects (meaning as the inadvertent capture of natural enemies and other non-target insects) of the traps. This issue has been studied on different kind of traps and attractant as Ceratrap ${ }^{\circledR}$, Tripack ${ }^{\circledR}$ and BioLure ${ }^{\circledR}$ in Tunisia (Boulahia Kheder et al. 2011, Hafsi et al. 2015) and the Tephri ${ }^{\circledR}$-type trap in Spain (Falco-Gari et al. 2006).

The tactic of attract and kill is called lure and kill when the insects are not retained inside a device, whereas mass trapping refers to the use of a trap that retains the pest (El-Sayed et al. 2009; Navarro-Llopis et al. 2014). Bait stations are defined as discrete containers of attractants and toxicants that attract the pest to the insecticide (Health et al. 2009), but in this case the toxicant can kill, sterilise (Navarro Llopis et al. 2010) or infect the target insect. The application of bait sprays with insecticide should be considered a lure-and-kill method, but using higher amounts of insecticide (Witzgall et al. 2010). Several bait station systems have been developed, which appear to be less expensive than current mass trapping systems (Navarro-Llopis et al. 2013) and more effective at reducing fruit loss by maintaining adult $C$. capitata numbers under the economic threshold. Several studies had proved the efficiency of this technique in Spain and Tunisia (Navarro-Llopis et al. 2014; Hafsi et al. 2015). The use of attract and kill techniques has increased in recent years, as these devices attract the insect to a killing agent avoiding the spraying of large quantities of each insecticide to reach the insects (Navarro-Llopis et al. 2013). A detailed classification of all attract and kill systems is presented in Table 1.4., following Navarro-Llopis and Vacas (2013).

\subsubsection{Chemosterilisation}

This technique relies on the attraction of adults to bait-containing devices (called traps, but without capturing any insect) where they are exposed to the Insect Growth Regulator (IGR) lufenuron. This compound is effective in reducing the viability of eggs laid by both chemosterilised females and unexposed females that had mated with lufenuron-treated males. The device contains both female and male attractants (ammonia-based and trimedlure dispensers, respectively) and a proteinaceous phagostimulant gel mixed with lufenuron. Flies landing on the trap come in contact with the gel, which induces a feeding response and the uptake of lufenuron. Bait stations have been deployed at a density of 24 units per ha, reducing 
medfly populations in Spanish citrus groves (Navarro-Llopis et al. 2007; Alemany et al. 2008; Del Rio and Cocco 2012). However, the baits are not at all 100\% medfly specific, and the sterilization of non-target insects could be detrimental to the ecosystem, and for the control program if beneficials are affected.

Table 1.4. Classification and commercially available products of attract and kill

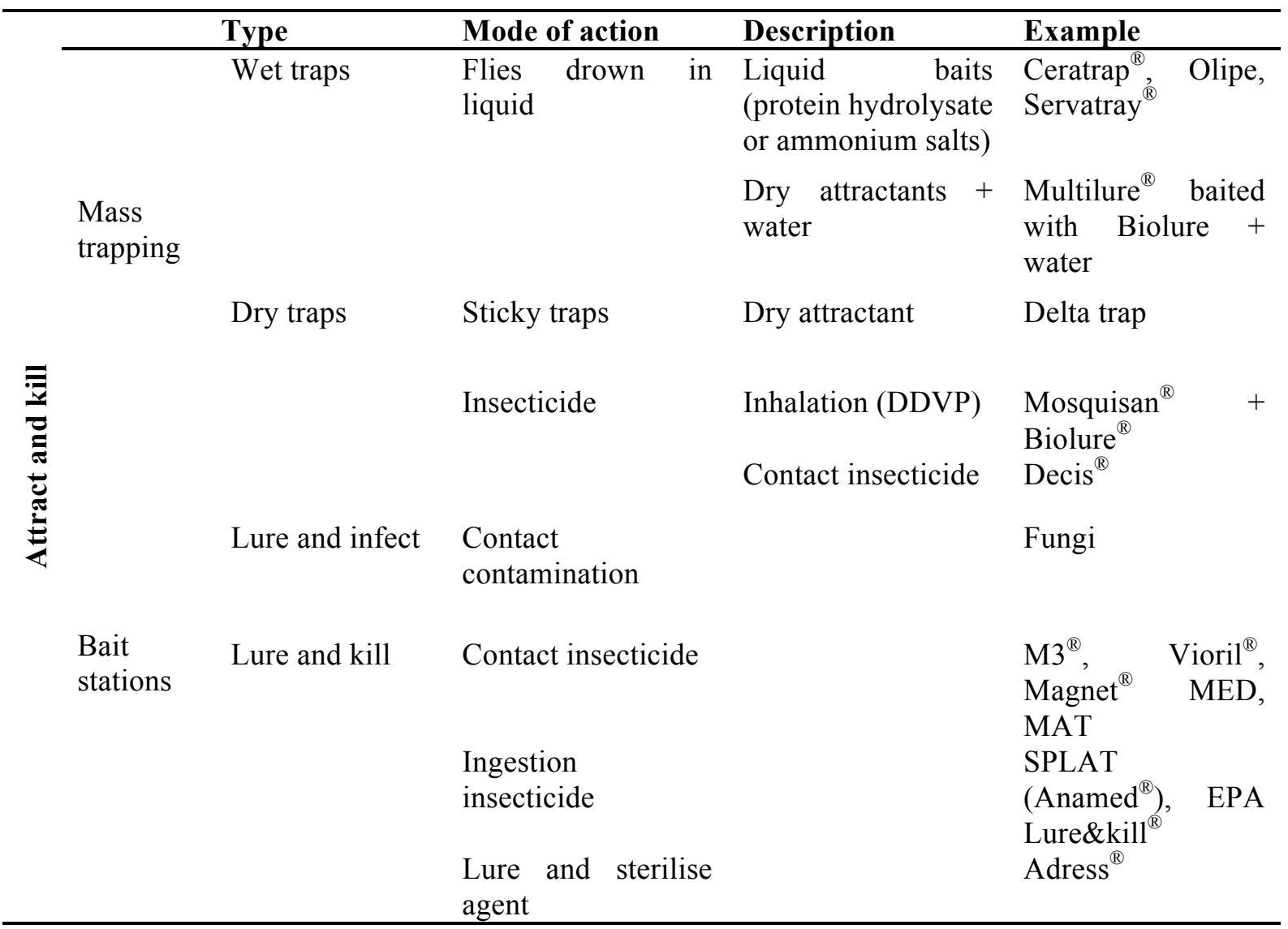

\subsubsection{Sterile Insect Technique}

The Sterile Insect Technique (SIT) involves the release of large numbers of reproductively sterile insects which should compete with the wild (fertile) males to achieve a mating with wild females. The sterile males induce a birth control in the natural population reducing the number of offspring that die due to the genetic mutations accumulated in their sperm (Knippling 1955). SIT is probably the most complex insect suppression method in use today, because it involves large-scale rearing of insects, sterilization, and release methods, as well as monitoring of insect quality and program success measurement. The first SIT program used against medfly was conducted on early 1970, when it was successfully applied in several countries, in some of them still in use to prevent the re-appearance of medfly and to suppress or eradicate some outbreaks (Klassen and Curtis 2005). 
In Valencia, a mass-rearing and sterilization facility was inaugurated in 2007. Around 1,800 sterile males/ha are released every week in Valencian citrus groves. This program is being applied to 152,500 ha and it has the capacity to produce around 540 million of sterile male pupae per week (Argilés and Tejedo 2007; GVA 2012).

In Tunisia, the mass-rearing and sterilization facility built in 2003, releases 1,000 sterile males/ha every week in the commercial citrus growing areas and another 2,000 sterile males/ha in the surrounding areas to reduce the possibility of re-infestations. The facility has a maximum rearing capacity of 12 million pupae per week (M'Saad Guerfali and Loussaief 2008).

Medfly rearing procedures have been improved and automated over the years, reducing the overall cost of the SIT process, making it competitive with other control strategies. The quality of sterile insects is strongly affected by many factors, from early steps as mass-egg production and egg boiling (to select only male eggs) to the very last step as release from aircraft or by a ground-machine. For this reason, produced sterile males are routinely monitored for traits as size, percent emergence, survival, flight ability, and ability to mate (Lance et al. 2014).

The success of SIT is being routinely determined by indirect measures as recapture ratio of males, or by some direct measures as induced sterility in the area population (as measured by counting viable and unviable eggs in infested fruits compared to a nearby control area) (reviewed in Juan-Blasco 2012). This methodology is under evaluation in field conditions by means of determining the mating success of released sterile males with the SpermID molecular method (Juan-Blasco et al 2013, 2014).

\subsubsection{Biological control}

The biological control method of an insect is defined as the use of its natural enemies to maintain pest populations to acceptable economical levels (van Driesche and Bellows 1996). It can be classified depending on the nature of the natural enemy used to control the pest, or in the way they are applied.

\section{Microbial control}

The microbial control methods use microorganisms as beneficial organisms to maintain the population below the acceptable economical damage level. Over the past decade, some studies have tested the effectiveness of microbial control agents on a number of tephritid fruit flies (Dimbi et al. 2009). Among these microbial control agents there are entomopathogenic viruses, fungi, nematodes, protozoa, and bacteria as biological control agents (Ortu et al. 2009) 
Several studies showed the pathogenicity of some species of fungi as Metarhizium anisopliae (Metschnicoff), Beauveria bassiana (Balsamo) and Paecilomyces fumosoroseus (Wize) on larvae, pupae and adults of C. capitata (Dimbi et al. 2003; Ekesi et al. 2003, Quesada-Moraga et al. 2006). These fungi are very promising biocontrol agents especially against adult fruit flies as they infect the host via the cuticule and do not have to be ingested like viruses or bacteria. Despite some attract and kill devices (Table 1.4) have been designed with these fungi as lureand-infect devices, to be spread by conspecifics either at mating (horizontal transmission) or from female to offspring (vertical transmission), its commercialization is still under development (Dimbi et al. 2003; Maniania et al. 2006). In addition, it has been demonstrated that these fungi may cause sublethal reproductive effects on target individuals; unfortunately, this is an understudied issue on C. capitata (Castillo et al. 2000; Quesada-Moraga et al. 2006). This technique can be integrated with the SIT, being the sterile males the carriers of entomopathogenic fungi (Flores et al. 2013). In Spain, B. bassiana formulations are registered and authorized to be used against C. capitata (MAGRAMA 2012b).

The genus Bacillus (Bacteria: Firmicutes) include some entomopathogenic bacteria species commercialized as natural agents for biological control of invertebrate pests, being the most important the species Bacillus thuringiensis (Berliner). Toxicity bioassays using several strains of $B$. thuringiensis have been carried out against medfly, recording maximum mortalities of only $30-40 \%$ (Vidal et al. 2008).

Entomopathogenic nematodes of the genera Heterorhabditis and Steinernema are considered effective biological control agents of insect pests that spend some stage in the soil (Efron et al. 2001) and represent a group with a high potential for use in fruit fly control, favored because they allow the use of an environmentally safe technology. Studies have indicated that tephritid larvae are susceptible to these nematodes, although pupae are more resistant (Beavers and Calkins 1984). Steinernema carpocapsae (Weiser) (Mexican isolate) has caused $87 \%$ mortality in C. capitata larvae at doses of up to 500 infective juveniles $/ \mathrm{cm}^{2}$ (Grewal et al. 2001; Almeida et al. 2007)

\section{Predators}

Other arthropods with potential for biological control against C. capitata are, particularly, polyphagous predators inhabitating in the crop soil. In Spain, a screening of C. capitata predator was performed (Monzó et al. 2007). Ants, spiders, beetles belonging to the Staphylinidae family and others were identified as $C$. capitata predators. Predators found were active at different seasonal periods, different moments of the day and they attacked different biological stages of 
medfly living in the soil, thus ensuring the predation action over the whole year (Monzó et al. 2009b, 2010).

\section{Parasitoids}

During the twentieth century, there have been several attempts concerning biological control of the medfly, mainly based on the release of exotic parasitoids (Wharton 1989). The greatest successes were achieved in Hawaii in the 50's with the introduction of three hymenopterans (Hymenoptera: Braconidae) Diachasmimorpha longicaudata Ashmead, Diachasmimorpha tryoni (Cameron) and Fopius arisanus Sonan (Wong et al. 1991). However, many problems arise after this first success like the time of the application, the need of acclimatization of exotic species into the new habitat, high pest biotic potential and low parasitism rate, size of affected fruit and the thickness of their epicarpe (Sivinski 1996).

Currently, the application of the biological control with parasitoids against C. capitata, alone or in combination with SIT, has been successfully used in South and Central America, Australia and Hawaii (USA) (Sivinski 1996; Ovruski et al. 2000). More specifically, Montoya and Cancino (2004) said that the augmentative releases of parasitoids can contribute efficiently on programs focused on the control or eradication of fruit fly, if they are made at appropriate densities and conditions.

In Spain, influenced by this success, imports of exotic parasitoids were conducted (reviewed in Sabater-Muñoz et al. 2012). In late 2002, the IVIA (Instituto Valenciano de Investigaciones Agrarias) introduced two exotic parasitoids from Hawaii (USA), F. arisanus and D. tryoni (Beitia et al. 2003; Falcó et al. 2003). The first one is an egg parasitoid and the second is a specialist on third instar larvae. Although the first studies and field tests demonstrated successful parasitism with rates between 10 to $25 \%$, both species are thought to be acclimatizing to the Mediterranean climatic conditions (Beitia et al. 2002, 2006; Falcó et al. 2003; Santiago et al. 2006). Beitia et al. (2011) introduced a third species, D. longicaudata, from Mexico, a parasitoid of third instar larvae of medfly, which demonstrated better efficacy in laboratory than the previous one, D. tryoni. In addition to parasitoid importation and release, a program of native parasitoids screening was initiated in 2002. This screening program revealed the presence of two species of pupal parasitoids affecting the medfly, Spalangia cameroni (Perkins) and Pachycrepoideus vindemmiae Rondani (Hymenoptera: Pteromalidae) (Falcó et al. 2003). And lately, in 2008-2009, the figitid Aganaspis daci Weld (Hymenoptera: Figitidae), a larvopupal parasitoid was found attacking the medfly on figs (Sabater-Muñoz et al. 2012; De Pedro et al. 2013). 
Concerning Tunisia, the medfly biological control started with the present thesis work. A screening of native medfly parasitoids was carried out during 4 years (2011-2015). Two parasitoids were identified, the braconid Psyttalia concolor Szépligeti (Hymenoptera: Braconidae), a parasitoid of third instar larvae of medfly used to control the olive fruit fly Bactrocera oleae Gmelin, and the pteromalid P. vindemmiae, an ectoparasitoid of pupal stages which is known also as hyperparasitoid (Harbi et al. 2015). Besides to that "native species", in 2013, D. longicaudata was introduced from Spain, to start a biological control program as presented in this thesis dissertation (Chapter 5). 


\subsection{Objectives and rationale}

As explained earlier, C. capitata is the key pest in citrus producing countries. Actual Plant Protection Directives, mainly from EU countries, are promoting the use of environmental safe techniques like SIT, mass trapping, chemosterilization and Biological Control within an Integrated Pest Management program to reduce insecticides impact in both ecosystem and human health. In this sense, of preservation of ecosystem (including agroecosystems) and human health, Biological Control arose as the best option by their direct impact on the target pest species. As indicated at the introduction, Biological Control against $C$. capitata is an almost neglected issue of Plant Protection plans in Mediterranean countries that deserves further attention. For this reason, the objectives of the present thesis are:

1. Determination of parasitic potential (and its affecting factors) of D. longicaudata against C. capitata.

2. Determination of biotic and abiotic factors affecting parasitic activity of D. longicaudata against $C$. capitata in different fruit hosts.

3. Identification of key points to integrate $D$. longicaudata within the IPM program in Spain.

4. Determine the key points to establish a Biological Control program based on $D$. longicaudata against $C$. capitata in Tunisia.

Each objective is justified and explained independently in the next four chapters. 


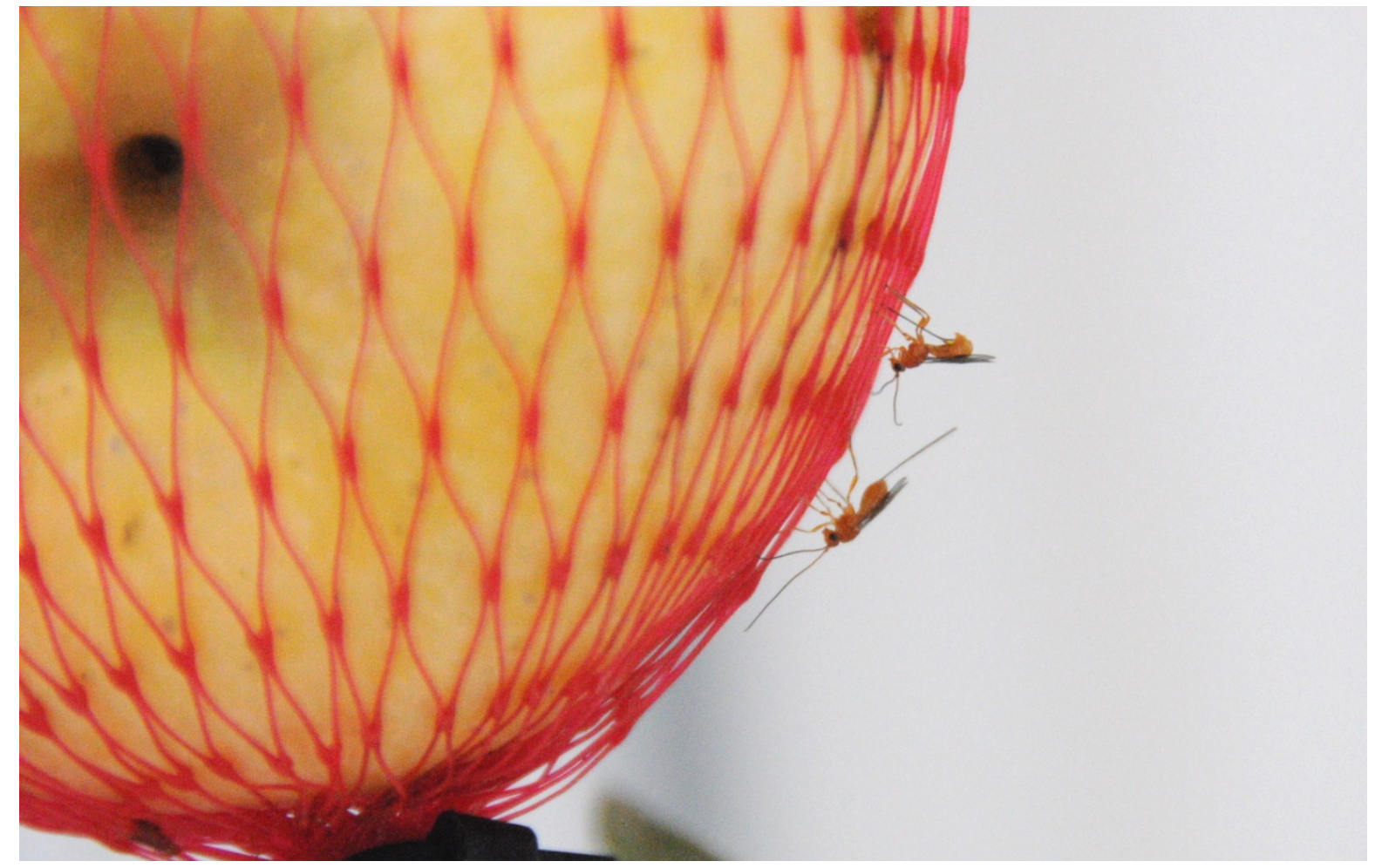

CHAPTER 2. Biotic and abiotic factors affecting parasitic activity of Diachasmimorpha longicaudata over the Mediterranean fruit fly, Ceratitis capitata 
To achieve the first objective of the thesis:

1. Determination of parasitic potential (and its affecting factors) of D. longicaudata against C. capitata.

I will develop in this chapter a short bibliographic report on the biology, biotic and abiotic factors affecting the species D. longicaudata, selected as biological control agent of the medfly, C. capitata, in Spain and Tunisia, followed by laboratory studies to fill the gap of knowledge that affects the parasitic potential of this parasitoid species when reared on C. capitata. The obtained results in the assays performed will be discussed to answer this objective.

\subsection{Diachasmimorpha longicaudata}

Opiine braconids Hymenoptera are widely used in the control of tephritid fruit flies because their relatively high host specificity and ability to inflict substantial mortality on their hosts (Aluja et al. 1990). About 100 braconid species have been found parasitizing tephritid larvae worldwide, many of these belong to the genera Diachasmimorpha Viereck, Psyttalia Walker, Utetes Foster or Opius Wesmael (Wharton 1989).

Among these braconids, we are interested on the species Diachasmimorpha longicaudata (Ashmead) as medfly parasitoid to evaluate and study its capacities and biology in controlling Ceratitis capitata in the Mediterranean region and especially in Spain and Tunisia after its introduction from Mexico.

\subsubsection{Taxonomic classification}

Class: Insecta

Order: Hymenoptera

Family: Braconidae

Subfamily: Opiinae

Genus: Diachasmimorpha

Species: Diachasmimorpha longicaudata (Ashmead 1905) 


\subsubsection{Origin and geographic distribution}

Diachasmimorpha longicaudata was originally collected in the Indo-Philippine region. It has been found in numerous countries in Southeastern Asia, where it parasitizes at least 14 species of Bactrocera spp. (Clausen et al. 1965; Wharton and Gilstrap 1983; White and Elson-Harris, 1992). However, over the last half century it has been introduced in the tropical and subtropical New World (Ovruski et al. 2000) where is widely mass reared for its use in inundative releases against both Anastrepha spp. and C. capitata fruit flies (Sivinski et al. 1996; Montoya et al. 2000).

\subsubsection{Description and biology}

Diachasmimorpha longicaudata is a larval-prepupal endoparasitoid of tephritid species. The female lays its eggs inside the fruit fly larvae, where they complete their development (Ibrahim et al. 1994; Montoya et al. 2000).

The complete immature development of this species, from egg to the emergence of the adults, took about 16 days (at $25^{\circ} \mathrm{C}, 85 \% \mathrm{RH}$ and 18:6 L:D photoperiod). The duration of each stage of development was 1.5 days for eggs as well as first instar larvae, 2.7 days for second instar larva, 1.5 days for third instar larvae, 2.5 days for prepupae, 3 days for pupae, and 3 days for pharate adults (Paladino, 2010). The description of each stage is described below and shown in Figure 2.2 (Palacio et al. 1992; Ibrahim et al. 1994; Paladino, 2010).

The egg: is hymenopteriform measuring $0.42 \mathrm{~mm}$ long and $0.09 \mathrm{~mm}$ wide when newly laid. A fully incubated egg measures $0.71 \mathrm{~mm}$ long and $0.23 \mathrm{~mm}$ wide. One day after, the eggs are slightly cylindrical, translucent, and very difficult to visualize amidst the host tissue. On the second day, the egss are brighter and more swollen.

First instar larva: The head is large, highly chitinized, and bore a pair of sickle-like mandibles that could usually be seen through the host larval cuticle. The body is translucent and segmented, but it becomes whitish as the digestive canal became gradually filled and swollen with globules of fat. The newly hatched larva measures $0.74 \mathrm{~mm}$ long and $0.08 \mathrm{~mm}$ wide at the early stage increasing to $1.13 \mathrm{~mm}$ long and $0.31 \mathrm{~mm}$ wide at its late stage.

Second instar larva: When the parasitoid larva reaches the second larval instar, the head could not be differentiated from the other body segments, and the mandibles were translucent and difficult to visualize. The body was entirely glabrous, and the segments 
were less distinguishable than in the previous instar. The larva measured $2.77 \mathrm{~mm}$ long and $0.98 \mathrm{~mm}$ wide.

Third instar larva: The parasitoid is much bigger and filled almost the entire host puparium, it is similar to the earlier instar except that it increased in size to $4.07 \mathrm{~mm}$ long and $1.33 \mathrm{~mm}$ wide. Pointed mandibles with brownish chitinizations at the tips and bases were distinguished on the head. The body is yellowish, well segmented, and large white cells were clearly visible under the integument. The larvae could move from side to side and change its orientation inside the puparium. A dark oval meconium could be seen through the cuticle at the caudal end. This meconium contained the digestive waste and is eliminated during the adult emergence.

Prepupa: The prepupa was characterized by a lack of mobility, compared to the third larval instar, and the beginning of a reddish pigmentation of the eyes. The development of the pupa could be seen through the cuticle as this instar proceeded. No visible changes in the mandibles' morphology were detected (Paladino, 2010).

Pupa: The shape of the pupa is similar to that of an adult, with a white body and fully pigmented red eyes. As pupation progresses, both the eyes and the body became darker. Sexual dimorphism is very noticeable. Females present a well-developed ovipositor bent to the dorsal side (Figure 2.2.i, arrow), and males have valves that corresponded to the external part of the reproductive system at the ventral-caudal region. Furthermore, the antennae are noticeably longer in males than in females. The female pupa measures 6.05 mm long and male $5.49 \mathrm{~mm}$ (Ibrahim et al. 1994; Paladino, 2010).

Pharate adult: The only difference from the pupa is that the body starts to acquire a brownish pigmentation, as the sclerotization process takes place.

Adult: The newly emerged adults have a brown ovipositor shaft with swollen and quadrisinuate apex (Palacio 1991). Female adults measure $5.6 \mathrm{~mm}$ long from head to tip of abdomen and were $1.3 \mathrm{~mm}$ wide at the thorax. The male adults is $5.2 \mathrm{~mm}$ long and $1.2 \mathrm{~mm}$ wide (Ibrahim et al. 1994). The antennae are longer than the body, shading to black from the fourth segment outward. Wings are clear. The gaster of the female often has a dorsal central black band. The gaster of male often has dark brown to black dorsal posterior segments. The ovipositor is black-tipped and longer than the female's entire body (Wharton and Marsh 1978; Thompson 2014) (Figure 2.3). 

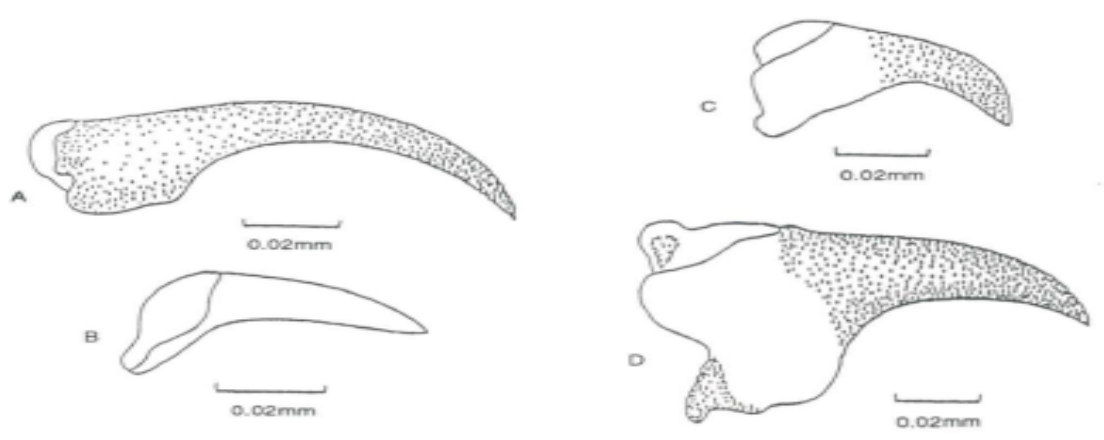

Figure 2.1. Mandibles of the larvae of D. longicaudata; A-D, first to fourth instars (Ibrahim et al. 1994).

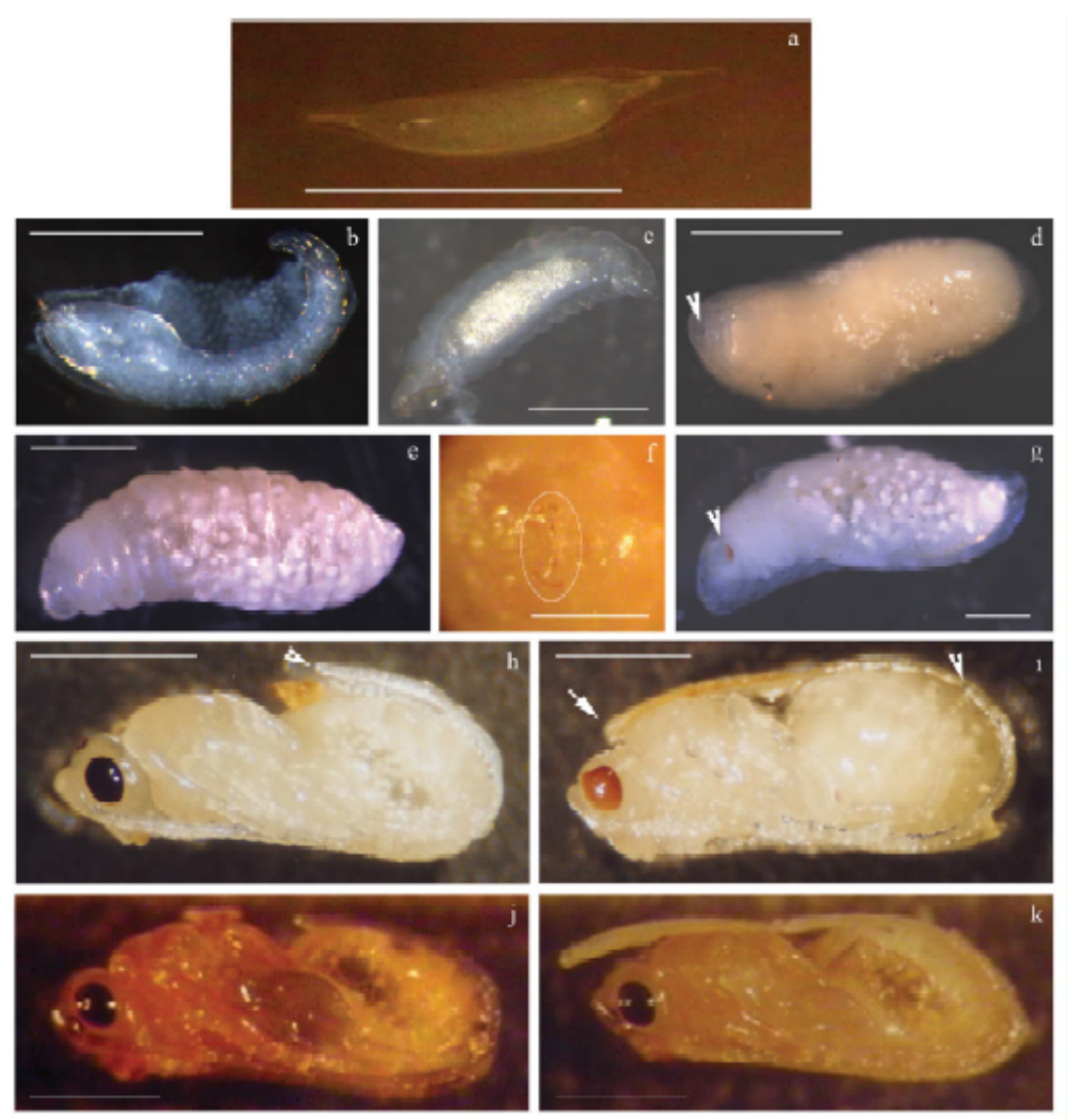

Figure 2.2. Immature stage of development of $D$. longicaudata. a: Egg. Bar: $500 \mu \mathrm{m}$; b: First instar larva; c: Late first instar larva; d: Second instar larva, arrowhead points to the mouth; e: Third instar larva; f: Mandibles of third instar larva. Bar: $500 \mu \mathrm{m}$; g: Prepupa, arrowhead pointed to the pigmented eyes; h: Male pupa, arrowhead points to the end of the antennae; i: Female pupa, arrowhead points to the end of the antennae, arrow shows the ovipositor; $\mathrm{j}$ : Male pharate adult; k: Female pharate adult. Bar: $1 \mathrm{~mm}$ (modified from Paladino 2010). 
A)

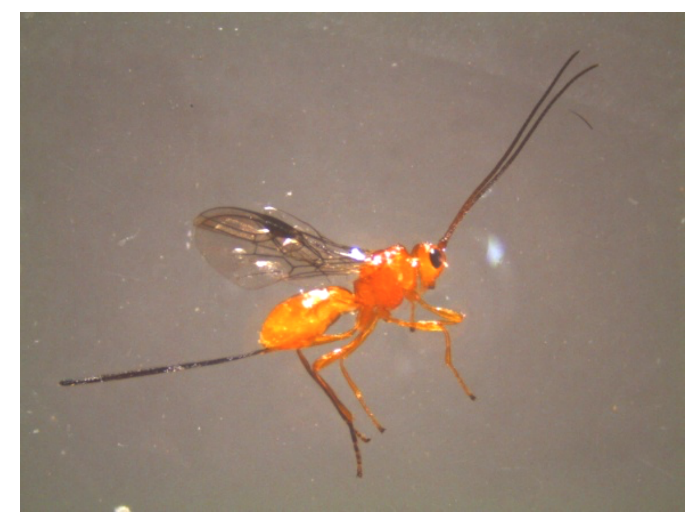

B)

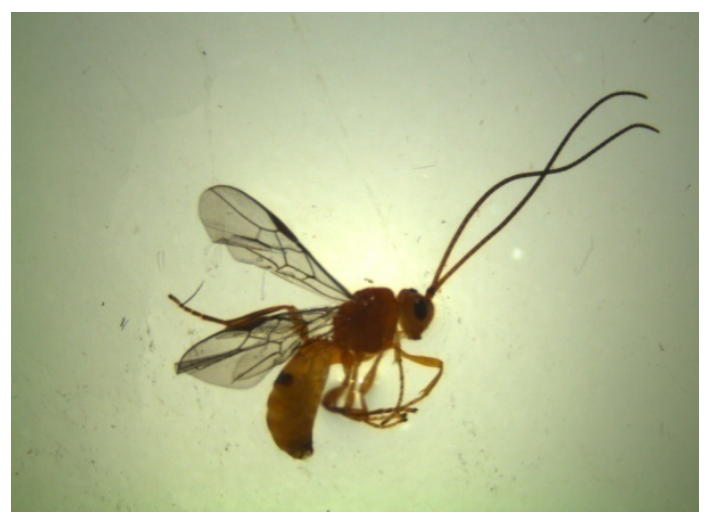

Figure 2.3. Diachasmimorpha longicaudata adult lateral view. A: Female; B: male.

\section{Biology}

Diachasmimorpha longicaudata is a koinobiont (allows host development after oviposition), solitary (only one parasitoid emerge from a single host), synovigenic (female mature own eggs throughout adult life and require host nutrients for egg production), endoparasitoid (parasitoid develops inside host), with arrhenotokous parthenogenesis reproduction system on which females develop from fertilized eggs (diploid) whereas males develop from unfertilized eggs (haploid). This haplodiploid sex-determination system is typical of Hymenoptera, which confers this species with a high reproductive potential (Fischer 1966; Wigglesworth 1972; Wharton and Marsh 1978; Wharton and Gilstrap 1983).

This species is described as solitary; however, it shows a high tendency towards selfsuperparasitism, even when non-parasitized hosts are present in abundance (Montoya et al. 2000a) or even being able to discriminate between non-parasitized and parasitized hosts (Montoya et al. 2003). Despite this fact, only one individual emerges from the parasitized host as supernumerary larvae are eliminated through physical or physiological means (Lawrence, 1988a; Montoya et al. 2000a).

Female size also influences reproductive potential; large females produce more offspring than small females (Kitthawee 2000). In average, the female lays 13 to 24 eggs per day (Lawrence et al. 1978) using her elongated ovipositor to reach the fly larvae inside fruit.

Females are attracted to fermentation products emanating from rotting fruit; the likely allow location of host larvae. In the absence of larvae, the attractant has been attributed to fungal fermentation products (Greany et al. 1977). Having found rotting fruit, the female parasite can detect the larvae by sound. The larvae of Anastrepha suspensa (Loew) (Diptera: Tephritidae) make sounds within macerated fruit and laboratory media (Lawrence 1981). When offered the 
choices of mobile larvae, anesthetized larvae or dead larvae, D. longicaudata females could only readily locate the moving larvae (Lawrence 1981).

\subsubsection{Importance of biological parameters of D. longicaudata for Biological Control}

The opiine braconid wasp D. longicaudata is considered among the successful parasitoid species currently used in biological control programs. It has a high capacity to adapt to the different environmental conditions where it has been introduced (Aluja et al. 1990; Eskafi 1990; Lopez et al. 1999), and can achieve higher levels of parasitism than other known parasitoids of fruit flies. Consequently, efficient mass-rearing methods and augmentative release procedures of this parasitic wasp have been extensively developed (Sivinski 1996; González et al. 2007). Diachasmimorpha longicaudata was introduced into Spain from Mexico in 2009, where it has been reared on Anastrepha ludens (Loew) (Diptera: Tephritidae), and subsequently it has been imported to Tunisia from Spain in 2013 in the framework of a cooperation project. The aim of these introductions is the inclusion of this parasitoid in an integrated control program of the medfly in citrus orchards in the two countries (Martins et al. 2010). When D. longicaudata was imported to Spain and then to Tunisia, a laboratory rearing of the parasitoid on C. capitata as host species was started to carry out several laboratory, semi-field and field experiments to assess its efficacy, optimize its use against the pest and assess its potential establishment in both countries.

The quality of reared parasitoids for later use in the field against a pest is assessed throughout the study of several biological parameters. It depends, among others, on the host used in its mass production as well as on the general conditions of the laboratory rearing (Cancino et al. 2003). Recently, many research works studying the basic biological parameters of $D$. longicaudata reared on C. capitata and using relatively similar experimental conditions as our rearing installed in Spain and Tunisia have been published showing many differences regarding reproductive fitness and life history parameters. This suggests that the parasitoid performance varies significantly among different laboratory strains (Vargas et al. 2002; Viscarret et al. 2006; Meirelles et al. 2013). 


\subsubsection{Effect of abiotic conditions on $\boldsymbol{D}$. longicaudata}

Biological control of Mediterranean fruit fly by the braconid D. longicaudata might be accomplished through "classical" release and establishment of the parasitoid. However, factors that affect the effectiveness of the parasitoid need further consideration.

Among these factors, climatic conditions can modify the performance and efficiency on the biological control of $D$. longicaudata. Climatic adaptation has been listed among the criteria for selecting potential biocontrol agents (van Lenteren, 1986), and temperature is often regarded as the most important factor governing acclimatization of introduced natural enemies (Loni 1997). For example, the Australian distribution of the opiine fruit fly parasitoid, F. arisanus, is limited by low winter temperature (Snowball and Lukins 1964). Another opiine, Doryctobracon crawfordi (Viereck) (Hymenoptera: Braconidae), has been shown to be more sensitive to high temperatures than its host, A. ludens (Darby 1933). Additionally, releases of both wild and mass-reared P. concolor in some parts of Italy have failed (Raspi and Loni 1994), possibly due to poor temperature adaptability (Fenili and Pegazzano 1971).

Low temperature exposure can have lethal effects on insect parasitoids (Hance et al. 2007) and, not surprisingly, overwintering survival of an introduced natural enemy is one of the major climatic obstacles to their successful establishment in new geographic ranges (Boivin et al. 2006; Hughes et al. 2010; Jenner et al. 2010). Sublethal effects from cold temperatures can be as deleterious for biological control programs when parasitoid fitness is negatively affected, including characteristics such as development (Colinet et al. 2006; Levie et al. 2005; Luczynski et al. 2007), body size, sex allocation, longevity, or fecundity (Pitcher et al. 2002; Torres et al. 2002; Hackermann et al. 2008; Lopez and Botto 2005) and foraging efficiency (van Baaren et al. 2005; Amice et al. 2008; Bourdais et al. 2012).

\subsubsection{Effect of biotic conditions on D. longicaudata}

Climatic adaptation is an important criterion for selecting potential biological control agents (van Lenteren 1986). Field-testing of natural enemies for selection for climatic adaptation can be very time consuming, especially if several candidates are involved. Hence, laboratory and greenhouse studies are useful for choosing a suitable candidate (Pak and van Lenteren 1988). Several biological characteristics, among them searching ability, fecundity, longevity and sex ratio, have been used to assess potential efficacy of a parasitoid. 
The effectiveness of a natural enemy to regulate pest populations has been traditionally related to its functional response (Hassell 1978; Fujii et al. 1986), which is defined as the relationship between the numbers of prey taken by the predator as a function of prey density (Holling 1959). These functional responses define the parasitoid searching efficiency and provide an understanding of the host-parasitoid interactions (Montoya et al. 2000; Greenberg et al. 2001). Recently, the experimental observations confirm that the initial densities of host and parasitoid populations can affect the classical biological control (Burnett 1960; Jones et al. 1999). Similarly, modelling of host-parasitoid dynamics suggests that the ability of a parasitoid to supress the abundance of an insect pest to a level at which it no longer cause economic damage depends on the initial density (i.e. their ratios) (Xiao and Tang 2008).

\subsection{Material and Methods}

\subsubsection{Insect rearing}

To realize this thesis, it was needed a functional semi-mass rearing of C. capitata and its parasitoid species D. longicaudata. First, it was established at the Entomology Department of the Valencian Institute of Agricultural Research (IVIA) (Moncada, Valencia, Spain), and later, at the Laboratory of Entomology of the Higher Agronomic Institute of Chott-Mariem (ISACM) (Tunisia).

\subsubsection{Ceratitis capitata rearing}

The establishment of the medfly rearing require in a first step the collection of a sufficient number of field infested fruits to accumulate a good quantity of pupa, enough to set-up a laboratory rearing. As newly laboratory emerged females require one or two generations for its adaptation to lay their eggs in the muslin of the cage, during this period, and to maintain the initial population of the medfly, we offered ripe fruits as an oviposition support.

The rearing was set up in a climatic chamber under a constant conditions $\left(25 \pm 2{ }^{\circ} \mathrm{C} ; 60 \% \pm\right.$ 10\% RH and 16:8 light:dark (L:D)) (Figure 2.4). The duration of the biological cycle of the medfly in these conditions is about 15 days. 


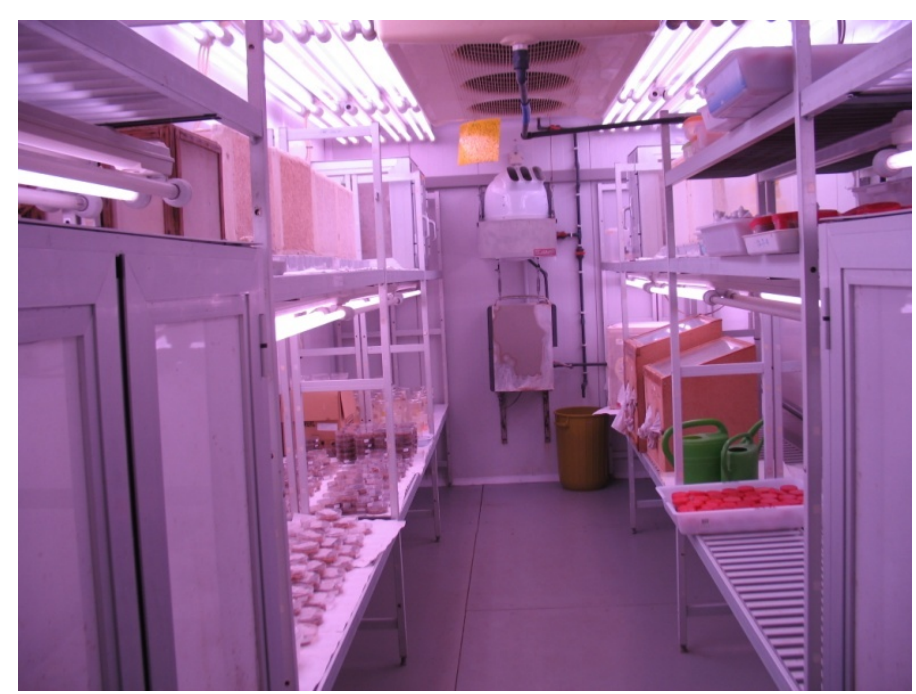

Figure 2.4. Climatic chamber (walking in; built-in-house) of the IVIA research station on which several insect species are reared and where some of the tests took place.

The medfly culture on artificial diet is maintained in plastic cages $(40 \times 30 \times 30 \mathrm{~cm})$ with one mesh-framed lateral side to allow the oviposition of females (Figure 2.5). In each cage a recipient containing $80 \mathrm{ml}$ of medfly pupa was disposed with ad libitum water and food (sugar and yeast hydrolysate at ratio of $4: 1$, respectively).

To collect the medfly eggs, a recipient with water was put under the rearing cage in the side of the muslin. Eggs were recuperated daily to seed them on the artificial diet (Table 2.1), and then allowed to develop into larva in special trays and plastic cages with ventilation (Figure 2.6).

Table 2.1. Ingredients of $C$. capitata artificial diet

\begin{tabular}{cc}
\hline Ingredient & Quantity \\
\hline Wheat bran & $1100 \mathrm{~g}$ \\
Sugar & $290 \mathrm{~g}$ \\
Yeast hydrolysate & $150 \mathrm{~g}$ \\
Nipagin & $12 \mathrm{~g}$ \\
Nipasol & $12 \mathrm{~g}$ \\
Benzoic acid & $13 \mathrm{~g}$ \\
Water & $2100 \mathrm{ml}$ \\
\hline
\end{tabular}



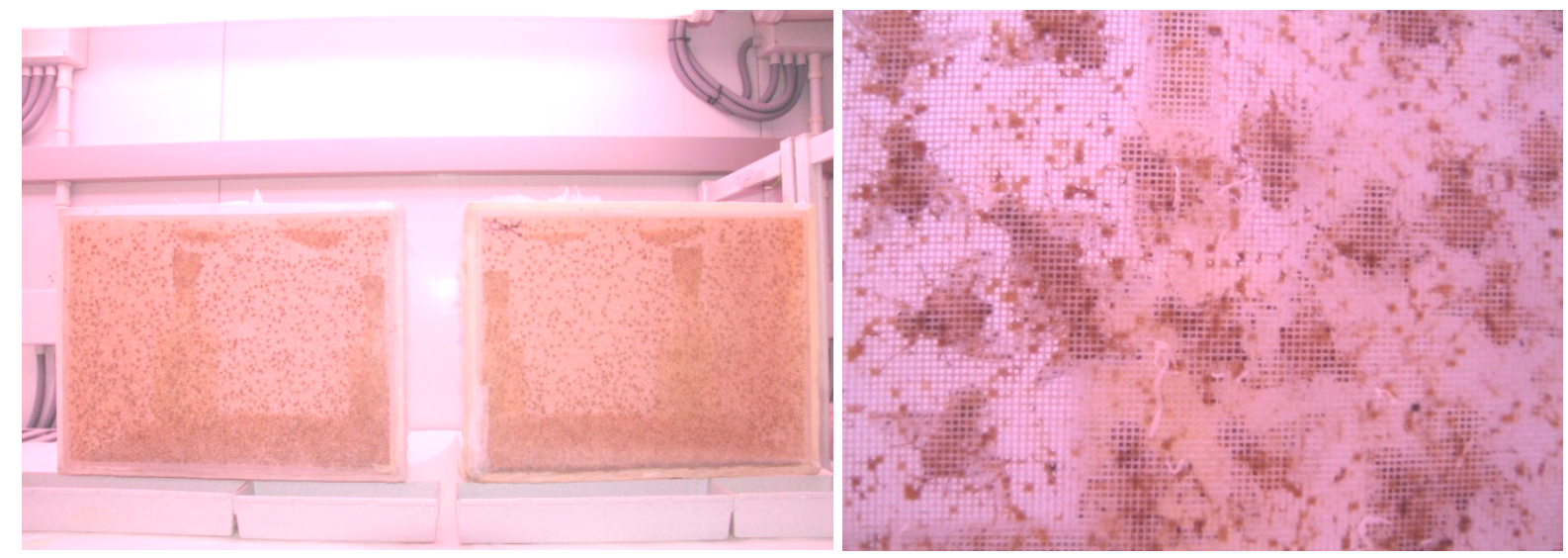

Figure 2.5. Medfly rearing cage with collecting-eggs recipients and a detail (right) of the oviposition mesh frame that attracts almost all medfly females.
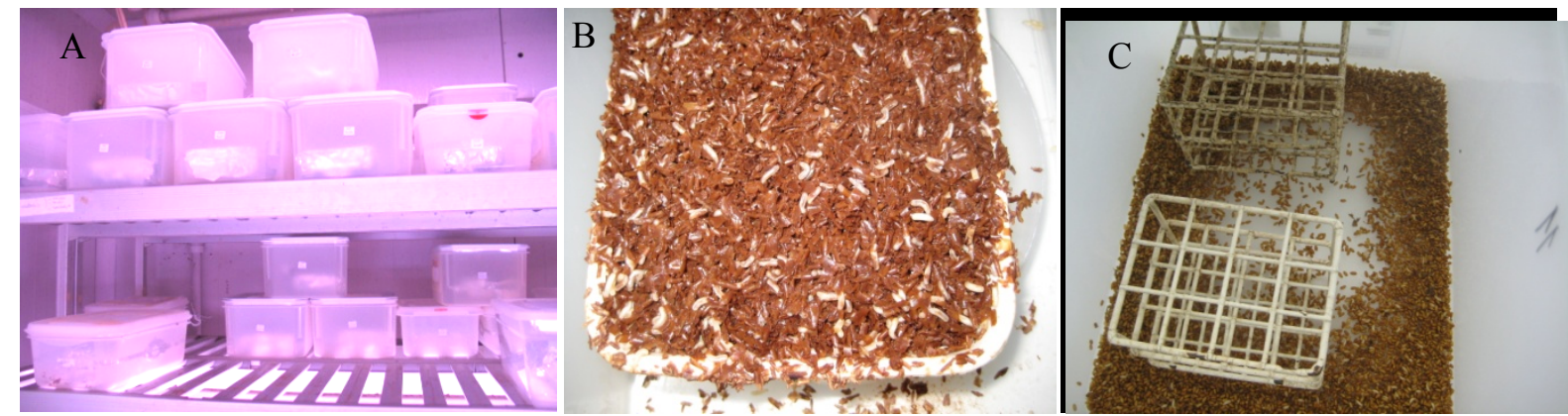

Figure 2.6. Development of medfly immature instars (from eggs to pupae) in different plastic cages. (A: Development of medfly immature instars (from eggs to pupae); B: Third instar larvae inside artificial diet. C: Medfly pupae on the bottom of a plastic cage).

\subsubsection{Diachasmimorpha longicaudata rearing}

Diachasmimorpha longicaudata rearing was initiated with individuals obtained from parasitized pupae of $A$. ludens provided by the "Centro Internacional de Capacitación en Moscas de la Fruta (CICMF), Plantas de Cría y Esterilización de Moscas del Mediterráneo y Mosca Mexicana de la Fruta", located at Metapa de Domínguez, Chiapas, Mexico, in 2009. The laboratory rearing of the parasitoid was maintained since then in the IVIA on larvae of $C$. capitata as host.

Diachasmimorpha longicaudata is reared on third instar larvae of medfly as host, in plastic cages $(40 \times 40 \times 40 \mathrm{~cm})$ using various adult densities $(4,000-5,000$ females per cage) that were provisioned ad libitum with water, honey and sugar (Figure 2.7). Medfly larvae are exposed daily to parasitism with the artificial diet, collected after $24 \mathrm{~h}$ of exposition and put in separate cages (Figure 2.8) until the emergence of the new parasitoid generation 14-16 days later. 


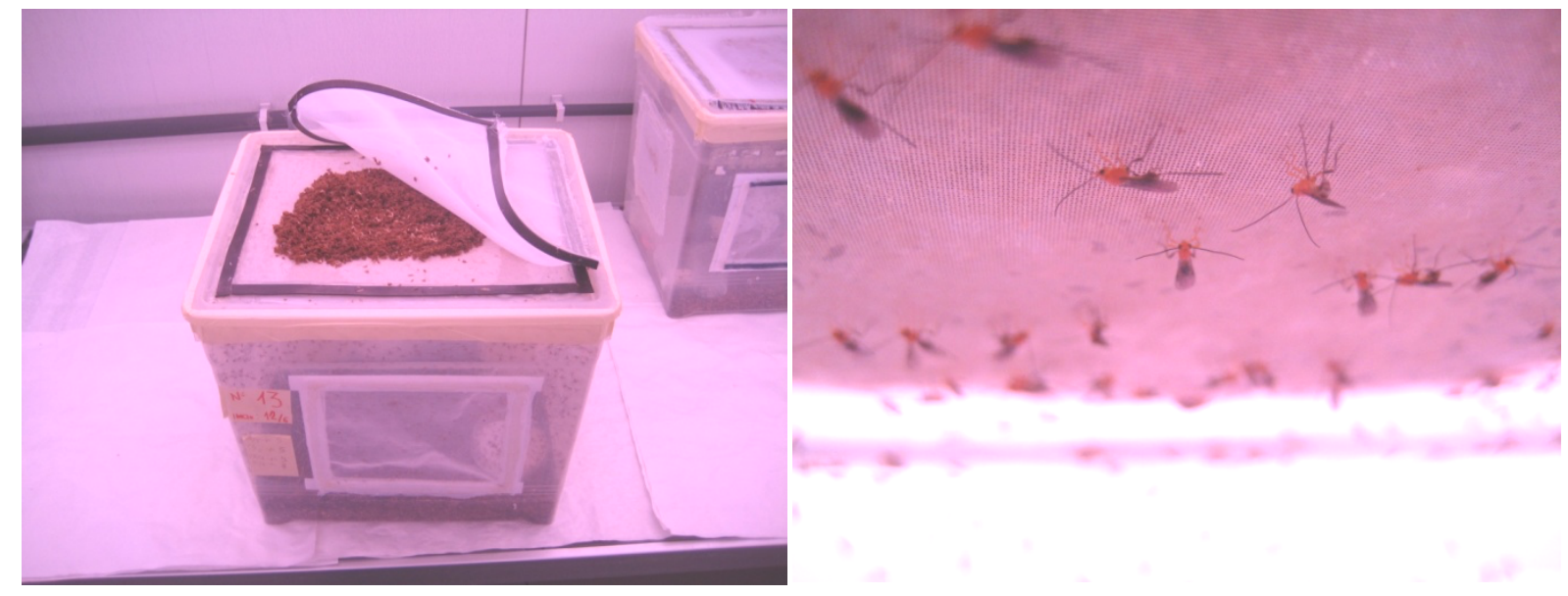

Figure 2.7. Diachasmimorpha longicaudata rearing cage (left) with a detail (right) of females upsidedown, some of them locating medfly larva for egg oviposition.

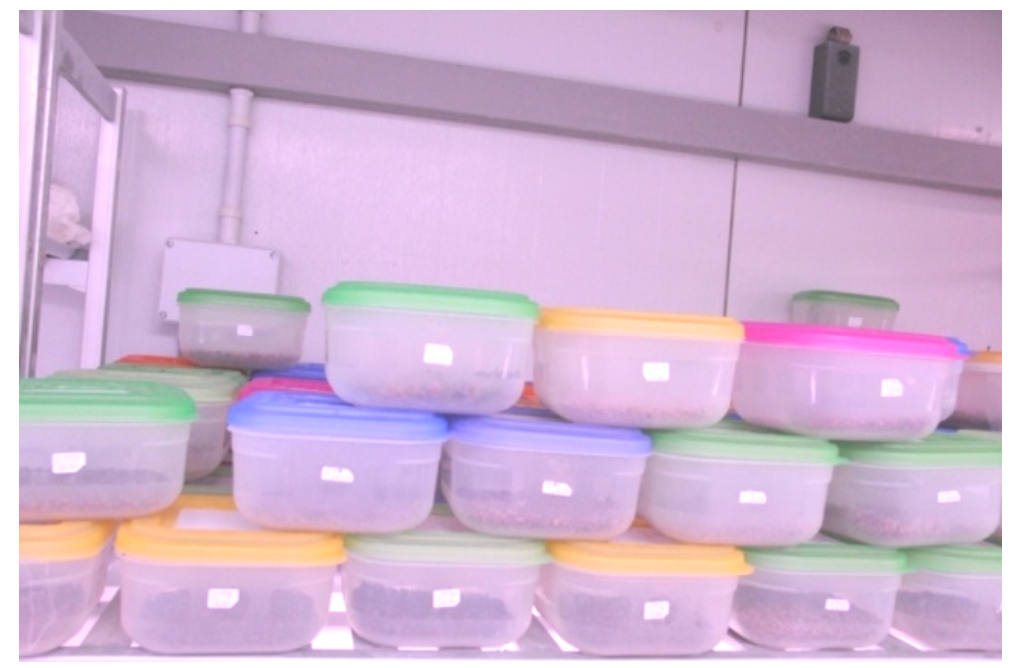

Figure 2.8. Developmental units where $D$. longicaudata parasitized medfly pupa were allowed to develop till emergency of male parasitoids (10-25 days).

The rearing cages are specially designed to parasitoids; their upper sides are covered with muslin as a laying support of $D$. longicaudata eggs (to facilitate the passage of the ovipositor of the parasitoid females to the target larvae), another muslin cover was added to reduce the mobility of C. capitata larvae (Figure 2.7 right). The different steps of the rearing of both insects are detailed in the following scheme (Figure 2.9). 
a. Medfly rearing

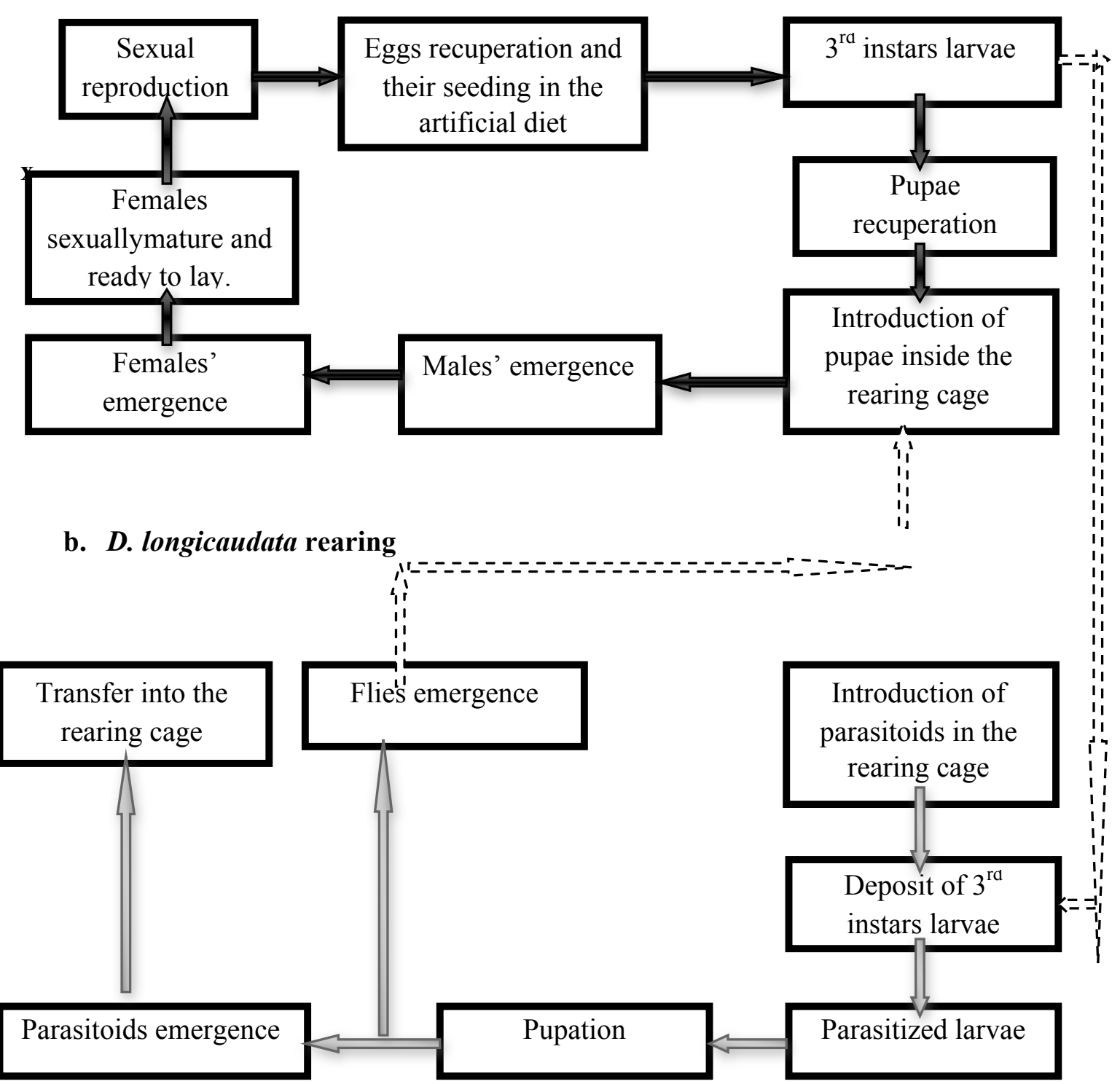

Figure 2.9. Flow diagram of $C$. capitata and D. longicaudata rearing established at ISA-CM (Tunisia) and IVIA (Spain).

\subsubsection{Life history parameters of $D$. longicaudata IVIA laboratory strain}

The aim of this research work is to evaluate biological parameters of our strain of $D$. longicaudata imported from Mexico, reared first on A. ludens and later on C. capitata and provide data to improve its laboratory rearing and to explore its potential as a biological control 
agent of the medfly in Spain and Tunisia, discussing the incidence of laboratory rearing conditions in the expected performance of the parasitoid as biocontrol agent.

\subsubsection{Experimental procedure}

A total of 20 coetaneous (one day-old) newly emerged parasitoid couples, were put separately in experimental arenas consisting of $15 \times 15 \times 10 \mathrm{~cm}$ transparent plastic boxes with side aeration windows of $16 \mathrm{~cm}^{2}$ and provided ad libitum with water, sugar and honey as adult complementary food (Figure 2.10). The upper part of each box was provided with a meshframed rectangular opening allowing the exposition of fruit fly larvae to the parasitoids. Twenty $3^{\text {rd }}$ instar larvae were offered daily to each of the parasitoid couples until the death of all females. After exposure, the putatively parasitized larvae/pupae were removed daily and kept in darkness until the emergence of adult fruit flies or parasitoids. The experiment was conducted in controlled climatic conditions chambers at $23 \pm 2^{\circ} \mathrm{C}, 65 \pm 10 \% \mathrm{RH}$ and $16: 8 \mathrm{~h}(\mathrm{~L}: \mathrm{D})$.
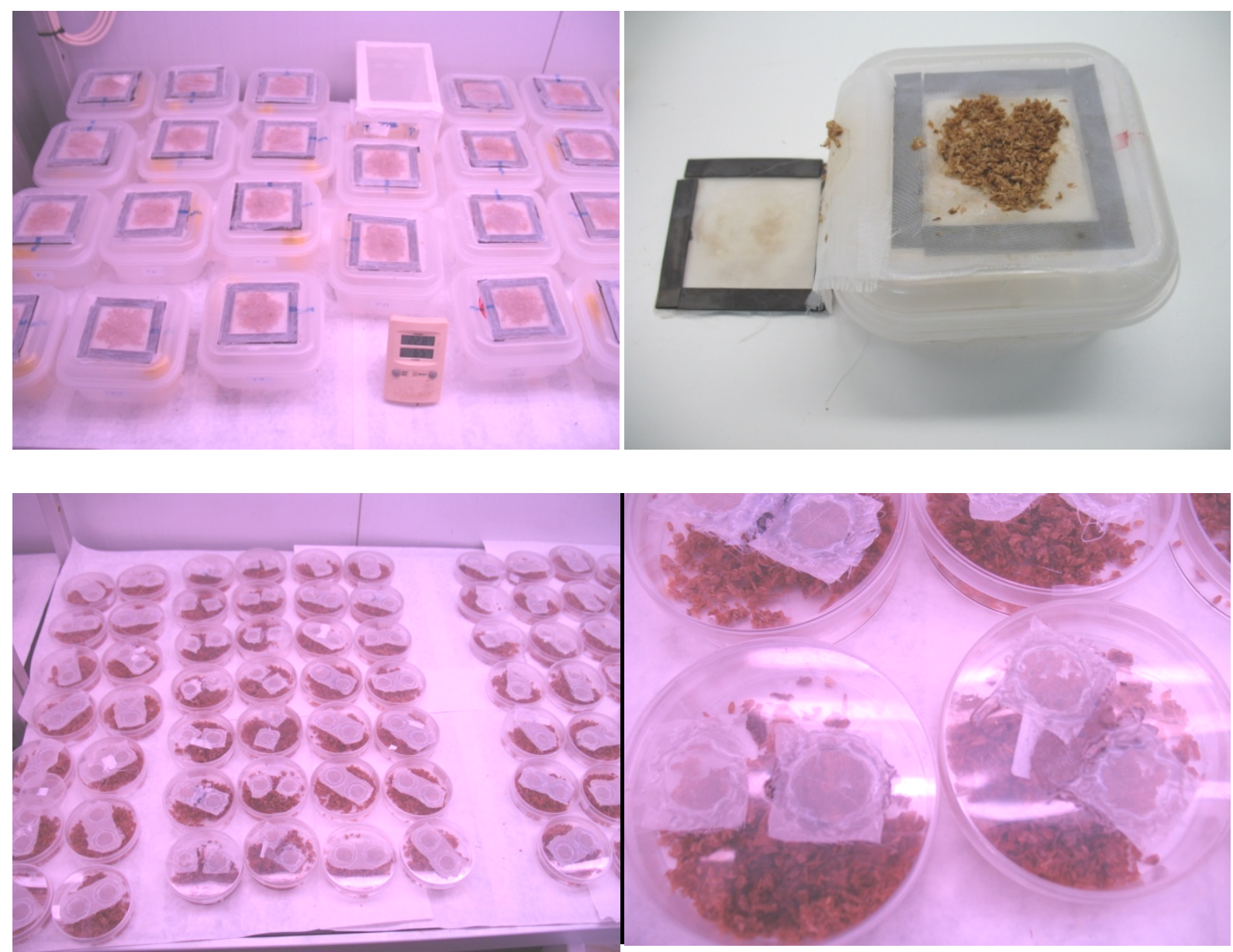

Figure 2.10. Experimental dispositive for the life table study of $D$. longicaudata. 


\subsubsection{Developmental and reproductive parameters}

Longevity of adults (male and female) and periods of pre-oviposition (the number of days between female emergence and the day of the first oviposition), post-oviposition (the number of days the female is alive after the last oviposition) and oviposition, as well as fertility (the total emerged progeny of females) were calculated. Longevity was assessed by checking the parasitoid couples daily whereas pre-oviposition, oviposition, post-oviposition periods as well as fertility were estimated by counting the emerged progeny of each couple.

Developmental time of immatures, from egg to adult emergence, was calculated from the daily progeny of females. The daily sex ratio was estimated as the proportion of female offspring in the total number of progeny (males + females) produced per day. The total sex ratio was assessed as the proportion of female offspring in the total number of progeny (males + females) produced during the life span of the female.

\subsubsection{Demographic parameters}

We based our study on several population parameters which are: net reproductive rate $\left(\mathrm{R}_{0}\right)$ (number of females produced by one female during its life), intrinsic rate of natural increase $\left(r_{m}\right)$ (rate at which the population increases in size), finite rate of increase (k) (factor by which a population increases in size from time $t$ to time $t+1$ ), doubling time (Dt) (the time span necessary for doubling the initial population) and mean generation time (T) (mean time span between the birth of an individual and the birth of its offspring) (Carey 1993).

\subsubsection{Data analysis}

Life tables were constructed using the daily survival values and the number of progeny produced by the females. The mentioned demographic parameters were calculated according to Birch (1948) and Mackauer (1983). Kaplan Meier survival curves of males and females were compared using Log-rank test with the statistical software IBM-SPSS statistics version 20.0.

\subsubsection{Effect of the temperature on the longevity of $D$. longicaudata adults}

The objective of this assay was to evaluate the effect of temperature on the longevity of $D$. longicaudata and define the thermal requirement to survive in the Mediterranean basin.

\subsubsection{Impact of constant temperature on longevity}

The longevity was assessed on five different constant temperatures: $15,20,25,30$ and $35^{\circ} \mathrm{C}$. The study was performed in different SANYO incubators (Figure 2.11) at the entomological laboratory of the IVIA, with a photoperiod of 16:8 (L: D) and a RH about $60 \pm 10 \%$. 


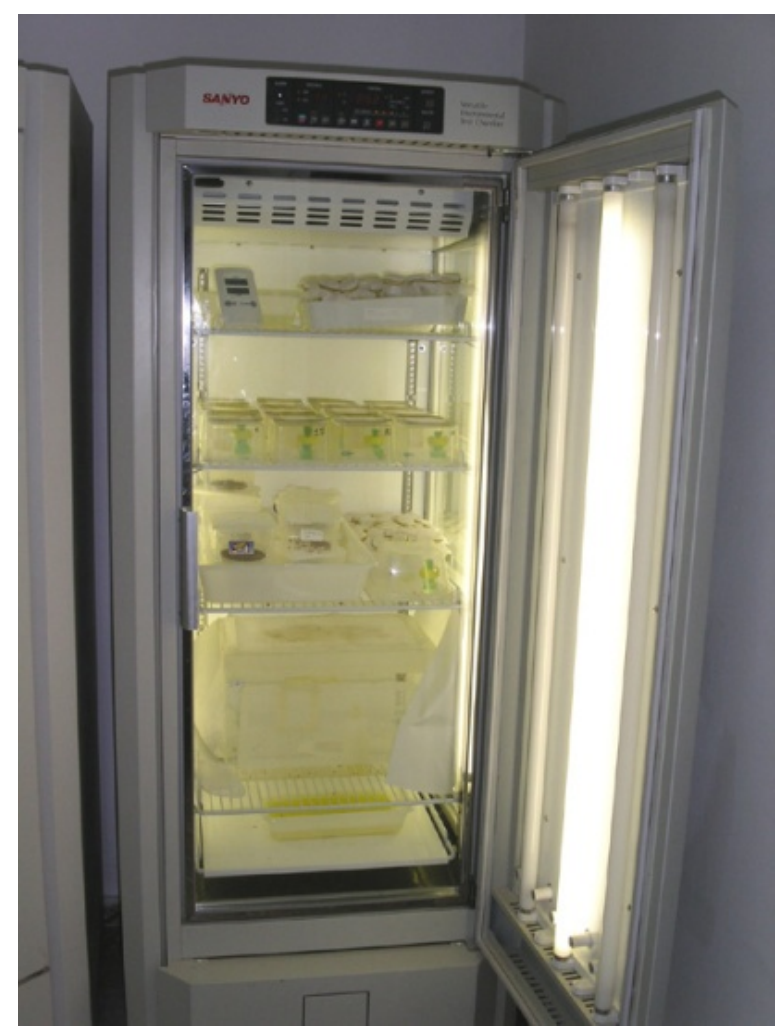

Figure 2.11. SANYO climatic chamber with temperature, humidity and photoperiod control used to determine effect of temperature on adult longevity.

Experimental units consisted on a ventilated cylinder containing 3 pairs of D. longicaudata ( 3 males and 3 females) each with a water supply recipient, which were provided with honey as adult food in a daily or bi-daily basis (Figure 2.12). Ten experimental units were used for each temperature, with a total of 30 couples.

The longevity was assessed daily from the first day ( 0 day old of the parasitoid, just after the emergence) until the death of the last individual in the cylinder.

For the statistic analysis, an ANOVA test was realized to compare the longevity on the different temperatures tested and a $t$ test to compare the longevity of males and females at each temperature. 


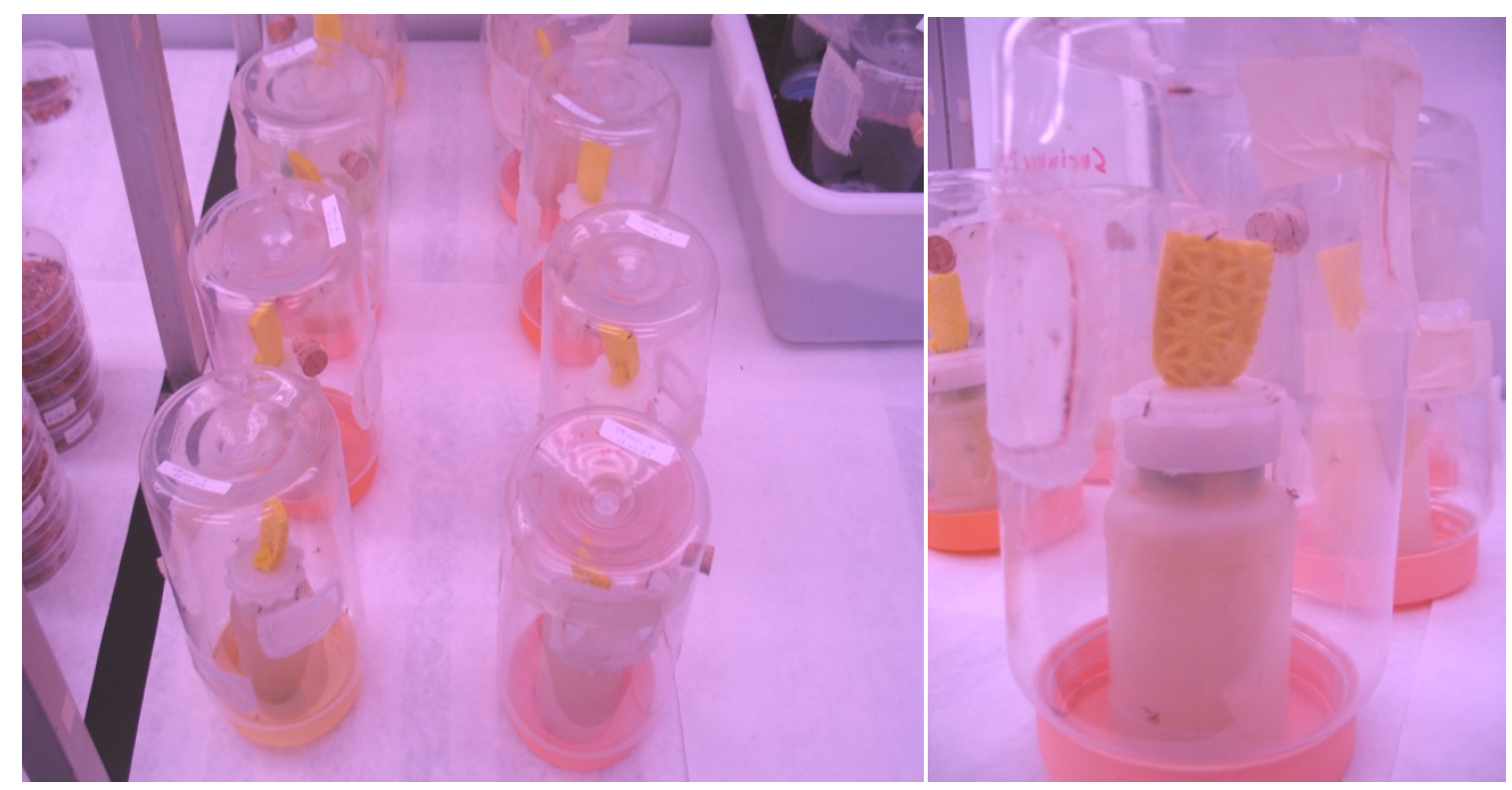

Figure 2.12. Experimental units used to determine adult longevity at each temperature, showing water container and ventilation frames.

\subsubsection{Impact of seasonality on $\boldsymbol{D}$. longicaudata longevity}

To study the impact of seasonality on the longevity, an experimental dispositive (Figure 2.13) was installed each season (winter, spring, summer and autumn) in the citrus orchard.

As in the precedent assay (2.2.3.1), each cylinder contained 3 couples of recently emerged adults, with ad libitum water and honey (honey was replaced in a 1-2 days period to avoid any effect) (Figure 2.12). For each season 10 cylinders (with a total of 30 couples) were distributed in wood-framed mesh cages located under the shadow of a lemon tree at the IVIA station (Figure 2.13). Mesh cages were used to provide shelter from predators and from strong weather elements (raining, wind, thunder, and lightning), as in natural conditions parasitoids will tend to search shelter below tree leaves. Ten other cylinders were settled at laboratory conditions, as batch control, to assess real differences due to climatic conditions, not to the parasitoid batch condition. Mortality was daily assessed until the death of all individuals in each cylinder.

Climatic conditions were registered with a data logger installed in the frame cage and with those of the IVIA research station meteorological station.

For the statistic analysis, an ANOVA test was realized to compare the longevity on the different temperatures tested and a $t$ test to compare the longevity of males and females at each temperature. 


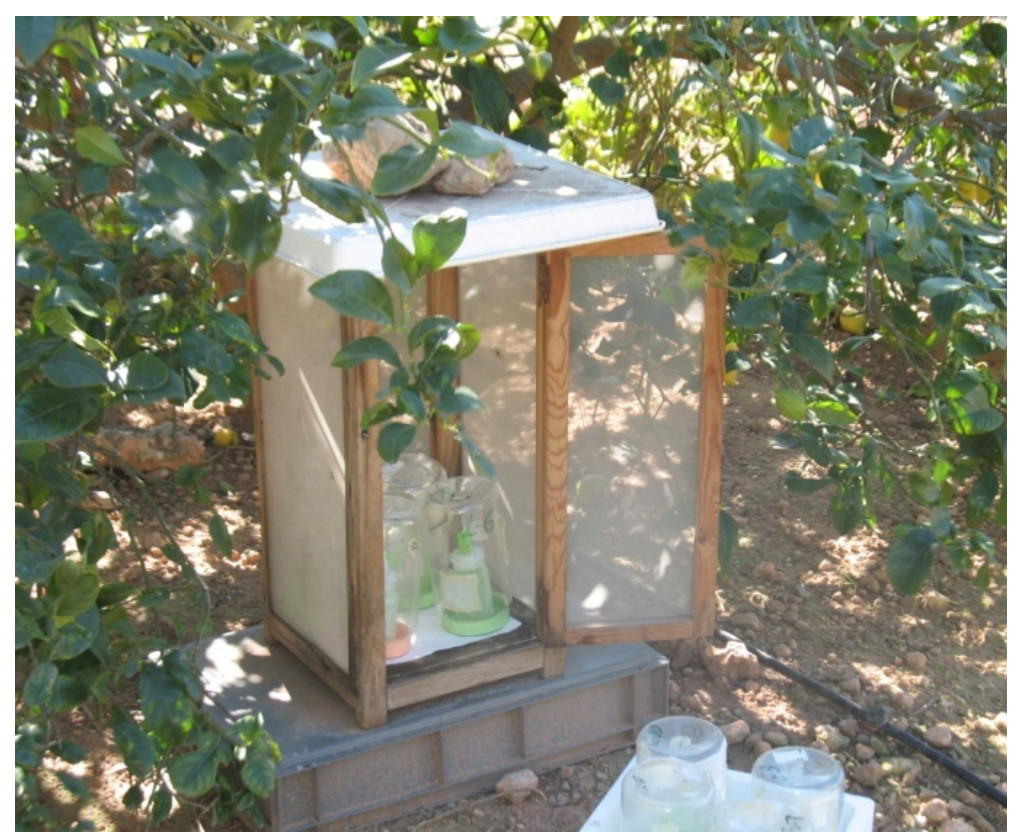

Figure 2.13. Field cage used to determine $D$. longicaudata longevity. Wood-framed cage was protected under the shadow of a lemon tree, plus covered with a plastic roof to protect experimental units from rain.

\subsubsection{Biotic and abiotic factors under laboratory conditions}

As a part of a comprehensive assessment of D. longicaudata as a natural enemy of $C$. capitata, it was needed to determine the type of functional response of this parasitoid exposed to varying densities of $C$. capitata larva at different temperatures in laboratory conditions.

\subsubsection{Effect of the density of direct exposed $C$. capitata larvae to $D$. longicaudata}

The present work was done in two different ranges of temperatures, the first one was between $20-24^{\circ} \mathrm{C}$ and the second one was between $25-29^{\circ} \mathrm{C}$. Temperature was recorded with a data logger.

Three different host densities were tested at each temperature range: 5, 20 and 40 medfly late second-third instars larvae per D. longicaudata female. Experimental units consisted in one 15 x 15 x $10 \mathrm{~cm}$ transparent plastic box with three 6-8 days-old $D$. longicaudata couples, provided with ad libitum water and honey (Figure 2.14). Therefore, each 24h, 15, 60 or 120 medfly larva were exposed at the corresponding density $(1: 5,1: 20$ or 1:40, D. longicaudata female: medfly larva). Each density was tested with 8 replicates, and each experimental unit was used during three consecutive days, obtaining the parasitism percentage and fecundity per female and day. Each density was tested at each temperature range, and repeated twice separated in time. In total we had 16 repetitions for each density and range of temperatures. In addition to these 
treatments, for each density, there were 9 boxes with larvae but without adult parasitoids as a control treatment to obtain an idea about the natural mortality without the parasitoid effect.

After $24 \mathrm{~h}$ of parasitism, exposed larvae were taken out and put in a Petri dish with aeration, till development of medfly and/or parasitoids.
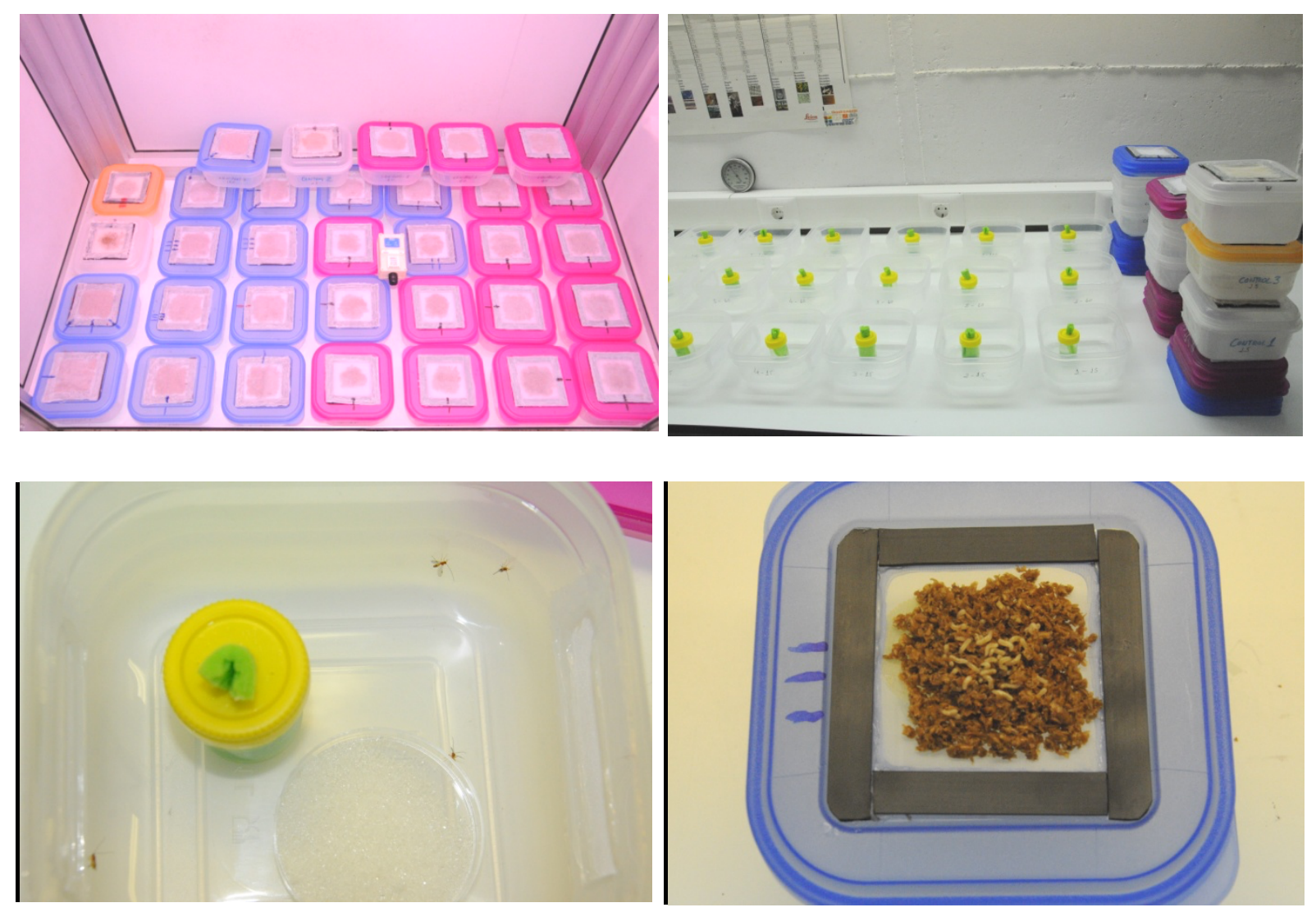

Figure 2.14. Experimental set up used to study the effect of host density on parasitism percentage.

Studied parameters in this work are: the parasitism percentage which was calculated as percentage of emerged adult parasitoids from recovered medfly pupae, the fertility, the sexratio (female/(female + male)) and the pupae mortality due to the parasitoid (induced mortality) compared to the mortality in the control treatment. Induced mortality was calculated with Abbott's formula (Abbott, 1925) as presented below:

Induced mortality $(\%)=\left((\right.$ Treatment mortality - Control mortality $) /\left(100-\right.$ Control $\left.\left._{\text {mortality }}\right)\right) x$ 100 


\subsubsection{Effect of the density of $C$. capitata larvae inside fruits}

In this part of the work, three different densities of $C$. capitata larvae inside fruits (apple) were tested to approve the study of its effect in condition more or less similar to the natural conditions (parasitoid parasitize medfly larvae inside the fruit). Apples, cultivar Royal Gala, were artificially infested with late second instar larvae of $C$. capitata. Ten holes were made in each apple, and three larvae placed in each hole (a total of 30 medfly larvae per apple). The holes were closed with apple plugs (Harbi et al. 2015) (Figure 2.15).
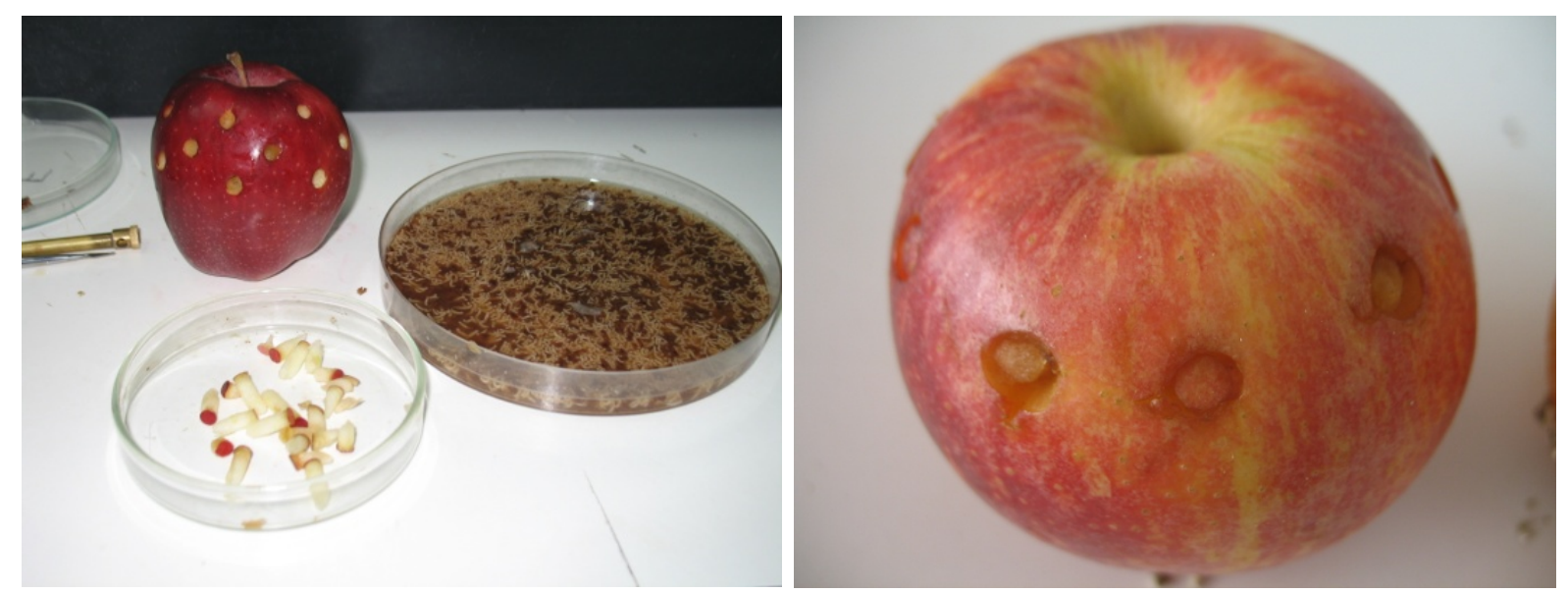

Figure 2.15. Apple artificial infestation system. At the left, medfly L2-L3 larva were selected by washing artificial rearing diet with a water: sugar solution, and distributing three larvae per hole, holes were closed with apple plugs reducing larva exposure (right).

The three studied densities were: 30, 60 and 90 medfly larvae per 3 couples of $D$. longicaudata with a ratio of: $1: 10 ; 1: 20$ and 1:30 (female of $D$. longicaudata per medfly larvae). This implied 1 apple, 2 apples and 3 apples for the corresponding densities. Each host: parasitoid female density was repeated 10 times.

Each repetition consisted in a plastic container $(30 \times 20 \times 20 \mathrm{~cm})$ with vermiculite in the bottom and an aeration opening in the cover, containing the infested apple or apples and the 3 couples of $D$. longicaudata. Larvae inside fruits were exposed to the parasitoid (6 to 8 days-old $D$. longicaudata aged) during 4 days in a climatic chamber $\left(25 \pm 10^{\circ} \mathrm{C} ; 60 \pm 10 \% \mathrm{RH}\right.$ and $16: 8 \mathrm{~h}$ (L:D) photoperiod). After 4 days, pupae were taken out from the vermiculite of each container and put in $150 \mathrm{ml}$ ventilated cylindrical vials until the adult emergence. 


\subsubsection{Influence of fruit location and host density in semi-field conditions}

This trial was carried out under a greenhouse conditions with controlled temperature $\left(21-26^{\circ} \mathrm{C}\right)$, RH (50-80\%) and with natural light conditions. The greenhouse was situated in the experimental station of the IVIA institute $\left(39^{\circ} 35^{\prime} 22.6^{\prime \prime} \mathrm{N} 0^{\circ} 23^{\prime} 41.0^{\prime \prime} \mathrm{W}\right.$, Valencia, Spain). Treatments were performed in aluminium framed mesh covered rectangular cages $(200 \times 150 \times 250 \mathrm{~cm})$ (Figure 2.16).

a)

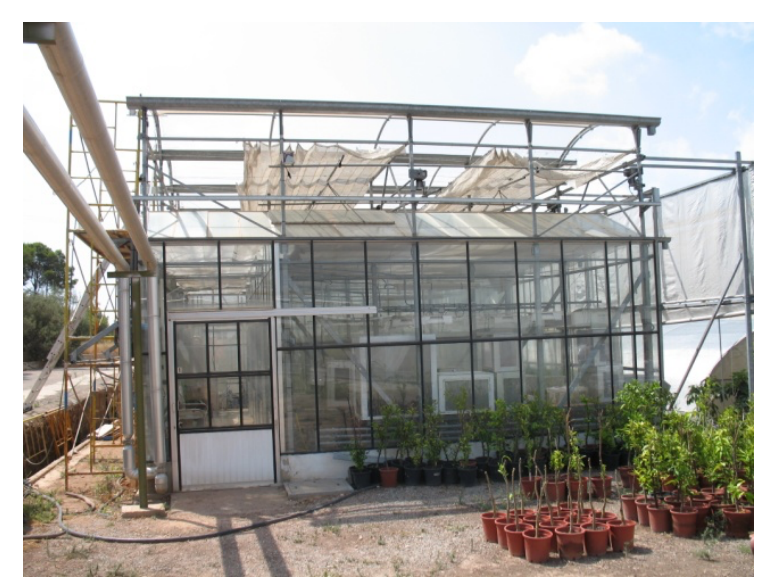

b)

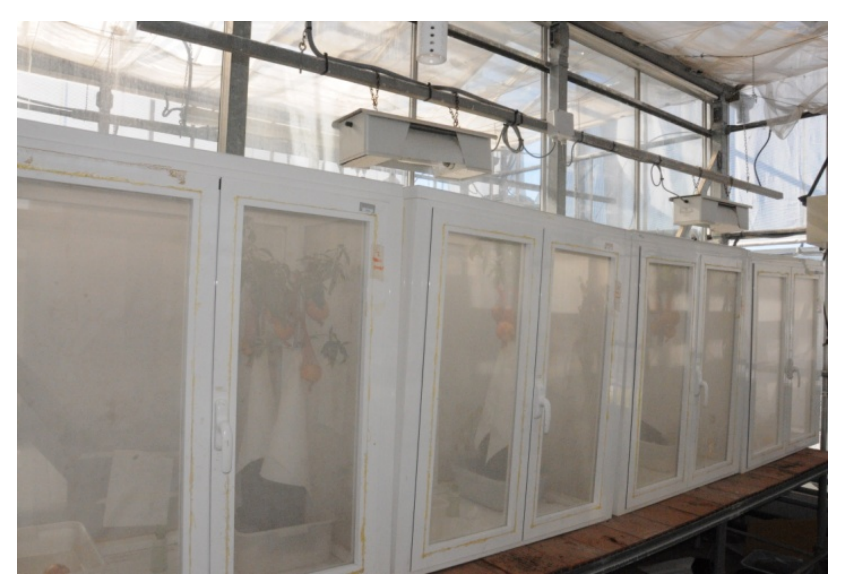

Figure 2.16. a) Greenhouse at the IVIA research station, b) cages installed inside one cabin at the greenhouse.

This work consists on the study of the foraging behavior of D. longicaudata over C. capitata, its vertical distribution (host location, the ground vs. the tree canopy), depending on the density of medfly larvae.

Ceratitis capitata L2-L3 larvae were retrieved from artificial diet by washing them in a sugar saturated solution. After this, larvae were hold in a $92 \times 16 \mathrm{~mm}$ Petri dish with water to facilitate selection (Figure 2.17). Apples, var. Royal Gala, were artificially infested with L2-L3 medfly larvae, at 3 larvae per $9 \mathrm{~mm}$ hole as described previously (Figure 2.17). The number of holes per apple depends on the host density tested (Figure 2.17).

Two treatments were performed to investigate the foraging behaviour of $D$. longicaudata.

i. The influence of the host density: Three different host densities were tested 1.2:1, 6:1 and 12:1 (L2-L3 medfly larvae per parasitoid female), by performing 2, 10 or 20 holes per apple (Figure 2.17). 
ii. Fruit location: Medfly larvae were supplied in two ways. Sentinel apples were hanged with random distribution among two 2-3-y-old Clementine tree (approximately $1 \mathrm{~m}$ height) (Figure 2.17) or in sentinel fruit disposed in a plastic tray $(50 \times 40 \times 25 \mathrm{~cm})$ (Figure 2.17), resembling unripe and ripe-fallen infested fruits respectively. In each position, 5 infested apples (C. capitata larvae per fruit depend on the studied density: 6, 30 or 60 larvae/apple) were distributed.

Treatments had in all cases 50 couples of D. longicaudata (3-d-old females and 5-6 d-old males) and were performed ten times in independent weeks. In each trial cage water and honey were offered ad libitum for the released wasps (Figure 2.17).

Control infested sentinel apples were set-up per triplicate in each trial to account the natural mortality of medfly, or the induced by the larvae manipulation. Controls were isolated in individual cylinders (Figure 2.17 C).

For each treatment, pupae were recovered one week after set-up, counted, and allowed to develop under laboratory conditions. Medfly, parasitoids and un-eclosed pupa were counted to determine parasitism percentage fertility, offspring sex-ratio and the percentage of induced mortality. Induced mortality was corrected by Abbot formula (Abbot 1925) as described above.

\subsubsection{Statistical analysis}

The fertility, parasitism percentage and offspring sex ratio of $D$. longicaudata for the different densities of $C$. capitata larvae were analyzed by the analysis of variance (ANOVA) using the Infostat software (2013). The normality of the data was analyzed by Shapiro Wilks' test and were transformed where nececery.

A generalised linear model was used to analyse the functional response, with the aim to discriminate between type II and type III responses. The data were fit to a binomial distribution with Logit link function, then fit to their corresponding functional response equation (Juliano 2001; Fernández-Arhex and Corley 2004; Vanaclocha et al. 2013a). For the type II response, the consumed prey (in our case represented by fertility) are a function of the attack rate $(a)$, the host density $(\mathrm{N})$, the time available in days $(\mathrm{T})$ and the prey-handling time $(T h)(\mathrm{y}=(a * \mathrm{~N} *$ $\mathrm{T}) /(1+a * \mathrm{~N} * T h)$. Data were adjusted by nonlinear least-squares regression using the iterative estimation method of Levenber-Maarquardt (Monzó 2010). From the adjustment of these equations, we estimated the parameters of the functional response, attack rate $(a)$ and handling time $(T h)$. Data were analysed using IBM SPSS 17.0. 
A)

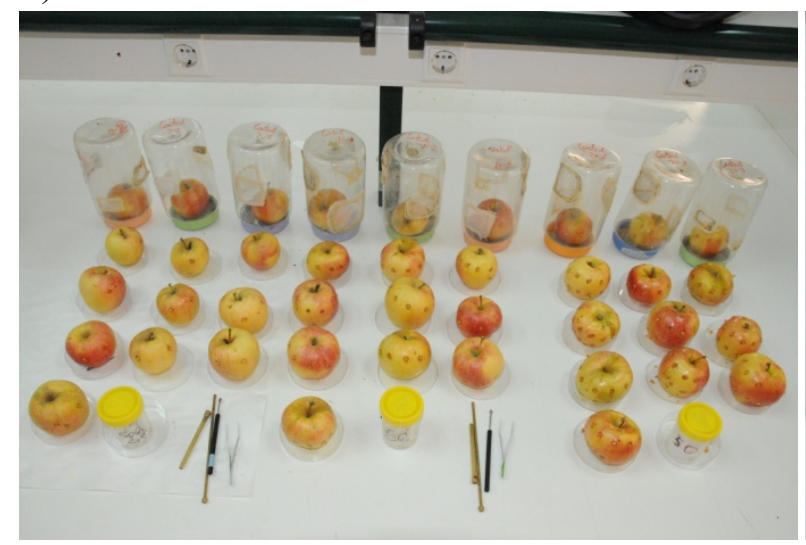

C)

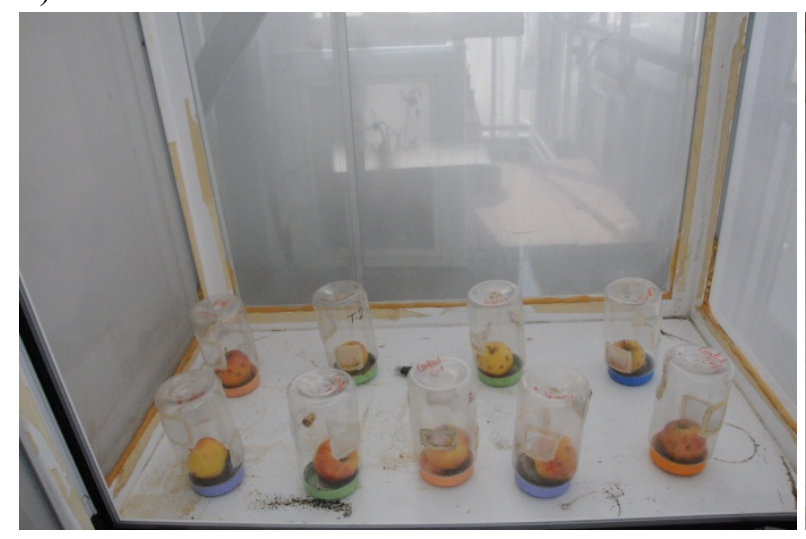

E)

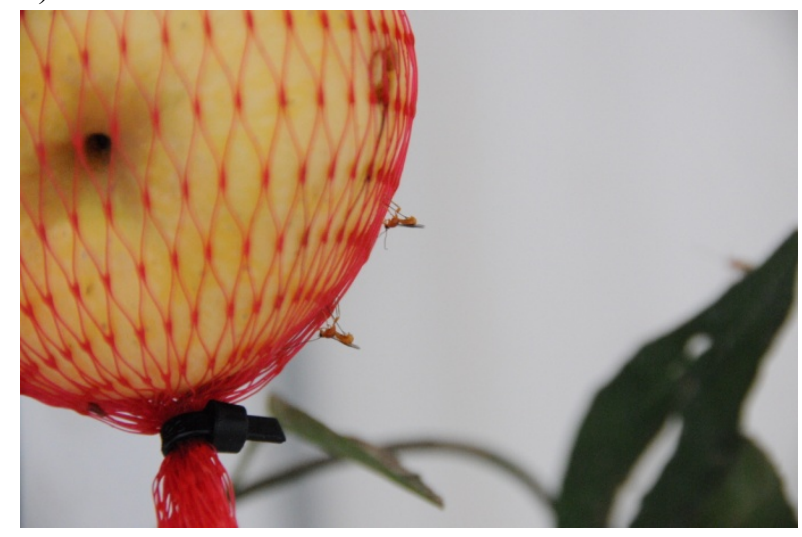

B)

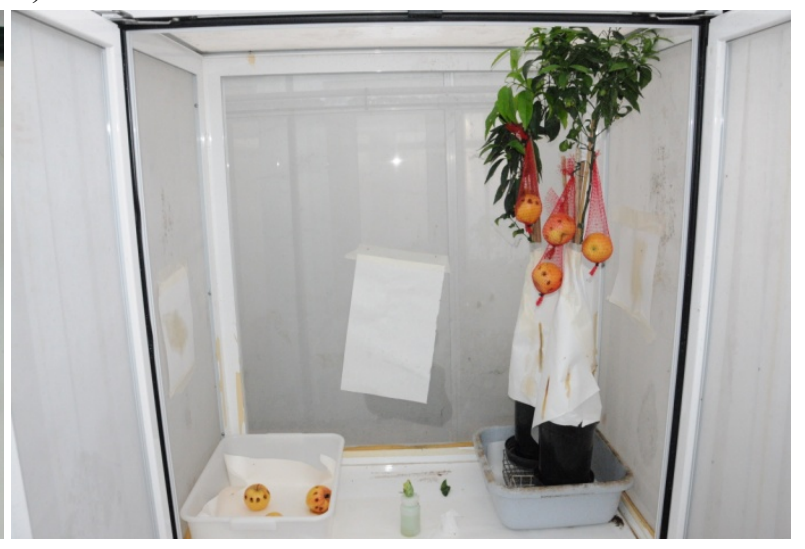

D)

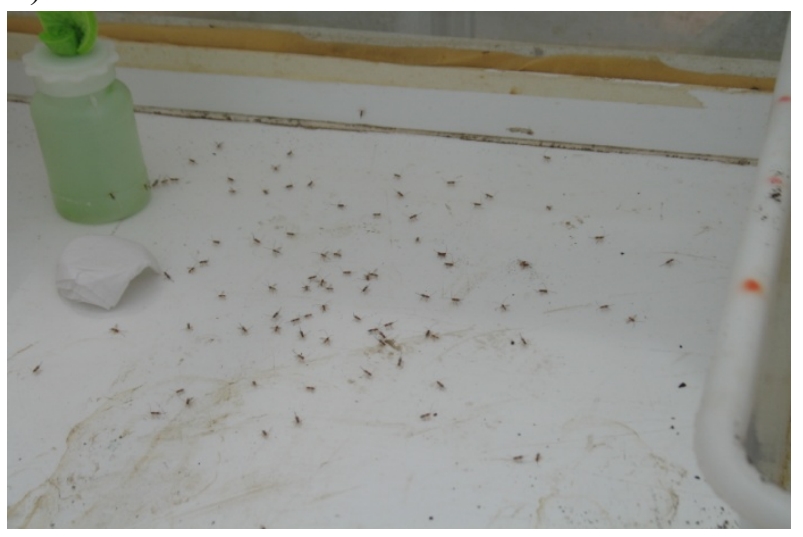

F)

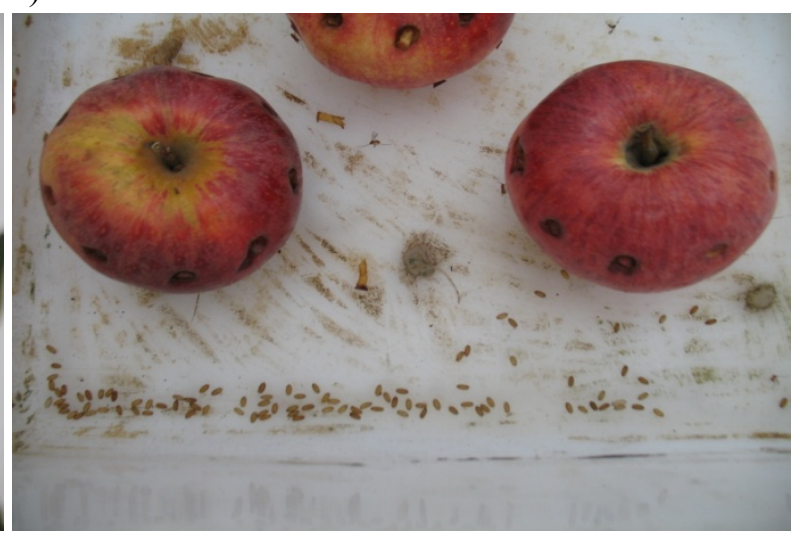

Figure 2.17. Experimental design. A) Prepared sentinel fruits, B) disposition of sentinel apples in citrus young tree and in a tray in each cage, C) control apples in individual cylinders, D) released parasitoid in the cage, E) D. longicaudata parasitizing their host on the canopy of the tree, F) D. longicaudata parasitizing larvae in the fruit on the ground. 


\subsection{Results and Discussion}

First of all, I would like to mention that I had successfully established two rearing systems, one for medfly as host, and the second for the parasitoid D. longicaudata, both of them required to develop this thesis.

\subsubsection{Life history parameters of D. longicaudata IVIA strain}

\subsubsection{Developmental and reproductive parameters on $C$. capitata}

The mean developmental time of immature stages, from egg to adult emergence, was $21.3 \pm 0.1$ days for males and $22.9 \pm 0.1$ days for females. Our results show that the pre-ovipostion period is very short or absent in some case almost inexistent, with an average time of $0.3 \pm 0.1$ days and a maximum of 2 days. The average post-ovipositon period was of $5.4 \pm 0.8$ days and the mean oviposition period was $16.4 \pm 0.8$ days.

The fertility was $71.2 \pm 6.4$ offspring per female, remained low the first day after emergence and then increased to reach its maximum at 7-9 individuals per female and day between the second and the sixth day after emergence. During this period, $75 \%$ of the total progeny of the females were produced. Beyond this period, the fertility decreased gradually until the end of the oviposition period (Figure 2.18).

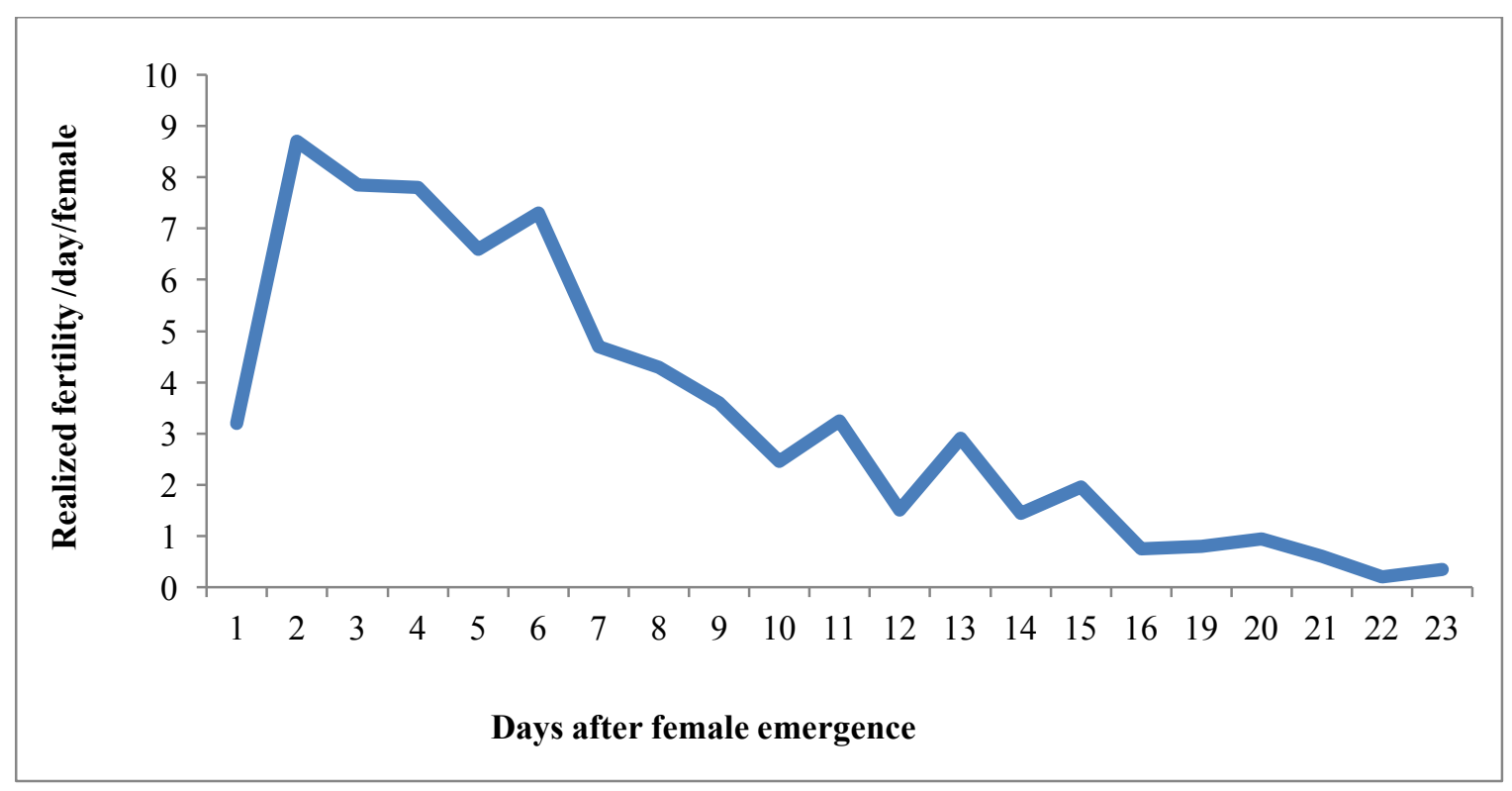

Figure 2.18. Daily fertility (mean) of D. longicaudata females reared on medfly.

Males were able to live significantly longer than females according to the survival analysis $\left(\chi^{2}=\right.$ $6.17 ; d f=1 ; P=0.013)$. The maximum longevity was 55 days for females and 57 days for males 
(Figure 2.19). The average longevity of females was $33.7 \pm 1.8$ days while that of males was $40.1 \pm 2.8$ days. The sex ratio of the wasps was female biased, 0.8:1 (male: female). During the first three days of the oviposition period, the produced progeny was mainly males while in the rest of the period a predominance of females was observed, so we found that the wasp reproduction is marked by a protandry, since males emerge earlier than females (Figure 2.20).

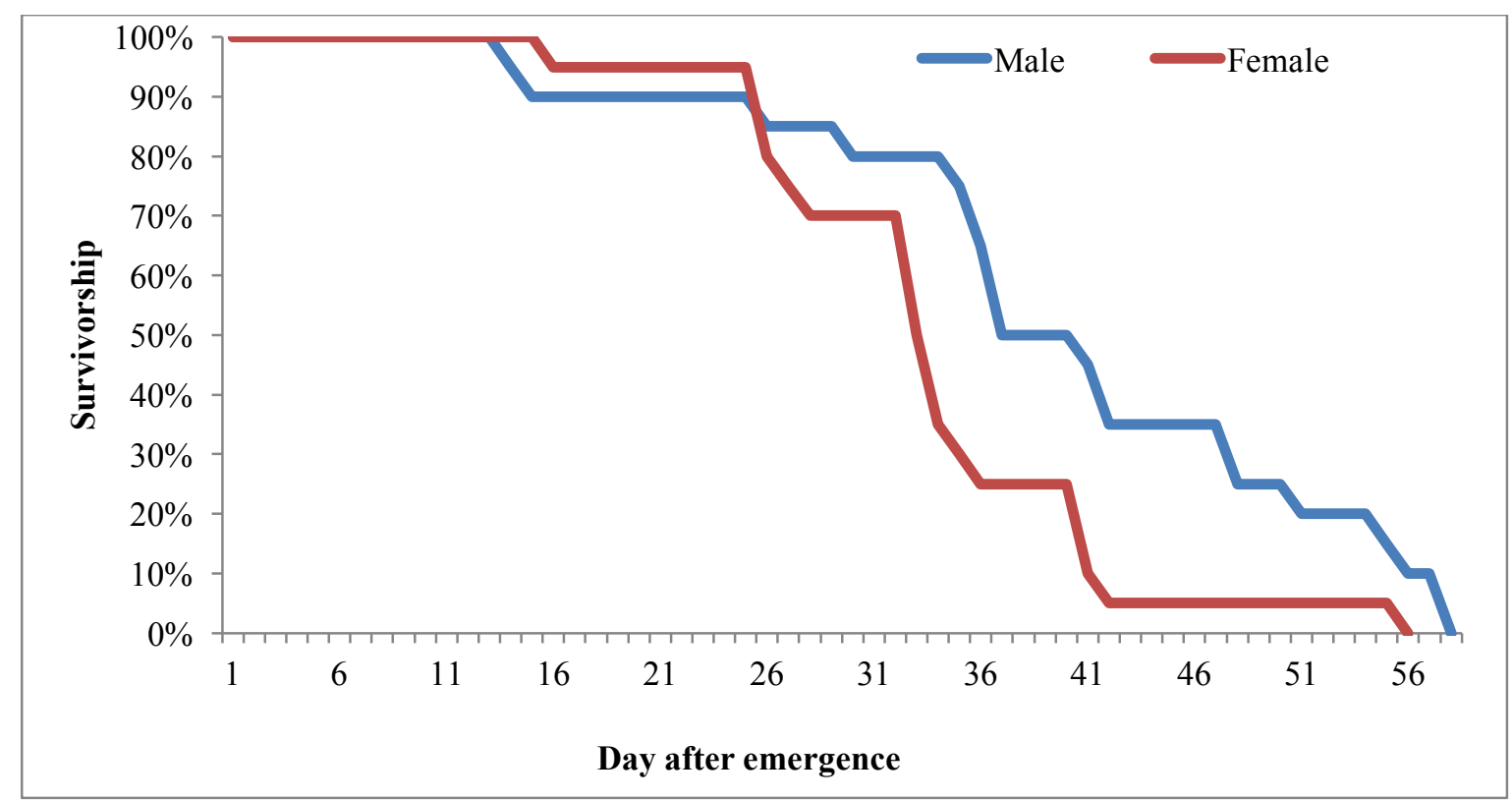

Figure 2.19. Survivorship $(l x)$ curves of $D$. longicaudata males and females reared on $C$. capitata third instar larva.

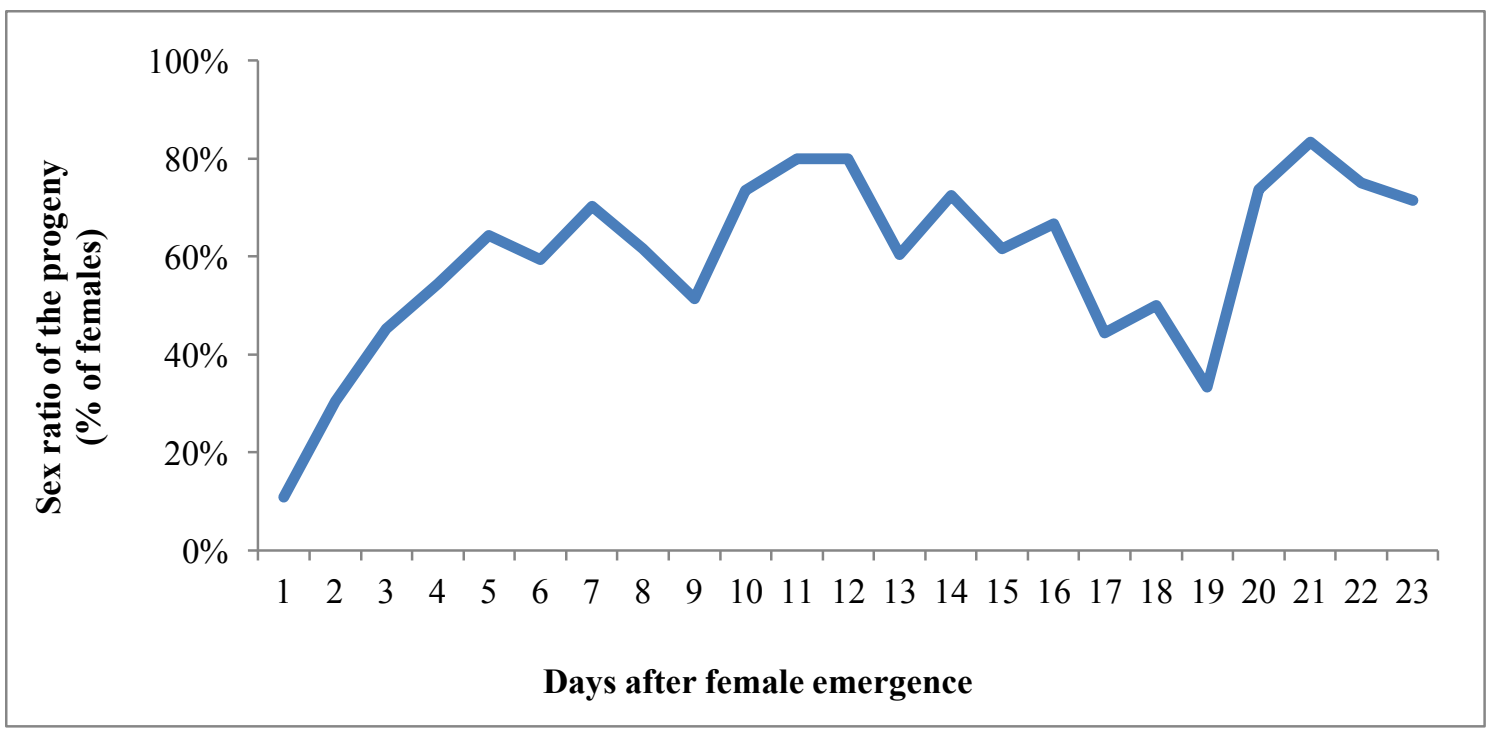

Figure 2.20. Dichasmimorpha longicaudata IVIA strain progeny daily sex ratio $\left(\mathrm{n}_{\mathrm{F}} / \mathrm{n}_{\mathrm{F}}+\mathrm{n}_{\mathrm{M}}\right)$, reared on C. capitata third instar larvae. 
This experiment was conducted to assess life history parameters of our laboratory strain of $D$. longicaudata and to compare the outcomes with available data of other strains. Life history parameters of several laboratory strains of this wasp maintained on different hosts of fruits flies are shown in table 2.2. Although reared on the same host species, C. capitata, and more or less under similar climatic conditions used in our experiment, fertility varies among our study and similar ones. Ovruski et al. (2011) found that the fertility of D. longicaudata (originally established in 1999 with individuals imported from Mexico (Ovruski et al. 2003) reared on $A$. ludens (Montoya et al. 2000) was of $32.1 \pm 1.5$ emerged adults, which is lower than that of our strain (71.2 \pm 6.4 individuals/female). Conversely, Meirelles et al. (2013) reported a higher fertility than that of our strain with $104.6 \pm 4.12$ individuals/female on the same host (the strain was obtained from "Embrapa Mandioca e Fruticultura Tropical", Cruz das Almas, state of Bahia, Brazil). On the other hand, Ovruski et al. (2011) found that the fecundity of their strain was $36.3 \pm 1.8$ emerged adults/female on A. fraterculus while Meirelles et al. (2013) reported a fertility of $124.8 \pm 1.11$ individuals/female on the same host species.

Significantly lower adult longevity than that found in this work was reported by other studies when rearing different strains of $D$. longicaudata on C. capitata, A. fraterculus and B. dorsalis (Vargas et al. 2002; Viscarret et al. 2006; Meirelles et al. 2013). By contrast, our strain presents a shorter oviposition period than that reported for other strains on all tested host flies species except on B. dorsalis (Table 2.2). Developmental duration from egg to adult of our strain was similar to those reported by Meirelles et al. (2013) on C. capitata and A. fraterculus. Concerning the sex ratio of the progeny it is female biased for all strains and on all host flies. 
Table 2.2. Biological parameters of $D$. longicaudata on different fruit fly host species.

\begin{tabular}{|c|c|c|c|c|c|c|c|}
\hline $\begin{array}{c}\text { Fruit fly } \\
\text { host }\end{array}$ & $\begin{array}{c}\text { Experimental } \\
\text { conditions } \\
\text { (Temperature, RH, } \\
\text { photoperiod) }\end{array}$ & $\begin{array}{c}\text { Adult } \\
\text { longevity } \\
\text { (days) }\end{array}$ & $\begin{array}{l}\text { Oviposition } \\
\text { period } \\
\text { (days) }\end{array}$ & $\begin{array}{c}\text { Fertility } \\
\text { (individuals/ } \\
+ \text { ) }\end{array}$ & $\begin{array}{l}\text { Egg to } \\
\text { adult } \\
\text { duration } \\
\text { (days) }\end{array}$ & $\begin{array}{c}\text { Females in } \\
\text { offspring } \\
(\%)\end{array}$ & Reference \\
\hline \multirow[b]{2}{*}{ C. capitata } & \multirow[b]{2}{*}{$\begin{array}{c}23 \pm 2^{\circ} \mathrm{C}, 65 \pm 10 \% \\
16: 8 \text { (L:D) }\end{array}$} & $\begin{array}{c}33.7 \pm 1.8 \\
(\text { (q) }\end{array}$ & \multirow[b]{2}{*}{$16.4 \pm 0.8$} & \multirow[b]{2}{*}{$71.2 \pm 6.4$} & $22.9 \pm 0.1($ ( $)$ & \multirow[b]{2}{*}{55} & \multirow[t]{2}{*}{ This work } \\
\hline & & $40.1 \pm 2.8$ & & & $\begin{array}{c}21.3 \pm 0.1 \\
(ठ)\end{array}$ & & \\
\hline
\end{tabular}

\begin{tabular}{|c|c|c|c|c|c|c|c|}
\hline \multirow{3}{*}{$\begin{array}{l}\text { C. capitata } \\
\qquad(+)\end{array}$} & Larvae and pupae: & & & & & & \multirow{4}{*}{$\begin{array}{l}\text { Viscarret } \\
\text { et al. } \\
(2006)\end{array}$} \\
\hline & $\begin{array}{c}24.61 \pm 0.33^{\circ} \mathrm{C} \\
65.00 \pm 2.75 \% \\
\text { continuous light. } \\
\text { Adults: }\end{array}$ & $28.33 \pm 2.07$ & $22.57 \pm 1.87$ & --- & --- & $56 \pm 0.5$ & \\
\hline & $\begin{array}{c}22.90 \pm 2.90^{\circ} \mathrm{C} \\
47.73 \pm 1.66 \%, 12: 12 \\
\text { (L:D) }\end{array}$ & & & & & & \\
\hline $\begin{array}{l}\text { C. capitata } \\
(\mathrm{sw})\end{array}$ & $\begin{array}{c}\text { Larvae and pupae: } \\
24.61 \pm 0.33^{\circ} \mathrm{C}, \\
65.00 \pm 2.75 \% \\
\text { continuous light. } \\
\text { Adults: } \\
22.90 \pm 2.90^{\circ} \mathrm{C}, \\
47.73 \pm 1.66 \%, 12: 12 \\
\text { (L:D) }\end{array}$ & $34.08 \pm 3.13$ & $28 \pm 2.56$ & --- & --- & $55 \pm 0.4$ & \\
\hline \multirow[t]{2}{*}{ C. capitata } & $\begin{array}{c}25 \pm 2^{\circ} \mathrm{C}, 65 \pm 10 \% \\
14: 10(\mathrm{~L}: \mathrm{D})\end{array}$ & $\begin{array}{l}20.7 \pm 2.11 \\
\quad(+) \\
14.2 \pm 2.03 \\
(\text { đ })\end{array}$ & $27.4 \pm 3.17$ & $104.6 \pm 4.12$ & $\begin{array}{c}19.2 \pm 0.23 \\
(\text { o) } \\
18.5 \pm 0.13 \\
(\text { ठ) }\end{array}$ & 55 & $\begin{array}{l}\text { Meirelles } \\
\text { et al. } \\
(2013)\end{array}$ \\
\hline & $\begin{array}{c}25 \pm 1^{\circ} \mathrm{C}, 75 \pm 5 \% \\
12: 12 \text { (L:D) }\end{array}$ & & & $32.1 \pm 1.5$ & --- & $50.7 \pm 2.8$ & $\begin{array}{l}\text { Ovruski et } \\
\text { al. }(2011)\end{array}$ \\
\hline \multirow[t]{2}{*}{$\begin{array}{c}\text { A. } \\
\text { fraterculus }\end{array}$} & $\begin{array}{c}25 \pm 2^{\circ} \mathrm{C}, 65 \pm 10 \% \\
14: 10(\mathrm{~L}: \mathrm{D})\end{array}$ & $\begin{array}{c}20.4 \pm 3.39 \\
(‡) \\
15.6 \pm 2.09 \\
(\text { Љ) }\end{array}$ & $29.6 \pm 2.98$ & $124.8 \pm 1.11$ & $\begin{array}{c}18.8 \pm 0.17 \\
(\text { O }) \\
17.2 \pm 0.13 \\
\text { (ठ) }\end{array}$ & 59 & $\begin{array}{l}\text { Meirelles } \\
\text { et al. } \\
(2013)\end{array}$ \\
\hline & $\begin{array}{c}25 \pm 1^{\circ} \mathrm{C}, 75 \pm 5 \% \\
12: 12 \text { (L:D) }\end{array}$ & --- & --- & $36.3 \pm 1.8$ & --- & $82.4 \pm 1.5$ & $\begin{array}{l}\text { Ovruski et } \\
\text { al. (2011) }\end{array}$ \\
\hline B. dorsalis & $\begin{array}{c}26 \pm 2^{\circ} \mathrm{C}, 60 \pm 10 \% \\
10: 14 \text { (L: D) }\end{array}$ & $15.67 \pm 4.10$ & $9.33 \pm 1.64$ & --- & --- & $59 \pm 0.5$ & $\begin{array}{l}\text { Vargas et } \\
\text { al. (2002) }\end{array}$ \\
\hline
\end{tabular}




\subsubsection{Demographic parameters: Life history}

For our D. longicaudata strain, reared on C. capitata $3^{\text {rd }}$ instar larvae, the generation time was 28.1 days, the reproductive rate was 39.2 , the intrinsic rate of increase was 0.125 , the doubling time was 5.2 days and the finite rate of increase (per day) was 1 .

Those reported in the literature are listed in Table 2.3. The generation time calculated for our strain of D. longicaudata was similar to that of other strains as reported by Vargas et al. (2002) and Meirelles et al. (2013) on B. dorsalis and C. capitata, respectively. Whereas, the strain tested by Viscarret et al. (2006) had longer generation time. Conversely, this parameter was shorter on A. fraterculus (Meirelles et al. 2013).

The reproductive rate was similar to that found by Viscarret et al. (2006), lower than that reported by Meirelles et al. (2013) on C. capitata and A. fraterculus and higher than that reported by Vargas et al. (2002) on B. dorsalis. The estimates the intrinsic rate of increase and the finite rate of increase were comparable in all presented studies. However, the doubling time of our strain was shorter than that found by Viscarret et al. (2006) on two strains of medfly and longer than that reported by Meirelles et al. (2013) either on C. capitata or A. fraterculus.

Table 2.3 Demographic population parameters of D. longicaudata reported in the literature on different fruit fly species

\begin{tabular}{|c|c|c|c|c|c|c|}
\hline Host fruit fly & $T$ & $R_{0}$ & $\bar{k}$ & $r_{m}$ & $\overline{D t}$ & Reference \\
\hline C. capitata & 28.1 & 39.2 & 1 & 0.125 & 5.2 & This work \\
\hline C. capitata $(+)$ & $37.93 \pm 0.68$ & $32.54 \pm 5.65$ & $1.102 \pm 0.006$ & $0.098 \pm 0.005$ & $7.11 \pm 0.38$ & $\begin{array}{l}\text { Viscarret et } \\
\text { al. (2006) }\end{array}$ \\
\hline C. capitata (sw) & $39.37 \pm 0.55$ & $33.84 \pm 5.14$ & $1.0990 \pm 0.004$ & $0.094 \pm 0.004$ & $7.36 \pm 0.28$ & $\begin{array}{l}\text { Viscarret et } \\
\text { al. (2006) }\end{array}$ \\
\hline C. capitata & $26.03 \pm 0.451$ & $45.56 \pm 5.685$ & $1.15 \pm 0.028$ & $0.14 \pm 0.019$ & $4.73 \pm 0.074$ & $\begin{array}{l}\text { Meirelles et } \\
\text { al. (2013) }\end{array}$ \\
\hline A. fraterculus & $22.57 \pm 0.594$ & $53.82 \pm 10.00$ & $1.19 \pm 0.051$ & $0.17 \pm 0.031$ & $3.92 \pm 0.082$ & $\begin{array}{l}\text { Meirelles et } \\
\text { al. (2013) }\end{array}$ \\
\hline B. dorsalis & 27.2 & 28.2 & 1.13 & 0.12 & --- & $\begin{array}{l}\text { Vargas et al. } \\
(2002)\end{array}$ \\
\hline
\end{tabular}

$\overline{T \text { (mean generation time, days); } R_{0} \text { (net reproductive rate, female/female); } k \text { (Finite rate of increase, per day); } r_{m}}$ (intrinsic rate of increase/day); Dt (doubling time, in days). $(+)$ : wild type strain of C. capitata. (sw): genetic sexing strain of $C$. capitata 


\subsubsection{Abiotic factors affecting $D$. longicaudata adult longevity: temperature}

Temperature is regarded as one of the most important factors in the acclimatization of introduced natural enemies. While insects normally develop faster at higher temperatures, the optima, maxima and minima temperature differ among species and the understanding of these traits has important consequences for establishing natural enemies in new environments.

\subsubsection{Impact of constant temperature on longevity}

The maximum longevity recorded was about 89 days for females and 70 days for males, finding a bell-shaped curve of longevity at different constant temperatures (Figure 2.21). This indicates a progressive decrease with increasing temperatures.

Diachasmimorpha longicaudata strain IVIA showed a longevity significantly affected by the rearing temperature $(F=251.57 ; d f=4,285 ; P<0.0001)$. Longevity showed a sex bias, being females significantly more long-lived than males $(F=23.82 ; d f=1,285 ; P<0.0001)$.

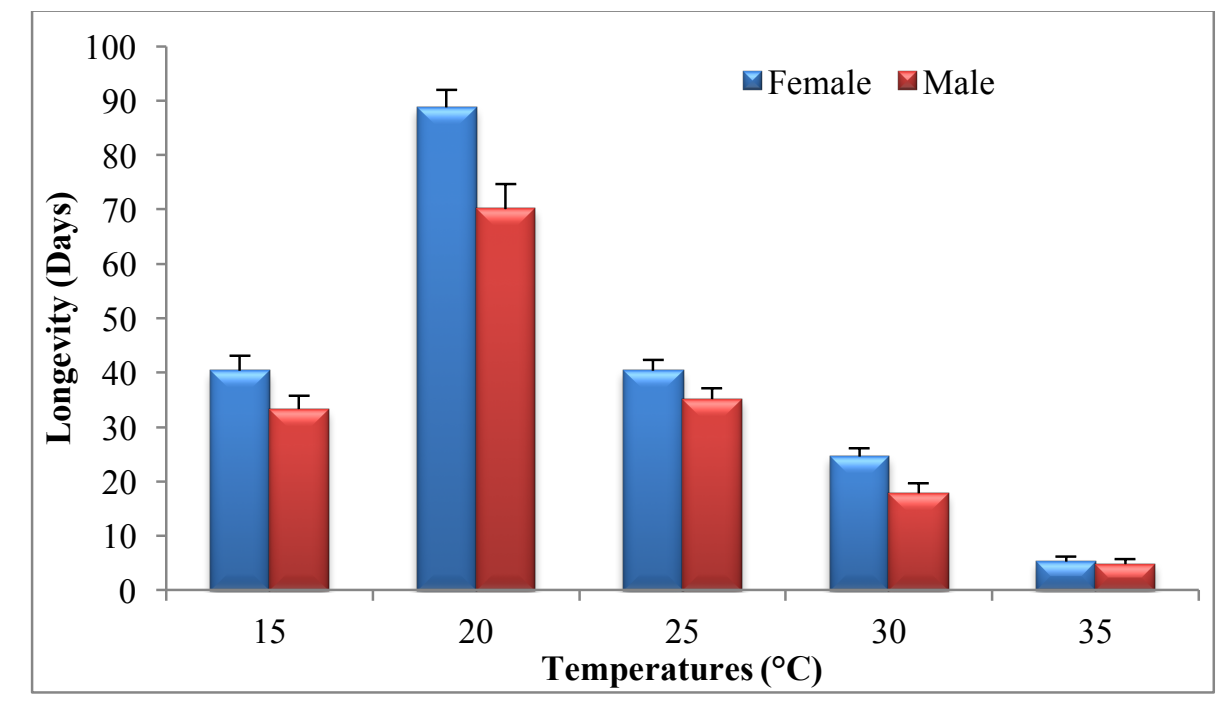

Figure 2.21. Average longevity $\left( \pm \mathrm{SE}\right.$ ) (in days) of D. longicaudata adults at constant temperatures $\left({ }^{\circ} \mathrm{C}\right)$, separated by sex. 


\subsubsection{Impact of seasonality on adult longevity}

Seasonality (meaning here variable daily temperatures, RH and photoperiod similar to those that happen at field conditions) affected adult longevity. Table 2.4 shortlists the recorded climatic conditions in this experiment.

The largest longevity was recorded on the coldest season, winter season, with an average of 81.6 days for females and 39 days for males. Whereas the shortest longevities, of 35 and 32 days (average) for females and males respectively, were recorded during the summer, with the highest temperatures (Figures 2.22, 2.23). The comparison of average longevity between control D. longicaudata batches (data on Figure 2.23) and batches subjected to field conditions (data on Figure 2.22) showed again differences among sexes $(t=-3.341: d f=1,80 ; P \leq 0.001)$ and among climatic season $(F=12.11 ; d f=3,80 ; P \leq 0.0001)$.

Table 2.4. Recorded climatic conditions (mean, maxima and minima temperature and relative humidity, and rainfall) for the field assay for D. longicaudata adult longevity.

\begin{tabular}{|c|c|c|c|c|c|c|c|}
\hline \multirow[b]{2}{*}{ Seasons } & \multicolumn{3}{|c|}{ Temperature $\left({ }^{\circ} \mathrm{C}\right)$} & \multicolumn{3}{|c|}{ Relative Humidity (RH, \%) } & \multirow{2}{*}{$\begin{array}{c}\text { Rainfall } \\
(\mathrm{mm})\end{array}$} \\
\hline & Mean & Maximum & Minimum & Mean & Maximum & Minimum & \\
\hline Winter & $12.02 \pm 2.17$ & $18.17 \pm 2.10$ & $6.11 \pm 2.04$ & $70.82 \pm 3.85$ & $91.90 \pm 9.44$ & $40.99 \pm 2.64$ & $11.66 \pm 2.92$ \\
\hline Spring & $22.75 \pm 3.58$ & $29.09 \pm 2.92$ & $16.60 \pm 3.53$ & $68.65 \pm 2.49$ & $89.79 \pm 0.87$ & $44.47 \pm 3.58$ & $2.1 \pm 1.3$ \\
\hline Summer & $22.13 \pm 3.51$ & $29.08 \pm 2.82$ & $15.40 \pm 5.17$ & $73.53 \pm 4.47$ & $91.92 \pm 3.47$ & $46.93 \pm 1.44$ & $23.96 \pm 22.89$ \\
\hline Autumn & $11.59 \pm 3.00$ & $18.59 \pm 4.35$ & $6.04 \pm 1.94$ & $70.31 \pm 4.04$ & $89.49 \pm 4.03$ & $41.90 \pm 5.19$ & $12.16 \pm 9.90$ \\
\hline
\end{tabular}




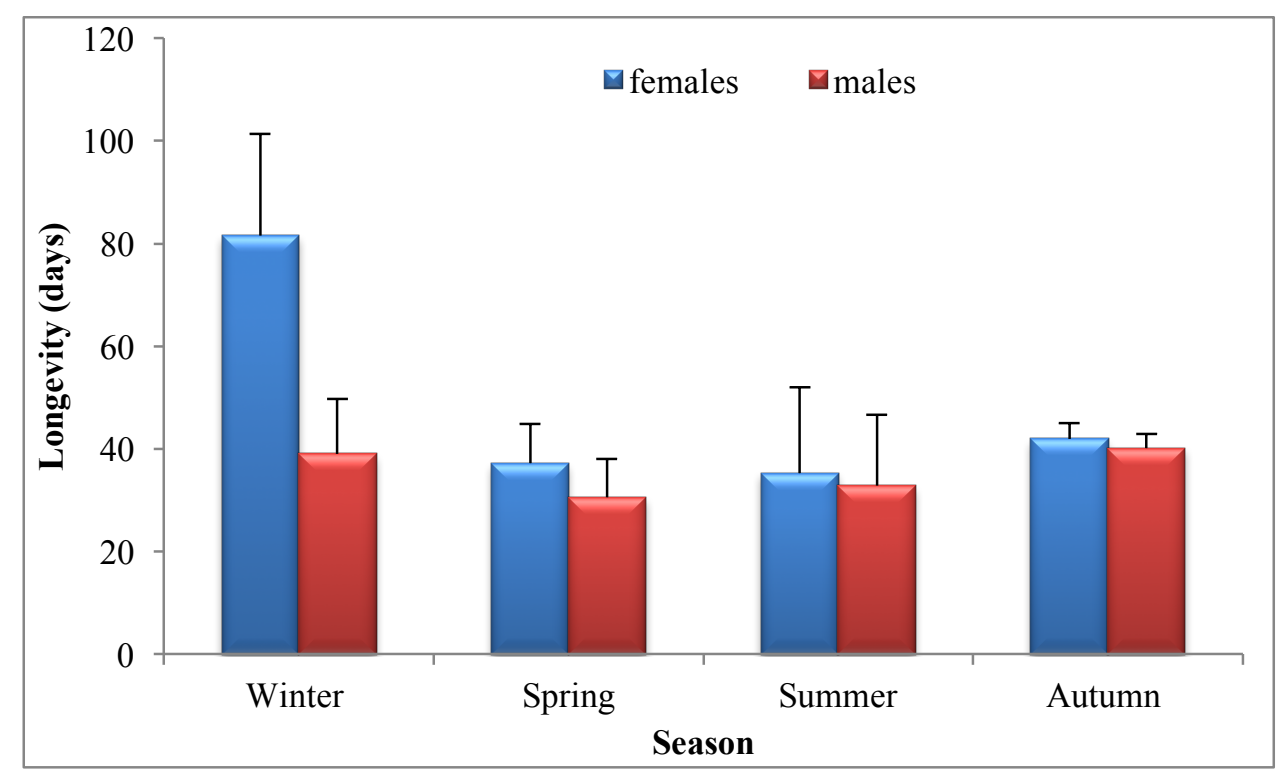

Figure 2.22. Longevity (mean $\pm \mathrm{SE}$ ) (days) of D. longicaudata adults at field conditions during the different seasons tested. Climatic data for these seasons are listed in Table 2.4.

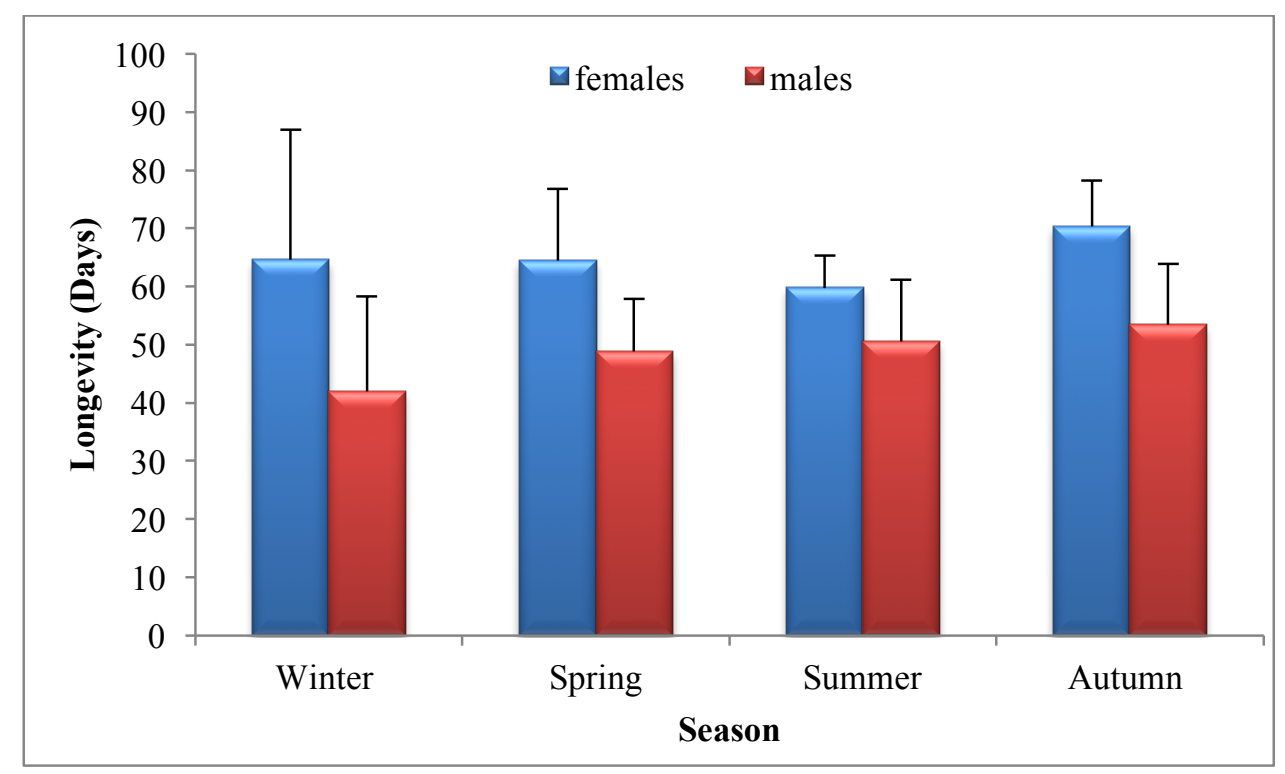

Figure 2.23. Longevity (mean $\pm \mathrm{SE}$ ) (days) of $D$. longicaudata adults (females in blue, males in red) batches at laboratory conditions $\left(25 \pm 2{ }^{\circ} \mathrm{C}, 50-70 \% \mathrm{RH}, 16: 8 \mathrm{~h} \mathrm{~L}: \mathrm{D}\right)$ used as controls for longevity at field conditions.

Our results are in agreement with other authors who confirm that temperature affect considerably the adult parasitoid lifespan with clear differences among sexes, which corroborate the need of such studies, as indicated above. Indeed, Appiah et al. (2013) found that the lifespan of D. longicaudata and F. arisanus adults varied with temperature for both sexes being shortest at $35^{\circ} \mathrm{C}$ and highest at $15^{\circ} \mathrm{C}$. Female wasps lived significantly longer than their 
corresponding males at all the temperatures tested. Similar findings were described by Mereilles et al. (2015) who confirmed the inverse relationship between the mean longevity of $D$. longicaudata and temperature when reared on A. fraterculus and C. capitata and recorded that individuals of $D$. longicaudata originating from $C$. capitata had a lower thermal threshold than those reared in A. fraterculus. Whereas Sime et al. (2006a) reported that the average adult longevity of $P$. concolor had a negative correlation depending on the temperature. Females of this parasitoid species lived significantly longer at $15^{\circ} \mathrm{C}$ and $22^{\circ} \mathrm{C}$. The same observations were obtained by Sime et al. (2006b) on their study of D. longicaudata and D. kraussii longevity. They found that the longevity of both species declined as the temperature increased, showing both sexes the same tendency. All these studies suggest that temperatures above $30^{\circ} \mathrm{C}$ reduce drastically $D$. longicaudata adult longevity, indicating that this species should not be able to establish in countries with high mean temperatures (tropical climate). Indeed, as demonstrated, D. longicaudata lifespan at a constant temperature of $30^{\circ} \mathrm{C}$ is of only 3 days, despite with our work we found that the lifespan is higher (Figure 2.22).

However, the low temperature threshold was set at $10^{\circ} \mathrm{C}$ (Sime et al. 2006b). Eitam et al. (2004) showed that the distribution of D. longicaudata in tropical climates, like in Florida or in California, has been delineated in part by minimum temperatures, being absent in cold winter areas (with an average temperature below $10.58^{\circ} \mathrm{C}$ ),

Paladino et al. (2010) demonstrated that the temperature and humidity of the rearing conditions affect the development of $D$. longicaudata, indirectly, by accelerating or reducing the development of the host rate, and directly affecting its own metabolic rate in the last stages of development.

\subsubsection{Abiotic and biotic factors: effect of the temperature and host larvae density on the offspring production of $D$. longicaudata reared on Ceratitis capitata larvae under laboratory conditions}

\subsubsection{Abiotic factors (temperature) affecting offspring production}

Overall, the parasitism percentage (the average of the three densities) was of $44.55 \pm 1.31 \%$ for $20-24^{\circ} \mathrm{C}$ and $46.43 \pm 1.31 \%$ for $25-29^{\circ} \mathrm{C}$. Whereas fertility was about $87.83 \pm 4.52$ and $89.04 \pm 4.52$ individuals per female for $20-24^{\circ} \mathrm{C}$ and $25-29^{\circ} \mathrm{C}$, respectively. The parasitism percentage produced by three females of $D$. longicaudata during three days of laying did not show a significant difference $(F=1.03 ; d f=1,95 ; P=0.3119)$ between the two ranges of temperature, 
nor for the three different densities of host medfly larvae. Similarly, no statistical differences were found when studying $D$. longicaudata fertility during the same period ( $F=0.04 ; d f=1,95$; $P=0.8506)$, nor when considering offspring sex-ratio $(F=2.94 ; d f=1,31 ; P=0.09)$.

These results can be explained by that both ranges of temperature are included in the range of the favorite range temperature for the development and reproduction of D. longicaudata on $C$. capitata, as demonstrated by Lui et al. (2012). Appiah et al. (2013) found that the most suitable temperature range for the optimum parasitism of $D$. longicaudata when using as host $B$. invadens is between 20 and $25^{\circ} \mathrm{C}$. Similarly, Sime et al. (2006) showed that moderate temperatures $\left(22-25^{\circ} \mathrm{C}\right)$ are optimal for the development of both $D$. longicaudata and $D$. kraussi on Bactrocera oleae Rossi (Diptera: Tephritidae).

\subsubsection{Biotic factor (available hosts) affecting D. longicaudata offspring production}

We conducted the following assay to determine the effect of host availability in parasitism percentage, fertility, offspring sex-ratio and induced mortality.

Despite parasitism percentage do not show statistical differences among tested temperature ranges (see point 2.3.2), we observed statistical differences, in parasitism percentage among available host densities $(F=15.04 ; d f=2,95 ; P<0.0001)$. In this study, D. longicaudata revealed higher parasitism percentage $(62.78 \pm 2.69 \%)$ at the lower host density (45 larvae per 3 females or $15: 1)$, and the smallest parasitism percentage $(42.10 \pm 3.23 \%)$ at the highest host density (360 larvae per 3 females or 120:1) (Figure 2.24). Meaning that when the larval densities increase the parasitism percentage decreases, as demonstrated when correlating the parasitism percentage with host density (Figure 2.25). 


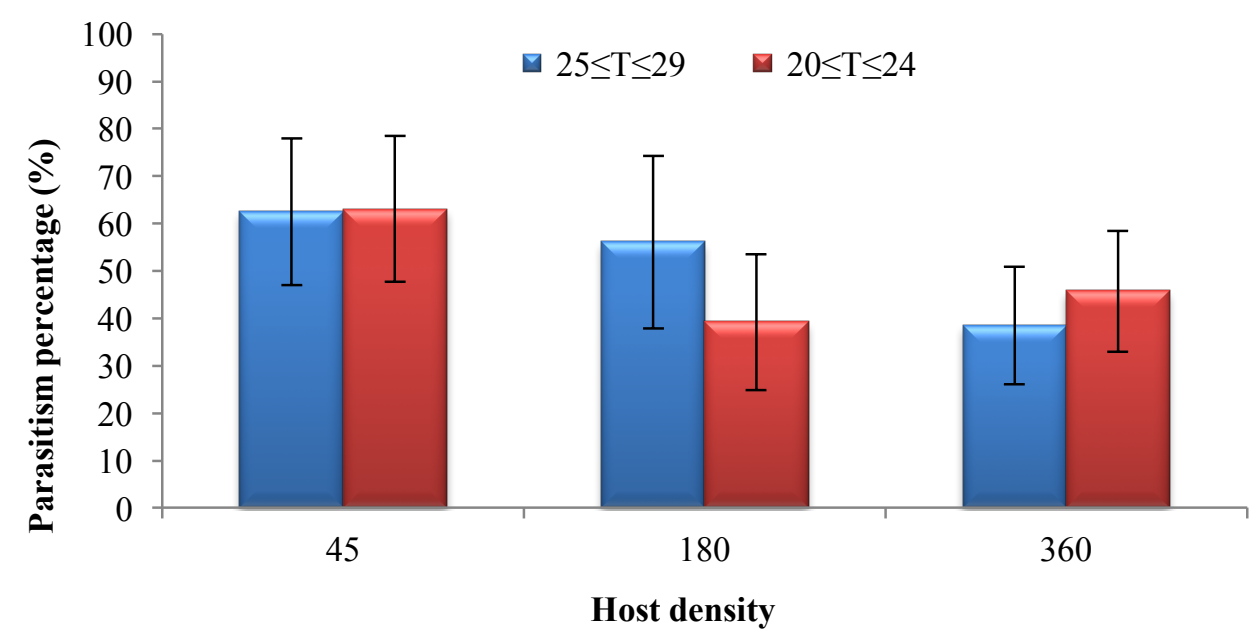

Figure 2.24. Parasitism percentage (\%) recorded for each third instart medfly larvae density $(45,180$ and 360$)$ at a different range of temperatures $\left({ }^{\circ} \mathrm{C}\right)$.

- $25 \leq \mathrm{T} \leq 29 \quad$ - $20 \leq \mathrm{T} \leq 24 \quad$ - Poly. $(25 \leq \mathrm{T} \leq 29) \quad$ - Poly. $(20 \leq \mathrm{T} \leq 24)$

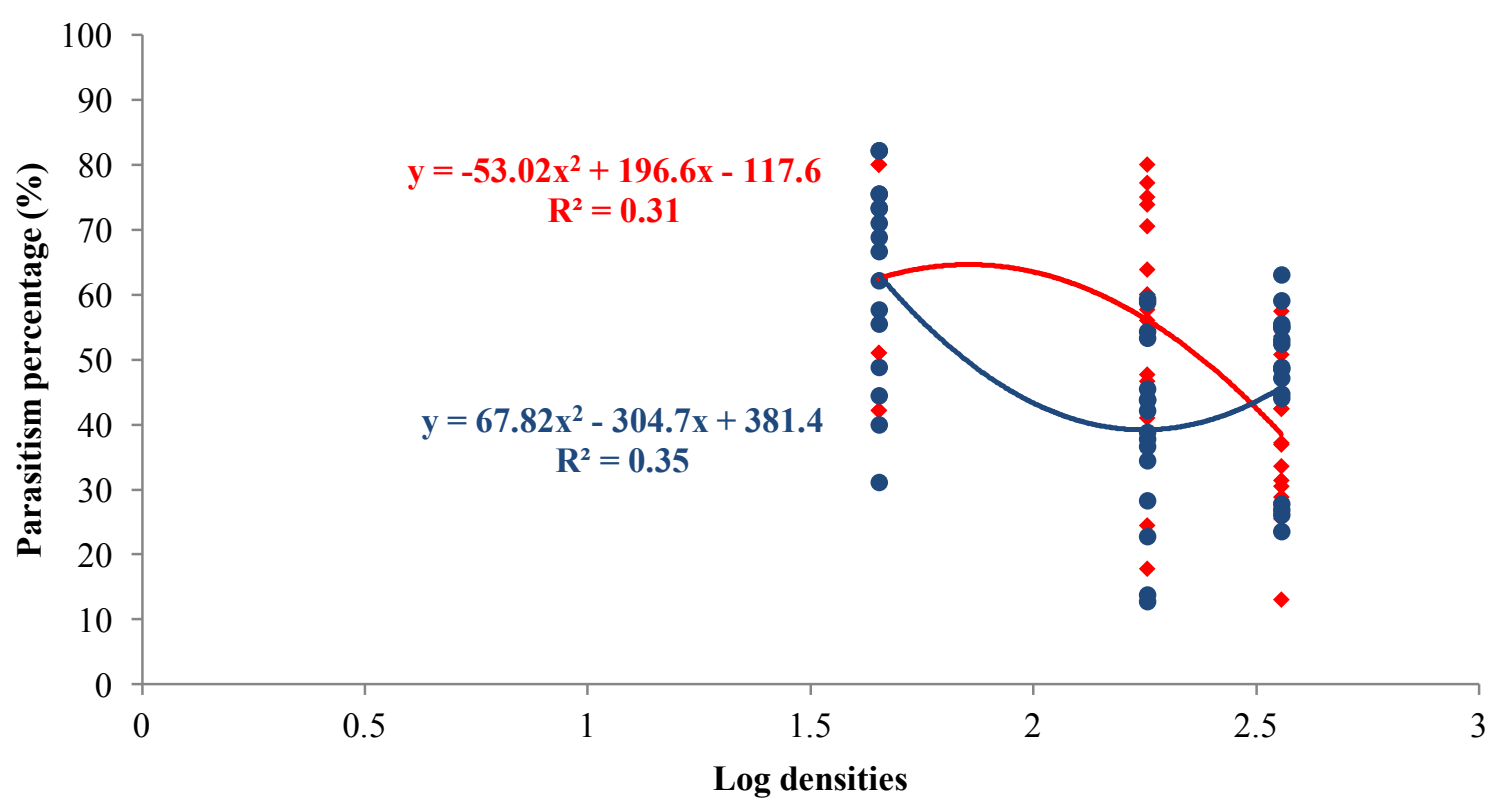

Figure 2.25. Relationship between the parasitism percentage of D. longicaudata and C. capitata third instart medfly larvae density (log density) at a different range of temperatures $\left({ }^{\circ} \mathrm{C}\right)$. 
Despite this negative correlation, when testing fertility, we found just the opposite; it increases as larval density increases for both ranges of temperatures (Figure 2.26). This increment is statistically significant $(F=124.04 ; d f=2,95 ; P<0.0001)$.

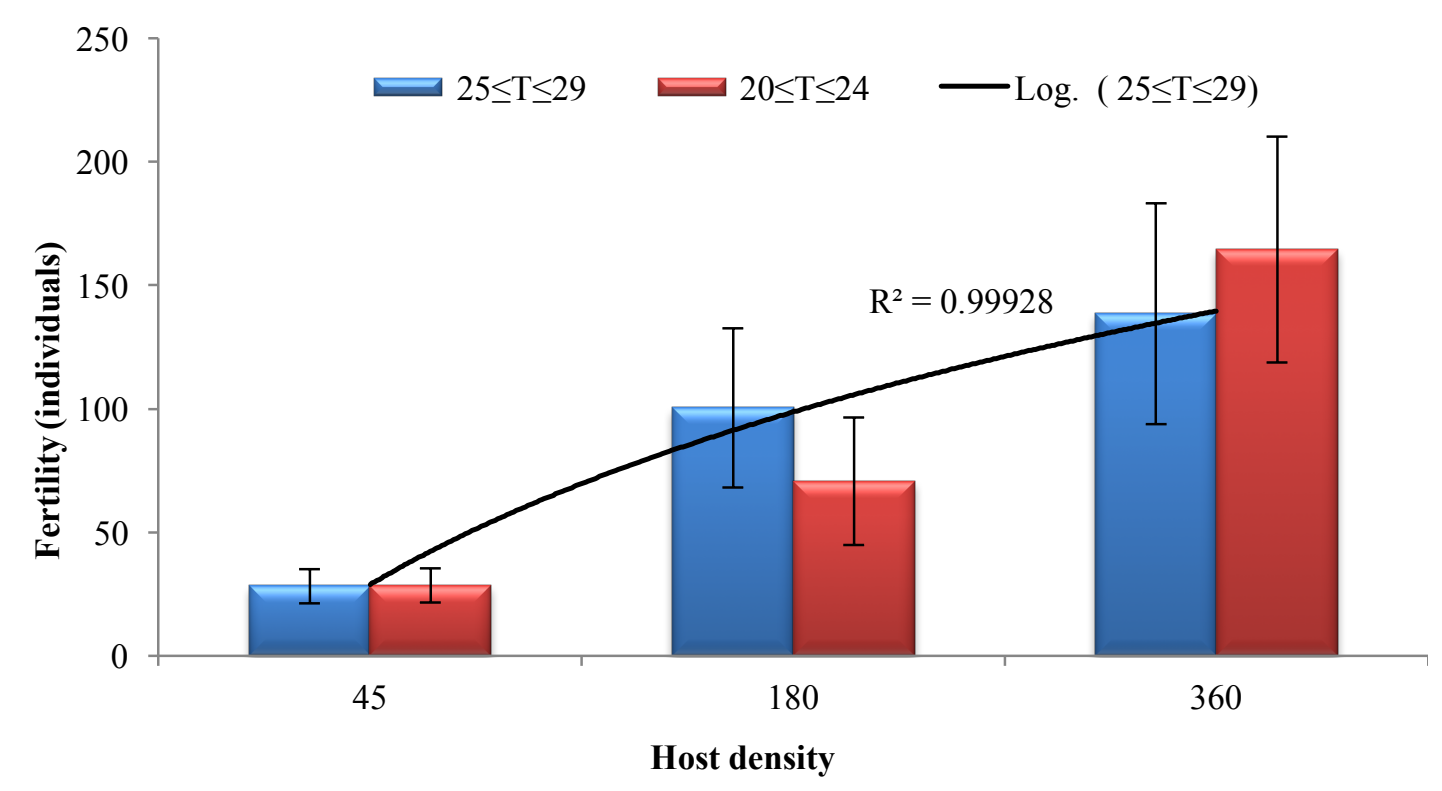

Figure 2.26. Fertility (as number of offspring $\pm \mathrm{SE}$ ) of $D$. longicaudata at different third instart medfly larvae densities $(45,180$ and 360$)$ and different range of temperatures $\left({ }^{\circ} \mathrm{C}\right)$. The trendline for the high temperatures range (logaritmic scale) is also shown with its $\mathrm{R}^{2}$ coefficient value.

The fertility data correlate with host density in a positive exponential regression with a $\mathrm{R}^{2}$ coefficient of 0.79 and 0.77 for $20-24^{\circ} \mathrm{C}$ and $25-29^{\circ} \mathrm{C}$ respectively (Figure 2.27).

In general, the fertility and the parasitism percentage were inversely related, the fertility responds positively as host density increases while the parasitism rate decreases (Figure 2.28). Concerning the offspring sex-ratio parameter, even if the average produced females ranged between 30 to $49 \%$, no statistical differences were obtained among temperature range or supplied host density (Figure 2.29). 
- $25 \leq \mathrm{T} \leq 29 \quad$ - $20 \leq \mathrm{T} \leq 24 \quad$ - Power $(25 \leq \mathrm{T} \leq 29) \quad$ - Expon. $(20 \leq \mathrm{T} \leq 24)$

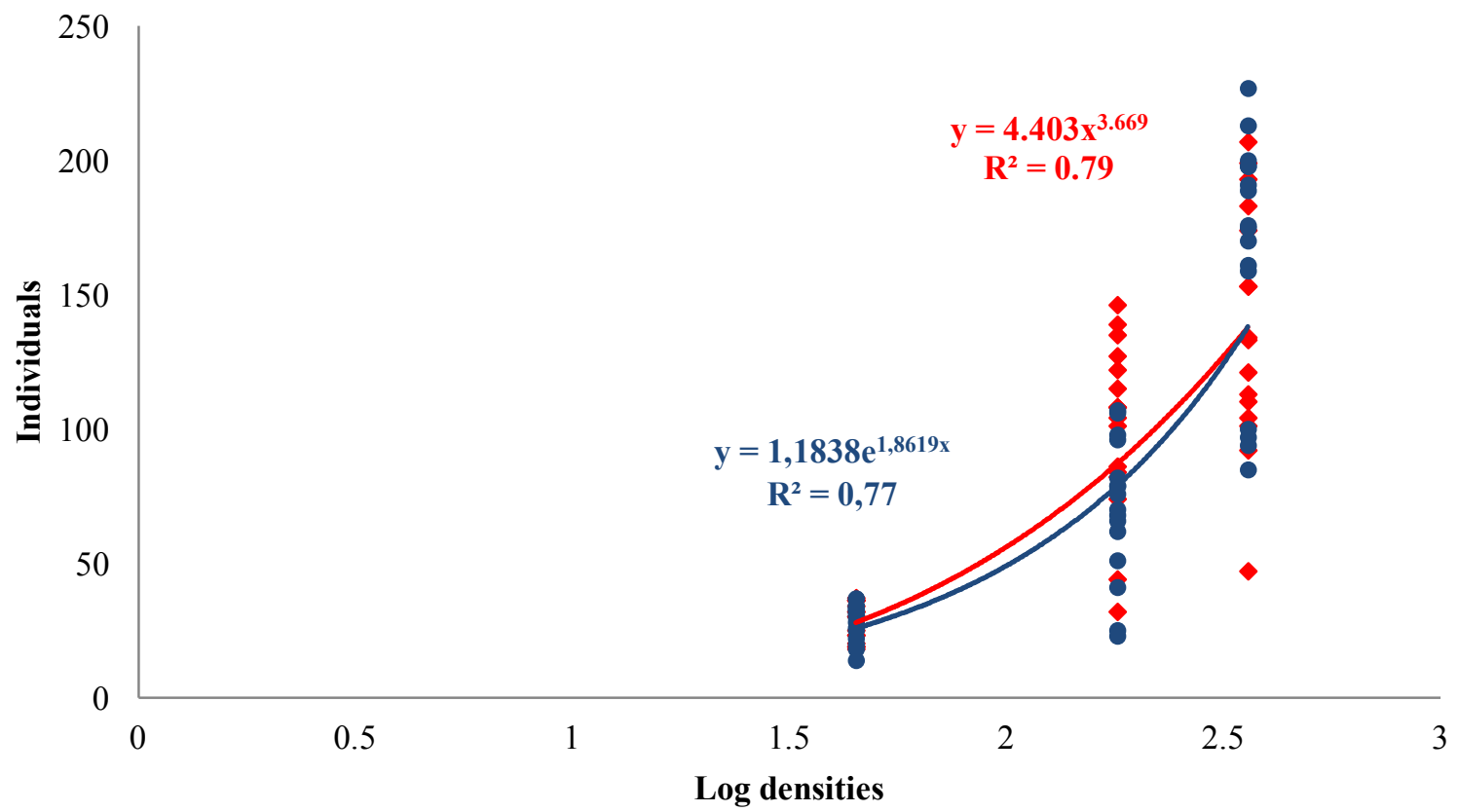

Figure 2.27. Relationship between the fertility (as number of offspring produced) of $D$. longicaudata and the supplied third instart medfly larvae densities (log density) at two different range of temperatures $\left({ }^{\circ} \mathrm{C}\right)$.

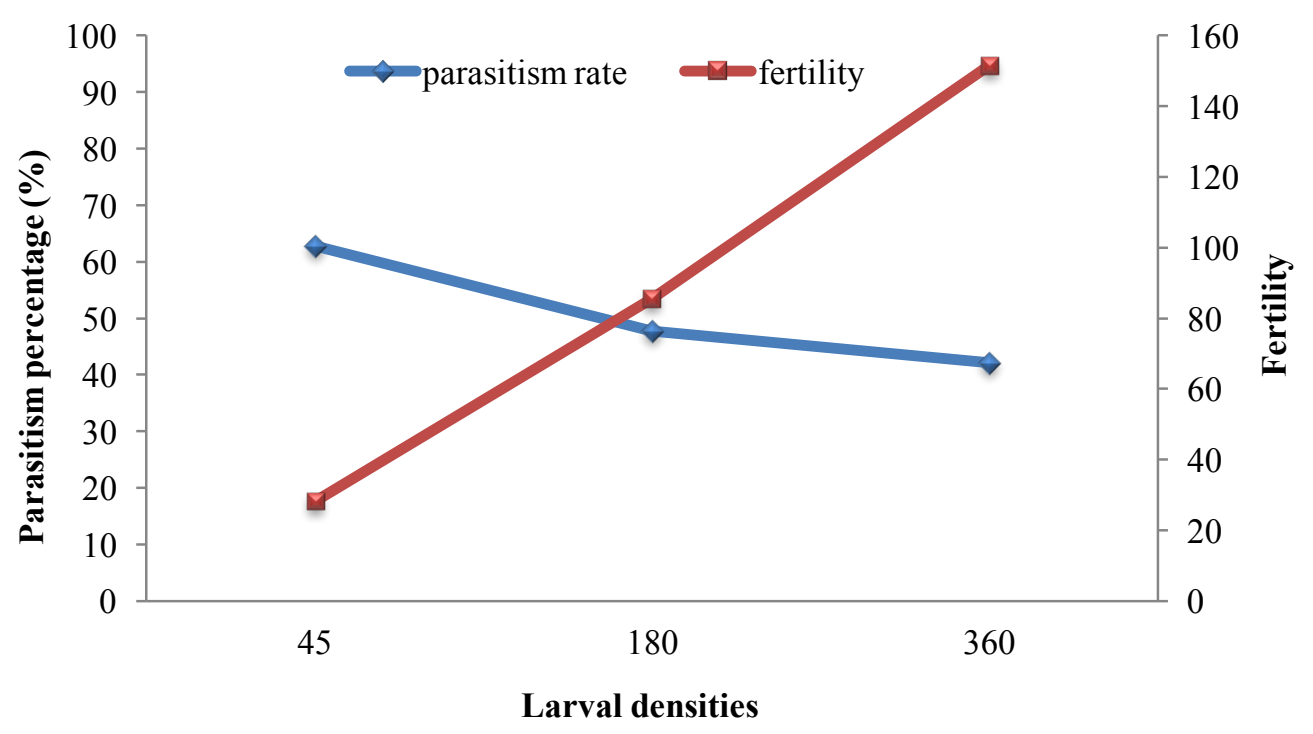

Figure 2.28. Variation of the parasitism percentage (\%) and the fertility (number of offspring produced) of D. longicaudata at three third instar medfly larvae density $(45,180$ or 360). 


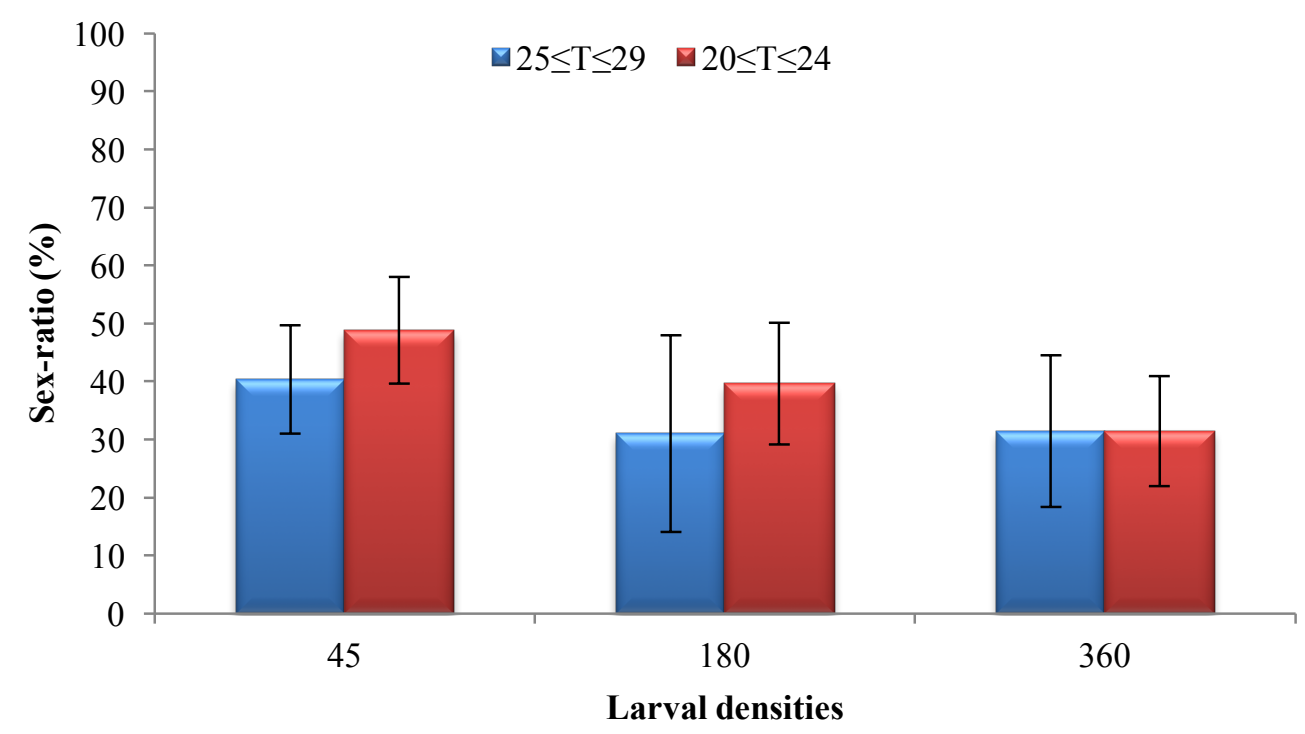

Figure 2.29. Sex ratio (expressed as offspring female percentage mean $\pm \mathrm{SE}$ ) of $D$. longicaudata offspring at two different range of temperatures $\left({ }^{\circ} \mathrm{C}\right)$ obtained at three different host densities $(45,180$ or 360; as number of provided medfly larvae).

A generalised linear model for the proportion of parasitized hosts showed the estimated negative linear and positive quadratic coefficients (Table 2.5), indicating a type II functional response (Juliano, 2001; Vanaclocha et al., 2013a). The estimated attack rate was $0.190 \pm 0.17$ days $^{-1}$, the handling time was $0.016 \pm 0.07$ days (Table 2.6).

Table 2.5. Maximum likelihood estimation parameters from the generalised linear model of the proportion of parasitised hosts as a function of initial host densities by fertilized $D$. longicaudata females under laboratory and greenhouse conditions.

\begin{tabular}{lllllll}
\hline & Parameter & Estimate & SE & $\chi^{2}$ & $d f$. & $P$ \\
\hline Host within diet in & Linear & -0.022 & 0.0043 & 27.24 & 1 & $<0.0001$ \\
laboratory condition & Quadratic & 0.0001 & $2.6717 \mathrm{E}-5$ & 15.41 & 1 & $<0.0001$ \\
\hline Host within fruits in & Linear & -0.190 & 0.1083 & 3.08 & 1 & $<0.01$ \\
laboratory condition & Quadratic & 0.004 & 0.0026 & 2.98 & 1 & $<0.02$ \\
\hline Host within fruits in & Linear & -0.001 & 0.0011 & 0.39 & 1 & $<0.04$ \\
semi-field condition & Quadratic & $2.141 \mathrm{E}-6$ & $1.3057 \mathrm{E}-6$ & 2.67 & 1 & $<0.01$ \\
\hline
\end{tabular}


Table 2.6. Attack rate (a) $\left(\right.$ days $\left.^{-1}\right)$ and estimated prey-handling time (Th) (days) obtained from nonlinear regression of the number of hosts by fertilized $D$. longicaudata females under laboratory and greenhouse conditions.

\begin{tabular}{lllllllr}
\hline & $a$ & SE & $95 \%$ CI & Th & SE. & $95 \%$ CI & $R^{2}$ \\
\hline $\begin{array}{l}\text { Host within diet in } \\
\text { laboratory condition }\end{array}$ & 0.190 & 0.17 & $0.01-0.210$ & 0.016 & 0.07 & $0.001-0.09$ & 0.80 \\
\hline $\begin{array}{l}\text { Host within fruits in } \\
\text { laboratory condition }\end{array}$ & 0.03 & 0.016 & $0.01-0.088$ & 0.001 & 0.52 & $0.0005-0.75$ & 0.750 \\
\hline $\begin{array}{l}\text { Host within fruits in } \\
\text { semi-field condition }\end{array}$ & 0.022 & 0.09 & $0.005-0.040$ & 0.0001 & 0.03 & $0.00005-0.050$ & 0.655 \\
\hline
\end{tabular}

Similarly, induced mortality decreases as host density increases, but there are not statistical differences among groups or between ranges of temperature (Figure 2.30).

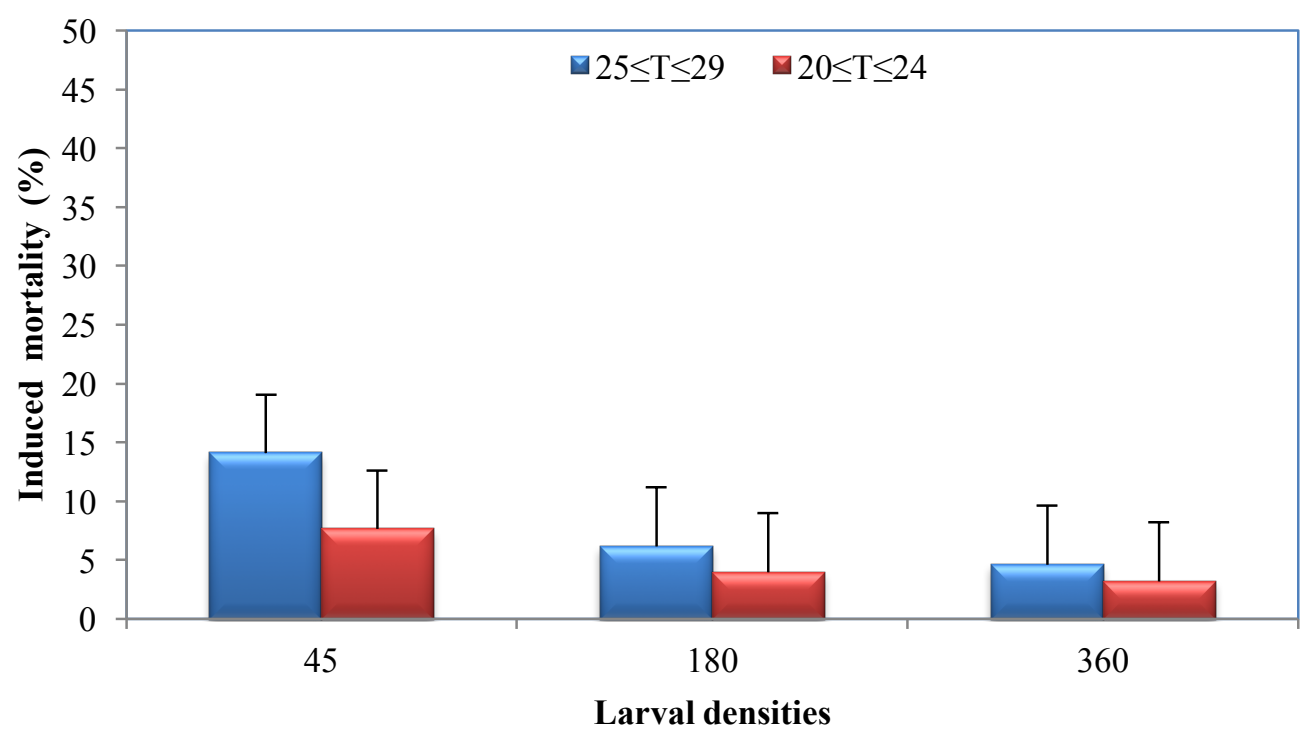

Figure 2.30. Induced mortality percentage (mean \pm SE) per medfly host density $(45,180$ or 360 ) obtained by $D$. longicaudata at two different range of temperatures $\left({ }^{\circ} \mathrm{C}\right)$.

The effectiveness of a natural enemy to regulate pest populations has been traditionally related to its functional response, which is defined as the relationship between the number of prey taken by the predator as a function of prey density (Holling 1959; Hassell 1978; Fujii et al. 1986). In this context, the study of the relationship governing the parasitism percentage provided by $D$. longicaudata and the density of $C$. capitata as host can provide valuable data when using this parasitoid in BC programs (Heimpel and Casas 2007). 
In our case, a reduction in the parasitism percentage was observed with increasing host density despite female fertility increased as host density increased (Figure 2.28). But in any case, it seems that there is an upper limit to the parasitism activity of each female. Taking into consideration the abovementioned definition of functional response, our data seems to fit to type II response (Figure 2.31) (as described by Hassell et al. 1977; Wajnberg and Ris 2007; Wajnberg et al. 2008; Zanuncio et al. 2013). This can be explained by two principal factors, firstly, egg depletion in females' ovaries at higher host densities and secondly, handling time limitation which prevents a parasitoid from attacking all of the available hosts (Hassell et al. 1977; Wajnberg and Ris 2007; Wajnberg et al. 2008; Zanuncio et al. 2013). In the presence of conspecifics, D. longicaudata females increase their host search activity. Female parasitoids spent more time searching in the presence of other females, although direct interference was not apparent among them (Montoya et al. 2000). At low host densities, there was strong competition for hosts and a high percentage of parasitism.

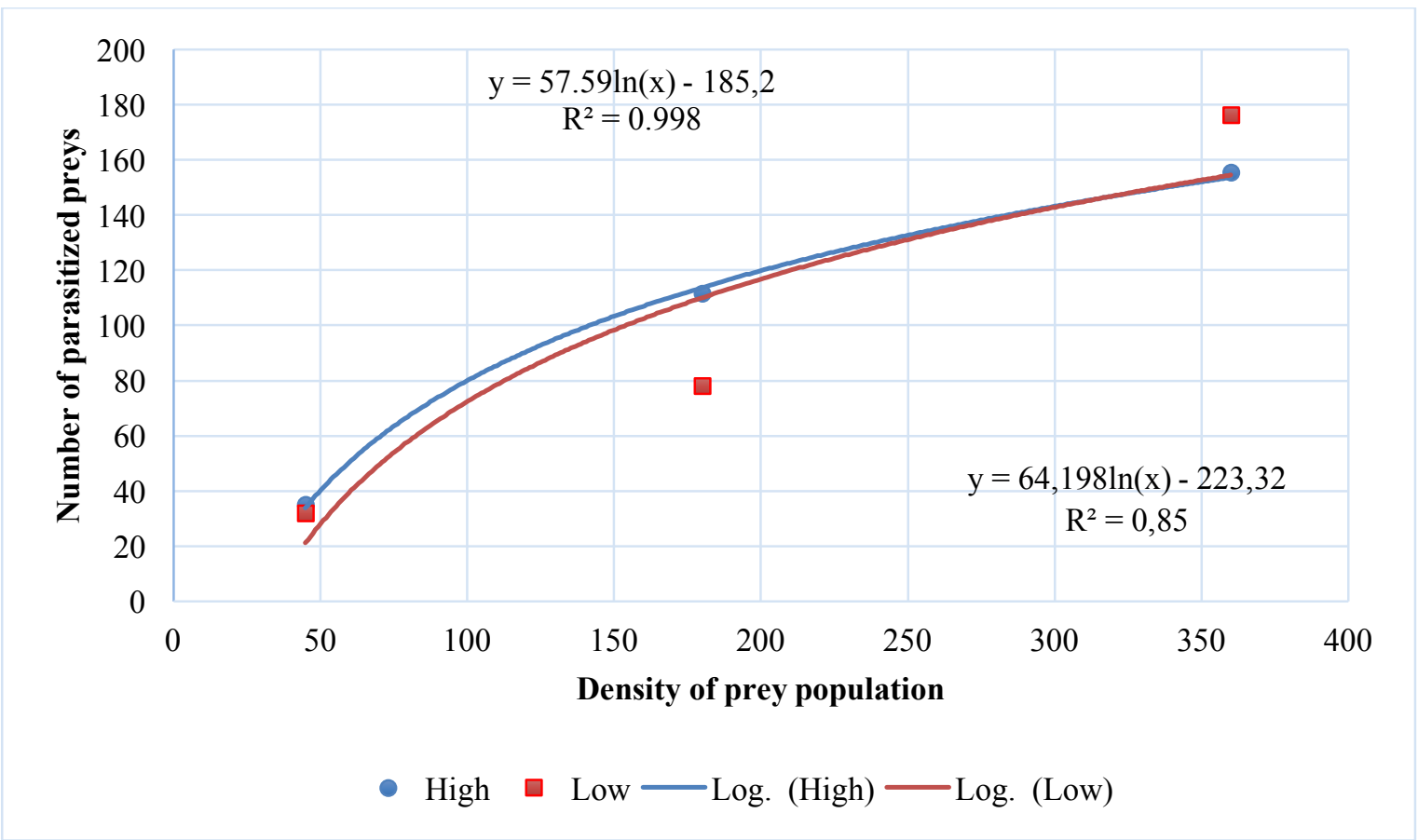

Figure 2.31. Functional response of $D$. longicaudata parasitizing $C$. capitata larvae at three different prey densities. Number of parasitized hosts was the averaged medfly larvae number (emerged parasitoids plus uneclosed pupa due to parasitoid activity). Data fitted to logarithmic equation at both temperature ranges.

At the other hand, in the present work, parasitism was analyzed as a percentage and not as the numbers of parasitized larvae as shown previously (Figure 2.24). At higher host densities, the number of parasitized hosts increased but the parasitism percentage declined. However, the 
fertility increased exponentially as host density increased (Figure 2.26 and 2.27). This phenomenon of inverse density dependent functional response was reported in several biological control agents, including parasitoids and predators. For example, the pupal parasitoid Spalangia endius Walker (Hymenoptera: Pteromalidae), when parasitized two tephritid host species in Thailand (Kitthawee et al., 2004) or D. longicaudata on A. ludens (Montoya et al., 2000). Moreover, Montoya et al. (2000) reported that when the parasitoid:host ratio was 1 or greater, larval mortality was consistently high but never exceeding $90 \%$, and that successful parasitoid emergence decreased as the parasitoid:host ratio increased.

Our data show that the induced mortality caused by the parasitoid decrease as host density was increased. This fact could be explained by the superparasitism caused by D. longicaudata, or by the fact that when enough host are available and the developmental conditions are at the optimun, parasitoid immatures mortality descends and by hence, induced mortality.

\subsubsection{Effect of host density (within fruits) on D. longicaudata parasitism}

As indicated previously, D. longicaudata parasitism percentage decrease with host density at laboratory conditions, despite the trials were performed without taking into consideration the fruit host. In this sub-section, we had studied the parasitism percentage at laboratory conditions when the host is within its natural fruit host, as it was determined that parasitism percentage can be influenced by fruit odours, fruit firmness and host larva location. Under these parameters, we observed that parasitism percentage varied from 18 to $21.85 \%$ (Figure 2.32), not observing statistical differences among averages $(F=0.14 ; d f=2,29 ; P=0.87)$ between the three studies host densities. 


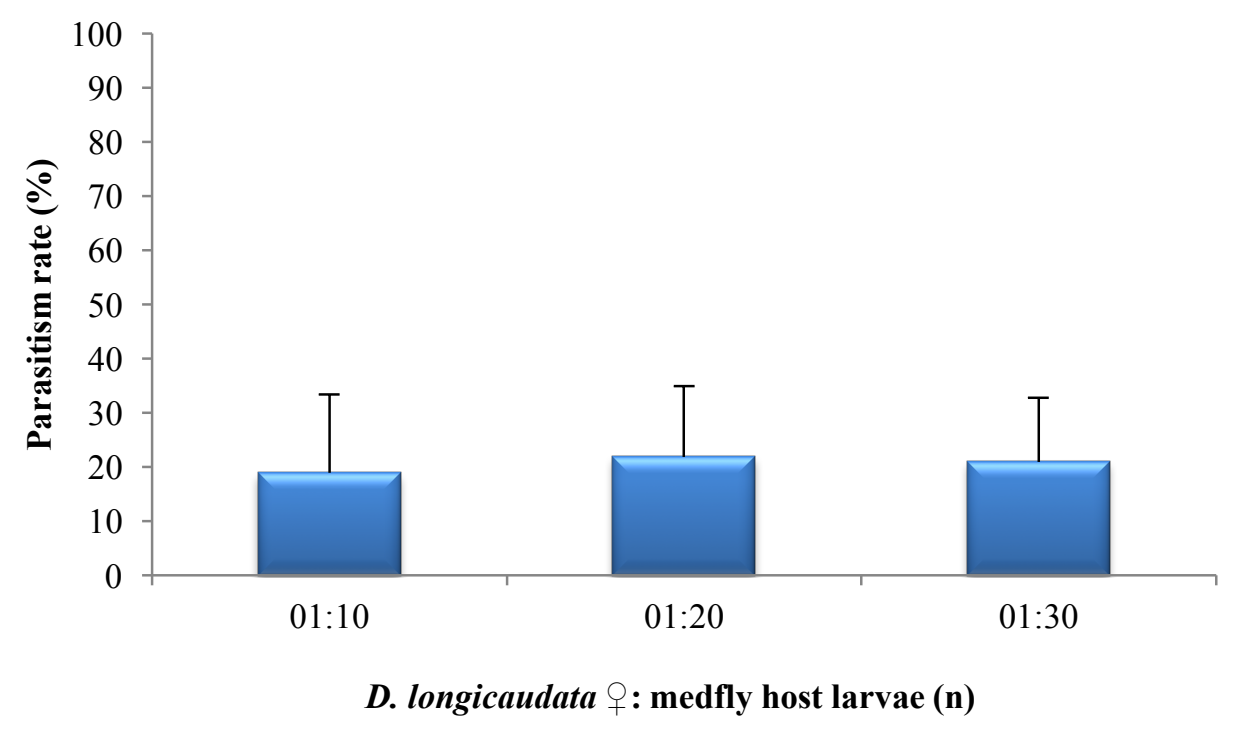

Figure 2.32. Diachasmimorpha longicaudata parasitism percentage (\%) (mean \pm SE) per medfly host density, when the host is provided within fruit, resembling natural conditions.

In contrast, fertility augmented simultaneously with increasing host availability (Figure 2.33), without showing significant differences between host densities $(F=3.31 ; d f=2,29 ; P=0.051)$. In fact, differences were among the lowest host density (10 hosts per parasitoid female) and the higher ones (either 20 or 30 hosts per parasitoid female), not finding statistical differences among the higher density groups.

A generalised linear model for the proportion of parasitized hosts showed the estimated negative linear and positive quadratic coefficients (Table 2.5), indicating a type II functional response (Juliano, 2001; Vanaclocha et al., 2013a). The estimated attack rate was $0.03 \pm 0.016$ days $^{-1}$ and the handling time was $0.0001 \pm 0.529$ days (Table 2.6). 


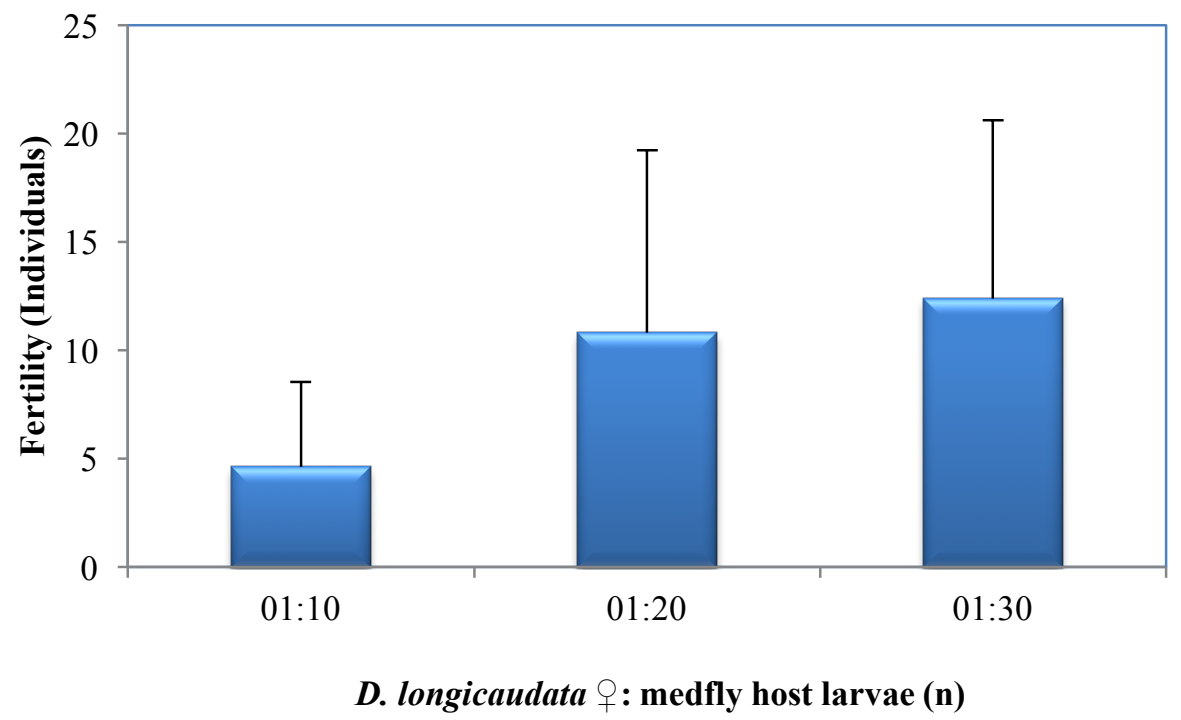

Figure 2.33. Diachasmimorpha longicaudata fertility (as number of offspring produced $\pm \mathrm{SE}$ ) per medfly host density, when the host is provided within fruit, resembling natural conditions.

The sex-ratio for the three studied densities was between 27 and 44\% (shown as percentage of females in the offspring) without showing significant differences between them $(F=0.69 ; d f=2$, 29; $P=0.51$ ) (Figure 2.34).

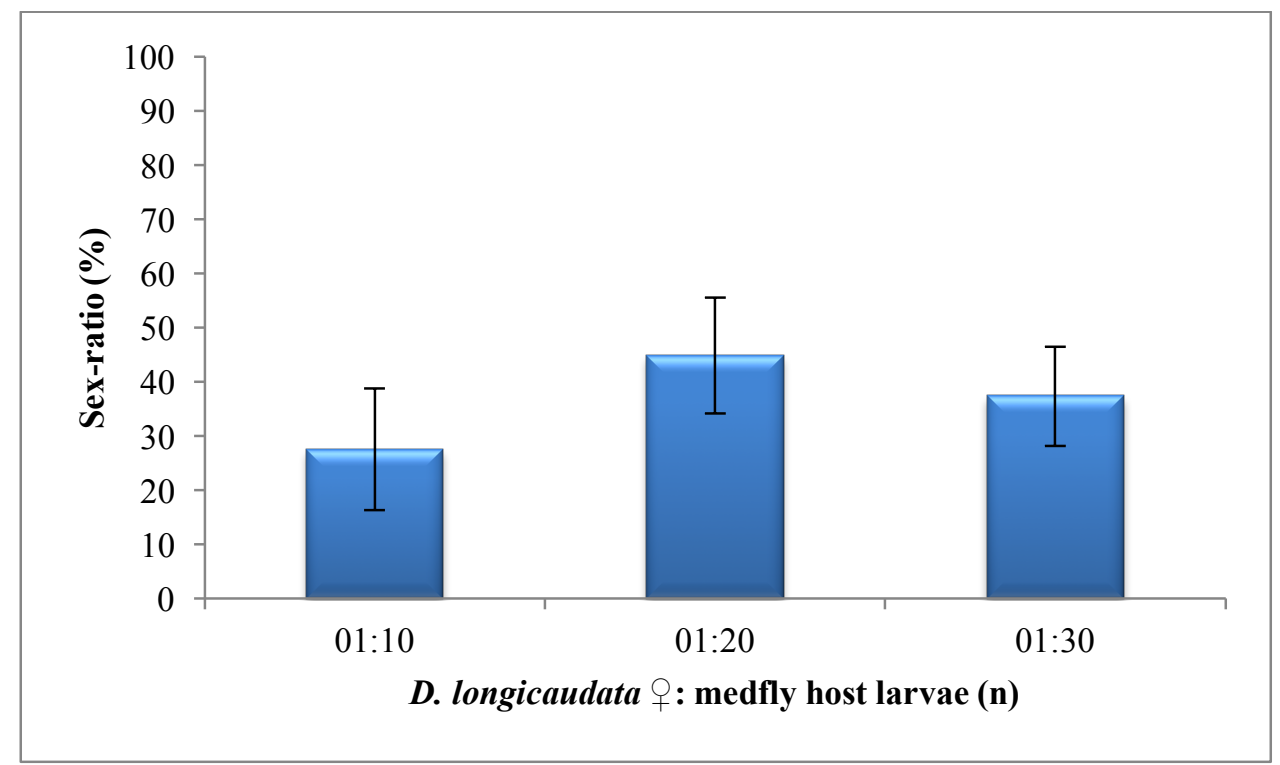

Figure 2.34. Diachasmimorpha longicaudata sex-ratio (\%) (as female percentage produced, mean \pm SE) per medfly host density, when the host is provided within fruit, resembling natural conditions.

As can be seen, in general the parasitism percentage, fertility and offspring sex-ratio showed the same tendency as in the laboratory series with directly exposed host larvae, but with lower numbers. This difference can be explained by the increased difficulties exerted to the 
parasitoids, as now, they should search its host inside the fruit and in a larger space than in the previous set-up. Despite this low numbers, this experimental approach is valid and with more resemblance to natural conditions, which give us an idea about performance, efficiency and ability of $D$. longicaudata to parasitize its host in semi-natural conditions and produce new generations, which can be applicable to the field.

\subsubsection{Influence of fruit location and host density in semi-field conditions on D. longicaudata performance}

As explained above, after setting-up the experimental protocol, the next step was to determine D. longicaudata abilities and performance under semi-field conditions. The same experiments with artificial infested fruits were performed in semi-field conditions (greenhouse), with one more variable, host location (as infested fruits at the canopy or in the ground, to resemble natural conditions).

Parasitism percentage was between 13 to $22.61 \%$ (Figure 2.35), not finding statistical significant differences among tested host densities $(F=3.07 ; d f=2,59 ; P=0.054)$ nor between host location $(F=0.29 ; d f=1,59 ; P=0.594)$ (on the ground or on the canopy of the tree).

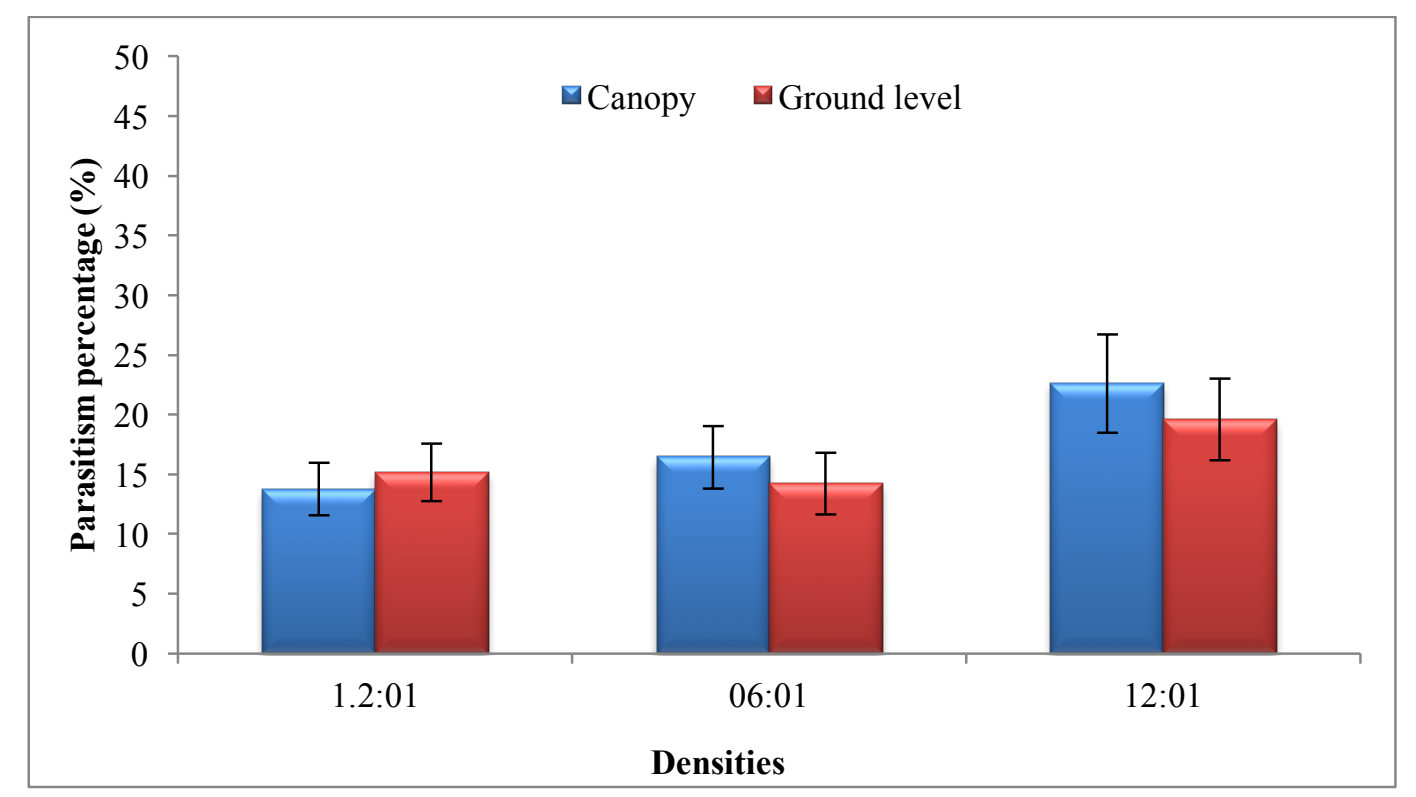

Figure 2.35. Parasitism percentage (mean $\% \pm \mathrm{SE}$ ) per host density and fruit locations (in blue fruits located at canopy, in red those located at ground level).

In this experiment fertility ranged from 3.3 to 51 (Figure 2.36), finding significantly differences among host densities $(F=42.53 ; d f=2,59 ; P<0.0001)$ but not among host location $(F=0.43$; 
$d f=1,59 ; P=0.5141)$. As for the laboratory series, fertility increased as host density did. A generalised linear model for the proportion of parasitized hosts showed the estimated negative linear and positive quadratic coefficients (Table 2.5), indicating a type II functional response (Juliano, 2001; Vanaclocha et al., 2013a). The estimated attack rate was $0.02 \pm 0.09$ days $^{-1}$, the handling time was $0.0001 \pm 0.03$ days (Table 2.6).

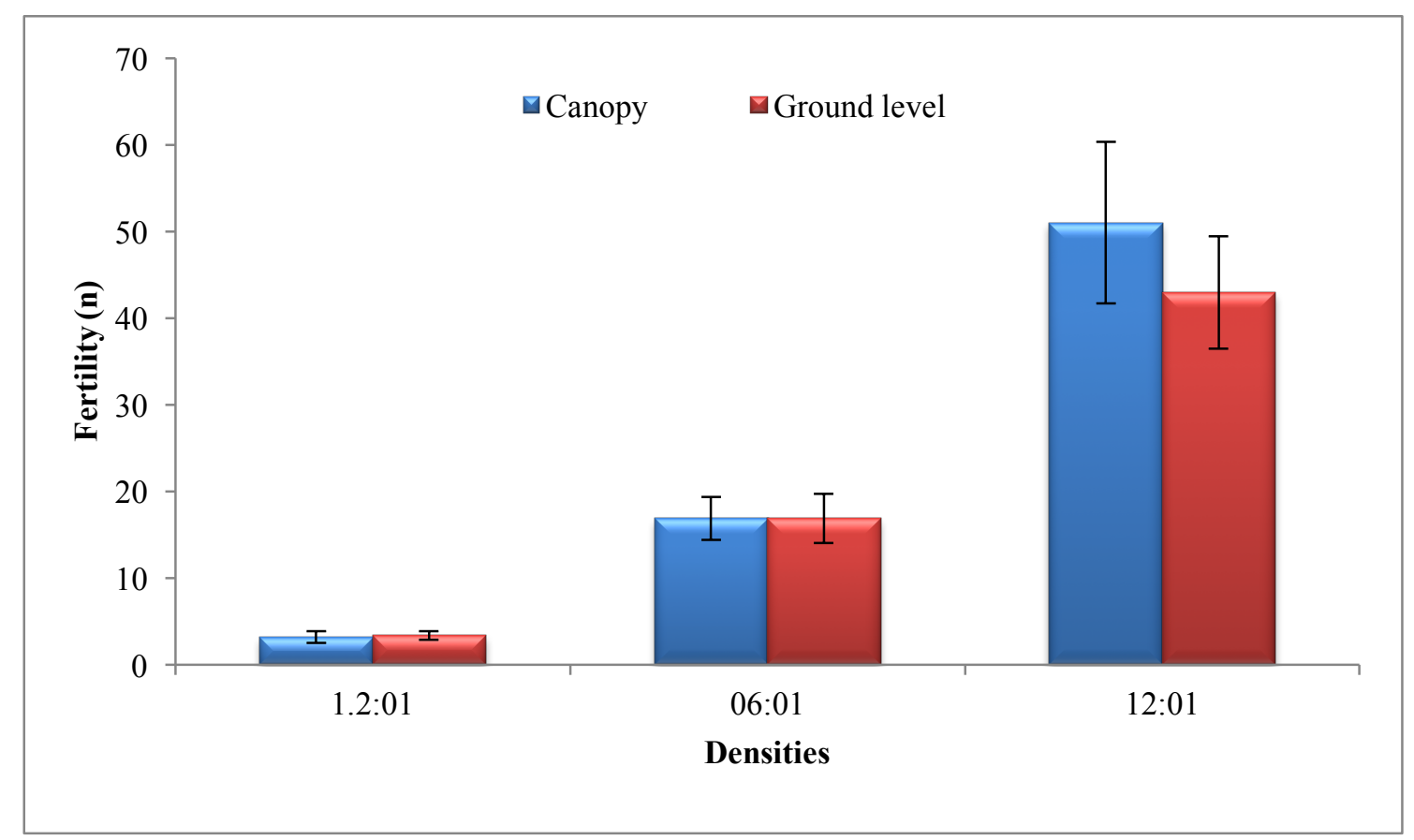

Figure 2.36. Fertility (mean \pm SE) per host density 1.2:1, 6:1 or 12:1 (L2-L3 medfly larvae per $D$. longicaudata female) and fruit location (canopy in blue or ground-level in red).

However, the offspring sex-ratio (female percentage of the descendants) decreased as host density increased, from 57 to as low as $31 \%$ (Figure 2.37). This ratio presented significant differences between host densities $(F=6.17 ; d f=2,59 ; P=0.0038)$ but not between host location $(F=1.60 ; d f=1,59 ; P=0.2113)$

The study of the induced mortality by D. longicaudata at the three different hosts densities did not demonstrate any statistical difference $(F=0.58 ; d f=2,59 ; P=0.57)$. However, it seems there is a negative tendency linked to increased host availability, meaning that at lower host density the higher induced mortality, whereas at higher host densities the lower induced mortality (Figure 2.38). 


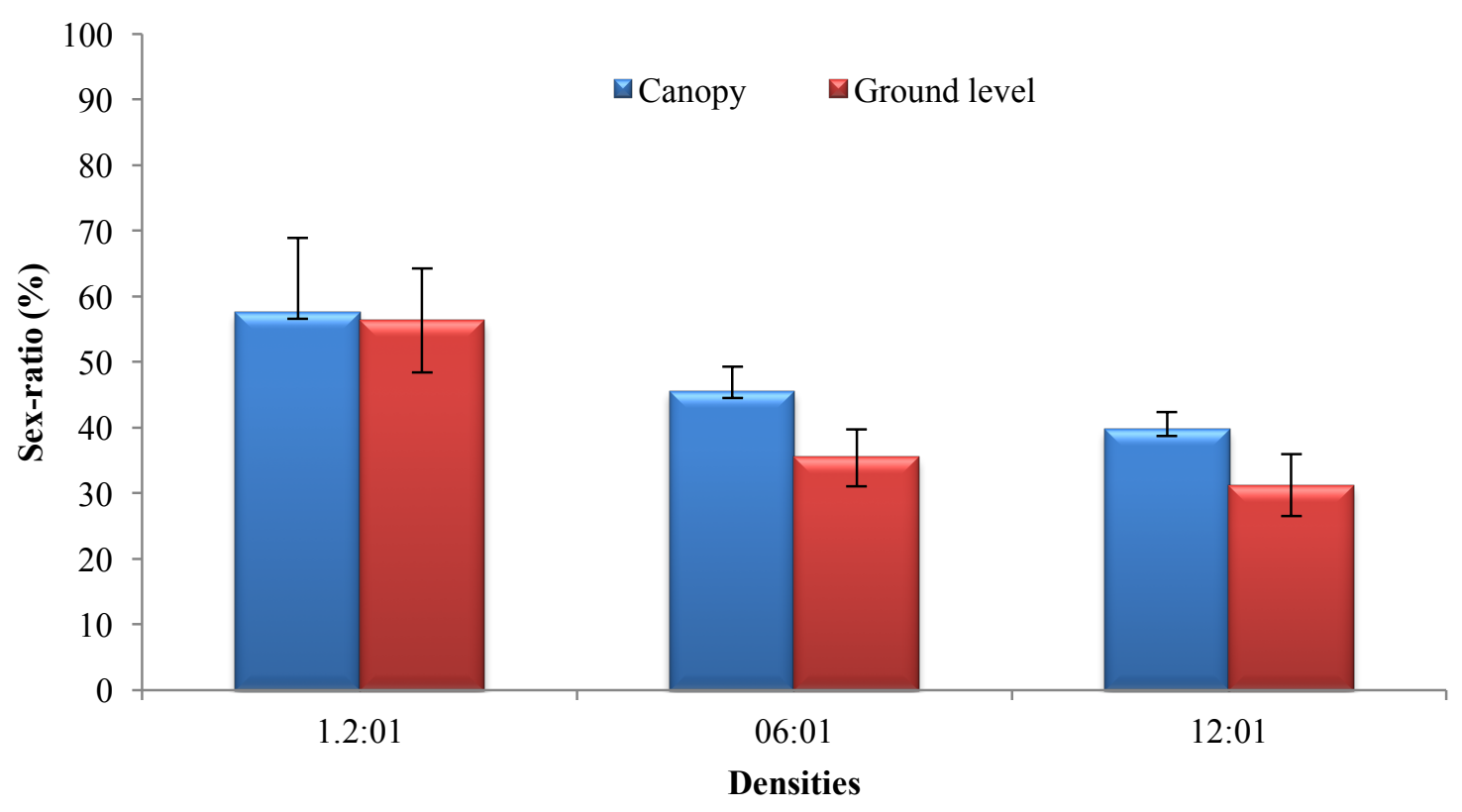

Figure 2.37. Sex-ratio (mean $\mathrm{n} \pm \mathrm{SE}$ ) of offspring per host density (1.2, 6 or 12 L2-L3 medfly larvae per D. longicaudata female) and fruit location (canopy or ground level).

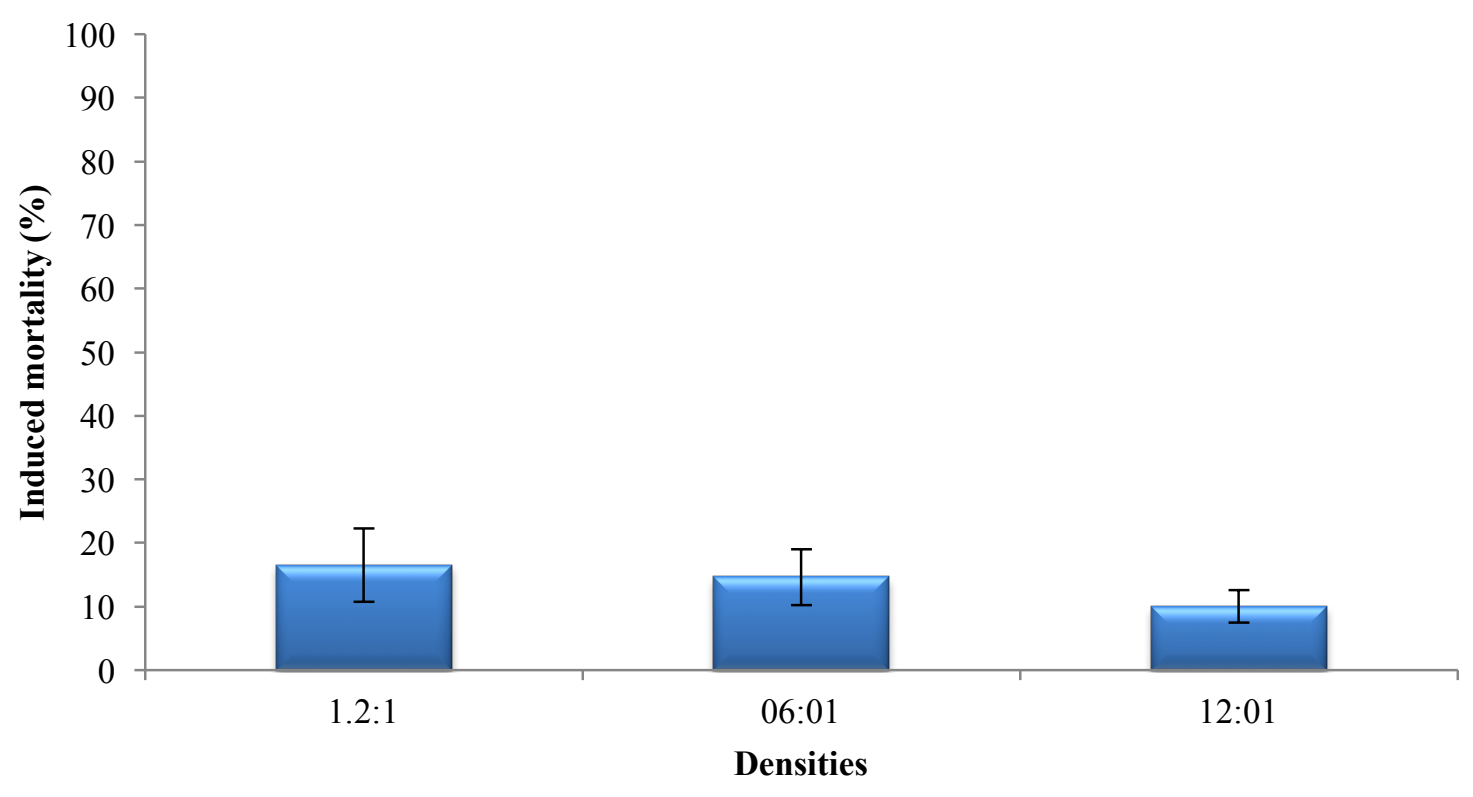

Figure 2.38. The induced mortality $(\%)(\operatorname{mean} \pm \mathrm{SE})$ per host density $(1.2,6$ or 12 L2-L3 medfly larvae per D. longicaudata female).

As indicated previously, the experimental design allowed simulating natural conditions, on which parasitoids should face with more distance to their host, increased required time to locate it, different fruit cues, and what is also important, the presence of conspecifics which should share the same host patch. Our results demonstrate that D. longicaudata has a response type II, 
on which fertility increases as host do, as well as do parasitism percentage (even at statistical significance limit) (Figures 2.35 and 2.36).

Regarding to the sex-ratio, it decreased when the density of $C$. capitata host increases (Figure 2.37), this is similar to result that approve the parasitoid when the density of their host is low they give more female then male to guarantee its future generations.

On the other hand, D. longicaudata did not show any foraging preference among canopy or ground-level infested fruits, being able to discriminate between low and high host densities in both substrates. Our findings are in agreement with those of Garcia-Medel et al. (2007) who demonstrated that $D$. longicaudata is able to parasitize its host located in the fruit fallen on the ground and also in the canopy of the tree and in high and low host densities in the presence or absence of competition of another parasitoid species. Purcell et al. (1994a) found in their research that $D$. longicaudata parasitize guava fruit fallen upon the ground. This result is a positive point for the wasp D. longicaudata, it can search, found and parasitize its host not only in the canopy of the tree but also on fruit dropped on the ground. Furthermore, these dropped fruits may be more infested by medfly larvae and therefore the parasitoid can parasitize more and produce more descendent in Mediterranean field conditions.

In addition to the produced parasitism rate recorded in the different larval densities and both fruit locations, $D$. longicaudata is able to increase medfly population control by $\approx 9-10 \%$ due to the induced mortality exerted in the host as compared with control, irrespectively of host density. This phenomenon was cited by Montoya et al. (2000) who explained it by the presence of superparasitism of the parasitoid and proved that the mortality decrease when the ratio parasitoid-host density increase.

In conclusion, $D$. longicaudata is able to control $\approx 30 \%$ of medfly population under the simulated Mediterranean conditions, $\approx 10 \%$ of this control do not contribute to the maintenance of D. longicaudata in the field, a fact that deserves further research.

\subsection{Conclusions}

\subsubsection{Life history parameters}

In summary, our data and those available in the literature suggest that differences in the origin of a parasitoid strain could have important effects on the reproductive and demographic traits of the parasitoid. Likewise, available data suggest also the presence of significant within-strain differences depending on the host species used for rearing $D$. longicaudata. In particular, the 
intrinsic rate of increase $\left(r_{m}\right)$, which is of high interest to determine the development capacity of a population in field and thus the potential capacity of a parasitoid in controlling a pest, presented important variations among and within strains and/or hosts. Further studies are needed, mainly on the genetic level to advance our knowledge on this wasp which can ultimately lead to a better understanding of the differences highlighted in this work.

From a practical perspective, we can conclude that, in the case of D. longicaudata, all the conditions of the rearing must be well considered and analyzed previous the use of the parasitoid in biological control programs against tephritid populations mainly the target pest species, the climatic conditions, the host species and the strain of the parasitoid to be reared. The good choice of these factors can improve the quality of produced natural enemies, which is a key factor for a successful biological control of insect pests.

\subsubsection{Abiotic factors affecting $D$. longicaudata}

Previous results obtained from the study of seasonality impact on the $D$. longicaudata longevity confirm precedent findings that the longevity depends inversely on the temperature and also the female's lifespan is higher than that of males.

Based on the obtained data of adults' longevity of $D$. longicaudata, we can conclude that it can be very interesting as an agent of biological control against $C$. capitata in the Mediterranean region and specially in Spain and Tunisia where it was introduced. Indeed, the climatic conditions are favorable for its establishment and mainly during the development period of the medfly. It can survive all the year and especially in autumn and winter when the medfly is present, and during the best moment to its release.

On the other hand, this result can help us to improve the mass rearing conditions by choosing the optimum development temperature of this parasitoid.

\subsubsection{Biotic factors affecting $D$. longicaudata parasitism}

In conclusion, D. longicaudata, in a temperature range between $20^{\circ} \mathrm{C}$ and $29^{\circ} \mathrm{C}$, showed a functional response type II and a parasitism percentage inversely dependent on host density, demonstrating that this parasitoid can search efficiently for specific hosts at low host densities, such as those likely to occur under natural conditions and demonstrate a good potential for use of this parasitoid in controlling C. capitata in mass or targeted releases. 


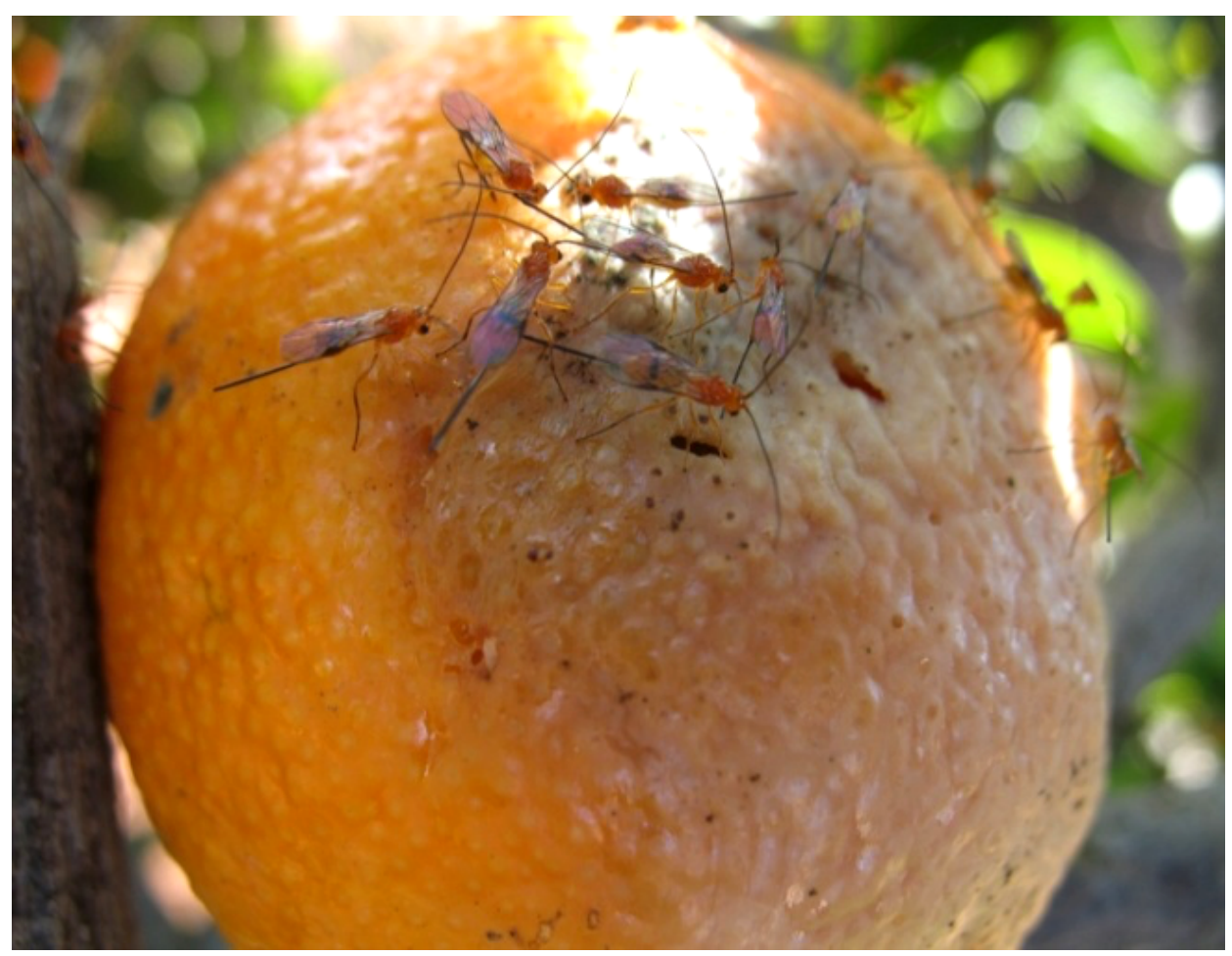

CHAPTER 3. Biotic and abiotic factors affecting parasitic activity of Diachasmimorpha longicaudata over the Mediterranean fruit fly, Ceratitis capitata, under Mediterranean conditions and different fruit hosts 
In this chapter I will show the biotic and abiotic factors affecting parasitic activity of $D$. longicaudata against the medfly under Mediterranean conditions either in semi-field assays to exert some control in external biotic variables, or in climatic chamber by using medfly natural hosts, as continuation of the precedent chapter, and to fulfill the second objective proposed for this thesis dissertation.

2. Determination of biotic and abiotic factors affecting parasitic activity of D. longicaudata against C. capitata in different fruit hosts.

The results showed here have been partially submitted to different SCI journals, including a chapter in Proceedings of the International Symposium on Fruit Flies of Economic Importance.

\subsection{Abiotic and biotic factors affecting parasitoids performance}

In agro-ecosystems, the biological control of pest species requires a comprehensive understanding of the bio-ecology of the targeted organism as well as those of its natural enemies (parasitoids and predators), including environmental stimuli governing their biological activities. For this reason, it was advisable to determine what biotic factors like influence of medfly fruit host, host density and host location and/or what environmental stimuli enhances or decreases D. longicaudata parasitism over C. capitata in the Mediterranean Basin. This knowledge will help state agents in the determination of the timeline for its implementation in an IPM program.

\subsubsection{Abiotic factors affecting parasitoid foraging abilities}

In the past two decades, a number of entomologists have attempted to use augmentative releases of mass-reared opine braconid parasitoids to control field populations of tephritid flies in tropical fruit and vegetable crops (Wong et al. 1991, 1992; Sivinski et al. 1996). For this reason, numerous studies were conducted to obtain bionomic data and establish rearing methods for these parasitoids (Ramadan et al. 1989; Wong and Ramadan 1992; Messing et al. 1993). However, relatively little work has been done on the behavioral parameters which are critical for these releases. As for example, flight behavior, dispersal capability, and response to abiotic factors (climatic conditions) (Messing et al. 1997).

The influence of weather phenomenons on the behavior of Hymenoptera has been well documented in several families as Apidae (Heard and Hendrikz 1993), Ichneumonidae (Idris and Grafius 1998), and Chalcididae (Barbosa and Frongillo 1977). From all these works, it was obtained a good conclusion, that the interactions of environmental factors with parasitoid host 
selection strongly influence the success of Biological Control programs against tephritid fruit flies (Rousse et al. 2009). Indeed, in the past decade, several studies highlighted the effect of environmental factors like temperature and humitidy in parasitoid survival, flight and parasitism percentage, as demonstrated by Rousse et al. (2009) with F. arisanus or by Wang et al. (2011) with Psyttalia lounsburyi Silvestri (Hymenoptera: Braconidae) and P. humilis Silvestri used against the olive fruit fly, B. oleae. For instance, it has been concluded that higher temperatures impact negatively on parasitoid establishment by either killing developing larva or foraging adults (Sime et al. 2006a; Daane et al. 2008). Similarly, lower temperatures also contribute to establishment failure, as explained with P. concolor in Europe (Wang et al. 2011). Concerning this thesis species subject, D. longicaudata, despite its relevant economic importance, has up to now received little attention regarding the impact of abiotic factors on parasitoid performance (Rousse et al. 2009). Previous works with this species had determined its efficacy in augmentative releases (Paranhos et al. 2007), the effect of wind (direction and speed) on its flight behavior (Messing et al. 1997), or even the effect parasitoid female age on fecundity for mass-rearing purposes (Ramadan et al. 1992, 1994; Bautista et al. 1999). However, there are still missing information regarding the field performance of $D$. longicaudata, mainly in the Mediterranean region, such as its ability to parasitize, and to survive, especially in relationship with climatic conditions.

To fill-in this knowledge gap, and to provide valuable information for stakeholders (who will decide on how implement a BC program), individuals from an established colony of $D$. longicaudata imported to Valencia (Spain) from Hawaii (USA) were evaluated in cage trials in the field. Field cages have long been used to estimate the impact of natural enemies, where manipulated densities of both the host pest and the natural enemy can be tested under natural field conditions (Luck et al. 1988). Our primary goal was to determine if $D$. longicaudata could parasitize C. capitata and survive under typical Mediterranean field conditions. Our secondary objective was to evaluate climatic conditions factors that might hinder their effectiveness on parasitism and/or limit its preimaginal development.

\subsubsection{Biotic factors affecting parasitoid foraging}

Insect behavioral responses are mainly mediated by visual and chemical cues. Many natural enemies, particularly parasitoids, use semiochemicals to locate their hosts (Vinson, 1985; Lewis and Martin, 1990; Vet and Dicke 1992), and tephritid fruit flies parasitoids are not an exception (reviewed in Quilici and Rousse 2012). Indeed, these parasitoids response to two main sources 
of semiochemicals, ones are produced by the fruits alone and the other produced by the tephritid larvae feeding on fruits (Stuhl et al. 2011; Segura et al. 2012; Benelli et al. 2014). These last ones vary between fruit fly species and among fruit host species.

For instance, D. longicaudata is attracted to many chemical compounds such as acetaldehyde, ethanol, and acetic acid, which are mainly released by infested fruits (Greany et al. 1977). It is also attracted by other fruit volatiles, not related with tephritid infestation (Eben et al. 2000). But visual cues like fruit color and/or mechanical cues (as larval movements) also play a key role its behavioral responses at foraging. This was investigated and confirmed by many studies (reviewed in Quilici and Rousse 2012). However, the impact of these stimuli on the biocontrol services of the parasitoid (i.e. parasitism) and its biological traits (i.e. fertility and sex ratio) are still poorly studied.

To fill-in this gap and to provide data of high practical importance in biological control programs, the present work was conducted measuring parasitic activity, fertility and offspring sex-ratio. First, we assessed the response of D. longicaudata to four types of fruits (apple, peach, clementines and navel oranges) at natural or medfly infested with an olfactometer. And in a second point, we conducted choice and no-choice assays using three fruits, (peach, clementine and orange) compared to apple, at two conditions (laboratory and semi-field), to confirm the olfactometer results.

\subsection{Material and Methods}

\subsubsection{Determination of abiotic factors influencing $D$. longicaudata parasitism activity over $\boldsymbol{C}$. capitata under semi-field conditions}

\section{Experimental area}

The trials were conducted in a lemon plot located in the experimental area of the IVIA (39॰35'22.6"N 0²3'41.0"W, Valencia, Spain).

\section{Insect rearing}

Ceratitis capitata and D. longicaudata were reared in climatic chambers at the IVIA research station, as indicated in the previous chapter. Rearing conditions were of $27 \pm 2^{\circ} \mathrm{C}, 65 \pm 10 \% \mathrm{RH}$ and 16:8 (L: D) for medfly; and of $22 \pm 2^{\circ} \mathrm{C} 65 \pm 10 \% \mathrm{RH}$ and 16:8 (L: D) for D. longicaudata (De Pedro et al. 2013; Harbi et al. 2015b). 


\section{Experimental protocol}

Twelve trials were conducted to cover the different climatic conditions in a year-round. The trial period was between May 2012 and June 2013. In each trial, 26 apples (var. "Royal Gala") were artificially infested with $2^{\text {nd }}$ to $3^{\text {rd }}$ instar C. capitata larvae (ten $8-9 \mathrm{~mm}$ diameter holes per fruit and three larvae per hole, in total 30 larvae per fruit), as described previously (Harbi et al. 2015a). Each infested apple was placed inside a ventilated plastic cylinder $(10 \times 28 \mathrm{~cm})$, on a vermiculite bed, provided with a water-supply $(50 \mathrm{ml})$ container and with honey as adult parasitoid food. Five D. longicaudata couples (five 6-days-old females and five 8-days-old males) were introduced into 20 experimental units; the remaining 6 were used as controls (no parasitoids) to assess natural medfly mortality. Experimental units were introduced into woodframed mesh cages and then placed under lemon trees (Figure 3.1).

Experimental units of each trial were kept in field conditions during seven days. After this week, experimental units were retrieved to the laboratory, parasitoids were discarded, and all medfly pupae were counted and collected. Collected pupae of each experimental unit (exposed batches and un-exposed ones) were transferred into $150 \mathrm{ml}$ ventilated plastic vials with some the vermiculite, as pupae protection. These vials were labeled with the corresponding code. Half of them, 10 of the exposed batches and 3 of the control, were kept at laboratory conditions $\left(25 \pm 2^{\circ} \mathrm{C}, 65 \pm 10 \% \mathrm{RH}, 16: 8 \mathrm{~h} \mathrm{~L}: \mathrm{D}\right)$ to ascertain parasitoid activity and to be used as inter-trial control. The other half, 10 of the exposed batches and 3 of the control, was retrieved to the wood-framed mesh cages under field conditions to determine the effect of climatic conditions on parasitism percentage (percentage of emerged parasitoids from total pupae recovered), offspring sex ratio (percentage of females from total emerged parasitoids), the induced mortality percentage (corrected mortality obtained from closed/dead pupae due to the activity of parasitoid as compared with controls) and the percentage of the population reduction (sum of parasitism percentage plus induced mortality, as representation of global decrease of medfly population).

The "corrected mortality" was calculated with Abbot's formula (Abbott, 1925):

Corrected mortality $(\%)=(($ Treatment mortality - Control mortality) / (100 - Control mortality)) $\times 100$ 
a)

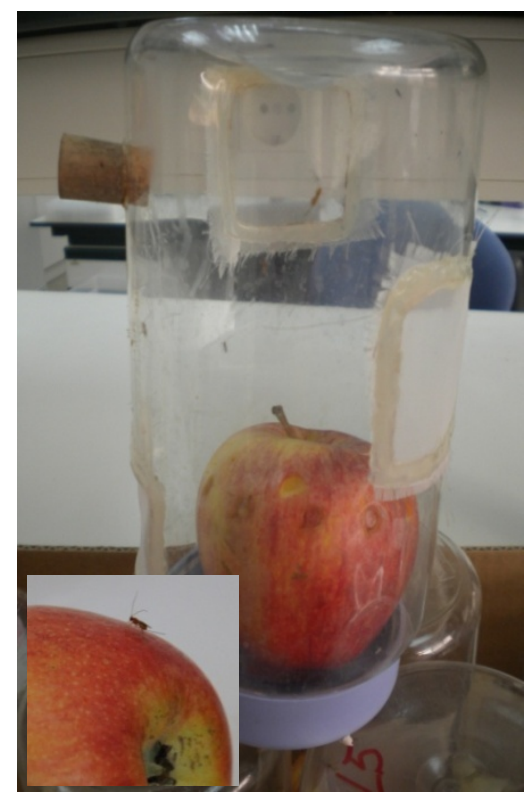

b)

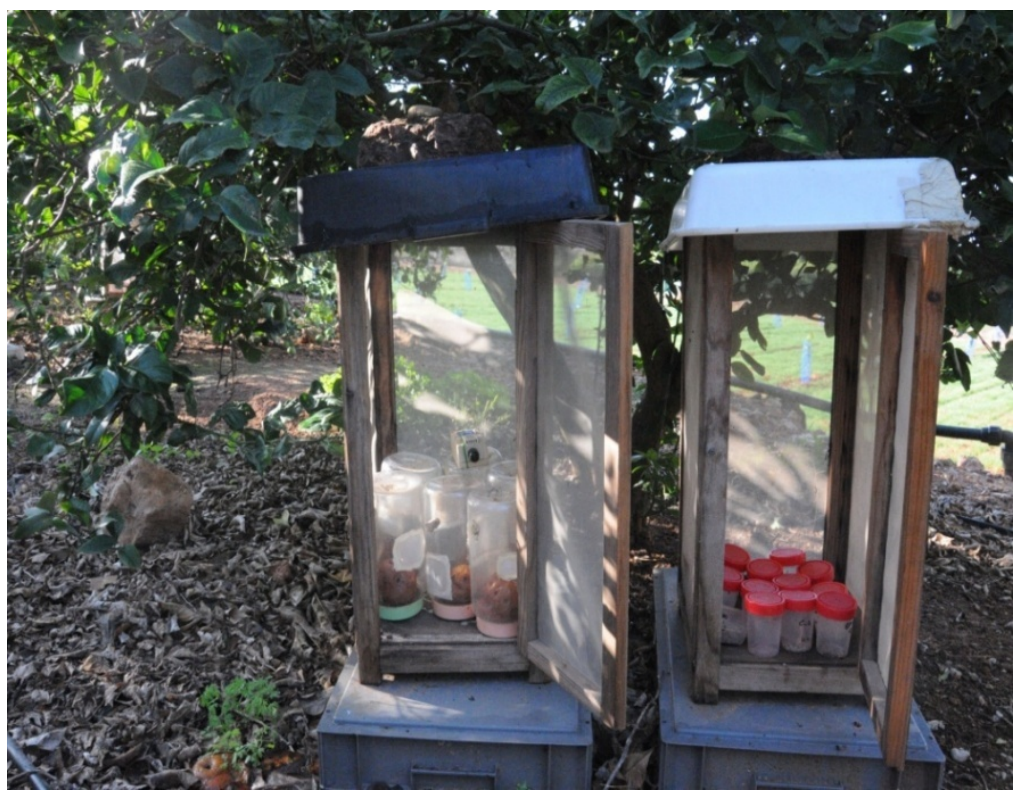

Figure 3.1. a) Experimental unit, b) experimental unit and parasitized pupae in the frame cage in the field.

\section{Climatic conditions}

Temperature and relative humidity were recorded by a data logger placed in one of the woodframed cages with the cylinders in the citrus plot; whereas other considered climatic conditions (wind speed, wind direction, rainfall, ...) were obtained from the IVIA climatic station (Figure $3.2)$.
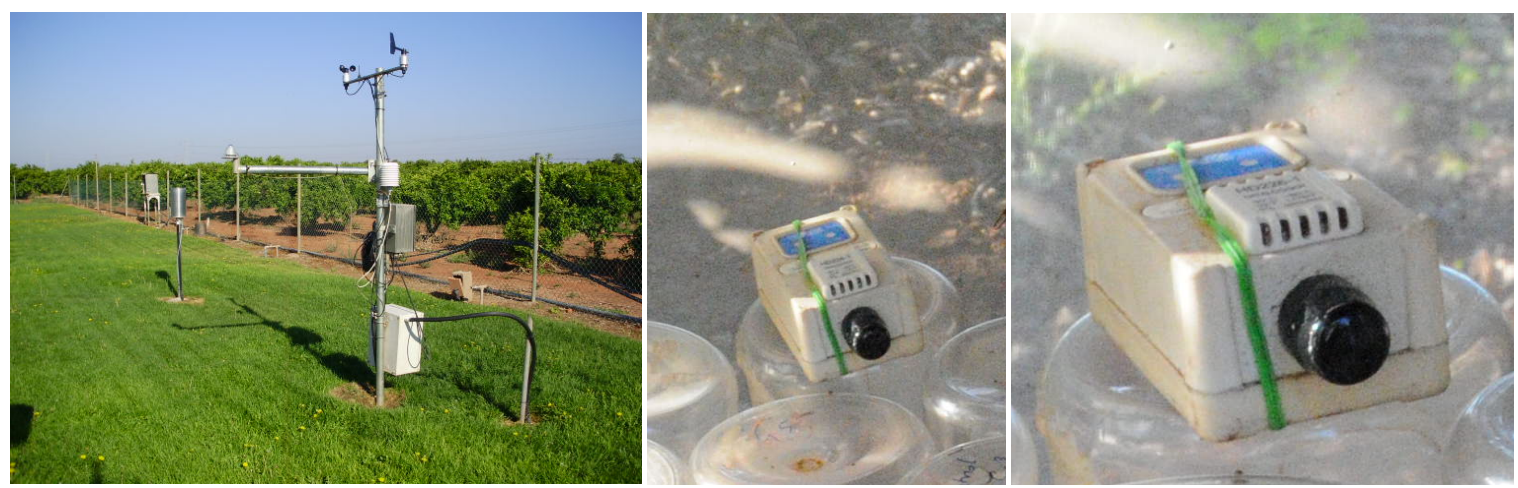

Figure 3.2. The climatic station at the IVIA research fields, and data logger used to record temperature and relative humidity inside the wood framed mesh cages used for the trials.

\section{Data analysis}

An analysis of variance (ANOVA) was realized to detect differences within tested variables (parasitism percentage, fertility, offspring sex ratio, and induced mortality or population 
reduction percentage) and among assays. A Fisher's LSD test was performed to identify those statistically different. The normality of values was always tested by the Shapiro Wilks test and the homocedasticity of the variance with the scatter plot. Analysis were realized with Infostat software (Di Rienzo et al, 2012).

A principal component analysis (PCA) (McGarigal 2000; Jackson 2003) was conducted to determine the environmental factors affecting the studied variables (parasitism percentage, fertility, offspring sex ratio, induced mortality or population reduction percentage), before obtaining a correlate regression model. The analysis was performed using the matrix of correlation, calculated from the average of the values obtained in each replication. The eigenvalues and proportions of explanation of variance were obtained for all major components, selected for analysis of the variables with the highest factor loading of components that helped explaining more than $10 \%$ of the total variance. The possible effect of these variables, their quadratic terms and interactions on the dependent variable was assessed through multiple linear regressions. The top models are simplified by backward elimination (manual backward stepwise selection). Factors and interactions with $\mathrm{p}<0.05$ were considered significant. Data for all variables were normally distributed. Analyses were performed using the statistical software XISTAT 2011 (Addinsoft).

\subsubsection{Determination of $\boldsymbol{D}$. longicaudata ability to control medfly focal points}

After determining in the previous sections that D. longicaudata responds to different host densities, it was necessary to determine its success in controlling medfly infestation focal points, as one of the putative targets of several inundative Biological Control programs. To achieve this objective, an assay resembling medfly focal points was conducted from June to September 2014, at the IVIA research station (when the highest populations of the Mediterranean fruit fly are usually trap-recorded in citrus orchards in the Mediterranean Region, mainly at the Valencian Community).

\section{Experimental area}

This assay was developed in a citrus orchard located at the IVIA research station $\left(39^{\circ} 35^{\prime} 22.6^{\prime \prime} \mathrm{N}\right.$ $0^{\circ} 23^{\prime} 41.0 " \mathrm{~W}$, Valencia, Spain). Selected trees (clementines var. Clemenules) were locked individually inside insect-proof cages (cages were $3 \times 3 \times 3 \mathrm{~m}$ with a zippered-door (1.5 $\mathrm{m}$ high) 
in one of the sides) (Figure 3.3). Clementine trees were drip-irrigated. Weeds and clementines (if any) were removed prior each assay.

\section{Insect rearing}

Ceratitis capitata and D. longicaudata, were reared in climatic chambers at the IVIA research station, as indicated previously. Climatic rearing conditions were of $27 \pm 2^{\circ} \mathrm{C}, 65 \pm 10 \% \mathrm{RH}$ and 16:8 h (L: D) for medfly; and of $22 \pm 2^{\circ} \mathrm{C} 65 \pm 10 \% \mathrm{RH}$ and 16:8 h (L: D) for D. longicaudata (De Pedro et al. 2013; Harbi et al. 2015b).

\section{Experimental procedure}

Each medfly focal point was simulated in each experimental arena with 1,050 L2-L3 larvae. As explained above, apples (var. Royal Gala) were artificially infested with 30 L2-L3 larvae (at a ratio of 3 larvae per $8-9 \mathrm{~mm}$ hole) per apple, meaning 35 infested apples per tree. Infested apples were distributed within plastic trays $(20 \times 20 \times 10 \mathrm{~cm})$ containing vermiculite to allow pupation. Plastic containers external surface was treated with Tanglefoot (BIAGRO SL., Valencia, Spain) as sticky coating trap for ants and other medfly pupae predators that could not be removed from the experimental arena (Figure 3.3).

In each experimental arena of each trial, 250 D. longicaudata couples (6-8 days-old), meaning a ratio of 1:4.2 (D. longicaudata female: medfly larvae), were released and allowed to forage on provided medfly larvae during 7 days. After this exposition period, trays were retrieved to the laboratory, pupae counted, collected and transferred to several $150 \mathrm{ml}$ ventilated plastic vials (as those previously used for pupae development). Exposed collected pupae were allowed to develop at laboratory conditions $\left(24 \pm 2^{\circ} \mathrm{C} 65 \pm 10 \% \mathrm{RH}\right.$ and 16:8 (L: D)). After one month, emerged parasitoids, medflies and uneclosed pupae were counted, and used to determine parasitism percentage (percentage of parasitoids from total collected pupae), mortality (percentage of uneclosed pupae from total collected pupae) and medfly population reduction (sum of previous percentages).

Each trial consisted in one experimental arena (plus D. longicaudata), and a control experimental arena (no parasitoids) to determine natural medfly mortality. A total of 7 trials were conducted in alternate weeks from June to September 2014. 


\section{Climatic conditions}

Temperature and relative humidity were recorded using a data-logger inside the cages (the same used in the precedent section; Figure 3.2), and/or the data from the climatic station at the IVIA research fields.

a)

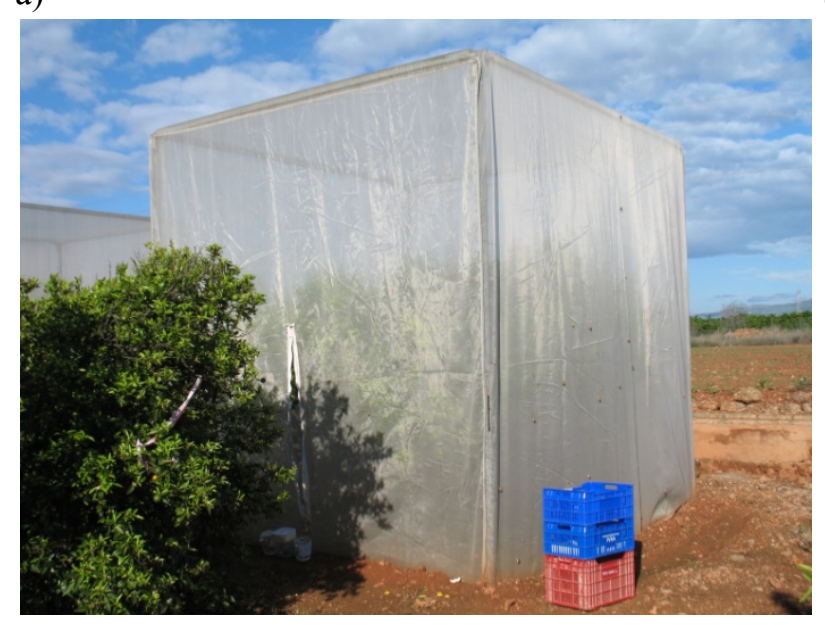

c)

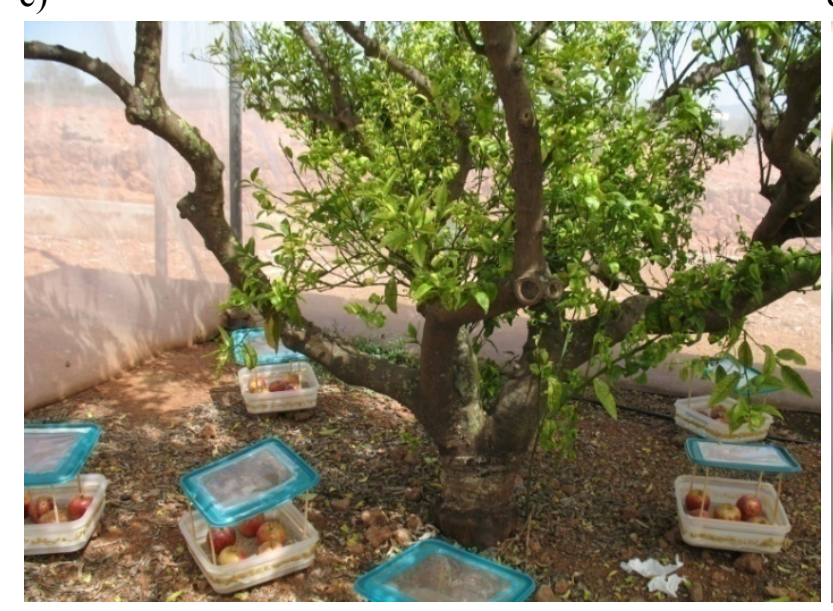

b)

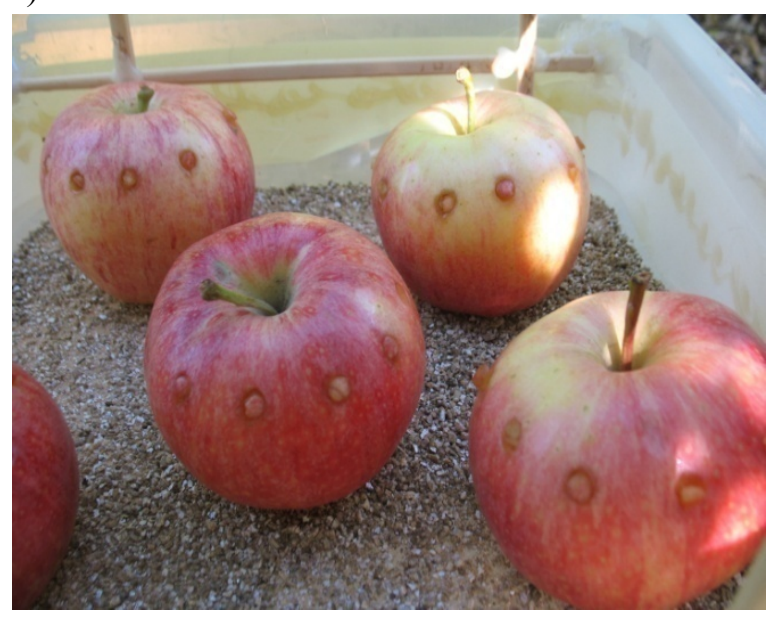

d)

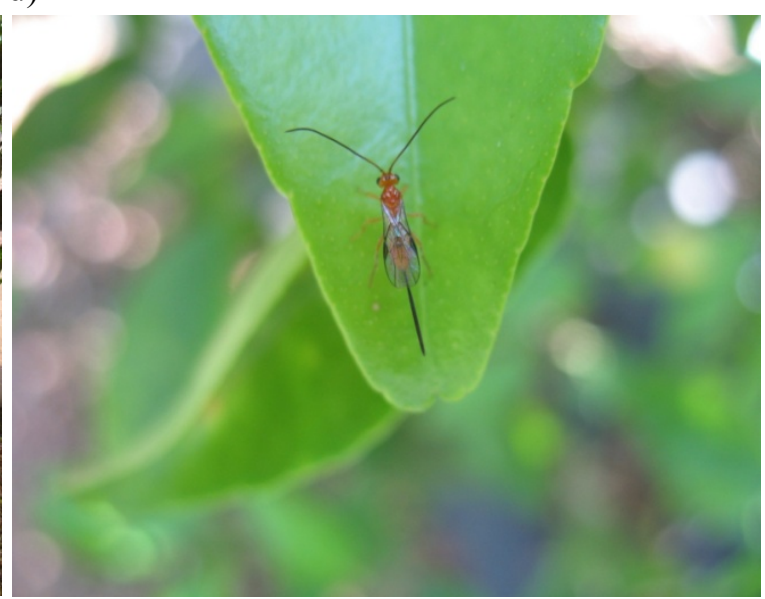

Figure 3.3. Experimental design for the medfly focal point control assays. a) One of the caged clementine (var. Clemenules) tree used; b) C. capitata artificially infested apples; c) experimental installation and d) released D. longicaudata on the caged tree. 


\subsubsection{Effect of $C$. capitata host fruit on the behavior of $D$. longicaudata: from chemical ecology to biological control}

This section was conducted to determine the influence of biotic factors on D. longicaudata foraging behavior, as indicated in the introduction of the chapter.

\subsubsection{Olfactory response trials}

To assess the olfactory response of $D$. longicaudata to infested and non-infested fruits, a series of olfactory essays were performed using an olfactometer. The olfactometer, an instrument to measure the odor sensitivity of insects, is formed by different pieces, being the most important the central Y-shaped glass tube (Figure 3.4).

The olfactometer used had a Y-shaped glass tube (Analytical Research Systems, Gainesville, FL) which main piece was of $2.4 \mathrm{~cm}$ in diameter and $13.5 \mathrm{~cm}$ long whereas the two arms were of $5.75 \mathrm{~cm}$ long. The Y-tube was connected to an air pump generating a unidirectional airflow running from the arms to the base of the $\mathrm{Y}$-tube at $150 \mathrm{~mL} / \mathrm{min}$. The arms of the olfactometer were connected via plastic tubes to two identical glass jars ( $5 \mathrm{~L}$ of volume), each of which contained the odor source. Four 60-cm-long fluorescent tubes (OSRAM, L18 W/765, OSRAM $\mathrm{GmbH}$, Germany) were positioned at $40 \mathrm{~cm}$ height above the olfactometer providing a light intensity of 2.516 lux throughout the experimental arena (measured with a ceptometer LP-80 AccuPAR, Decagon Devices, Inc. Pullman, WA). The environmental conditions were $23 \pm 2{ }^{\circ} \mathrm{C}$, $60 \pm 10 \%$ RH.

In a first series of Y-tube experiments and with the goal of determining the impact of the presence of the medfly larvae in the fruits, we tested the response of $D$. longicaudata females to the presence of one and four-day C. capitata infested apple fruits (artificially infested as indicated previously) against non-infested ones. In a second step, to assess the influence of the age of the infestation by C. capitata on the D. longicaudata females foraging choice, we assessed their olfactory response to the presence of one day infested oranges against four day infested ones. We finally compared the olfactory responses of D. longicaudata females to the presence of infested apple, peach and clementine fruits in all possible combinations. 
a)

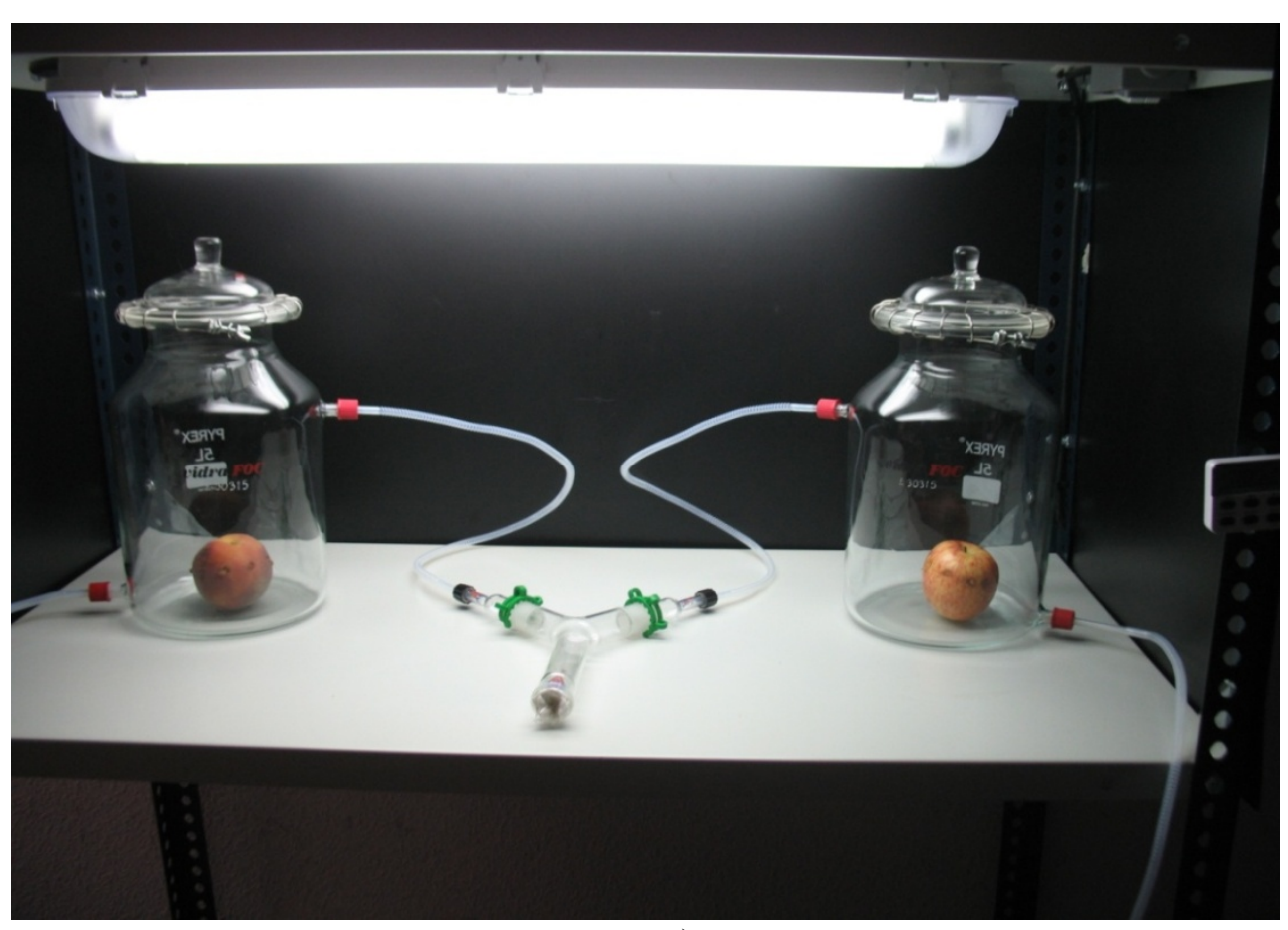

b)

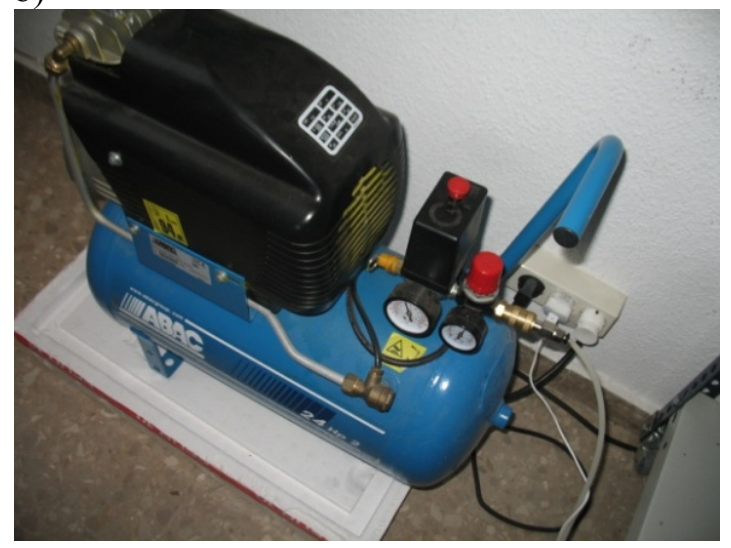

d)
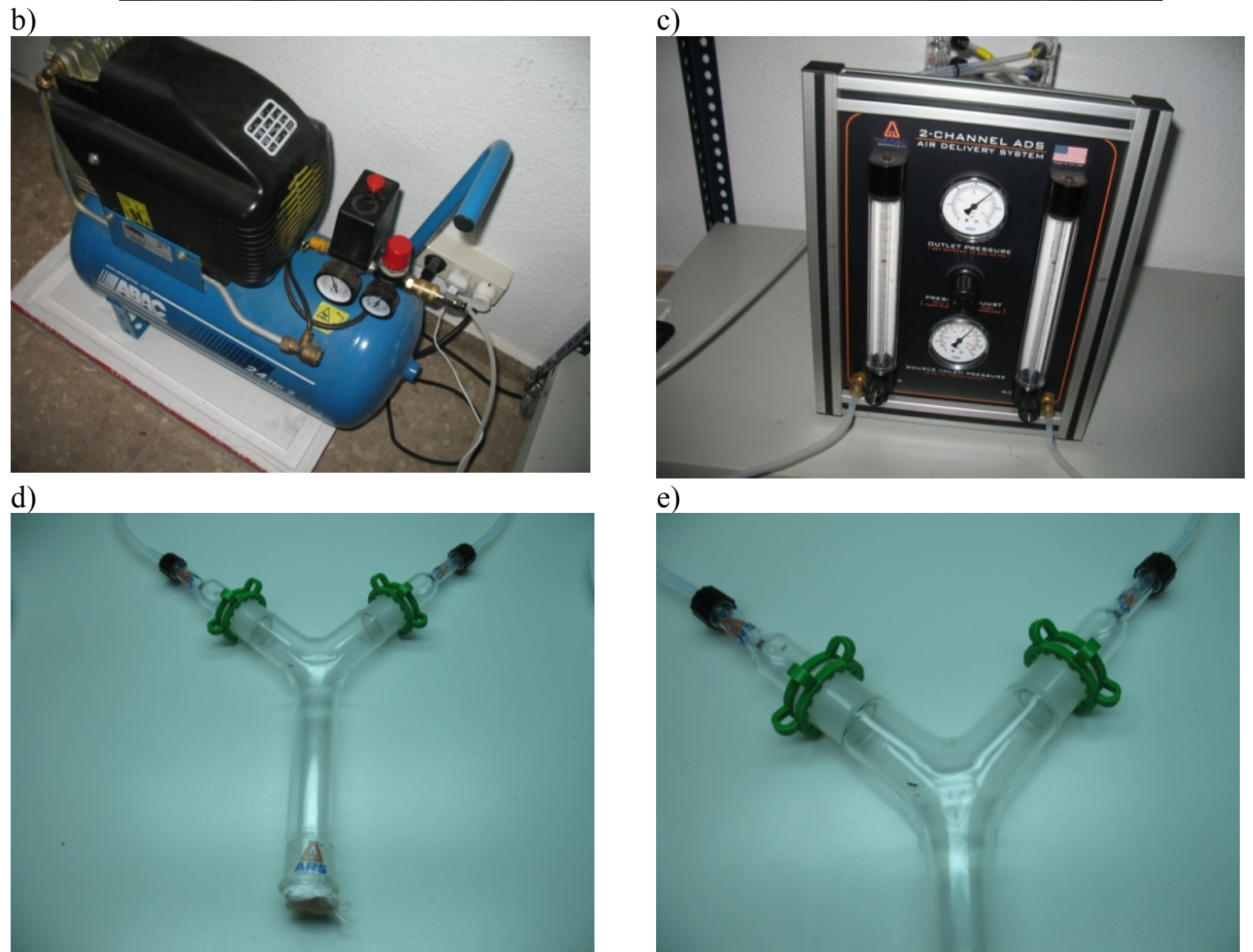

e)

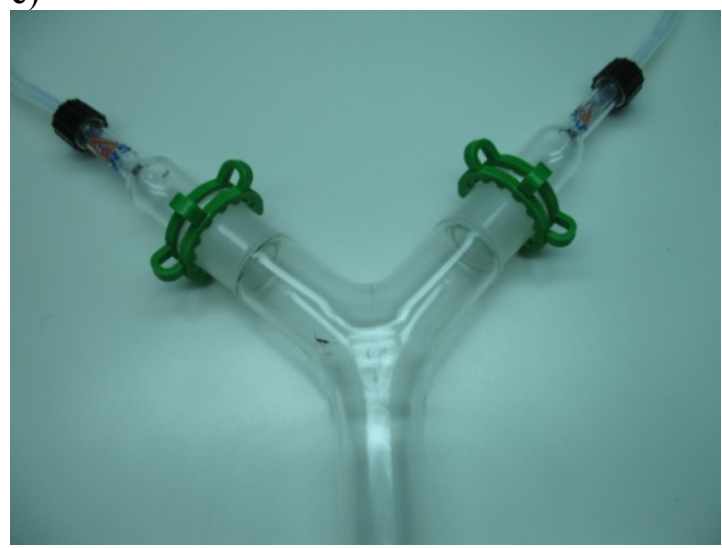

Figure 3.4. Olfactometer device set up at the IVIA research station. a) Dark room and illumination over the olfactometer; b) and c) compressed air pump and manometer; d) and e) detail of Y-shaped tube. 
For all these olfactory essays, we used coetaneous 6 to 8-days-old D. longicaudata females. These females were first individually isolated in $10 \mathrm{~mL}$ plastic tubes, left for at least two hours at the olfactometer room to adapt to assay conditions. After this acclimatation time, each female was tested independently, by placing her on the base of the Y-tube using a soft paint brush, and then become observed, until she had walked at least $3 \mathrm{~cm}$ up one of the arms or until $15 \mathrm{~min}$ had elapsed (McGregor and Gillespie 2004). Females who had not made a choice within these 15 min were considered as 'non-responders', being discarded in the subsequent analysis. This procedure was repeated until recording 30 positive responses for each pair of odor sources. As part of the experimental setup, when five females had been tested, the olfactometer arms were flipped around $\left(180^{\circ}\right)$ to minimize spatial effect on choices. When ten females had been bioassayed, the olfactometer set-up was rinsed with soap, water and acetone and then air-dried, before continuing with the next 10 females.

\subsubsection{Host fruit influence on parasitism activity: Laboratory trials}

Dichasmimorpha longicaudata fitness trials were performed in a climatic chamber (in-house built, with normal conditions $25 \pm 2^{\circ} \mathrm{C}, 60 \pm 10 \% \mathrm{RH}$ and $\left.16: 8 \mathrm{~h} \mathrm{~L}: \mathrm{D}\right)$. The assessment was based on parasitism percentage, fertility of females and the sex ration of offspring, in dual choice and no-choice assays with different fruit host for medfly (apple, clementines and peaches).

Fruits were artificially infested, as indicated previously, with 30 L2-L3 C. capitata. Each infested fruit was isolated in a $200 \mathrm{ml}$ plastic cup containing a thin layer of vermiculite (as pupating substrate). Each experimental unit was formed by 3 or 6 isolated-infested fruits deposited in a ventilated clear plastic box $(20 \times 20 \times 40 \mathrm{~cm})$ for no-choice or dual choice respectively. This experimental unit was replicated 15 times for each fruit or fruit combination obtaining a total of 45 fruits for no-choice and 90 fruits for dual choice assay (Figure 3.5).

In each experimental unit, three coetaneous 6 to 8-days-old D. longicaudata couples were released and allowed to parasitize medfly larvae during 7 days. After this exposition period, experimental units were retrieved to the lab, and all pupae were counted and isolated in ventilated $150 \mathrm{ml}$ vials. Collected pupae were allowed to develop under controlled conditions until the emergence of parasitoids and/or medflies. Emerged parasitoid adults were counted, sexed and assigned to the corresponding species to account for fertility, parasitism percentage and sex ratio. 
a)

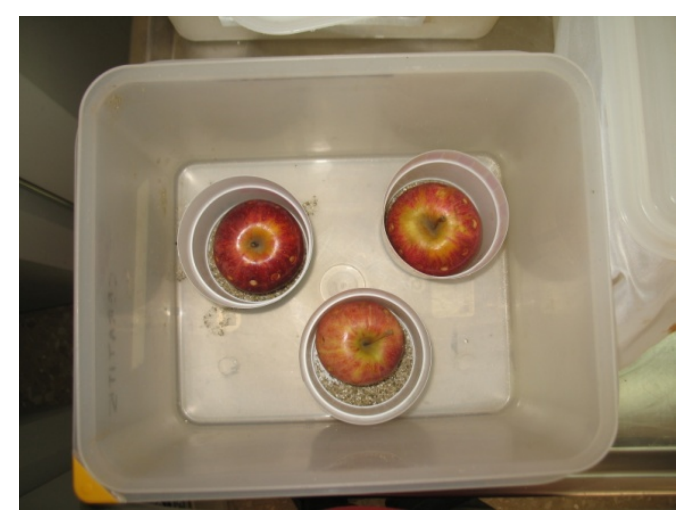

c)

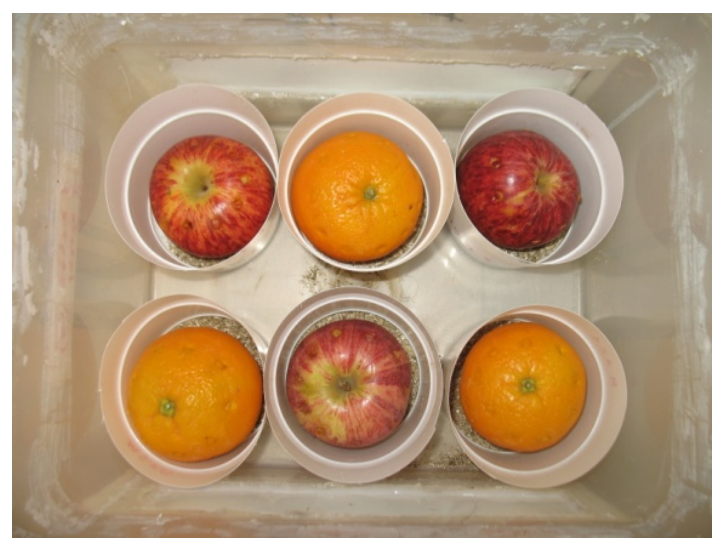

e)

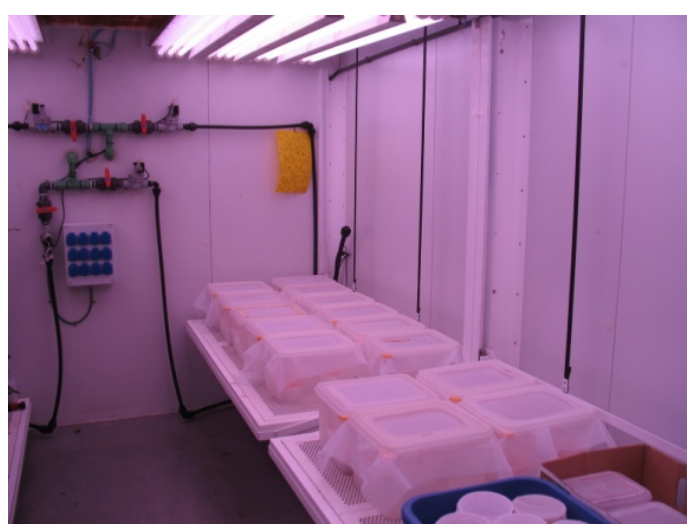

b)

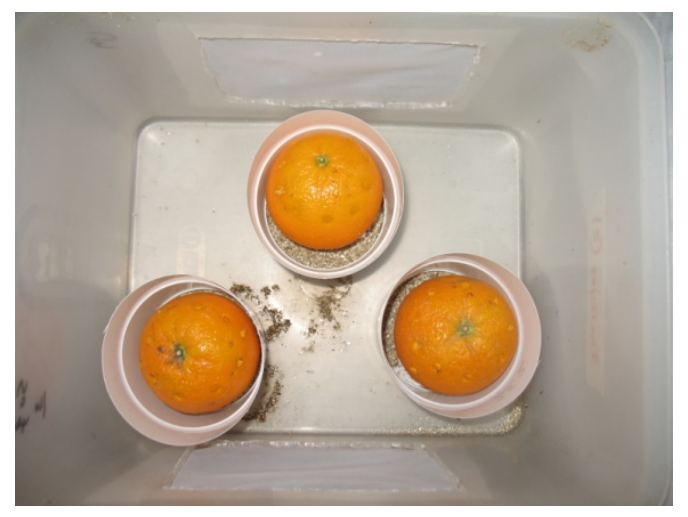

d)

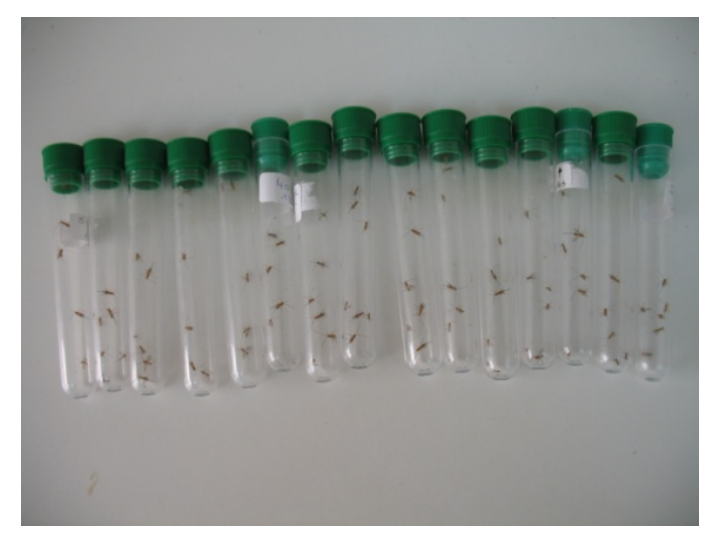

f)

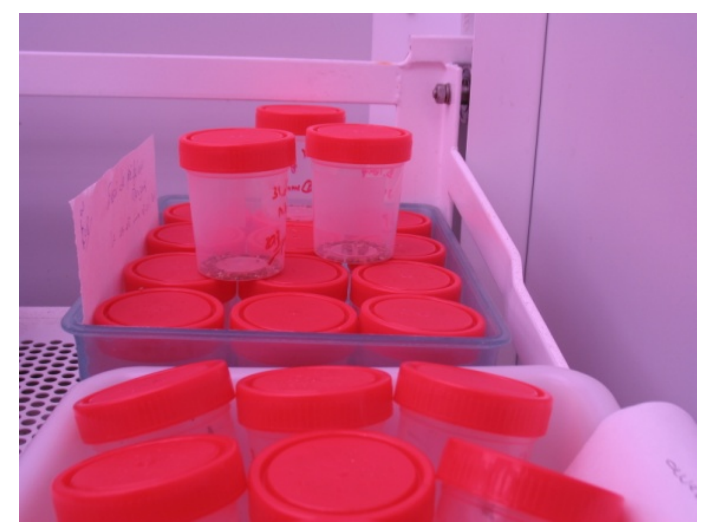

Figure 3.5. Setup for fruit host cues as biotic factor affecting D. longicaudata parasitism. a) and b) nochoice experimental units containing Royal gala apples or clementines; c) dual-choice experimental unit with Royal gala apples and clementines; d) isolated 6 to 8-d-old D. longicaudata couples ready for release; e) view of climatic chamber with one assay; f) recovered pupae isolated in $150 \mathrm{ml}$ ventilated vials for adult emergence. 


\subsubsection{Host fruit influence on parasitism activity: Semi-field trials}

As above mentioned, D. longicaudata performance was tested in dual-choice assays, with three fruits varieties (Royal gala apples, clementines and nectarines) as medfly hosts (fruits were artificial infested as described previously with 30 L2-L3 medfly larvae). Here, we would like to test also the importance of bigger spaces and semi-natural conditions on parasitism activity. The essays were realized in a greenhouse to simulate natural conditions offering larger space and distance between parasitoids and hosts as well as a higher number of infested fruits. The experimental unit consisted of $2 \times 1.5 \times 4$ m cabinet containing two transparent top-open boxes $(40 \times 40 \times 40 \mathrm{~cm})$, each with one fruit species (Figure 3.6). Each box contained 9 medfly-infested fruits deposited on a thin layer of vermiculite. Three coetaneous 6 to 8 -day old D. longicaudata couples were released in each experimental unit and left to parasitize for one week. After this exposition period, experimental units were retrieved to the lab, and all pupae were counted and isolated in ventilated $150 \mathrm{ml}$ vials. Collected pupae were allowed to develop under controlled conditions until the emergence of parasitoids and/or medflies. Emerged adults were counted, sexed and assigned to the corresponding species to account for fertility, parasitism percentage and sex ratio. Each dual-choice assay was tested four times.

\section{Data analysis}

Chi squared goodness of fit test $\left(\chi^{2}\right)$ was used to test the hypothesis that the distribution of sidearm choices between pairs of odors affected the olfactory responses in the experiments. For the laboratory and the greenhouse trials, a pair-wise comparison $t$ test was performed to compare the parasitism percentage, the fertility and the sex-ratio produced by D. longicaudata in the different combination of tested fruits. Statistical analyses were performed using the Graphpad software (Graphpad Prism5 2007). 
a)

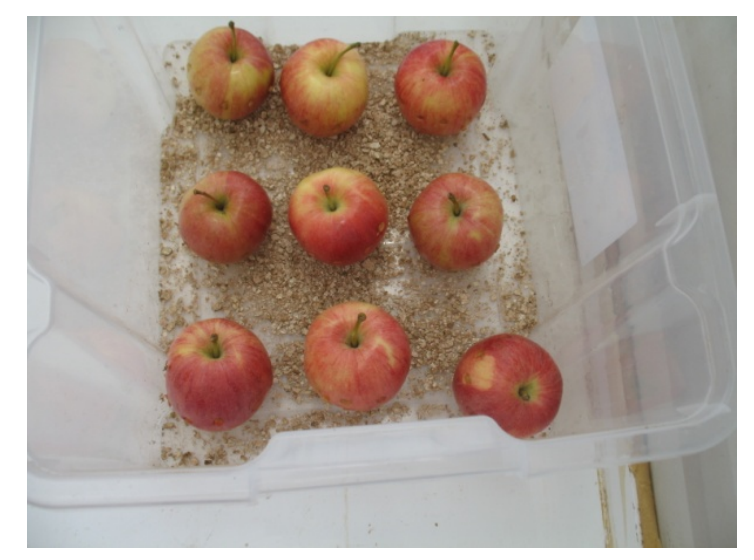

c)

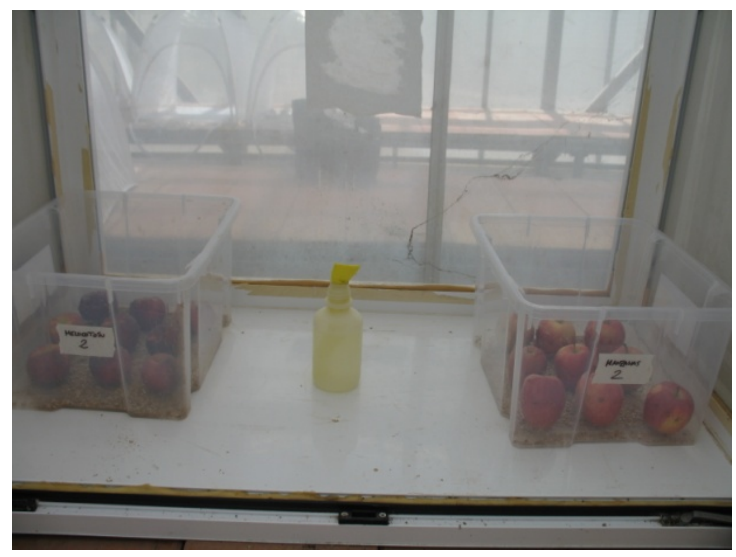

b)

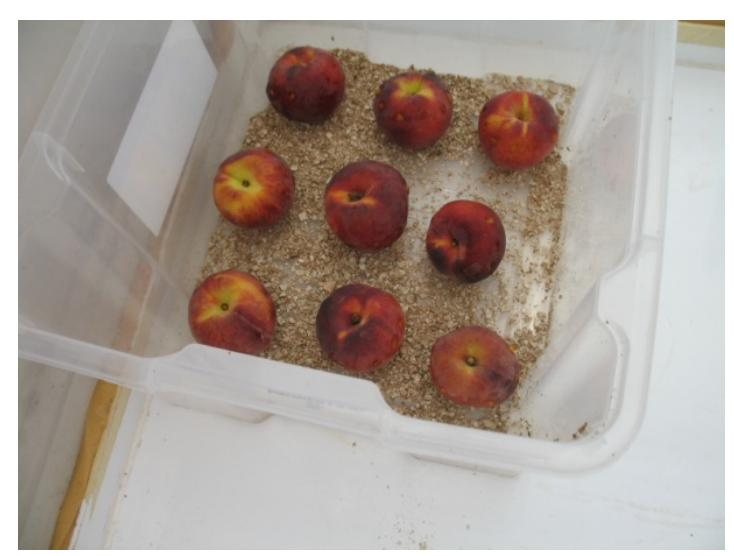

d)

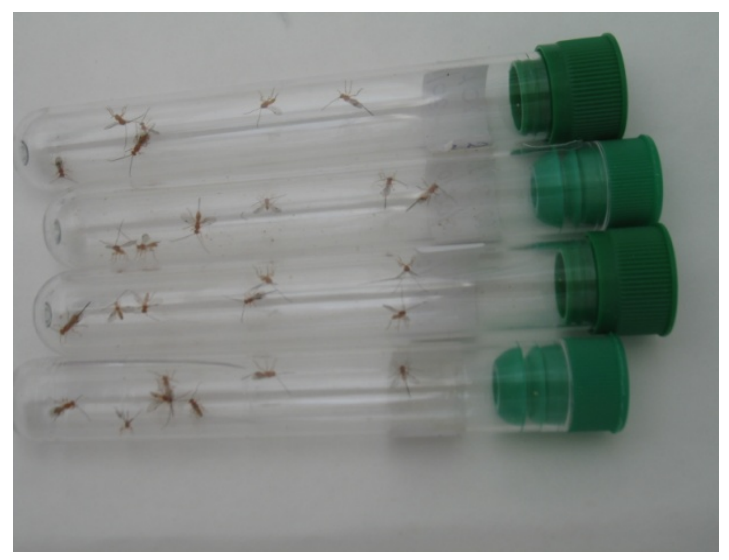

e)

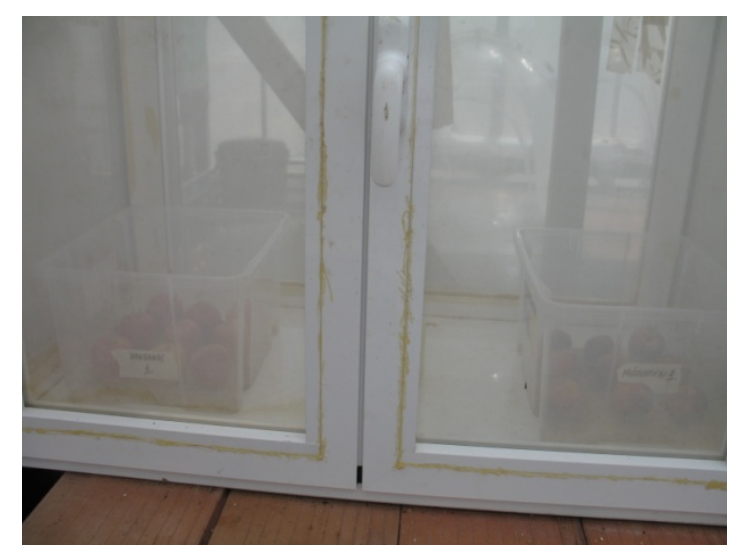

Figure 3.6. Setup for fruit host cues as biotic factor affecting D. longicaudata parasitism under semifield trials. a) and b) top view of inside of experimental units containing medfly infested Royal gala apples or nectarines; c) lateral view of the cabinet; d) isolated 6 to 8-d-old D. longicaudata couples ready for release; e) view of closed experimental unit with one assay. 


\subsection{Results and Discussion}

\subsubsection{Determination of abiotic factors influencing $D$. longicaudata parasitism activity over $C$. capitata under semi-field conditions}

Here I present the results obtained for each variable tested (parasitism percentage, induced mortality, fertility, offspring sex ratio, and medfly population reduction), and its relationships with climatic variables, thanks to the comparison of field with field-laboratory series.

Parasitism percentage in field series varied significantly along the months, from almost zero (mainly during cold periods) to a maximum of $41 \%$ ( $F=16.57$; $d f=11,119 ; P<0.0001)$ (Figure 3.7). Whereas in the field-lab series parasitism percentage fluctuated from a minimum of $12 \%$ to a maximum of $65 \%$ presenting statistical differences between the different trials ( $F=12.82$; $d f=11,119 ; P<0.0001$ ) (Figure 3.8).

The comparison of the parasitism percentage produced by $D$. longicaudata between the two series (field versus field-lab) demonstrated that climatic conditions affected preimaginal development of the parasitoid. As parasitoids were allowed to exert parasitism to the same cohort of medfly larvae, and all the parasitoid in each series come from the same cohort (see material and methods section for further clarifications). The significant differences were recorded on August $2012(F=53.77 ; d f=1,19 ; P \leq 0.0001)$, October $2012(F=8.91 ; d f=1,19$; $P=0.007)$, November $2012(F=306.1 ; d f=1,19 ; P \leq 0.0001)$, December $2012(F=10.32 ; d f=1$, 19; $P=0.004)$ and February $2013(F=17.17 ; d f=1,19 ; P=0.0006)$, which match with the coldest trials (Figure 3.9).

Induced mortality was accounted from uneclosed pupa, as explained in material and methods, taking into consideration medfly natural mortality. To be sure, we dissected some batches and observed that, as expected, many of these uneclosed pupa contained parasitoid immature stages like pharate parasitoids individuals (Figure 3.10).

Induced medfly mortality in field series ranged from $5.9 \%$ to $80.58 \%$, being significantly different between trials $(F=13.51 ; d f=11,119 ; P<0.0001)$ (Figure 3.11). 


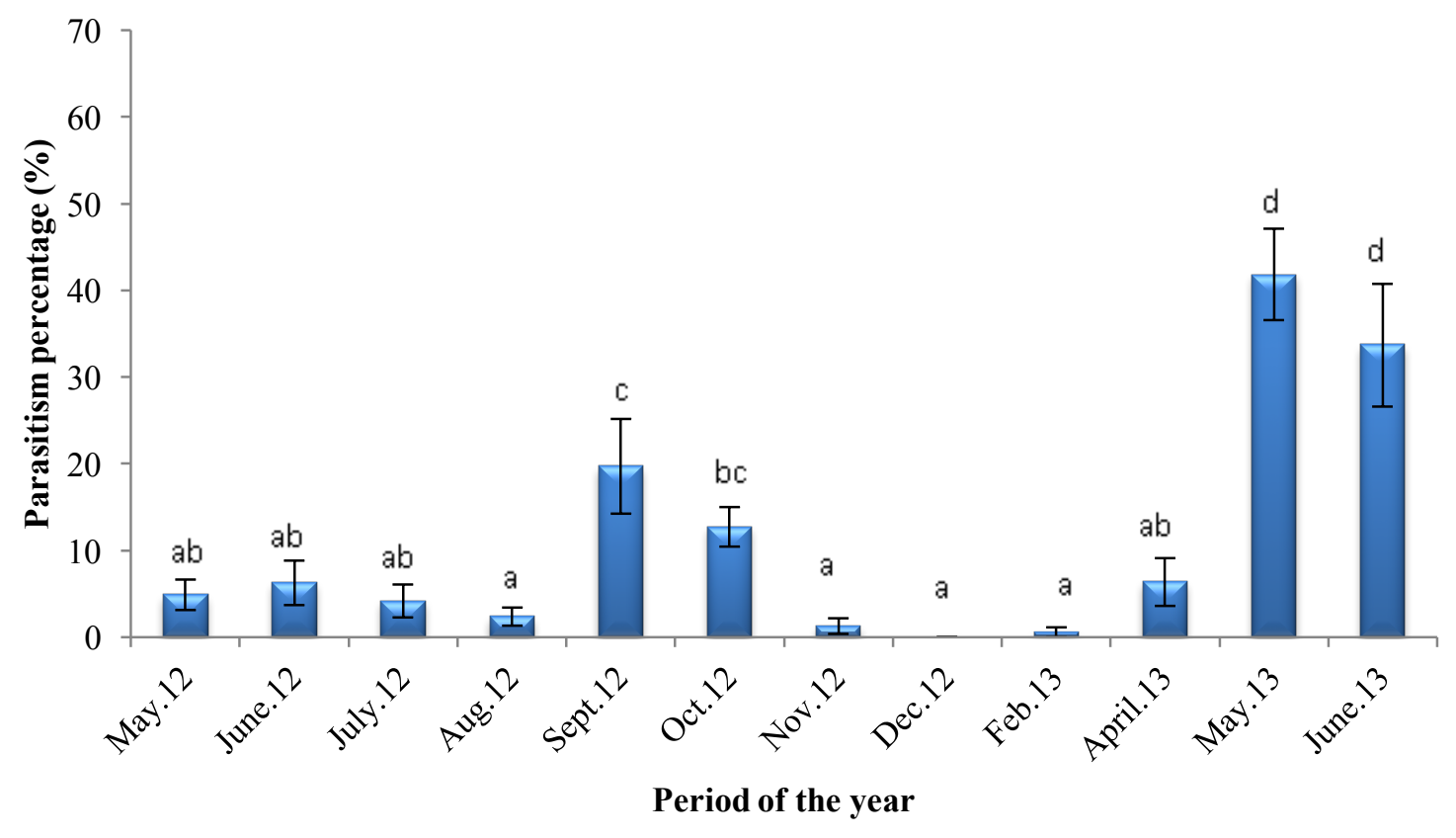

Figure 3.7. Parasitism percentage $\%$ (mean $\pm \mathrm{SE}$ ) induced by $D$. longicaudata on $C$. capitata infested fruits subjected to field climatic conditions along a year-round assay. Different letters above the bars indicate statistical differences among means.

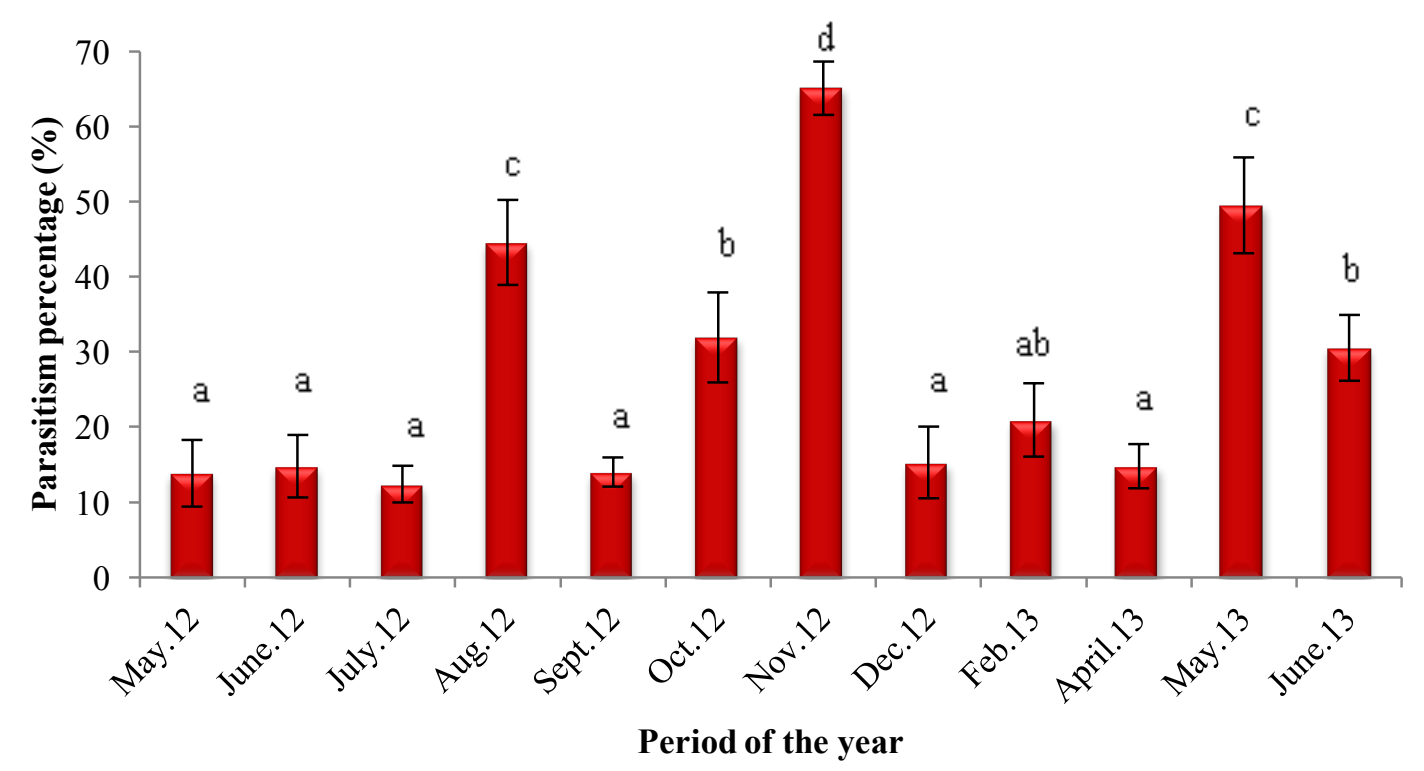

Figure 3.8. Parasitism percentage $\%$ (mean $\pm \mathrm{SE}$ ) induced by $D$. longicaudata on $C$. capitata infested fruits subjected to field climatic conditions along a year-round assay and transferred to laboratory to avoid parasitoid immature death (field-lab series). Different letters above the bars indicate statistical differences among means. 


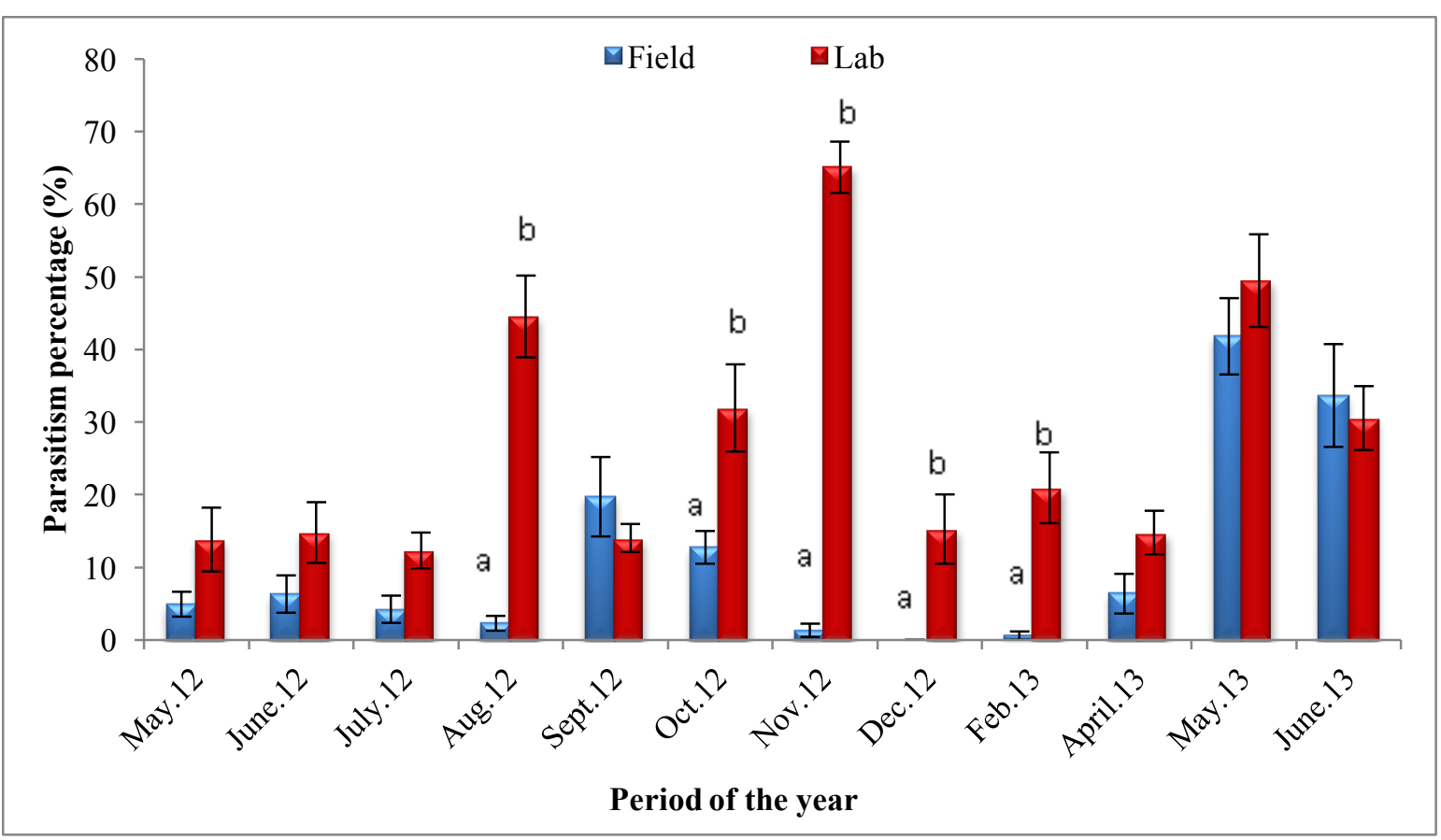

Figure 3.9. Comparision of parasitism percentage \% (mean $\pm \mathrm{SE}$ ) induced by $D$. longicaudata on $C$. capitata infested fruits subjected to field climatic conditions along a year-round assay or transferred to laboratory to avoid parasitoid immature death. Different letters indicate above the bars indicate statistical differences $(\mathrm{P}<0.05)$ among each pair of values on the same month.

a)

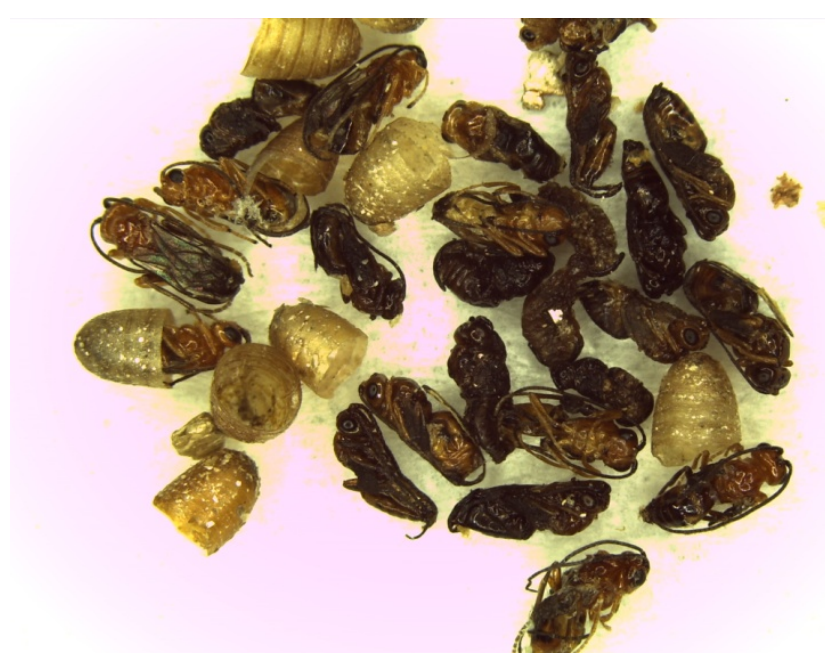

b)

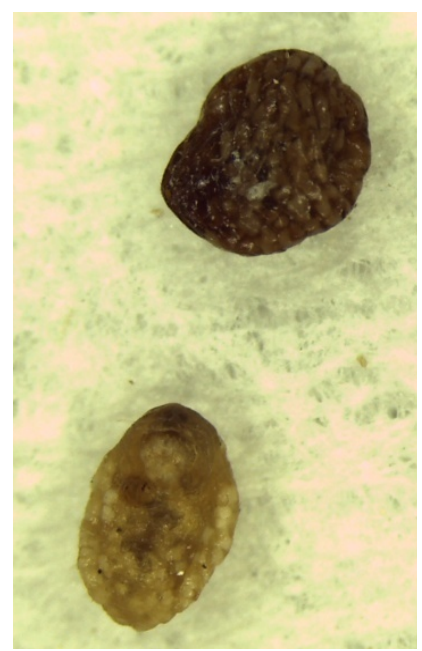

Figure 3.10. Identification of specimens from dissected uneclosed medfly pupae subjected to parasitism by $D$. longicaudata. a) visualization of non-emerged $D$. longicaudata pharate adults; and b) some $D$. longicaudata late third instar larva or early pupa observed in dissected uneclosed pupae. 


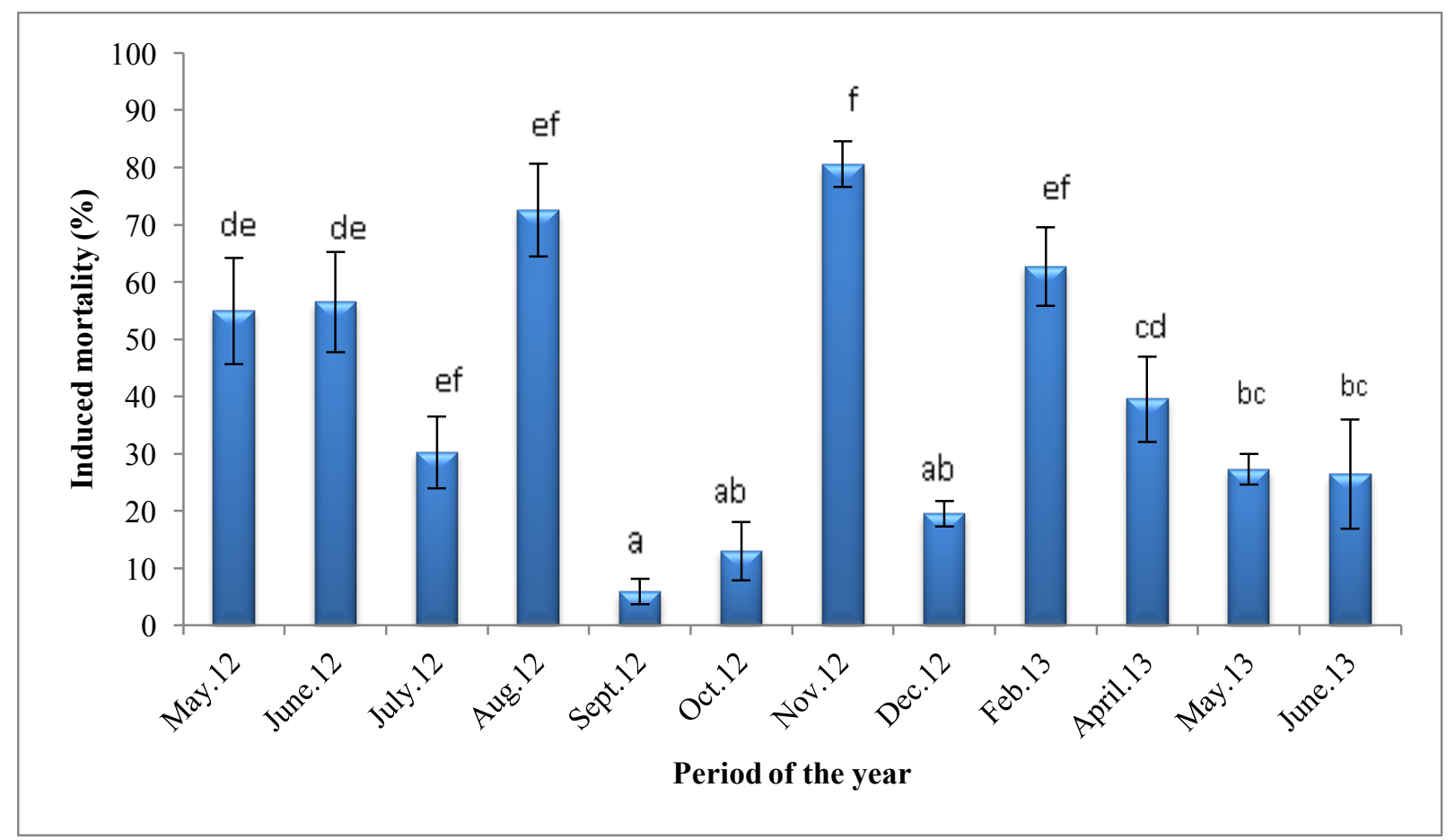

Figure 3.11. Induced mortality $\%$ (mean $\pm \mathrm{SE}$ ) by $D$. longicaudata on $C$. capitata infested fruits subjected to field climatic conditions along a year-round assay. Different letters above the bars indicate statistical differences $(\mathrm{P}<0.05)$ among means of each trial.

Setting side-by-side both datasets, we can observe that the induced mortality was high when the parasitism was low and vice versa (Figure 3.12). It can be a complementary action of the parasitoid or meaning a higher parasitoid immature mortality percentage. Despite this, it means that the parasitoid D. longicaudata was active during all the year, contributing to the reduction of medfly population, which varied from 20 to $81 \%$ (Figure 3.13 ). 


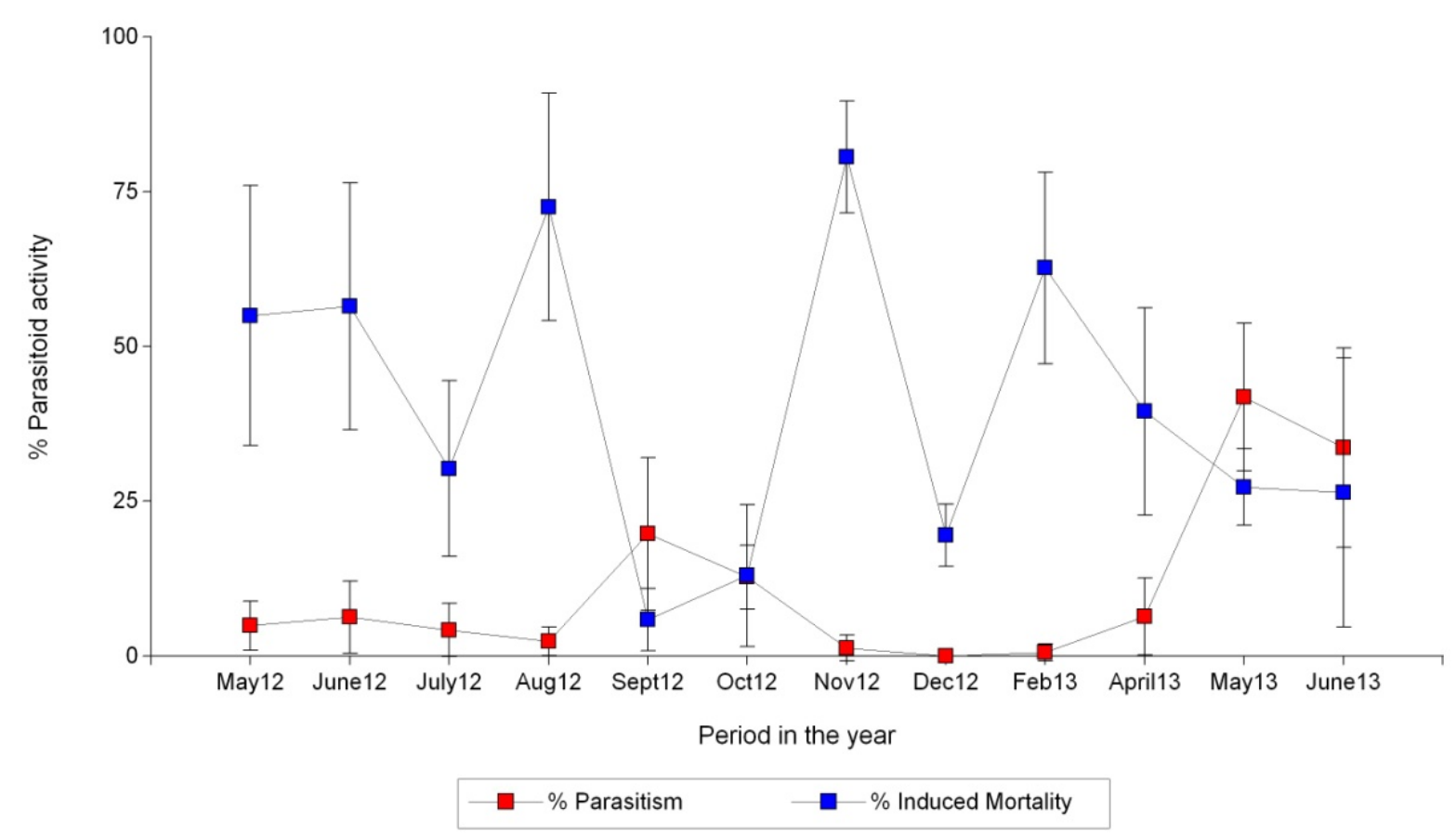

Figure 3.12. Variation of parasitism activity $\%$ (mean \pm SE) and mean induced mortality $\%$ (means \pm SE) of D. longicaudata on C. capitata infested fruits subjected to field climatic conditions along a yearround assay.

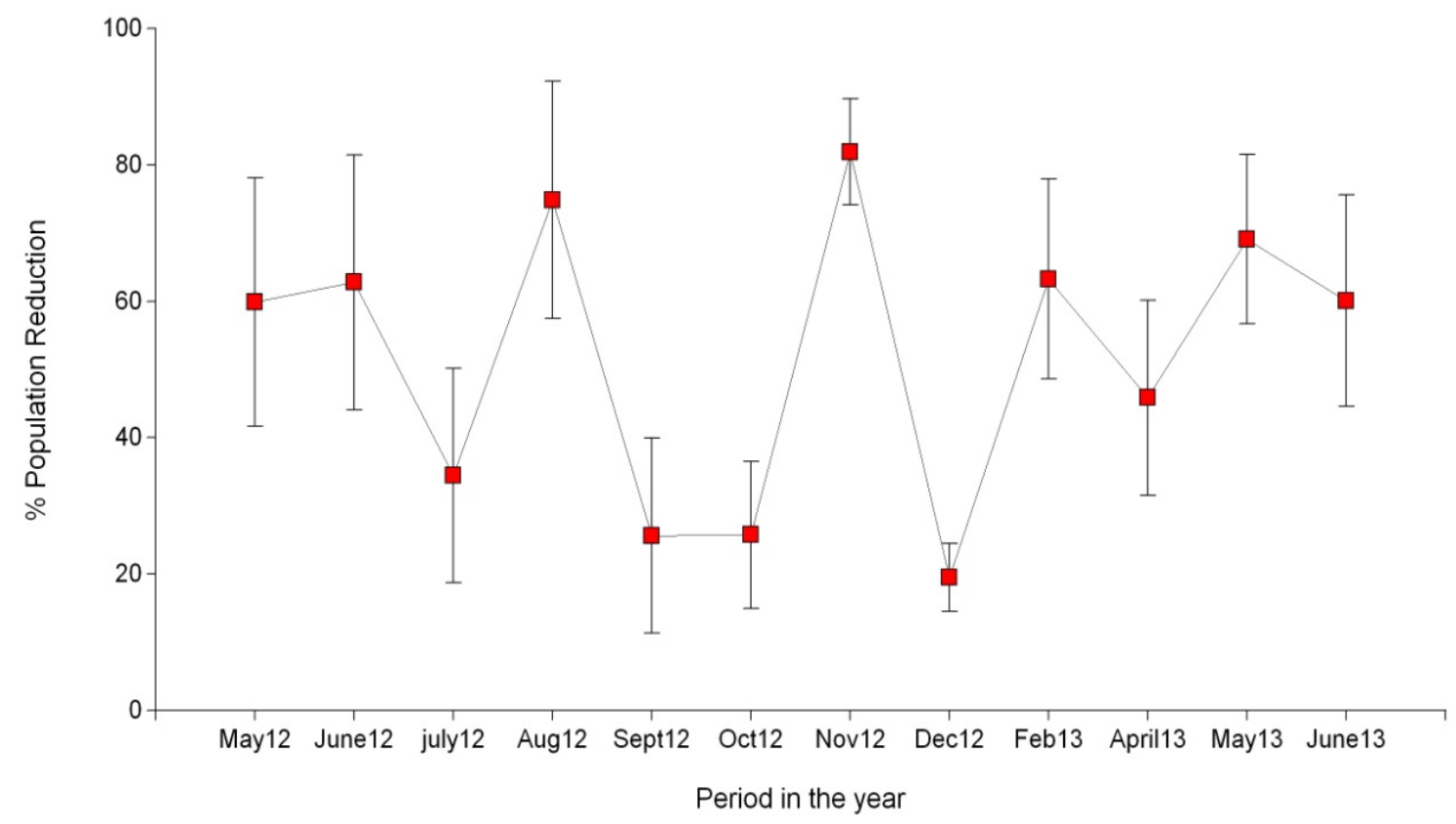

Figure 3.13. Medfly population reduction $\%$ (mean \pm SE) by the activity of $D$. longicaudata along a year-round assay under Mediterranean natural conditions. 
Despite these positive results, parasitism percentage was low. We considered that the real parasitism produced by $D$. longicaudata was higher than that obtained in our experiment. Thanks to the field-laboratory series (those series transferred to the lab to avoid harsh conditions) we could estimate the real parasitism percentage in the different periods of the year, highlighting that parasitoid immature stages are the most sensitive stage to climatic conditions. To ascertain correlation between biological and abiotic factors, we obtained climatic conditions for parasitoid exposition time (one week) and for parasitoid immature development (one month), as indicated at material and methods section with a data logger inside experimental units, or with the IVIA climatic station, situated 500 meters awau from the study plot.

Temperatures oscillated between 7 and $35.5^{\circ} \mathrm{C}$, whereas relative humidity (RH) oscillated between 24 and 98\% (averaged values of minimal and maximum temperature). Climatic data for exposition time is presented in Table 3.1 and 3.2 shows climatic data for the whole experiment (exposition time plus immature development).

Table 3.1. Climatic conditions recorded during the parasitoid exposition period.

\begin{tabular}{|c|c|c|c|c|c|c|c|c|c|c|c|c|}
\hline \multirow[b]{2}{*}{ Trial } & \multicolumn{4}{|c|}{ Temperature $\left({ }^{\circ} \mathrm{C}\right)$} & \multirow[b]{2}{*}{ 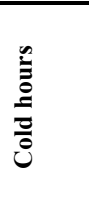 } & \multicolumn{4}{|c|}{ Relative Humidity (\%) } & \multirow[b]{2}{*}{ 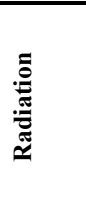 } & \multirow[b]{2}{*}{ 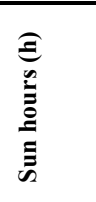 } & \multirow{2}{*}{ 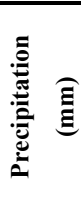 } \\
\hline & $\stackrel{\Xi}{\Sigma}^{\tilde{E}}$ & 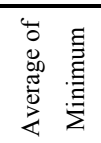 & 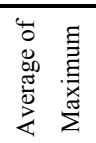 & 己 & & $\sum_{\Sigma}^{\bar{\Xi}}$ & 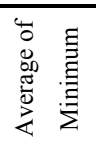 & 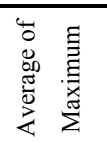 & 己 & & & \\
\hline May 2012 & 23.96 & 15.07 & 33.64 & 28.82 & 0.00 & 55.44 & 31.89 & 82.90 & 39.13 & 29.37 & 13.08 & 0.03 \\
\hline June 2012 & 25.54 & 19.13 & 32.89 & 20.23 & 0.00 & 68.93 & 34.87 & 96.87 & 33.62 & 27.87 & 13.09 & 0.00 \\
\hline July 2012 & 27.24 & 18.83 & 35.99 & 25.18 & 0.00 & 58.67 & 31.50 & 90.13 & 43.88 & 29.46 & 13.42 & 0.00 \\
\hline August 2012 & 26.87 & 20.01 & 34.00 & 19.71 & 0.00 & 75.62 & 44.17 & 99.31 & 29.63 & 28.38 & 13.08 & 0.00 \\
\hline September 2012 & 24.30 & 20.18 & 30.13 & 14.70 & 0.00 & 86.93 & 73.17 & 95.93 & 25.49 & 15.93 & 10.19 & 1.31 \\
\hline Octob & 21.62 & 15.20 & 30.62 & 25.35 & 0.00 & 74.54 & 58.28 & 94.14 & 23.11 & 15.70 & 9.88 & 0.03 \\
\hline November 2012 & 16.89 & 12.24 & 22.41 & 21.75 & 0.00 & 73.79 & 47.99 & 94.53 & 29.31 & 9.26 & 6.79 & 0.20 \\
\hline December 2012 & 13.92 & 10.44 & 18.84 & 24.48 & 9.50 & 92.36 & 72.34 & 100.00 & 16.60 & 6.37 & 6.49 & 3.26 \\
\hline Febru & 11.03 & 6.23 & 16.67 & 40.7 & 37.50 & 53.41 & 29.17 & 78.97 & 43.25 & 14.36 & 9.37 & 0.06 \\
\hline April 2013 & 13.81 & 7.39 & 28.10 & 47.78 & 23.00 & 62.18 & 21.37 & 91.51 & 42.25 & 17.16 & 9.85 & 1.29 \\
\hline May 2013 & 18.91 & 9.33 & 26.21 & 32.80 & 0.00 & 54.47 & 44.33 & 97.89 & 32.92 & 26.28 & 12.01 & 0.14 \\
\hline June 2013 & 22.81 & 15.53 & 32.97 & 25.20 & 0.00 & 48.59 & 27.09 & 68.53 & 33.52 & 24.97 & 10.63 & 0.00 \\
\hline
\end{tabular}

$\overline{\mathrm{CV}}=$ coefficient of variation (=relative standard deviation (RSD))

\section{PCA analysis and correlations}

Environmental variables were chosen by correlation analysis to be included in the Principal analysis component PCA, as indicated previously to determine the correlation between biological and abiotic factors. 
The influence of eleven of these variables on D. longicaudata parasitism percentage on each tested year period are summarized in Table 3.3. The first three principal components explain $91.5 \%$ of the total variance. The first principal component $(\mathrm{F} 1=56.4 \%)$ represents basically the temperature and photoperiod, while $\mathrm{RH}$ is represented in the second $(\mathrm{F} 2=24.5 \%)$ and the third (F3=10.6\%) components (Table 3.3, Figure 3.14).

Table 3.2. Climatic conditions during the parasitism and the immature development periods.

\begin{tabular}{|c|c|c|c|c|c|c|c|c|c|c|c|c|}
\hline \multirow[b]{2}{*}{ Period } & \multicolumn{4}{|c|}{ Temperature $\left({ }^{\circ} \mathrm{C}\right)$} & \multirow[b]{2}{*}{ 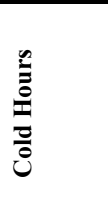 } & \multicolumn{4}{|c|}{ Relative Humidity (RH, \%) } & \multirow[b]{2}{*}{ 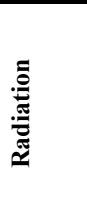 } & \multirow[b]{2}{*}{$\begin{array}{l}\widehat{\Xi} \\
\vdots \\
\vdots \\
\vdots \\
\vdots \\
\bar{n}\end{array}$} & \multirow[b]{2}{*}{ 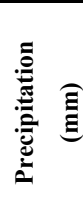 } \\
\hline & 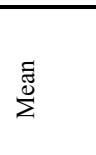 & 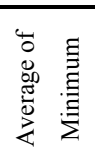 & 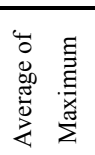 & $\vec{u}$ & & 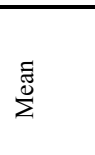 & 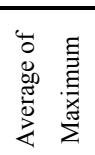 & 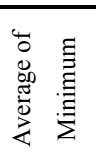 & $\overrightarrow{0}$ & & & \\
\hline May 2012 & 25.31 & 17.15 & 34.42 & 24.21 & 0.00 & 60.23 & 88.34 & 32.87 & 37.54 & 28.27 & 13.00 & 0.09 \\
\hline June 2012 & 26.21 & 19.32 & 33.95 & 21.51 & 0.00 & 68.69 & 96.14 & 36.28 & 34.76 & 27.35 & 12.96 & 0.06 \\
\hline July 2012 & 27.24 & 19.65 & 35.49 & 20.93 & 0.00 & 63.74 & 92.25 & 34.41 & 35.88 & 27.78 & 13.07 & 0.00 \\
\hline August 2012 & 27.33 & 20.62 & 35.11 & 19.38 & 0.00 & 71.83 & 97.06 & 39.98 & 33.41 & 26.72 & 12.83 & 0.00 \\
\hline September 2012 & 22.22 & 17.58 & 29.34 & 24.28 & 0.00 & 83.19 & 94.93 & 64.40 & 25.96 & 14.34 & 9.57 & 1.85 \\
\hline October 2012 & 19.74 & 13.85 & 28.40 & 30.60 & 22.50 & 77.20 & 94.77 & 57.77 & 26.35 & 13.15 & 8.90 & 0.97 \\
\hline November 2012 & 14.63 & 10.20 & 20.69 & 35.56 & 105.00 & 79.54 & 96.12 & 54.66 & 25.25 & 8.55 & 6.90 & 0.88 \\
\hline December 2012 & 12.70 & 8.73 & 18.70 & 39.76 & 177.00 & 86.72 & 98.56 & 48.34 & 49.90 & 7.30 & 6.93 & 2.05 \\
\hline February 2013 & 11.97 & 7.02 & 18.23 & 40.62 & 146.50 & 60.19 & 83.98 & 35.01 & 37.89 & 14.58 & 12.95 & 1.65 \\
\hline April 2013 & 15.75 & 8.77 & 30.70 & 45.05 & 58.50 & 65.14 & 92.95 & 24.15 & 40.58 & 19.53 & 10.62 & 1.73 \\
\hline May 2013 & 20.88 & 12.40 & 30.34 & 28.49 & 0.00 & 53.27 & 85.32 & 35.65 & 33.07 & 26.97 & 12.08 & 0.24 \\
\hline June 2013 & 23.52 & 16.20 & 34.42 & 25.00 & 0.00 & 52.59 & 72.68 & 29.19 & 30.02 & 26.53 & 11.38 & 0.17 \\
\hline
\end{tabular}

Table 3.3. Contribution to Principal components extracted and quantitative characters.

\begin{tabular}{lccc}
\hline Environmental variable & F1 & F2 & F3 \\
\hline Mean T & 0.913 & 0.382 & 0.113 \\
Mean of Max T & 0.909 & 0.158 & 0.107 \\
Mean of Min T & 0.808 & 0.551 & 0.122 \\
(CV-T) & -0.815 & -0.522 & 0.029 \\
Mean RH & -0.648 & 0.701 & 0.271 \\
Mean of Max RH & -0.370 & 0.626 & 0.594 \\
Mean of Min RH & -0.497 & 0.799 & -0.243 \\
(CV-RH) & -0.211 & -0.523 & 0.773 \\
Pluviometry & -0.884 & -0.084 & 0.073 \\
Radiation & 0.967 & -0.194 & 0.118 \\
Sun hours & 0.814 & -0.340 & 0.139 \\
\hline
\end{tabular}

$\overline{\mathrm{CV}}=$ coefficient of variation (=relative standard deviation (RSD)) 
a)

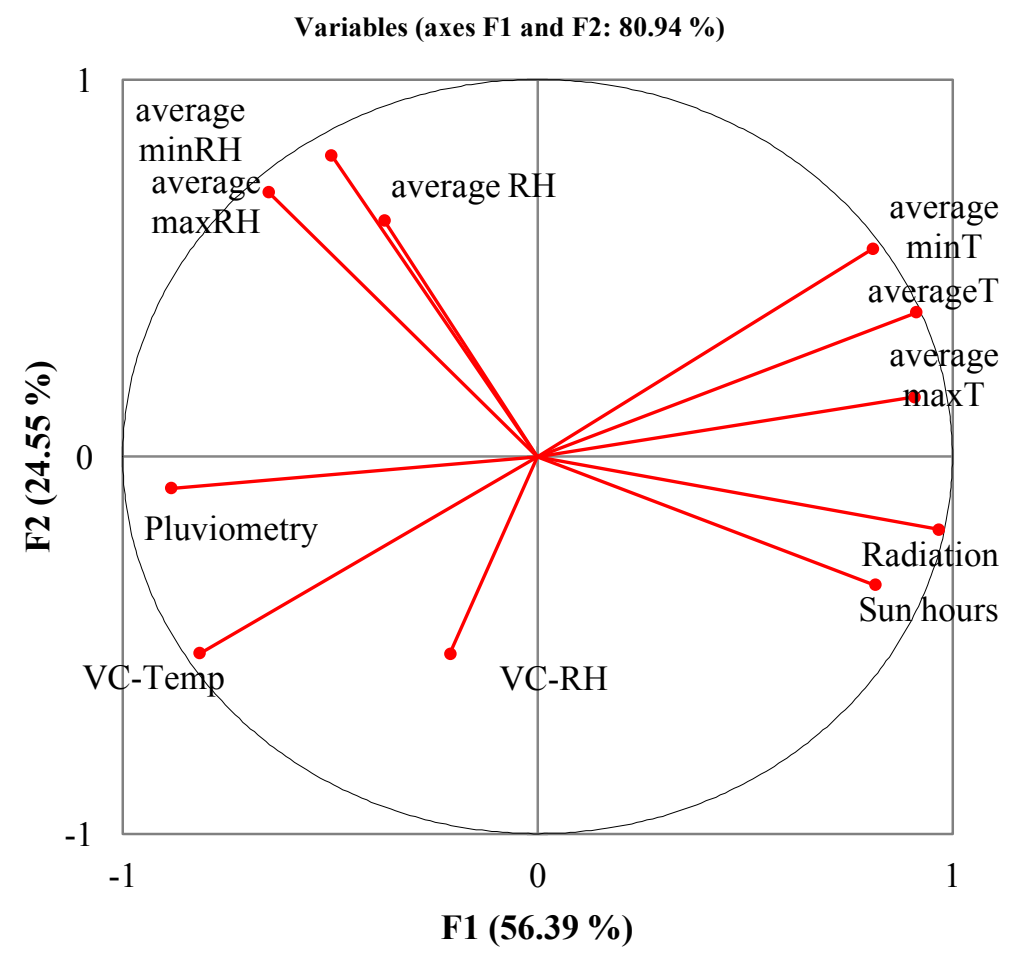

b)

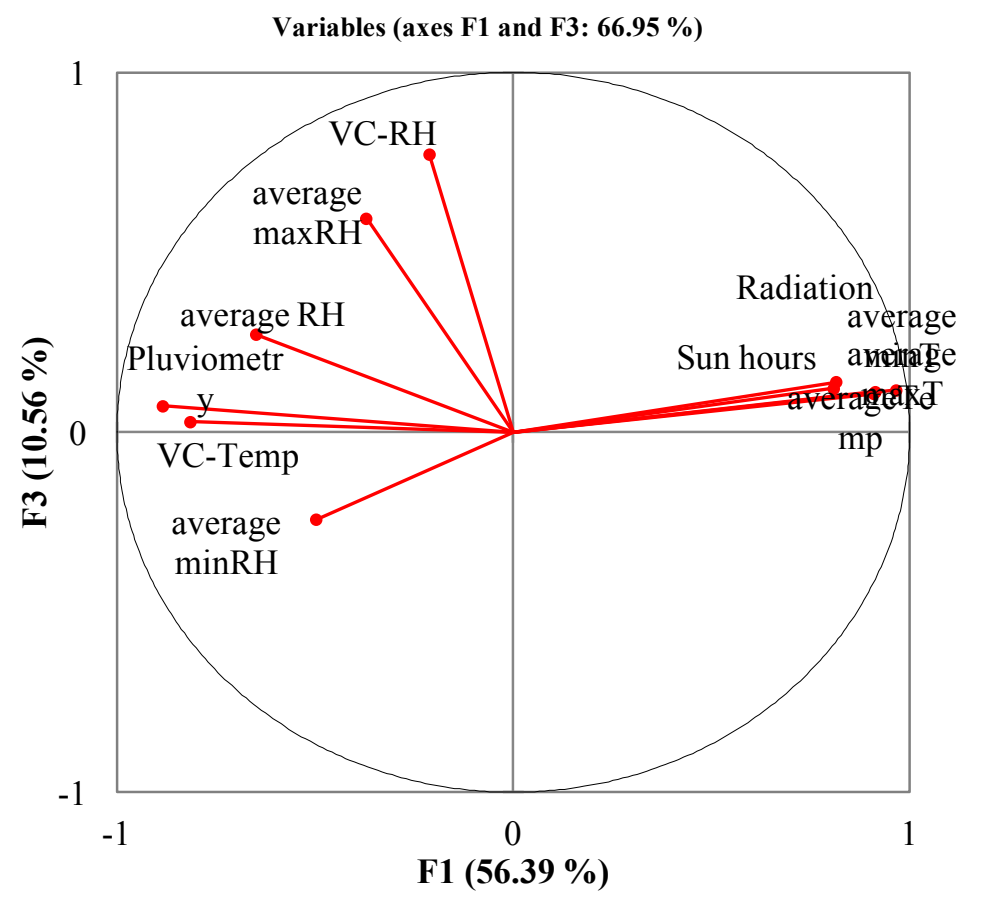

Figure 3.14. PCA ordination graph of the correlation among the $D$. longicaudata parasitism percentage and environmental variables. a) F1 and F2; b) F1 and F3. Principal component 1 (F1) explained $56.4 \%$ of the variability of the data; principal component 2 (F2) explained $24.5 \%$ of the variability and the principal component 3 (F3) explained $10.6 \%$ of the variability.

From the studied variables, different relationships between them were deduced. Firstly, the temperature, sunshine hours and radiation had a direct relationship, whereas these variables 
showed an inverse relationship with precipitation and the relative humidity coefficient of variation. Second, temperature and relative humidity are independent. And third, relative humidity coefficient of variation did not show a relationship with the temperature and photoperiod.

The model of the multiple linear regressions revealed the presence of a significant effect of both factors, Temperature and Relative humidity, on the parasitism percentage produced by $D$. longicaudata $\left(R_{a j}^{2}=0.831 ; F=14.48 ; P<0.002\right)$ (Figure 3.15). These factors modulated the parasitism percentage following the equation/model:

Parasitism percentage $(\%)=211.366+13.765 *$ Tmed $-0.332 *$ Tmed $^{2}-9.316 * \mathrm{Hmed}^{+}$ $0.063 * \mathrm{Hmed}^{2}$

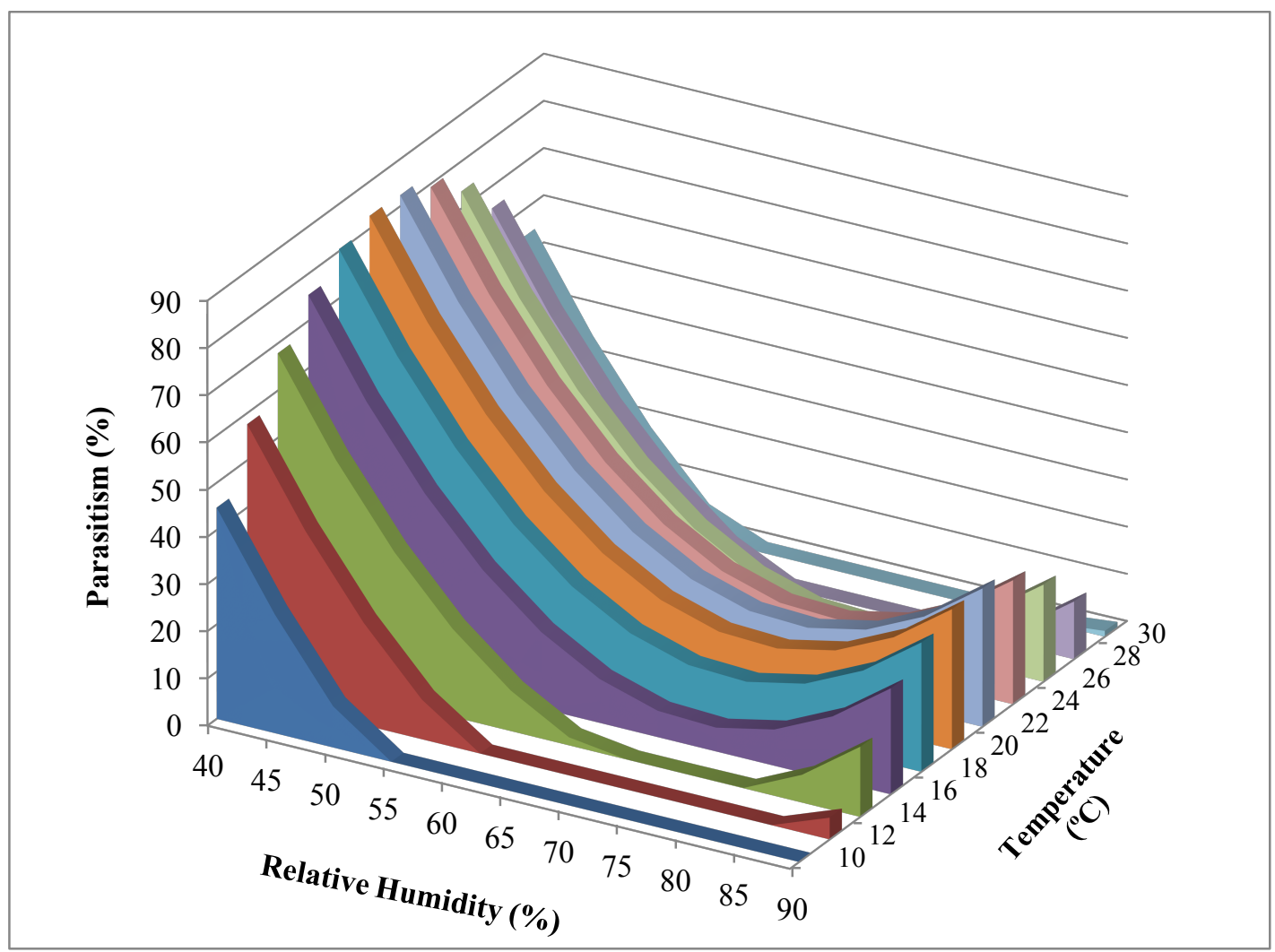

Figure 3.15. Pattern of $D$. longicaudata parasitism percentage depending on temperature and relative humidity obtained from the proposed ML regression model.

As a general rule, insect development depends on thermal requirements as they are temperature driven organisms. At the species level, each insect has an optimal temperature range for its development which is limited by lower and upper thresholds. Beyond these temperature limits, development is stopped (Haddad et al. 1999 in Ricalde et al. 2012). Within the optimal 
temperature interval, insects accumulate degree-days and are able to normally develop. In addition, the thermal requirements of a species vary with developmental stage and geographic origin (Haddad et al. 1999 in Ricalde et al. 2012). The base temperature tends to decrease with increasing latitude. Insect species that live in the tropics have a higher base temperature (13.7 ${ }^{\circ} \mathrm{C}$ ) than those living in subtropical $\left(10.5^{\circ} \mathrm{C}\right)$ or temperate regions $\left(7.9^{\circ} \mathrm{C}\right)$ (Honék 1996). In the case of D. longicaudata, Appiah et al. (2013) showed that above a threshold of $10.4^{\circ} \mathrm{C}$, it requires 281.6 DD to complete its development.

Obtained results demonstrated that $D$. longicaudata can successfully reproduce on $C$. capitata larvae in Mediterranean basin during all the year under variable environmental conditions characterizing this region. Moreover, it can reduce the medfly populations either by reproducing or through induced mortality of larvae when parasitizing. In our trials performed under Mediterranean climatic conditions, D. longicaudata exhibited a high parasitism percentage compared to other parasitoids of $C$. capitata such as A. daci (Harbi et al. 2016). We showed that the major factors influencing the parasitic activity of the wasp are mainly temperature and relative humidity. In other words, parasitism increased with temperature and decreased with relative humidity (Figure 3.15).

These results are in accordance with those of Lui et al. (2012) that found that, in the laboratory and under constant temperature, the optimal temperature range for the development and reproduction of $D$. longicaudata on $C$. capitata is from $24^{\circ} \mathrm{C}$ to $27^{\circ} \mathrm{C}$. They concluded that extreme temperatures had negative effects on the development of the parasitoid. This range of temperature was reported as suitable for the development of D. longicaudata eggs on $A$. suspensa by Lawrence et al. (1976). Our results are also consistent with those published by Appiah et al. (2013), who found that the most suitable temperature range for the optimum parasitism of $D$. longicaudata on $B$. invadens is between $20-25^{\circ} \mathrm{C}$. Similarly, Sime et al. (2006b) showed that moderate temperatures $\left(22-25^{\circ} \mathrm{C}\right)$ are optimal for the development of both D. longicaudata and D. kraussi on B. oleae. Conversely, temperatures lower than $15^{\circ} \mathrm{C}$ adversely affect insects'flight activity and reproduction, including parasitoids (Hebert et al. 1989; Duale 2005). As mentioned by Paranhos et al. (2007), low temperatures can negatively impact the mobility and the flight activity of parasitoids during winter. Likewise, rainfall is also expected to negatively affect the biocontrol services of $D$. longicaudata in winter. For instance, the impact of biotic and abiotic factors on the flight activity of $F$. arisanus was studied and it has been elucidated that both flight and parasitism were mainly affected by temperature and humidity (Rousse et al. 2009). In the same context, P. lounsburyi and P. humilis were evaluated 
in California for their potential to control the invasive olive fruit fly, B. oleae and it was demonstrated that adult parasitoid survival was low during summer because of the high prevailing temperatures (Wang et al. 2011) causing high mortality of Psyttalia sp. as in different developmental stages (Daane et al. 2008; Sime et al. 2006a; Yokoyama et al. 2010). As a matter of fact, temperature can lead $\mathrm{BC}$ programs to failure like the case of $P$. concolor which failed to establish in southern Europe (Raspi and Loni 1994 in Wang et al. 2011).

Apart from parasitism, other life traits or biological services of hymenopteran parasitoids can be affected by climatic conditions. In our study, when analyzing induced mortality percentage, we performed a Principal Component Analysis (PCA) of the environmental variables to find out which of assessed climatic variables contributed on the variability of this parameter (Table $3.5)$.

The PCA showed that F1, F2 and F3 accounted for more than $90 \%$ of the global variance in the environmental factors. F1 was mainly composed by factors clearly related with temperature (minimum T, maximum $\mathrm{T}$, mean $\mathrm{T}$, coefficient of variation of $\mathrm{T}$, solar radiation, and sum of cold hours), all of these six variables contribute together to $67 \%$ of the total variance of F1. Whereas F2 was mainly composed by two factors clearly related with humidity (minimum Humidity and mean Humidity), these two variables contribute together to almost half of the total variance of F2. Finally, F3 was also mainly composed by factors related with humidity, but in this case, they were clearly maximum Humidity and coefficient of variation of Humidity, together contributing to $80 \%$ of the total variance of F3 (Figure 3.16).

The Multiple Linear Regression model for the induced mortality showed an $\mathrm{R}^{2}$ of 0.104 , and the analysis of variance of the model was significant $(F=4.48 ; P=0.005)$. In addition, the Type III Sum of Squares analysis showed a large effect of F3, and a marginally significant effect of F2, on the induced mortality (Table 3.4). F2 and F3 (Relative humidity) affected the induced mortality in different directions, with a positive effect of F3 and a negative effect of F2 (Table 3.5). Thus, induced mortality increases when F3 increases, and it decreases when F2 increases (Figure 3.16). Because both F2 and F3 are mainly composed of factors related with humidity, it is clear that humidity plays an important role on determining the induced mortality in the field. It increases when the values of the minimum and the average of relative humidity decrease and the maximum and coefficient of variance of relative humidity increase (Figure 3.17). 


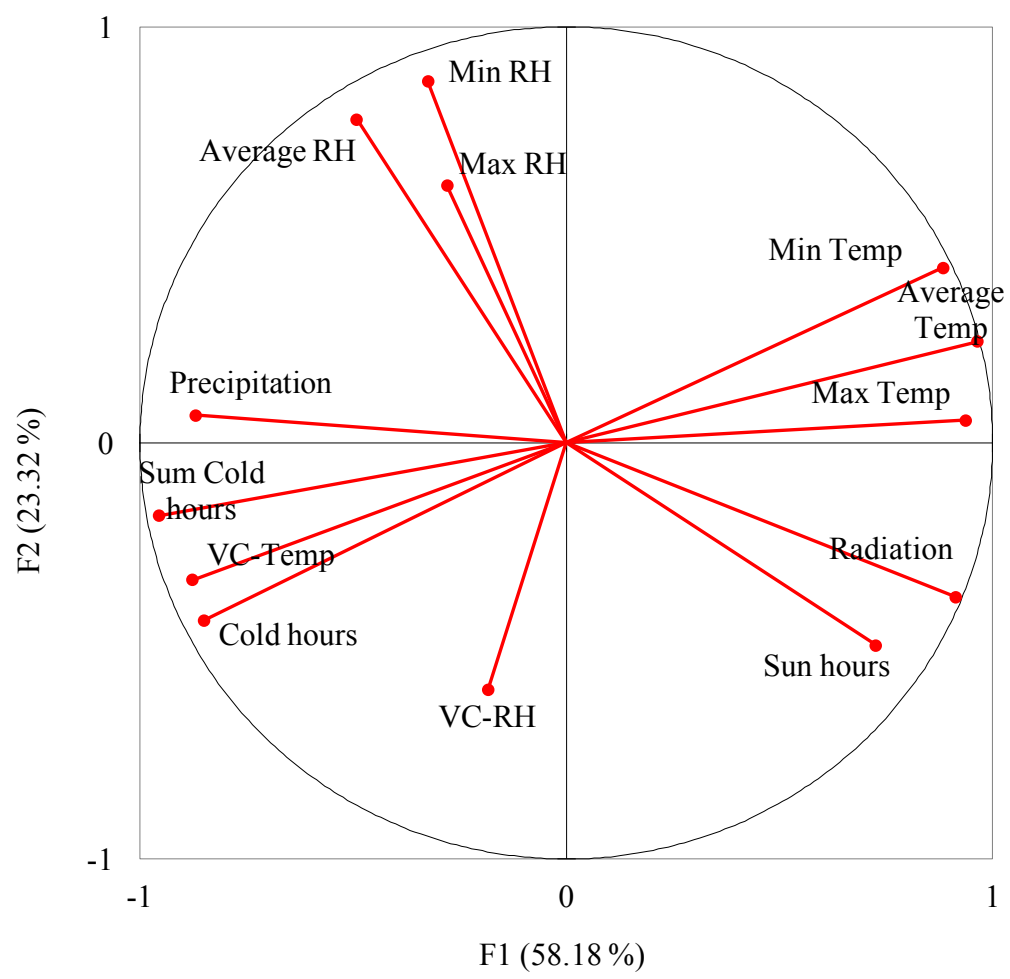

Figure 3.16. PCA ordination graph of the correlation among the induced mortality percentage and environmental factors measured in 12 different trials.

Table 3.4. Results of Type III Sum of Squares analysis on the factors affecting the induced mortality

\begin{tabular}{lccccc}
\hline Source & DF & Sum of squares & Mean squares & $\boldsymbol{F}$ & $\boldsymbol{P}$ \\
\hline F1 & 1 & 0.004 & 0.004 & 0.176 & 0.676 \\
F2 & 1 & 0.089 & 0.089 & 3.677 & 0.058 \\
F3 & 1 & 0.233 & 0.233 & 9.593 & 0.002 \\
\hline
\end{tabular}

Table 3.5. Results of the analysis of the different principal component affecting the induced mortality

\begin{tabular}{lcccccc}
\hline Source & Value & Standard error & $\boldsymbol{t}$ & $\boldsymbol{P}$ & Lower bound (95\%) & Upper bound (95\%) \\
\hline Intercept & 0.746 & 0.014 & 52.465 & $<0.0001$ & 0.718 & 0.774 \\
F1 & -0.002 & 0.005 & -0.419 & 0.676 & -0.012 & 0.008 \\
F2 & -0.016 & 0.008 & -1.918 & 0.058 & -0.032 & 0.001 \\
F3 & 0.041 & 0.013 & 3.097 & 0.002 & 0.015 & 0.067 \\
\hline
\end{tabular}




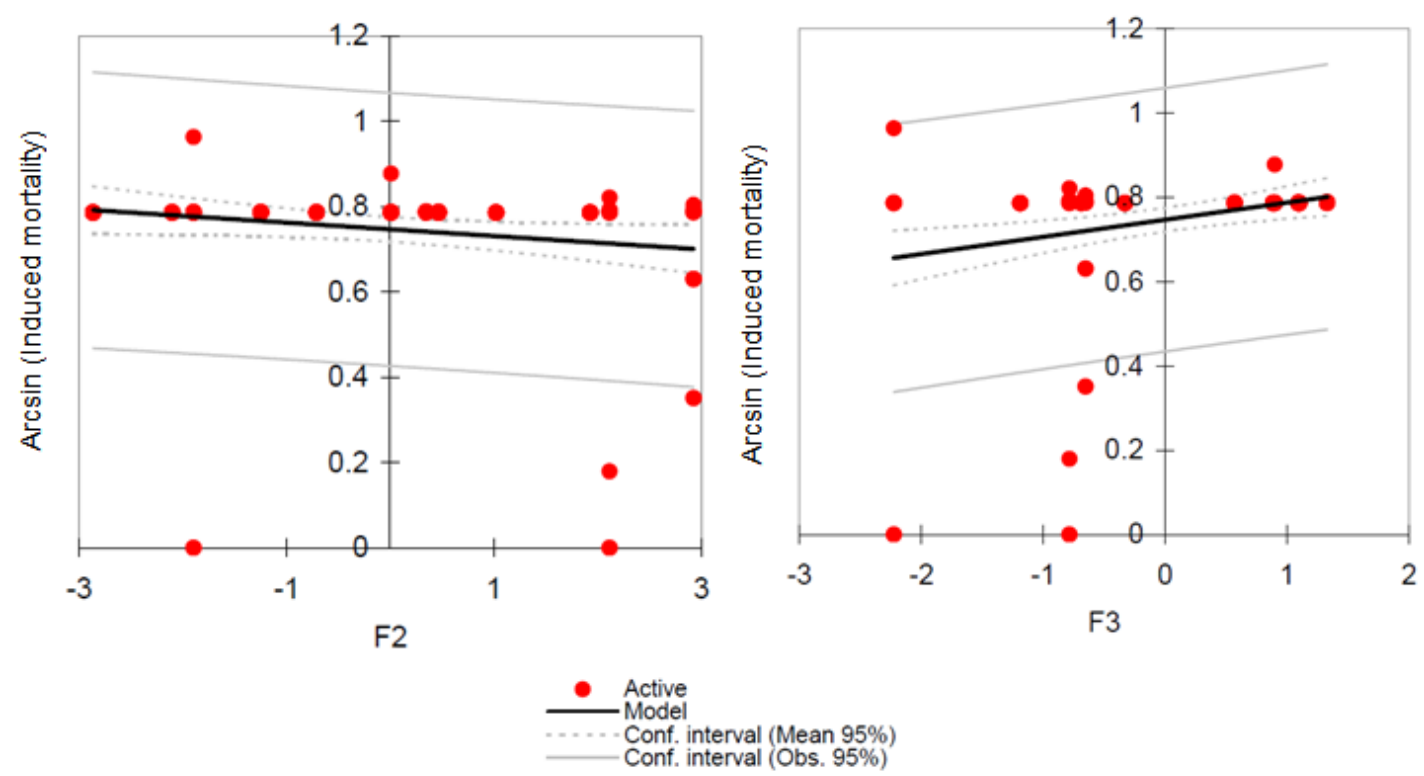

Figure 3.17. Relationship between the induced mortality and the relative humidity parameters (at the left, F2: Min RH + Mean RH; at the right, F3: Max RH + CV RH).

These data showed that the induced mortality of D. longicaudata on C. capitata (i.e. preimaginal development) was influenced mainly by relative humidity. This suggests that $D$. longicaudata can parasitize and cause mortality of $C$. capitata larvae during the whole year but parasitized larvae cannot achieve their development in different period of the year influenced mainly by relative humidity, and then temperature (Figure 3.17). Our result are in harmony with those obtained by Ashley et al. (1976) whom demonstrated that mortality in D. longicaudata is humidity and temperature-dependant. Similarly, Appiah et al. (2013) showed that the percentage of uneclosed pupae of D. longicaudata varied significantly among temperature and was the highest at $15^{\circ} \mathrm{C}$. In the same context, Carvalho (2005) showed that possible mortality factors of fruit flies and their parasitoid were dehydration (63.7\%), fungi (13.8\%), bacteria (0.4 $\%)$. Alternatively, inadequate temperatures can trigger diapauses in D. longicaudata up to 10 months.

Concerning the sex ratio, we could not perform the analysis of its variation in the field due to the absence of emerged parasitoid in some trials as a result of the high mortality of the preimaginal stages. For the laboratory part of the trial, analysis of the sex ratio did not demonstrate significant differences during the different period of the year. It seems that throughout the year, the sex ratio was close to $1: 1$ of males and females suggesting that it is genetically controlled. This result was confirmed by Appiah et al. (2013) who found in their 
work that the sex-ratio of $D$. longicaudata offspring even female-biased was not affected by temperature.

\subsubsection{Determination of $\boldsymbol{D}$. longicaudata ability to control medfly focal points}

Assays resembling medfly focal points were recreated at the IVIA facilities. From which we determined parasitism percentage, induced mortality percentage, and population reduction, exherted by released small D. longicaudata population (Table 3.6).

Table 3.6. Parasitism percentage, mortality percentage and population reduction induced by $D$. longicaudata activity on medfly larvae during the different medfly focal points control trials.

\begin{tabular}{lccc}
\hline Trial & $\begin{array}{c}\text { Parasitism } \\
\text { percentage (\%) }\end{array}$ & $\begin{array}{c}\text { Mortality } \\
\text { percentage (\%) }\end{array}$ & Population reduction (\%) \\
\hline 1 (June) & 22.1 & 11.2 & 33.3 \\
2 (June) & 20.2 & 8.5 & 28.7 \\
3 (June-July) & 21.5 & 12.4 & 33.9 \\
4 (July) & 40.1 & 12.9 & 53.0 \\
5 (July-August) & 38.9 & 23.6 & 62.5 \\
6 (September) & 33.7 & 11.0 & 44.7 \\
7 (September) & 26.3 & 25.0 & 51.3 \\
\hline
\end{tabular}

The climatic conditions (temperature and relative humidity) occurring during the trials are presented in Table 3.7 .

Table 3.7. Climatic conditions recorded during the different medfly focal points control trials.

\begin{tabular}{lcc}
\hline \multicolumn{1}{c}{ Trial (period) } & Mean Temperature $\left({ }^{\circ} \mathbf{C}\right)$ & Mean Relative Humidity (\%) \\
\hline 1 (June) & 23.3 & 61.8 \\
2 (June) & 21.1 & 64.9 \\
3 (June-July) & 21.5 & 69.7 \\
4 (July) & 25.5 & 64.9 \\
5 (July-August) & 25.3 & 69.0 \\
6 (September) & 22.6 & 72.5 \\
7 (September) & 23.3 & 68.3 \\
\hline
\end{tabular}

Isolated fruit trees, also known as alternative hosts, constitute a great problem for citriculture and other crops affected by the medfly, as they can act as medfly populations reservoirs, being the source of new migrants into the surounding crops. These trees/medfly isolated populations are also known as medfly focal points, which under the Spanish normative, and also protected 
by the European council, deserve a great attention. Within this section, we have demonstrated that $D$. longicaudata could control these focal points successfully, achieving from the worse to the best conditions from 30 to $63 \%$ of medfly population reduction (Table 3.6). A parameter that also includes the parasitoid perpetuation, establishment, in the field (corresponding to produced offspring or parasitism percentage in Table 3.6), which is advisable for control purposes.

Despite all the trials were conducted at different periods, covering from late spring to the end of the summer, which in normal years will show high differences in mean temperatures. Within our study, we bumped into nearly the optimal temperature and $\mathrm{RH}$ conditions for $D$. longicaudata parasitism success (Table 3.7), as highlighted in the precedent chapter and section, factors that justify the observed good performance of the parasitoid.

Similarly, it has been recorded in other works that the optimal range of temperature for $D$. longicaudata is between 24 and $27^{\circ} \mathrm{C}$ (Lui et al. 2012), as it has been already reported in the previous chapter and sections of this thesis dissertation.

According to these results, we can say that the period with the highest Medfly populations in the Mediterranean region (by the end of spring to starting autumn) is optimal for the activity of D. longicaudata.

\subsubsection{Effect of $C$. capitata host fruit on the behavior of $D$. longicaudata: from chemical ecology to biological control}

\subsubsection{Diachasmimorpha longicaudata olfactory response}

For the olfactory test (Figure 3.18), females of D. longicaudata were significantly more attracted to $C$. capitata infested apple compared to healthy ones in both infestation ages, (1and 4-d-old) $\left(\chi^{2}=13.07 ; P=0.0003\right)$. Whereas no significant preference were found between the two infestation ages of the rest of the tested fruits $\left(\chi^{2}=2.40 ; P=0.12\right)$.

In the case of the comparison of the attractiveness of different tested fruit combination, $D$. longicaudata did not exhibit a significant preference between apple and orange $\left(\chi^{2}=2.40\right.$; $P=0.12$ ). However, significant attractiveness to the peach and Clementine odors were detected compared to apple odor $\left(\chi^{2}=17.07 ; P<0.0001\right.$; and $\chi^{2}=9.60 ; P=0.0019$; respectively). When comparing the choice of $D$. longicaudata between orange compared to peach and Clementine, results demonstrated a clear preference to peach and Clementine compared to orange $\left(\chi^{2}=4.26\right.$; $P=0.03$ for both combinations). 


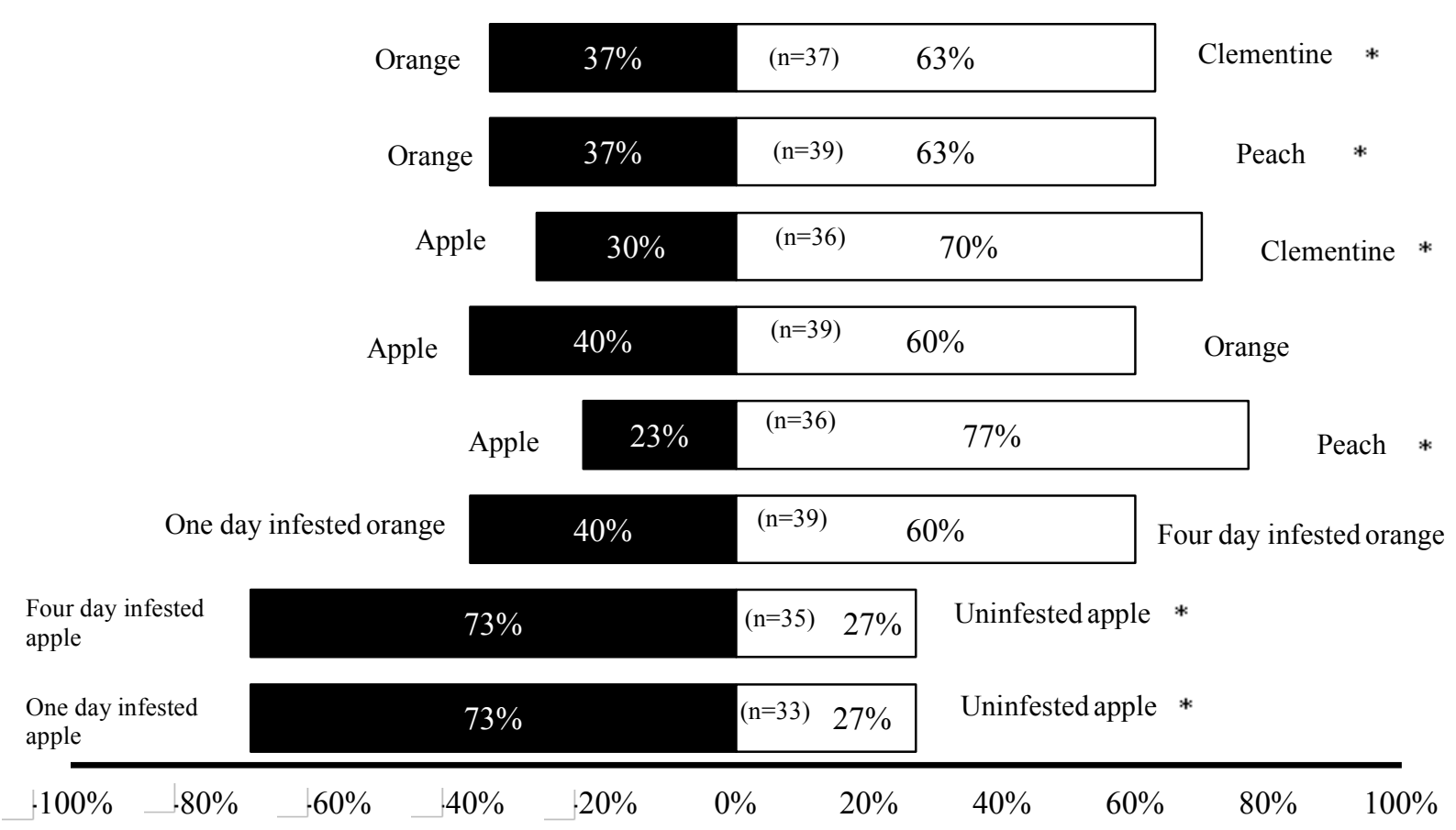

Figure 3.18. Diachasmimorpha longicaudata female odour response to different odour sources in percentage of responding females. Data were obtained with a Y-tube olfactometer, with different fruit host combinations, including medfly infested and uninfested fruits, as indicated in the graph. The number of individuals recorded (n) for each odor pair is shown between brackets. Asterisk represents significant $(P<0.05)$ differences in the distribution of sidearm choices.

\subsubsection{Host fruit influence on parasitism activity: Laboratory trials}

The assessment of the pattern of preference of D. longicaudata among apple orange, Clementine and peach in the laboratory conditions in non-choice and dual choice tests, revealed results similar to those obtained in the olfactory trials.

During the trial, apple was the less attractive than other compared fruits except the case of apple and orange where no significant differences in the parasitism percentage, the fertility and the sex-ratio for both non-choice test and dual choice tests were registered (Table 3.8).

In case of apple versus clementine, the parasitism percentage performed by D. longicaudata females on $C$. capitata larvae on clementine as host fruit was significantly higher than that on apple with significant statistical differences $(P=0.040$ and $P=0.006$ for non-choice test and dual choice test, respectively). Regarding, the fertility and the sex-ratio, they did not show statistically significant differences in non-choice test while it did in the dual choice tests ( $P=0.006$ and $P=0.004$ for the fertility and the sex-ratio, respectively). The parasitism percentage recorded on peach was higher than that on apple $(P=0.0005$ and $P=0.0047$ for the non-choice test and the dual choice tests, respectively). Female fertility presented significant differences between the tested fruits $(P<0.0077$ and $P<0.023$ for the non-choice test and dual 
choice test, respectively) while no significant differences were recorded concerning the sexratio (Table 3.8).

Table 3.8. Mean parasitism percentage (mean \pm S.E.), fertility (mean \pm S.E.) and sex ratio (mean \pm S.E.) of D. longicaudata comparing different fruit species in a non-choice and a dual choice test.

\begin{tabular}{|c|c|c|c|c|c|c|c|}
\hline & & \multicolumn{3}{|c|}{ Non-choice test } & \multicolumn{3}{|c|}{ Dual choice test } \\
\hline & & $\begin{array}{c}\text { Parasitism } \\
\text { percentage } \\
(\%)\end{array}$ & Fertility & Sex-ratio & $\begin{array}{c}\text { Parasitism } \\
\text { percentage } \\
(\%)\end{array}$ & Fertility & Sex-ratio \\
\hline \multirow[t]{5}{*}{$\begin{array}{l}\text { Apple/ } \\
\text { Orange }\end{array}$} & Apple & $\begin{array}{c}12.92 \pm \\
2.61\end{array}$ & $8.87 \pm 1.63$ & $33.42 \pm 6.95$ & $11.47 \pm 2.19$ & $8.60 \pm 1.70$ & $\begin{array}{c}21.14 \pm \\
4.80\end{array}$ \\
\hline & Orange & $\begin{array}{c}12.10 \pm \\
2.46\end{array}$ & $7.93 \pm 1.66$ & $33.02 \pm 8.83$ & $11.72 \pm 1.93$ & $7.20 \pm 1.17$ & $\begin{array}{c}35.92 \pm \\
6.44\end{array}$ \\
\hline & $t$ & 0.23 & 0.4 & 0.08 & 0.09 & 0.68 & 1.82 \\
\hline & df & 1,28 & 1,28 & 1,28 & 1,28 & 1,28 & 1,28 \\
\hline & $P$ & 0.821 & 0.691 & 0.937 & 0.932 & 0.503 & 0.081 \\
\hline \multirow[t]{5}{*}{$\begin{array}{l}\text { Apple/ } \\
\text { Clementine }\end{array}$} & Apple & $\begin{array}{c}12.47 \pm \\
2.83\end{array}$ & $9.53 \pm 2.20$ & $23.50 \pm 7.97$ & $4.86 \pm 1.22$ & $3.73 \pm 0.95$ & $5.77 \pm 5.41$ \\
\hline & Clementine & $\begin{array}{c}21.87 \pm \\
3.33\end{array}$ & $16.20 \pm 2.63$ & $29.57 \pm 5.56$ & $18.14 \pm 4.06$ & $12.60 \pm 2.70$ & $\begin{array}{c}32.46 \pm \\
5.63\end{array}$ \\
\hline & $t$ & 2.15 & 1.94 & 0.63 & 3.13 & 3.10 & 3.33 \\
\hline & df & 1,28 & 1,28 & 1,27 & 1,28 & 1,28 & 1,28 \\
\hline & $P$ & 0.040 & 0.061 & 0.533 & 0.006 & 0.006 & 0.004 \\
\hline \multirow[t]{5}{*}{$\begin{array}{l}\text { Apple/ } \\
\text { Peach }\end{array}$} & Apple & $8.85 \pm 1.79$ & $6.20 \pm 1.38$ & $52.85 \pm 8.13$ & $5.98 \pm 1.23$ & $3.73 \pm 0.81$ & $\begin{array}{c}36.06 \pm \\
9.85\end{array}$ \\
\hline & Peach & $\begin{array}{c}19.27 \pm \\
1.94\end{array}$ & $11.13 \pm 1.02$ & $48.55 \pm 6.79$ & $14.19 \pm 2.30$ & $7.13 \pm 1.12$ & $\begin{array}{c}46.00 \pm \\
6.53\end{array}$ \\
\hline & $t$ & -3.95 & -2.87 & 0.41 & -3.15 & -2.46 & -0.85 \\
\hline & $\mathrm{df}$ & 1,28 & 1,28 & 1,28 & 1,28 & 1,28 & 1,28 \\
\hline & $P$ & 0.001 & 0.008 & 0.688 & 0.005 & 0.023 & 0.402 \\
\hline
\end{tabular}

\subsubsection{Host fruit influence on parasitism activity: Semi-field trials}

When the trial was conducted in the greenhouse (meaning semi-natural conditions with natural photoperiod), the recorded parasitism percentage and fertility were lower than those recorded in the laboratory (Table 3.9).

In this essay, all the studied parameters revealed the significant preference of D. longicaudata to orange, clementine and peach over apple (Table 3.9). In terms of parasitism percentage which was higher in orange, clementine and peach than apple $(P=0.0031, P=0.0020$ and $P=0.0016)$. We recorded the same pattern with the fertility, $(P=0.0040, P=0.0008$ and $P=0.0011)$. Concerning the sex-ratio, it was higher on apple when compared with orange $(P=0.0111)$, lower on apple when compared with clementine $(P=0.0098)$ and similar on apple and peach. 
Table 3.9. Mean parasitism percentage (mean \pm S.E.), fertility (mean \pm S.E.) and sex ratio (mean \pm S.E.) of D. longicaudata produced on C. capitata larvae comparing different fruit species in a non choice test and a dual choice test in a laboratory conditions.

\begin{tabular}{llccc}
\hline & & \multicolumn{3}{c}{ Dual choice test } \\
\cline { 3 - 5 } Apple/Orange & Parasitism & Fertility & Sex-ratio \\
& & percentage (\%) & \\
& Apple & $2.62 \pm 0.72$ & $5.92 \pm 1.63$ & $80.22 \pm 6.77$ \\
& Orange & $15.34 \pm 3.37$ & $35.00 \pm 8.03$ & $51.79 \pm 7.24$ \\
& $t$ & -3.69 & -3.55 & 2.85 \\
& df & 1,22 & 1,22 & 1,17 \\
& $P$ & 0.003 & 0.004 & 0.011 \\
Apple/ Clementine & Apple & $0.81 \pm 0.55$ & $1.83 \pm 1.24$ & $6.33 \pm 4.84$ \\
& Clementine & $6.55 \pm 1.42$ & $13.25 \pm 2.50$ & $32.75 \pm 5.62$ \\
& $t$ & 3.78 & 4.09 & 3.02 \\
& df & 1,22 & 1,22 & 1,13 \\
& $P$ & 0.002 & 0.001 & 0.010 \\
& Apple & $2.79 \pm 0.92$ & $6.75 \pm 2.33$ & $29.64 \pm 10.99$ \\
& Peach & $14.58 \pm 2.83$ & $32.08 \pm 5.86$ & $36.43 \pm 5.05$ \\
& $t$ & -3.97 & -4.02 & -0.56 \\
& df & 1,22 & 1,22 & 1,21 \\
& $P$ & 0.002 & 0.001 & 0.584 \\
\hline
\end{tabular}

We studied the effect of the type of host fruit of $C$. capitata on the biocontrol services of its imported parasitoids D. longicaudata in multistep essay. Apple, peach, orange and Clementine are relevant fruits in the Mediterranean region and their cultivations are relevant sectors both on the economic and social levels. These crops are considered among the most susceptible to the attacks of the Mediterranean fruit fly which limits their production and exportations The olfactometer trials showed that D. longicaudata was attracted by infested fruit by $C$. capitata larvae more than healthy ones. These results coincide with the findings of other studies suggesting that products derived from larval activity inside the fruit are considered as direct cues used by $D$. longicaudata to locate its host which increase the host searching activity in response to a compound that is released by tephritid larvae (Segura et al. 2012). Duan and Messing (2000) reported that $D$. longicaudata increases its oviposition activity when foraging on artificial larval medium that had hosted larvae, and suggested that this behavior is due to chemical signals excreted by host larvae. Similarity, considering our results using $C$. capitata larvae on apple fruit and those obtained by Segura et al. (2012) working on C. capitata on orange fruit and by Duan and Messing (2000) using A. ludens, suggest that these cues are similar among host larvae from different species. Stuhl et al. (2011) have identified a com pound, Paraethylacetophenone, released by larvae from several tephritid species whichenhances host searching behavior in D. longicaudata females. Sensillae on both the antennae and ovipositor 
of the opiine braconid fruit fly parasitoid, D. longicaudata, responded to the paraethylacetophenone in larval volatiles (Stuhl et al. 2011). According to Greany et al. (1977) D. longicaudata is attracted to many chemical compounds such as acetaldehyde, ethanol, and acetic acid released by attacked fruits. Furthermore, it has been demonstrated by Lawrence (1981) that during host searching D. longicaudata used vibratory signals produced by larvae. In the second series of the olfactory response, although the comparison of the age of infested fruits did not show a significant difference, a preference to the old infested fruit over the recent one were remarked. This can be explained by the fact that rotten fruit are attracted more frequently by the parasitoid as it was mentioned by Segura et al. (2012) who demonstrated that female parasitoids preferred visiting rotten over ripe oranges, suggesting that parasitoids are attracted to compounds released by the fruit even in total absence of host larvae. Similarly, Silva et al. (2007) found that D. longicaudata females preferred visiting rotting over unripe guavas fruits. Infested fruit become rotten more rapidly than un-infested ones, and hence volatiles released by rotten fruit will indicate infestation with a higher probability than ripe fruit. The olfactory comparison of the fruit preference revealed the higher attraction of peach, clementine and orange over apple and the preference of the peach and clementine over orange. This can be explained by the difference of the attractant compounds released from each fruit. These results are in accordance with those obtained by Segura et al. (2016) who found that fig is more attractive to D. longicaudata while apple is the less attractive among tested fruits.

Our findings on the olfactory trials were confirmed by those of the laboratory and the semifield trials. In fact, the parasitism percentage and fertility were higher in peach, cementine and orange than on apple. This was the same for Segura et al. (2016) and in contradiction with the results obtained by Leyva et al. (1991) and Ovruski et al. (2012) who indicated the absence of clear association between the preferred host fruit and the parasitism percentage of $D$. longicaudata, at least not an association that completely explains the preference for host habitats.

Difference on fruit preference of $D$. longicaudata between the laboratory and the greenhouse trials can be explained by differences in visual stimuli as color, shape and size of the fruit that can interfere with how fruit preference alongside volatile cues. In our case, tested fruits had more or less the same size and the color was in the range of the red. However, the texture of the fruit is known to affect the movements of larvae inside host and as consequence the quantity and the quality of the cues derived from each one. Our results revealed that D. longicaudata is able to detect its host in different host fruits and can parasitize and produce new generations in all tested host fruits indicating that it can be released in different crop productions and including 
apple, orange, clementine and peach as well as fig, guava, grapefruit, and mango as proved by Carrasco et al. (2005), Quilici and Rousse (2012) and Segura et al. (2016).

\subsection{Conclusions}

\subsubsection{Determination of abiotic factors influencing $D$. longicaudata parasitism activity over $\boldsymbol{C}$. capitata under semi-field conditions}

Overall, findings from this study provide some guidance for future mass rearing, field releases and modeling the impact of $D$. longicaudata on the Mediterranean fruit fly $C$. capitata in the Mediterranean climatic conditions. Field releases of this wasp should be planned taking into account the impacts of climatic conditions on the parasitoid performance mainly temperature and relative humidity. Modeling of the influence of climatic parameters on the wasp's performance is a valuable tool to predict the outcome of BC programs in the new dispersion area and mainly temperate regions where climate can be a primary challenge when using exotic parasitoids.

\subsubsection{Determination of $\boldsymbol{D}$. longicaudata ability to control medfly focal points}

According to our results, we can say that the period with the highest medfly populations in the Mediterranean region (by the end of spring to starting autumn) is optimal for the activity of $D$. longicaudata.

\subsubsection{Effect of $C$. capitata host' fruit on the behavior of $D$. longicaudata: from chemical ecology to biological control}

The olfactometer trials showed that D. longicaudata was attracted by infested fruit by $C$. capitata larvae more than healthy ones and by the old infested fruit more than the recent ones. These preferences are due to the activity of $C$. capitata larvae inside fruits.

In the different trials (olfactory trial, lab and semi-field one), D. longicaudata showed the same preferences to the tested $C$. capitata host fruits. Peach, clementine and orange are more attractive than apple. These fruits are the most susceptible to C. capitata in Spain and Tunisia and the Mediterranean region, which enhance us to use the D. longicauadata as a biological organism to control the medfly on an IPM program. On the other hand, the attractiveness of these fruits to D. longicaudata is based on olfactory and visual stimuli which can be useful to prepare attractive traps to the parasitoid to the orchard. 


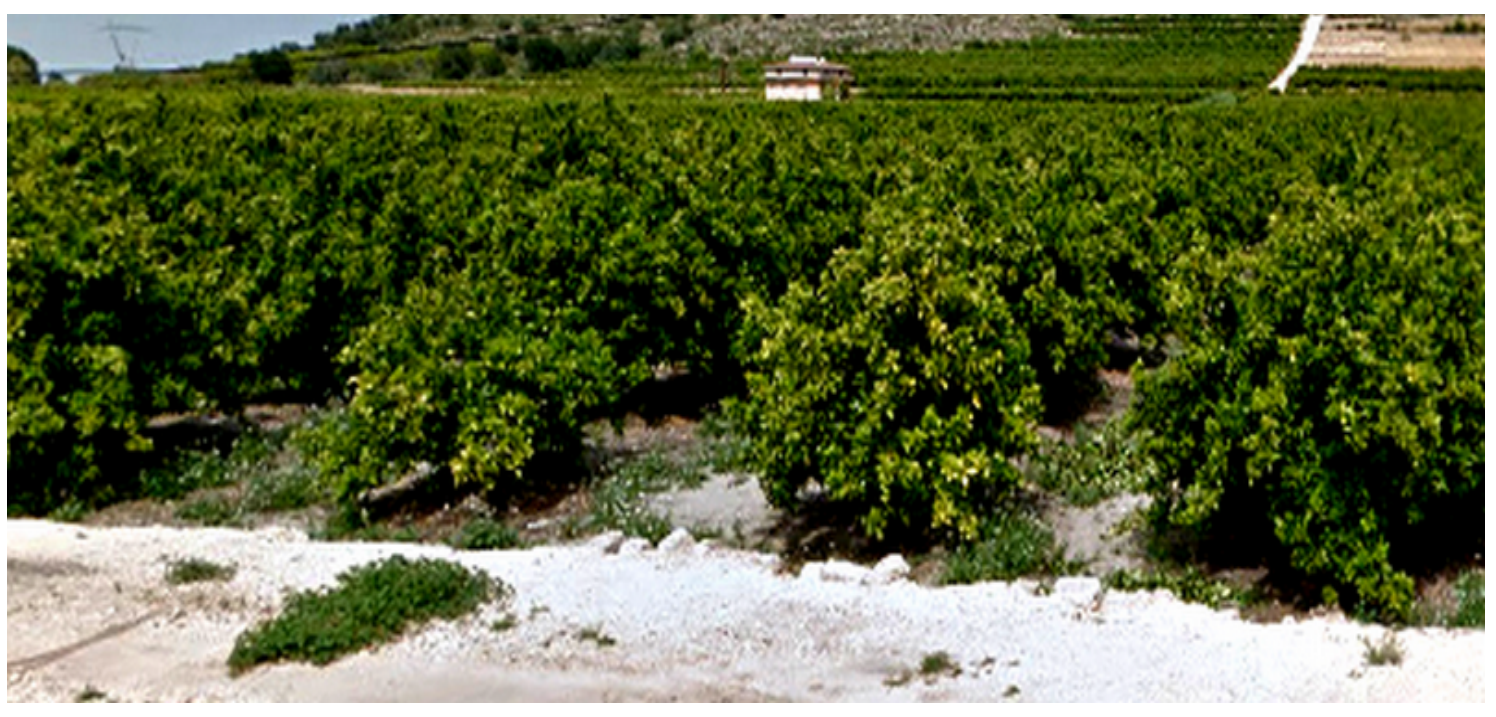

CHAPTER 4. Integration of Biological control within the IPM program against Ceratitis capitata in Spain. 
In this chapter, as continuation of the precedent chapter, I will first briefly describe the sterile insect technique (SIT) against the medfly in Spain which constitutes the central core of IPM against this pest species. To fulfill the third objective proposed for this thesis dissertation, I will identify key points to integrate $D$. longicaudata within the IPM program in Spain.

The results showed here have been partially submitted to different SCI journals including a special number of Acta Horticulturae.

\subsection{Introduction: the IPM program against $C$. capitata in Spain}

Pest control practitioners are becoming increasingly aware of the fact that no single control measure is able to provide full control of a pest. For this reason, integrating methods are becoming a common practice (Cladera et al. 2006).

As indicated in the general introduction (sections 1.1.3 and 1.2.7) the Spanish national plant protection directive is performed under the umbrella of IPM, following the European normatives 2009/128/CE, CE 1107/2009 and Spanish Royal order 1311/2012 for the sustainable use of phytosanitary products. Concerning the control of the medfly, the IPM program in Spain varies between provinces, directed mainly by the economic importance of citrus on each one. At the Valencian Community, the first producer of fresh citrus for export (FAO 2016), the program relies on joint use of cultural methods, rationalized chemical treatments, mass-trapping, chemosterilization, on releases of sterile medfly males (SIT) and on surveillance studies of natural enemies and the integration of Biological Control with exotic parasitoids, along postharvest thermal treatment to fullfil the quarantine protocols of some importer countries (Castañera 2003; Primo-Millo et al. 2003; Beitia et al. 2007; Chueca et al. 2007; Jacas and Urbaneja 2010).

Focused on the control of medfly, chemical treatments have been reduced, and nowadays only applied by growers following directives (GVA 2012) due to the emergence of resistant populations due to the massive treatments applied in the past decades (Ortego et al. 2005; Magaña et al. 2007; Couso-Ferrer et al. 2011). Mass-trapping is applied, following directives, with different devices, attractants and killer substances, and with different number of traps per hectarea (Navarro-Llopis et al. 2007, 2008; Escudero et al. 2009; Martínez-Ferrer et al. 2010; Peñarrubia 2010; Navarro-Llopis and Vacas 2014). Whereas the SIT is being applied in an areawide basis and controlled by the Valencian government. Aerial releases of sterile males are performed covering the citrus production area, thanks to a mass-rearing and sterilization facility with a production capacity of nearly 600 million of sterile pupae per week (Argilés and Tejedo 
2007; GVA 2012). Concerning BC, the surveillance studies on natural enemies highlighted the contribution of generalists' predators (Monzó et al., 2007, 2009a, 2010, 2011) and the presence of several parasitoids attacking pupae (Beitia et al. 2003; Falcó et al. 2003), whereas entomopathogens still remains under study (Castillo et al. 2000; Quesada-Moraga et al. 2006; Vidal-Quist et al. 2008; San Andrés et al., 2008). In addition to these surveillance studies, several attemps of import and naturalization were performed (revised on Jacas and Urbaneja 2010; Sabater-Muñoz et al. 2012), but only the ones performed during the 2000's gived some positive results (Beitia et al. 2002, 2006; Falcó et al. 2003; Santiago et al. 2006).

Thus, the IPM program against the medfly in Spain accomplish the legal measures, including environment and human health concern issues, whereas establishing a portfolio of control measures that limit the appearance of resistant populations, or that limit population outbreaks, also following international standars (Cladera et al. 2006). But, some issues are still neglected deserving further research, as the integration of a classic biological control program within the IPM, and more precisely, the integration of D. longicaudata, as exotic parasitoid, within the SIT program, which is the focus of this chapter.

\subsubsection{Natural enemy release methods within Biological control programs}

As indicated previously in the general introduction (section 1.1.3), a Biological control program can be classified as classical, augmentative or conservative, depending mainly on the parasitoids' ability for geographical spread and self perpetuation in the new territory.

As revealed by the results in the precedent chapters, self perpetuation is influenced by abiotic and biotic factors. But, for plant protection practicioners, released parasitoids should also exhibit either great dispersal ability and a good performance when foraging for hosts' activity allowing pest population reduction. In ecology, 'Dispersion' is the exploratory, undirected movement of the wasp away from the release point and into the surrounding landscape. Parasitoid spread depends on dispersal behaviour of females, which are the responsibles of laying eggs assuring species establishment (Hochberg and Ives 2000). Although, dispersal distance is potentially a species-specific trait, as it depends upon longevity and flight power, it can be affected by abiotic and biotic characteristics of the surrounding landscape (Messing et al. 1997; Mills et al. 2006). Thus, dispersal studies are a pre-requisite for management programs, as the rate of parasitoids spread provide valuable information for control program designers (ie. when and how perform a release), including conservative protocols (ie. what chemicals should be avoided, interaction with another species, ...) (reviewed in Hochberg and 
Ives 2000). Despite this importance, studies devoted to parasitoid spread are still low. This is the result of the difficulty of mark-recapture experiments in open field due to the minute size of parasitoid specimens, the absence of reliable trapping systems and because these experiments (mark-recapture) do not provide the key information about parasitoids egg-laying location (parasitoids performance). Ecological models indicate that to improve the accuracy of recapture, when traps with species specific lure are not available, it is advisable to increase the density of traps per area unit, despite that the presence of a high number of traps will reduce the dispersal rate of released parasitoids (Mills et al. 2006).

Relative to tephritid fruit flies parasitoids, releases (within a BC program) are performed in an unsupervised fashion, meaning, that released specimens are either not labelled or not recaptured after release (Paranhos et al. 2007; Bokonon-Ganta et al. 2013; Camargos et al. 2016). Indeed, recapture studies hadve provided opposed results, not revealing any clear methodology that allow the determination of dispersion and parasitism percentage (as measure of egg-laying location) at the same time or with the same efficacy. Indeed, Cornelius et al. (1999) indicate that D. longicaudata showed a preference for yellow traps, while Segura et al. (2007) determined that this parasitoid species do not show any visual preference for chromatic traps. Only one field work showed that this species can be monitorized with yellow sticky traps when the traps were at a high density covering all cardinal directions within 1-2 meters from release point limiting its dispersal rate (Paranhos et al. 2007). In summary, these works indicate the lack of an efficient labelling method and recapture protocol advisable to perform a reliable dispersal study of $D$. longicaudata, letting us to develop a system to evaluate its dispersal capacity within the natural conditions in the Mediterranean basin.

The first part of this chapter deals with this issue, having in mind the fact that one key point is determining egg-laying point distance from release point. Therefore, the objective was to determine the dispersal capacity and parasitism percentage of $D$. longicaudata in citrus fields under natural Mediterranean climatic conditions, and to assess the different abiotic factors influencing dispersion capacity and parasitism percentage. All these with the aim to determine future release methods suitable for Mediterranean areas (like Valencia (Spain) and Tunisia) within a Biological control program against the Mediterranean fruit fly.

\subsubsection{Integration of Biological Control and the Sterile Insect technique}

The SIT success relies on the mating success of overflooding released sterile males (see section 1.2.7.7 for a full description of the technique), that requires mass-rearing facilities to achieve 
these overflooded ratios. Parasitoids work best against high pest populations, where foraging activity is enhanced by chemical cues (see precedent chapter) and parasitoid population can be maintained by the host population (reviewed in Dyck et al. 2005). From the methodological point of view of practicioners, an augmentative release program is an attractive extension of SIT, as mass-rearing facilities of sterile insects could also provide support a parasitoid species mass-rearing without increasing substantially the costs (Sivinski 1996; Thomas 2007). Moreover, empirical studies and population modeling strongly suggest that the synergistic interaction of sterile males and parasitoids may give a fast and cheaper pest suppression, as both insect species can spread over a pest-invaded territory where other techniques like aerial chemical treatments are forbidden (Sivinski 1996).

In Spain, since the implementation of the Area wide (aw)-SIT program, sterile males are routinely subjected to quality control measures which include flight ability, dispersion, longevity and mating success, among others (Argilés and Tejedo 2007; FAO/IAEA/USDA 2003). More recently, the Spanish aw-SIT program was subjected to a more applied quality control, by measuring the impact of sterile males in reducing next medfly population (JuanBlasco 2012; Juan-Blasco et al. 2013a, 2013b, 2014). From these studies in Mediterranean conditions, it was obtained that the ratio 5:1 (sterile: wild medfly males) contribute to a medfly population reduction up to $80 \%$ as compared to control (no sterile males) in almost all seasons. These studies also confirmed the owerwintering ability of medfly as larvae inside fruits or as adults, but highlighted the thermal threshold for mating and oviposition, reducing the possibilities of performing any field study with parasitoids or sterile males during the winter season (Juan Blasco 2012). Thus, studies for the integration of D. longicaudata within the SIT program should be avoided during winter, as we expect no oviposition from medfly females and no oviposition by D. longicaudata females as obtained in the precedent chapter.

The second part of this chapter deals with the studies on integration of D. longicaudata with the aw-SIT program. Hence, as continuation of the precedent sub-section, releases were planned as a single point release, at different release ratio of $D$. longicaudata females per wild-type medfly female, to ascertain the contribution of Biological control to medfly population reduction by SIT under Mediterranean climatic conditions, determining also abiotic factors affecting parasitoid performance. 


\subsection{Material and Methods}

\subsubsection{Dispersion studies in citrus groves}

\section{Study site and release protocol}

The study was carried out during two consecutive years, 2011 and 2012, covering the four seasons in each period. The first year the study took place in a 1-ha citrus plot, whereas the second year the study site was moved one $\mathrm{km}$ far away. In both cases, citrus plots were located within the IVIA Experimental station $\left(39^{\circ} 35^{\prime} 22.6^{\prime \prime} \mathrm{N} 0^{\circ} 23^{\prime} 41.0^{\prime \prime} \mathrm{W}\right.$, Valencia, Spain). An official meteorological station located midway between these two selected plots provided for climatic parameters (rainfall, wind direction, wind speed, RH, min and max temperature). Each study site was divided in a grid of $20 \times 20 \mathrm{~m}$ ( 5 rows per 5 columns), allowing the setup of 25 selected trees as sampling points evenly distributed in 1 ha (Figure 4.1).

A)

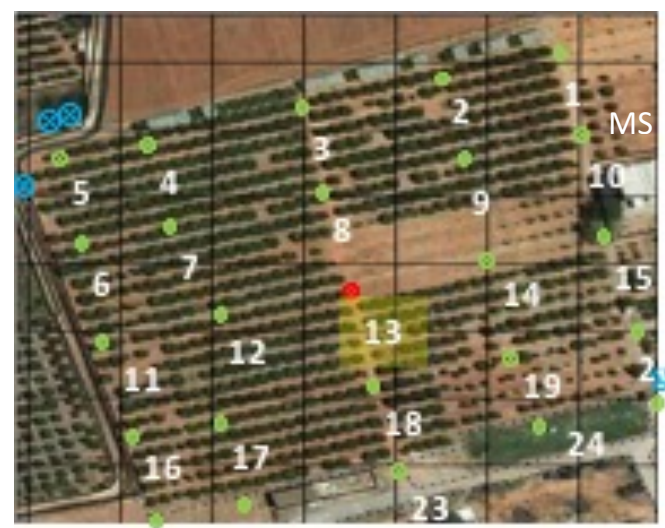

B)

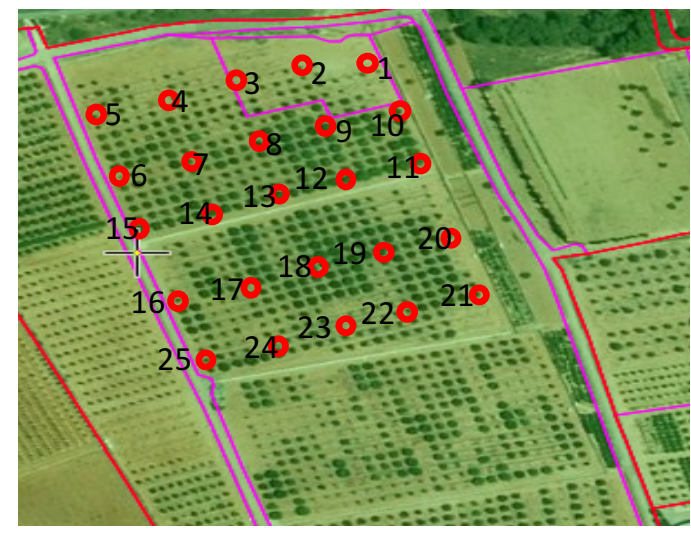

Figure 4.1. Aerial pictures of the two 1-ha citrus plots used for this study with indication of the releasing point, sampling points and numbers, and location of Meteorological station (MS) in site for first year (A) and second year (B). Both plots are within the IVIA Research station and separated less than $1 \mathrm{~km}$. The blanks within the pictures do not mean absence of trees, these aerial pictures were done in some cases 5 years before this experiment.

Parasitoid cohorts were kept in the climatic chamber till release at female age of 5-6-days old. Two days prior to the release, four artificially medfly-infested apples var. Royal Gala were deposited in each cohort cage for the adaptation of the parasitoids to the host odor clues of the designed monitorization system (see below). Medfly-infested apples were removed at least one hour prior release. Release took place on the center of the 1-ha plot by opening and gently soaking of all cohort cages in the four cardinal directions. 
A total of eight releases were performed, each one in a different season with a variable number of parasitoid females (Table 4.1), as was the maximum obtained in our rearing system at each data. A data-logger was set-up to record temperature and RH during each trial, other climatic data were retrieved from the official meteorological station located within the study site.

Table 4.1. Number of released D. longicaudata during the different trials.

\begin{tabular}{|c|c|c|c|c|c|c|c|c|}
\hline Trial & $\begin{array}{l}\text { Spring } \\
2011\end{array}$ & $\begin{array}{l}\text { Summer } \\
2011\end{array}$ & $\begin{array}{l}\text { Autumn } \\
2011\end{array}$ & $\begin{array}{l}\text { Winter } \\
2012\end{array}$ & $\begin{array}{l}\text { Spring } \\
2012\end{array}$ & $\begin{array}{l}\text { Summer } \\
2012\end{array}$ & $\begin{array}{l}\text { Autumn } \\
2012\end{array}$ & $\begin{array}{l}\text { Winter } \\
2013\end{array}$ \\
\hline \multicolumn{9}{|l|}{ No. of females } \\
\hline & 3,000 & 40,000 & 40,000 & 15,000 & 15,000 & 15,000 & 15,000 & 15,000 \\
\hline
\end{tabular}

a)

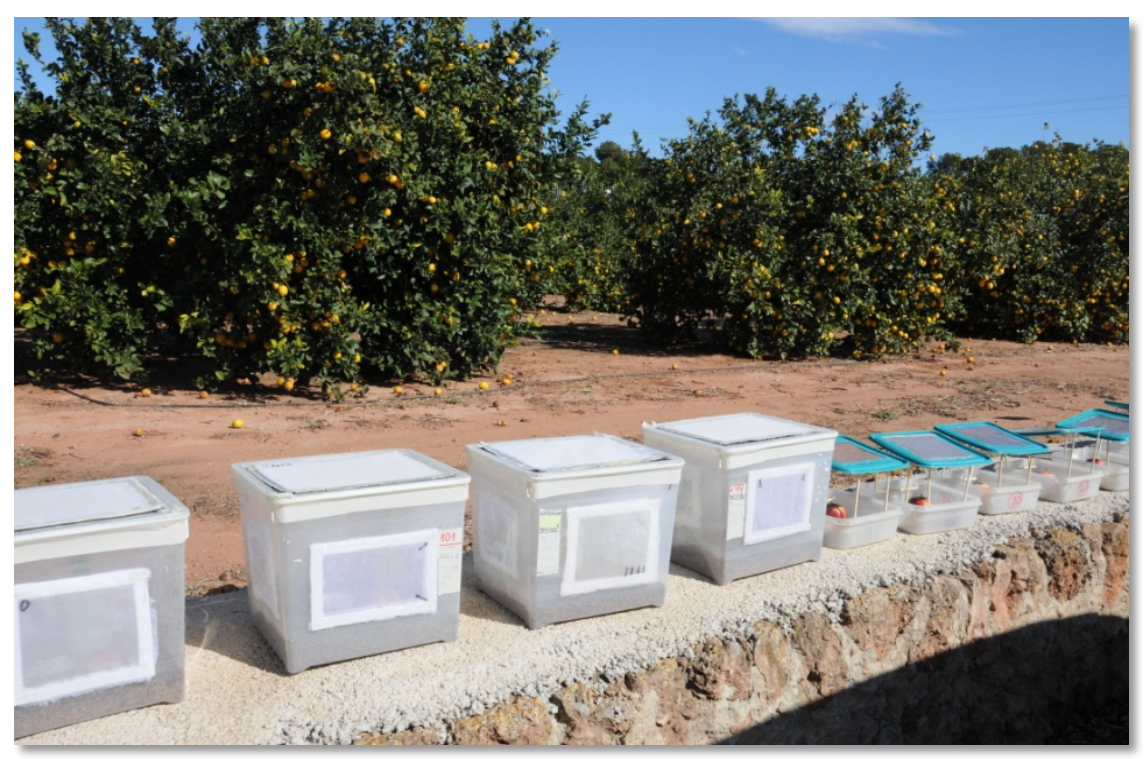

b)

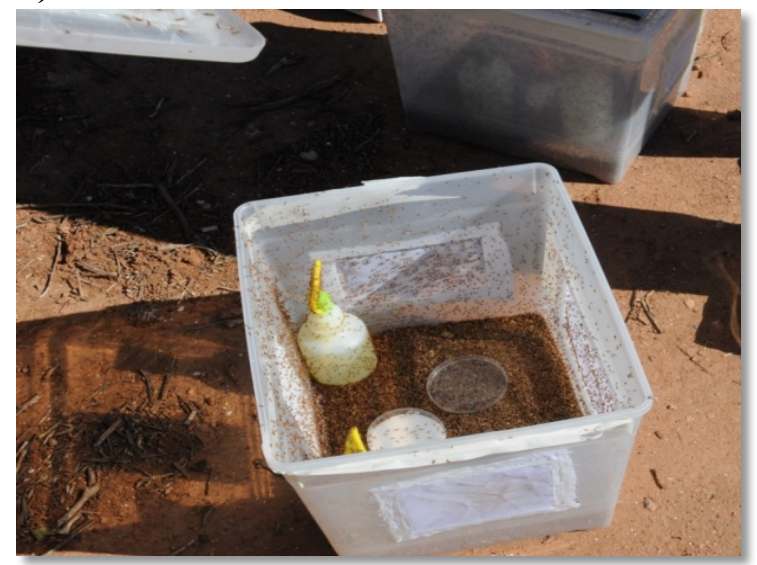

c)

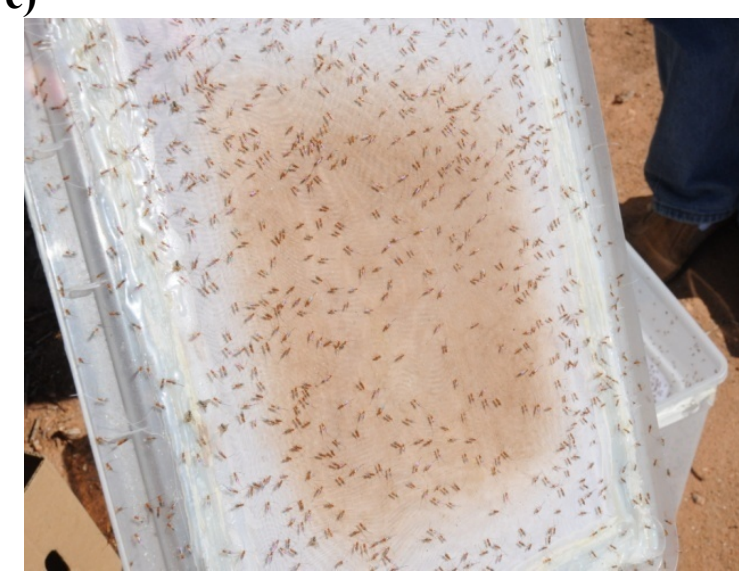

Figure 4.2. Releasing cages of $D$. longicaudata used in the experiment. a) All the cages and sentinel traps in the trial field; b) a close view of a open release-cage; and c) close view of $D$. longicaudata individuals resting at the cage top-door. 


\section{Parasitoid monitorization}

A monitorization system was developed to follow parasitoid movement and activity/efficacy in the field. Parasitoid movement was assessed with twenty-four yellow sticky traps (220x 350 $\mathrm{mm}$; Biagro SL, Valencia, Spain) placed in the sampling points, except in the one corresponding to release point (point no. 13) (Figure 4.3). This trap was not set up to avoid the massive trapping at release point and by hence, limiting the number of specimens that were going to be followed. Traps were setup 24-hr prior parasitoid release to avoid extreme attraction of aphids or other pests insects present in the study plots. Each trap was placed in the southwest part of each selected tree and was checked at 5, 7 and 15 days after the release.

a)

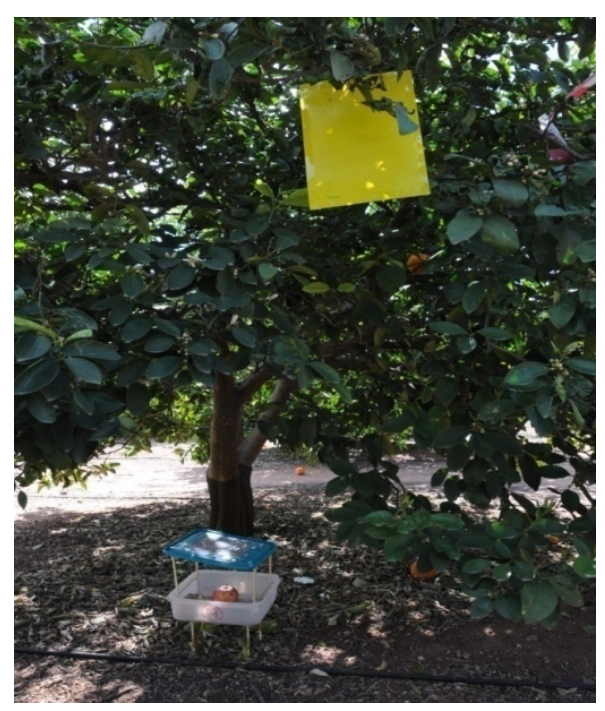

b)

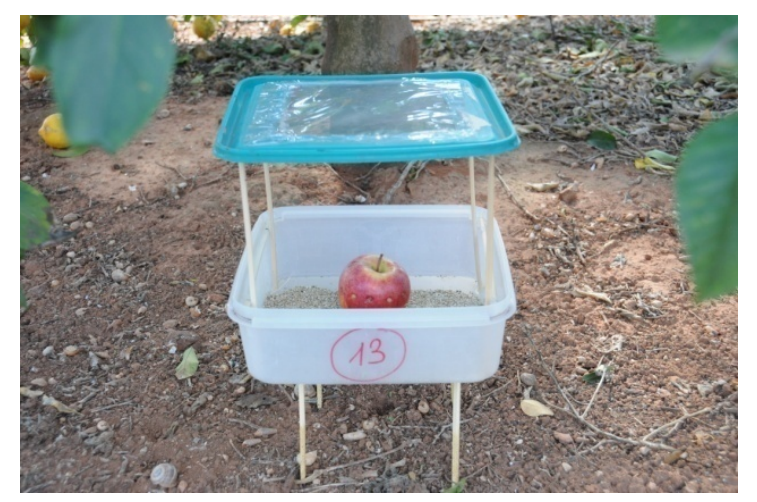

c)

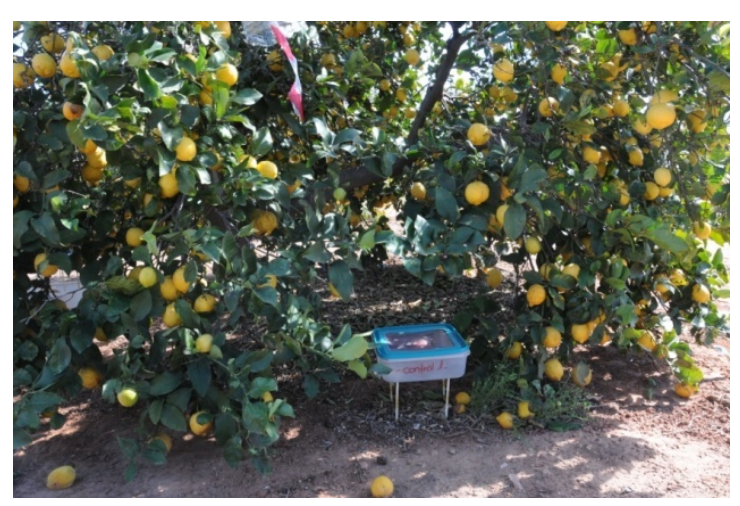

Figure 4.3. Experimental dispositive to assess the dispersion and the parasitism of released $D$. longicaudata. a) a sticky-yellow plate located above the sentinel fruit; b) a container containing an infested sentinel apple, within a semiprotective environment; and c) location of whole set-up under a lemon tree. 
Parasitoid efficacy (induced parasitism) was assessed with sentinel fruits which were located in the 25 sampling points. Sentinel fruits consisted in apples (var. Royal Gala) artificially infested with 30 L2-L3 C. capitata larvae distributed in 10 holes (Ø $5 \mathrm{~mm}$ ) along all apple perimeter. Sentinel fruits were placed inside a rectangular opened container (household Tupperware-like of $20 \times 20 \times 7 \mathrm{~cm}$ ) containing vermiculite to facilitate the pupation of provided hosts. Three control sentinel fruits were placed in the release point, inside of mess-covered cages (parasitoidfree), to assess natural mortality of each C. capitata larva lot or mortality induced by extreme climatic conditions. Sentinel fruits were in field till day 7 after release, but each sentinel station was checked for the presence of jumping larvae or pupae at day 3 and 5, time at which any larvae or pupae were collected, after this time, sentinel stations were retrieved to the laboratory. Jumping larva and pupae were collected and placed in small containers (150 $\mathrm{ml}$ cups), labeled with the corresponding sampling point code, and allowed to develop at laboratory conditions ( $60 \% \mathrm{RH}, 25 \pm 5^{\circ} \mathrm{C}$, with natural daylight). After 15-30 days, emerged individuals were identified and sexed. Uneclosed pupae were kept for another month, and if not eclosed, labeled as such (uneclosed).

\subsubsection{Joint use of SIT and D. longicaudata releases}

\section{Experimental site}

The field test was conducted at the experimental station of the IVIA $\left(39^{\circ} 35^{\prime} 22.6^{\prime \prime} \mathrm{N}\right.$ $0^{\circ} 23^{\prime} 41.0^{\prime \prime} \mathrm{W}$, Moncada, Valencia, Spain), with 12-17 years-old clementine trees. Trees were permanently kept isolated inside screened anti-thrips cages $(3 \times 3 \times 3 \mathrm{~m})$ with a zippered-door (1.5 $\mathrm{m}$ high) in one of the sides (Figure 4.4).

\section{Insects' strains and rearing conditions}

The wild-type strain (wt) adults of C. capitata and sterile male puparia of the Vienna-8 (V8) were obtained from TRAGSA emergence facility (Moncada, Valencia, Spain). The refreshment of the (wt) adults colony is carried out annually with wild flies collected from field-infested fruit to avoid high levels of endogamy. Sterile male puparia of the Vienna-8 (V8) temperature sensitive lethal (tsl) Genetic Sexing Strain (GSS) mix 2002 strain, were obtained two days prior to fly emergence. These puparia were marked with pink fluorescent dye (Day-Glo® Color Corp., Cleveland, OH, USA) so that released adults resulted in being marked with the dye by contact with the puparia during emergence. V8 pupae were irradiated under hypoxia using beta irradiation at a dose of $105 \pm 10 \mathrm{~Gy}$, since at these doses the digestive physiology and the longevity of irradiated medflies is not affected (San Andrés et al. 2007b). 
Diachasmimorpha longicaudata strain was obtained from the laboratory colony housed in rearing climatic chamber of IVIA (Moncada, Valencia, Spain).

a)

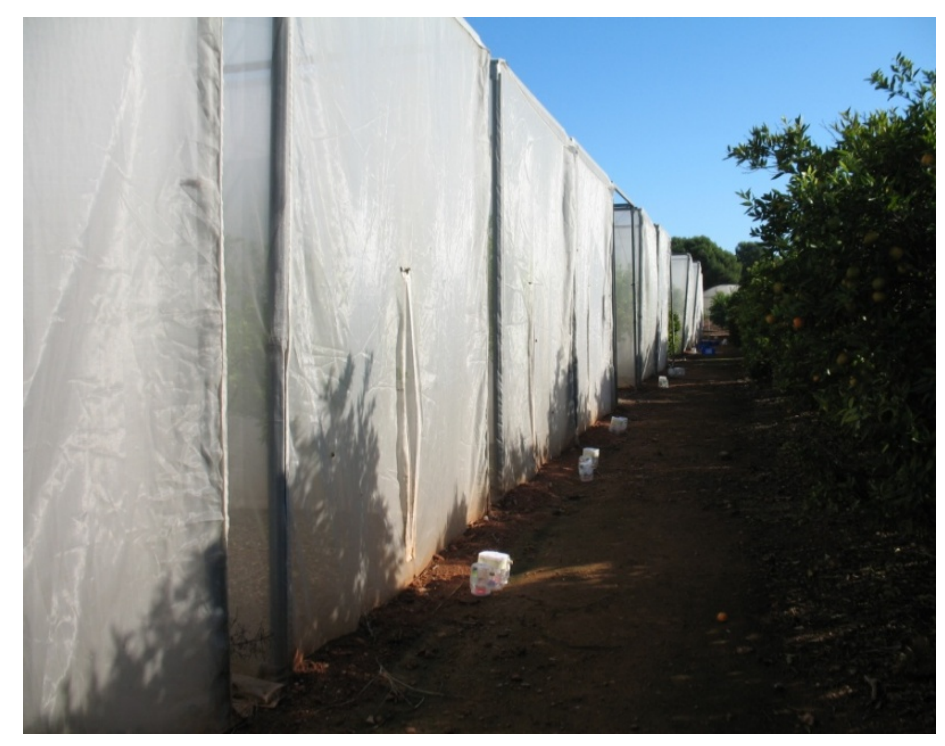

b)

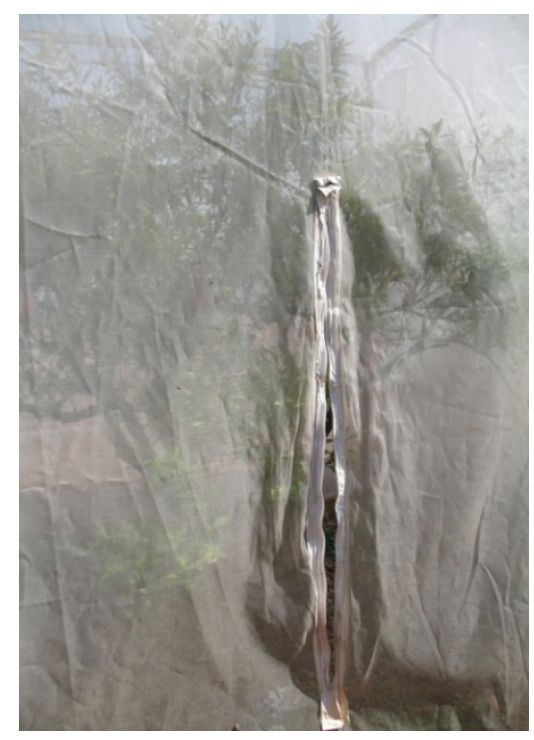

Figure 4.4. Experimental Citrus clementina field with a row of single-isolated trees with antithrips screened cages for field trials purpose. a) panoramic view with some of the isolated trees and insects; and b) a detail of the zippered door in one of the sides.

\section{Experimental protocol}

To use the results obtained by Juan-Blasco et al. (2013), the same protocol was conducted for the preparation and the release of the insect sterile at a ratio of 1:5 (fertile males: sterile males). Indeed, the age of all used flies was $<24 \mathrm{~h}$ old. Adult wt females, wt males, and sterileV8 males were maintained separately in Perspex cages $(20 \times 20 \times 20 \mathrm{~cm})$ with one ventilated window $(16$ $\times 16 \mathrm{~cm}$ ) per cage in the lid. Each cage contained a maximum of 250 individuals. To simulate the real scenario, wt adult flies were fed with a mixed diet of sugar and hydrolyzed yeast (Biokar Diagnostics Co., Pantin, France) (4:1; w:w) since it is assumed that they have access to sugar and protein supplies in the field (San Andrés et al. 2009). V8 males were fed with sugar, which is used as standard pre-release diet in the Spanish SIT program. Water and the corresponding diets were provided ad libitum. Wt adult flies were separated by sex in different rooms to prevent any effect due to contact with sex pheromones from the opposite sex until used (5 dayold for the wt females and 5 day-old for the wt males) that would interfere with posterior mating performance during the tests. Rooms were maintained at $25 \pm 4^{\circ} \mathrm{C}, 75 \pm 5 \% \mathrm{RH}$ with natural light. V8 males were maintained at $25 \pm 4^{\circ} \mathrm{C}, 75 \pm 5 \% \mathrm{RH}$ and complete darkness in the emergence facility to simulate actual pre-release conditions until used (3-4 day-old). Likewise, 
sterile V8 males were subjected to aromatherapy treatment with Ginger Root Oil (GRO) [Zingiber officinale Roscoe (Zingiberaceae)] (dose of $320 \mu \mathrm{l} / \mathrm{m}^{3}$ ) for $6 \mathrm{~h}$ in a large room (149 $\mathrm{m}^{3}$ ) in which the GRO aroma was dispersed by air fans to enhance mating competitiveness (Juan-Blasco et al. 2013b).

Prior to introduction into the field cages, the insects were handled in the following manner: newly emerged wt females and wt males, were maintained in polypropylene (PP) jars (500 and $1000 \mathrm{ml}$ respectively) with a ventilated area of $9 \times 8 \mathrm{~cm}$. A density of 50 individuals (females or wt males) per jar was used. Newly emerged sterile V8 males were maintained in PP jars $(4000 \mathrm{ml})$ with a ventilated area of $12 \times 11 \mathrm{~cm}$ with 250 sterile males (V8) per jar (Figure 4.5$)$.

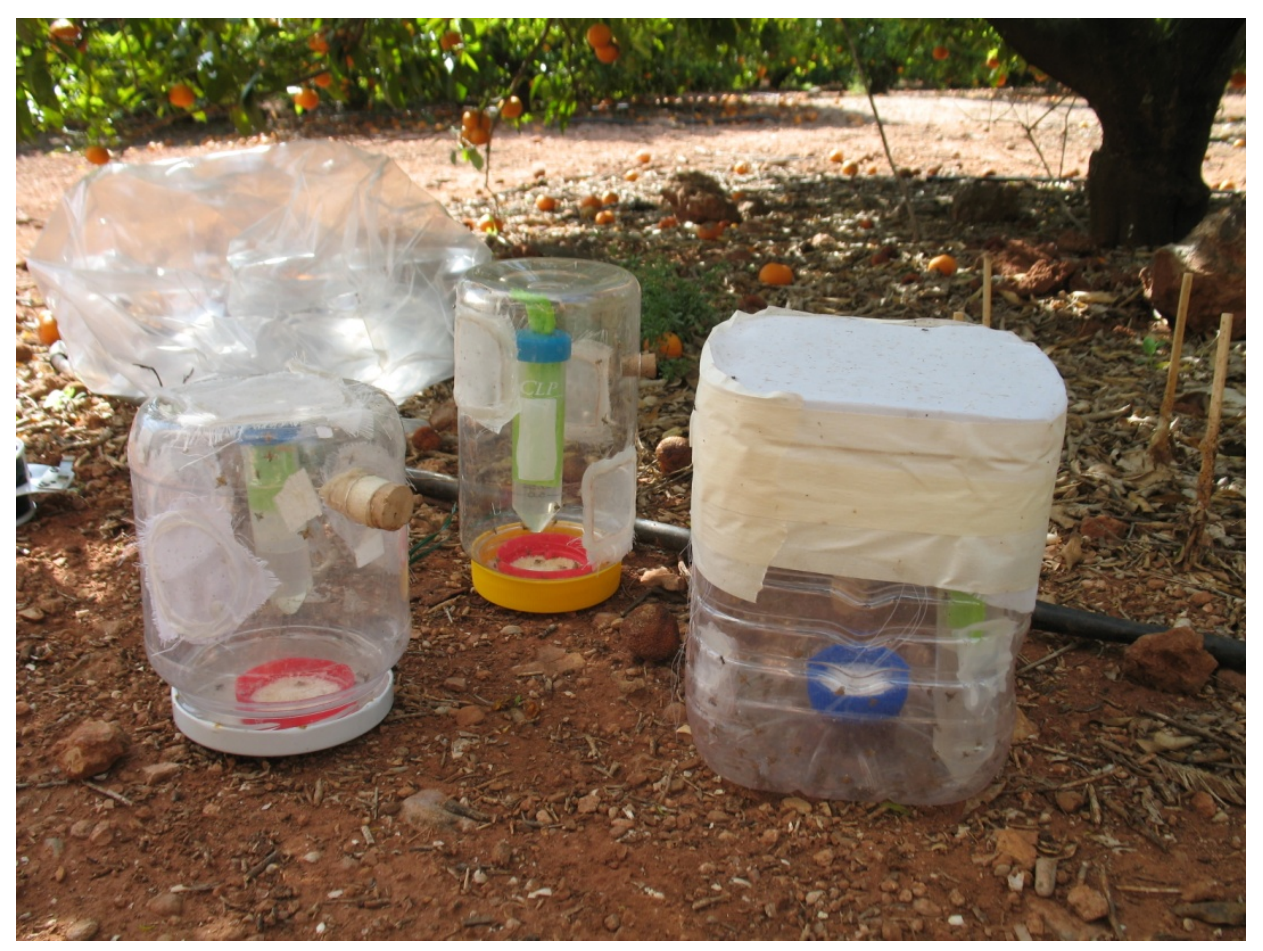

Figure 4.5. Jars used to maintain adult flies from emergence to introduction into field cages.

The apples were individually fitted inside a polyethylene (PE) mesh (holes of $1 \mathrm{~cm}$ diameter) and were randomly hung within the tree canopy (Figure 4.6). Twelve sentinel apples were offered per tree. The tree cages were kept free of pests, and weeds were removed before the test following IPM guidelines (Urbaneja et al. 2012), though pesticide treatments were avoided. The ground community of arthropods naturally occurring in Spanish citrus orchards (Urbaneja et al. 2006, Monzó et al. 2011a, 2011b) was not prevented in the experimental tree cages. The 
test started in the morning by hanging the 12 sentinel apples in each tree. Afterwards, males (wt and sterile V8) and females (wt) were released into the cages. Males were introduced 15-30 minutes prior to females to allow them to disperse and establish territories (FAO/IAEA/USDA 2003).

48 hour after that, a Tephri trap (Sorygar S.L., Madrid, Spain) baited with the female-targeted attractant Biolure Tripack MedFly Lure ${ }^{\circledR}$ (Suterra Corporate, Bend, OR, USA) and 1/6 of a tablet of the insecticide dichlorvos (DDVP) (Suterra España Biocontrol S.L., Cerdanyola del Vallès, Spain) was hung on each tree (Figure 4.6). Two days after, traps were removed and the hanged apples were put in container with vermiculite under the tree. These apples were kept in the field cages during 8-10 days controlling the stage of its infestation each 2-3 days till the presence of $2^{\text {nd }}-3^{\text {rd }}$ instars larvae of C. capitata (Figure 4.7).
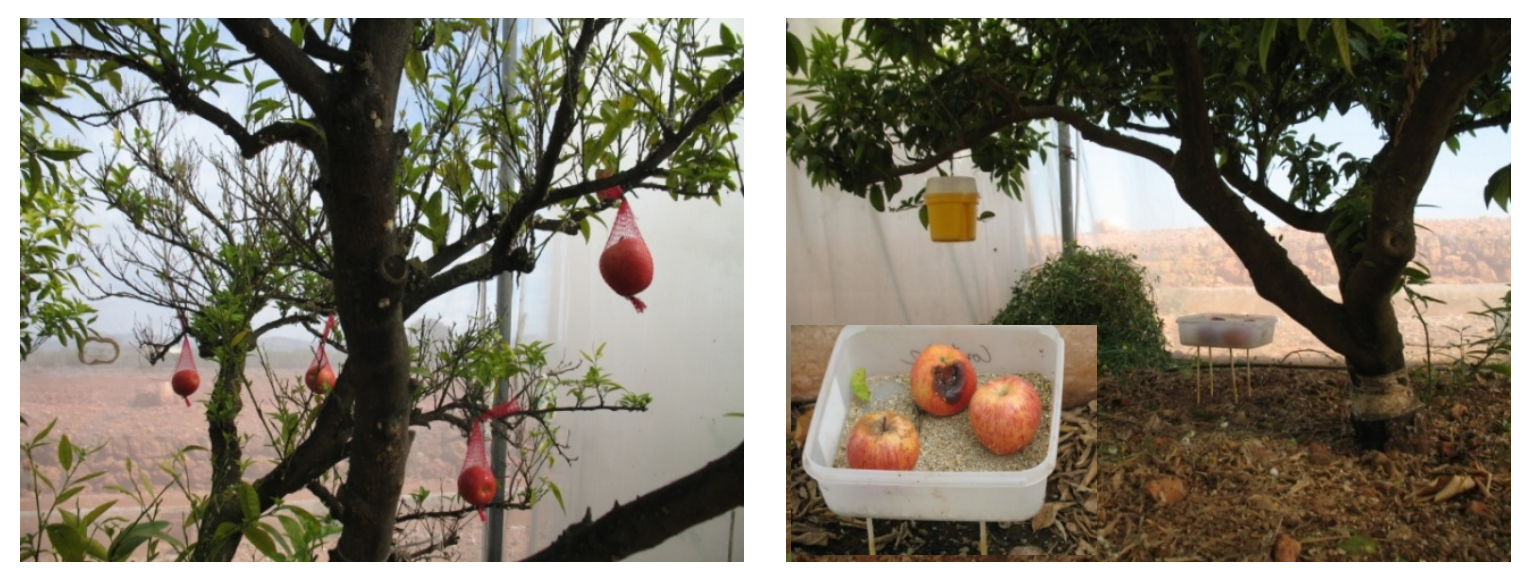

Figure 4.6. Experimental set up inside the field cages trees. At the left, sentinel apples hanged in the three. At the right, a detail of the medfly infested apples within the cage and the Tephri-Trap used to control the activity of medflies.

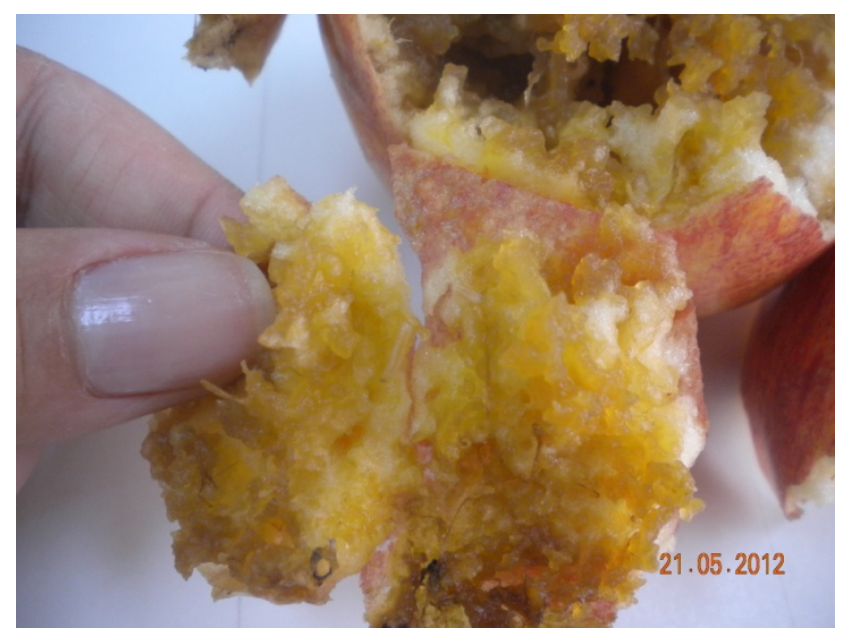

Figure 4.7. Controlling the presence of C. capitata L2-L3 instar larvae inside the sentinel apple. 
When medfly larvae inside sentinel apple were in the $2^{\text {nd }}-3^{\text {rd }}$ instars, we could apply our experimental treatment. Treatments consisted of applying different (D. longicaudata female:wt female:wt male:sterile V8 male) ratios in individual cages. The ratios tested were 0:1:1:5, 1:1:1:5, 3:1:1:5 and 5:1:1:5. These treatments consisted on $50 \mathrm{wt}$ females, $50 \mathrm{wt}$ males, 250 sterile V8 males, and 0, 50, 150 or 250 couples of D. longicaudata (Figure 4.8). The released parasitoids were kept in the field cage during one week and then apples were removed and taken to the laboratory and the pupae were recuperated from the vermiculite and saved in aired cylindrical bottles till adults' emergence (Figure 4.8).

Three replicates were conducted per treatment with a random distribution of the replicates among the cages. The field test was carried out during four different seasons to evaluate the impact of climatic conditions on the treatments (May 2012, July 2012, November 2012 and May 2013).
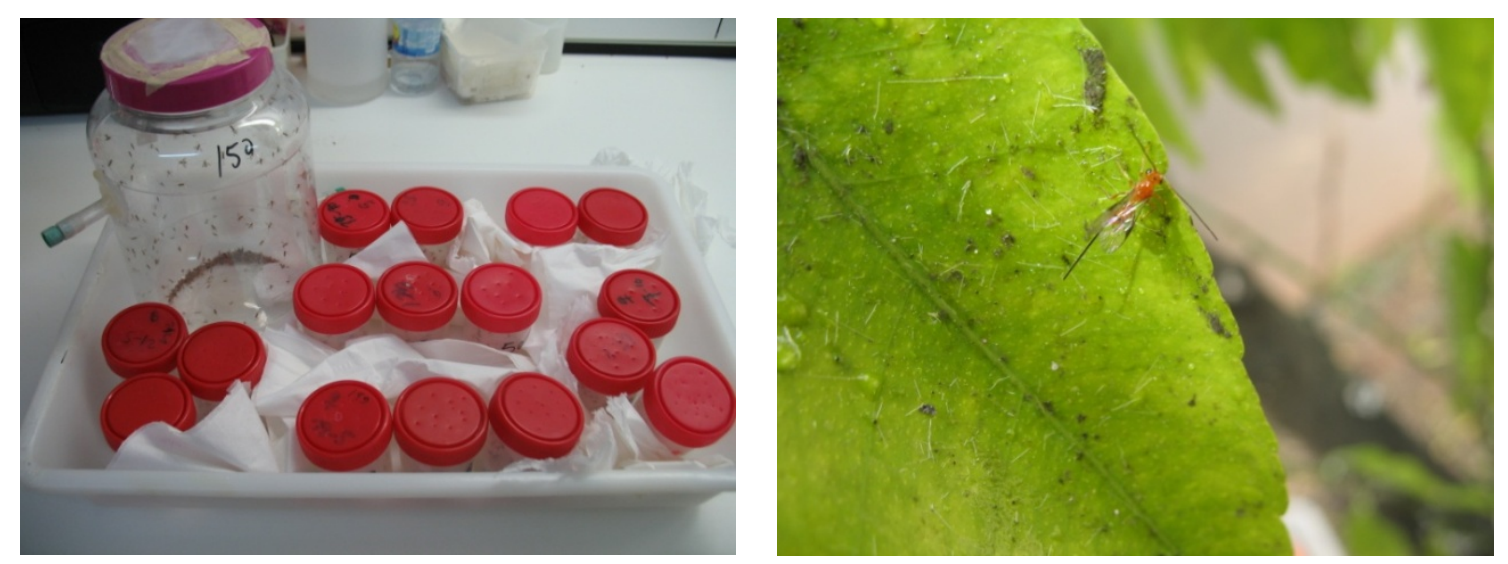

Figure 4.8. Set up with collected females in the release pots (left picture) and a detailed released $D$. longicaudata female (right picture) within the cage.

\section{Climatic conditions data}

The climatic conditions during the different trials were obtained by a data logger hung in one of the tree field cage.

\section{Data analysis}

For each treatment recovered pupa were counted before being allowed to develop under laboratory conditions. Medfly, parasitoids and uneclosed pupa were also counted to determine $\%$ of parasitism, $\%$ of induced mortality and average medfly population reduction due to sterile males and parasitoids (based on Juan-Blasco et al. 2013). In order to compare different treatments, $\%$ of parasitism and \% of induced mortality were subjected to one way Analysis of Variance (ANOVA) followed by the post hoc test of Duncan. 


\subsection{Results and Discussion}

\subsubsection{Dispersion pattern under natural conditions in citrus groves}

The total recovered parasitoid number in the yellow sticky traps during all trials was not significant different compared to the released wasp number, obtaining only 20 individuals (14 and $6 \hat{\circ})$ and 14 individuals $(13 \propto$ and $1 \overbrace{}^{\Uparrow})$ for the first and the second orchard, respectively. This number did not exceed the $0.02 \%$ of the released parasitoids and it was depending on the climatic conditions which are recorded by the data logger and the meteorological station (Table 4.2). In all the trials, the most recovered parasitoids were in the North direction which corresponded with main wind direction. The highest recovered D. longicaudata was recorded when there was no rain (Table 4.3). The released parasitoid densities did not reflect a high correlation with the percentage of the recovered wasp number. And the highest number was recorded with the lowest released number which coincided with best climatic conditions in spring of 2011 (Table 4.2). D. longicaudata was able to disperse till the furthest point in the orchard with a distance of $75 \mathrm{~m}$ in both experimental orchard and in different seasons of the year.

The results derived from the recovered parasitoid number in the yellow sticky traps are endorsed and confirmed by the second system to the monitoring which is the sentinel fruit trap. In addition to its ability to demonstrate that the parasitoid can disperse, it shows that $D$. longicaudata can parasitize C. capitata larvae and produce other generation of the parasitoid in both orchards (Table 4.3). The D. longicaudata parasitism in the fruit traps is the result of the female movement and thus can be used as an indirect method to detect adult dispersion (Figures 4.9 and 4.10)

In all the trials and in both orchards, despite of the high number of released parasitoid, the parasitism in the sentinel fruits was relatively low and focused in the center of the orchard which it was the release point.

In the first citrus plot, the parasitism percentage of $D$. longicaudata, in summer and the winter was acceptable; it was between 20 and 50\%. A total of 25 (16 + and $\left.9{ }^{\Uparrow}\right)$ and 34 adults (16ㅇ and $18 \hat{\jmath}$ ) emerged pm July and March trials, respectively. On spring of 2011, there was no parasitism in the autumn, despite the high number of released parasitoids (40,000 individuals), the parasitism was focused in the release point only.

In the second orchard, and with the same density of released parasitoids in the different essays $(15,000$ individuals per release) the parasitism was different. It was dispersed in all the orchard reaching $40 \%$ of parasitism in the spring of 2012 recorded at $50 \mathrm{~m}$ far away the release point in 
the north direction, and it was absent in the winter of 2013 trial and focused just in the release point of the orchard.

In total, the recovered parasitoids number as a new generation in the spring 2012 trial was 42 individuals $\left(18 q+24 \varsigma^{\Uparrow}\right)$; in the summer essay, it was 7 adults $(6 q+1 \overbrace{}^{\Uparrow})$ and in autumn the recovered $D$. longicaudata number was 14 individuals $\left(10 \propto+4{ }^{\Uparrow}\right)$.

Table 4.2. Climatic data for each trial, with indication of mean values for the week on which was conducted each one.

\begin{tabular}{lccccc}
\hline Trial & $\begin{array}{c}\text { Temperature } \\
\left({ }^{\circ} \mathbf{C}\right)\end{array}$ & $\begin{array}{c}\text { Humidity } \\
(\mathbf{\%})\end{array}$ & $\begin{array}{c}\text { Rainfall } \\
(\mathbf{m m})\end{array}$ & Wind direction & $\begin{array}{c}\text { Wind speed } \\
(\mathbf{m} / \mathbf{s})\end{array}$ \\
\hline Spring 2011 & 22.82 & 72.83 & 0 & $\mathrm{~N}$ & 4.56 \\
Summer 2011 & 23.54 & 71.97 & 6.2 & $\mathrm{~N}$ & 4.61 \\
Autumn 2011 & 15.16 & 82.86 & 3.3 & $\mathrm{~N}$ & 3.07 \\
Winter 2012 & 13.78 & 61.76 & 0 & $\mathrm{~N}$ & 4.01 \\
Spring 2012 & 23.05 & 56.85 & 3.3 & $\mathrm{~N}$ & 4.56 \\
Summer 2012 & 28.67 & 56.24 & 0 & $\mathrm{~N}$ & 3.53 \\
Autumn 2012 & 18.86 & 73.83 & 6.2 & $\mathrm{~N}$ & 4.71 \\
Winter 2013 & 13.27 & 54.77 & 3.3 & $\mathrm{~N}$ & 4.01 \\
\hline
\end{tabular}




\section{First orchard}

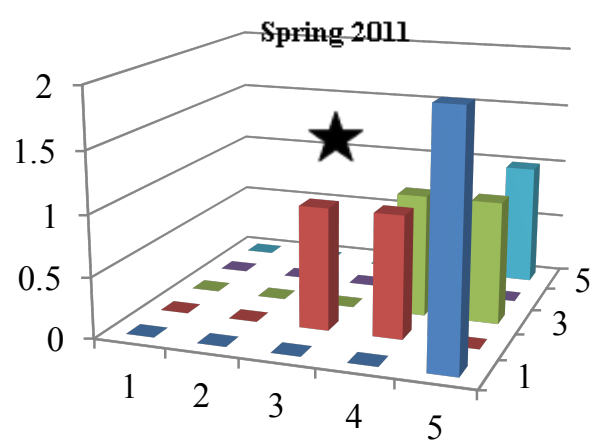

हैं
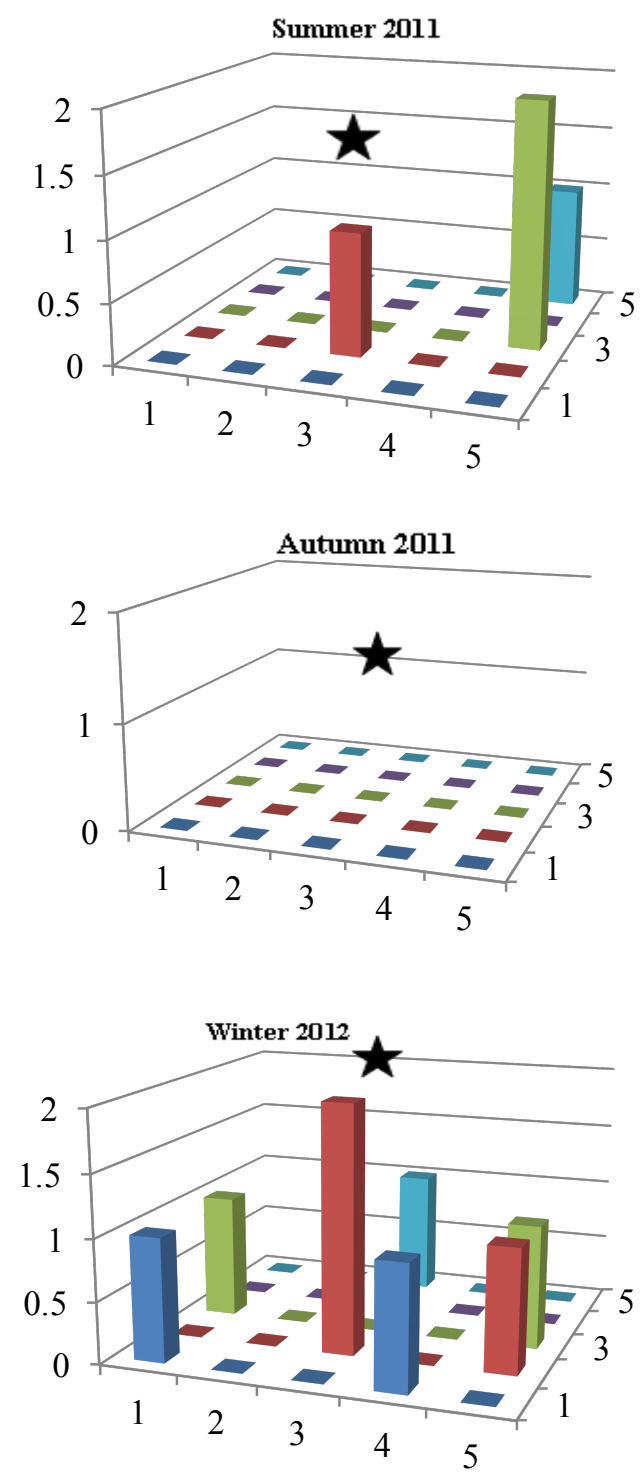

Second orchard
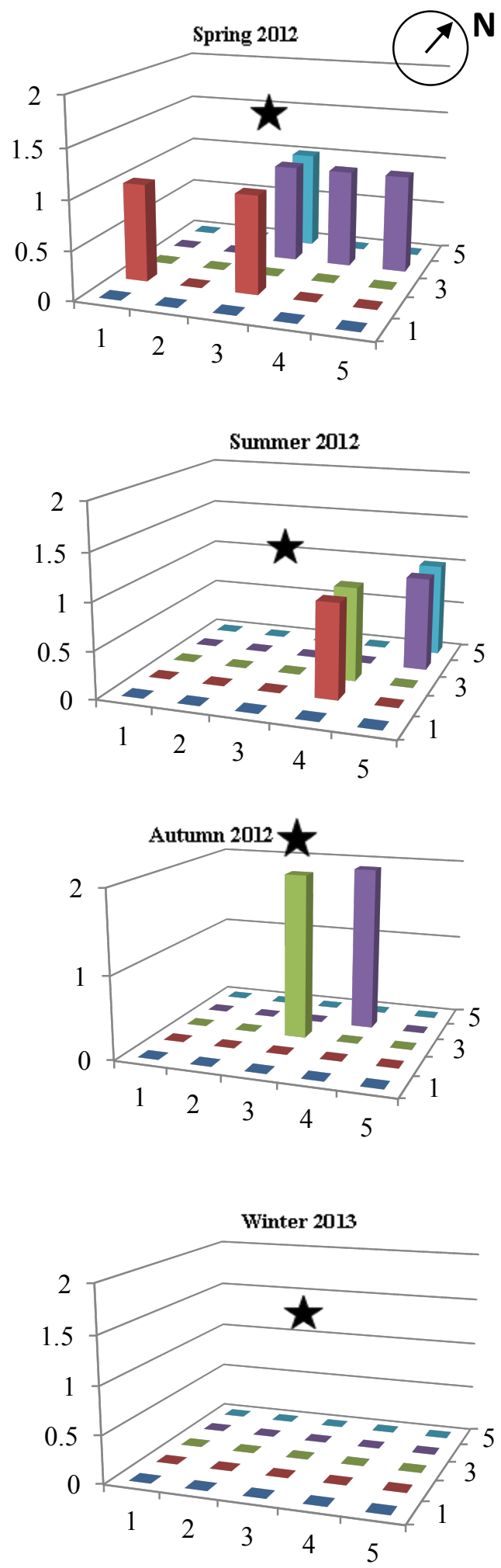

Citrus tree series

Figure 4.9. Average parasitoids number captured with yellow sticky traps at each trial. The star on the graphs correspond to the release point and the center of the orchard which is the release point. Each color represents a tree row with a trap, numbers indicate the tree number within each row. 
First orchard
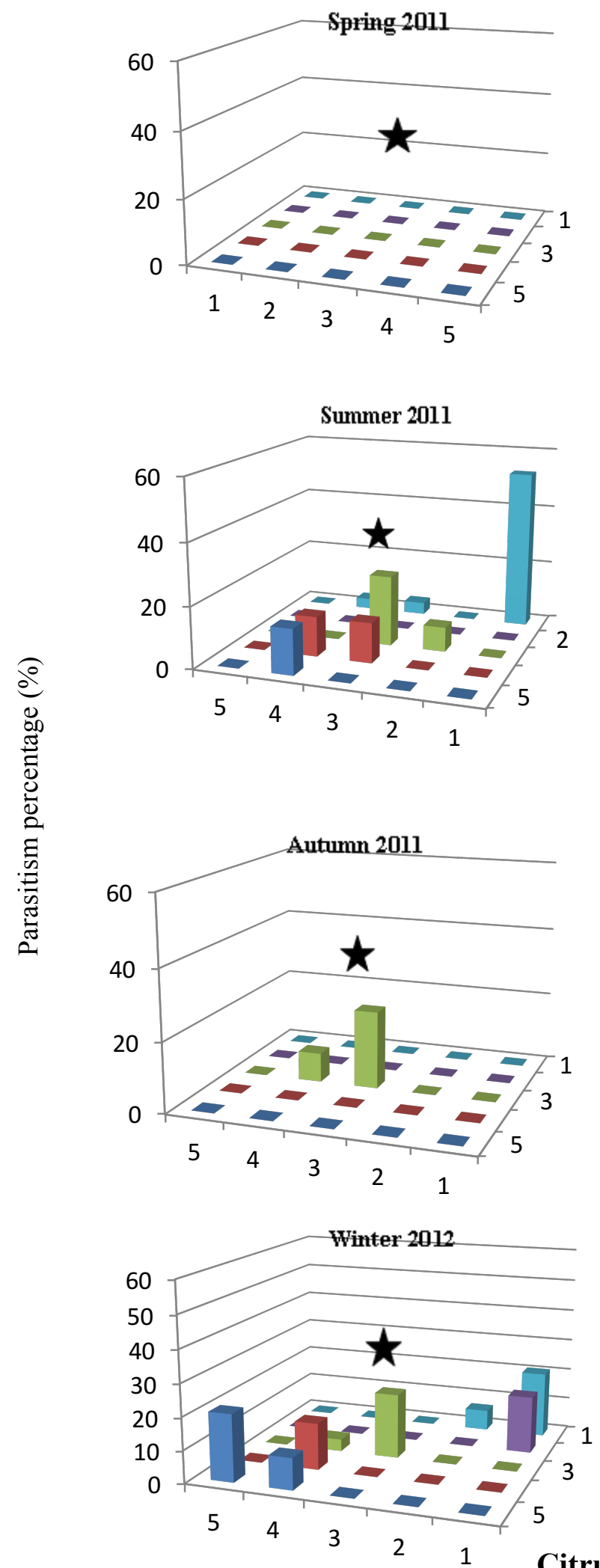

\section{Second orchard}
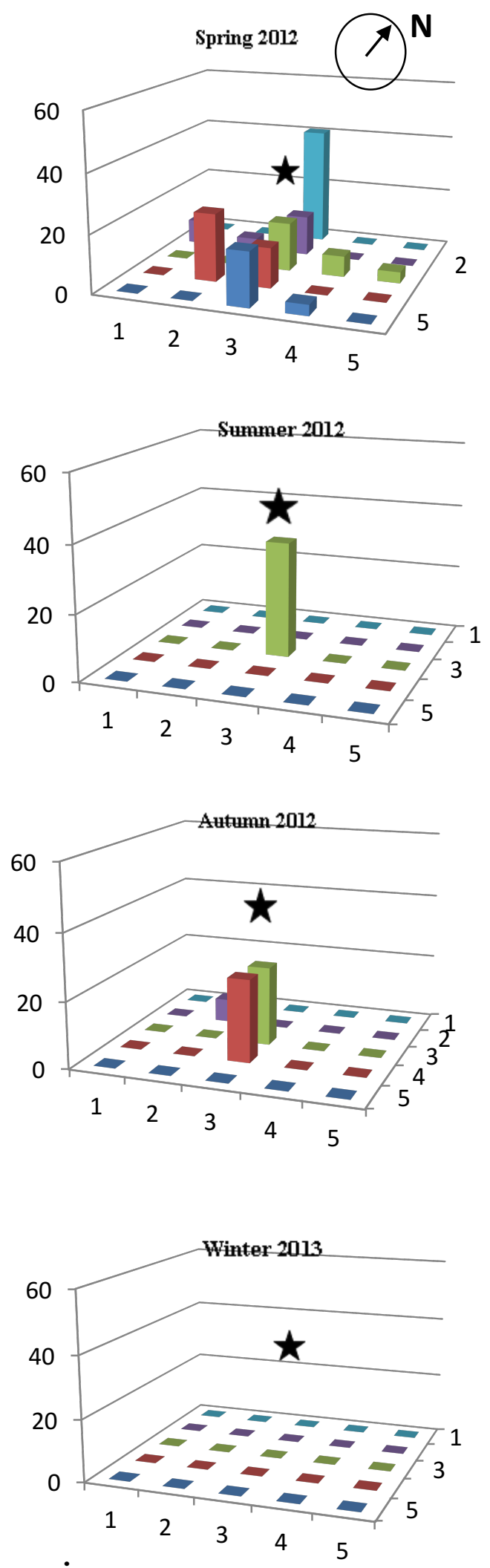

Citrus tree series

Figure 4.10. Parasitism percentage generated by the released $D$. longicaudata in the different trials. The star on the graphs correspond to the release point and the center of the orchard which is the release point. Each color represents a tree row with a trap, numbers indicate the tree number within each row. 
Table 4.3 (first half). Number and sex of recovered parasitoids in each trap and trial. The release point trap is trap no. 13 (in grey).

\begin{tabular}{|c|c|c|c|c|c|c|c|c|c|c|c|c|c|}
\hline \begin{tabular}{|l}
\multicolumn{1}{|c}{ Traps } \\
Trials
\end{tabular} & 1 & 2 & 3 & 4 & 5 & 6 & 7 & 8 & 9 & 10 & 11 & 12 & 13 \\
\hline Spring 2011 & - & - & - & - & - & - & - & - & - & - & - & - & \\
\hline Summer 2011 & $\begin{array}{c}8 \hat{q}^{+} \\
2 \hat{0}\end{array}$ & - & 19 & 1 우 & - & - & - & - & - & - & - & 2 q & $3 \hat{0}$ \\
\hline Autumn 2011 & - & - & - & - & - & - & - & - & - & - & - & - & $1 q+5$ \\
\hline Winter 2012 & - & - & $\begin{array}{c}5 q+ \\
10^{\lambda}\end{array}$ & $2 \hat{\sigma}$ & - & $\begin{array}{l}19+ \\
4 \hat{\circ}\end{array}$ & - & - & - & - & - & - & $\begin{array}{c}2++ \\
4 \hat{0}\end{array}$ \\
\hline Spring 2012 & - & 2 우 & - & - & - & - & $\begin{array}{c}7 q+2 \\
\text { 万 }\end{array}$ & - & $10^{\pi}$ & - & $\begin{array}{c}6 q+5 \\
0\end{array}$ & $40^{\hat{T}}$ & $\begin{array}{c}19+4 \\
\hat{0}\end{array}$ \\
\hline Summer 2012 & - & - & - & - & - & - & - & - & - & - & - & - & $\begin{array}{c}6 q+1 \\
0\end{array}$ \\
\hline \begin{tabular}{|l|} 
Autumn 2012 \\
\end{tabular} & - & - & - & - & - & - & $2 \hat{\sigma}$ & - & - & - & - & 69 & $\begin{array}{c}4 q+2 \\
\hat{0}\end{array}$ \\
\hline Winter 2013 & - & - & - & - & - & - & - & - & - & - & - & - & \\
\hline
\end{tabular}

The obtained results from the present work show that $D$. longicaudata can disperse and move till a long distance influenced by the climatic conditions and the release density, in both citrus plots (Table 1 and 2). It is able to disperse at least more than 70m from the release point, exerting parasitism in sentinel fruits (Figure 4.10), mainly following the dominant wind direction (in this case North). This confirms observations of Messing et al. (1997), who described that when mass-reared $D$. longicaudata adults were released under natural conditions, the wasps tended to remain on the rim of the release recipient and to take off (in a downwind direction) during the intervals between wind gusts. 
Table 4.3. Number and sex of recovered parasitoids in each trap and trial. The release point trap is trap no. 13.

\begin{tabular}{|c|c|c|c|c|c|c|c|c|c|c|c|c|c|c|}
\hline \begin{tabular}{|l}
\multicolumn{1}{|c}{ Traps } \\
Trials
\end{tabular} & 13 & 14 & 15 & 16 & 17 & 18 & 19 & 20 & 21 & 22 & 23 & 24 & 25 & Total \\
\hline Spring 2011 & & - & - & - & - & - & - & - & - & - & - & - & - & 0 \\
\hline $\begin{array}{l}\text { Summer } \\
2011\end{array}$ & $3 \hat{\sigma}^{\lambda}$ & - & - & - & $\begin{array}{l}19+ \\
2{ }^{\lambda}\end{array}$ & 19 & - & - & - & - & - & $\begin{array}{l}2 q+ \\
2 \hat{0}\end{array}$ & - & 25 \\
\hline Autumn 2011 & $1 q+5$ & - & - & - & - & - & - & - & - & - & - & - & - & 6 \\
\hline Winter 2012 & $\begin{array}{c}2++ \\
40^{\hat{\sigma}}\end{array}$ & - & - & - & $\begin{array}{l}19+ \\
30^{\lambda}\end{array}$ & - & - & - & - & - & - & $3 \delta^{1}$ & $\begin{array}{l}69+ \\
10^{\lambda}\end{array}$ & 34 \\
\hline Spring 2012 & $\begin{array}{c}19+4 \\
0\end{array}$ & $\begin{array}{c}1 \text { ㅇ+3 } \\
0\end{array}$ & $\begin{array}{c}2 q+3 \\
0\end{array}$ & $10^{\pi}$ & - & \begin{tabular}{c}
$1 q+1$ \\
\multirow{0}{1}{}
\end{tabular} & - & - & - & - & $1 \delta^{\lambda}$ & - & - & 42 \\
\hline $\begin{array}{l}\text { Summer } \\
2012\end{array}$ & $\begin{array}{c}69+1 \\
0\end{array}$ & - & - & - & - & - & - & - & - & - & - & - & - & 7 \\
\hline Autumn 2012 & $\begin{array}{c}4 \rho+2 \\
0\end{array}$ & - & - & - & - & - & - & - & - & - & - & - & - & 14 \\
\hline Winter 2013 & & - & - & - & - & - & - & - & - & - & - & - & - & 0 \\
\hline
\end{tabular}

Dispersal from a central point is subject to an area-dilution effect, whereby as individuals move further away from a central release point they spread over a progressively greater area and consequently become more difficult to recapture (Mills et al. 2006). To improve the accuracy of recapture data, greater number of recapture point could be used, although it is often impractical to monitor a greater number of traps effectively (Mills et al. 2006).

In our case, the yellow sticky traps were not the best option to follow dispersal of parasitoids when using a low trap-density (24 per ha) and distributed evenly (each $25 \mathrm{~m}$ ) contrary to it was described in other work (Paranhos et al. 2007). In fact, the number of traps was insufficient comparing to the released parasitoid number and the parasitoid may escape far away from the trap. In addition, according to Paranhos et al. (2007), D. longicaudata prefers parasitizing in the ground and not in a high height of the ground. Studies on D. longicaudata (Cornelius et al. 1999) showed an innate preference for yellow targets, while Leyva et al. (1991) and Segura et al. (2007) could not determine any hue preference for females of this species. Although 
providing general, positive, visual stimulus for insects (Messing and Jang 1992) yellow sticky traps might not be very attractive for adult D. longicaudata (Paranhos et al. 2007).

Indeed, as can be noticed in table 4.3 and Figure 4.10, during the third trial (at the first orchard (Autumn 2011)), no parasitoids were recorded in yellow sticky-traps nor parasitism detected on sentinel fruits. However, these negative results with our system respond to the presence of naturally infested clementine fruits in the orchard during the trial. Availability of naturally infested fruits can influence the dispersion of parasitoids by the presence of several attractants odours, as demosntrated previously (Messing and Jang 1992). In several bioassays, parasitoids have demonstrated an attraction to host fruit volatiles, without the presence of visual cues (Quilici and Rousse 2012).

In accordance with IPM directives, attraction and trapping techniques are required to determine pest and natural enemy distribution and densities in the field which help in determining what control type should be applied. With this work, we have outlined that the yellow sticky traps are not suitable for determining $D$. longicaudata fine tunning-movement when natural infested fruits are available in the study area. However, the use of sentinel fruit allows determining parasitoid movement and the success of the released parasitoids, which are at the end, the two key points of Biological control programs.

Alternatively, baits, in the form of foods, hosts, or kairomones, have been used to increase the attractiveness of recapture points, and provide a more practical approach to counteracting the dilution effect (Mills et al. 2006).

Moreover, the use of sentinel fruit allowed identifying a new parasitoid species. In the first trial A. daci was identified (Sabater Munoz et al. 2012). Its presence in the trial plot could explain the results for the first $D$. longicaudata release, as this species seems to be more successful (unpublished data) when in competition. Besides the presence of $A$. daci in the first trial of the first orchard, the absence of the parasitism can be explained by the low density of released $D$. longicaudata adults (3,000 individuals only).

In the second experimental orchard, the released parasitoid density was similar in all the trial, but the dispersal pattern was different. The parasitism was relatively evenly distributed in the entire citrus orchard during the spring trial, quite central during the summer and autumn trials and completely absent during the winter trial. These differences can be attributed to climatic condition effects. Indeed, during the spring trial, the parasitoid had the perfect climatic conditions to move and parasitize in the entire orchard with a mean temperature of $23^{\circ} \mathrm{C}$ and a relative humidity of $56 \%$. 
While during the winter essay, the dispersion was affected by the low temperature and the rainfall as previously determined by our semi-field assays, and in other work (Paranhos et al. 2007).

In the other hand, during the summer and that of the autumnal trial the dispersion was weak; as recorded with our system, and this can be due to the presence of the natural infested fruit within this experimental citrus plot and/or in the nearby ones.

\subsubsection{Integration of $D$. longicaudata within the SIT program to control $C$. capitata}

In the Mediterranean basin, a temperate climatic region with contrasted climate among seasons, the most variable parameter is temperature as it can be seen in figure 4.11. For instance, in the study site, mean monthly temperature ranged from $7.44^{\circ} \mathrm{C}$ in February to $26.27^{\circ} \mathrm{C}$ in August. Relative humidity seems to be less variable as recorded values of mean relative humidity were between $53.6 \%$ and $83.31 \%$.

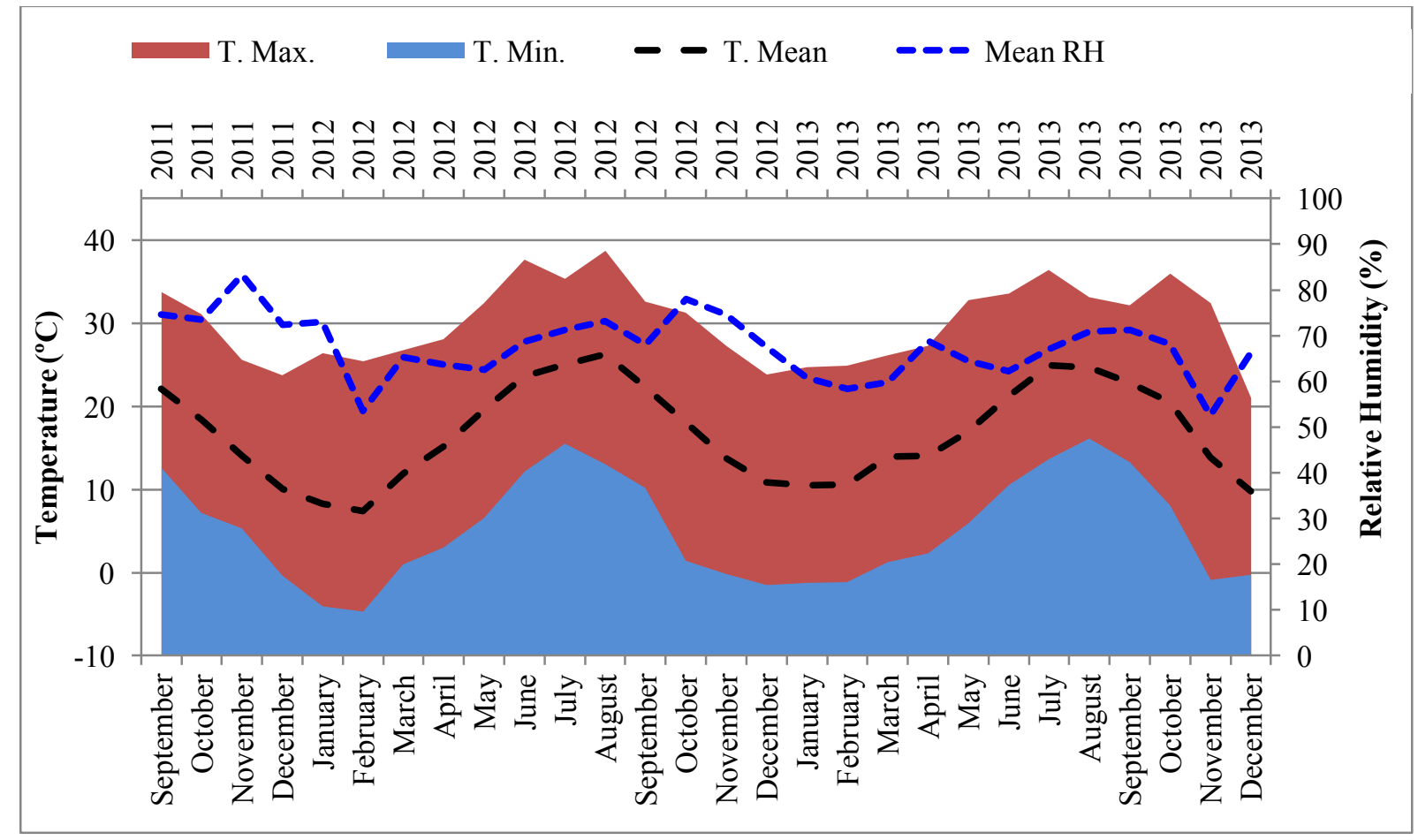

Figure 4.11. Pattern of monitored climatic conditions during trial in field cages.

The assessment of D. longicaudata parasitism percentage at the different treatments showed differences as function of the treatment and season (spring, summer, and autumn) (Figure 4.12). 
Overall, parasitism was higher in summer and spring compared to autumn. Independently of the season, the parasitoid release density of 5:1 (D. longicaudata $\bigcirc$ : medfly $\bigcirc$ ) exhibited the highest parasitism percentage with statistical differences compared to the other two treatments (1:1 and 3:1) (D. longicaudata $q$ : medfly $\left.{ }_{+}\right)$. These treatments resulted in similar average parasitism percentages in all tested seasons. Winter was not tested due to previous works, on which no medfly population control could be determined by the extreme temperatures (JuanBlasco et al. 2013, 2014), thus if no available hosts it was unnecessary to release parasitoids.

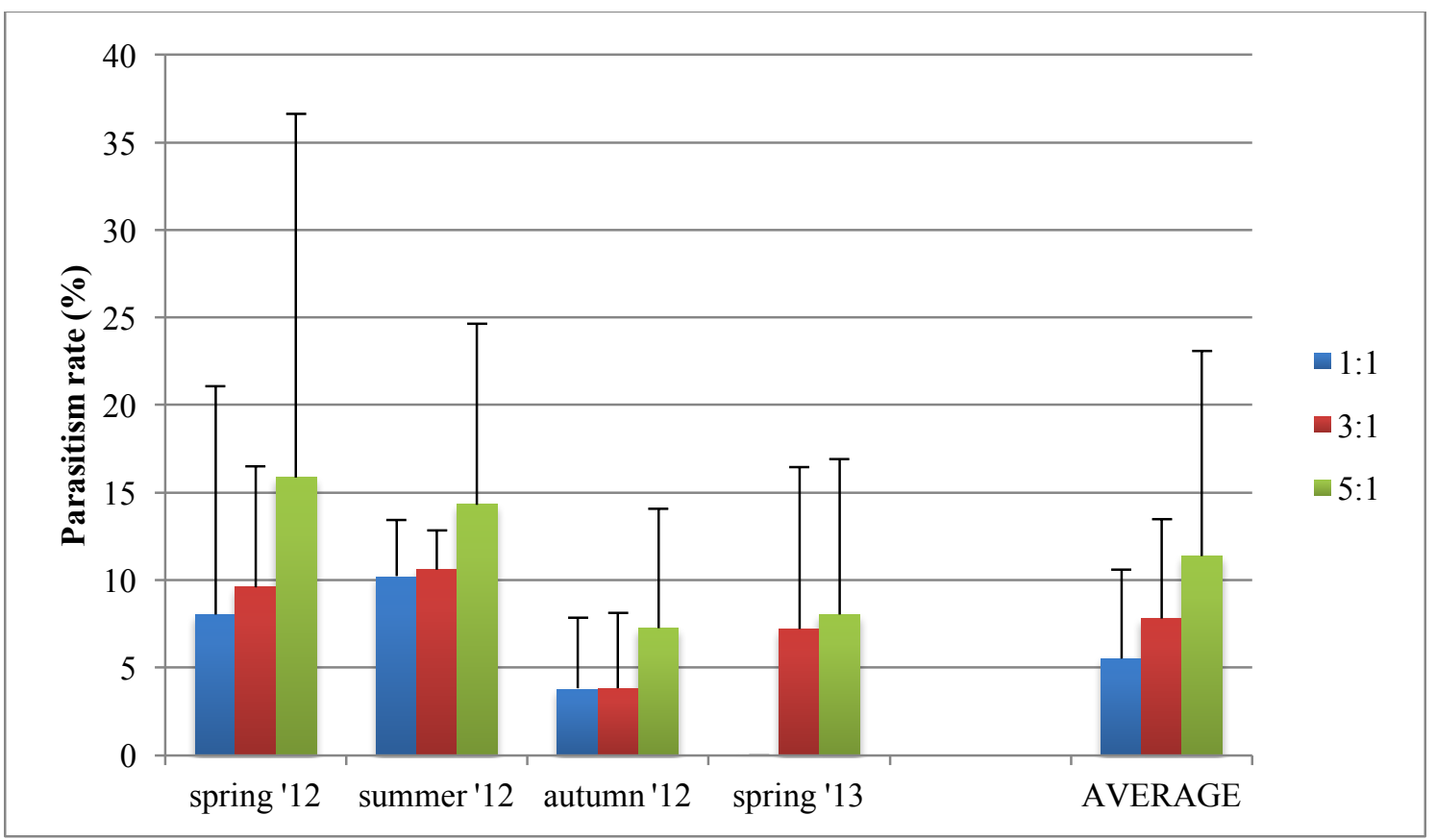

Figure 4.12. Parasitism percentage $(\%$, average $\pm \mathrm{SE})$ obtained at each successful trial. Statistical differences were found between $D$. longicaudata release ratios $(1: 1,3: 1$ and 5:1) and among trials $(t$ paired).

The induced mortality of medfly pupae showed high variability among releases ratios and seasons. The highest induced mortality was recorded with the release ratio 1:1 in summer 2012 with $21.19 \%$ while the lowest was $8.72 \%$ in autumn 2012 . Independently of seasons, the highest induced mortality was obtained with the release ratios of $1: 1$ and $5: 1$ with $11.60 \%$ and $8.79 \%$, respectively, without statistical differences (Figure 4.13). It is worth noting that the presence of outliers in all the release ratios was observed with statistical differences $(F=4.517 ; d f=2,11$; $P=0.018$ ) (Figure 4.14). 


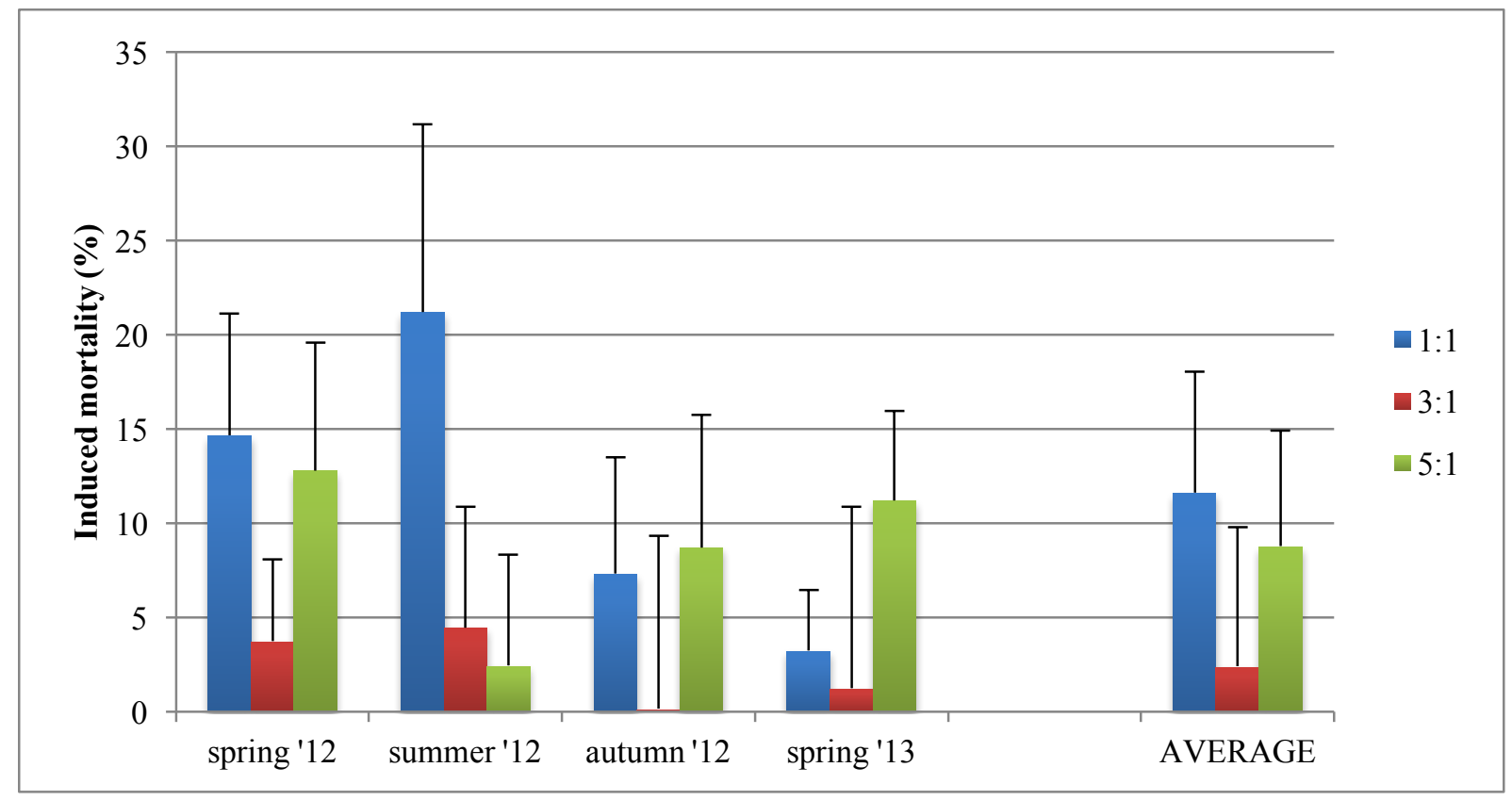

Figure 4.13. Induced mortality ( $\% \pm \mathrm{SE}$; corrected by natural mortality in control plots) exerted by $D$. longicaudata at different release ratios $(1: 1,3: 1$ and $5: 1)$.

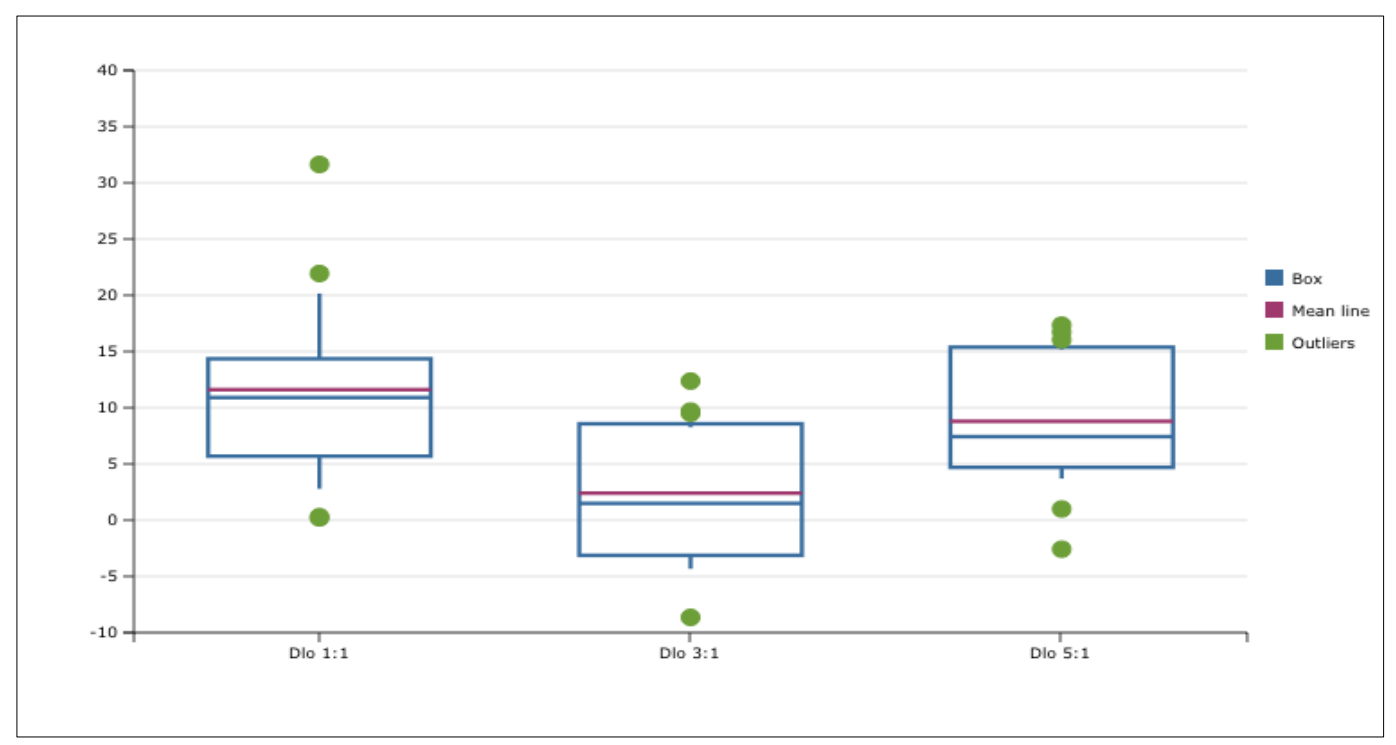

Figure 4.14. Box plot of Induced mortality (corrected by natural mortality in control plots) exerted by D. longicaudata at different release ratios $(1: 1,3: 1$ and $5: 1)$, where it can be observed the presence of outliers in all the release ratios with statistical differences $(F=4.517 ; d f=2,8 ; P=0.018)$. As demonstrated in previous studies, seasonality is affecting parasitoid performance.

Population reduction has been determined after Juan-Blasco et al. (2013), for sterile males contribution, taking in consideration induced mortality and parasitism percentages as additive factors. As shown in figure 4.15, C. capitata reduction percentage in all releases ratios was affected by seasonality as great variability was detected among seasons. It was higher in spring 
and summer compared to autumn. The release ratio of 5:1 gave the most important medfly population reduction percentage ranging from $13 \%$ to $50 \%$.

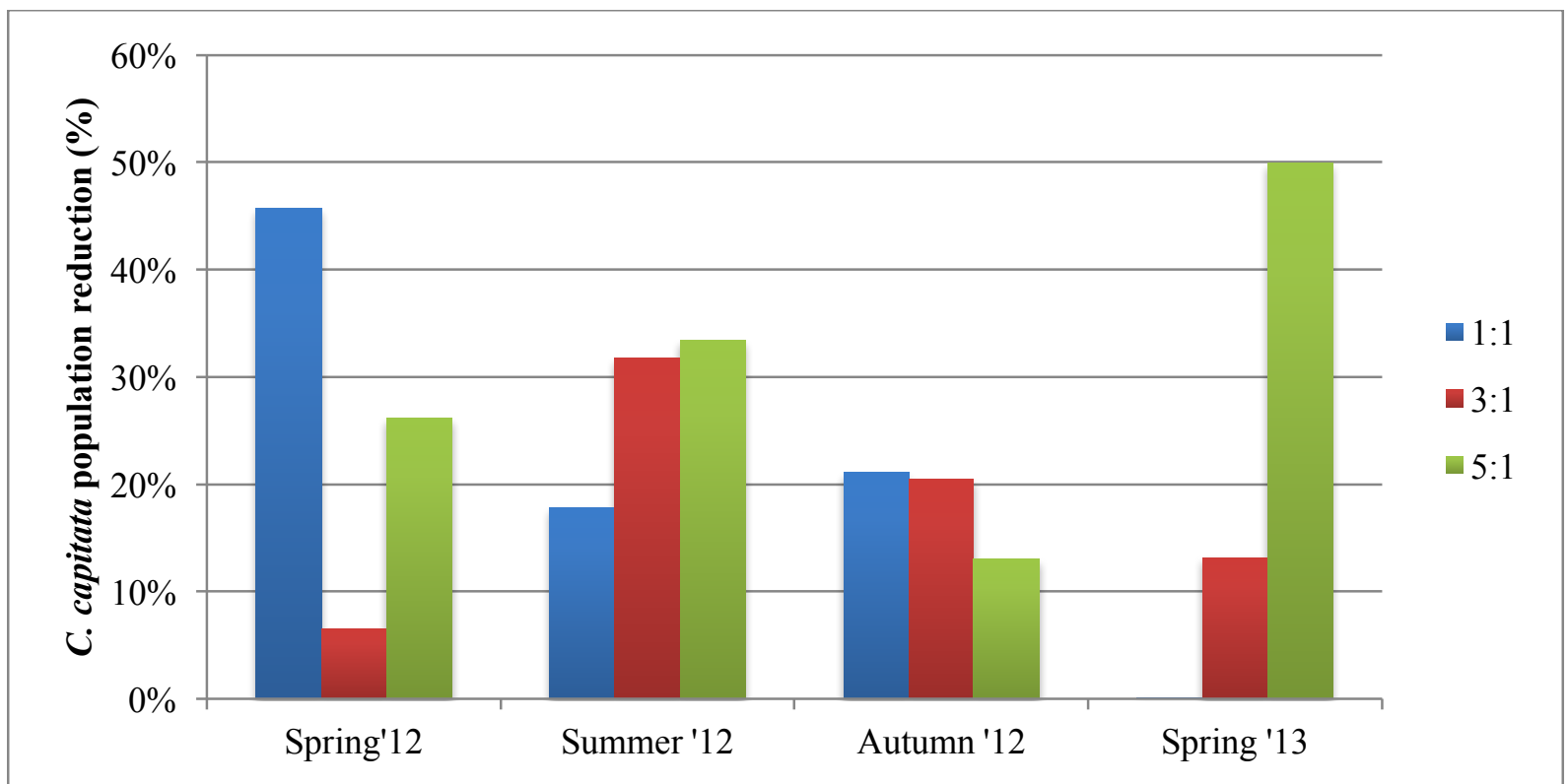

Figure 4.15. Corrected average $C$. capitata population reduction (\%) by the joint use of v8 sterile males and D. longicaudata at different release ratios (1:1, 3:1 and 5:1).

Results showed that the parasitoids were more effective during spring and autumn, as the very high and low temperatures of winter and summer were not favorable for parasitoid development, and also negatively affected the sterile medfly males. It was not possible to determine the precise model that demonstrates the synergistic effect of using both parasitoids and sterile medfly males to effectively suppress medfly population.

In a way similar to Steinberg and Cayol (2009), the joint use of BC with D. longicaudata and sterile males, could benefit not only the growers, if not the stakeholders, and sterile males facilities. As with little production cost increase, the facility could derive by-products (last steps of jumping larvae enriched on females with recombined marker traits or in males with female phenotype markers, that are actualy discarded and killed) for the production of parasitoids to be used in the $\mathrm{BC}$ program, for the control of population focal outbreaks, or for the joint use along SIT. 


\subsection{Conclusions and Perspectives}

\subsubsection{Dispersal mode of $\boldsymbol{D}$. longicaudata under Mediterranean conditions}

As has been shown, D. longicaudata is able to disperse under natural Mediterranean conditions influenced by the wind direction, but which is most important, the dispersion is governed by the presence of hosts, being drived by the odours hosts induce in fruits. Despite what was already cited, yellow traps were not useful to determine dispersion modes, but the developed system with sentinel fruits allowed determining a radial dispersion pattern along determination of parasitism percentage as indicator of egg-laying locations, which is an ecological measure more robust than dispersion distance itself.

This new methodology could be used at the first stages of BC implementation, as gives information about parasitoid dispersion distance, exherted parasitism percentage under natural conditions, and what is also important, would give information about other natural enemies already present in the trial areas not monitorized previously.

\subsubsection{Integration of $D$. longicaudata releases within SIT program}

As has been shown, D. longicaudata releases performed within an SIT program enhances the medfly population reduction power of SIT alone. Despite this success, control of medfly population by $D$. longicaudata was mainly due to induced mortality, not by the increase of parasitoid offspring. These results had indicated that at the actual SIT conditions, with an objective to achieve a 5: 1 ratio (sterile: wild type medfly males), could induce nearly $60-80 \%$ of population reduction, that can be increased to nearly $95 \%$ by the addition of $D$. longicaudata, even than only $5-10 \%$ can be explained by fertility.

Even promising, further research is required to complete a mathematical model that could explain the non-additive effect of BC to the SIT program, and that could predict the outcomes of the program without the requirement of continuous assessment of parasitoid dispersion and success. 


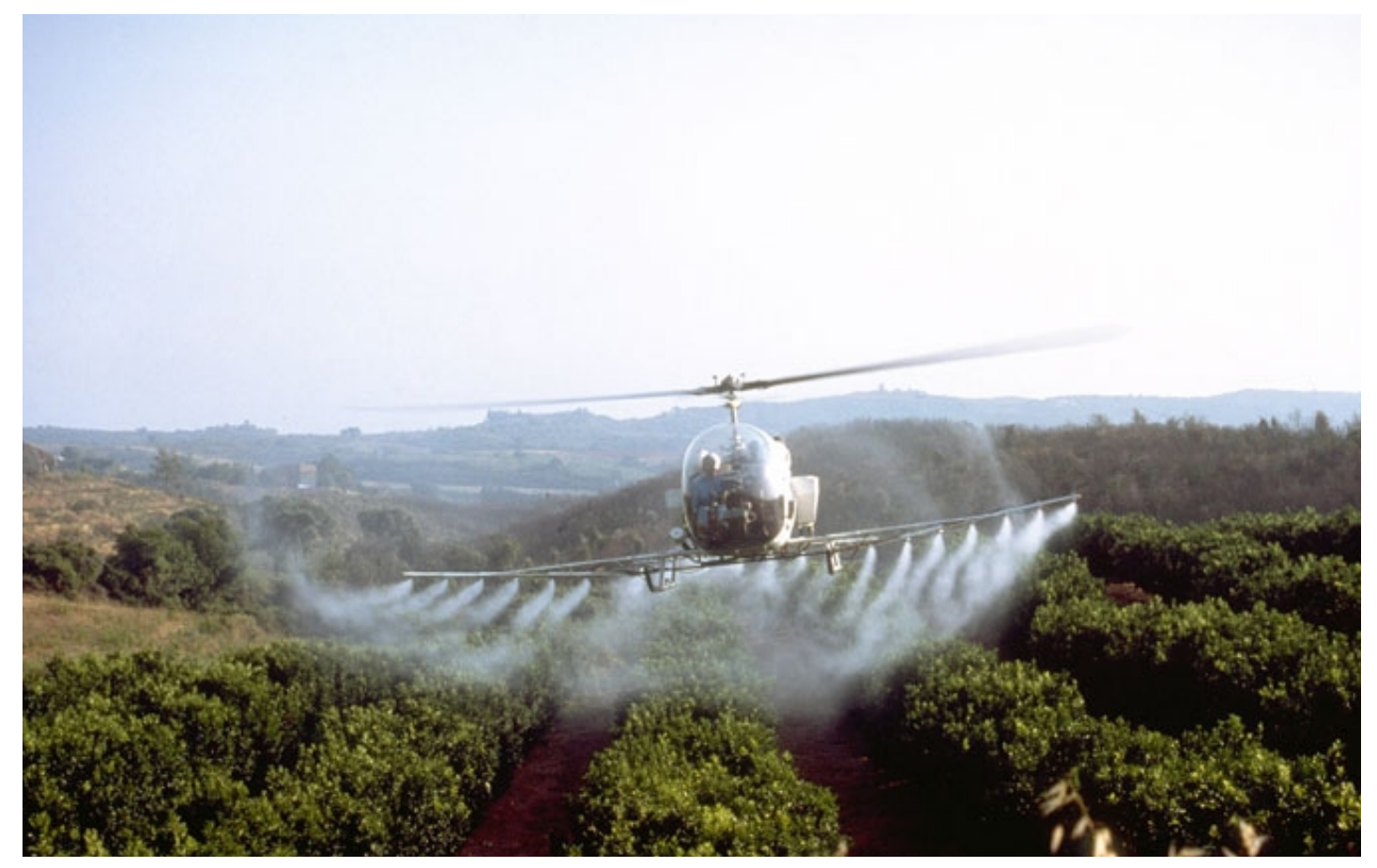

CHAPTER 5. How to integrate Diachasmimorpha longicaudata in the Ceratitis capitata control program in Tunisia? 
The next step, following the trials in Spain, was to adapt in Tunisia all the generated knowledge to the establishment of a Biological control program against the medfly based on the exotic parasitoid D. longicaudata, as indicated in the last proposed objective for this thesis dissertation:

4. Determine the key points to establish a Biological Control program based on $D$. longicaudata against C. capitata in Tunisia.

The results showed here have been partially published and/or submitted to different SCI journals.

\subsection{The Ceratitis capitata control program in Tunisia}

The citrus agro-industry is a strategic sector for Tunisia. It occupies approximately 21,000 ha of which $67 \%$ (14,000 ha) are concentrated at the Cap Bon peninsula. The annual production is nearly 20,000 tones of oranges per year, destined to the fresh-fruit export market (Lebdi Grissa 2010, FAO 2016). Citrus agroecosystems are threatened by a plethora of pest arthropods, among these, the true fruit flies (Diptera: Tephritidae) are considered as key pests worldwide (as reviewed in the general introduction; Liquido et al. 1990, Jerraya 2003, Primo et al. 2003; Urbaneja et al. 2009). The medfly, C. capitata, is the most invasive species of all members of the Tephritidae (Zucchi 2001) and a key pest of citrus and other fruits in the Mediterranean countries, including Tunisia (Enkerlin and Mumford 1997; Jerraya 2003). This species is an EPPO A2 quarantine pest, considered of quarantine significance throughout the world (CPPC, NAPPO, APPPC), especially for Japan, USA and New Zealand (EPPO 2014), with more than 300 plant species recorded as putative viable hosts (White and Elson-Harris 1992). For this reason, many countries restrict the import of susceptible fruits unless strict pre- and post-harvest control treatments having been applied by the exporter. In addition to these quarantine measures, this species induce direct and indirect damages that increase crop losses (Jerraya 2003). In Tunisia, crop losses due to C. capitata had been measured, ranging from 80 to $100 \%$, being the citrus the most affected crop with nearly 40\% of annual income (Driouchi 1990; Lebdi Grissa 2010).

Similarly to what occurred in other countries (see general introduction), during many decades the suppression of $C$. capitata in Tunisian citrus orchards relied on calendar broad-spectrum 
applications of synthetic insecticides, mainly carbamates and organophosphates (Jerraya 2003, Braham et al. 2007, Boulahia-Kheder et al. 2012). More recently, the new European legislations regarding the use of insecticides and their tolerated residues in imported commodities (EEC/CEE 2009), as well as the emergence of genetic resistance and cross resistance to several insecticides in Mediterranean populations of C. capitata, forced stakeholders to review control strategies adopted against this economic pest (Magaña et al. 2007, Couso-Ferrer et al. 2011, Vontas et al. 2011, Arouri et al. 2015). As result, alternative control tactics were introduced and promoted in Tunisia including mass-trapping and attract-and-kill techniques leading, when properly applied, to a relative decrease in the frequency of insecticide applications (BoulahiaKheder et al. 2012, Braham 2013, Navarro Llopis et al. 2013, Hafsi et al. 2015). In addition to these environmental friendly techniques, a pilot SIT program was initiated in late 70's and restarted in the earlies 2000's (Howell et al. 1975; Cayol and Zarai 1999; M'saad Guerfali et al. 2005 as reviewed in Dyck et al. 2005). Nowadays, the citrus protection plan against the medfly also incorporates a Classic Biological Control program, as part of the present thesis dissertation, as I would show in the following sections of this chapter.

\subsubsection{Native versus imported exotic parasitoids}

Classic Biological control (CBC) programs are regulated in a way on which equilibrium between effectiveness, target pest specificity, native parasitoids diversity and national legislations are obtained (see Messing and Purcell 2001 as an example of legislation unbalanced equilibrium that do not accept the introduction of more exotic species in Hawaii islands). To this end, FAO and EPPO established protocols for importation and release of exotic parasitoids that should be filled-in and authorized by the national agencies prior first introduction (FAO 1996; EPPO 1999, 2001, 2014). Within these protocols, it was highlighted the importance of surveillance studies for location and identification of native parasitoids, and the requirement of laboratory trials with non-target pest species or closely related species to determine the specificity of the exotic parasitoid by demonstrating the lack of side-effects on other species (i.e. those plant pathogen species introduced to control weeds).

Parasitoids are widely used against $C$. capitata in many countries, especially in Central and South America (Montoya and Cancino 2004). In the Mediterranean basin some attempts have been initiated in using parasitoids against this pest, mainly in Spain (reviewed in Sabater-Muñoz et al. 2013). The use of indigenous natural enemies is a clear priority in the application of biological control. However, despite the long history of C. capitata in the Mediterranean basin, 
there were no records on field parasitism by native species until Papadopoulos and Katsoyannos (2003) recorded A. daci parasitizing larvae of C. capitata on the Greek Island of Chios. Thereafter, other workers reported natural parasitism of C. capitata in Spain by several species targeting mainly the pupal stages as $P$. vindemmiae (Falcó et al. 2006, Beitia et al. 2007; PérezHinarejos and Beitia 2008; De Pedro et al. 2013).

Despite there is a record of native parasitoids in the Mediterranean basin, in Tunisia these records were absent (Lebdi Grissa 2010). Taking into consideration FAO and EPPO standards for the safe use of biological control, Tunisia started surveillance studies for medfly parasitoids in early 2010's, without success (Skouri 2010).

Following this failure, and with the aim to establish a Biological control program in Tunisia, the first part of this chapter had the objectives of pursuing a new medfly native parasitoid surveillance study, followed by laboratory trials for the importation and release of the exotic parasitoid D. longicaudata.

\subsubsection{Integrated pest management: the use of insecticides and their impact on D. longicaudata}

To enhance the establishment and adaptation of an exotic parasitoid into a new environment, and to guarantee efficient IPM strategies, many factors should be taken into consideration. Among these factors, the side effects on the released biocontrol agent of IPM selected pesticides against other citrus key pests are a keystone. This issue is very important to ensure the sustainability of IPM programs via the use of selective insecticides that can coexist alongside auxiliary fauna in a timeline fashion while keeping control of target pests (Urbaneja et al. 2009, Biondi et al. 2012, 2013; Juan-Blasco et al. 2013, Vanaclocha et al. 2013b). Diachasmimorpha longicaudata is considered an exotic parasitoid in many parts of the world, originally coming from Southeast Asia where it hosted other tephritid fruit fly species (mainly from Bactrocera genus, as indicated in the general introduction and at the introduction of chapter 2). This parasitoid species has been successfully used in many countries for the control of Anastrepha, Bactrocera and Ceratitis species, by being released mainly in combination with sterile insects (within aw-SIT programs) (Baranowski et al. 1993, Vargas et al. 2001, Orozco et al. 2002). Despite this wide use of this parasitoid species as biological control agent, a low number of studies have been performed concerning the side effect of pesticides on it, being in most cases focused on only one chemical molecule each time (Stark et al. 1992, 2004; Purcell et al. 1994, Vargas et al. 2001). 
Therefore, in this chapter, with the objective of supplying this knowledge gap and improve the Tunisian IPM program, we have assessed the toxicity of seven pesticides (covering four pesticides families plus two natural-derived compounds) to D. longicaudata in laboratory conditions by using an adapted exposure method that mimicries field conditions.

\subsection{Material and Methods}

\subsubsection{Insect rearing}

The rearing of medfly and Diachasmimorpha longicaudata was initiated in 2012 in the entomological laboratory of the High Agronomic Institute of Chott-Mariem. It was carried out in a climatic chamber with standard climatic condition $\left(25 \pm 2^{\circ} \mathrm{C} ; 60 \pm 10 \% \mathrm{RH}\right.$ and $16: 8 \mathrm{~h}(\mathrm{~L}: \mathrm{D})$ photoperiod), similarly as described in Chapter 2.

\subsubsection{Native parasitoids surveillance}

\subsubsection{Screening sites}

Three regions along the north-eastern Tunisian coastline were selected: Tunis $\left(36^{\circ} 49^{\prime} 07.95^{\prime \prime} \mathrm{N}\right.$, $10^{\circ}$ 09'57.31" E, elevation 24m) (Governorate of Tunis), Cap Bon (36³8'59.65" N, $10^{\circ} 35^{\prime} 27.49^{\prime \prime}$ E, elevation $51 \mathrm{~m}$ ) (Governorate of Nabeul) and Chott-Mariem (35 55'08.12” N, 10³4'17.11” E, elevation: $6 \mathrm{~m}$ ) (Governorate of Sousse) (Figure 5.1).

In the region of Tunis, mainly ornamental citrus orchard, variety Bitter Orange, were used as experimental sites. The screening in this region was carried out during the year 2013.

In the Cap Bon zone, four citrus orchards planted mainly by Maltaise and Washington Navel were sampled from 2012 to 2014 . The management of these orchards was conventional which are depending on broad spectrum application of infecticide. In the region of Chott-Mariem two orchards were selected for sampling: the first one was a 1-ha organic citrus orchard containing three varieties - Maltaise, Washington Navel and Bitter Orange, and the second (1 km distant) was a 0.5-ha ornamental citrus orchard planted with Bitter Orange. Both orchards were managed without chemical pesticide treatments. This work was performed from 2012 to 2015 . 


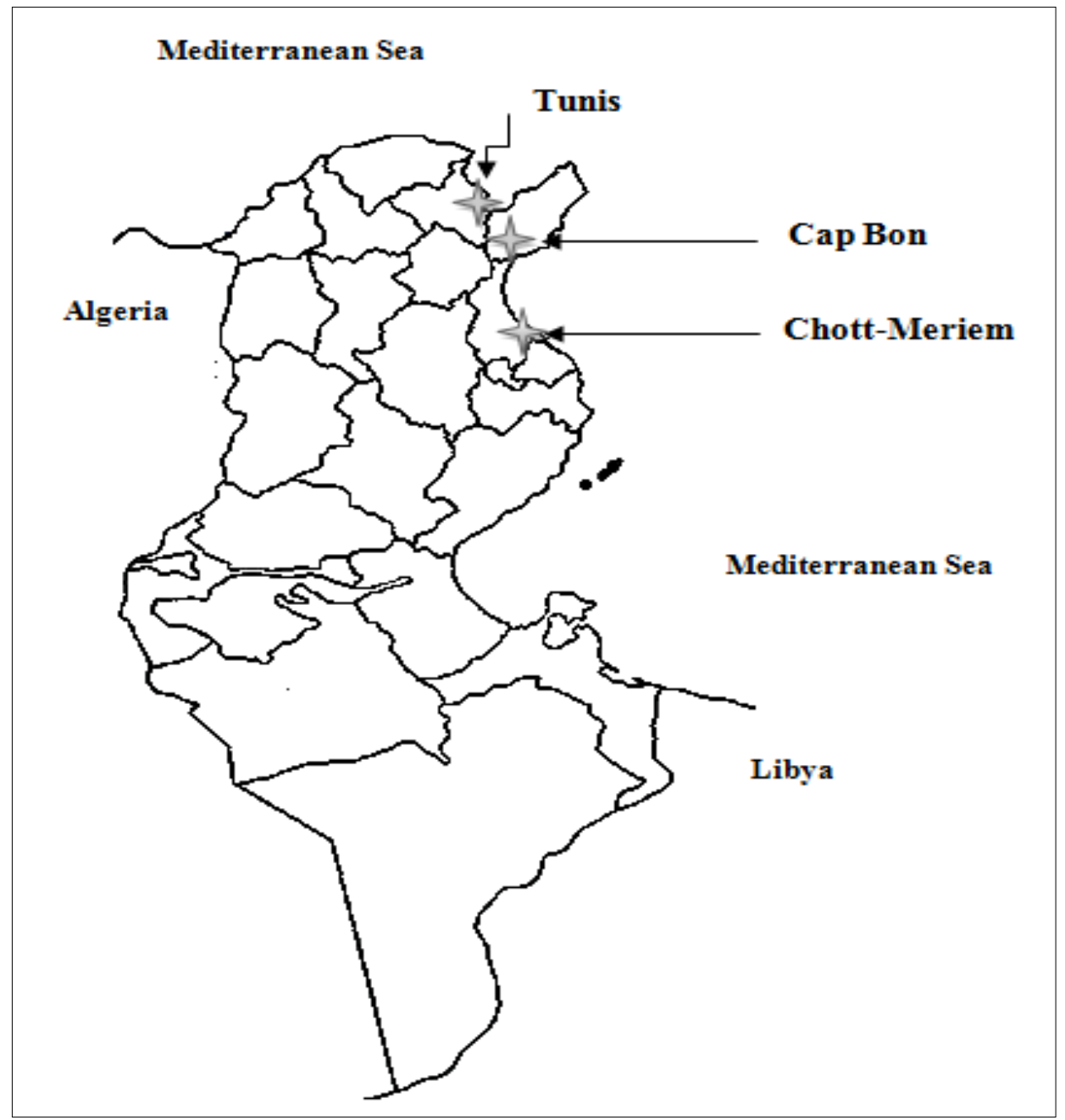

Figure 5.1. Map of Tunisia and location of three experimental sites (stars) where the screening of native Medfly parasitoids was carried out.

\subsubsection{Sampling methods}

Three sampling methods were established:

1) Infested fruit collection. The first method consists of collecting infested fruit from the different citrus orchards and recuperating C. capitata larvae and pupae from the sand which were placed in a container (Figure 5.2). This method was used in the three screening sites.

2) Sentinel fruits. Sentinel fruits (apples, cultivar Golden Sweet) were artificially infested with late $2^{\text {nd }}$ instar larvae of $C$. capitata from our laboratory rearing. Ten holes were made in each apple, and three larvae were placed in each hole (a total of 30 larvae per apple). The holes were closed with apple plugs (as in chapter 2, point 2.2.3.2). Every fortnight (the $1^{\text {st }}$ and $3^{\text {rd }}$ week of each month) from September 2013 to March 2014, 10 of these sentinel fruits were put in a container with vermiculite to allow any mature $C$. 
capitata larvae emerging from the fruit to pupate in the vermiculite. Containers were placed under citrus trees at both sampling sites of Chott-Mariem region, for 1 week to allow parasitism by any larval or pupal parasitoids present in the area.

3) Sentinel free-hosts. Two hundred 1 to 2-day-old C. capitata pupae (ISA-CM rearing colony) were placed fortnightly (as indicated above, the $1^{\text {st }}$ and $3^{\text {rd }}$ week of each month, from September 2013 to March 2014) into rectangular trays placed on the ground under the trees sheltered from the sun in the citrus orchard at Chott-Meriem for four days to allow pupal parasitism.

After each respective exposure period, larvae and pupae were collected, taken to the laboratory and maintained at $21-26^{\circ} \mathrm{C}, 65-90 \% \mathrm{RH}$ and 16:8 (L:D) for development and emergence of any parasitoid adults (Figure 5.2).

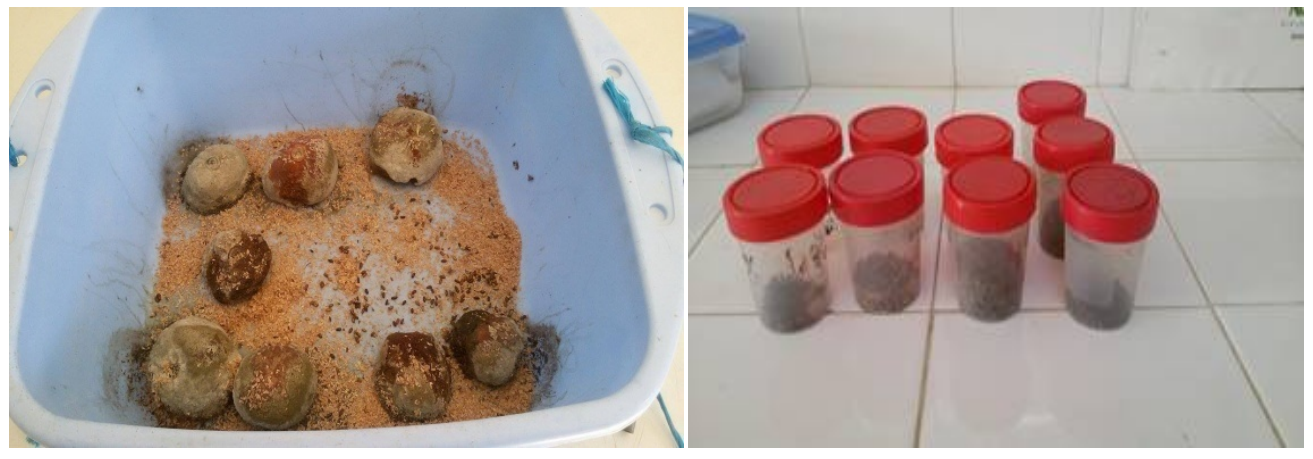

Figure 5.2. Medfly infested fruits recovered and retrieved to the laboratory for parasitoid screening (left), and containers used to allow development of recovered medfly pupae (right).

\subsubsection{Specimen identification}

Parasitoid specimens were stored in ethanol, then air-dried and mounted in entomological pins, as indicated by Goulet and Huber (1993). Voucher specimens were deposited at the entomological collections housed at the Higher Agronomic Institute of Chott-Mariem (Tunisia) and at IVIA (Moncada, Spain).

Mounted specimens were visualized under a binocular stereoscope to determine the number of antennae segments, the presence and kind of wing veins and the thorax patterning, among other taxonomical characters. These characters were used to identify specimens to the species level using Acta Zoologica taxonomical keys (Goulet and Huber, 1993). For some species the identification was confirmed by corresponding experts,. The identification of $P$. vindemmiae 
was done by J.V. Falcó (University of Valencia, Spain), J. Tormos (University of Salamanca, Spain) and F. Beitia (IVIA, Moncada, Spain).

\subsubsection{Pilot releases and naturalization of $D$. longicaudata}

\subsubsection{Release site}

An organic citrus orchard, The Centre Technique d'Agriculture Biologique (CTAB) (Technical Center of Organic Agriculture), situated in the region of Chott-Meriem (Governorate of Sousse; figure 5.1) was chosen as release site. The area of this orchard is about 1ha and it is planted by 2 different citrus varieties: Maltaise and Washington Navel (Figure 5.3).

On this pilot site, CTAB, there is a local weather station that was used to ollectlimatic data during the study period.

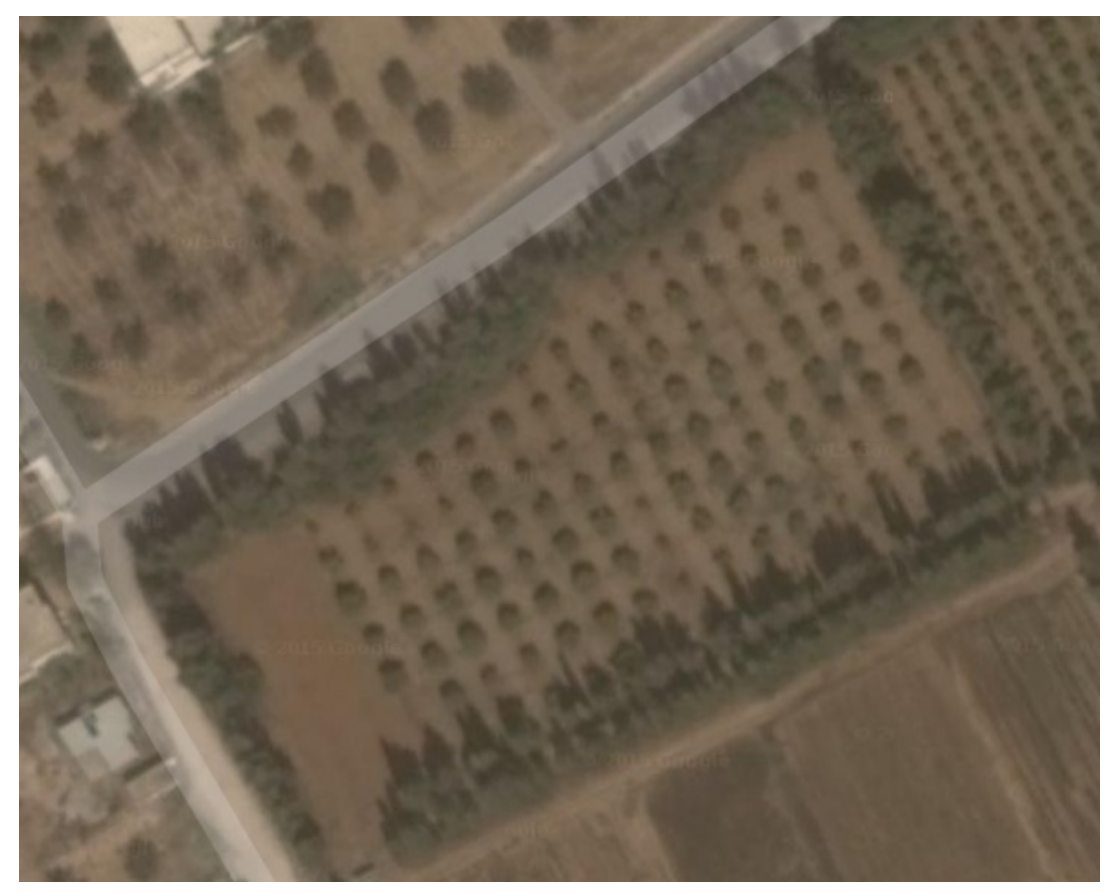

Figure 5.3. Aereal view of the Technical Center of Organic Agriculture (CTAB) experimental site aerial view. As can be seen, the 1-hectare orchard is evenly planted with citrus, and surrounded by cypress in the entire perimeter. 


\subsubsection{Release conditions}

Four successive releases were performed between September and December 2013, covering autumn and winter, the period of maximum presence of medfly populations in citrus orchards in the Tunisian conditions (Table 5.1).

Diachasmimorpha longicaudata individuals came from the rearing colony, reared as described in Chapter 2. A cohort of about 500 couples was set-up and distributed in a single 'bug dorm' cage $(25 \times 25 \times 25 \mathrm{~cm})$ with a slipping window frame. Each cage had ad libitum water and honey, since male emergency. Age at release date was of 8- or 6-days-old for males and females, respectively. Aging was performed at the rearing chamber, to allow sexual maturation and mating of released individuals.

The release was conducted between 2-4 hours after sunrise, by opening the slipping window of the 'bug dorm' cage in the center of the orchard to let parasitoids fly away to the field (Figure 5.4).

Table 5.1. Number of released $D$. longicaudata individuals at each trial.

Release date $\quad$ Released D. longicaudata (individuals)

\begin{tabular}{ll}
\hline $30 / 09 / 2013$ & 1,000 \\
$21 / 10 / 2013$ & 1,000 \\
$11 / 11 / 2013$ & 1,000 \\
$02 / 12 / 2013$ & 1,000 \\
\hline
\end{tabular}
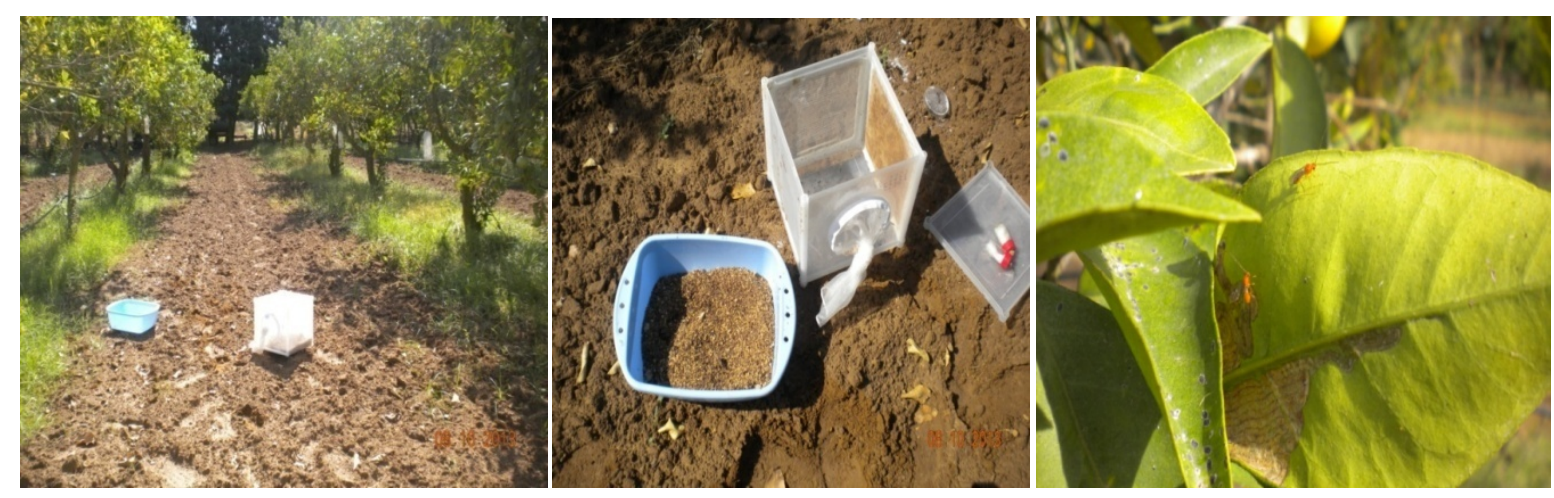

Figure 5.4. Diachasmimorpha longicaudata release in the CTAB experimental site. As can be seen, one 'bug dorm' cage was placed in the center of the citrus plot, allowing leave of parasitoids by opening one window. Some parasitoids landed in the citrus leaves. 


\subsubsection{Monitorization of parasitoid releases}

To assess the presence and the dispersion of the released D. longicaudata, two monitorization methods were used: i) sentinel fruits; and ii) naturally infested citrus fruits recovery (Figure $5.5)$.

i) Sentinel fruits. Twenty sentinel apples (as described in chapter 2, each apple was filled with 30 medfly L2-L3 larvae) were individually placed in recipients containing sand. Sentinel apples were evenly distributed, covering the whole orchard including the release point, one week after the release. Sentinel fruits were placed in field for one week, recovering pupated pupae each two days (to avoid any loose by birds feeding behavior).

ii) Naturally infested fruits recovery. Maltaise and Navel oranges ripe-dropped were collected and checked for the presence of medfly larvae. Infested citrus fruits were grouped and collected one week after parasitoid release. Picked infested fruits were retrieved to the laboratory and all emerged pupae counted and allowed to complete development into medfly or parasitoids.

To evaluate the overwintering of the parasitoid, sampling of the infested fruit from the orchard was continued till April 2014.
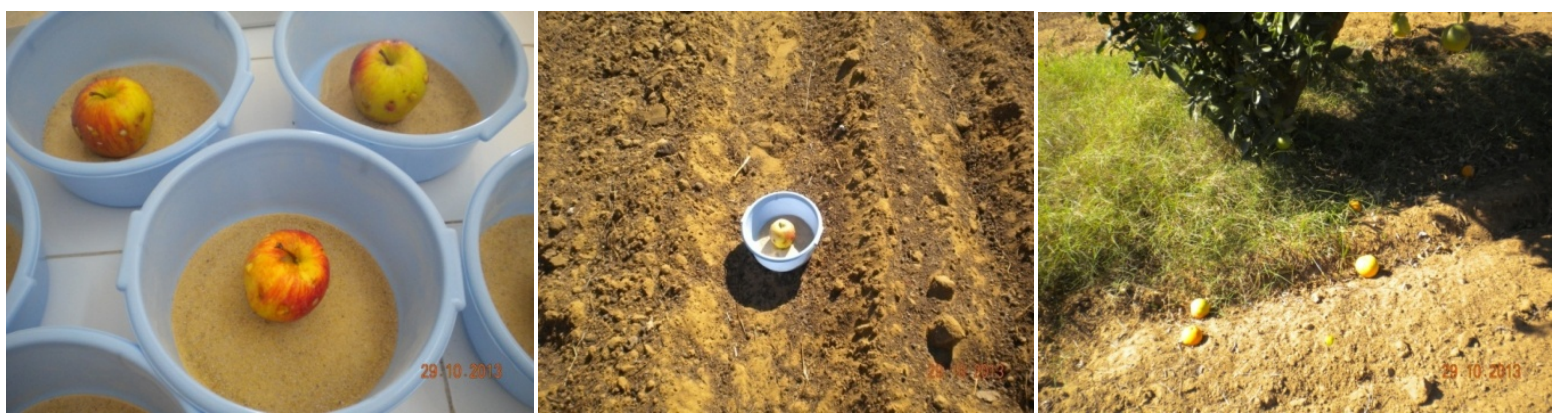

Figure 5.5. Diachasmimorpha longicaudata releases monitorization system. The left picture shows a sentinel fruit within a pupa containment system. The center picture shows one of the sentinel fruit situated within the release site. The right picture shows some ripe citrus fruits, naturally infested, collected for parasitism determination. 


\subsubsection{Biotic factors of $D$. longicaudata under Tunisian climatic conditions}

\section{Longevity}

The study of the longevity of $D$. longicaudata adults was performed in different seasons of the year under Tunisian conditions. For each season, 5 replicates were performed. Each replication consisted on 10 couples of the wasps newly emerged closed on a ventilated recipient $(15 \times 15$ $\mathrm{x} 9 \mathrm{~cm}$ ) containing ad libitum water and honey for their nutrition (the same procedure as in Chapter 2, point 2.2.3.3). These containers were placed in a field cage in the citrus orchard of the experimental area of ISA-CM (Figure 5.6). The longevity was assessed daily till the death of the last individual, with differentiation among gender.

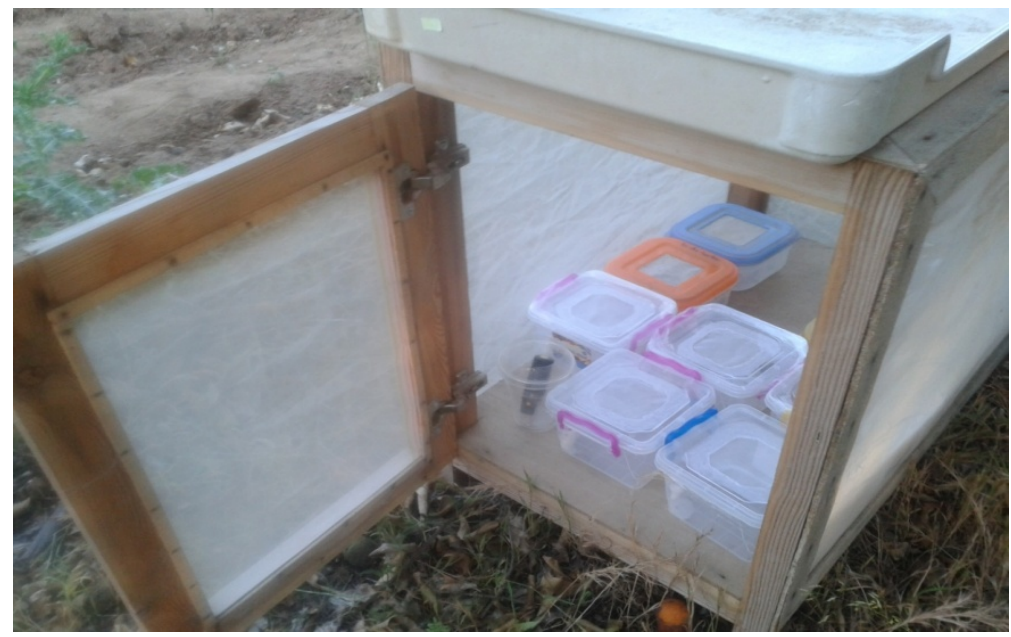

Figure 5.6. Diachasmimorpha longicaudata adult longevity determination system. The wood-framed cage was protected with a rigid plastic cover as shelter for rain. A data logger was placed inside to determine the climatic parameters of each season.

\section{Immature development}

This essay was conducted to study the abilities of $D$. longicaudata immature stage to develop, survive and emerge during the winter in Tunisia (cold condition). Trials were started on 02/12/2013 and continued until 15/04/2014. To perform it, 100 parasitized C. capitata larvae/ pupae were taken out from the rearing cage 24 hours after parasitism and put on a rectangular ventilated box (Figure 5.6 left). Each 15 days, two boxes were prepared, one kept in the climatic chamber and the second placed in a field cage in a citrus orchard (Figure 5.7 right). Adult emergence was assessed daily. Temperatures were recorded with a datalogger placed inside the wood-framed cage. 

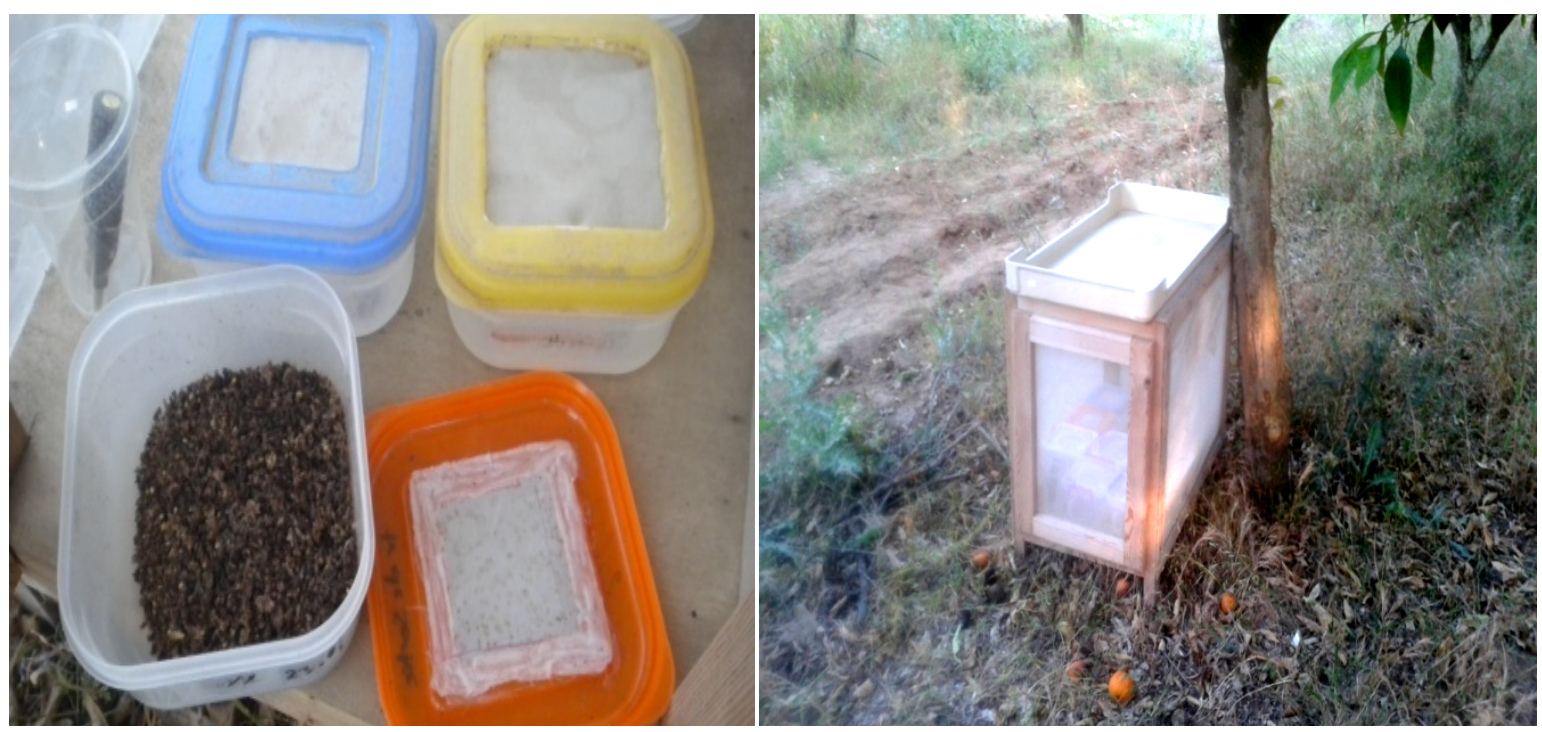

Figure 5.7. Experimental dispositive to assess Diachasmimorpha longicaudata immature development under Tunisian natural climatic conditions. Left picture shows the boxes used to contain the parasitized medfly pupae. Right picture shows the disposition of boxes within wood-framed cage under citrus shadow at the ISA-CM experimental site.

\subsubsection{Residual toxicity assessment in D. longicaudata}

\subsubsection{Pesticides tested}

The pesticides used in this work are listed in Table 5.2, reporting their active ingredient/s, chemical family, application dose and mode of action. All assessed insecticides were stocked, prepared and applied according to manufacturer guidelines. The concentration tested was the highest manufacturer field rate recommended for citrus crops (Table 5.2). 
Table 5.2. Insecticides evaluated for their acute toxicity to $D$. longicaudata adults

\begin{tabular}{|c|c|c|c|c|c|}
\hline $\begin{array}{l}\text { Active } \\
\text { ingredient }\end{array}$ & Trade name & $\begin{array}{l}\text { Field } \\
\text { rate }\end{array}$ & $\begin{array}{l}\text { Chemical } \\
\text { family }\end{array}$ & $\begin{array}{l}\text { Target pests in } \\
\text { citrus orchards }\end{array}$ & Mode of action \\
\hline Malathion & Fyfanon $\left.50^{(}\right)$ & $200 \mathrm{cc} / \mathrm{hl}$ & Organophosphate & $\begin{array}{l}\text { Aphids, fruit flies, } \\
\text { mites and thrips }\end{array}$ & AChE inhibitor \\
\hline Methidathion & $\begin{array}{l}\text { Ultracide } 40 \\
\text { EC }^{\circledR}\end{array}$ & $150 \mathrm{cc} / \mathrm{hl}$ & Organophosphate & Scales, whiteflies & $\begin{array}{l}\text { Modulator of the } \\
\text { sodium channel. }\end{array}$ \\
\hline Acetamiprid & $\begin{array}{l}\text { Mospilan } 20 \\
\text { SL }^{\circledR}\end{array}$ & $30 \mathrm{cc} / \mathrm{hl}$ & Neonicotinoid & Leafminers, mites & AChE inhibitor \\
\hline Azadaractin & Oïkos EC ${ }^{(\mathbb{R}}$ & $60 \mathrm{cc} / \mathrm{hl}$ & Botanical & Leafminers & $\begin{array}{l}\text { Agonism/perturbation } \\
\text { of ecdysone. }\end{array}$ \\
\hline Abamectin & Vertimec $^{(B)}$ & $60 \mathrm{cc} / \mathrm{hl}$ & Avermetin & Mites & $\begin{array}{l}\text { Activation of chloride } \\
\text { channel. Interference } \\
\text { with the GABA } \\
\text { receptor in insects }\end{array}$ \\
\hline $\begin{array}{l}\text { Deltametrin+ } \\
\text { Thiacloprid }\end{array}$ & Proteus ${ }^{\circledR}$ & $60 \mathrm{cc} / \mathrm{hl}$ & $\begin{array}{l}\text { Pyrethroid }+ \\
\text { chloronicotinyl }\end{array}$ & $\begin{array}{l}\text { Aphids, } \\
\text { leafminers, fruit } \\
\text { flies, scales }\end{array}$ & $\begin{array}{l}\text { Modulator of the } \\
\text { sodium channel. + } \\
\text { AChE inhibitor }\end{array}$ \\
\hline Spinosad & $\begin{array}{l}\text { Success- } \\
\text { Appât }^{\circledR}\end{array}$ & $1.25 \mathrm{l} / \mathrm{hl}$ & Spynosin & $\begin{array}{l}\text { Leafminers, } \\
\text { thrips, fruit flies }\end{array}$ & $\begin{array}{l}\text { Disruption } \\
\text { ofnicotinic/gamma } \\
\text { amino butyric acid- } \\
\text { gated chloride } \\
\text { channels }\end{array}$ \\
\hline
\end{tabular}

\subsubsection{Toxicity assessment}

To evaluate the residual toxicity of pesticides in D. longicaudata, a laboratory method was used (Contreras et al. 2005). Briefly described, sour orange (Citrus x aurantium) fully expanded young leaves (approximately 10 days after flush fully expanded) were collected from 10-y-old ornamental untreated trees located at ISA-CM (Chott-Mariem, Tunisia) and rinsed in distilled water and delicately brushed to remove dust, bird feces or other accidently present arthropods, prior treatment. Clean leaves were treated with selected pesticides (Table 1) by the leaf-dip method (Immaraju et al. 1990). Distilled water was used as control throughout the bioassay. Treated leaves were placed individually in experimental units (isolators), and allowed to weather in the laboratory for 1 hour (fresh residue), 3, 7, 14, 21 or 28-d under ambient conditions, including light exposure to simulate open field conditions (Figure 5.8). Ambient conditions including sunlight exposure (what we call field conditions) have been stated to decrease the activity and cause degradation (by sun fotobleaching) of several insecticide residues which are not taken up by tree leaves, as Abamectin and Spinosad (Demchak and Dybas, 1997; Urbaneja et al. 2009). Isolators consisted on two superimposed plastic glasses $(600 \mathrm{ml}$ and $100 \mathrm{ml})$, the small one $(100 \mathrm{ml})$ containing water, that allow for keeping leaf 
turgidity and metabolic actions while maintaining leaf isolation during the pesticide aging process (Figure 5.8). This cup system was previously validated in side effects tests by Zappalà et al. (2012) and Biondi et al. (2013).

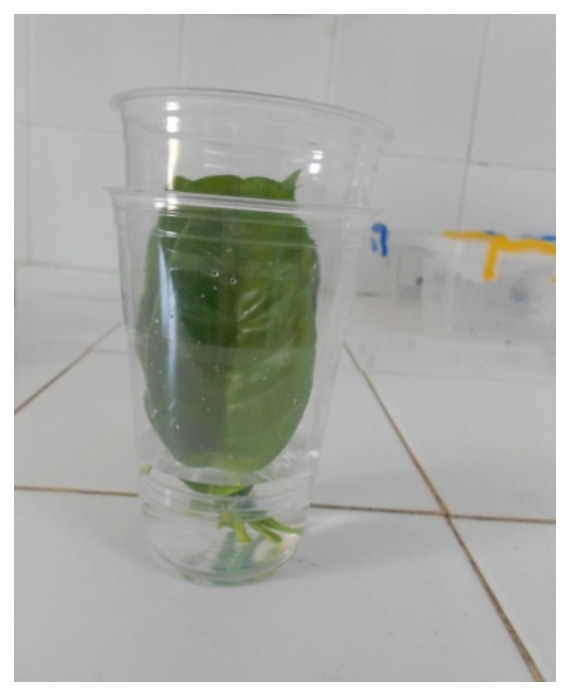

Figure 5.8. Isolator. Experimental dispositive to conserve turgid the pesticide treated leaves.

The bioassay was conducted under controlled environmental conditions $\left(25 \pm 2^{\circ} \mathrm{C}, 60 \pm 10 \% \mathrm{RH}\right.$, 16:8 h L:D) in a climatic chamber. Bioassay arena consisted in polypropylene transparent box $(14 \times 1 \times 9 \mathrm{~cm})$ with a mesh covered aeration window $\left(10 \mathrm{~cm}^{2}\right)$ in the lid. Treated leaves were transferred individually to bioassay arena, replacing the $100 \mathrm{ml}$ water container by a $1.5 \mathrm{ml}$ micro-centrifuge vial and attaching it with modeling clay to the bottom of bioassay arena. A cohort of 40 6-8 days-old $D$. longicaudata adults $(\approx 1: 1$ females: males ratio) was used in each replica, being provided with a honey solution (in a cylindrical $0.5 \times 1.5 \mathrm{~cm}$ (diameter $\mathrm{x}$ length) dental cotton roll) as food source. Residues of the selected pesticides were assayed at $1 \mathrm{~h}$ (fresh), $3,7,14,21$ or 28 days-old post application in a sequential way (i.e. aged residues, which do not show significant differences with control, were not further continued).

Each treatment was replicated tree times, assessing mortality after three days of exposure to treated leaves under controlled conditions $\left(25 \pm 2{ }^{\circ} \mathrm{C}, 60 \pm 10 \% \mathrm{RH}, 16: 8 \mathrm{~L}: \mathrm{D}\right)$. Wasps were considered as dead if no response was observed under stereomicroscope after being stimulated with the tip of a soft paintbrush. 


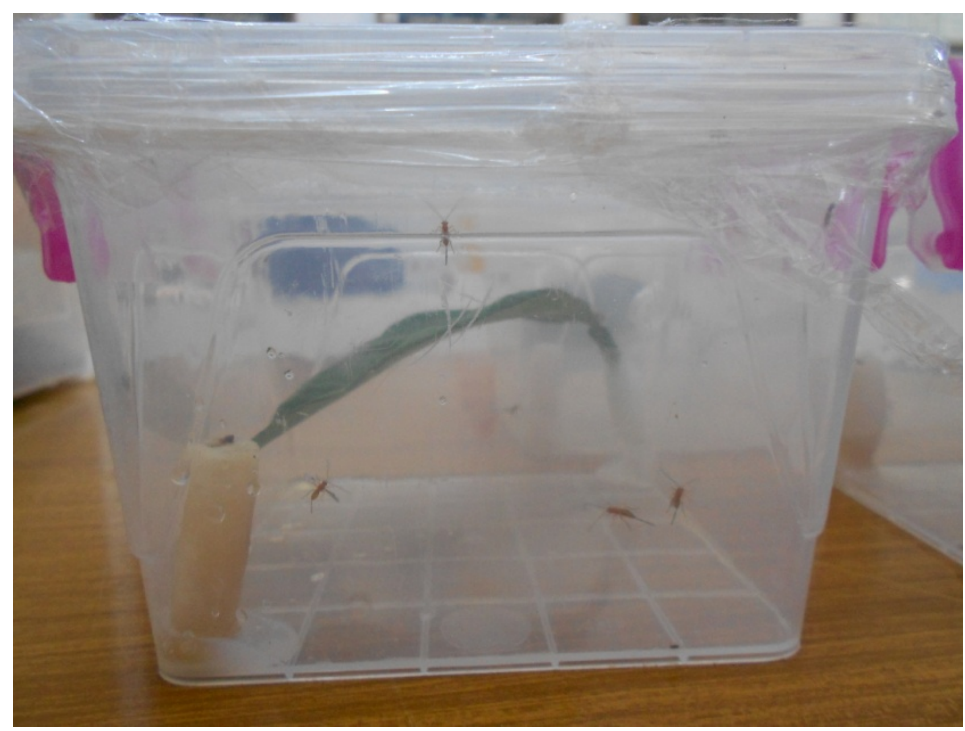

Figure 5.9. Experimental dispositive (unit) to assess $D$. longicaudata adult susceptibility to selected pesticides.

\subsubsection{Data analysis}

Data were first tested for normality and homogeneity of variance using Shapiro-Wilk test (SPSS20 2011). The mortality was then compared using one-way analysis of variance (ANOVA) at $P<0.05$. Means were then separated using the LSD post hoc test. When significant differences were detected, the mortality values were corrected using Abbot's formula (Abbott 1925). Then, corrected mortality percentages were used to rank insecticides and their residues according to the International Organization for Biological and IntegratedControl (IOBC)Working group "Pesticides and Beneficial Organisms" standards toxicity classes as follow: (1) harmless, mortality lower than 30\%; (2) slightly harmful, between 30 and 79\%; (3) moderately harmful, between 80 and 99\%; and (4) harmful, mortality higher than 99\% (Sterk et al. 1999).

\subsection{Results and Discussion}

\subsubsection{Native parasitoids surveillance}

A total of 10,940 medfly pupae were collected from infested fruits. Table 5.3 presents the distribution by collection place, and emerged individuals. Parasitoids were only found in the Chott-Meriem region, during the screening period. 
Parasitoids were identified only in Chott-Meriem region, most probably due to application of IPM directives in the region, with a reduced number of pesticides applications, that enhance natural enemies' presence for control of almost all other citrus pest species.

Table 5.3. Number of fruits, recovered pupae, emerged medfly and parasitoids identified, per screening region.

\begin{tabular}{|c|c|c|c|c|}
\hline Region & Fruits (n) & Pupae (n) & $\begin{array}{l}\text { Emerged medfly } \\
\text { (n) }\end{array}$ & $\begin{array}{l}\text { Recovered } \\
\text { parasitoids (n) }\end{array}$ \\
\hline \multicolumn{5}{|c|}{ Naturally infested fruits } \\
\hline Tunis & 156 & 270 & 197 & 0 \\
\hline Cap Bon & 1200 & 2200 & 960 & 0 \\
\hline Chott-Meriem & 1460 & 8470 & 6750 & $18^{1}$ \\
\hline \multicolumn{5}{|l|}{ Sentinel fruits } \\
\hline Chott-Meriem & 200 & 4480 & 3554 & $61^{2}$ \\
\hline \multicolumn{5}{|c|}{ Sentinel pupae hosts } \\
\hline Chott-Meriem & NA & 1200 & 729 & $20^{3}$ \\
\hline
\end{tabular}

As can be seen in Table 5.3 several parasitoid species have been found only in the region of Chott-Meriem.

Among the species identified, we have found the pupal parasitoid $P$. vindemmiae (53 and 20 from sentinel fruits and sentinel pupae hosts, respectively) (Figures 5.10, 5.11). Pachycrepoideus vindemmiae is an idiobiont parasitoid of pupae of a wide range of Diptera species in the families Anthomyiidae, Calliphoridae, Drosophilidae, Muscidae, Sarcophagidae, Tachinidae and Tephritidae (Wharton 1989; Marchiori and Barbaresco 2007; Tormos et al. 2009). Among the Tephritidae, various species such as A. fraterculus, A. suspensa, B. oleae and C. capitata are known as appropriate hosts (Noyes 2002; Ovruski et al. 2006; Beitia et al. 2007). Pachycrepoideus vindemmiae is a cosmopolitan species widely distributed through the world (Noyes 2014; Wharton and Yoder 2014), and it has been previously recorded from Tunisia, as a parasitoid of drosophilid species (Diptera: Drosophilidae), like Drosophila melanogaster 
(cited by Delpuech et al. 1994 by its synonym, Pachycrepoideus dubius Ashmead). In this work, we determine for the first time its occurrence as parasitoid of medfly (Harbi et al. 2015a).
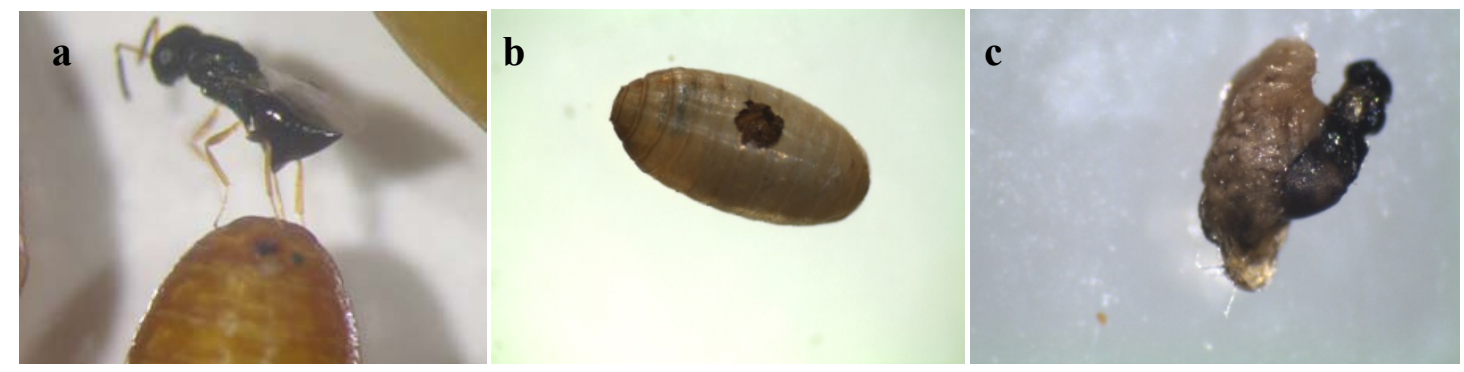

Figure 5.10. a) $P$. vindemmiae female parasitizing a pupa of $C$. capitata; b) the emergence hole of $P$. vindemmiae in the puparium of $C$. capitata; c) P. vindemmiae pupa over C. capitata pupa.

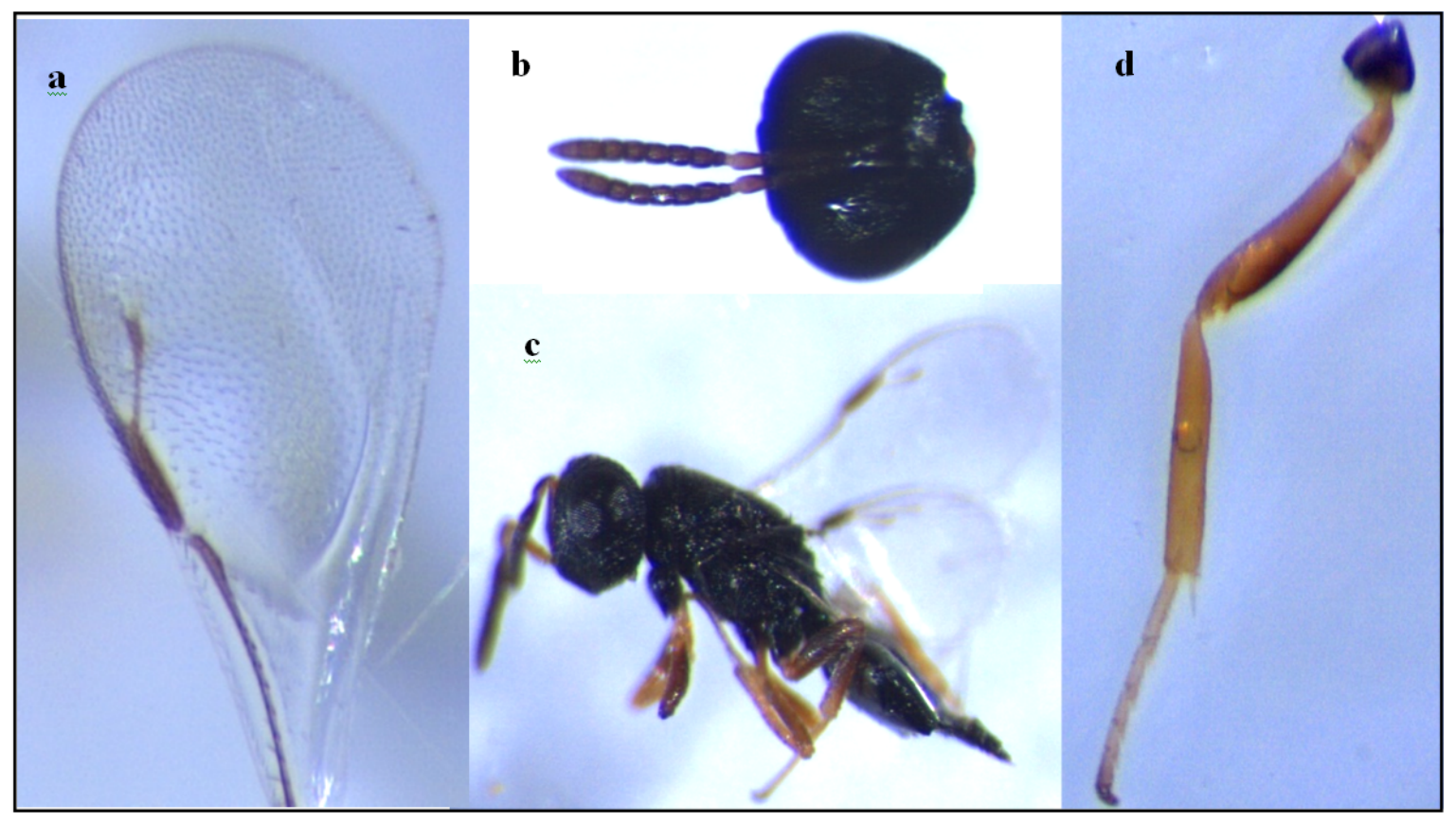

Figure 5.11. Some morphologic characters of $P$. vindemmiae. a) the wing, b) the male antennae, c) $P$. vindemmiae female in dorsal view, d) the leg.

The second most numerous parasitoid species found was the braconid $P$. concolor with a total of 19 individuals (Figure 5.12). This is a koinobiont endoparasitoid of many Tephritidae (Diptera) larvae, including medfly and the olive fruit fly B. oleae (Marchal 1910), on which was previously cited in Tunisia (Figure 5.12). This species is being used as natural enemy of many tephritid fruit flies, but due to the length of its oviscaptor, is more efficient when the tephritid fruit host is a small fruit like the olives. 

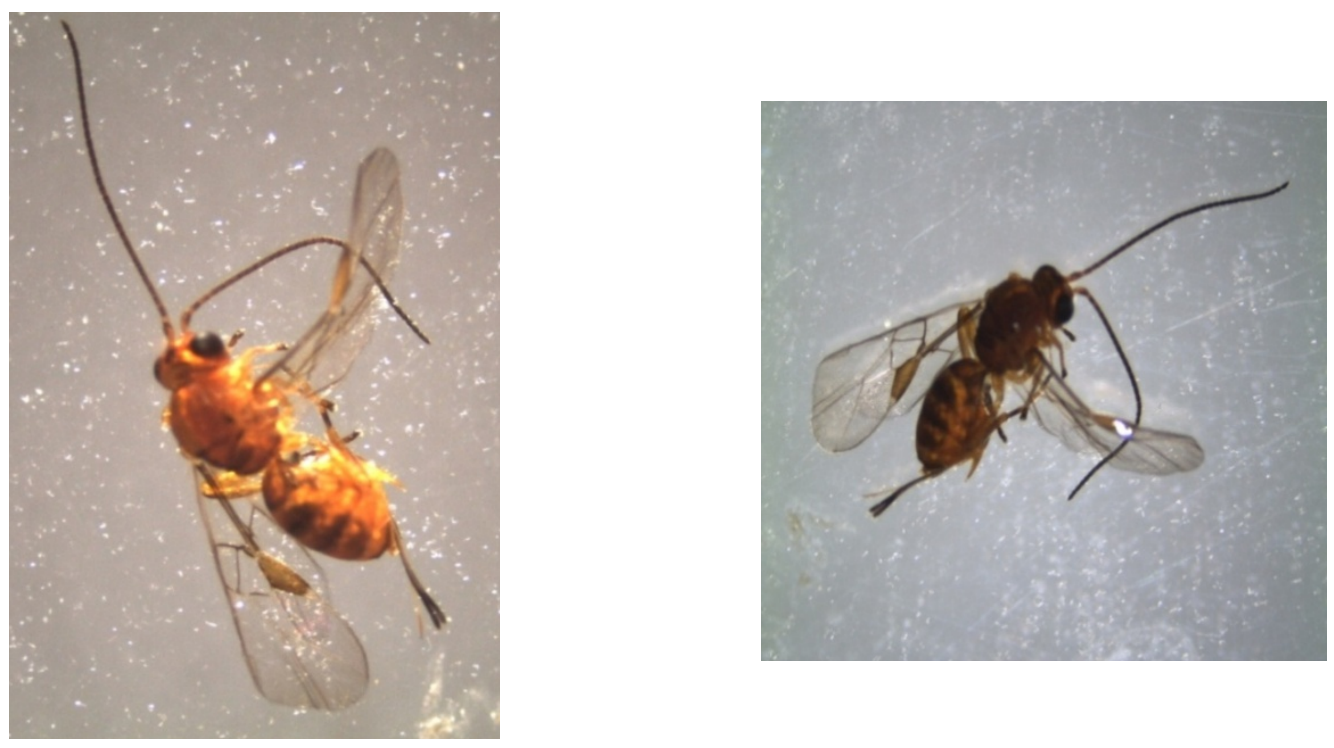

Figure 5.12. Some Psyttalia concolor (Szépligeti, 1910) female individuals found in Chott-Meriem region. Notice the short ovipositor compared with the abdomen length.

In addition to these two parasitoids species, another two putative species were found. The species level of these individuals was impossible to ascertain, at the time of writing this report. One group of individuals was assigned to the family Eulophidae, more precisely to the subfamily Tetrastichinae (Figure 5.13), which include endoparasitoid species of eggs, larvae and pupae of several Dipteran species. While the other group, was assigned to the family Diapriidae (Hymenoptera: Diapriidae) by the characteristic antennae, which are inserted above the clypeus on a conspicuous transversal edge (Figure 5.14). The Diapriidae are typically parasitoids of larvae and pupae of a wide range of insects, especially dipterans, however, a few Diapriidae species are hyperparasitoids, meaning that are parasitoids of other hymenopterans. Diapriids are small hymenopterans with average body size of 2-4 $\mathrm{mm}$, present a smooth and polished body surface of mainly black or dark-brown coloration (in most European species) (Masner, 1995). 


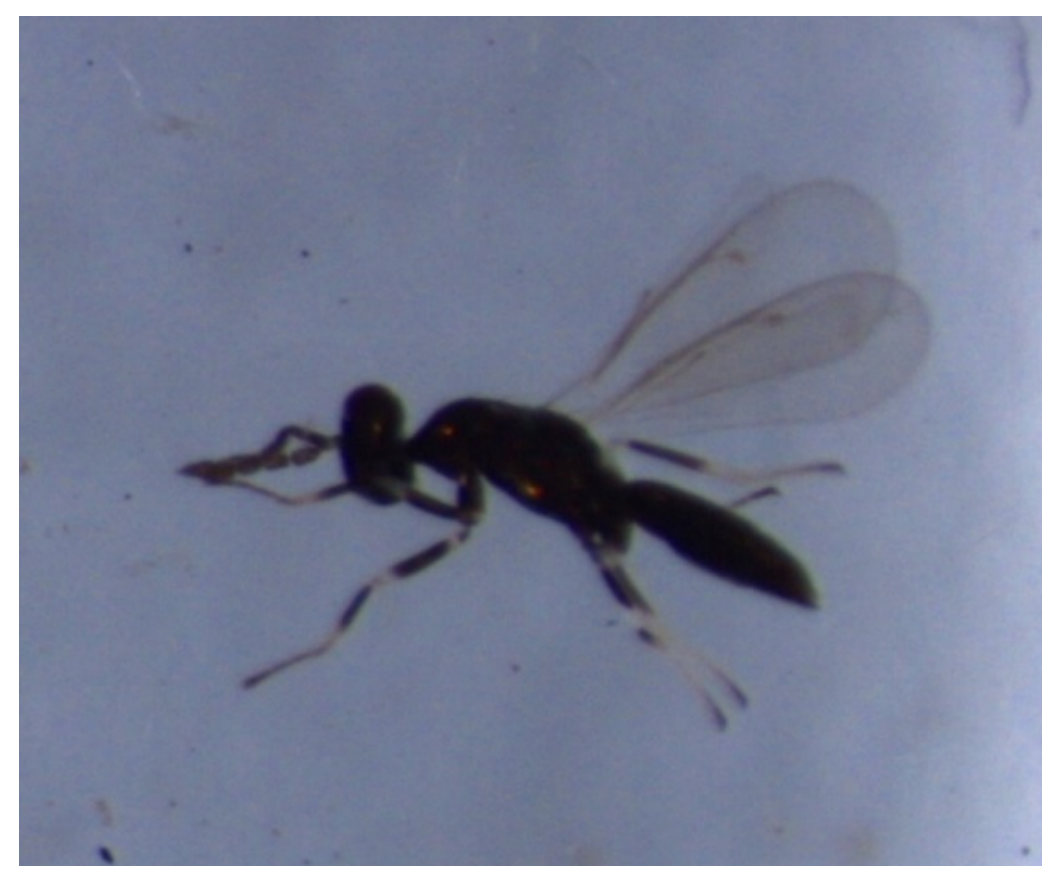

Figure 5.13. Individual identified as Eulophidae, Tetraschinae, emerged from C.capitata pupa infesting citrus orchards in Tunisia.

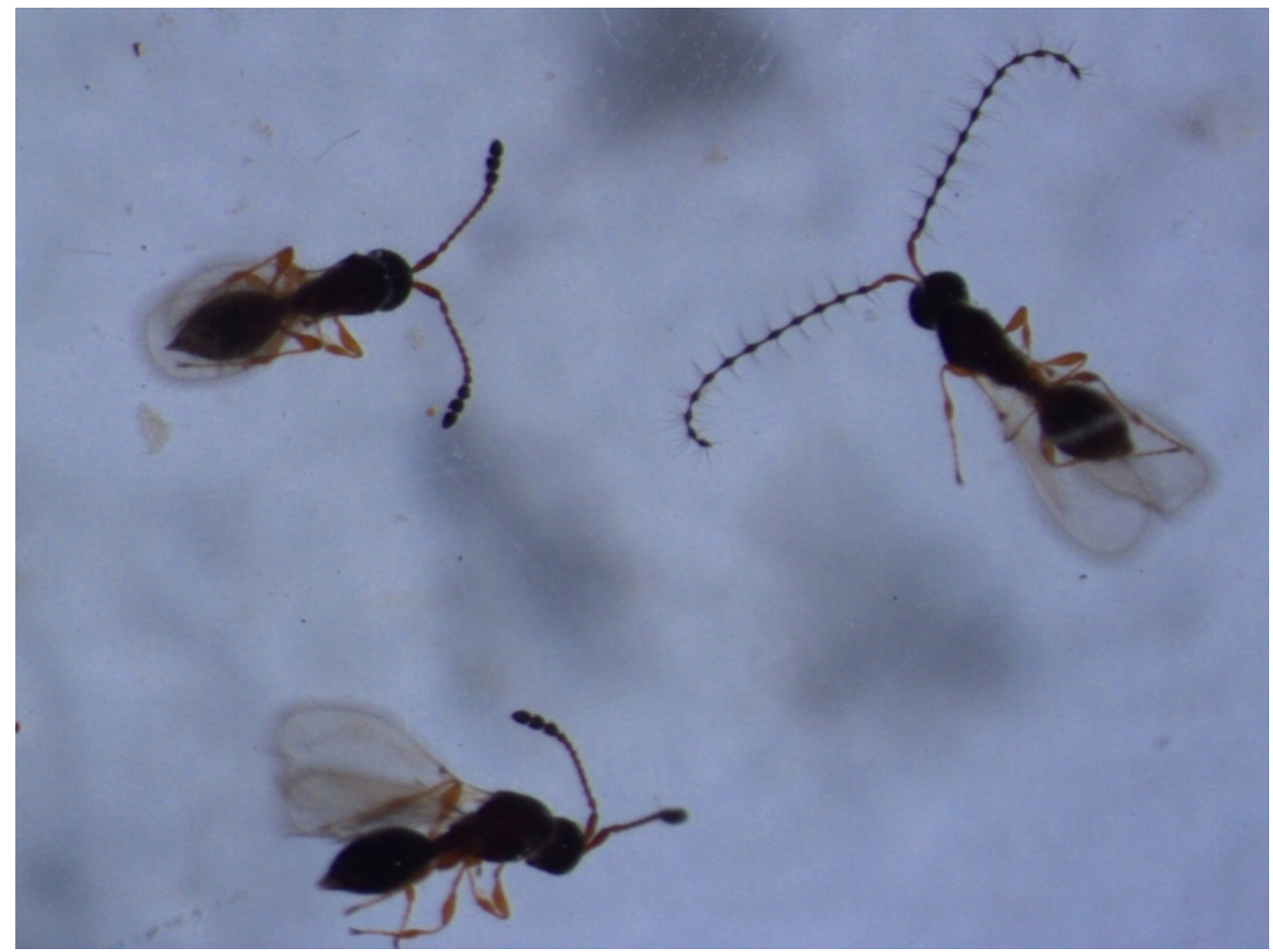

Figure 5.14. Individuals identified as Diapriidae emerged from C. capitata pupae collected from citrus orchards in Tunisia. 
The percentage of parasitism was quite low in the two orchards at Chott-Meriem. This low parasitism is similar to that found in Spain for the same species in natural conditions (Falco et al. 2006) and possibly due to P. vindemmiae being a generalist parasitoid. Nevertheless, the results demonstrate the viability of the two sampling systems to detect the presence of the parasitoid in the field: sentinel fruits infested by C. capitata larvae and exposed pupae.

The Chott-Meriem studied orchards are managed organically, promoting the presence and the development of parasitoids. This is not the case in the orchards at Cap Bon and Tunis which receive several insecticide treatments with malathion, which is harmful to beneficial fauna (Urbaneja et al. 2004). All other parasitoid species found in the parasitoid screening program, P. concolor, the Eulophidae and the Diapriidae were always in the organic Chott-Meriem orchards.

Despite the low parasitism percentage of $P$. vindemmiae on $C$. capitata detected in this study, its discovery in Tunisia is important for the future development of integrated and biological control programs against $C$. capitata in this country. However, it is a controversial species. Firstly, because it is well known as a facultative hyperparasitoid of other primary fruitfly parasitoids, such as F. arisanus and D. longicaudata (Wang and Messing 2004); and secondly, because it is a generalist parasitoid of Diptera (Wharton and Yoder 2014) which could deviate its attention for the devised medfly target. For this reason, its usefulness as a control agent of tephritids is sometimes doubted. Nevertheless, in some countries like Colombia, P. vindemmiae is mass-reared for use against tephritid species, where the insect is produced by Productos Biológicos Perkins Ltda. (Anonymous 2014). There are also some reports on its use in biological control programs against other tephritid pests (Ovruski et al. 2000; Badii and Abreu 2006). In addition, in Spain it has been proposed that $P$. vindemmiae should form part of the parasitoid complex used for the control of C. capitata (Falcó et al. 2006, Beitia et al. 2007; Sabater-Muñoz et al. 2013).

Knowledge of the presence of $P$. vindemmiae in Tunisian citrus orchards is important for the development of a biological control program for C. capitata populations on citrus using native or imported parasitoid species. 


\subsubsection{Pilot releases and naturalization of $\boldsymbol{D}$. longicaudata}

\subsubsection{Climatic conditions}

The climatic conditions recorded during the period of the work are registered in the following table (Table 5.4).

Table 5.4. Climatic conditions registered in the release site of Technical center of organic agriculture $(\mathrm{CTAB})$ in Chott-Meriem region.

\begin{tabular}{lcccccccc}
\hline & \multicolumn{3}{c}{$\begin{array}{c}\text { Temperature } \\
\left({ }^{\circ} \mathrm{C}\right)\end{array}$} & & \multicolumn{2}{c}{$\begin{array}{c}\text { Relative Humidity } \\
(\%)\end{array}$} & $\begin{array}{c}\text { Precipitations } \\
(\mathrm{mm} / \text { day })\end{array}$ & $\begin{array}{c}\text { Wind speed } \\
(\mathrm{km} / \mathrm{h})\end{array}$ \\
\cline { 2 - 8 } & Mean & Min. & Max. & Mean & Min. & Max. & & \\
\hline September 2013 & 27.03 & 15.65 & 38.41 & 57.5 & 16 & 99 & 0.72 & 1.077 \\
October 2013 & 23.61 & 12.96 & 34.26 & 58 & 17 & 99 & 0.07 & 0.74 \\
November 2013 & 19.8 & 5.34 & 34.26 & 58 & 17 & 99 & 0.84 & 0.81 \\
December 2013 & 19.17 & 4.09 & 34.26 & 58 & 17 & 99 & 2.22 & 0.80 \\
January 2014 & 12.37 & 3.38 & 21.37 & 63.5 & 28 & 99 & 0.81 & 0.58 \\
February 2014 & 15.51 & 3.38 & 27.63 & 59,5 & 20 & 99 & 1.36 & 0.76 \\
March 2014 & 15.51 & 3.38 & 27.63 & 59.5 & 20 & 99 & 1.50 & 0.94 \\
April 2014 & 20.3 & 8.8 & 32.9 & 61.85 & 18 & 98 & 1.35 & 0.85 \\
May 2014 & 21.76 & 10.88 & 33.99 & 59.99 & 15.95 & 96.7 & 0.75 & 0.74 \\
June 2014 & 25.82 & 15.15 & 37.37 & 61.6 & 21.74 & 93.5 & 0.05 & 0.95 \\
July 2014 & 27.52 & 18.93 & 38.61 & 63.69 & 11.5 & 94.7 & 0 & 0.86 \\
August 2014 & 28.72 & 21.49 & 42.22 & 68.63 & 10.11 & 93.9 & 0 & 0.58 \\
\hline
\end{tabular}

\subsubsection{Pilot releases}

Diachasmimorpha longicaudata were recovered in sentinel fruits that were put as a trap one week after each release and in the infested fruit samples collected in the same orchard, indicating that the parasitoids were in good condition upon release, being able to locate hosts and to develop one or two generations in the field. Indeed, the parasitoid could produce a 
parasitism percentage about $8.33 \%, 11.75 \%, 14.28 \%$ and $8.33 \%$ for the first, second, third and fourth releases respectively (Figure 5.15) in the sentinel fruits. These maximum of parasitism percentages were recorded in the center of the orchard around the release point but also some wasps were recovered in a different position of the sentinel fruit in the orchard far away of the point of the release with variation of the parasitism percentage. These results demonstrate the capacities of $D$. longicaudata to disperse and attend their hosts on a long distance (about 100 m) and also parasitize and produce new generations in the Tunisian conditions. The highest parasitism percentages were recorded after the second and the third releases.
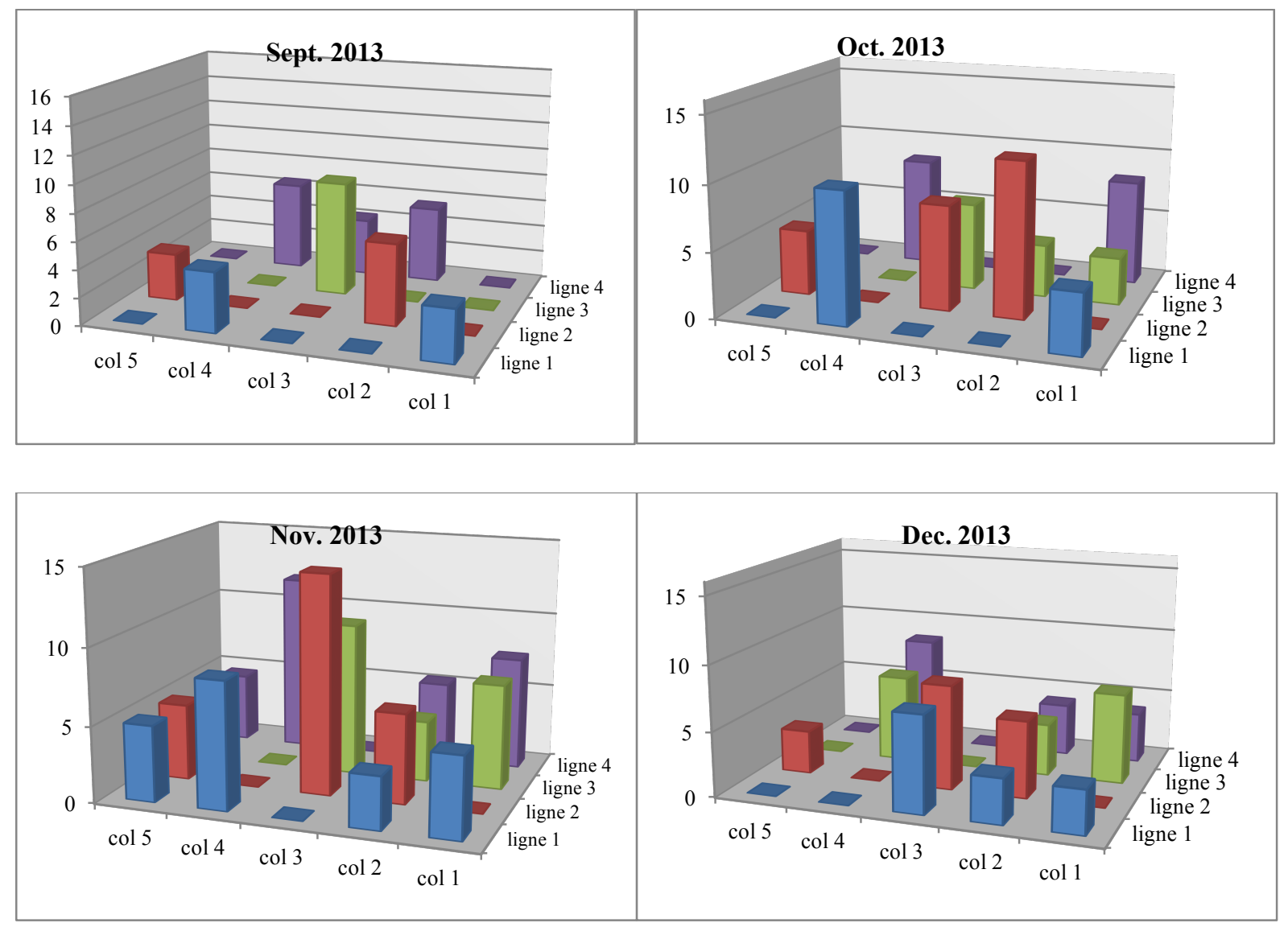

Figure 5.15. Parasitism percentage (\%) induced by released $D$. longicaudata. Parasitism was recorded in sentinel fruits distributed in 20 points (5 columns and 4 rows of citrus trees). Each graph corresponds to the parasitism percentage obtained in each release (from Sept. 2013 to Dec. 2013). Each color represents a tree row with a trap, numbers indicate the tree number within each row. 
On the other hand, the released braconids were found in the collected naturally infested fruits after releases. Out of 650 fruit samples, more than 993 medfly pupae were recovered after the four release trials. Of these, just 25 D. longicaudata were found (Table 5.5). The recovered parasitoids were not numerous after the first release and the major quantities were recorded after the second and the third releases and then the recovered number increases (Table 5.5). Another medfly larval parasitoid was found among the emerged individuals, $P$. concolor, which was recorded after the $2^{\text {nd }}$ and the $3^{\text {rd }}$ releases in the same orchard.

Table 5.5. Number and identity of recovered specimens from naturally infested fruits from the Pilot release citrus plot one week after each release.

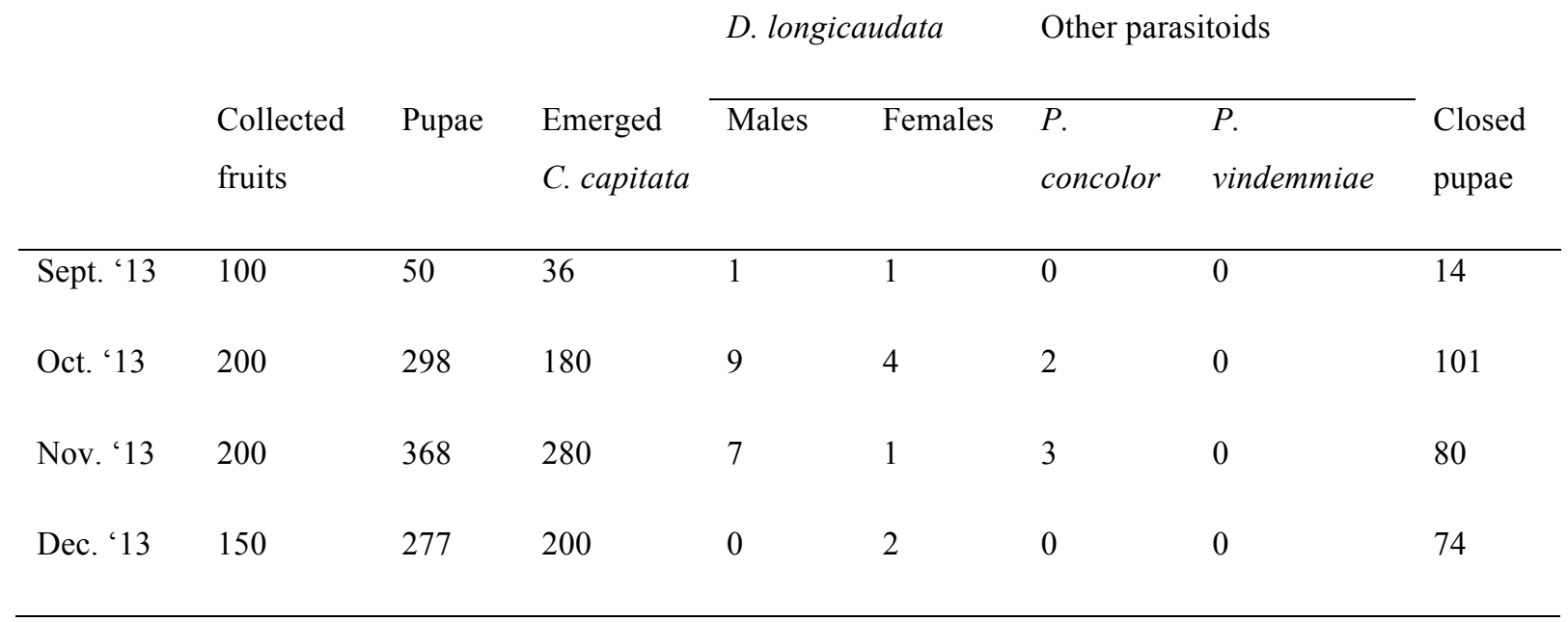

The assessment of the establishment of the released parasitoid in the field was realized one month after the last release and during the winter season (during December 2013 two samplings took place, the first after the release, and the second one, nearly one month after the release to ascertain its presence). Result showed that the parasitoid D. longicaudata is still present in the field just one month after the last release (about 10 recovered individuals from 376 medfly collected pupae) and then disappeared in the rest of the winter (Table 5.6). 
Table 5.6. Number and identity of recovered specimens from naturally infested fruits from the Pilot release citrus plot one month after the last release.

\begin{tabular}{|c|c|c|c|c|c|c|c|c|}
\hline & & & & D. long & audata & Oher par & toids & \\
\hline & $\begin{array}{l}\text { Collect } \\
\text { ed fruit }\end{array}$ & Pupae & $\begin{array}{l}\text { Emerged } \\
\text { C.capitata }\end{array}$ & Males & Females & $\begin{array}{l}P . \\
\text { concolor }\end{array}$ & $\begin{array}{l}P . \\
\text { vindemmiae }\end{array}$ & $\begin{array}{l}\text { Closed } \\
\text { pupae }\end{array}$ \\
\hline Dec. '13 & 170 & 376 & 237 & 4 & 6 & 0 & 0 & 96 \\
\hline Jan. '14 & 105 & 317 & 286 & 0 & 0 & 0 & 0 & 32 \\
\hline Feb. '14 & 87 & 230 & 156 & 0 & 0 & 0 & 0 & 85 \\
\hline Mar. '14 & 56 & 170 & 87 & 0 & 0 & 0 & 0 & 75 \\
\hline Apr. '14 & 27 & 56 & 38 & 0 & 0 & 0 & 0 & 14 \\
\hline
\end{tabular}

\subsubsection{Biotic factors of $\boldsymbol{D}$. longicaudata under Tunisian climatic conditions}

\section{Diachasmimorpha longicaudata adults' longevity}

The assessment of the adult longevity of $D$. longicaudata during the different season in Tunisia revealed that it varied depending on the season variation and presented a significant difference $(F=67.92 ; d f=3,39 ; P \leq 0.0001)$. The longer longevity was recorded during the winter while the shorter in the summer season. Diachasmimorpha longicaudata longevity was between $19.44 \pm$ 3.30 and $26.56 \pm 4.13$ days for male and female, respectively, in the summer and $35.26 \pm 8.16$ and $48.74 \pm 11.84$ for male and females, respectively, in the winter season. Female longevity was longer than that of males with statistically significant differences $(t$ test, $P \leq 0.001)$ (Figure 5.16). 


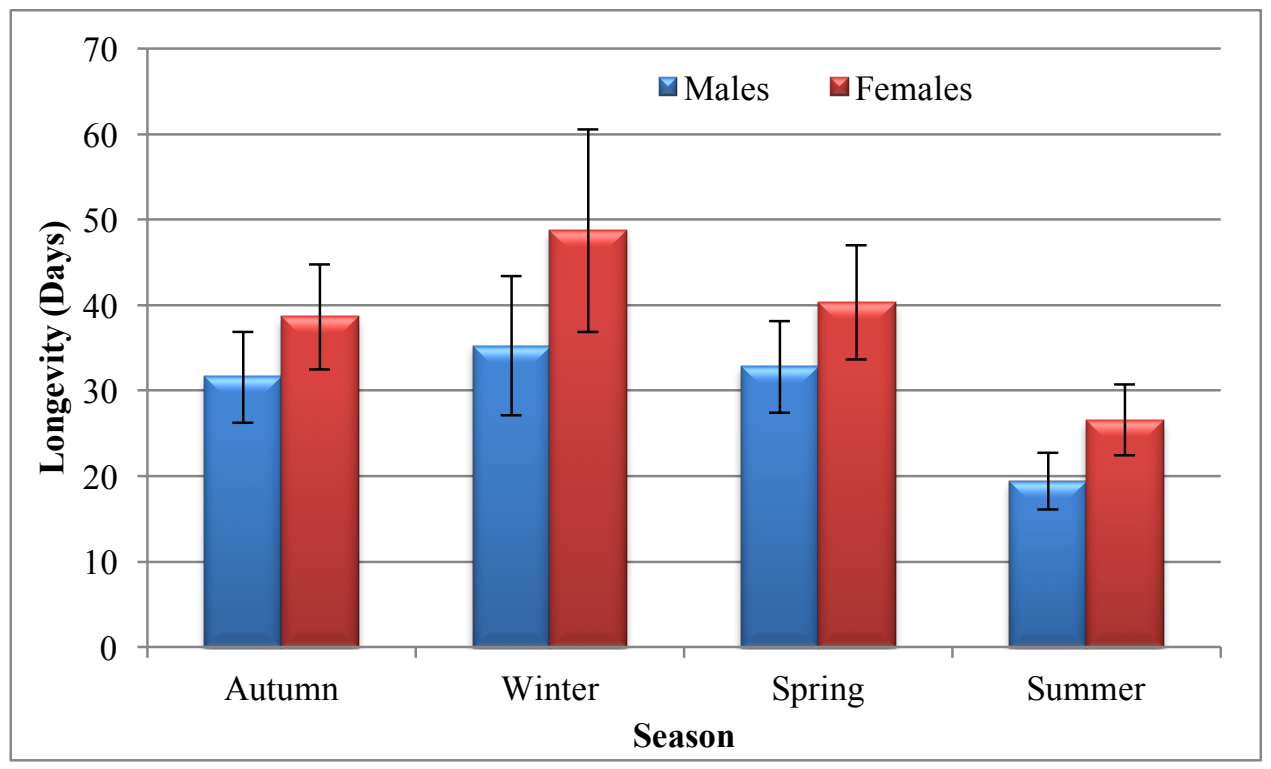

Figure 5.16. Longevity (mean $\pm \mathrm{SE}$ ) in days of $D$. longicaudata adults (males in blue, females in red) during the different seasons in Tunisia.

\section{Diachasmimorpha longicaudata immature development during Tunisian winter conditions}

The study of the immature development of C. capitata and its parasitoid D. longicaudata in the cold period of Tunisia revealed the absence of emergence of both insects from the beginning of the assay until the 18/02/2014 for the medfly and 01/04/2014 for D. longicaudata. Furthermore, the first emergency was notably low. Indeed, the first emergence for C. capitata was of 2 individuals and of $1 \delta$ in the case of its parasitoid (Table 5.7). The development time of both insect decreased with the augmentation of the temperature, it was 35 days for C. capitata in the trial of $18 / 02 / 2014$ when the mean temperature was about $13^{\circ} \mathrm{C}$ and 15 days when the mean temperature was about $18.66^{\circ} \mathrm{C}$ in the trial of $15 / 04 / 2014$. The same observations were observed for D. longicaudata.

In the laboratory (control treatment), the emergence percentage was always high for the medfly and the braconid from the beginning of the essay till the end with an average of $63 \%$. The developmental time of the medfly from pupae until the emergence was between 7 and 9 days while the developmental time of $D$. longicaudata from eggs to adults was about 14-17 days. This demonstrated that the used individuals were in their optimal performance and the emergence success was due to the climatic conditions. 
Table 5.7. Temperature conditions, developmental time (in days) and emerged number of individuals during the trials for immature development under Tunisian winter climatic conditions.

\begin{tabular}{|c|c|c|c|c|c|c|c|}
\hline \multirow[b]{2}{*}{ Trials } & \multicolumn{3}{|c|}{ Temperature $\left({ }^{\circ} \mathrm{C}\right)$} & \multicolumn{2}{|c|}{ Developmental time (days) } & \multicolumn{2}{|c|}{ Emerged (n) } \\
\hline & Min. & Mean & Max. & C. capitata & $\begin{array}{c}D . \\
\text { longicaudata }\end{array}$ & $\begin{array}{c}C . \\
\text { capitata }\end{array}$ & $\begin{array}{c}D . \\
\text { longicaudata }\end{array}$ \\
\hline $18 / 02 / 2014$ & 5.11 & 13.08 & 25.39 & 35 & - & 2 & 0 \\
\hline $04 / 03 / 2014$ & 5.03 & 13.13 & 25.39 & 35 & - & 5 & 0 \\
\hline $18 / 03 / 2014$ & 5.03 & 14.11 & 25.39 & 33 & - & 5 & 0 \\
\hline $01 / 04 / 2014$ & 8.84 & 15.51 & 22.97 & 21 & 40 & 7 & $10^{\lambda}$ \\
\hline $15 / 04 / 2014$ & 9.19 & 18.66 & 27.39 & 15 & 33 & 12 & $4 \hat{\circ}+3 ㅇ$ \\
\hline
\end{tabular}

\section{Discussion}

Since 2010 there were several attemps to determine the presence of medfly parasitoids, despite intensive surveillance, no parasitoid species were determined (Skouri 2010). Only as results of the present work (this thesis dissertation), in 2013 two species were found parasitizing medfly naturally, $P$. concolor and the pupal parasitoid $P$. vindemmiae (Harbi et al. 2015a). Despite this finding, these parasitoids do not induce a significant impact on medfly populations, probably due to the fact that these species are not specialists of medfly. Indeed, $P$. concolor was previously reported in Tunisia as parasitoid of the olive fruit fly $B$. oleae, whereas $P$. vindemmiae has been reported as a generalist parasitoid of dipterans worldwide (Tormos et al. 2009).

In this context, and following IOBC directives to establish a BC program, the parasitoid species D. longicaudata was introduced into Tunisia from Spain, being subjected to quarantine measures (to remove any host specimen that could propagate in Tunisia increasing genetic reservoir and/or introducing insecticide resistant individuals). After this first step, $D$. longicaudata biological parameters were determined under Tunisian climatic conditions.

Overall, our results indicate that the established rearing system is producing high quality individuals, as released specimens were able to survive, to parasitize, and to disperse far away of release point (more than $100 \mathrm{~m}$ ), even at semi-arid conditions similar to some regions of Argentina (Suarez et al. 2014). Indeed, medfly naturally infested citrus fruits were the source of new D. longicaudata in Sousse (Tunisia), indicating a foraging behavior that allow them to 
survive and locate hosts under semi-arid conditions, as also indicated in other studies (Sime et al. 2006b; Appiah et al. 2013; Mereilles et al. 2015).

As highlighted in the precedent chapters and in the presented results, D. longicaudata performance is influenced by the climatic conditions of the country (already described previously, see Messing et al. 1997) and by biotic factors (presence of hosts, fruit hosts, among others). However, as also indicated by Paranhos et al. (2007), abiotic factors exhert a contradictory effect, showing no effect during the most favorable conditions, but at the most restrictive season (winter), temperature and rainfall affected dispersion rate in an opposite direction. Indeed, these facts could explain our Tunisian winter data, with a decrease in recovered parasitoids and in the parasitism percentage, due to low temperatues and extraordinary rainfall (December 2013; tables 5.5 to 5.7). In addition, also explain the good results of the second and third releases, which, as explained above, offspring of second release contributed to increased parasitism percentage of third release thanks to the presence of hosts in the groves.

In addition to this fact, that indicate a naturalization event for the introduction of $D$. longicaudata in Tunisian citrus groves, the 'sentinel fruits system' arose as the perfect parasitoid surveillance method, by two reasons. First, this system allows determining dispersal mode and parasitoid performance in a single study, allowing the ecological study of the species under natural conditions, including determination of developmental abiotic thresholds (see results in Tunisia and those of previous chapters, and the comparison performed with Eitam et al. 2004; Mereilles et al. 2015). However, due to the structure of the study groves (presence of wind-breaks), we were unable to determine the effect of some abiotic factors (ie. wind speed) that affect parasitoid dispersion. Last but not least, this system also allows for a continuous surveillance of native or naturalized parasitoids, including, the determination of intraguild competition that could lead to a decrease in parasitism percentage of released species (Flavio et al. 2013).

In conclusion, the experimental set-up, its validation and the results obtained, allowed us to determine that $D$. longicaudata will not be able to survive the Tunisian winter, requiring of inoculative releases for the establishment of a Biological control program based on this species. However, due to the dispersal ability, survival as adults, and parasitism success, we can adopt a strategy of augmentative releases during C. capitata outbreaks in citrus orchards (in Tunisia between September and January) in an area-wide basis (Wong et al. 1991; Knipling 1992; Sivinski et al. 1996; Montoya et al. 2000a) to achieve a great control releasing enough number 
of specimens that could establish and overwint on small oasis within the country. But to achieve any of these two BC types, we have to intensify the parasitoid rearing system.

\subsubsection{Residual toxicity of some insecticides on D. longicaudata}

Three days after exposure to fresh $(1 \mathrm{~h})$ and 3-d-old residues were enough to indicate acute toxicity of almost all tested pesticides (Table 5.8$)$. The highest mortality percentages $(100 \%)$ were registered for Malathion, Deltametrin+Thiacloprid, Acetamiprid and Methidathion without statistical differences among fresh residues. These insecticides were classified as harmful (IOBC class 4) according to the IOBC standards. The rest were classified as slightly harmful (IOBC class 2) causing mortality percentages ranging between 65.25 and $78.81 \%$ (Table 5.9).

Table 5.8. Percent mortality (mean $\pm \mathrm{SE}$ ) of $D$. longicaudata adults after 3 days of exposure to selected residues and water-treated control

\begin{tabular}{|c|c|c|c|c|c|c|}
\hline \multirow[b]{2}{*}{ Active ingredient } & \multicolumn{6}{|c|}{ Residue age (days-old) } \\
\hline & Fresh $(1 \mathrm{~h})$ & 3 & 7 & 14 & 21 & 28 \\
\hline Abemectine & $78.81 \pm 6.39 \mathrm{c}$ & $78.44 \pm 6.50 \mathrm{c}$ & $59.64 \pm 11.86 \mathrm{c}$ & $23.63 \pm 8.18 \mathrm{~b}$ & $15.93 \pm 6.13 \mathrm{ab}$ & $(-)$ \\
\hline Acetamipride & $100.00 \pm 0.00 \mathrm{~d}$ & $96.55 \pm 2.98 \mathrm{de}$ & $86.84 \pm 4.55 \mathrm{~d}$ & $78.18 \pm 8.18 \mathrm{~d}$ & $76.10 \pm 7.02 \mathrm{c}$ & $52.58 \pm 10.45 \mathrm{~cd}$ \\
\hline Azadarachtine & $71.18 \pm 5.29 \mathrm{bc}$ & $33.62 \pm 2.98 b$ & $10.52 \pm 2.63 \mathrm{ab}$ & $(-)$ & $(-)$ & $(-)$ \\
\hline $\begin{array}{l}\text { Deltametrine }+ \text { Thiacl } \\
\text { opride }\end{array}$ & $100.00 \pm 0.00 \mathrm{~d}$ & $90.51 \pm 5.38 \mathrm{~d}$ & $82.45 \pm 6.62 \mathrm{~d}$ & $61.81 \pm 9.83 \mathrm{c}$ & $23.89 \pm 10.05 b$ & $18.10 \pm 5.97 b$ \\
\hline Malathion & $100.0 \pm 0.00 \mathrm{~d}$ & $100.00 \pm 0.00 \mathrm{e}$ & $100.00 \pm 0.00 \mathrm{e}$ & $94.54 \pm 4.72 \mathrm{e}$ & $90.26 \pm 4.05 \mathrm{~d}$ & $81.03 \pm 5.38 \mathrm{~d}$ \\
\hline Methidathion & $100.00 \pm 0.00 \mathrm{~d}$ & $93.96 \pm 3.95 \mathrm{de}$ & $85.08 \pm 3.03 \mathrm{~d}$ & $85.45 \pm 3.14 \mathrm{de}$ & $78.76 \pm 9.57 \mathrm{~cd}$ & $44.82 \pm 5.38 \mathrm{c}$ \\
\hline Spinosad & $65.25 \pm 10.58 \mathrm{~b}$ & $37.06 \pm 5.38 \mathrm{~b}$ & $15.78 \pm 2.63 \mathrm{~b}$ & $13.63 \pm 8.33 \mathrm{ab}$ & $(-)$ & $(-)$ \\
\hline Statistics & & & & & & \\
\hline $\bar{F}$ & 149.21 & 218.08 & 148.79 & 81.12 & 83.43 & 67.50 \\
\hline$\overline{d . f .}$ & 7,23 & 7,23 & 7,23 & 6,20 & 5,17 & 4,14 \\
\hline $\bar{P}$ & $<0.0001$ & $<0.0001$ & $<0.0001$ & $<0.0001$ & $<0.0001$ & $<0.0001$ \\
\hline
\end{tabular}

Different letters within each set of columns indicate significantly different values of mortality $(P<0.05)$. (-); as indicated in the text, data were not determined as in the precedent residue age, no statistical differences were observed with control.

When considering the effect of 3-d-old residues, only Deltametrin+Thiacloprid and Methidathion reduced its toxicity category. Toxicity evolution was slow for Malathion, Methidathion and Acetamiprid from 3-d-old residues onwards. After 14-d post-treatment Malathion and Methidathion were still classified as moderately harmful (IOBC class 3), 
Abemectin decreased to class 2 and Spinosad become harmless (IOBC class 1). After 21 days post-treatment, Malathion remained as moderately harmful, Methidathion and Acetamiprid decreased to slightly harmful (IOBC class 2) and Deltametrin+thiacloprid and Abemectin become harmless (IOBC class 1) even if they induce mortality at $15-24 \%$, with statistical difference among them (Table 5.8 and 5.9). At this residue age, Malathion and Methidathion residues remained the most toxic to $D$. longicaudata adults, even mortality percentage allowed to assign to different IOBC classes they do not show statistical differences in induced mortality (Table 5.8). At the most distantly treatment time point, 28-d, Malathion still remained as moderately harmful (IOBC class 3), Methidathion and Acetamiprid, even if show a reduction in induced mortality, remained as slightly harmful (IOBC class 2).

Table 5.9. Classification of selected pesticides at different residue age on D. longicaudata 6-8 days-old adults, according to IOBC classification.

\begin{tabular}{lcccccc}
\hline Active ingredient & \multicolumn{5}{c}{ Residue age(days-old) } \\
\cline { 2 - 7 } & Fresh (1 h) & $\mathbf{3}$ & $\mathbf{7}$ & $\mathbf{1 4}$ & $\mathbf{2 1}$ & $\mathbf{2 8}$ \\
Abemectin & 2 & 2 & 2 & 1 & 1 & - \\
Acetamiprid & $\mathbf{4}$ & 3 & 3 & 2 & 2 & 2 \\
Azadarachtin & 2 & 2 & 1 & - & - & - \\
Deltametrin+Thiacloprid & $\mathbf{4}$ & 3 & 3 & 2 & 1 & 1 \\
Malathion & $\mathbf{4}$ & $\mathbf{4}$ & $\mathbf{4}$ & 3 & 3 & 3 \\
Methidathion & $\mathbf{4}$ & 3 & 3 & 3 & 2 & 2 \\
Spinosad & 2 & 2 & 2 & 1 & - & - \\
\hline $\begin{array}{l}\text { OOBC toxicity categories: } 1 \text { harmless, mortality lower than } 30 \% ; 2 \text { slightly harmful, mortality between } 30 \text { and } 79 \% ; 3 \text { moderately harmful, } \\
\text { mortality between } 80 \text { and } 99 \% ; 4 \text { harmful, mortality higher than } 99 \%\end{array}$
\end{tabular}

In this work, we assessed the toxicity to the introduced larval-pupal endoparasitoid $D$. longicaudata of the seven most used pesticides in Tunisian citrus orchards. This information is necessary for the correct implementation of Biological Control program, based on this parasitoid species, within the Integrated Pest Management program for citrus. As explained, tephritid fruit flies parasitoids constitute the most neglected natural enemies group in pesticides side effects studies, which constitute the main objective of the present work.

Taking into consideration the persistence of selected pesticides residues along time we found that Malathion, despite its toxicity to medfly adults, should be removed from IPM program, as is the most toxic and persistent. Whereas the two natural/botanical compounds, Spinosad and 
Azadarachtin, show the lowest toxic category and persistence, and thus could be incorporated in the IPM program with the corresponding security time delay (14 and 7 days, respectively, as can be seen in table2) on the condition of causing tolerable sublethal side effects on the wasp. This toxicity evolution aggrupation will be followed to discuss our results.

Malathion and Methidathion belong to the same organophosphate chemical family (Table 5.2), with differentiated mode of action, which could account for the differential results obtained in this work (IOBC class 4 as fresh residue, and class 4 and 3 respectively even at 7d-post treatment). Despite these insecticides have been recently banned from the European Union (OJEU, 2015) by their human health concerns (Flessel et al. 1993; Marty et al. 1994) and their harmful effects on non-target arthropods (Ehler andEndicott, 1984; Urbaneja et al. 2009) which lead in some cases to outbreaks of secondary agricultural pests that were under control of natural enemies, Malathion is still used in the Mediterranean area (including some EU members by some considerations in the OJEU 2015) as efficient pesticide against $C$. capitata. However, control failures have been recently reported owing the high frequency of sprays causing the emergence of resistant populations of the medfly (Magaña et al. 2007; Vontas et al. 2011). The EU had registered some alternative control tools, including bait stations and mass trapping. In this context, trapping has been implemented with lures activated with organophosphates insecticides or with insecticidal adhesive powder, which showed good potential due to intraspecific transmission (Rogers et al. 2014; Hsu et al. 2015).

These two techniques were successfully implemented in Tunisian peach orchards against $C$. capitata and proved to have minimal adverse effects on beneficial arthropods (Hafsi et al. 2015). Chemical alternatives to Malathion for controlling C. capitata were also tested in Spain concluding that a Spinosad bait-formulation gave good results in relationship with the pest and its natural enemies (Medina et al. 2004; Contreras et al. 2005; Chueca et al. 2007). Some other chemicals like Lambda-cyhalothrin, are promising candidates even thought they do not kill $C$. capitata adults; they induce disabling effects like inability to fly, uncontrolled bodymovements, reduced fecundity and fertility; and are inducing resistance mediated by P450 (Urbaneja et al. 2009; Arouri et al. 2015).

Acetamiprid belongs to the neonicotinoids pesticide family and have been considered as rational alternatives to the organophosphates due to their high specificity, elevated efficacy and relatively low toxicity to the environment (Tomizawa andCasida, 2005). Neonicotinoids are widely used in Tunisian citrus orchards to control hemipteran pests species considering their ovicidal and larvicidal activities and systemic action. However, in the past 3-5 years ecotoxicological studies revealed a wide range of adverse side effects on non-target arthropods, 
including the worldwide-threatened honey bee Apis mellifera L. (Hymenoptera: Apidae), which remains the model organism against the use of neonicotinoids (Laurino et al. 2011). Fogel et al. (2013) assessed the impact of Acetamiprid on immature stages of the predator Eriopis connexa Germar (Coleoptera: Coccinellidae) reporting reduced egg hatching, disruption of embryogenesis, larval mortality and altered demographic traits of adults. Similar studies reported great differences in toxicity according to species. For example, it was moderately harmful to Chrysoperla carnea Stephens, harmless to Neoseiulus cucumeris Oudemans (Acari: Phytoseiidae) and harmful to Viereck (Hymenoptera: Braconidae) Nasreen et al. 2005). Tabozada et al. (2015) demonstrated that Thiacloprid was toxic on the parasitoid, Bracon brevicornis Wesmael (Hymenoptera: Braconidae) causing low number of emerged adults and reduced male and female longevity. In the case of the egg parasitoid Trichogramma cacoeciae Marchall (Hymenoptera: Trichogrammatidae), a common egg parasitoid of lepidopteran pests in Tunisia, Schuld and Schmuck (2000) reported more benign toxicological profile of this insecticide. Regarding tephritid fruit flies' parasitoids, neonicotinoids have been previously tested, being the active ingredient Imidacloprid. Liburd et al. (2004) determined lethal effects on D. longicaudata when used in treated spheres for the management of key fruit fly pests. Adán et al. (2011) assessed lethal and sublethal toxicity of Imidacloprid, on the braconid $P$. concolor Szépligeti, depending on application mode (cover sprays become lethal whereas bait sprays remained sublethal). So, taking in consideration our results, we can confirm that neonicotinoids should be used with caution when beneficial hymenopterans are present in the agro-ecosystem.

Abamectin, a mixture of avermectins, is one natural insecticidal, acaricidal and nematicidal compound derived from Streptomyces avermitilis. This agricultural compound was approved as a plant protection agent and as a veterinary drug for control of endo- and ecto-parasites (FAO, 1996). Despite its natural bacterial origin, some lethal effects on some biocontrol agents have been previously recorded, including slightly harmful (IOBC class 2) classification for $D$. longicaudata as obtained in this work either as fresh or even 7-d-old residue. Bueno and Freitas (2004) found no lethal effects on eggs and larvae of Chrysoperla externa Hagen (Neuroptera: Chrysopidae). Whereas it was classified as harmful (IOBC class 4) for Orius laevigatus Fieber (Hemiptera: Anthocoridae) irrespectively of residue age (1-h, 7- and 14-d-old) (Biondi et al. 2012). Another natural enemy affected by Abamectin (IOBC class 4 ) is the mealybug ladybird Cryptolaemus montrouzieri Mulsant (Coleoptera: Coccinellidae), a very efficient predator of the mealybug Planococcus citri Risso (Hemiptera: Pseudococcidae), which should be protected in all citrus IPM programs (Rahmouni et al. 2015). Interestingly, although Biondi et al. (2013) 
did not find a significant acute Abamectin toxicity toward females of the braconid parasitoid, Bracon nigricans Szépligeti (Hymenopetra: Braconidae), found strong sublethal detrimental effects on biocontrol activity, progeny production and sex-ratio. Considering these data, we stress the fact that the acute toxicity assessment for biological control agents should be completed upon the establishment of the wasp in Tunisian citrus cultivations by assessing sublethal effects of toxicants to provide an overall assessment of the chemical side effects.

Detametrin+Thiacloprid, the first belongs to the pyrethroids class while the second belongs to the neonicotinoids class. Many insecticides risk assessment studies concluded that neonicotinoid insecticides containing a nitro group suchas Imidacloprid and Thiamethoxam caused the highest adverse side effects to auxiliary arthropods, while the cyano group inthiacloprid showed to have relatively lower toxicity. It has been found also that Thiacloprid can be considered safe for the bumblebee Bombus terrestris (Hymenoptera: Apidae) and for the honey bee A. mellifera (Iwasa et al. 2004; Mommaerts et al. 2010). The lower side-effects of the cyano group was attributed to the existence of different nicotinic acetylcholine receptor (nAChR) subtypes as well as significant differences in metabolism and/or the toxicity of produced secondary metabolites between the two neonicotinoid groups (Suchail et al. 2004; Jones et al. 2006). However, recent studies have demonstrated that beneficial arthropods in contact with Thiacloprid can exhibit sublethal side effects such us disturbance of navigation ability in honeybees (Fischer et al. 2014) and significant reduction of the attack rate and an increase in handling time in Macrolophus pygmaeus Rambur (Hemiptera: Miridae) (Martinou 2014). In the case of Trichogramma cacoeciae Marchal (Hymenoptera: Trichogrammatidae), adults were not adversely affected by a spray treatment with Thiacloprid while emergence success was significantly reduced. Regarding pyrethroids, their lethal and sublethal side effects on non-target arthropods seem to respond variably depending on the tested species. They were classified as safe for Trichogramma ostriniae Peng \& Chen (Hymenoptera: Trichogrammatidae) and Trichogramma nubilale Ertle \& Davis (Hymenoptera: Trichogrammatidae) (with the exception of butane-fipronil and fipronil) (Wang et al. 2012a,b), harmful on the insect egg parasitoid Telenomus remus Nixon (Hymenoptera: Scelionidae) and Trichogramma cordubensis Vargas \& Cabello (Hymenoptera: Trichogrammatidae) (Garcia et al. 2009; Carmo et al. 2010) and seriously harmful (100\% mortality) to three whitefly parasitoid species, Eretmocerus mundus Mercet (Hymenopetra: Aphelinidae), Eretmocerus eremicus Rose \& Zolnerowich (Hymenopetra: Aphelinidae) and Encarsia formosa Gahan (Hymenopetra: Aphelinidae) (Sugiyama et al. 2011). In addition, they are known to alter sex ratio by decreasing the number of female offspring of Aphidius uzbekistanicus Luzhetzki 
(Hymenoptera: Aphidiidae) (Krepsi et al. 1991). In our trials, although the acute toxicity of Detametrin+Thiacloprid based product significantly decreased with time, the use of such insecticide in a framework of IPM programs using D. longicaudata is still risky as both insecticides are susceptible to cause significant lethal and sublethal effects on other Hymenoptera. More research is needed especially regarding long-term toxicity of this product against the imported wasp.

Spinosad, bacterial insecticide derived from the actinomycete Saccharopolyspora spinosa, shares some relations with Abamectin. Even though we have classified it as slightly harmful against $D$. longicaudata as in other risk assessment studies (Stark et al. 2004), opinions are still divergent about its compatibility with many biocontrol agents, especially parasitoids, with emphasis on its possible trans-generational sublethal side effects (Biondi et al. 2012b; Costa et al. 2014; Abbes et al. 2015). According to most eco-toxicological studies of chemicals used in citrus, this insecticide seems to be selective to predators such as C. montrouzieri and Rodolia cardinalis Mulsant (Coleoptera: Coccinellidae) (Medina et al. 2004; Urbaneja et al. 2009; Rahmouni et al. 2015) more than to parasitoids like the aphid parasitoid Lysiphlebus testaceipes Cresson (Hymenoptera: Braconidae), the armored scale parasitoid Aphytis melinus De Bach (Hymenoptera: Aphelinidae) (Michaud, 2003), the key parasitoid of the citrus leafminer in the Mediterranean area Citrostichus phyllocnistoides Narayan (Hymenoptera: Eulophidae), the mealybug parasitoid Anagyrus pseudococci Girault (Hymenoptera: Encyrtidae) and the leafminer parasitoid Diglyphus isaea Walter (Hymenoptera: Eulophidae), which were all susceptible to Spinosad applications either in laboratory, semi field or field assays (Urbaneja et al. 2009). Some studies reported lower adverse effects of Spinosad when applied in bait treatments whereas some others demonstrated potential negative impacts on non-target beneficial flies' species such as Eutreta xanthochaeta Aldrich (Diptera: Tephritidae), Tetreuaresta obscuriventris (Loew) (Diptera: Tephritidae) and Ensina sonchi (L.) (Diptera: Tephritidae) imported for weed biological control in Hawaii (Wang and Messing, 2006). Although in our study, Spinosad was classified as slightly harmful (IOBC class 2), the high acute toxicity of this insecticide was demonstrated especially against Hymenoptera and its adverse affects on non-target arthropods can differ depending on the commercial product or fruit-fly bait used and more specifically, on the quantity of active ingredient applied (Biondi et al. 2012b).

Azadarachtin, a limonoid tetranortriterpenoid chemical derived from neem tree (Azadiractha indica), has been extensively used in other countries for the control of phytophagous and livestock arthropod pests by its environmental compatibility and extremely low acute 
mammalian toxicity (Schmutterer, 1990 and references herein). Our results indicate that this was the less harmful pesticide for D. longicaudata, even as fresh residue. In previous studies, it has been proved that D. longicaudata and D. tryoni Cameron (Hymenoptera: Braconidae) emerged from Dacus dorsalis Hendel (Diptera: Tephritidae) and C. capitata exposed to differential Azadarachtin concentrations that inhibited flies' emergence (Stark et al. 1992). Furthermore, survival of parasitoids that emerged from exposed flies was similar to control (Stark et al. 1992). Conversely, Alvarenga et al. (2012) found that emergence of $D$. longicaudata was significant lower from flies fed on neem seed cake. Ruiu et al. (2008) tested different concentrations of azadirachtin on the muscoid fly pupal parasitoid Muscidifurax raptor Girault and Sanders (Hymenoptera: Pteromalidae). They concluded that the effects of Azadirachtin on M. raptor are minimal compared to those in major livestock pests, and that the use of azadirachtin-based formulations is considered as compatible with integrated livestock pest management programs. Similarly, Stara et al. (2011) tested the side effects of pure and formulated azadirachtin on three non-target species, namely Aphidius colemani, Aphidoletes aphidimyza Rodani (Diptera: Cecidomyiidae), and N. cucumeris. Although, this insecticide had overall low toxicological profile compared to synthetic insecticides on some of the tested model species, inconsistent results were reported especially with $A$. colemanii, which exhibited $100 \%$ mortality after 48 -h exposure to fresh residues.

Considering these data and our results it can be concluded that, although Abamectin, Azadarachtin and Spinosad were classified as slightly harmful (IOBC class 2), their use in Tunisian citrus orchards should also take into consideration their lethal effects on other beneficial insects. In addition, further studies are needed to address the possible sublethal effects on D. longicaudata of these three pesticides, as has been addressed in another species. In case of augmentative releases of $D$. longicaudata, they should be preferably performed at least 14-d after insecticide treatment with Abamectin or Spinosad, but can be performed 7-d post-treatment if performed with Azadirachtin. However, when releases are being planned at the same time that $C$. montrouzieri is present in orchards, Azadirachtin should be favored over Abamectin or Spinosad. Despite this limitation, we suggest minimizing Spinosad and Abamectin side effects by using them in bait stations with $C$. capitata specific attractant.

The most harmful tested pesticides (Acetamiprid, Deltametrin+Thiacloprid, Methidathion and Malathion) should be avoided, as seems to be the most limiting factor facing the implementation of Biological Control with D. longicaudata within the IPM program to protect citrus. The use of these insecticides should switch to bait station technique and localized bait sprays in combination with mass trapping to enhance the biocontrol services of predators and parasitoids 
which should ultimately result in more sustainable protection scheme against $C$. capitata in accordance with the new regulations of the European Union.

In conclusion, our study could be the first step aiming to integrate D. longicaudata with chemical control against $C$. capitata, within an IPM program in Tunisian citrus agroecosystems, while preserving its establishment possibilities and enhancing its biological impact on target pest reduction.

\subsection{Conclusions}

Taking into consideration all the factors studied in this chapter, we can conclude that a Biological control program based on the importation and release of D. longicaudata can be established in Tunisia. However, due to climatic conditions, we know that released specimens and/or their descendants will not be able to overwinter in great number, being required a strategy based on inoculative releases. To achieve this, it is advisable to expand the rearing system, from the actual low production to a semi-mass rearing facility to obtain the desired release densities for controlling the medfly.

In addition, to integrate $D$. longicaudata within the Biological control program of citrus' pests species, it is advisable to reduce the number of pesticide applications, banning all organophosphorated and neonicotinoids substances, and relying almost exclusively on the Azadarachtin and Spinosad, with the established security period of 7-days post-application. 
CHAPTER 6. General Discussion 
Ceratitis capitata is one of the major pests of commercial fruits in the world. Among them citrus fruits represent the most important fruit attacked by the medfly. Spain and Tunisia are two Mediterranean countries on which citrus represents one key crop that deserves a special plant protection program. For this reason, it is necessary to improve and develop an efficient control program against this pest which, incorporated within the IPM program, minimizes harmful residues for beneficials, the environment and humans, and mantains or reduces the emergence of resistant pest populations. One of such methods is the Biological Control, by which the pest population is reduced by the effect of a natural enemy, either predator or parasitoid, that is usually linked to the pest species. However, in the case of C capitata, a great number of predators have been established, but none of them has been determined as speciesspecific to it, and many of them are predators of jumping larvae, pupae or recently emerged imagos (Monzó, 2010). In the case of parasitoids, only a limited number of species belonging to the family Braconidae have been described for C. capitata along the word. Parasitoids are stage specific, finding some that attack only eggs, or only L2-L3 larva, and/or only pupae. Despite this great portfolio of natural enemies, only parasitoids had been used successfully in other countries against $C$. capitata within an area-wide IPM program.

In this context, D. longicaudata, a braconid larval endoparasitoid species highly used in other American and Australasian countries, was introduced firstly in Spain and later in Tunisia, as highlighted in this thesis dissertation. The final goal was to determine its possible inclusion within an area-wide IPM program by determining biotic and abiotic factors that could affect its role as control agent of C. capitata.

\subsection{Determination of $D$. longicaudata parasitic potential (and its affecting factors) against $C$. capitata.}

We have determined the demographic parameters and fitness of $D$. longicaudata when reared in the medfly, instead the original mexfly (A. ludens). Compared to other host species or $C$. capitata strains, results were similar with a biased offspring sex ratio towards females, an oviposition period of $\sim 16$ days and a of fertility $\sim 70$ specimens per female, whereas the adult longevity was found linked to temperature (see Table 2.2; Vargas et al. 2002; Viscarret et al. 2006; Ovruski et al. 2011; Mireilles et al. 2013). When translating this data to demographic parameters, results were more closely related to these obtained by Viscarret et al. (2006) and Meirelles et al. (2013) (see Table 2.3). 
Diachasmimorpha longicaudata, when reared in medfly, shows a longevity that depends inversely on temperature, being the females more long-lived than males. When tested in natural conditions, we found that $D$. longicaudata can survive during the different seasons, even in the cold seasons (winter and autumn), when the medfly is still present on citrus orchards of Spain and other Mediterranean countries and the release of the parasitoid can be successful and efficient. These results are opposite to those of Eitam et al. (2004) and Sime et al. (2006), who showed a developmental temperature threshold of $10^{\circ} \mathrm{C}$.

In a range of temperature between 20 and $29^{\circ} \mathrm{C}, D$. longicaudata can parasitize efficiently $C$. capitata larvae either at low or high density, being the parasitism percentage inversely dependent on the host density, despite only residual significance was obtained. This phenomenon is known as functional response type II, which indicate that there is an upper limit for medfly population reduction depending on host numbers per released fertile female. This temperature range was similar to those obtained for this parasitoid species when reared on $B$. invadens (Sime et al. 2006; Lui et al. 2012; Appiah et al. 2013), and what is most appropriate for this thesis dissertation, that is the average temperature range observed in the Mediterranean basin coastal areas.

We had also determined that, D. longicaudata can look for C. capitata larval stages and parasitize either located on the canopy or on the ground, not finding statistical differences among host location or host density, as previously reported for D. longicaudata parasitizing other hosts species (Purcell et al. 1994a; García-Medel et al. 2007).

The key point determined here is that D. longicaudata is able to control $\approx 30 \%$ of medfly population under the simulated Mediterranean conditions. But this percentage of population reduction does not contribute equally with $D$. longicaudata population increase. Nearly $10 \%$ medfly mortality is assigned to induced mortality, a phenomemon cited by Montoya et al. (2000) and assigned to the superparasitism that is shown by this species under mass-rearing when using A. ludens as host, a fact that deserves further research. 


\subsection{Biotic and abiotic factors affecting parasitic activity of $\boldsymbol{D}$. longicaudata against $C$. capitata.}

Diachasmimorpha longicaudata shows an optimal temperature range for development ranging from $24^{\circ} \mathrm{C}$ to $27^{\circ} \mathrm{C}$ when reared in medfly, as similarly determined by Lui et al. (2012); range that was also similar to those observed when reared on A. suspensa (Lawrence et al. 1976) or when reared in B. invadens (Appiah et al. 2013). But temperature is not the only abiotic factor that can affect $D$. longicaudata parasitic activity. We had demonstrated (chapter 3) by PCA that temperature (minimum, maximum, mean, its coefficient of variation, or even the sum of cold hours) and humidity (minimum, maximum, mean and $\mathrm{RH}$ coefficient of variation) contribute greatly to $D$. longicaudata parasitism percentage and induced mortality over C. capitata. Results are in concordance with those obtained previously with other hosts species (Ashley et al. 1976; Carvalho, 2005; Appiah et al. 2013). Only the offspring sex-ratio parameter remained untestable due to lack of data in some months. In other works, it was determined that this ratio was female biased and not affected by temperature (Appiah et al. 2013). Thus, this part of results require further research to determine which abiotic factors could affect or not offspring sexratio parameter.

Parasitic activity is also affected by biotic factors which are mainly defined as parasitoid behavioural responses linked to host and fruit host species and host density (reviewed in Quilici and Rousse, 2012 and references herein). Foraging behaviour is mediated mainly, but not exclusively, by visual and chemical cues. These cues are linked to fruit fly host species, and to the fruit fly species itself. Indeed, D. longicaudata can locate its host by the chemical compound, para-ethylacetophenone, released by feeding larvae (Stuhl et al. 2011). However, the exact determination of oviposition point is sensed by antennae that locate the larva by its vibratory signals within the fruit (Lawrence 1981). This released compound increases $D$. longicaudata host searching activity (Segura et al. 2012) and increases its oviposition activity even when host larva is reared in artificial diet rather than in its natural fruit host (Duan and Messing 2000). Previously to the finding of this compound, it was determined that $D$. longicaudata was attracted to acetaldehyde, ethanol, and acetic acid released by attacked fruits that ripen earlier than unattacked ones (Greany et al. 1977). By the use of the olfactometer we have determined that D. longicaudata was significantly attracted to $C$. capitata infested fruits compared to healthy ones, according to the previous findings using C. capitata or A. ludens as hosts (Duand and Messing 2000; Segura et al. 2012). And respect to the fruit host, we had 
determined a sequential preference of host as peach $>$ clementines $>$ oranges over apples, being apples the less attractive among the tested fruits as also recorded by Segura et al. (2016). Moreover, we have determined a link between host fruit preference parasitism rate and fertility in a similar way as determined by Segura et al. (2016) but of opposite sign to Leyva et al. (1991) and Ovruski et al. (2012). With our focal point control trials, we obtained 30-63\% of medfly population reduction (Table 3.6), that corresponds to a higher parasitism rate when compared to laboratory conditions either obtained by us or by other researchers.

Overall, it has been demonstrated that $D$. longicaudata can parasitize the medfly during all the year in the Mediterranean region. Being parasitism percentage affected mainly by temperature and relative humidity whereas the immature development was strongly affected by temperature, showing a $10^{\circ} \mathrm{C}$ threshold that minimizes its ability to overwinter as immatures. Among the biotic factors, we have determined that $D$. longicaudata parasitism percentage and fertility is affected by fruit host species, ripening stage and host availability. These parameters should be taken into account when establishing a mass-rearing system (i.e. optimal temperature and $\mathrm{RH}$, ratio of host per parasitoid female, ...), and for the establishment of Biological Control program (i.e. determining release type, special releases during spring/winter, time delay between releases, ...).

\subsection{Integration of $D$. longicaudata within the IPM program in Spain}

As in other countries, the Spanish Plant protection program relies on IPM, with a reduced number of chemical applications and authorized substances, along a great portfolio of control measaures. When targeting C. capitata, the most susceptible commodities are citrus species, which have its own protection plan integrating several control measures (Castañera 2003; Primo-Millo et al. 2003). After this, a SIT program was established on 2003, which still continues, to enhance the portfolio of control measures. But, one control measure, the Biological Control was still neglected. Its implementation required a survey of natural enemies, the study on their performance, and the importation of exotic parasitoids when natural enemies are not found in the area. As indicated in the previous chapters, and at the beginning of this discussion section, Spain imported the braconid D. longicaudata for the implementation of BC within the IPM in citrus against $C$. capitata. After determining the parasitic activity under laboratory and semi-field conditions, it was time to determine its potential in open-field trials. 
The first step was to determine its dispersion ability, and to achieve this, it was necessary to determine a successful re-capture method. Despite what it was described in the literature (Leyva et al. 1991; Cornelius et al. 1999; Paranhos et al. 2007; Segura et al. 2007), yellow sticky traps showed limited efficacy. However, the developed system of sentinel fruits recovered data not only from movement, but also from parasitic capacity of released females, a key point not always considered in other works. On the other hand, as what it could happen in uncontrolled conditions, the presence of naturally infested fruits could distort the dispersion pattern delimited by the use of sentinel fruits. This is also linked to the visual and odour cues that drive parasitic activity of D. longicaudata (Messing and Jang 1992; Quilici and Rousse 2012), even when the parasitoid is targeting the medfly (see previous subsection). We have determined that $D$. longicaudata performance in open field also depends on climatic conditions, a key factor to be considered when planning area-wide releases.

As a second step for the integration of BC (with D. longicaudata) within the citrus IPM program, we had tested $D$. longicaudata in combination with SIT, as the key point for medfly management. We had obtained a significant medfly population reduction when compared to only SIT (Juan-Blasco et al. 2013, 2014). Moreover, we determined that a ratio of 5:1 D. longicaudata females per medfly female rendered the best parasitism percentage, significantly different from $3: 1$ or 1:1. Seasonality (climatic conditions) had influenced parasitoid performance, finding a great immature mortality shown as induced mortality and a low fertility. As indicated previously, all temperature and $\mathrm{RH}$ variables account for statistical differences. However, only one parasitoid release per season and tested ratio was performed (meaning that for each ratio when susceptible medfly larval stage was detected only one release was performed in each cage). Therefore, we were unable to compare our results to those obtained in other programs on which was determined the requirement of augmentative releases for a successful control of medfly populations (Montoya and Cancino 2004). Despite this, we could determine as key points for the integration of BC within SIT, the timely releases of parasitoids and the released female densities to achieve at least $30 \%$ of population reduction. Further research is required for a fine tunning of this integration in terms of medfly population reduction which is the final target of any control measure. 


\subsection{Key points for the establishment of a Biological Control program, based on D. longicaudata, against $C$. capitata in Tunisia}

The introduction of $D$. longicaudata in Tunisia has required several steps following the IOBC (International Organization for Biological Control), EPPO and FAO recommendations.

As a first step, we have established a rearing colony of this species and its host, C. capitata, at the Entomological laboratories of ISA Chott-Mariem (Tunisia), following the directives of Entomology unit of IVIA, but making adaptations to the local available resources. This was necessary to obtain the specimens for trial releases and other studies.

In a second step, a screening of native $C$. capitata parasitoids was performed in different regions (with different management programs, either organic or conventional) to determine the putative competence with the introduced species. Four species were found, Psyttalia concolor, Pachycrepoideus vindemmiae, and two others, one belonging to the subfamily Tetrastichinae and the other to the Diapriidae families. P. concolor and P. vindemmiae have also been found attacking C. capitata in other Mediterranean countries (Beitia et al. 2007), Whereas, the last two species deserve further reseach. This fact indicates that both Psytallia species are wide spreaded in the Mediterranean basin, but they do not exhert a great control of medfly populations. This lack of control has been linked to the pest management policies, as these parasitoids were found only in organic orchards, being absent in the conventional ones. This pattern highlights two key points for the establishment of exotic parasitoids. First the requirement of side-effect studies with the most frequently used pesticides. And second, the application of chemical products should be reduced and rationalized in all the country.

Linked to this point, we have performed a side-effect study on D. longicaudata with seven pesticides commonly used in Tunisian orchards against several pests including C. capitata. Three of them (Spinosad, Abamectin and Azadarachtin), even chemically classified as botanicals or naturals, were classified as slightly harmful or IOBC class 2 for D. longicaudata adults. Whereas some of the organophosphorated and neonicotinoids tested were classified as IOBC class 4, as fresh residues, increasing the lethality induced in D. longicaudata as determined previously with similar substances in closely related tephritid braconid parasitoids (Liburd et al. 2004; Adán et al. 2011). This classification denotes that those classified as IOBC class 4 should be banned from IPM in citrus, those classified as IOBC class 3 should be used only when other natural enemies are not present in the orchard, nor planned any release, and those classified as IOBC class 2 should be used with caution keeping the security delay for $D$. longicaudata releases. 
After these preliminary studies, we conducted pilot releases in an organic citrus orchard to determine the best conditions for the parasitoid establishment. The results presented in this thesis proved the $D$. longicaudata capacity to disperse and parasitize $C$. capitata under Tunisian natural conditions. Despite these pilot releases determined that D. longicaudata was unable to overpass the winter, as happened in other countries (Etiam et al. 2004; Sime et al. 2006b; Appiah et al. 2013, Mereilles et al. 2015), it was stated that probably it was a consequence of the low number of specimens released.

In overall, after these studies, we have determined that to warrant the success of $D$. longicaudata as biological control agent of $C$. capitata in Tunisia, we should: (i) intensify the mass rearing to increase the number of female specimens in each release; (ii) take into account the susceptibility of $D$. longicaudata for each substance when applying chemical control as part of IPM in citrus orchards; and (iii) switch to inoculative releases during each spring to increase the number of successful overwinting specimens. The Biological control program should be through inoculative releases during each spring to increase the number of successful overwinting specimens. 
CHAPTER 7. Conclusions 
The conclusions obtained in the present $\mathrm{PhD}$ thesis for the proposed objectives are:

Objective 1. Determination of parasitic potential (and its affecting factors) of $D$. longicaudata against $C$. capitata.

1. The study of the fitness of the parasitoid is important to determine the development capacity of a population in the field and thus the potential capacity of a parasitoid in controlling a pest.

2. The biological parameters of $D$. longicaudata depend on the strain parasitoid/host and on the climatic conditions of the rearing and of the field when released.

3. The longevity of $D$. longicaudata depends inversely on the temperature and the female's lifespan is higher than that of males.

4. Diachasmimorpha longicaudata can be very interesting as an agent of biological control against $C$. capitata in the Mediterranean region and especially in Spain and Tunisia where the climatic conditions are favorable for its establishment and mainly during the development period of the medfly.

5. In the Mediterranean region, D. longicaudata can survive all the year around and its longevityis higher in autumn and winter which correspond to the peak of the medfly population on citrus.

6. Diachasmimorpha longicaudata, in a temperature range between $20^{\circ} \mathrm{C}$ and $29^{\circ} \mathrm{C}$, showed a functional response type II and a parasitism percentage inversely dependent on host density, demonstrating that this parasitoid can search efficiently for specific hosts at low host densities, such as those likely to occur under natural conditions and demonstrate a good potential for use of this parasitoid in controlling C. capitata in mass or targeted releases.

\section{Objective 2. Determination of biotic and abiotic factors affecting parasitic activity of $D$.} longicaudata against $C$. capitata in different fruit hosts.

1. Diachasmimorpha longicaudata can be active and parasitize during the whole year in the different seasons in the Mediterranean region.

2. The biological activity of the parasitoid D. longicaudata depended on the climatic parameters. Indeed, the parasitism depends mainly on temperature and relative humidity and 
the induced mortality depends on relative humidity. This should be taken into consideration for the mass rearing and the field releases of the wasp D. longicaudata.

3. The braconide $D$. longicaudata can be a valuable tool to control a focal infestation of $C$. capitata in a citrus orchard in the Mediterranean region.

4. Diachasmimorpha longicaudata is more attractive to infested fruits than healthy ones.

5. Our parasitoid can parasitize the most susceptible fruits to C. capitata in the Mediterranean basin with preference of attractiveness as peach, clementine, orange and apple. Then, the parasitoid can found its host during all the year.

Objective 3. Identification of key points to integrate $D$. longicaudata within the IPM program in Spain.

1. Diachasmimorpha longicaudata is able to parasitize up to $50 \%$ of medfly larvae.

2. Diachasmimorpha longicaudata can disperse till a long distance in citrus orchards in the Mediterranean region. These capacities are influenced by the climatic conditions and also the release density.

3. With the obtained results, we can manage and improve the field releases by the choice of the better moment and the best density for a better medfly control.

4. In an IPM program the combination of the Insect Sterile Technique and the biological control by the release of the parasitoid D. longicaudata can be employed successfully in Spanish citrus orchards.

5. Both, the sterile medfly males and D. longicaudata are negatively affected by high and low temperature and they are more efficient during spring and autumn.

Objective 4. Determine key point to establish a Biological Control program against $C$. capitata in Tunisia, based on D. longicaudata.

1. Tunisia harbors several species of native parasitoids, namely Pachycrepoideus vindemmiae (Rondani), Psytallia concolor (Szépligeti), with potential to control Ceratitis capitata 
infestations under organic management. Other putative parasitoids from Tetrastichinae subfamily and Diapriidae family deserve further research.

2. A rearing colony of $D$. longicaudata has been established In Tunisia, in the rearing facilities of the High Agronomic Institute of Chott-Meriem (ISA-CM).

3. Imported D. longicaudata are able to disperse in field plots and exert a medfly control of about $15 \%$. To increase the parasitism percentage, release densities should be increased.

4. Performance of D. longicaudata depends on climate. Adults are the most resistant stage, whereas immature stages could not survive on Tunisian winter conditions, requiring inoculative releases during each spring.

5. The implementation of D. longicaudata within Tunisia IPM program against $C$. capitata requires minimization of Spinosad, Abamectin and Azadarachtin treatments, even than these active substances were classified as slightly harmful (IOBC class 2). 


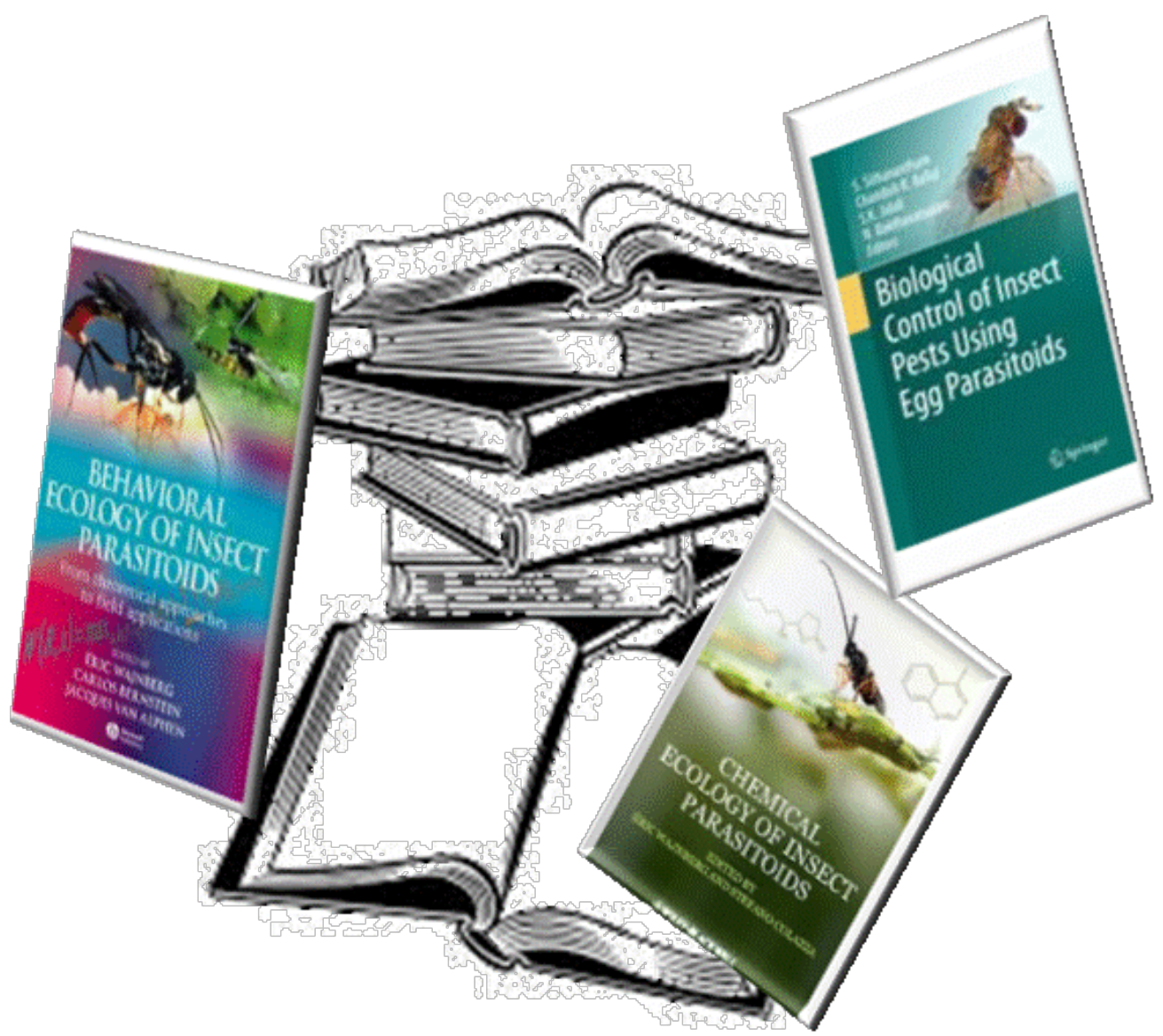

Literature cited 


\section{A}

Abbes K, Biondi A, Kurtulus A, Ricupero M, Russo A, Siscaro G, Chermiti B, Zappalà L. 2015. Combined non-target effects of insecticide and high temperature on the parasitoid Bracon nigricans. PLoS ONE 10(9): e0138411.

Abbott WS. 1925. A method for computing the effectiveness of an insecticide. Journal of Economic Entomology 18: 265-267.

Adán A, Viñuela E, Bengochea P, Budia F, Del Estal P, Aguado P, Medina P. 2011. Lethal and sublethal toxicity of fipronil and imidacloprid on Psyttalia concolor (Hymenoptera: Braconidae). Journal of Economic Entomology 104(5):1541-1549.

Agnello AM, Spanler SM, Reissig WH. 1990. Development and evolution of a more efficient monitoring system for apple maggot (Diptera: Tephritidae). Journal of Economic Entomology 83:539-546.

Albajes R, Santiago-Alvarez C. 1980. Influencia de la temperatura en el desarrollo de Ceratitis capitata (Wied.). Anales INIA, Serie Agrícola 13: 183-190.

Alemany A, Gonzales A, Juan A, Tur C. 2008. Evaluation of a chemosterilization strategy against Ceratitis capitata (Diptera: Tephritidae) in Mallorca island (Spain). Journal of Applied Entomology 132: 746-52.

Almeida JEM, Filho AB, Oliveira FC, Raga EA. 2007. Pathogenicity of the Entomopathogenic Fungi and Nematode on Medfly Ceratitis capitata (Wied.) (Diptera: Tephritidae). BioAssay 2:7 Available online at: www.bioassay.org.br/articles/2.7

Aluja M, Guillén J, Liedo P, Cabrera M, Ríos E, De la Rosa G, Celedonio H. 1990. Fruit infesting tephritids (Dipt.: Tephritidae) and associated parasitoids in Chiapas, México. Entomophaga 35: 39-48

Aluja, M. 1993. Manejo integrado de la mosca de la fruta. Ed. Trillas, México D.F. pp. 251

Alvarenga CD, França WM, Augusta T. 2012. Toxicity of Neem (Azadirachtaindica) seed cake to larvae of the Mediterranean fruit fly, Ceratitis capitata (Diptera: Tephritidae), and its parasitoid, Diachasmimorpha longicaudata (Hymenoptera: Braconidae). Florida Entomologist 95:57-62.

Amice G, Vernon P, Outreman Y, van Alphen J, van Baaren J. 2008. Variability in responses to thermal stress in parasitoids. Ecological Entomology 33:701-708.

Anonymous. 2014. Productos Biológicos Ltda., Colombia. Online at: http://perkinsltda.com.co/ 
Appiah EF, Ekesi S, Salifu D, Afreh-Nuamah K, Obeng-Ofori D, Khamis F, Mohamed SA. 2013. Effect of temperature on immature development and longevity of two introduced opiine parasitoids on Bactrocera invadens. Journal of Applied Entomology 137: 571-579.

Argilés R, Tejedo J. 2007. La lucha de la mosca de la fruta mediante la técnica del insecto estéril en la Comunitat Valenciana. Levante Agrícola Revista Internacional de Cítricos $385: 157-162$

Argov Y, Gazit Y. 2008. Biological control of the Mediterranean fruit fly in Israel: Introduction and establishment of natural enemies. Biological Control.46: 502-507.

Arouri R, Le Goff G, Hemden H, Navarro-Llopis V. 2015. Resistance to lambda-cyhalothrin in Spanish field populations of Ceratitis capitata and metabolic resistance mediated by P450 in a resistant strain. Pest Management Science 71 (9): 1281-1291.

Ashley TR, Greany PD, Chambers DL. 1976. Adult emergence in Biosteres (Opius) longicaudatus and Anastrepha suspensa in relation to the temperature and moisture concentration of the pupation medium. Florida Entomologist 59(4): 391-396.

Ayvaz, A., Karasu, E., Karaborklu, S., Yilmaz, S.2008.Dispersal ability and parasitization performance of egg parasitoid Trichogramma evanescens Westwood (Hymenoptera: Trichogrammatidae) in field and storage conditions. Turkish Journal of Biology 32(2): 127-133.

\section{B}

Badii MH, Abreu JL. 2006. Control Biológico una forma sustentable de control de plagas. Daena: International Journal of Good Conscience 1(1): 82-89.

Baranowski R, Glenn H, Sivinski J. 1993. Biological Control of the Caribbean Fruit Fly (Diptera: Tephritidae). Florida Entomologist 76 (2): 245-251.

Barbosa P, Frongillo EAJ. 1977. Influence of light intensity and temperature on the locomotry and flight activity of Brachymeria intermedia (Hym.: Chalcididae), a pupal parasitoid of the gypsy moth. Entomophaga 22: 405-411.

Bautista RC, Mochizuki N, Spencer JP, Harris EJ, Ichimura DM. 1999. Mass-rearing of the tephritid fruit fly parasitoid Fopius arisanus (Hymenoptera: Braconidae). Biological Control 15: 137-144. 
Beavers JB, CO, Calkins. 1984. Susceptibility of Anastrepha suspensa (Diptera: Tephritidae) to Steinernematid and Heterorhabidit nematodes in laboratory studies. Environmental Entomology 13: 137-139.

Beilstein M, Bournay E. 2011. Environment and Security in the Mediterranean: Desertification, ENVSEC, 2009. World Bank, World Development Indicators, online database, accessed October 2011. http://www.grida.no/graphicslib/detail/agricultureand-population-in-the-mediterranean-basin f8f5

Beitia F. Pérez-Hinarejos M, Garzón E, Santiago S, Tarazona I, Malagón J, Tormos J, Falcó JV. 2007. Himenópteros parasitoides autóctonos: lucha biológica contra Ceratitis capitata. Terralia 63: 34-44.

Benelli G, Carpita A, Simoncini S, Raspi A, Canale A. 2014. For sex and more: attraction of the tephritid parasitoid Psyttalia concolor (Hymenoptera: Braconidae) to male sex pheromone of the olive fruit fly, Bactrocera oleae. Journal of Pest Science 87(3): 449457.

Benfatto D, Longo S, Siscaro G. 1987. Four years' comparative analysis on population dynamics trend of Ceratitis capitata (Wied.) (Diptera, Tephritidae) on citrus. Proc Int Symposium Fruit Flies of Economic Importance. Rome, Italy, April 7-10. pp. 35-40.

Benmahmoud K, Jedidi E, Najar A, Ghezel R, Kevers C, Jemmali A, Elloumi N. 2015. Adventitious organogenesis induced in sweet orange (Citrus sinensis L.) var. "halfblood" maltese: morphogenetic and histological study. International Journal of Agronomy and Agricultural Research 6(2): 1-7.

Biondi A, Desneux N, Siscaro G, Zappalà L. 2012a. Using organic-certified rather than synthetic pesticides may not be safer for biological control agents: Selectivity and side effects of 14 pesticides on the predator Orius laevigatus. Chemosphere 87(7): 803-812.

Biondi A, Mommaerts V, Smagghe G, Viñuela E, Zappalà L, Desneux N. 2012b. The nontarget impact of spinosyns on beneficial arthropods. Pest Management Science 68(12): 1523-1536.

Biondi A, Zappalà L, Stark JD, Desneux N. 2013. Do biopesticides affect the demographic traits of a parasitoid wasp and its biocontrol services through sublethal effects? PLoSOne 8(9): e76548.

Biondi A, Campolo O, Desneux N, Siscaro G, Palmeri V, Zappala L. 2015. Life stagedependent susceptibility of Aphytis melinus DeBach (Hymenoptera: Aphelinidae) to two pesticides commonly used in citrus orchards. Chemosphere 128: 142-147. 
Birch LC. 1948. The intrinsic rate of natural increase of an insect population. Journal of Animal Ecology. 17: 15-26.

Bodenheimer FS. 1951. Citrus entomology. Ed. Dio. Junk. Denhang. pp. 663.

Boivin G, Kolliker-Ott UM, Bale JS, Bigler F. 2006. Assessing the establishment potential of inundative biological control agents. In: Bigler F, Babendreier D, Kuhlmann U (Eds) Environmental impact of invertebrates for biological control of Arthropods: methods and risk assessment. CABI Publication, Wallingford, UK, pp 98-113.

Bokonon-Ganta A, McQuate GT, Messing RH, Jang EB. 2013. Release and establishment of the parasitoid Diachasmimorpha kraussii against the tephritid fruit fly Bactrocera latifrons in Hawaii. Journal of Insect Science 13: 7. doi: 10.1673/031.013.0701

Boulahia Kheder S, Salleh W, Awadi N, Fezzani M, Jrad F. 2011. Efficiency of different traps and baits used in mass-trapping of the Mediterranean fly Ceratitis capitata (Wied.) (Diptera; Tephritidae). Integrated Control in Citrus Fruit Crops. IOBC/WPRS Bulletin 62:215-219.

Boulahia-Kheder S, Loussaïef F, Ben Hmidene A, Trabelsi I, Jrad F, Akkari Y, Fezzani M. 2012a. Evaluation of two IPM programs based on mass trapping against the Mediterranean fruit fly Ceratitis capitata on citrus orchards. Tunisia Journal of Plant Protection 7: 55-68.

Boulahia Kheder S, Trabelsi I, Aouadi N. 2012b. From chemicals to IPM against the Mediterranean fruit fly Ceratitis capitata (Diptera, Tephritidae). In: Larramendi M, Soloneski S (Eds) Integrated pest management and pest control - current and future tactics. InTech. Available from: http://www.intechopen.com/books

Bourdais D, Vernon P, Krespi L, van Baaren J. 2012. Behavioural consequences of cold exposure on males and females of Aphidius rhopalosiphi De Stephani Perez (Hymenoptera: Braconidae). BioControl 57: 349-360.

Braham M. 2013. Trapping Adults of the Medfly Ceratitis capitata and nonTarget Insects: Comparison of Low-Cost Traps and Lures. Tunisia Journal of Plant Protection 8(2): 107-118.

Braham M, Pasqualini E, Ncira N. 2007. Efficacy of kaolin, spinosad and malathion against Ceratitis capitata in citrus orchards. Bulletin of Insectology 60(1): 39-47.

Bueno AF, Freitas S. 2004. Effect of the insecticides abamectin and lufenuron on eggs and larvae of Chrysoperla externa under laboratory conditions. BioControl 49(3): 277-283.

Burnett T.1960. Effects of initial densities and periods of infestation on the growth forms of a host and parasite population. Canadian Journal of Zoology 38:1063-77. 


\section{C}

Camargos MG, Alvarenga CD, Giustolin TA, Paranhos BAJ, Oliveira PCC, Rabelo MM. 2016. Dispersal capacity of fruit fly parasitoid Diachasmimorpha longicaudata (Hymenoptera: Braconidae) in irrigated coffe plantations. Scientia Agricola 73(3): 227233.

Cancino, J., Cancino, J.L., Martínez, M. and Liedo, P. 2003. Quality control parameters of wild and mass reared Diachasmimorpha longicaudata (Ashmead), a fruit fly parasitoid. In: Leppla NC, Bloem KA, Luck RF. (Eds.) Proceedings of the 8th and $9^{\text {th }}$ Workshop of the global IOBC Working Group Quality control of mass reared arthropods, Gainesville, University of Florida, USA. pp. 84-94.

Carey JR. 1993. Applied demography for biologists: with special emphasis on insects. Oxfod University Press, New York. 206 pp.

Carmo EL, Bueno AF, Bueno RCOF. 2010. Pesticide selectivity for the insect egg parasitoid Telenomus remus. BioControl 55(4): 455-464.

Carrasco M, Montoya P, Cruz-López L, Rojas JC. 2005. Responses of the fruit fly parasitoid Diachasmimorpha longicaudata (Hymenoptera: Braconidae) to mango fruit volatiles. Environmental Entomology 34: 576-583.

Carvalho RdS. 2005. Diapause in fruit fly parasitoids in the Recôncavo Baiano, Brazil. Neotropical Entomology 34: 613-618.

Castañera P. 2003. Control Integrado de la mosca mediterránea de la fruta, Ceratitis capitata (Wiedemann) (Diptera: Tephritidae) en cítricos. Phytoma España 153: 131-133.

Castillo MA, Moya P, Hernandez E, Primo-Yufera E. 2000. Susceptibility of Ceratitis capitata Wiedemann (Diptera: Tephritidae) to entomopathogenic fungi and their extracts. Biological Control 19: 274-282.

Cayol JP, Causse R, Louis C, Barthes J. 1994. Medfly Ceratitis capitata as a rot vector in laboratory conditions. Journal of Applied Entomology 117: 338-343.

Cayol, J. P., and M. Zarai. 1999. Field releases of two genetic sexing strains of the Mediterranean fruit fly (Ceratitis capitata Wied.) in two isolated oases of Tozeur governorate, Tunisia. Journal of Applied Entomology 123: 613-619.

Chueca P. 2007. Mecanización de métodos de control de Ceratitis capitata (Wiedemann) en cítricos. PhD dissertation thesis. Departamento de mecanización y tecnología agraria. Universidad Politécnica de Valencia, Valencia, 246 pp. 
Chueca P, Monton H, Luis-Ripolles J, Castanera P, Molto E, Urbaneja A. 2007. Spinosad bait treatments as alternative to malathion to control the Mediterranean fruit fly Ceratitis capitata (Diptera: Tephritidae) in the Mediterranean Basin. Journal of Pesticide Science 32(4): 407-411.

Cladera JL, Viscarret MM, Soria MA, Paladino LZC, Pietrek A, Ovruski SM. 2006. "More than two": integrating biological control and sterile insects, from factory to field, and the possibility of its implementation in Argentina. In: Sugayama RL, Zucchi RA, Ovruski SM, Sivinski J. (Eds.) Proceedings of the 7th International Symposium on Fruit Flies of Economic Importance: From Basic to Applied Knowledge. Salvador, Brazil pp. 143-155.

CLAM (Comité de Liaison de l'Agrumiculture Méditerranéenne) 2007. Les exportations d'agrumes du basin Méditerranéen. Statistiques, evaluations, repartitions, situation 2006-2007. Madrid, España, 121pp.

Clausen CP, Clancy DW, Chock CQ. 1965. Biological control of the oriental fruit fly (Dacus dorsalis Hendel) and other fruit flies in Hawaii. U. S. Department of Agriculture Technical Bulletin1322, 102 pp.

Colinet H, Boivin G. 2011. The insect parasitoids cold storage: a comprehensive review of factors of variability and consequences. Biological Control 58: 83-95.

Contreras G, Medina P, Adan A, Zapata AN, Viñuela E. 2005.Effects of modern bait formulated pesticides on larvae and adults of Chrysoperla carnea under extended laboratory conditions. IOBC/wprs Bulletin 28(7): 245-250.

Cornelius ML, Duan JJ, Messing RH. 1999. Visual stimuli and the response of female oriental fruit flies (Diptera: Tephritidae) to fruit-mimicking traps. Journal of Economic Entomology 92: 121-129.

Costa MA, Moscardini VF, da Costa Gontijo P, Carvalho GA, de Oliveira RL, de Oliveira HN. 2014. Sublethal and transgenerational effects of insecticides in developing Trichogrammagalloi (Hymenoptera: Trichogrammatidae): toxicity of insecticides to Trichogrammagalloi. Ecotoxicology 23(8): 1399-1408.

Couso-Ferrer F, Arouri R, Beroiz B, Perera N, Cervera A, Navarro-Llopis V, Castañera P, Hernández-Crespo P, Ortegoa F. 2011. Cross-resistance to insecticides in a malathion-resistant strain of Ceratitis capitata (Diptera: Tephritidae). Journal of Economic Entomology 104(4): 1349-1356. 


\section{D}

Daane KM, Sime KR, Wang XG, Nadel H, Johnson MW, Walton VM. 2008. Psyttalia lounsburyi (Hymenoptera: Braconidae), potential biological control agent for the olive fruit fly in California. Biological Control 44: 78-89.

Darby H. 1933. Insect and micro-climate. Nature 131: 839.

De Pedro L, Martínez R, Harbi A, Ferrara F, Tormos J, Asís JD, Sabater-Muñoz B. Beitia F. 2013. Un nuevo enemigo natural de Ceratitis capitata (Diptera: Tephritidae) identificado en la Comunidad Valenciana: el parasitoide Aganaspis daci (Hymenoptera, Figitidae). Revista Internacional de Cítricos Levante Agrícola 416: 153-157.

Del Pino A. 2000. Efecto de factores abióticos y edáficos naturales en el ciclo biológico de Ceratitis capitata, (Wiedemann), Diptera: Tephritidae. $\mathrm{PhD}$ dissertation thesis. Polytechnic university of Valencia (UPV), Valencia, Spain. pp. 118-120.

Delpuech JM, Frey F, Carton Y. 1994.Genetic and epigenetic variation in suitability of A Drosophilahost to three parasitoid species. Canadian Journal of Zoology 72: 1940-1944.

Delrio G. 1986. Tephritid pests in citriculture. In: Cavalloro R, Di Martino E. (eds) Integrated pest control in citrus groves: proceedings of the experts meeting. A.A. Balkema, Rotterdam, Netherlands, pp. 135-149.

Delrio G, Cocco A. 2012. Tephritidae. In: Vacante V. Gerson U. (Eds) Integrated control of citrus pests in the Mediterranean region. Bentham Science publishers, Dubai, U.A.E. pp. 206-222.

Demchak RJ, Dybas RA. 1997. Photostability of abamectin/zein microspheres. Journal of Agricultural and Food Chemistry 45: 260-262.

Di Rienzo JA, Casanoves F, Balzarini MG, Gonzalez L, Tablada M, Robledo CW. InfoStat versión 2012. Grupo InfoStat, FCA, Universidad Nacional de Córdoba, Argentina. URL http://www.infostat.com.ar.

Dimbi S, Maniania NK, Lux SA, Ekesi S, Mueke JK. 2003. Pathogenicity of Metarhizium anisopliae (Metsch.) Sorokin and Beauveria bassiana (Balsamo) Vuillemin, to three adult fruit flyspecies: Ceratitis capitata (Weidemann), C. rosa var. fasciventris (Karsch) and C. cosyra (Walker) (Diptera: Tephritidae). Mycopathologia 156: 375-382.

Driouchi A. 1990. Evaluation economique des pertes causées par la mouche Méditerranéenne des fruits: cas de l'économie agricole Tunisienne rapport de mission d'un expert consultant IAEA/FAO. Division de l'assistance technique et de la coopération. 22 pp. 
Duale AH. 2005. Effect of temperature and relative humidity on the biology of the stem borer parasitoid Pediobius furvus (Gahan) (Hymenoptera: Eulophidae) for the management of stem borers. Environmental Entomology 34:1-5.

Duan JJ, Messing RH. 2000. Effects of host substrate and vibration cues on ovipositor-probing behavior in two larval parasitoids of Tephritid fruit flies. Journal of Insect Behavior 13(2): 175-186.

Ducamp Collin MN, Arnaud C, Kagy V, Didier C.2007. Fruit flies: disinfestation, techniques used, possible application to mango. Fruits 62(4): 223-236.

Dyck VA, Hendrichs J, Robinson AS. 2005. Sterile insect technique: Principles and practice in area-wide integrated pest management. Springer, Dordreacht, The Netherlands. 799 pp.

\section{$\mathbf{E}$}

Eben A, Benrey B, Sivinski J, Aluja M. 2000. Host species and host plant effects on preference and performance of Diachasmimorpha longicaudata (Hymenoptera: Braconidae). Environmental Entomology 29: 87-94.

EEC/CEE. 2009. Commission Directive 2009/128/EC. Journal of the European Community 309: 71-86.

Efron D, Nestel D, Glazer I. 2001. Spatial analysis of entomopathogenic nematodes and insect hosts in a citrus grove in a semi-arid region in Israel. Environmental Entomology 30: 254-261.

Ehler LE, Endicott PC. 1984. Effect of malathion bait sprays on biological control of insect pest of olive, citrus, and walnut. Hilgardia 52: 1-47.

Eitam A, Sivinski J, Holler T, Aluja M. 2004. Biogeography of braconid parasitoids of the Caribbean fruit fly (Diptera: Tephritidae) in Florida. Annals of the Entomological Society of America 97: 928-939.

Ekesi S, Maniania NK, Lux SA. 2003. Effect of soil temperature and moisture on survival and infectivity of Metarhizium anisopliae to four tephritid fruit fly puparia. Journal of Invertebrate Pathology 83: 157-167.

Ekesi S, Billah MK. 2007. A field guide to the management of economically important Tephritid fruit flies in Africa. Icipe Science press second edition, Kenya. 106 pp. 
El-Sayed AM, Suckling DM, Byers JA, Jang EB, Wearing CH. 2009. Potential of 'lure and kill' in long-term pest management and eradication of invasive species. Journal of Economic Entomology102:815-835.

Enkerlin W, Mumford JD. 1997. Economic evaluation of three alternative methods for control of the Mediterranean fruit fly (Diptera: Tephritidae) in Israel, Palestinian Territories, and Jordan. Journal of Economic Entomology 90: 1066-1072.

EPPO, European and Mediterranean Plant Protection Organization 1981. Data sheets on quarantine organisms, No. 105, Ceratitis capitata. OEPP/EPPO Bulletin 11: 1-17.

EPPO. 1999. EPPO Standards. Guidelines on the safe use of biological control. EPPO standard PM6/1. OEPP/EPPO Bulletin 29: 269-270.

EPPO. 2001. EPPO Standards. Safe use of biological control: import and release of exotic biological control agents. EPPO standard PM6/2(1). OEPP/EPPO Bulletin 31: 29-35.

EPPO. 2009. http://archives.eppo.org/EPPO Standards/biocontrol_web/biolist.htm\#classic

EPPO. 2010. Safe use of biological control. Import and release of non-indigenous biological control agents. EPPO standard PM6/2 (2). OEPP/EPPO Bulletin 40: 335-344.

EPPO 2014. PQR database. Paris, France: European and Mediterranean Plant Protection Organization. http://www.eppo.int/DATABASES/pqr/pqr.htm

Escudero LA, Vilajeliu M, Peñarrubia E, Batllori L. 2009. Estudios comparativos de la capacidad de captura de difusores de atrayentes, modelos de mosqueros y diversos insecticidas para Ceratitis capitata (Wiedemann) (Diptera: Tephritidae). In: $\mathrm{VI}^{\text {th }}$ Congreso Anual de Entomología Aplicada, Palma de Mallorca.

Eskafi FM. 1990. Parasitism of fruit flies Ceratitis capitata and Anastrepha spp. (Diptera: Tephritidae) in Guatemala. Entomophaga 35: 355-362.

\section{$\mathbf{F}$}

Falcó JV, Garzón-Luque E, Pérezhinarejos M, Tarazona I, Malagón J, Beitia F. 2006. Two native pupal parasitoids of Ceratitis Capitata (Diptera, Tephritidae) found in Spain. IOBC/WPRS Bulletin 29(3): 71-74.

Falco-Gari JV, Verdu MJ, Bolinches JV, Cuenca F, Alfaro F. 2006. Incidencia del trampeo masivo de Ceratitis capitata sobre Cryptolaemus montrouziere y otros depredadores y parasitoides en una parcela de navelina en cultivo ecologico. Revista internacional de Citricos Levante Agricola 390: 152-157. 
FAO 1996. Joint FAO/WHO Meeting on Pesticide Residues (JMPR): FAO Plant Production and Protection Paper 133, 1996. http:/www.fao.org/docrep/w4601e/w4601e04.htm

FAO 2016. Food and Agriculture Organization Of The United Nations. citrus fruit statistics 2015. Rome, 2016. 48p

FAO/IAEA/USDA Food and Agriculture Organization of the United Nations/International Atomic Energy Agency/United States Department of Agriculture. 2003. Manual for product quality control and shippingprocedures for sterile mass-reared tephritid fruit flies. Version 5.0. IAEA, Vienna, Austria.

Fein BL, Reissig WH, Roelofs WL. 1982. Identification of apple volatiles attractive to the apple maggot, Rhagoletis pomonella. Journal of Chemical Ecology 8:1473-1487.

Fenilli G, Pegazzano F. 1971. Contributo alla conoscenza dei parassiti delDacus oleae Gmelin. Ricerche eseguite in Toscana negli anni 1967 e 1968. Redia 52:1-29.

Fernandez-Arhex V, Corley JC. 2004. La respuesta funcional: una revision y guía experimental. Ecología austral 14: 83-93.

Filippi JB. 2003. Une architecture logicielle pour la multi-modelisation et la simulation a evenements discrets de systemes naturels complexes. $\mathrm{PhD}$ dissertation thesis. University of Corse PASQUALE PAOLI, France. 162 pp.

Fimiani P. 1989. Mediterranean region. In: Robinson AS, Hooper GH. (Eds.) Fruit flies: Their biology, natural enemies and control, Vol. 3. Elsevier, Amsterdam, The Netherlands. Pp: 37-55.

Fischer M. 1966. Revision der Indo-Australischen Opiinae. W Junk, The Hague.

Fischer J, Müller T, Spatz AK, Greggers U, Grünewald B, Menzel R. 2014. Neonicotinoids interfere with specific components of navigation in honeybees. PLoS ONE 9(3): e91364.

Flávio R. M. Garcia and Marcelo P. Ricalde 2013.Augmentative biological control using parasitoids for fruit fly management in Brazil. Insect 4: 55-70.

Flessel P, Quintana PJE, Hooper K. 1993. Genetic toxicity of malathion: a review. Environmental and Molecular Mutagenesis 22: 7-17.

Fletcher J. 1989. Movements of Tephritidae fruit flies. In: Robinson AS, Hooper GH (eds.), Fruit flies: Their biology, natural enemies and control, Vol. 3. Elsevier, Amsterdam, The Netherlands. Pp: 209-217.

Flores S, Campos S, Villaseñor A, Valle Á, Enkerlin W, Toledo J, Liedo P, Montoya P. 2013. Sterile males of Ceratitis capitata (Diptera: Tephritidae) as disseminators of 
Beauveria bassiana conidia for IPM strategies. Biocontrol Science And Technology 23(10): 1186-1198.

Fogel MN, Schneider MI, Desneux N, González B, Ronco AE. 2013. Impact of the neonicotinoid acetamiprid on immature stages of the predator Eriopis connexa (Coleoptera: Coccinellidae). Ecotoxicology 22(6):1063-1071.

Franco JC, Garcia-Mari F, Ramos AP, Besri M. 2006. Survey on the situation of citrus pest management in Mediterranean countries. Integrated Control in Citrus Fruit Crops IOBC/WPRS Bulletin 29(3):335-346.

Fujii K, Holling CS, Mace PM. 1986. A simple generalized model attack by predators and parasites. Ecological Research 1: 141-156.

\section{G}

Garcia PV, Pereira N, Oliveira LM. 2009. Side-effects of organic and synthetic pesticides on cold-stored diapausing prepupae of Trichogramma cordubensis. Biocontrol 54(3): 451458.

Garcia-Medel D, Sivinski J, Diaz-Fleischer F, Ramirez-Romero R, Aluja M. 2007. Foraging behavior by six fruit fly parasitoids (Hymenoptera: Braconidae) released as single- or multiple-species cohorts in field cages: Influence of fruit location and host density. Biological Control 43: 12-22.

Garzón E, Beitia F. 2009. Quality control in the production of beneficial used in biological control of pests: is it a real need? Pest Technology 3(1): 22-24.

Gazit Y, Rossler Y, Epsky ND, Heath RR. 1998. Trapping females of the Mediterranean fruit fly (Diptera: Tephritidae) in Israel: comparison of lures and trap type. Journal of Economic Entomology 91: 1335-1359.

Gonzales L.2013. Agricultural importance in Spain. MINTEC. Issue 64. https://www.mintecglobal.com/newsletter/agricultural-importance-in-spain/

González PI, Montoya P, Perez-Lachaud G, Cancino J, Leido P. 2007.Superparasitism in mass reared Diachasmimorpha longicaudata (Ashmead) (Hymenoptera: Braconidae), a parasitoid of fruit flies (Diptera: Tephritidae). Biological Control 40: 320-326.

Goulet H, Huber JT. 1993. Hymenoptera of the world: an identification guide to families. Research Branch Agriculture Canada Publication, Ottawa, Canada. 668p. 
Greany PD, Tumlinson JH, Chambers DL, Boush GM. 1977. Chemical mediated host finding by Biosteres (Opius) longicaudatus, a parasitoid of tephritid fruit fly larvae. Journal of Chemical Ecology 3(2): 189-195.

Greenberg SM, Legaspi Junior BC, Jones WA. 2001. Comparison of functional response and mutual interference between two aphelinid parasitoids of Bemisia argentifolii (Homoptera: Aleyrodidae). Journal of Entomological Science 36(1): 1-8.

Grewal PS, De Nardo EAB, Aguillera MM. 2001. Entomopathogenic nematodes: potential for exploration and use in South America. Neotropical Entomology 30: 191-205.

GVA Generalitat Valenciana. 2012. Campaña contra la mosca de la fruta (Ceratitis capitata Wied). Conselleria d'Agricultura, Pesca, Alimentació i Aigua.Dirección general de producción agraria ganadera. http://www.caecv.com/docs/Campa\%C3\%B1a\%20Trampeo\%20Masivo\%20Ceratitis \%202012.pdf

\section{$\mathbf{H}$}

Hafsi A, Abbes K, Harbi A, Duyck PF, Chermiti B. 2015. Attract-and-kill systems efficiency against Ceratitis capitata (Diptera: Tephritidae) and effects on non-target insects in peach orchards. Journal of Applied Entomology 140(1-2): 28-36.

Hafsi A, Harbi A, Rahmouni R, Chermiti B. 2015. Evaluation of the efficiency of mass trapping of Ceratitis capitata (Wiedemann) (Diptera: Tephritidae) in Tunisian citrus orchards using two types of traps: Ceratrap and Tripack. Acta Horticulturae 1065: 10491056.

Hance T, van Baaren J, Vernon P, Boivin G. 2007. Impact of extreme temperatures on parasitoids in a climate change perspective. Annual Review of Entomology 52: 107126.

Harbi, A, de Pedro L, Ferrara F, Tormos J, Beitia F, Sabater-Muñoz B. 2016. Parasitism activity of Diachasmimorpha longicaudata (Ashmead) (Hymenoptera: Braconidae) and Aganaspis daci (Weld) (Hymenoptera: Figitidae) against Ceratitis capitata (Wiedemann) (Diptera: Tephritidae) under Mediterranean climati conditions. In Beatriz Sabater-Munoz B, Vera T, Pereira R, Orankanok W. (Eds). Prceedings of the 9th International Symposium on Fruit Flies of Economic Importance (ISFFEI), Bangkok, Thailand. The Editors.Pp: 401-410. 
Harbi A, Beitia F, Sabater-Muñoz B, Falcó JV, Chermiti B. 2015a. First record of Pachycrepoideus vindemmiae (Rondani) (Hymenoptera: Pteromalidae) parasitizing pupae of Ceratitis capitata (Wiedemann) (Diptera: Tephritidae) in Tunisia. African Entomology 23(2): 514-518.

Harbi A, Beitia FJ, Tur C, Chermiti B, Verdú MJ, Sabater-Muñoz B. 2015b. Field releases of the larval parasitoid Diachasmimorpha longicaudatain Spain: first results on dispersal pattern. Acta Horticulturae 1065: 1057-1062.

Harris EJ, Vargas RI, Gilmore JRE. 1993. Seasonality in occurrence and distribution of Mediterranean fruit fly (Diptera, Tephritidae) in upland and lowland areas on Kauai, Hawaii. Environmental Entomology 22: 404-410.

Hassell MP. 1978. The dynamics of arthropod predator-prey systems. Princeton University Press, Princeton, NJ, USA. 248 pp

Hassell PM, Lawton JH, Beddington JR, 1977. Sigmoid functional by invertebrate predators and parasitoids. Journal of Animal Ecology 46: 249-262.

Heard TA, Hendrikz JK. 1993. Factors influencing flight activity of colonies of the stingless bee Trigona carbonaria (Hymenoptera: Apidae). Australian Journal of Zoology 41: 343-353.

Heath RR, Lavallee SG, Schnell E, Midgarden DG, Epsky ND. 2009. Laboratory and field cage studies on female-targeted attract-and kill bait stations for Anastrepha suspensa (Diptera: Tephritidae). Pest Management Science65:672-677.

Hebert C, Cloutier C, Regniere J. 1989.Factors affecting the flight activity of Winthemia fumiferanae (Diptera: Tachinidae). Environrnental Entomology 19:293-302.

Heimpel GE, Casas J. 2007. Parasitoid foraging and oviposition behaviour in the field. In: Wajnberg E., Bernstein C. \& Van Alphen JJM. (Eds). Behavioural ecology of insect parasitoids. Blackwell Publishing, Oxford, UK. pp. 51-70.

Hendrichs J, Robinson AS, Cayol JP, Enkerlin W. 2002. Medfly areawide sterile insect technique programmes for prevention, suppression or eradication: the importance of mating behavior studies. Florida Entomologist85:1-13.

Hochberg ME, Ives AR. 2000. Parasitoid population biology. Princeton University Press, Princeton, NJ. 366 pp.

Holling CS. 1959. Some characteristics of simple types of predation and parasitism. The Canadian Entomologist 91: 385-398.

Honek A. 1996. Geographical variation in thermal requirements for insect development. European Journal of Entomology 93: 303-312. 
Howell, J. F., M. Cheikh, H. Ben Salah, P. Crnjanski, W. Pils, and E. J. Harris. 1975. Suppression of Mediterranean fruit fly in Tunisia: a new method for aerial distribution of sterile flies from fixed wing aircraft. Journal of Economic Entomology 68: 244-246.

Hsu JC, Huang LH, Feng HT, Su WY. 2015. Do organophosphate-based traps reduce control efficiency of resistant tephritid flies? Journal of Pest Science 88(1): 181-190.

Hughes GE, Bale JS, Sterk G. 2010. Thermal biology and establishment potential in temperate climates of the predatory mirid Nesidiocoris tenuis. BioControl 56: 19-33.

IAEA 1999. International Atomic Energy Agency. Development of female Medfly attractant systems for trapping and sterility assessment. Vienna, Austria.

IAEA-TECDOC 1099. Proceedings of a final Research Co-ordination Meeting organized by the Joint FAO/IAEA Division of Nuclear Techniques in Food and Agriculture and held in Penang, Malaysia, 28 May- 1 June 1998.

IBM SPSS 20. 2011. IBM SPSS Statistics 20 Command Syntax Reference. 2502pp.

Ibrahim AG, Palacio IP, Rohani I. 1994. Biology of Diachasmimorpha longicaudata, a parasitoid of carambola fruit fly, (Diptera; Tephritidae). Pertanika Journal of Tropical Agricultural Science (2): 139-143

Idris AB, Grafius E. 1998. Diurnal flight activity of Diadegma insulare (Hymenoptera: Ichneumonidae), a parasitoid of the diamondback moth (Lepidoptera: Pluttelidae), in the field. Environmental Entomology 27: 406-414.

Immaraju JA, Morse JG, Hobza RF. 1990. Field evaluation of insecticide rotation and mixtures as strategies for citrus thrips (Thysanoptera: Thripidae) resistance management in California. Journal of Economic Entomology 83: 306-314.

Israely N, Ritte U, Oman SD. 2004. Inability of Ceratitis capitata (Diptera: Tephritidae) to overwinter in the Judean hills. Journal of Economic Entomology 97: 33-42.

Israely N, Ziv Y, Calun R. 2005. Metapopulation spatial-temporal distribution patterns of Mediterranean fruit fly (Diptera: Tephritidae) in a patchy environment. Annals of the Entomological Society of America 98(3): 302-308.

Iwasa T, Motoyama N, Ambrose JT, Michael Roe R. 2004. Mechanism for the differential toxicity of neonicotinoid insecticides in the honey bee, Apis mellifera. Crop Protection 23: $371-378$. 


\section{$\mathbf{J}$}

Jacas JA, Urbaneja A. 2010. Biological control in citrus in Spain: from classical to conservation biological control. In: Ciancio A, Mukerji KG (eds.), Integrated management of arthropod pests and insect borne diseases. Integrated management of plant pests and diseases Series 5. Springer Science and Busisness media B.V., the Netherlands. Pp 61-72.

Jacas, J. A., Urbaneja, A., Viñuela, E. 2006. History and future of introduction of exotic arthropod biological control agents in Spain: A dilemma? BioControl 51: 1-30.

Jackson JE. 2003. A user's guide to principal components analysis. Wiley, Hoboken, NJ, USA. $\mathrm{Pp}$.

Jenner WH, Cappuccino N, Kuhlmann U, Mason PG. 2010. Prerelease analysis of the overwintering capacity of a classical biological control agent supporting prediction of establishment. BioControl 55: 351-362.

Jerraya A. 2003. Principaux nuisibles des plantes cultivées et des denrées stockées en Afrique du Nord. Leur biologie, leurs ennemis naturels, leurs dégâts et leur contrôle. Edition Climat Pub Tunisia, 415 pp.

Jiménez-Pérez A, Villa-Ayala P., López-Martínez V. 2007. First record of Diachasmimorpha longicaudata (Ashmead) (Hymenoptera: Braconidae) attacking Toxotrypana curvicauda Gerstaecker (Diptera: Tephritidae). Neotropical Entomology 36(3): 482-483.

Jones AK, Raymond-Delpech V, Thany SH, Gauthier M, Sattelle DB. 2006. The nicotinicacetylcholine receptor gene family of the honey bee, Apis mellifera. Genome Research 16: 1422-1430.

Jones VP, Davis DW. 1989. Evaluation of traps for apple maggot (Diptera: Tephritidae) populations associated with cherry and hawthorn in Utah. Environmental Entomology 18: $521-525$.

Jones VP. 1988. Longevity of Apple maggot (Diptera: Tephritidae) lures under laboratory and field conditions in Utah. Environmental Entomology 17: 704-708.

Jones WA, Greenberg SM, Legaspi JR.1999. The effect of varying Bemisia argentifolii and Eretmocerus mundus ratios on parasitism. Biocontrol 44:13-28.

Juan Blasco MA. 2012. Control biorracional de Ceratitis capitata (Wiedemann): Mejora, aplicación y evaluación de la técnica del insecto estéril. $\mathrm{PhD}$ dissertation thesis. University Jaume I, Castellon, Spain. 250p 
Juan-Blasco M, Sabater-Muñoz B, Argilés R, Jacas JA, Castañera P, Urbaneja A. 2013a. Molecular sterile sperm detection to monitor Ceratitis capitata population reduction in SIT programs. Pest Management Science 69: 857-864.

Juan-Blasco M, Sabater-Muñoz B, Argilés R, Jacas JA, Ortego F, Urbaneja A. 2013b. Effects of pesticides used on citrus grown in Spain on the mortality of Ceratitis capitata (Diptera: Tephritidae) Vienna-8 strains sterile males. Journal of Economic Entomology 106(3): 1226-1233.

Juan-Blasco M, San Andrés V, Martínez-Utrillas MA, Argilés R, Pla I, Urbaneja A, Sabater-Muñoz B. 2013c. Alternatives to ginger root oilaromatherapy for improved mating performance of sterile Ceratitiscapitata (Diptera: Tephritidae) males. Journal of Applied Entomology 137: 244-251.

Juliano SA. 2001. Nonlinear curve fitting: predation and functional response curves. In: Scheiner SM, Gurevitch J. (Eds.), Design and Analysis of Ecological Experiments. Oxford University Press, New York, pp. 178-196.

\section{K}

Katsoyannos BI, Kouloussis NA, Carey JR. 1998. Seasonal and annual occurrence of the Mediterranean fruit fly (Diptera: Tephritidae) on Chios Island, Greece: differences between two neighboring citrus groves. Annals of the Entomological Society of America 91(1): 43-51.

Katsoyannos BI, Heath RR, Papadopoulos NT, Epsky ND, Hendrichs J. 1999a. Field evaluation of Mediterranean fruit fly (Diptera: Tephritidae) female selective attractants for use in monitoring programs. Journal of Economic Entomology 92(3): 583-589.

Katsoyannos BI, Papadopoulos NT, Kouloussis NA, Heath R, Hendrichs J. 1999b. Method of assessing the fertility of wild Ceratitis capitata (Diptera: Tephritidae) females for use in sterile insect technique programs. Journal of Economic Entomology 92(3): 590-597.

Katsoyannos BI, Papadopoulos NT. 2004. Evaluation of synthetic female attractants against Ceratitis capitate (Diptera: Tephritidae) in sticky coated spheres and McPhail type traps. Journal of Economic Entomology 97: 21-26.

Kitthawee S. 2000. Seasonal occurrence of Diachasmimorpha longicaudata (Ashmead) (Hymenoptera: Braconidae), a parasitoid of Bactrocera correcta (Bezzi) (Diptera: Tephritidae) in a guava orchard in Central Thailand. Science Asia.26: 87-92. 
Kitthawee S, Sriplang K, Brockelman WY, Baimai V. 2004. Laboratory evaluation of density relationships of the parasitoid, Spalangia endius (Hymenoptera : Pteromalidae), with two species of tephritid fruit fly pupal hosts in Thailand Science Asia 30: 391-397.

Kitthawee S, Dujardin JP. 2009.Diachasmimorpha longicaudata: reproductive isolation and geometrics morphometrics of the wings. Biological Control 51(1): 191-197.

Klassen W, Curtis C. 2005. History of the Sterile Insect Technique. In: Dyck VA, Hendrichs J, Robinson AS (Eds), Sterile Insect Technique. Principles and Practice in Area-Wide Integrated Pest Management. Springer, Dordrecht, the Netherlands. pp. 3-36

Knipling EF. 1992. Principles of Insect Parasitism analyzed from new perspectives. ARSUSDA, Agriculture Handbook No. 693, Washington, D.C., 335 p.

Knippling EF. 1955. Possibilities of insect control or eradication through the use of sexual sterile males. Journal of Economic Entomology 48: 459-462.

Krespi L, Rabasse JM, Dedryver CA, Nenon JP. 1991. Effect of three insecticides on the life cycle of Aphidius uzbekistanicus Luz. (Hym, Aphidiidae). Journal of Applied Entomology 111: 113-119.

\section{$\mathbf{L}$}

Laajimi A, Ben Mimoun M. 2007. EuroMedCitrusNet "Safe and High Quality Supply Chains and Networks for the Citrus Industry between Mediterranean Partner Countries and Europe” Deliverable 9: National Citrus Sector Analysis: Tunisia. 22pp.

Lacirignola C, D'Onghia AM. 2009 The Mediterranean citriculture: productions and perspectives. In: D 'Onghia AM, D jelouah K, Roistacher CN (eds.). Citrus tristeza virus and Toxopteracitricidus: a serious threat to the Mediterranean citrus industry.Bari: CIHEAM, 2009. p. 13-17 (Options Méditerranéennes: Série B. Etudes et Recherches; n. 65)

Lance DR, Woods WM, Stefan M. 2014. Invasive insects in plant biosecurity: case study Mediterranean fruit fly. In Gordh G, McKirdy S (eds.), The handbook of plant biosecurity: Principles and practices for the identification, containment and control of organisms that threaten agriculture and the environment globally. Springer Science and Business media, Dordrecht. pp: 447-484.

Laurino D, Porporato M, Patetta A, Manino A. 2011. Toxicity of neonicotinoid insecticides to honey bees, laboratory tests. Bulletin of Insectology 164: 107-113. 
Lawrence PO, Baranowski RM, Greany PD, Nation JL. 1976. Effect of host age on development of Biosteres (Opius) longicaudatus, a parasitoid of the Caribbean fruit fly, Anastrepha suspensa. Florida Entomologist 59: 33-39.

Lawrence PO, Greany PD, Nation JL, Baranowski RM. 1978. Oviposition behavior of Biosteres longicaudatus, a parasite of the Caribbean fruit fly, Anastrepha suspensa. Annals of the Entomological Society of America 71: 253-256.

Lawrence PO. 1981. Host vibration a cue to host location by the parasite, Biosteres longicaudatus. Oecologia 48: 249-251.

Lawrence PO. 1988. Superparasitism of the Caribbean fruit-fly Anastrepha suspensa (Diptera: Tephritidae) by Biosteres longicaudatus (Hym: Braconidae). Implications for host regulation. Annals of the Entomological Society of America 81(2): 233-239.

Lebdi-Grissa K. 2010. Etude de base sur les cultures d'agrumes et de tomates en Tunisie. Regional Integrated Pest Management Program in the Near East, 13- 60

Lewis WJ, Martin WR. 1990. Semiochemicals for use with parasitoids: Status and future. Journal of Chemical Ecology 16(11): 3067-3089.

Leyva JL, Browning HW, Gilstrap FE. 1991. Effect of host fruit species, size, and color on parazitation of Anastrepha ludens (Diptera: Tephritidae) by Diachasmimorpha longicaudata (Hymenoptera: Braconidae). Annals of the Entomological Society of America 20: 1469-1474.

Liburd OE, Holler TC, Moses AL. 2004. Toxicity of imidacloprid-treated spheres to Caribbean fruit fly, Anastrepha suspensa (Diptera: Tephritidae) and its parasitoid Diachasmimorpha longicaudata (Hymenoptera: Braconidae) in the laboratory. Journal of Economic Entomology 97(2): 525-529.

Liquido NJ, Cunningham RT, Nakagawa S. 1990. Host plants of Mediterranean fruit fly (Diptera: Tephritidae) on the Island of Hawaii. Journal of Economic Entomology 83: 1863-1878.

Liquido NJ, Shinod LA, Cunningham RT. 1991. Host plants of the Mediterranean fruit fly, Diptera: Tephritidae: an annotated world review. Miscellaneous Publications of the Entomological Society of America 77:1-52.

Liu CY, Chen KW, Zeng L. 2012. Effects of temperature on the development and fecundity of Diachasmimorpha longicaudata (Ashmead). Yingyong Shengtai Xuebao 23(11): 3051-3056. PMID: 23431790

Loni A 1997. Developmental rate of Opius concolor (Hymenoptera: Braconidae) at various constant temperatures. Entomophaga 42: 359-366. 
López M, Aluja M, Sivinski J. 1999. Hymenopterous larval-pupal and pupal parasitoids of Anastrepha flies (Diptera: Tephritidae) in Mexico. Biological Control 15: 119-129.

Lopez SN, Botto E. 2005. Effect of cold storage on some biological parameters of Eretmocerus corni and Encarsia formosa (Hymenoptera: Aphelinidae). Biological Control 33: 123 130 .

Luck RF, Shepard BM, Kenmore PE. 1988. Experimental methods for evaluating arthropod natural enemies. Annual Review of Entomology 33:367-391.

\section{M}

Mackauer M. 1983. Quantitative assessment of Aphidius smithi (Hymenoptera: Aphidiidae): fecundity, intrinsic rate of increase, and functional response. The Canadian Entomologist 115: 399-415.

Magaña C, Hernandez-Crespo p, Ortego F, Castañera P. 2007. Resistance to malathion in field populations of Ceratitis capitata. Journal of Economic Entomology 100: 18361843

MAGRAMA. Ministerio de Agricultura, Alimentación y Medio Ambiente. 2012a. Resolución de autorización excepcional para la comercialización deproductos difusores de diclorvos en campañas de trampeo contra moscade la fruta (Ceratitis capitata). www.magrama.gob.es

MAGRAMA. Ministerio de Agricultura, Alimentación y Medio Ambiente. 2012b. Registro de productos fitosanitarios http://www.magrama.gob.es/es/agricultura/temas/mediosdeproduccion/ productos-fitosanitarios/fitos.asp

MAGRAMA, 2015. Ministerio de Agricultura, Alimentación y Medio Ambiente. Madrid (España). Anuario de Estadística avance 2015.

Malacrida AR, Marinoni F, Torti C, Gomulski LM, Sebastiani F, Bonvicini C, Gasperi G, Guglielmino CR. 1998. Genetic aspects of the worldwide colonization process of Ceratitis capitata. Journal of Heredity 89: 501-507.

Malacrida AR, Gomulski LM, Bonizzoni M, Bertin S, Gasperi G, Guglielmino CR. 2007. Globalization and fruitfly invasion and expansion: themedfly paradigm. Genetica 131: $1-9$.

Maniania NK, Ekesi S, Odulaja A, Okech MA, Nadel NJ. 2006. Prospects of a funguscontamination devicefor the control of tsetse fly Glossina fuscipes fuscipes. Biocontrol Science and Technology 16: 129-139. 
Mañosa S, Mateo R, Guitart R. 2001. A review of the effects of agricultural and industrial contamination on the Ebro delta biota and wildlife. Environmental Monitoring and Assessment 71: 187-205.

Marchal P. 1910. Sur un Braconide nouveau, parasite de Dacus oleae. Bulletin de la Societe Entomologique de France 13: 243-244.

Marchiori CH, Barbaresco LF. 2007. Occurrence of Pachycrepoideus Vindemmiae (Rondani, 1875) (Hymenoptera: Pteromalidae) as a parasitoid of Megaselia scalaris (Loew, 1866) (Diptera: Phoridae) iIn Brazil. Brazilian Journal of Biology 67(3): 577-578.

Martínez-Ferrer MT, Navarro C, Campos JM, Marzal C, Fibla JM, Bargues L, GarciaMarí F. 2010. Seasonal and annual trends in field population of Mediterranean fruit fly, Ceratitis capitata, in Mediterranean citrus groves: comparison of two geographic areas in eastern Spain. Spanish Journal of Agricultural Research 8: 757-765.

Martinou AF, Seraphides N, Stavrinides MC. 2014. Lethal and behavioral effects of pesticides on the insect predator Macrolophus pygmaeus. Chemosphere 96:167-173

Martins D.S, Skouri W, Chermiti B, Aboussaid H, El Messoussi S, Oufdou K, Carbonell E, Sabater-Muñoz B, Beitia F. 2010. Analysis of two larval-pupal parasitoids (Hymenoptera, Braconidae) in the biological control of Ceratitis capitata (Wiedemann) in Spanish Mediterranean areas. In: Sabater-Muñoz B, V. Navarro, A. Urbaneja (Eds) Proceedings $8^{\text {th }}$ International Symposium on Fruit Flies of Economic Importance. Editorial Universidad Politecnica de Valencia, Valencia, Spain. p. 252-258.

Marty MA, Dawson SV, Bradman MA, Harnly ME, Dibartolomeis MJ. 1994. Assessment of exposure to malathion and maloxon due to aerial application overurban areas of southern California. Journal of Exposure Analysis and Environmental Epidemiology 4: 65-81.

Masner L. 1995. The proctotrupoid families. In: Hanson PE, Gauld ID (Eds), The Hymenoptera of Costa Rica. Oxford University Press, Oxford, UK. pp 209-246.

Mavrikakis PG, Economopoulos AP, Carey JR. 2000. Continuous winter reproduction and growth of the Mediterranean fruit fly (Diptera: Tephritidae) in Heraklion, Crete, southern Greece. Environmental Entomology 29:1180-1187.

McGarigal K, Cushman S, Stafford S. 2000. Multivariate statistics for wildlife and ecology research. Springer-Verlag, New York, USA. 283 pp.

McGregor RR, Gillespie DR. 2004. Olfactory responses of the omnivorous generalist predator Dicyphus hesperus to plant and prey odours. Entomologia Experimentalis et Applicata 112: 201-205. 
Meats A, Smallridge CJ. 2007. Short- and long-range dispersal of medfly, Ceratitis capitata (Dipt., Tephritidae), and its invasive potential. Journal of Applied Entomology 131(8): 518-523.

Medina P, Pérez I, Budia F, Adán A, Viñuela E. 2004. Development of an extended laboratory method to test novel insecticides in bait formulation. IOBC/WPRS Bulletin 27(6): 59-66.

Meirelles RN, Redaelli LR, Ourique CB. 2013. Comparative biology of Diachasmimorpha longicaudata (Hymenoptera: Braconidae) reared on Anastrepha fraterculus and Ceratitis capitata (Diptera: Tephritidae). Florida Entomologist 96(2): 412-418.

Meirelles RN, Redaelli LR, Ourique CB. 2015. Thermal requirements and annual number of generations of Diachasmimorpha longicaudata (Hymenoptera: Braconidae) reared in the South American fruit fly and the Mediterranean fruit fly (Diptera: Tephritidae). Florida Entomologist 98(4): 1223-1226.

Messing RH, Jang EB. 1992. Response of the fruit fly parasitoid Diachasmimorpha longicaudata (Hymenoptera: Braconidae) to host fruit stimuli. Environmental Entomology 21: 1189-1195.

Messing RH, Klungness LM, Purcell M, Wong TTY. 1993. Quality-control parameters of mass-reared opiine parasitoids used in augmentative biological control of tephritid fruit flies in Hawaii. Biological Control 3: 140-147.

Messing RH, Klungness LM, Jang EB. 1997. Effects of wind on movement of Diachasmimorpha longicaudata, a parasitoid of tephritid fruit flies, in a laboratory flight tunnel. Entomologia Experimentalis et Applicata 82: 147-152.

Michaud JP. 2003. Toxicity of fruit fly baits to benefcial insects in citrus. Journal of Insect Science 3: 8. DOI: http://dx.doi.org/10.1673/031.003.0801

Michelakis SE. 1992. Phenology of the Mediterranean fruit fly, Ceratitis capitata Wiedemann in Crete. Israel Journal of entomology 25: 177-180.

Mills NJ, Babendreier D, Loomans AJM. 2006. Methods for monitoring the dispersal of natural enemies from point source releases associated with augmentative biological control. In: Bigler F, Babendreier D, Kuhlmann U. (eds). Environmental impact of invertebrates for biological control of arthropods: methods and risk assessment. CAB Int Wallingford, pp 114-131.

Mommaerts V, Sterk G, Smagghe G. 2006. Bumblebees can be used in combination with juvenile hormone analogues and ecdysone agonists. Ecotoxicology 15: 513-521. 
Montoya P, Liedo P, Benrey B, Barrera JF, Cancino J, Aluja M. 2000. Functional response and superparasitism by Diachasmimorpha longicaudata (Hymenoptera: Braconidae), a parasitoid of fruit flies (Diptera: Tephritidae). Annals of the Entomological Society of America 93: 47-54.

Montoya P, Liedo P, Benrey B, Cancino J, Barrera JF, Sivinski J, Aluja M. 2000. Biological control of Anastrepha spp. (Diptera: Tephritidae) in mango orchards through augmentative releases of Diachasmimorpha longicaudata (Ashmead) (Hymenoptera: Braconidae). Biological Control 18: 216-224.

Montoya P, Benrey B, Barrera JF, Zenil M, Ruiz L, Liedo P. 2003. Oviposition behavior and conspecific host discrimination in Diachasmimorpha longicaudata (Hymenoptera: Braconidae), a fruit fly parasitoid. Biocontrol Science and Technology 13: 683-690.

Montoya P, Cancino J. 2004. Control biológico por aumento en moscas de la fruta (Diptera: Tephritidae). Folia Entomológica Mexicana43: 257-270.

Montoya P, Cancino J, Zenil M, Gómez E, Villaseñor A. 2005. Parasitoid releases in the control of Ceratitis Capitata (Diptera: Tephritidae) outbreaks in coffee growing zones of Chiapas, Mexico. Vedalia 12(1): 85-89.

Monzó C. 2010. Artrópodos depredadores potenciales de Ceratitis capitata (Wiedemann) presentes en el suelo de cítricos. $\mathrm{PhD}$ thesis dissertation. Universidad Politécnica de Valencia, Valencia, Spain, p. 225.

Monzó C, Mollá O, Montón H, Urbaneja A, Castañera P. 2007. Artrópodos depredadores potenciales de Ceratitis capitata presentes enel suelo de los cítricos. Levante Agrícola Revista Internacional de Cítricos 385:152-156.

Monzó C, Sabater-Muñoz B, Catañera P, Urbaneja A. 2009. Control biológico de conservación en los suelos de cítricos: Influencia sobre la mosca del mediterráneo Ceratitis capitata (Wiedemann) (Diptera: Tephritidae). VI Congreso Nacional de Entomología Aplicada, Palma de Mallorca 19-23 Octubre, 2009, pp. 57.

Monzó C, Sabater-Muñoz B, Urbaneja A, Castañera P. 2010. Tracking medfly predation by the wolf spider, Pardosa cribrata Simon, in citrus orchards using PCR based gutcontent analysis. Bulletin of Entomological Research 100: 145-152.

Monzó C, Mollá O, Vanaclocha P, Montón H, Melic A, Castañera P, Urbaneja A. 2011a. Citrus-orchard ground harbours a diverse, wellestablishedand abundant grounddwellling spider fauna. Spanish Journal of Agricultural Research 9: 606-616. 
Monzó C, Sabater-Muñoz B, Urbaneja A, Castañera P. 2011b. The ground beetle Pseudophonus rufipes revealed as predator of Ceratitis capitata in citrus orchards. Biological Control 56(1): 17-21.

M'saad-Guerfali M, Loussaief F, 2008. The Sterile Insect Technique for the control of Ceratitis capitata (Weideman) in oranges orchards in Beni Khaled, Tunisia. First Meeting of TEAM, Palma de Mallorca 7-8 April, 2008, pp. 78.

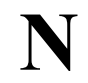

Nasreen A, Mustafa G, Ashfaq M. 2005. Mortality of Chrysoperla carnea (Stephens) (Neuroptera: Chrysopidae) after exposure to some insecticides; laboratory studies. South Pacific Studies 26(1): 1- 6.

Navarro-Llopis V, Vacas S. 2014. Mass Trapping for Fruit Fly Control. In: Shelly T, Epsky N, Jang EB, Reyes-Flores J, Vargas R. (eds.), Trapping and the detection, control, and regulation of tephritid fruit flies, Springer Science+Business Media Dordrecht, USA. Pp: 513-555.

Navarro-Llopis V, Primo J, Vacas S. 2014. Bait station devices can improve mass trapping performance for the control of the Mediterranean fruit fly. Pest Management Science 71: 923-927.

Navarro-Llopis V, Primo J, Vacas S. 2013. Efficacy of attract-and-kill devices for the control of Ceratitis capitata. Pest Management Science 69: 478-482.

Navarro-Llopis V, Vacas S. 2013. Attract-and-kill devices for fruit fly control. TEAM Newsl 13: $3-8$

Navarro-Llopis V, Alfaro F, Dominguez J, Sanchis J, Primo J. 2008. Evaluation of traps and lures for mass trapping of Mediterranean fruit fly in citrus groves. Journal of Economic Entomology 101: 126-131.

Navarro-Llopis V, Domínguez-Ruiz J, Zarzo M, Alfaro C, Primo J. 2010.Mediterranean fruit fly suppression using chemosterilants for areawide integrated pest management. Pest Management Science 66: 511-519.

Navarro-Llopis V, Sanchis J, Primo-Millo J, Primo-Yufera E. 2007. Chemosterilants as control agents of Ceratitis capitata (Diptera: Tephritidae) in field trials. Bulletin of Entomological Research (2007) 97, 359-368 
Navarro-Llopis V, Sanchís-Cabanes J, Ayala I, Casaña-Giner V, Primo-Yúfera E. 2004. Efficacy of lufenuron as chemosterilant against Ceratitis capitata in field trials. Pest Management Science 60:914-920.

Nigg HN, Mallory LL, Simpson SE, Callaham SB, Toth JP, Fraser S, Klim M, Nagy S, Nation JL, Attaway JA. 1994. Caribbean fruit fly, Anastrepha suspensa (Loew), attraction to host fruit and host kairomones. Journal of Chemical Ecology 20: 727-743

Noyes JS. 2002. Interactive catalogue of world Chalcidoidea (2001 - 2nd Edition). Cd-Rom. Taxapad, Vancouver, Canada, and The Natural History Museum, London, U.K.

Noyes JS. 2014. Universal Chalcidoidea Database. World Wide Web Electronic Publication. Online At: Http://Www.Nhm.Ac.Uk./Chalcidoids.

\section{$\mathrm{O}$}

OEJU. 2015. Official Journal of the European Union. Amending annexes II, III and V to Regulation (EC) no. 396/2005. Published on 14/03/2015. https://www.fsai.ie/uploadedFiles/Legislation/Food Legisation_Links/Pesticides Resi dues in food/Reg2015 399.pdf (last accessed 29/01/2016).

Ordax M, Piquer-Salcedo JE, Santander RD, Sabater-Muñoz B, Biosca EG, López MM, Marco-Noales E. 2015. Medfly Ceratitis capitata as Potential Vector for Fire Blight Pathogen Erwinia amylovora: Survival and Transmission. PLoS ONE 10(5): e0127560. doi:10.1371/journal.pone.0127560

Orozco D, Domínguez J, Reyes J, Villaseñor A, Gutiérrez JM. 2002. SIT and biological control of Anastrepha fruit flies in Mexico. In: Barnes B (Ed), Proceedings of the 6th International Symposium on fruit flies of economic importance, Stellenbosch, South Africa, pp. 245-249.

Ortego F, Magaña C, Hernández-Crespo P, Castañera P. 2005. Detección de resistencia a insecticidas en Ceratitis capitata: bases bioquímicas y moleculares. Phytoma España 173: 63-66.

Ortiz Moreno G. 2001. Training in medfly monitoring activities. Expert Mission Report, September 2001. Establishment of a medfly mass-rearing facility and introduction of a pilot sterile insect technique control programme, TUN/5/020. IAEA, Vienna, Austria.

Ortu S, Cocco A, Dau R. 2009. Evaluation of the entomopathogenic fungus Beauveria bassiana strain ATCC 74040 for the management of Ceratitis capitata. Bulletin of Insectology 62(2): 245-252. 
Ortu S, Lentini A, Cocco A. 2005. Strategie di lotta per il contenimento di Ceratitis capitata (Wied.) in agrumicoltura. Informatore Fitopatologico 28-32.

Ovruski M, Aluja MA, Sivinski J, Wharton RA. 2000. Hymenopteran parasitoids on fruitinfesting Tephritidae (Diptera) in Latin America and the southern United States: diversity, distribution, taxonomic status and their use in fruit fly biological control. Integrated Pest Management Reviews 5: 81-107.

Ovruski SM, Bezdjian LP, van Nieuwenhove GA, Albornoz-Medina P, Schliserman P. 2011. Host preference by Diachasmimorpha longicaudata (Hymneoptera: Braconidae) reared on larvae of Anastrepha fraterculus and Ceratitis capitata (Diptera: Tephritidae). Florida entomologist 94: 195-200.

Ovruski SM, Schliserman P, Aluja M. 2003. Native and introduced host plants of Anastrepha fraterculus and Ceratitis capitata (Diptera: tephritidae) in northwestern Argentina. Journal of Economic Entomology 96: 1108-1118.

Ovruski SM, Schliserman P, Aluja M. 2003. Native and introduced host plants of Anastrepha fraterculus and Ceratitis capitata (Diptera: tephritidae) in northwestern Argentina. Journal of Economic Entomology 96: 1108-1118.

Ovruski SM, van Nieuwenhove G, Bezdjian L, Albornoz-Medina P, Schliserman P.2012. Evaluation of Diachasmimorpha longicaudata (Hymenoptera: Braconidae) as a mortality factor of Ceratitis capitata (Diptera: Tephritidae) infesting citrus species under laboratory and field-cage conditions. Biocontrol Science and Technology 22: $187-$ 202.

\section{$\mathbf{P}$}

Paini DR, Shepparda AW, Cookc DC, De Barroe PJ, Wornerf SP, Thomasg MB. 2016. Global threat to agriculture from invasive species. Proceedings of the National Academy of Sciences USA 113(27): 7575-7579.

Pak GA, van Lenteren JC. 1988. Criteria and methods for the prerelease evaluation of different Trichogramma spp. strains. In: Voegele J, Waage J, van Lenteren JC. ( Eds.). Trichogramma and other egg parasitoids, Proceedings of 2nd International Symposium on Trichogramma, Guangzhou, PR China, No. 43 Les colloques de 1INRA, Paris, pp. $433-442$. 
Palacio IP, Rohani L, Ibrahim AG. 1992. Identification of immatures and male adults of the opiine parasitoids of the Oriental fruit fly. The Philippine Entomologist 8(5): 11241146.

Palacio IP. 1991. Biology of selected opiine parasitoids (Braconidae) and their abundance relative to the host. Bactrocera dorsalis on carambola. $\mathrm{PhD}$ Thesis. Universiti Pertanian Malaysia. 240 p.

Paladino LZC, Papeschi AG, Cladera JL. 2010. Immature stages of development in the parasitoid wasp, Diachasmimorpha longicaudata. Journal of Insect Science 10(56): 113.

Papadopoulos NT, Katsoyannos BI. 2003. Field parasitism of Ceratitis capitata larvae by Aganaspis daci in Chios, Greece. Biocontrol 48: 191-195.

Papadopoulos NT, Katsoyannos BI, Carey JR, Kouloussis NA. 2001. Seasonal and annual occurrence of the Mediterranean fruit fly (Diptera: Tephritidae) in northern Greece. Annals of the Entomological Society of America 94: 41-50.

Papadopoulos NT, Katasoyannos BI, Kouloussis NA, Hendrichs J, Carey JR, Heath RR. 2001. Early detection and population monitoring of Ceratitis capitata (Diptera: Tephritidae) in a mixed-fruit orchard in northern Greece. Journal of Economic Entomology 94(4): 971-978.

Papadopoulos NT, Katsoyannos BI, Carey JR. 2002. Demographic parameters of the Mediterranean fruit fly (Diptera: Tephritidae) reared in apples. Annals of the Entomological Society of America 95: 564-569.

Paranhos BAJ, Mendes PCD, Papadopoulos NT, Walder JMM. 2007. Dispersion patterns of Diachasmimorpha longicaudata (Hymenoptera: Braconidae) in citrus orchards in southeast Brazil. Biocontrol Science and Technology 17(4): 375-385.

Paranhos BAJ, Costa MLZ, Ovruski SM, Alves RM, Blummer L, Wlader JMM. 2008. Offspring in response to parental female densities in fruit fly parasitoid Diachasmimorpha longicaudata (Hymenoptera: Braconidae: Opiinae). Florida Entomologist 91(4): 628-635.

Peñarrubia-María IE. 2010. Biology studies and improvement of Ceratitis capitata (Wiedemann) mass trapping control technique. Tesis Doctoral. Universitatde Lleida.

Pérez-Hinarejos M, Beitia F. 2008. Parasitism of Spalangia Cameroni (Hymenoptera, Pteromalidae), an idiobiont parasitoid on pupae of Ceratitis capitata (Diptera, Tephritidae). IOBC/WPRS Bulletin 38: 130-133. 
Pierre RY. 2007. Economic impact of a Mediterranean fruit fly outbreak in Florida. Thesis University of Florida, USA. 172pp.

Pitcher SA, Hoffmann MP, Wright MG, Gardner J, Kuhar TP. 2002. Cold storage of Trichogramma ostriniae reared on Sitotroga cerealella eggs. BioControl 47: 525-535.

Primo-Millo E, Argilés-Herrero R, Alfaro-Lassala F. 2003. Plan de actuación contra la mosca de las frutas (Ceratitis capitata) en la Comunidad Valenciana. Phytoma España153: 127-130.

Prokopy RJ, Vargas RI. 1996. Attraction of Ceratitis capitata (Diptera: Tephritidae) flies to odor of coffee fruit. Journal of Chemical Ecology 22(4):807-820.

Prokopy RJ, Hu XP, Jang EB, Vargas RI, Warthen JD. 1998. Attraction of mature Ceratitis capitata females to 2-heptanone, a component of coffee fruit odor. Journal of Chemical Ecology 24: 1293-1304.

Purcell, M.F., Jackson, C.G., Long, J.P., Batchelor, M.A., 1994a. Influence of guava ripening on parasitism of the oriental fruit fly, Bactrocera dorsalis (Hendel) (Diptera: Tephritidae), by Diachasmimorpha longicaudata (Ashmead) (Hymenoptera: Braconidae) and other parasitoids. Biological Control 4: 396-403.

Purcell MF, Stark JD, Messing RH. 1994b. Insecticide effect on three tephritid fruit flies and associated braconid parasitoids in Hawaii. Journal of Economic Entomology 87: 14551462.

\section{Q}

Quayle HJ. 1914. Citrus fruit insects in Mediterranean countries. Bulletin of the U.S. department of agriculture. 134. 35pp

Quesada-Moraga E, Ruiz-García A, Santiago-Álvarez C. 2006. Laboratory evaluation of entomopathogenic fungi Beauveria bassiana and Metarhizium anisopliae against puparia and adults of Ceratitis capitata (Diptera: Tephritidae). Journal of Economic Entomology 99: 1955-1966.

Quilici S, Rousse P. 2012. Location of host and host habitat by fruit fly parasitoids. Insects:3: 1220-1235. 
Rahmouni R, Harbi A, Chermiti B. 2015. Impact of pesticides used in citrus orchards on the beneficial insect Cryptolaemus montrouzieri Mulsant (Coleoptera: Coccinellidae). Acta Horticulturae 1065: 1173-1179.

Ramadan MM, Wong TTY, Beardsley JW. 1989. Survivorship, potential and realized fecundity of Biosteres tryoni (Hym.: Braconidae), a larval parasitoid of Ceratitis capitata (Diptera: Tephritidae). Entomophaga 34: 291-297.

Ramadan MM, Wong TTY, Beardsley JW. 1992. Reproductive behavior of Biosteres arisanus (Sonan) (Hymenoptera: Braconidae), an egg-larval parasitoid of the Oriental fruit fly (Diptera: Tephritidae). Biological Control 2: 28-34.

Ramadan MM, Wong TTY, McInnis DO. 1994. Reproductive biology of Biosteres arisanus (Sonan), an egg-larval parasitoid of the Oriental fruit fly. Biological Control 4: 93-100.

Raspi A, Loni A. 1994. Alcune note sull'allevamento massale di Opius concolor Szepligeti (Hymenoptera: Braconidae) e su recenti tentativi d'introduzione della specie in Toscana e liguria. Frust Entomology 30:135-145.

Reissig WH, Stanley BH, Roelofs WL, Schwarz MR. 1985. Tests of synthetic apple volatiles in traps as attractants for apple maggot flies (Diptera: Tephritidae) in commercial apple orchards. Environmental Entomology 14(1):55-59.

Ricalde MP, Nava DE, Loeck AE, Donatti MG. 2012.Temperature-dependent development and survival of Brazilian populations of the Mediterranean fruit fly, Ceratitis capitata, from tropical, subtropical and temperate regions. Journal of Insect Science 12:33.

Richards OW, Davies RG. 1984. Tratado de Entomología Imms vol 1l. Clasificación y Biología. Ed. Omega SA. Barcelona, España. 998pp.

Robacker DC, Heath RR. 1996. Attraction of Mexican fruit flies (Diptera: Tephritidae) to lures emitting host-fruit volatiles in a citrus orchard. Florida Entomologist 79: 600-602.

Robacker DC, Warfield WC, Flath RA. 1992. A four-component attractant for the Mexican fruit fly, Anastrepha ludens (Diptera: Tephritidae), from host fruit. Journal of Chemical Ecology 18: 1239 -1254.

Rogers CD, Armsworth CG, Poppy GM. 2014. Conspecific transmission of insecticidal adhesive powder through mating in the Mediterranean fruit fly, Ceratitis capitata. Journal of Pest Science 87(2): 361-369.

Ros JP. 1988. La Mosca Mediterranea de la fruta, Ceratitis capitata Wied. Biología y métodos de control. Hojas Divulgadoras, Ministerio de Agricultura, Pesca y Alimentacion, España 8: 28. 
Rousse P, Gourdon F, Chiroleu F, Quilici S. 2009. Biotic and abiotic factors affecting the flight activity of Fopius arisanus, an egg pupal parasitoid of fruit fly pests. Environmental Entomology 38: 896-903.

Ruiu L, Satta A, Floris I. 2008. Effects of an azadirachtin-based formulation on the non-target muscoid fly parasitoid Muscidifurax raptor (Hymenoptera: Pteromalidae). Biological Control 47(1): 66-70.

\section{$\mathbf{S}$}

Sabater-Muñoz B, Martins DS, Skouri W, Laurín C, Tur C, Beitia F. 2009. Primeros ensayos sobre la utilización de Diachasmimorpha tryoni (Hymenoptera, Braconidae) parael control biológico de Ceratitis capitata (Diptera, Tephritidae) en la Comunidad Valenciana. Revista internacional de cítricos Levante Agrícola Revista Internacional de Cítricos 398: 372-376.

Sabater-Muñoz B., Falcó V, De Pedro L, Tormos J, Asis JD, Papadopoulos NT, Verdú MJ, Beitia FJ. 2012. First record, surveillance and biological parameters of Aganaspis daci (Hymenoptera: Figitidae), as parasitoid of Ceratitis capitata (Diptera: Tephritidae) in Spain. 2nd International Symposium of TEAM Kolymbari, 3-6 July 2012.

Sabater-Muñoz B, Beitia F, Hendrichs J. 2013. Los tefrítidos en los cítricos: nuevas perspectivas para su control (“Fruit Flies”). Levante Agrícola Revista Internacional de Cítricos 415: 63-66.

San Andrés V, Ortego F, Castañera P. 2007.Effects of gamma-radiation on midgut proteases of Ceratitis capitata (Diptera: Tephritidae). Archives of Insect Biochemistry and Physiology 65:11-19.

San Andrés V, Pérez-Panadés J, Carbonell E, Castañera P, Urbaneja A. 2009. Effects of post-teneral nutrition and ginger root oil exposure on longevity and attraction to bait treatments of sterile male Ceratitis capitata (Diptera: Tephritidae). Entomologia Experimentalis et Applicata 132:256-263.

Schmutterer H. 1990. Properties and potential of natural pesticides from the neem tree, Azadirachta indica. Annual Review of Entomology 35: 271-297

Schneider-Orelli O. 1947. Entomoligisches praktikum. Aarau: Sauerlander. 149p.

Schuld M, Schmuck R. 2000. Effects of Thiacloprid, a New Chloronicotinyl Insecticide, on the egg parasitoid Trichogramma cacaoeciae. Ecotoxicology 9(3): 197-205. 
Segura DF, Viscarret M M, Carabajal Paladino LZ, Ovruski SM, Cladera JL. 2007. Role of visual information and learning in habitat selection by a generalist parasitoid foraging for concealed hosts. Animal Behaviour 74: 131-142.

Segura DF, Viscarret MM, Ovruski SM, Cladera JL. 2012. Response of the fruit fly parasitoid Diachasmimorpha longicaudata to host and host-habitat volatile cues. Entomologia Experimentalis et Applicata 143: 164-176.

Segura DF, Nussenbaum AL, Viscarret MM, Devescovi F, Bachmann GE, Corley JC, Ovruski SM, Cladera JL. 2016. Innate host habitat preference in the parasitoid Diachasmimorpha longicaudata: functional significance and modifications through learning. PLoS ONE 11(3): e0152222.

Silva JWP, Bento JMS, Zucchi RA. 2007. Olfactory response of three parasitoid species (Hymenoptera: Braconidae) to volatiles of guavas infested or not with fruit fly larvae (Diptera: Tephritidae). Biological Control 41: 304-311.

Sime KR, Daane KM, Messing RH, Johnson MW. 2006a. Comparison of two laboratory cultures of Psyttalia concolor (Hymenoptera: Braconidae) as a parasitoid of the olive fruit fly. Biological Control 39: 248-255.

Sime K, Daane K, Nadel H, Funk C, Messing RH, Andrews J, Johnson M, Pickett C. 2006b.Diachasmimorpha longicaudata and Diachasmimorpha kraussii (Hymenoptera: Braconidae), potential parasitoids of the olive fruit fly. Biocontrol Science and Technology 16: 169-179.

Sivinski JM. 1996. The past and potential of biological control of fruit flies. In: McPheron BA, Steck GJ. (eds) Fruit fly pests: a world assessment of their biology and management, St. Lucie Press, Delray Beach, Florida, USA, pp. 369-375.

Sivinski JM, Calkins CO, Baranowski R, Harris D, Brambila J, Diaz J, Burns RE, Holler T, Dodson G. 1996. Suppression of a Caribbean fruit fly (Anastrepha suspensa (Loew) (Diptera: Tephritidae) population through augmented releases of the parasitoid Diachasmimorpha longicaudata (Ashmead) (Hymenoptera: Braconidae). Biological Control 6: 177-185.

Skouri W. 2010. Contribution A L'évaluation Des Potentialities De Diachasmimorpha Tryoni (Cameron) Et Diachasmimorpha Longicaudata (Ashmead) (Hymenoptera : Braconidae) Comme Agents De Lutte Biologique Contre La Mouche Méditerranéenne Des Fruits Ceratitis Capitata (Wiedemann) (Diptera : Tephritidae). Memoire De Mastère, Protection Des Plantes Et Environnement, Institut Supérieure Agronomique De Chott Mariem, Université De Sousse, Tunis. 91 pp 
Snowball GJ, Lukins RG. 1964. Status of introduced parasites of Queensland fruit fly (Strumeta tryoni), 1960_1862. Australian Journal of Agricultural Research 15:586-608.

Stara J, Ourednickova J, Kocourek F. 2011. Laboratory evaluation of the side effects of insecticides on Aphidius colemani (Hymenoptera: Aphidiidae), Aphidoletes aphidimyza (Diptera: Cecidomyiidae), and Neoseiulus cucumeris (Acari: Phytoseidae). Journal of Pest Science 84: 25-31.

Stark JD, Wong TTY, Vargas RI, Thalman RK. 1992. Survival, longevity, and reproduction of tephritid fruit fly parasitoids (Hymenoptera: Braconidae) reared from fruit flies exposed to azadirachtin. Journal of Economic Entomology 85(4): 1125-1129.

Stark, J.D., R.I. Vargas, and N. Miller. 2004. Toxicity of spinosal in protein bait to three economically important tephritid fruit fly species (Diptera: Tephritidae) and their parasitoids (Hymenoptera: Braconidae). Journal of Economic Entomology 97(3): 911915.

Sterk G., Hassan SA, Baillod M, Bakker F, Bigler F, Blumel S, Bogenschutz H, Boller E, Bromand B, BrunJ, Calis JNM, Coremans-Pelseneer J, Duso C, Garrido A, Grove A, Heimbach U, Hokkanen H, Jacas J, Lewis G, Moreth L, Polgar I, Roversti L, Samsoe-Petersen L, Sauphanor B, Schaub L, Stäubli A, Tuset JJ, Vainio A, Van De Veire M, Viggiani G, Viñuela E, Vogt H. 1999. Results of the seventh joint pesticide testing programme carried out by the IOBC/WPRS-Working Group "Pesticides and Beneficial Organisms.” BioControl 44: 99-117.

Stuhl C, Sivinski J, Teal P, Paranhos B, Aluja M. 2011. A compound produced by fruigivorous Tephritidae (Diptera) larvae promotes oviposition behavior by the biological control agent Diachasmimorpha longicaudata (Hymenoptera: Braconidae). Environmental Entomology 40(3):727-736.

Suarez L, Murua F, Lara N, Escobar J, Taret G, Rubio JL, Van Nieuwenhove G, Bezdjian L, Schliserman P, Ovruski SM. 2014. Biological control of Ceratitis capitata (Diptera: Tephritidae) in Argentina: releases of Diachasmimorpha longicaudata (Hymenoptera: Braconidae) in fruit-producing semi-arid areas of San Juan. Natural Science 6: 664-675.

Suchail S, Debrauwer L, Belzunces LP. 2004. Metabolism of imidacloprid in Apis mellifera. Pest Management Science 60: 291-296.

Sugiyama K, Katayama H, Saito T. 2011. Effect of insecticides on the mortalities of three whitefly parasitoid species, Eretmocerus mundus, Eretmocerus eremicus and Encarsia formosa (Hymenoptera: Aphelinidae). Applied Entomology and Zoology 46(3): 311317. 


\section{$\mathbf{T}$}

Tabozada EO, Sayed SM, El-arnaouty SA. 2015. Side effects of sublethal concentration of two neonicotinoids; thiamethoxam and thiacloprid on the larval parasitoid, Braconbrevicornis (Hymenoptera: Braconidae). American Journal of Experimental Agriculture 5(1): 29-35.

Tena A, Garcia-Marí F. 2011. Current situation of citrus pests and diseases in the Mediterranean basin. Integrated Control in Citrus Fruit Crops IOBC/WPRS Bulletin 62: $365-378$.

Thomas MC, Heppner JB, Woodruff RE, Weems HV, Steck GJ, Fasulo TR. 2014. Mediterranean fruit fly, Ceratitis capitata (Wiedemann) (Insecta: Diptera: Tephritidae). EENY-214 (IN371). UF/IFAS Extension (University of Florida/Institute of Food and Agricultural Sciences). 16pp.

Thomas DB. 2007. Integrated pest management with the sterile insect technique. In: Koul O, Cuperus G.W. (Eds.), Ecologically Based Integrated Pest Management. CAB International, Wallingford, UK. pp. 200-221.

Thompson CR. 2014. A parasitoid wasp, Diachasmimorpha longicaudata (Ashmead) (Insecta: Hymenoptera: Braconidae). Entomology and Nematology Department, UF/IFAS Extension: EENY193. http://edis.ifas.ufl.edu (last accessed August 2014).

Tomizawa M, Casida JE. 2005. Neonicotinoidinsecticide toxicology: mechanisms of selective action. Annual Review of Pharmacology and Toxicology 45:247-268.

Tormos J, Beitia F, Böckmann EA, Asís JD, Fernández S. 2009. The preimaginal phases and development of Pachycrepoideus vindemmiae (Hymenoptera, Pteromalidae) on Mediterranean fruit fly, Ceratitis Capitata (Diptera, Tephritidae). Microscopy and Microanalysis15: 422-434.

Torres JB, Musolin DL, Zanuncio JC. 2002. Thermal requirements and parasitism capacity of Trissolcus brochymenae (Ashmead) (Hymenoptera: Scelionidae) under constant and fluctuating temperatures, and assessment of development in field conditions. Biocontrol Science and Technology 12: 583-593. 
Urbaneja A, Dembilio O, Tortosa D, Viñuela E, Castañera P. 2004. Efectos secundarios de tratamientos cebo usados para el control de Ceratitis Capitata, sobre fauna útil. Phytoma España 160: 28-40.

Urbaneja A, García-Marí F, Tortosa D, Navarro C, Vanaclocha P, Bargues L, Castañera P. 2006. Influence of ground predators on the survival of theMediterranean fruit fly pupae, Ceratitis capitata, in Spanish citrus orchards. Biocontrol51: 611-626.

Urbaneja A, Chueca P, Montón H, Pascual-Ruiz S, Dembilio O, Vanaclocha P, AbadMoyano R, Pina T, Castañera P. 2009. Chemical alternatives to malathion for controlling Ceratitis capitata (Diptera: Tephritidae), and their side effects on natural enemies in spanish citrus orchards. Journal of Economic Entomology 102(1): 144-151.

Urbaneja A, Catalán J, Tena A, Jacas J. 2012. Gestión Integrada de Plagas de Cítricos. http://gipcitricos.ivia.es

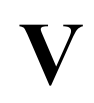

Vacante V. 2012. The History of IPM in the Mediterranean Citriculture. In: Vacante V, Gerson U. (Eds). Integrated Control of Citrus Pests in the Mediterranean Region. Bentham Science Publishers, Dubai, United Arab Emirates, pp 19-27.

Vacante V, Bonsignore CP. 2012. Implementation of IPM in Citriculture. In: Vacante V. Gerson U. (Eds) Integrated control of citrus pests in the Mediterranean region. Bentham Science publishers, Dubai, U.A.E. pp. 28-55.

Van Baaren J, Outreman Y. 2005. Effect of low temperature exposure on oviposition behavior and patch exploitation strategy in parasitic wasps. Animal Behaviour 70: 153163.

Van Driesche R, Bellows TS Jr. 1996. Biological control. Chapman \& Hall, Kluwer academic publishers, Massachusetts, USA. 539 pp.

Van Driesche RG, Hoddle MS, Center TD. 2007. Control de plagas y malezas por enemigos naturales. Forest Health Technology Enterprise Team (FHTET-2007-02), USDA (Washington, USA), $751 \mathrm{pp}$.

Van Lenteren JC. 1986. Parasitoids in the greenhouses: Successes with seasonal inoculative release systems. In: Waage J, Greathead D (eds.) Insect parasitoids. London Academic Press, London, UK. pp 341-374. 
Vanaclocha P, Papacek D, Monzo C, Verdú MJ, Urbaneja A, 2013a. Intra-guild interactions between the parasitoid Aphytis lingnanensis and the predator Chilocorus circumdatus: implications for the biological control of armoured scales. Biological Control 65: 169175.

Vanaclocha P, Vidal QC, Oheix S, Monton H, Planes L, Catalan J, Tena A, Verdu MJ, Urbaneja A. 2013b. Acute toxicity in laboratory tests of fresh and aged residues of pesticides used in citrus on the parasitoid Aphytis melinus. Journal of Pest Science 86: 329-336.

Vargas RI, Peck SL, Mcquate GT, Jackson CG, Stark JD, Armstrong JW. 2001. Potential for area wide integrated management of Mediterranean fruit fly (Diptera: Tephritidae) with a braconid parasitoid and novel bait spray. Journal of Economic Entomology 94: $817-825$.

Vargas RI, Ramadan M, Hussain T, Mochizuki N, Bautista RC, Stark JD. 2002. Comparative demographic of six fruit fly (Diptera: Thephritidae) parasitoids (Hymenoptera: Braconidae). Biological Control 25: 30-40.

Vet L, Dicke M.1992. Ecology of infochemical use by natural enemies in a tritrophic context. Annual Review of Entomology 37: 141-172.

Vidal-Quist JC, Castanera P, Gonzalez-Cabrera J. 2009. Diversity of Bacillus thuringiensis strains isolated from citrus orchards in Spain and evaluation of their insecticidal activity against Ceratitis capitata. Journal of Microbiology and Biotechnology 19(8): 749-759

Vinson SB. 1985. The behavior of parasitoids. In: GA Kerkut \& LI Gilbert (Eds.) Comprehensive insect physiology, biochemistry and pharmacology, Vol. 9. Pergamon Press, New York, NY, USA, pp. 417-469.

Viscarret MM, La Rossa R, Segura DF, Ovruski SM, Cladera JL. 2005. Evaluation of the parasitoid Diachasmimorpha longicaudata (Ashmead) (Hymenoptera: Braconidae) reared on a genetic sexing strain of Ceratitiscapitata (Wied.) (Diptera: Tephritidae). Biological Control 36: 147-153.

Vontas J, Hernandez-Crespo P, Margaritopoulos JT, Ortego F, Feng HT, Mathiopoulos KD, Hsu JC. 2011. Insecticide resistance in Tephritid flies. Pest Biochemistry and Physiology 100: 199-205. 
Wajnberg É, Bernstein C, van Alphen J. 2008. Behavioral ecology of insect parasitoids: from theoretical approaches to field applications. Willey-Blackwell Publishing, MA, USA. 464pp.

Wajnberg E, Ris N. 2007. Parasitisme et lutte biologique. In: Thomas F, Guégan JF, Renaud F. (eds.), Ecologie et Evolution des Systèmes Parasités. De Boeck Université, Bruxelles, Belgique. pp: 257-299.

Wang XG, Johnson MW, Yokoyama VY, Pickett CH, Daane KM. 2011. Comparative field evaluation of two olive fruit fly parasitoids under different climatic conditions. BioControl 56: 283-293.

Wang XG, Messing RH. 2004. The ectoparasitic pupal parasitoid, Pachycrepoideus vindemmiae (Hymenoptera: Pteromalidae), attacks other primary tephritid fruit fly parasitoids: host expansion and potential non-target impact. Biological Control 31: 227236.

Wang Y, Chen L, Yu R, Zhao X, Wu C, Cang T. Wang Q. 2012a. Insecticide toxic effects on Trichogramma ostriniae (Hymenoptera: Trichogrammatidae). Pest Management Science 68(12): 1564-1571.

Wang Y, Chen L, Yu R, Zhao X, Wu C, Cang T, Wang Q. 2012b. Susceptibility of adult Trichogramma nubilale (Hymenoptera: Trichogrammatidae) to selected insecticides with different modes of action. Crop Protection 34: 76-82.

Warthen JD, Lee CJ, Jang EB, Lance DR, McInnis DO. 1997. Volatile, potential attractants from ripe coffee fruit for female Mediterranean fruit fly. Journal of Chemical Ecology 23: 1891-1900.

Wharton RA .1989. Classical biological control of fruitinfesting tephritidae. In: Robinson AS and Hooper G (Eds.) World crop pests, vol. 3B. Fruit flies: their biology, natural enemies and control. Elsevier, Amsterdam. Pp: 303-313.

Wharton RA, Marsh PM. 1978. New world Opiinae (Hymenoptera: Braconidae) parasitic on Tephritidae (Diptera). Journal of the Washinton Academy of Sciences 68: 147-167.

Wharton RA, Gilstrap FE. 1983. Key to and status of opine braconid (Hymenoptera) parasitoid used in biological control of Ceratitis and Dacus s.l. (Diptera: Tephritidae). Annals of the Entomological Society of America 76: 721-742.

Wharton RA, Trostle MK, Messing RH, Copeland RS, Kimani-Njogu SW, Lux S, Overholt WA, Mohamed S, Sivinski J. 2000. Parasitoids of medfly, Ceratitis capitata, and related tephritids in Kenyan coffee: a predominantly koinobiont assemblage. Bulletin of Entomological Research 90: 517-526. 
Wharton RA, Yoder MJ. 2014. Parasitoids of fruit-infesting tephritidae. Online At: Http://Paroffit. Org (Accessed 28 March 2014).

White IM, Elson-Haris MM. 1992. Fruit flies of economic significance: their identification and bionomics. CAB International, Wallinford, UK. pp. 12-601.

Wigglesworth VB. 1972. The principles of insect physiology, 7th Edition. Chapman and Hall Ldt, London, UK.

Witzgall P, Kirsch $\mathbf{P}$ and Cork A. 2010. Sex pheromones and their impact on pest management. Journal of Chemical Ecology 36: 80-100.

Wong TTY, Ramadan MM, McInnis DO, Mochizuki J. Nishimoto A, Herr JC. 1991. Augmentative releases of Diachasmimorpha tryoni to suppress a Mediterranean fruit fly population in Kula, Maui, Hawaii. Biological Control 1: 2-7.

Wong TTY, Ramadan MM. 1992. Mass-rearing biology of larval parasitoids of tephritid flies in Hawaii. In: T. E. Anderson \& N. C. Leppla (eds), Advances in insect rearing for research and pest management. WestviewPress, Boulder, Colorado, pp. 405-426.

Wong TTY, Ramadan MM, Herr JC, McInnis DO. 1992. Suppression of a Mediterranean fruit fly population with concurrent parasitoid and sterile fly releases in Kula, Maui, Hawaii. Journal of Economic Entomology 85: 1671-1681.

\section{$\mathbf{X}$}

Xiao Y, Tang S. 2008. The effect of initial density and parasitoid intergenerational survival rate on classical biological control. Chaos, Solitons and Fractals 37: 1048-1058.

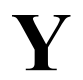

Yokoyama VY, Caceres CE, Kuenen LPS, Wang X-G, Rendon PA, Johnson MW, Daane KM. 2010. Field performance and fitness of an olive fruit fly parasitoid, Psyttalia humilis (Hymenoptera: Braconidae), mass reared on irradiated Medfly. Biological Control 54: 90-99.

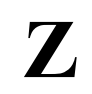

Zanuncio JC, Matos Neto FDC, Tavares WDS, Cruz I, Leite GLD, Serrão JE. 2013. Functional and numerical responses and reproduction of Campoletis flavicincta parasitizing Spodoptera frugiperda caterpillars. Acta Scientiarum Agronomy 35: 419426. doi:10.4025/actasciagron. v35i4.15871 
Zappalà L, Siscaro G, Biondi A, Mollá O, González Cabrera J, Urbaneja A. 2012. Efficacy of sulphur on Tuta absolutaand its side effects on the predator Nesidiocoris tenuis. Journal of Applied Entomology 136: 401-409.

Zucchi RA. 2001. Mosca Do Mediterrâneo, Ceratitis Capitata (Diptera, Tephritidae). In: Vilela EF, Zucchi RA, Cantor F (Eds) Histórico e impacto das pragas introduzidas no Brasil. Holos, Ribeirão Preto, Brazil. Pp.15-22. 